\title{
Relationship Management im Agribusiness
}

\author{
Dissertation \\ zur Erlangung des Doktorgrades \\ der Fakultät für Agrarwissenschaften \\ der Georg-August-Universität Göttingen
}

vorgelegt von

Sabine Gerlach

geboren in Marsberg

Göttingen, im Mai 2006 
D 7

1. Referent: $\quad$ Prof. Dr. Achim Spiller

2. Korreferent: $\quad$ Prof. Dr. Ludwig Theuvsen

Tag der mündlichen Prüfung: 8. Mai 2006 
EINLEITUNG

Relationship Management im Agribusiness.

\section{KAPITEL I}

Customer Relationship Management

I.1 Zur Zukunft des Biofachhandels: Eine Befragung von Bio-Intensivkäufern

I.2 Kundenbindung und Wechselbereitschaft im Bio-Fachhandel:

Ein multinomiales Logit-Modell

I.3 Die Zukunft des Bio-Großhandels in der Wertschöpfungskette

\section{KAPITEL II}

Supplier Relationship Management

II.1 Geschäftsbeziehungsqualität als Schlüssel zu einem effizienten Supply Chain Management

II.2 Landwirte als Lieferanten und Unternehmenseigner: Zum Management von Supplier- und Investor-Relations im Agribusiness

II.3 Supplier Relationship Management in der Milchwirtschaft: Ein Regressionsmodell zur Messung der Geschäftsbeziehungsqualität

II.4 Supplier Relationship Management in the German Dairy Industry.

II.5 Der Markt für Milch und Milcherzeugnisse 2005

II.6 Der Markt für Milch und Milcherzeugnisse 2006

\section{KAPITEL III}

Stakeholder Relationship Management

III.1 Die Agrarwende - Neustrukturierung eines Politikfeldes

III.2 Anwohnerkonflikte bei landwirtschaftlichen Stallbauten: Hintergründe und Einflussfaktoren - Ergebnisse einer empirischen Analyse

III.3 Stallbaukonflikte in Nicht-Veredlungsregionen: Empirische Analyse und Folgerungen für effiziente Governancestrukturen 


\section{EINLEITUNG}

Relationship Management im Agribusiness 


\section{Relationship Management im Agribusiness}

Aktuelle Probleme in der Agrarbranche 6

2.1 AGRARPROTEKTION ALS HEMMNIS FÜR EINE KONSEQUENTE MARKTORIENTIERUNG.......7

2.2 AgRARPROTEKTION ALS HEMMNISSE FÜR EINE STÄRKERE

LIEFERANTENORIENTIERUNG

2.3 POLITISCHE UND GESELLSCHAFTLICHE STAKEHOLDER - VERSCHIEBUNGEN DER

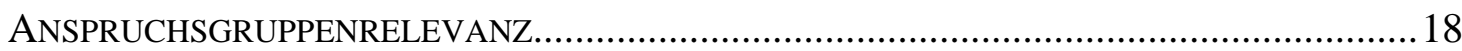

3 Relationship Management zur Beziehungsoptimierung..............................................24

3.1 GRUNDANNAHMEN DES RELATIONSHIP MANAGEMENTS...........................................24

3.2 Blickrichtung Kunde: Customer Relationship ManAGEMENT ............................29

3.3 BLICKRICHTUNG LIEFERANTEN: SUPPLIER RELATIONSHIP MANAGEMENT .....................32

3.4 BLICKRICHTUNG STAKEHOLDER: STAKEHOLDER RELATIONSHIP MANAGEMENT ...........35

$4 \quad$ Relationship Management im Agribusiness ..........................................................42

\section{Abbildungsverzeichnis}

Abbildung 1: Koordination der Geschäftsbeziehungen zwischen Molkereien und

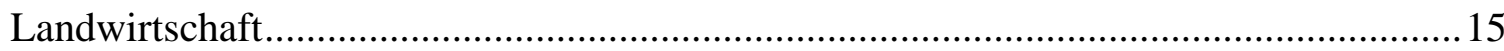

Abbildung 2: Typisierung in Geschäftsbeziehungen ........................................................2

Abbildung 3: Praktische Erscheinungsformen des Business-to-Business Marketings ..................30

Abbildung 4: Grad des Vertrauens in Bezug auf Lebensmittelskandale......................................36

Abbildung 5: Stakehodler-Typen nach Mitchell et al. (1997: 874)..........................................41

Abbildung 6: Blickwinkel des erweiterten Relationship Managements .................................... 43

\section{Tabellenverzeichnis}

Tabelle 1: Merkmale zur Differenzierung von partnerschaftlichen und marktlichen

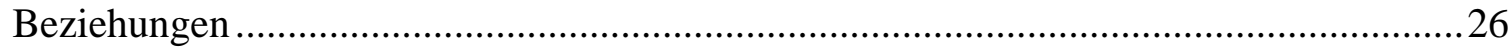

Tabelle 2: Vergleich Beeinflussungs- versus Beziehungsmarketing ....................................... 29

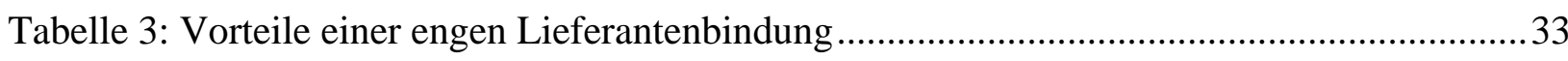

Tabelle 4: Die Leistungen der Anspruchsgruppen für die Unternehmung und die dafür

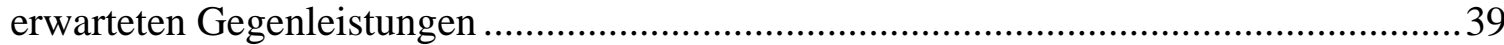

Tabelle 5: Stakeholderidentifikation anhand von Macht, Legitimität und Dringlichkeit..............40

Tabelle 6: Gegenüberstellung der verschiedenen Relationship-Konzepte ................................44 


\section{Aktuelle Probleme in der Agrarbranche}

Die Land- und Ernährungswirtschaft hat traditionell eine Sonderstellung im Wirtschaftsgefüge der BRD und auch der Europäischen Union, zum einen aufgrund der Nähe zur und Abhängigkeit von der Natur, zum anderen wegen ihrer Bedeutung für die Sicherstellung der Lebensmittelversorgung der Bevölkerung (Hartenstein 1997: 11). Mit diesen Argumenten wurden landwirtschaftliche Subventionsmaßnahmen gerechtfertigt, und es entwickelte sich ein Agrarsektor, der stark von öffentlichen Zuwendungen abhängig ist. Aufgrund der prioritären Bedeutung der Agrarpolitik hat sich eine Branchenkultur entwickelt, die zwar sehr gut auf das agrarpolitische Politikfeld ausgerichtet war, sich aber relativ wenig an Verbraucherinteressen orientieren musste (Waskow/Rehaag 2004: 4; Feindt et al. 2004: 12). Unter anderem aufgrund dieser Branchenentwicklung fällt es vielen Unternehmen des Agribusiness heute schwer, sich an ändernde Markt- und Umfeldbedingungen anzupassen. Diese Überforderung wird an verschiedenen Stellen deutlich. Die Ursachen werden in den folgenden Kapiteln kurz diskutiert. Dabei liegt dieser Arbeit ein sehr weiter Begriff des Agribusiness zugrunde, der die gesamte Wertschöpfungskette der Lebensmittelproduktion vom vorgelagerten Bereich bis zum Lebensmitteleinzelhandel einschließt (Strecker et al. 1996: 21). Einzelne Wertschöpfungsstufen werden je nach Fragestellung scheinwerferartig betrachtet.

Das Agribusiness ist ein Wirtschaftssektor, der zumindest auf der landwirtschaftlichen Erzeugerstufe immer mehr an ökonomischer Bedeutung verliert (BMELV 2006a: 1). In diesem einleitenden Beitrag zum Relationship Management im Agribusiness soll aber nicht die ökonomische Situation des Agribusiness im Mittelpunkt stehen, sondern vielmehr ein Blick darauf geworfen werden, mit welchen grundsätzlichen Problemen die Branche durch die sich ändernden Rahmenbedingungen und gesamtgesellschaftlichen Entwicklungen konfrontiert wird und wie mit diesen Änderungen umgegangen werden kann. Kernthese ist, dass durch die jahrzehntelange Konzentration der Außenbeziehungen auf die Agrarpolitik die Markt- und Gesellschaftsorientierung vernachlässigt wurde.

Seit einigen Jahren ist die Land- und Ernährungswirtschaft jedoch von irreversiblen Veränderungen betroffen. Dazu zählt eine Neuorientierung der Agrarpolitik auf nationaler und europäischer Ebene, die steigende Relevanz des Lieferantenmanagements und zunehmende gesellschaftliche Ansprüche, die von verschiedenen neuen Stakeholdern formuliert 
werden. Mit Hilfe des Relationship Management-Ansatzes werden im Weiteren Möglichkeiten vorgestellt, wie Unternehmen des Agribusiness diese neuen Anforderungen bewältigen können. Relationship Management beinhaltet ein Set von strategischen und instrumentellen Variablen für eine stärkere Öffnung der Branche für Außenbeziehungen. Auch andere Ansätze und Theorien sind geeignet, sich den Veränderungen zu nähern. Das Relationship Management mit seinen unterschiedlichen Ausprägungen ist aber bislang nur fragmentarisch im Agribusiness angewandt worden (vgl. Gerlach et al. 2004; Spiller et al. 2005; Gerlach et al. 2005a; Gerlach et al. 2005b) und verspricht daher neue Aspekte für die Diskussion. Zunächst soll jedoch in groben Zügen erläutert werden, inwieweit die bisherige Ausgestaltung der Agrarpolitik eine konsequente Markt- und Lieferantenorientierung der Unternehmen des Agribusiness behindert hat und weshalb die Beachtung von Stakeholderinteressen bislang wenig relevant war. Ein erweitertes Relationship Management bietet Optionen für eine stärkere Vernetzung der Unternehmen des Agribusiness mit Kunden, Lieferanten und Stakeholdern.

\section{Agrarbranche vor der Neuausrichtung}

\subsection{Agrarprotektion als Hemmnis für eine konsequente Marktorientierung}

Die Agrarbranche ist traditionell durch einen starken politischen Einfluss geprägt. Freie Märkte sind nur in Teilbereichen des Agrarmarktes (z. B. Schweinefleisch, Eier) vorzufinden, viele Produktionsbereiche sind durch staatliche Intervention, einen hohen Außenschutz und inländische Subventionen geschützt.

Der Eingriff des Staates in den Agrarhandel und damit die Agrarbranche begann mit verschiedenen Schutzzöllen für Getreide und Zuckerrüben sowie dem Branntweinsteuergesetz bereits in der zweiten Hälfte des 19. Jahrhunderts (Priebe 1985: 48; Tracy 1989: 20; Tracy 1993: 148). Der erste Weltkrieg und die darauf folgenden Nachkriegsjahre waren durch Störungen der Agrarproduktion gekennzeichnet und überdeckten die langfristige Tendenz des Angebotsüberhangs auf den Weltagrarmärkten. In der „zweiten Welle der Agrarprotektion“ (Tracy 1993: 152) Ende der 1920er Jahre wurden neben Außenschutz auch Interventionsmaßnahmen auf den Binnenmärkten sowie direkte Subventionen für die Landwirtschaft gewährt, nicht zuletzt als Reaktion auf steigende Agrarimporte und Auswirkungen der allgemeinen gesamtwirtschaftlichen Depression (Henrichsmeyer/Witzke 1994: 543). Zur Zeit des National- 
sozialismus wurde im Rahmen des „Reichsnährstandes“ ein System von Marktordnungen implementiert, das Marktrisiken ausschloss und Festpreise etablierte (Priebe 1985: 48).

Nach dem Ende des zweiten Weltkrieges bildeten der Lebensmittelmangel sowie die neue westeuropäische Solidarität den Hintergrund für die Entstehung der Europäischen Wirtschaftsgemeinschaft (EWG) und der Gemeinsamen Agrarpolitik (GAP). Mit der Schaffung eines gemeinsamen Handelsraums sollte eine stärkere Stabilität der Märkte und Preise erreicht werden. Diesem standen national unterschiedliche Regelungen, Preisgarantien etc. entgegen. Daher konnten nur sehr allgemein formulierte Ziele der GAP in Artikel 39, Abs. 1 des EWG-Vertrags vom 25.03.1957 niedergelegt werden. Zu ihnen zählen (Kluge 1989: 238; Henrichsmeyer/Witzke 1994: 34):

- Steigerung der landwirtschaftlichen Produktivität durch Förderung des technischen

Fortschritts, Rationalisierung der landwirtschaftlichen Erzeugung und bestmöglichen

Einsatz der Produktionsfaktoren, insbesondere der Arbeitskräfte,

- Gewährleistung einer angemessenen Lebenshaltung der landwirtschaftlichen

Bevölkerung,

- Stabilisierung der Märkte,

- Sicherstellung der Versorgung,

- Belieferung der Verbraucher zu angemessenen Preisen.

Die Ausgestaltung der GAP fußt auf verschiedenen Entscheidungen zwischen 1960 und 1965. $\mathrm{Zu}$ den umstrittensten zählt die Organisation der gemeinsamen Agrarpolitik, die Höhe des Getreidemindestpreises und die Finanzierung der GAP (Freisberg 1965; Tracy 1989: 255 ff.). Starke Produktionssteigerungen und stagnierende Nachfrage führten zu einer Überschussproduktion besonders bei Milch, sodass 1984 eine Milchquotenregelung erlassen wurde, um das Angebot zu verknappen und „Milchseen“ und „Butterberge“ zu begrenzen (Kommission der Europäischen Gemeinschaft 2002; Isermeyer 2005: 1). Trotz Anpassung einzelner Marktordnungen stiegen jedoch die Haushaltsausgaben für die GAP. Die internen Budgetgrenzen der EU sowie der zunehmende internationale Druck machten Anfang der 1990er Jahre eine Reform der GAP unumgänglich. Besonders die USA warfen der EU vor, durch die Exportunterstützungen den Weltmarkt zu verzerren. In der Uruguay Runde des General Agreement on Tariffs and Trade (GATT) standen als Folge vor allem agrarpolitische Fragestellungen auf der Agenda. Mit der so genannten „MacSharry“-Reform 1992 wurden aufgrund des internationalen Drucks erstmals einschneidende Veränderungen vorgenommen. Dabei wurden 
Mindestpreise vor allem bei Getreide (-33 \%) und Rindfleisch (-15\%) und der Interventionspreis für Butter (-9,5 \%) gesenkt sowie Flächenstilllegungsprogramme initiiert. Die Einkommensverluste der Landwirte wurden durch Direktzahlungen ausgeglichen (Folmer et al. 1994: 17; Henning et al. 2004: 6).

Der Trend zur produktionsunabhängigen Förderung der Landwirtschaft setzte sich mit der Agenda 2000 und deren Midterm-Review 2003 fort. Aufgrund des hohen Anteils der Agrarausgaben am EU-Haushalt sowie der EU-Osterweiterung zum 01.05.2004 um zehn neue Mitgliedsländer, die etwa 7 Mio. Landwirte mit in die EU brachten, wurde eine weitere Reform der GAP unausweichlich. Aber auch die WTO-Verhandlungen und die Wahrung der gesellschaftlichen Akzeptanz von Direktzahlungen für die Landwirtschaft sind zentrale langfristige Treiber einer Reduktion der klassischen (produktionsbezogenen) Agrarstützung. Mit der Agenda 2000 und den Beschlüssen zur Reform der GAP vom Juni 2003 (LuxemburgerBeschlüsse) wurden Direktzahlungen weitestgehend von der Produktion entkoppelt. Außerdem wurden Standards in den Bereichen Umwelt- und Tierschutz sowie Lebens- und Futtermittelsicherheit mit den Direktzahlungen verknüpft (Cross Compliance) und durch Kürzungen der Direktzahlungen (Modulation) Maßnahmen zur Förderung der ländlichen Entwicklung bereitgestellt (Huth/Prinz 2005: 121; BMELV 2006b: 11). Hiermit soll eine stärker marktorientierte und wettbewerbsfähige Landwirtschaft gefördert werden (Lacroix 2003: 1).

Dieser kurze Überblick über die Entstehung und Entwicklung der Agrarpolitik verdeutlicht die hohe Relevanz von politischen Maßnahmen im Agrarmarkt. Immer noch liegt der Anteil staatlicher Transferzahlungen am landwirtschaftlichen Einkommen, die je nach Betriebsform deutlich streuen, in Europa im Durchschnitt bei ca. 35 \% (OECD 2004: 48). Auf Basis ausgeklügelter Marktordnungen mit Interventionspreisen, Exportbeihilfen etc. wurden Systeme aufgebaut, die letztlich dafür sorgten, dass die Vermarktung der landwirtschaftlichen Produkte gewährleistet war. Konnten Produkte nicht auf dem inländischen Markt abgesetzt werden, wurden sie notfalls in die Intervention gegeben. Die Situation, die sich für landwirtschaftliche Betriebe daraus ergab, hat Isermeyer (1989: 30) auf einer Podiumsdiskussion treffend formuliert: „Die deutschen Bauern hängen an der Agrarpolitik wie der Krankenhauspatient am Tropf. Es scheint mir so, als seien viele mit ihren wirtschaftlichen Einstellungen direkt von der Leibeigenschaft über die Ablieferungswirtschaft des Reichsnährstandes in die staatliche Subventionswirtschaft hinübergeglitten, ohne je gelernt zu haben, sich in einer Marktwirtschaft zurechtzufinden.“ 
Eine besondere Nähe zum Kunden mussten weite Teile der Agrar- und Ernährungsbranche mithin nicht entwickeln. Dies gilt vor allem für die von den Marktordnungen betroffenen Produkte Milch, Zucker, Getreide und Rindfleisch. Die Mehrzahl der Produkte wurde garantiert abgenommen, interveniert und/oder mit Exporterstattungen exportiert. Erst durch die schrittweise Absenkung der Interventionspreise und die Entkopplung der Subventionszahlungen wurde eine stärkere Ausrichtung der Produktion auf den Weltmarkt eingeleitet. Gleichzeitig werden derzeit aber mit der Förderung der landwirtschaftlichen Energieproduktion (Biogas), Photovoltaik und der Windenergie neue Subventionsfelder für die Landwirte geschaffen (Walenda 2004: 178; Hartmann 2005: 81). Die schnelle Akzeptanz dieser Geschäftsfelder verweist einmal mehr auf die immer noch fortbestehende Subventionsorientierung des Agribusiness.

Die besondere Problematik einer zu starken Fixierung auf die Produktionsseite und eine Vernachlässigung der Abnehmerbedürfnisse wird in der Marketing- und Managementforschung seit geraumer Zeit unter dem Begriff „Marktorientierung“ lebhaft diskutiert. Zielrichtung dieses Konzeptes ist die Messung von tief verankerten Verhaltensweisen und Werten, welche die Ausrichtung eines Unternehmens prägen und den wirtschaftlichen Erfolg bestimmen. Diejenige Ausrichtung, durch die marketinggetriebene Unternehmen gekennzeichnet sind, wird dabei als Market Orientation bezeichnet (Kohli/Jaworski 1990; Narver/ Slater 1990). Marktorientierung oder synonyme Begriffe wie Kundenorientierung bzw. Kundennähe postulieren, dass in einem wettbewerbsintensiven Käufermarkt das Verständnis für Markttrends erfolgsentscheidend sein kann. In zahlreichen empirischen Studien wurde nachgewiesen, dass es tatsächlich einen erheblichen Zusammenhang zwischen der Marktorientierung und dem Unternehmenserfolg gibt (Narver/Slater 1990).

Das Konzept der Marktorientierung kann der im Agribusiness dominierenden Produktionsund Subventionsorientierung gegenüber gestellt werden. Produktionsorientierung beschreibt eine Unternehmenskultur, die kostenorientiert auf operative Exzellenz und interne Steuerungsgrößen ausgerichtet ist, während die Sensibilität für Marktdaten und Kundenanforderungen gering bleibt (Kotler 1988). In einem solchen Unternehmen rückt die Erzielung von Economies of Scale in den Mittelpunkt des Managements, was mit einer zentralisierten Organisationsstruktur und der hohen Relevanz operativer Controllinginstrumente gekoppelt ist. Subventionsorientierung meint die ausgeprägte Sensibilität für 
politische Entscheidungen und die damit verknüpften Veränderungen von Kosten- und Preisstrukturen. Im Zuge eines durch starke Wirtschaftsverbände organisierten Lobbyismusprozesses wird die Politik nicht nur aktiv begleitet, sondern bisweilen im eigenen Sinne instrumentalisiert (Sturn 1998: 41). Die Unternehmenskultur der Betriebe ist in diesem Fall auf Unterstützung des rent seeking (Organisationsgrad, Demonstrationsbereitschaft usf.) und Anpassungsstrategien an Veränderungen der relativen Preise ausgerichtet. Produktions- und Subventionsorientierung verstärken sich durch ihren komplementären Charakter gegenseitig. ${ }^{1}$

Eine marktorientierte Grundhaltung richtet sich dagegen an kundenbezogenen Planungsgrößen aus, ist langfristig orientiert und setzt vielfach auf Differenzierungsstrategien. Damit sind dezentralere Organisationsstrukturen verknüpft. Unternehmen mit einer ausgeprägten Marktorientierung differenzieren sich im Wettbewerb u. a. in folgenden Teilbereichen (Harris 2000; Homburg/Krohmer 2003: 1090 ff.; Schramm et al. 2004: 75):

- Unternehmenskultur: Übernahme der Marketing-Philosophie, offenes Klima, Freiräume für Kreativität, Servicebereitschaft.

- Strategie: Differenzierungsstrategie durch Produktinnovationen und Marktsegmentierung, Langfristorientierung bei proaktiver Strategieformulierung mit hoher analytischer Kompetenz.

- Organisation: Begrenzte Hierarchie, Delegation/Empowerment, hohe hierarchische Ansiedlung von Marketing/Vertrieb, Vermeidung von zu starker Prozessstandardisierung, interne Kunden-Lieferanten-Beziehungen, interfunktionale Organisation.

- Personalführung: Personalauswahl im Hinblick auf Kundennähe und Empathie, Personalbeurteilung und -entlohnung unter Einschluss der Kundenzufriedenheit, kundenorientiertes Führungsverhalten bei Beachtung der Mitarbeiterzufriedenheit.

- Informationssystem: Ausgeprägte Markt- und Wettbewerbsforschung, Auswertung von Kundendienstinformationen, Wissensmanagement, das für die Weiterleitung von Marktinformationen im gesamten Unternehmen sorgt.

- Planungs- und Kontrollsystem: Outside-in-Perspektive, hohe Relevanz von Marketingzielen und -budgets, Einbeziehung von Marktdaten in das Controlling.

\footnotetext{
${ }^{1}$ Vgl. die Ergebnisse empirischer Arbeiten im Anhang. So zeigen sich signifikante Mittelwertunterschiede bei Milch- und Schweineproduzenten bei Statements zur Subventionsorientierung und wahrgenommener unternehmerischer Entscheidungsfreiheit. Die Unterschiede lassen sich zum einen aus der unterschiedlichen Fristigkeit der Lieferbeziehung erklären (Milch: langjährige Lieferbeziehung; Schweineproduzenten i. d. R. kurzfristig) zum anderen durch die Stärke der agrarpolitischen Reglementierung der Märkte. Während der Milchmarkt durch eine Vielzahl von Maßnahmen geschützt ist, hat der Schweinemarkt nur einen schwachen Außenschutz.
} 
Marktorientierung und Interventionssysteme der klassischen Agrarpolitik stehen ganz offensichtlich in einem Widerspruch zueinander, was Auswirkungen sowohl auf die landwirtschaftlichen Betriebe als auch auf die vor- und nachgelagerte Industrie hat (Kemper 2005: 150). Der Transformationsprozess der Branche von einer an Marktordnungen und Politiksteuerung ausgerichteten Wirtschaft zu einer umfassenden Marktsteuerung ist seit vielen Jahren im Gang. Die folgenden Ausführungen werden allerdings verdeutlichen, dass diese Entwicklung zum einen noch nicht abgeschlossen ist und zum anderen die Orientierung am Endverbraucher nicht mehr ausreicht. Hinzu treten steigende Anforderungen im Hinblick auf die Ausgestaltung der gesamten Supply Chain und kritische Stakeholder. Mit der fortschreitenden Liberalisierung der Märkte ist ein steigender Wettbewerbsdruck auf die gesamte Wertschöpfungskette zu erwarten, der ein professionelles Lieferantenmanagement nötig macht. Auf diesen Punkt wird im Folgenden näher eingegangen.

\subsection{Agrarprotektion als Hemmnisse für eine stärkere Lieferantenorientierung}

Die beschriebene Entwicklung und Ausgestaltung der GAP hat dazu geführt, dass nicht nur eine Teilmenge der landwirtschaftlichen Betriebe ihre Erzeugung auf die durch die Agrarpolitik lukrativ gemachten Produkte im Sinne des rent seeking konzentrierte. ${ }^{2}$ Auch bei den nachgelagerten Wertschöpfungsstufen kann beobachtet werden, dass eine konsequente Ausrichtung auf den Markt nur in Teilbereichen stattgefunden hat, was u. a. auf die oben skizzierten agrarpolitischen Maßnahmen zurückzuführen ist. Im Folgenden werden daher die Besonderheiten der Lieferantenbeziehung im Agribusiness vorgestellt und Punkte erläutert, die bisher einem strategischen Lieferantenmanagement entgegengestanden haben.

Obwohl das Wachstum auch auf landwirtschaftlicher Seite für größere Betriebseinheiten gesorgt hat, ist der Konzentrationsprozess auf der nachgelagerten Stufe ungleich weiter fortgeschritten (Odening/Bokelmann 1999: 245). Die daraus resultierende Vielzahl von gleichartigen Lieferanten ist eine Besonderheit des Agribusiness, vor allem verglichen mit anderen Wirtschaftssektoren, z. B. der Automobilindustrie, in der es teilweise nur einen oder nur sehr wenige Lieferanten für ein Teil oder eine Materialart gibt (Stölzle 1999: 4). Aufgrund der großen Anzahl an Lieferanten ist die Bedeutung des einzelnen Landwirts für die abnehmende

\footnotetext{
${ }^{2}$ Isermeyer (1989: 36): „Es ist doch bereits heute so, dass viele Landwirte sich nicht mehr vorrangig Gedanken darüber machen, wie sie vernünftig Landwirtschaft betreiben, sondern darüber, wie sie ihren Betrieb am geschicktesten in die staatlichen Subventionsmaschinen einpassen“.
} 
Hand i. d. R. gering und eine besondere Beziehung zu diesem meist unnötig. Dies gilt besonders dann, wenn standardisierte Rohprodukte im Überschuss produziert werden und Lieferanten austauschbar sind. Es fallen daher keine spezifischen Investitionen in die Geschäftsbeziehung an, sodass sowohl Abnehmer als auch Lieferanten austauschbar sind und ein Lieferantenmanagement unnötig ist.

In Märkten mit Quotensystemen gibt es entweder Garantiepreise oder Interventionspreise, die die Preisuntergrenze determinieren (z. B. Butter und Milchpulver) (Hamm 1991: 27). Damit sind Preisverhandlungen mit den Lieferanten nur begrenzt möglich. Teilweise werden aber Zusatzleistungen wie Mietenabdeckung und Transport von Zuckerrüben honoriert und verhandelt. Auch in Märkten ohne Quotensysteme wird in den meisten Fällen Standardware produziert. Preisverhandlungen für spezielle Produktqualitäten sind Ausnahmefälle (z. B. Markenfleischprogramme). Obwohl die Preise von Agrarprodukten stark durch politische Maßnahmen beeinflusst sind, gibt es Unterschiede bei der Vergütung seitens des nachgelagerten Bereiches und damit auch Konfliktpotenzial. Aber nur in wenigen Märkten (Getreide, Schweine- und Rindfleischproduktion) können diese teilweise kurzfristigen Preisunterschiede von den Lieferanten ausgenutzt werden, da als eine weitere Besonderheit der Lieferbeziehung bei einigen Agrarprodukten Abnahmeverpflichtungen der weiterverarbeitenden Industrie aufgrund langfristiger Verträge bestehen. ${ }^{3}$

Am Beispiel der Milchwirtschaft: Durch die große Bedeutung von genossenschaftlichen Molkereien mit ihren langfristigen Verträgen zeichnet sich die Milchwirtschaft im Grunde durch relativ langjährige und stabile Geschäftsbeziehungen aus (vgl. Abbildung 1). Historisch ist dies durch die Anforderungen des Produktes zu erklären. Milch verlangte traditionell eine möglichst produktionsnahe Verarbeitung, gleichzeitig amortisiert sich die Investition in eine Molkerei nur, wenn der Auslastungsgrad hoch ist. Letztlich bedeutete dies, dass innerhalb eines begrenzten räumlichen Gebiets der Aufbau von mehr als einer Molkerei ökonomisch nicht sinnvoll war. Um der daraus resultierenden Gefahr einer Abhängigkeit von der Molkerei zu begegnen, schlossen sich die Landwirte in Produktionsgenossenschaften zusammen. Der Fortschritt der Transport-, Kühlungs- und Verarbeitungstechniken hat diese historische Be-

3 Bei Zucker sind die Quoten an die Zuckerfabriken gekoppelt, ein Wechsel zu anderen Fabriken ist nur mit Verkauf der Anteile möglich (Dohms 2002). Bei Milch beträgt die Vertragslaufzeit bei genossenschaftlich organisierten Molkereien normalerweise zwei Jahre, privatwirtschaftliche Molkereien haben unterschiedliche vertragliche Regelungen. 
gründung der Genossenschaften jedoch mittlerweile weitgehend aufgelöst. Heute kann Milch von größeren Landwirten relativ problemlos in einem Umkreis von rund $200 \mathrm{~km}$ vermarktet werden. Damit verfügen größere landwirtschaftliche Betriebe trotz der Konzentration auf Industrieseite in vielen Regionen über reale Vermarktungsalternativen.

Diese Entwicklung gewinnt vor dem Hintergrund der abnehmenden Marktregulierung an Brisanz. Mit sinkenden Garantiepreisen wächst der Wettbewerbsdruck in der Landwirtschaft erheblich. Die Bemühungen des Bundesverbands Deutscher Milchviehhalter (BDM) sind aus ökonomischer Sicht der Versuch, durch countervailing power den Wertschöpfungsanteil der Landwirtschaft zu erhöhen. Dazu wird eine veränderte Koordination der Geschäftsbeziehungen angestrebt. Die Bündelung von Milchmengen durch landwirtschaftliche Kooperationen (sei es durch den BDM oder durch größere Erzeugergemeinschaften) führt zu einem steigenden Spotmarkt-Anteil (siehe Abbildung 1). Bei dieser Entwicklung dominieren trotz eines hohen Genossenschaftsanteils kurzfristige Marktbeziehungen mit Fokus auf den Auszahlungspreis, was für gut informierte und leistungsfähige Akteure durchaus Chancen mit sich bringt und den Strukturwandel in Landwirtschaft und Industrie vorantreibt. Insgesamt steigt die Bereitschaft der Landwirte, die Molkerei zu wechseln, die Bindungen an den Abnehmer werden lockerer und der Milchauszahlungspreis tritt immer mehr in den Vordergrund. 


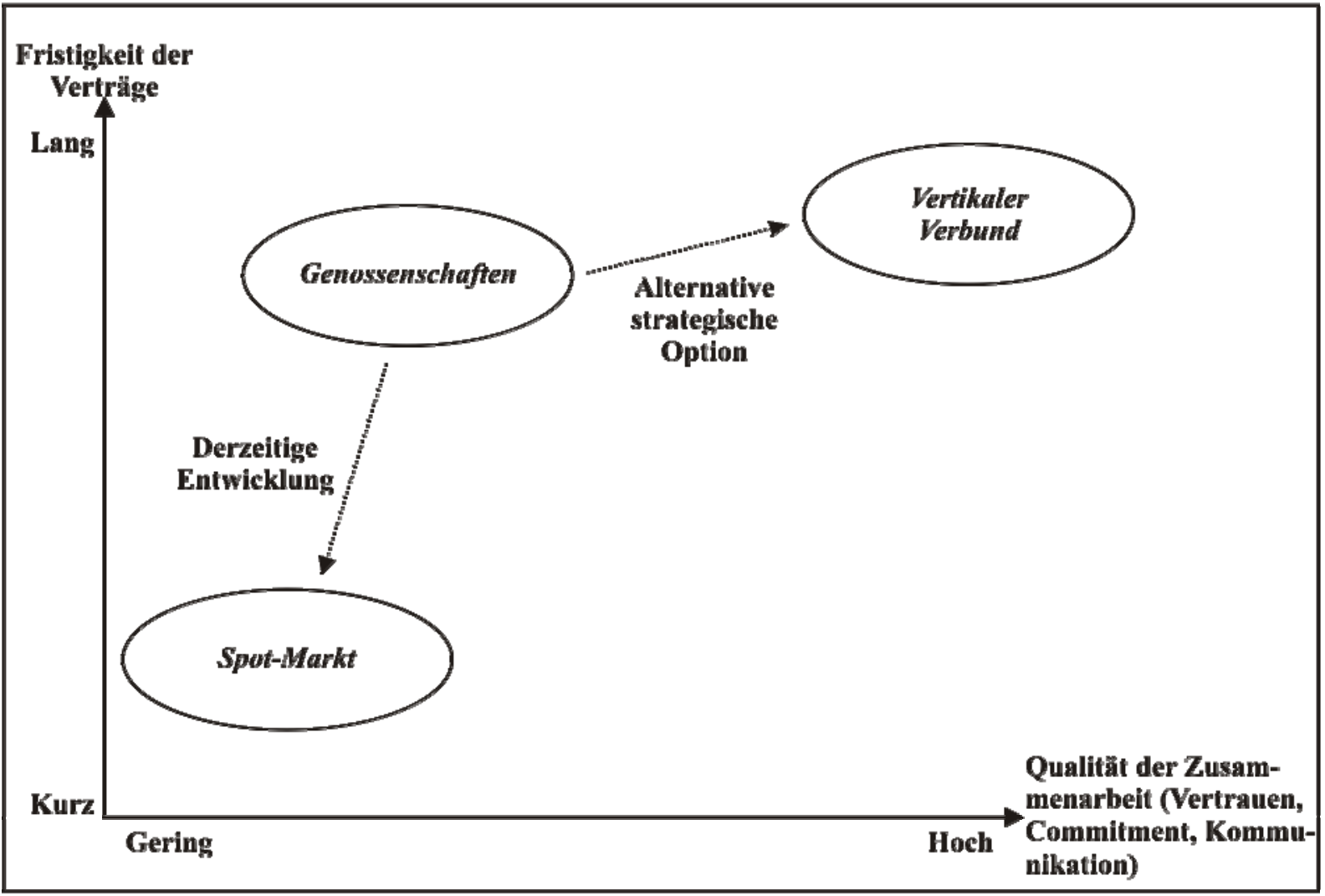

Quelle: eigene Darstellung

Das Beispiel Milchwirtschaft verdeutlicht, dass mit abnehmender Marktregulierung die traditionell fest gefügten Lieferantenbeziehungen des Agribusiness an Stabilität verlieren.

Eine weitere Besonderheit von Lieferbeziehungen im Agribusiness ist die Vermischung von Lieferanten- und Kapitalgeberinteressen. Im Bereich der Zuckerwirtschaft, der Fleischproduktion und der Milchindustrie sind viele Landwirte als Genossen oder Aktionäre auch Anteilseigner der Unternehmen. Damit ist der Einfluss der Mitglieder auf die Unternehmensführung groß und stellt viele genossenschaftliche Unternehmen vor große Herausforderungen. Diese Dichotomie bringt bei vielen Unternehmensentscheidungen Zielkonflikte mit sich, wie z. B. die Orientierung am kurzfristigen Auszahlungspreis versus langfristige Investitionen ins Unternehmen. Dieser Komplex ist in einer Vielzahl von Publikationen behandelt worden (vgl. Bonus 1986/1987a/1987b; Staatz 1989; Cook et al. 2004; Schramm et al. 2004) und soll an dieser Stelle nicht weiter diskutiert werden.

Das Augenmerk soll vielmehr darauf gerichtet werden, dass besonders genossenschaftliche Industrieunternehmen des Agribusiness durch die Änderung der Marktordnung vor großen 
Problemen stehen. Bislang haben z. B. deutsche genossenschaftliche Molkereien weniger im Bereich der Differenzierung bzw. durch starke Endverbrauchermarken, sondern eher durch eine Kostenorientierung auf sich aufmerksam gemacht. Durch die Änderungen in der Milchmarktordnung mit einer Milchquotenausweitung und Senkung der Interventionspreise ist von einem verstärkten Wettbewerb auszugehen. Infolgedessen sinken Milchauszahlungspreise sowie die Milchquotenpreise, wozu auch eine Liberalisierung des Quotenhandels beitragen würde. Zusätzlichen Druck auf die Milchpreise wird die spätestens für das Jahr 2013 international zugesagte Abschaffung der Exportbeihilfen ausüben. Im Jahr 2004 hat die EU 13,5 Mio. t Milchäquivalent in Drittländer exportiert und nur 3,3 Mio. t importiert (Weindlmaier 2005).

Vor dem Hintergrund eines solchen Szenarios mit sinkenden Erzeugerpreisen wird sich in der Landwirtschaft der Standortwettbewerb verschärfen, wodurch sich die Milchproduktion noch stärker auf bestimmte Regionen konzentrierten wird. Vieles spricht dafür, dass es bei einer Marktliberalisierung zunächst zu einer Aufstockung der Bestände kommt, was die bereits jetzt vorhandenen Angebotsüberschüsse verstärken und den Marktpreis noch weiter senken wird. In der Folge nicht ausreichender Markterlöse wird es zu Betriebsaufgaben bzw. Insolvenzen bei kleineren Betrieben und Milcherzeugern mit Liquiditätsproblemen kommen, sodass mittel- bis langfristig die Überschüsse zurückgehen werden (Isermeyer 2005: 11).

Welche Auswirkungen hat die stärkere regionale Konzentration der Milchviehhaltung auf die Molkereien? Sie senkt aus Sicht der Industrie die relative Bedeutung der Erfassungskosten im Vergleich zu den Herstellungskosten und erlaubt damit größere Molkereien. Die optimale Betriebsgröße steigt. Der gleiche Effekt geht von der wachsenden Betriebsgröße in der Landwirtschaft aus. Auch dies ermöglicht aufgrund der abnehmenden Stoppkosten größere Betriebsstätten. Regionale Verdichtung der Landwirtschaft und Konzentration im Molkereigewerbe verstärken sich mithin gegenseitig. Zukünftig entscheidet immer weniger allein die Leistungsfähigkeit von Landwirten oder Molkereien über den Erfolg im Standortwettbewerb, sondern die Effizienz der gesamten Wertschöpfungskette. Kostengünstige Molkereien sind solche mit geringen Rohstoffkosten, großen, spezialisierten Betriebsstätten, geringen Erfassungskosten, flexibler Logistik und schlanker Verwaltung. Sie benötigen eine landwirtschaftliche Basis, die bei relativ geringen Auszahlungspreisen rentabel arbeiten kann und räumlich arrondiert ist. 
Wie besonders genossenschaftliche Systeme mit ihrem rechtlich eingeschränkten Spielraum der Mitgliederdiskriminierung mit diesen Veränderungen in der Milchproduktion umgehen werden, ist ungewiss. Vieles deutet darauf hin, dass Änderungen in der Unternehmensform unausweichlich sind. So plant die größte Genossenschaftsmolkerei Nordmilch bereits, das operative Geschäft in Form einer AG auszulagern (o. V. 2006a). Aber auch über Anpassungen im Genossenschaftsgesetz, die neben einer sachlichen eine stärkere zeitliche Diskriminierung erlauben, sollte nachgedacht werden.

Zwischenfazit: Für das Agribusiness und die vorhandenen Geschäftsbeziehungen zwischen landwirtschaftlichen Erzeugern und abnehmender Hand lässt sich feststellen, dass die traditionellen Bindungen zunehmend brüchiger werden. Viele Landwirte sehen die Genossenschaften nicht mehr als „ihr Unternehmen“ und sind eher breit, den Abnehmer zu wechseln (Wocken 2004: 101). Die in der Vergangenheit ausgeprägte Nähe zwischen den Landwirten und dem nachgelagerten Bereich schwindet zunehmend. In der Vergangenheit war das Management von Genossenschaften eng verbunden mit der Landwirtschaft. Viele Geschäftsführer/Vorstände waren Bauernsöhne und/oder hatten Agrarwissenschaften studiert, so dass aufgrund des gemeinsamen Hintergrunds ein enger, persönlicher Kontakt zu den Landwirten bestand.

Die Beispiele der Nordzucker AG und der Nordmilch eG zeigen, dass heute verstärkt Vorstandsvorsitzende von außen eingekauft werden. Sowohl Dr. Ulrich Nöhle, der Vorstandsvorsitzende der Nordzucker AG, als auch Stephan Tomat, Vorstandsvorsitzender der Nordmilch e G, waren bei Nestlé, einem internationalen Markenartikler beschäftigt (Chwalleck 2003; o. V. 2004a). Ihre Vorgänger, Goetz von Engelbrechten (Nordzucker) als Landwirt bzw. Dr. Manfred Tag (Nordmilch), mit Ausbildung im Molkereifach und Betriebswirtschaftsstudium, hatten dagegen schon über das Elternhaus Kontakt mit der Branche (Fiddelke 2001; 0. V. 2005). Mit diesem Wechsel wird eine Neuausrichtung der Unternehmen angestrebt, was nicht immer ohne Konflikte abläuft, wie die jüngsten Auseinandersetzungen bei der Nordzucker AG zeigen (o. V. 2006b). Neben diesen personellen Änderungen, die sich auch auf die Unternehmenskultur ${ }^{4}$ auswirken, werden Verarbeitungsunternehmen stärker als bisher zwischen den Lieferanten differenzieren, teilweise auch selektieren. Erste Ansätze

\footnotetext{
${ }^{4}$ So äußerte sich Dr. Nöhle bei einer Vortragsveranstaltung über sein neues Amt als Vorstandsvorsitzender der Nordzucker AG, dass ihm diese Aufgabe sehr gefalle, er sich aber noch als Nestlé Mitarbeiter nie hat vorstellen können, einmal bei der „Gummistiefelfraktion“ zu arbeiten.
} 
finden sich bei Stoppgeldern von Molkereien, aber auch bei den Vorkosten der Schlachtunternehmen.

Insgesamt kann ein Auseinanderdriften von Landwirtschaft und nachgelagerter Industrie beobachtet werden, das bislang in der Forschung nicht systematisch aufgearbeitet wurde. Bislang wurden die Anpassungen an das veränderte Unternehmensumfeld nur im Bereich der Genossenschaftsforschung in Ansätzen diskutiert. Chaddad und Cook (2004: 348) schlagen verschiedene Typen für die Weiterentwicklung der klassischen Genossenschaft vor. Dabei werden Veränderungen bei den Genossenschaftsanteilen in Abhängigkeit vom Nutzen vorgeschlagen (Proportional Investment Cooperatives), zusätzliche Kapitaleinlagen mit gesonderter Rendite für die Mitglieder (Member-Investor Cooperatives) oder die Handelbarkeit von Lieferrechten innerhalb des Lieferantenkreises (New Generation Cooperatives). Damit stellt sich allerdings grundsätzlich die Frage, wie mit einer stärkeren Diskriminierung als das Genossenschaftsrecht sie bislang vorsieht, umgegangen wird. Neben diesen zu diskutierenden Fragestellungen, die vor allem rechtlichen Charakter haben bzw. die Frage der Rechtsformwahl betreffen, kann das Relationship Management gegebenenfalls neue Blickwinkel auf dieses Problem eröffnen. Die beispielhaft für die Molkereiwirtschaft skizzierten Entwicklungen zeigen aber, dass ein neuer Umgang mit landwirtschaftlichen Lieferanten notwendig ist. Ein möglicher Ansatzpunkt bietet hier das erweiterte Relationship Management, das in dem Kapitel 3 vorgestellt wird.

\subsection{Politische und gesellschaftliche Stakeholder - Verschiebungen der Anspruchs- gruppenrelevanz}

Die Herausforderungen für das Agribusiness gehen über die unmittelbaren Geschäftsbeziehungen in der Wertschöpfungskette hinaus. Nicht zuletzt die vielfältigen öffentlichen Diskussionen und Krisenerscheinungen (BSE, MKS und aktuell die Vogelgrippe) haben die latente Schwelle der Aufmerksamkeit für agrarpolitische Themen herabgesenkt. Themen wie Tierschutz, Lebensmittelsicherheit und Ernährungspolitik haben sich einen dauerhaft vorderen Platz auf der Agenda der Politik gesichert - außerhalb und häufig in Konkurrenz zur klassischen Agrarpolitik. Im Folgenden sollen die Ursachen und Entwicklungen für eine Verschiebung in der Relevanz der Anspruchsgruppen dargestellt werden.

Agrarpolitik wurde über Jahrzehnte sowohl auf Bundes- wie auf Landesebene „von Bauern für Bauern“ gemacht. Dabei spielte vor allem die Zweierbeziehung Landwirtschaft - Politik, 
die auch als Basissystem des Agrarsektors bezeichnet wird, eine besondere Rolle (Henrichsmeyer/Witzke 1994: 504). Aus Sicht der neuen Politischen Ökonomie kann die Agrarpolitik vor der BSE-Krise als Erfolg von gut organisierten Interessensgruppen charakterisiert werden (Henrichsmeyer/Witzke 1994; Hagedorn 1996; Waskow/Rehaag 2004). Politische Lobbyarbeit wird durch die zu vergebenden Subventionen lukrativ und das Rent Seeking wirkt sich auf einzelbetrieblicher Ebene deutlich positiv aus, wenn je nach Betriebsform gut die Hälfte des landwirtschaftlichen Einkommens durch staatliche Förderung bestimmt wird (OECD 2005; 48; DBV 2005: 181).

Damit ist Agrarpolitik besonders für die betroffenen Landwirte interessant, fand jedoch vor BSE und der proklamierten Agrarwende aufgrund der komplexen Politikstrukturen der EUAgrarpolitik kaum öffentliche Beachtung und war wenig entscheidend für Nicht-Landwirte bei der Stimmabgabe (Engels et al. 1985: 91). Anpassungen der GAP wurden vor allem durch Druck von Einsparung bzw. den Abbau von Handelsbeschränkungen motiviert (siehe Kap. 2.1). Mit diesem kurzen Abriss wird deutlich, dass Agrarpolitik primär auf landwirtschaftliche Interessen fokussierte, die Integration von Umwelt-, Verbraucher- und Gesundheitspolitik fand nur am Rande statt.

Mit dem Begriff der „Multifunktionellen Landwirtschaft“, der eine größere Verbreitung im Zuge der Agenda 2000 erhalten hat, werden erstmals umfassend die positiven externen Effekte bzw. die Funktionen der Landwirtschaft für den ländlichen Raum thematisiert (Heissenhuber/Lippert 2000: 249). Dabei bilden diese Funktionen (Erholungsfunktionen, Standortfunktionen und ökologische Funktionen) eine neue Legitimitätsgrundlage für Transferzahlungen. Wie „Multifunktionelle Landwirtschaft“ aussieht, wird in den einzelnen Interessensgruppen sehr kontrovers diskutiert (Gerlach et al. 2005c: 16). Deutlich wird aber, dass Landwirtschaft sich teilweise an außerökonomischen Kriterien orientieren soll, um in den Genuss gesellschaftlicher Förderung zu gelangen. Die derzeitigen Cross-ComplianceRegelungen, die zunächst einmal nur die Einhaltung von Umwelt- und Tierschutzauflagen verlangen, sind nur ein erster Schritt in diese Richtung.

Das Einbeziehen von Verbraucherinteressen in die Landwirtschaftspolitik fand im Gefolge der BSE-Krise und der damit verbundenen Dynamik in der deutschen (und europäischen) Agrarpolitik statt und war damit im politikwissenschaftlichen Sinne ein „window of opportunity“. Die von Renate Künast ausgerufene Agrarwende verdeutlicht in ihrer sprach- 
lichen Symbolik die angestrebte Neuausrichtung. Auch wenn die erste grüne Landwirtschaftsministerin „ohne Stallgeruch“ inzwischen abgelöst wurde, sind Veränderungen im Politikfeld eingetreten, die auch nach der letzten Regierungsumbildung unumkehrbar sind. Dazu zählt die erwähnte stärkere Einbeziehung von Verbraucherinteressen in die Landwirtschaftspolitik. Auch wenn das ehemalige Landwirtschaftministerium mit einem Kabinettsbeschluss vom Bundesministerium für Verbraucherschutz, Ernährung und Landwirtschaft (BMVEL) zum Bundesministerium für Ernährung, Landwirtschaft und Verbraucherschutz (BMELV) umbenannt wurde (BMELV 2006c), wird doch weiterhin der Bezug zur Ernährung und zum Verbraucherschutz deutlich. Die Kompetenzfelder, die im Zuge der BSE-Krise dazugekommen sind, personelle Neubesetzungen sowie die neuen politikberatenden Institute ${ }^{5}$ zeigen eine institutionelle Öffnung, die nicht mehr rückgängig gemacht werden kann.

Das Thema Ernährung bzw. Fehlernährung wird langfristig an Bedeutung zunehmen und auch das Agribusiness wird sich mit diesem Gebiet auseinandersetzen müssen. Neben der Forderung, Subventionen verstärkt für die Produktion von gesunden Produkten wie Obst und Gemüse zu zahlen und nicht potenziell ungesunde Produkte wie Fleisch zu subventionieren (Reisch 2005), verdeutlicht die Diskussion um übergewichtige Kinder und Jugendliche, die zunehmend von ernährungsbedingten Krankheiten betroffen sind und $\mathrm{zu}$ chronischen Erkrankungen im Erwachsenenalter führen können, die Relevanz des Themas. Nach Auffassung des Robert Koch-Instituts (RKI) gelten 10 bis $20 \%$ der Kinder und Jugendlichen als übergewichtig (Benecke 2004), andere Autoren geben 10 bis $18 \%$ als übergewichtig und 4 bis 8 \% als adipös an (Reinehr/Wabitsch 2003: 758; Kromeyer-Hausschild/Wabitsch 2004: 2; Pohlabeln et al. 2004: 211; Wabitsch 2004: 251). Die daraus resultierenden Spätfolgen stellen wiederum eine erhebliche Belastung für das Gesundheitssystem dar. Es zeichnen sich deutliche volkswirtschaftliche Kostensteigerungen aufgrund der Zunahme von Adipositas bzw. Adipositas-abhängigen Krankheiten ab, so dass auch Politik und Öffentlichkeit ein wachsendes Interesse an gesundheitlichen Präventionsmaßnahmen zeigen (Heseker/Schmidt 2000: 478 ff.). Dabei wird Unternehmen des Agribusiness eine Teilschuld an diesem Problem gegeben, da versteckte Zucker und Fette sowie spezielle Kommunikationsmaßen für die Zielgruppe Kinder und Jugendliche einen Beitrag am Ernährungsproblem leisten (Krönert 2003).

\footnotetext{
5 Bundesinstitut für Risikobewertung und Risikokommunikation (BFR), Bundesamt für gesundheitlichen Verbraucherschutz und Lebensmittelsicherheit (BVL)
} 
Aber auch weltweit ist zu beobachten, dass ernährungsbedingte Krankheiten an Relevanz gewinnen. So zeigt sich in Entwicklungs- und Schwellenländern überraschenderweise ein umstandsloser Übergang von der Mangelernährung zu Übergewichtsproblemen und einem damit zusammenhängenden starken Anstieg von nicht-ansteckenden Krankheiten (noncommunicable diseases (NCD)) (Schmidhuber 2003: 32).

Neben dem erwähnten institutionellen Wandel hat die Land- und Ernährungswirtschaft eine veränderte mediale Aufmerksamkeit erfahren, wie auch aktuell an der Berichterstattung über Gammelfleisch und Vogelgrippe deutlich wird. Mit dieser stärkeren öffentlichen Beachtung von Landwirtschafts- und Ernährungsthemen gewinnen auch Nicht-Regierungsorganisationen (NGOs) an Bedeutung, was sich auch in der Gründung von neuen Kampagnenorganisationen wie Foodwatch ausdrückt. Diese NGOs, im Bereich des Agribusiness seien exemplarisch Greenpeace, BUND, Peta und der NABU genannt, konfrontieren Unternehmen des Agribusiness verstärkt mit zugespitzten gesellschaftlichen Ansprüchen. Dabei sind Markenartikler und ihre Zulieferer besonders exponiert. Dies zeigt zum Beispiel eine Aktionsserie von Greenpeace im August 2001, in der auf die Haltungsbedingungen von Puten aufmerksam gemacht werden sollte. Um die Produktionsmethoden zu brandmarken, wurde in Putenställe von Landwirten, die Lieferanten der Firma Heidemark waren, eingebrochen und gefilmt. Mit dem Filmmaterial und Analysen des Trinkwassers, über das Antibiotika verabreicht wurde, versuchte Greenpeace letztlich Unilever und deren Marke „du darfst“ anzugreifen, da Heidemark Hauptlieferant des Putenfleisches war. Heidemark, ein mittelständisches Unternehmen, war mit der medialen Auseinandersetzung, die auch über das Fernsehen ausgetragen wurde, überfordert. Durch schnelle professionelle Reaktion von Unilever mit der Einrichtung eines runden Tisches, konnte letztlich ein Agreement erzielt werden. Heidemark versprach verbesserte Aufzuchtbedingungen für einen Teil der Produktion (Extensive Tierhaltung), in dem die Besatzdichte der Ställe reduziert wurde und Greenpeace kommunizierte diese Umstellung als Erfolg ihrer Kampagne (Greenpeace 2001: 7; o. V. 2001). ${ }^{6}$ Der Fall verdeutlicht die selektive Kampagnenpolitik von NGOs, die Unternehmen der gesamten Kette treffen kann und damit auch bisher weitgehend anonyme Zulieferer

\footnotetext{
${ }^{6}$ Nebenbei bemerkt machen Puten aus extensiver Tierhaltung, die Haltungsform, die durch diese Kampagne initiiert wurde, einen Anteil von 0,1 \% des Umsatzes von Heidemark aus, sodass Kritiker Greenpeace und Heidemark vorwarfen, hier nur scheinbar eine Verbesserung im Tierschutz erreicht zu haben (Jenner 2002).
} 
erreicht, die nicht auf die modernen Formen gesellschaftlicher Medienauseinandersetzungen ausgerichtet sind.

Aber auch die Genmilch-Kampagne von Greenpeace sei an dieser Stelle erwähnt. Greenpeace veröffentlichte unter anderem einen Ratgeber, in dem aufgezeigt wurde, welche Milchprodukte von Kühen stammen, die gentechnisch verändertes Futter bekommen haben (Langelüddeke/Deichmann 2004). Greenpeace hat darüber hinaus im vergangenen Jahr damit begonnen, auf Produkten, zunächst von Müller, inzwischen auch auf der Campina-Marke „Landliebe“ Sticker mit dem Aufdruck „GEN-MILCH“ aufzubringen. Obwohl die Branche bislang auf die Angriffe verhalten reagierte (der Deutsche Raiffeisen Verband rät seinen Mitgliedern, auf die Anfragen von Greenpeace nicht zu antworten), zeigt das deutliche Nein der Schweizer zum Einsatz von Gentechnik in der Landwirtschaft, dass eine Akzeptanz der Verbraucher bislang nicht vorausgesetzt werden kann (FAZ-NET 2005). Dass es möglicherweise einen Markt für Milch gibt, die von Tieren ohne gentechnisch behandeltes Futter stammt, zeigt die Einführung von Milch „garantiert ohne Gentechnik“ bei Tegut (LZNet: 2005) und bei Rewe und Plus in Österreich (Österreichische Milch- \& Lebensmittelwirtschaft 2005: 877). Dieses Beispiel verdeutlicht aber vor allem, dass gesellschaftliche Akzeptanz von neuen Produktionsmethoden nicht uneingeschränkt vorausgesetzt werden darf. In einer aktuellen Studie der Universität Göttingen zeigen sich die weit reichenden Rückwirkungen: Bei einer Befragung von Landwirten zur Akzeptanz von GMO-Saatgut wurde deutlich, dass der entscheidende Faktor aus Sicht eines Landwirts die Position der eigenen Familie und des dörflichen Umfeldes ist. Fehlt hier die Unterstützung, können auch wirtschaftliche Vorteile Landwirte derzeit kaum zur Nutzung von GMO-Saatgut bewegen (Voss/Spiller 2006).

Aber nicht nur für Unternehmen der Ernährungsbranche, sondern auch für den einzelnen landwirtschaftlichen Betrieb sind die zunehmenden gesellschaftlichen Veränderungen mit sich verändernden Ansprüchen an die Landwirtschaft relevant. Fast jeder Landwirt kann über Probleme mit Anwohnern berichten (Oberbeck/Oppermann 1994: 263; Becker 1996: 28). Bei Investitionen in Stallbauten, aber auch Biogasanlagen und Windenergie kommt es zu Problemen im sozialen Umfeld oder mit Genehmigungsbehörden (Neumann 2001: 40; Dorsch 2004: 14; o. V. 2004b: 97). Auch der Wissenschaftliche Beirat des Bundesministeriums für Verbraucherschutz, Ernährung und Landwirtschaft sieht durch die schwindende Akzeptanz der Tierhaltung in viehschwachen Regionen verstärkte Probleme beim Neu- bzw. Ausbau von 
Tierhaltungssystemen (BMVEL 2005: 33). Aber nicht nur die Anzahl der Akzeptanzprobleme nimmt zu, die Initiatoren der Proteste sind zunehmend professionell organisiert. So bietet beispielsweise der BUND im Internet zum kostenlosen Download einen Leitfaden zum Protest gegen Massentierhaltung an (BUND 2004), zudem können Bürgerinitiativen auf die Hilfe von spezialisierten Rechtsanwälten zurückgreifen (Pitschmann 2005: 15).

Wie das Agribusiness mit steigenden gesellschaftlichen Forderungen umgeht, ist bislang nur wenig erforscht. Einige Hinweise können allerdings den Arbeiten zu den Auswirkungen von Lebensmittelkrisen entnommen werden, die z. B. auf die Relevanz der Medien (Wildner 2002; Hagenhoff 2003; Kleinschmit/Feindt 2004) und die Dynamik und Zeitdauer von Verbraucherreaktionen (Frewer 1998) hinweisen. Wichtig sind auch die empirischen Imageforschungen, die für Deutschland das positive Bild der Öffentlichkeit vom einzelnen Landwirt im Kontrast zum fast vollständig fehlenden Vertrauen in die Unternehmen des Agribusiness und staatliche Institutionen nachzeichnen (Piel 2003: 15). Neben diesen Untersuchungen wurde eine erste Studie durchgeführt, die sich mit dem großen Kontrast zwischen der wachsenden öffentlichen Exponiertheit des Agribusiness und der vermuteten unternehmerischen Steuerungsfähigkeit beschäftigt (Jäckel/ Spiller 2005).

Die Studie von Jäckel und Spiller (2005) weist insgesamt auf deutliche Schwachstellen im Agribusiness hin. Es fehlt bisher in vielen Unternehmen an einem strukturierten Ansatz für den Umgang mit kritischen Anspruchsgruppen. Im Vergleich zu allen übrigen Stakeholdern werden NGOs im Durchschnitt als weniger relevant eingestuft. Ihnen wird von den meisten Unternehmen nur eine randständige Bedeutung zugemessen, sie werden zu spät beachtet und zu selten systematisch analysiert. Die Ergebnisse zeigen, dass Unternehmen, die hier ein offeneres und offensiveres Vorgehen wählen, erfolgreicher in der Öffentlichkeitsarbeit sind. Ein anderer zentraler Punkt ist die häufig negative Haltung gegenüber Journalisten, was zum Teil auch auf Einstellungs- und Kenntnisdefizite in der Führungsebene zurückzuführen sein dürfte. Auf der Verhaltensebene zeichnet sich eine Professionalisierung der Medienarbeit ab, doch deuten die dahinter stehenden Grundeinstellungen eher auf ein konfrontatives als auf ein kooperatives Vorgehen in diesem Bereich hin.

Der Umgang mit kritischen Anspruchsgruppen und die Sensibilität von Unternehmen für gesellschaftliche Ansprüche diskutieren Jäckel und Spiller (2005) unter dem Begriff Öffentlichkeitsorientierung. Dazu wurde das schon erwähnte Konzept der Marktorientierung 
(vgl. Kap. 2.1) um die Dimension Öffentlichkeit erweitert, da hier die gesellschaftliche Legitimation als Erfolgsfaktor einen Einfluss haben kann (Dyllick 1990: 198). In der empirischen Analyse zeigt sich, dass mit dem Konzept der Öffentlichkeitsorientierung zwar Erfolgsvariablen des Unternehmens identifiziert werden können. Wie eine „Öffentlichkeitsorientierung“ aber institutionell umgesetzt werden kann, ist wie beim Stakeholdermanagement bislang noch nicht gelöst. Im Rahmen eines erweiterten Relationship Managements steht in erster Linie die Öffnung des Blickwinkels für nicht-marktliche Beziehungen im Vordergrund, da Stakeholder einen relevanten Einfluss auf den Unternehmenserfolg nehmen können.

Zwischenfazit: Dem Agribusiness kommt durch die dargestellten Änderungen verstärkt öffentliche Beachtung zu. Der Einfluss neuer Politikbereiche und externer Anspruchsgruppen auf Unternehmen ist an jeder Stufe der Wertschöpfungskette wahrnehmbar. Insgesamt müssen sich Unternehmen des Agribusiness auf diese veränderten Rahmenbedingungen einstellen und sich strategisch auf den Umgang mit Stakeholdern einrichten. Das erweiterte Relationship Management kann eine Hilfestellung für die Strategieplanung leisten, letztlich ist es aber im Sinne der strategischen Frühaufklärung wichtig, potenzielle Ansprüche von Stakeholdern im Unternehmenshandeln zu berücksichtigen.

\section{Relationship Management zur Beziehungsoptimierung}

\subsection{Grundannahmen des Relationship Managements}

Die skizzierten Herausforderungen an das Agribusiness von Seiten der Kunden, der Lieferanten und der Öffentlichkeit werden im Weiteren vor dem Hintergrund betriebswirtschaftlicher Überlegungen zum Relationship Management diskutiert. Unter Relationship Management bzw. Beziehungsmanagement wird die systematische Anbahnung, Steuerung, Analyse und Gestaltung von Geschäftsbeziehungen verstanden. Dabei wird von der Annahme ausgegangen, dass die Beteiligten grundsätzlich bestrebt sind, ihre Beziehungen über mehrere Transaktionen hinweg aufrechtzuerhalten (Diller/Kusterer 1988: 4; Diller 1997: 573). Begreiflicherweise ist das Relationship Management nicht einheitlich definiert (Klee 2000: 33). Während Diller das Relationship Management als übergeordnetes Konzept versteht und das Relationship Marketing als eine Anwendungsform des Beziehungsmanagements betrachtet (Diller 2001: 165), sehen Stölze und Heusler (2003: 172) die Unterschiede in den 
verschiedenen Blickwinkeln. Aus ihrer Sicht wurde das Konzept des Beziehungsmanagement nach und nach um Beziehungen zu anderen unternehmensexternen Akteuren erweitert, das Relationship Marketing wurde dagegen auf die Erzielung von Kundenzufriedenheit und Kundenbindung spezifiziert. Plinke hingegen verwendet die Begriffe Relationship Management, Beziehungsmanagement, Relationship Marketing und Geschäftsbeziehungsmanagement synonym (Plinke 1997: 5). Eine genaue Auseinandersetzung mit den Unterschieden zwischen Relationship Management und Relationship Marketing soll auch hier unterbleiben. Das Relationship Management wird in der zugrunde liegenden Arbeit sehr weit gefasst und bezieht neben den von Diller (1997: 573) genannten Aspekten der systematischen Anbahnung, Steuerung, Analyse und Gestaltung von Geschäftsbeziehungen auch Beziehungen des Unternehmens außerhalb marktlicher Akteure mit ein. Es werden also neben Geschäftsbeziehungen auch Beziehungen zu Anspruchsgruppen analysiert. Im Folgenden soll kurz auf die Ursprünge des Beziehungsmanagements und deren Annahmen eingegangen und damit eine Einordnung in den wissenschaftlichen Kontext vorgenommen werden.

Der Begriff Relationship Marketing wurde zuerst von Berry (1983) in einem Konferenzbeitrag zum Dienstleistungsmarketing und zwei Jahre später von Jackson (1985) im Businsess-to-Business Kontext benutzt (Grönroos 2004: 99). Im amerikanischen Investitionsgütermarketing ist Relationship Marketing ein relativ neuer Forschungsschwerpunkt. Es stehen die langfristigen Geschäftsbeziehungen im Vordergrund und nicht mehr nur einzelne Interaktionsprozesse (Backhaus 1997: 43).

Die Relationship Management-Forschung hat ihren Ursprung in Interaktionsansätzen des Investitionsgütermarketings, die durch die Transaktionskostentheorie ergänzt wurden. Dabei spielt vor allem der IMP-Interaktionsansatz der Industrial Marketing and Purchasing Group (IMP-Group) eine wichtige Rolle (Backhaus 1997: 44). Diskutiert wurde ein dyadischorganisationales Modell, das nicht nur einen Leistungsaustausch zwischen Lieferant und Abnehmer zum Thema hat, sondern auch das Interaktionsgeflecht der Akteure und ihre Rollen und Erwartungen an diese untersucht. Als Modellgrößen werden im Interaktionsmodell der IMP-Group der Interaktionsprozess, die beiden beteiligten Institutionen, das Umfeld des Interaktionsprozesses sowie die Atmosphäre der Interaktionsbeziehung betrachtet (Blois 1996: 163; Stölzle 1999: 3). Hauptunterscheidungspunkt vom dominierenden Beeinflussungsmarketing ist der Gedanke, dass Marketingentscheidungen sich erst aus der Auseinander- 
setzung mit wichtigen Abnehmern ergeben und nicht vom Zulieferer allein getroffen werden können.

Das Beziehungsmanagement knüpft an das Interaktionsmodell insofern an, als ein transaktionsübergreifendes Beziehungsverständnis proklamiert wird, d. h. nicht nur einzelne Transaktionen, sondern eine längerfristige Geschäftsbeziehung im Mittelpunkt steht (Blois 1996: 162). Explizit finden dabei auch Interaktionen zwischen den Beteiligten Berücksichtigung. Dabei unterscheidet sich die Geschäftsbeziehungsintensität zwischen marktlichen und partnerschaftlichen Beziehungen sehr deutlich. Eine klare definitorische Abgrenzung zwischen partnerschaftlichen und marktlichen Beziehungen ist dennoch schwierig. Die in Tabelle 1 aufgeführten Merkmale verdeutlichen aber die unterschiedlichen Charakteristika.

\section{TABELLE 1: MERKMALE ZUR DIFFERENZIERUNG VON PARTNERSCHAFTLICHEN UND} MARKTLICHEN BEZIEHUNGEN

\begin{tabular}{|c|c|c|}
\hline Merkmal & $\begin{array}{l}\text { Partnerschaftliche } \\
\text { Beziehung }\end{array}$ & $\begin{array}{l}\text { Rein marktliche } \\
\text { Beziehung }\end{array}$ \\
\hline $\begin{array}{l}\text { Dauer der Geschäftsbeziehung zwischen Zulieferer und } \\
\text { Kunden }\end{array}$ & Langfristig & Kurzfristig \\
\hline Grundlage von Preisänderungen & $\begin{array}{l}\text { Kosteneinsparungs- } \\
\text { potenziale für beide } \\
\text { Partner }\end{array}$ & Keine Angabe \\
\hline $\begin{array}{l}\text { Lieferantenstamm (für ein bestimmtes Produkt oder eine } \\
\text { Dienstleistung) }\end{array}$ & $\begin{array}{l}\text { Ein oder zwei } \\
\text { Zulieferer }\end{array}$ & Viele Zulieferer \\
\hline Wareneingangskontrolle & Nein & Ja \\
\hline $\begin{array}{l}\text { Erhebung der Zulieferer- und Kundenleistung und } \\
\text { Vereinbarung über regelmäßige Rückmeldungen }\end{array}$ & $\mathrm{Ja}$ & Nein \\
\hline $\begin{array}{l}\text { Weiterbildungsprogramme und technische Unterstützung } \\
\text { des Lieferanten }\end{array}$ & $\begin{array}{l}\text { Umfassend oder } \\
\text { zumindest im Ansatz }\end{array}$ & Keine \\
\hline Einrichtung von Teams für Verbesserungsmaßnahmen & $\begin{array}{l}\text { Umfassend oder } \\
\text { zumindest im Ansatz }\end{array}$ & $\begin{array}{l}\text { Gewöhnlich keine, } \\
\text { allenfalls begrenzt }\end{array}$ \\
\hline Mitwirkung bei der Produktgestaltung & $\begin{array}{l}\text { Umfassend oder } \\
\text { zumindest im Ansatz }\end{array}$ & $\begin{array}{l}\text { Gewöhnlich keine, } \\
\text { allenfalls begrenzt }\end{array}$ \\
\hline Mitwirkung bei der Gestaltung von Logistikprozessen & $\begin{array}{l}\text { Umfassend oder } \\
\text { zumindest im Ansatz }\end{array}$ & $\begin{array}{l}\text { Gewöhnlich keine, } \\
\text { allenfalls begrenzt }\end{array}$ \\
\hline Regelmäßige Treffen auf leitender Managementebene & $\begin{array}{l}\text { Umfassend oder } \\
\text { zumindest im Ansatz }\end{array}$ & $\begin{array}{l}\text { Gewöhnlich keine, } \\
\text { allenfalls begrenzt }\end{array}$ \\
\hline $\begin{array}{l}\text { Mitteilen von strategischen Informationen und } \\
\text { Kostendaten }\end{array}$ & $\begin{array}{l}\text { Umfassend oder } \\
\text { zumindest im Ansatz }\end{array}$ & $\begin{array}{l}\text { Gewöhnlich keine, } \\
\text { allenfalls begrenzt }\end{array}$ \\
\hline Gemeinsame Investitionsplanung & $\begin{array}{l}\text { Umfassend oder } \\
\text { zumindest im Ansatz }\end{array}$ & $\begin{array}{l}\text { Gewöhnlich keine, } \\
\text { allenfalls begrenzt }\end{array}$ \\
\hline $\begin{array}{l}\text { Austausch der Daten über Bedarfsvorhersagen, } \\
\text { Umsatzentwicklung, Lagerbestandshöhen, Produktions- } \\
\text { und Lieferpläne und deren Aktualisierung. }\end{array}$ & $\begin{array}{l}\text { Umfassend oder } \\
\text { zumindest im Ansatz }\end{array}$ & $\begin{array}{l}\text { Gewöhnlich keine, } \\
\text { allenfalls begrenzt }\end{array}$ \\
\hline
\end{tabular}

Quelle: Grönroos 1994: 11; Stölzle/Heusler 2003: 173

Dabei spielt die Art der Geschäftsbeziehung, die z. B. vom Grad spezifischer Investitionen abhängt, eine Rolle (Kaas 1995: 26; Stölzle/Heusler 2003: 174). Plinke (1989: 309) meint 
sogar, dass das besondere Merkmal beim Relationship Management im Vergleich zum Beeinflussungsmarketing darin liegt, dass Investitionen geleistet werden müssen, um eine Beziehung aufzubauen und zu erhalten. Das Relationship Management thematisiert vor allem den Beziehungstyp „Strategische Partnerschaft“, der durch hohe spezifische Investitionen beider Seiten gekennzeichnet ist. Bei niedrigen spezifischen Investitionen von Zulieferern und Abnehmern ist häufig eine reine Marktbeziehung vorhanden. Sind die spezifischen Investitionen des Abnehmers hoch und die des Zulieferers gering, gerät der Abnehmer in eine Gefangenen-Situation, bei umgekehrter Struktur ist der Zulieferer in dieser Position. Haben sowohl Zulieferer wie auch Abnehmer hohe spezifische Investitionen, entsteht eine strategische Partnerschaft (siehe Abbildung 2). Diese spezifischen Investitionen können zum einen in Form von Humankapital unbewusst oder durch spezielle Investitionen, z. B. Just-intime-Belieferungen entstehen (Kaas 1995: 35). Durch die Einsparung von Transaktions- und Produktionskosten sowie höhere Erlöse und geringere Risiken, die nur in dieser Geschäftsbeziehung realisiert werden, entstehen Quasi-Renten. Diese bewirken auf der einen Seite, dass der Anbieter in einer Geschäftsbeziehung gegenüber Konkurrenten Vorteile hat und sie unterbieten kann (fundamentale Transformation). Auf der anderen Seite kann der Abnehmer sich opportunistisch verhalten und mehr verlangen als ihm freiwillig gewährt wird (hold-up-Problematik).

ABBILDUNG 2: TYPISIERUNG IN GESCHÄFTSBEZIEHUNGEN

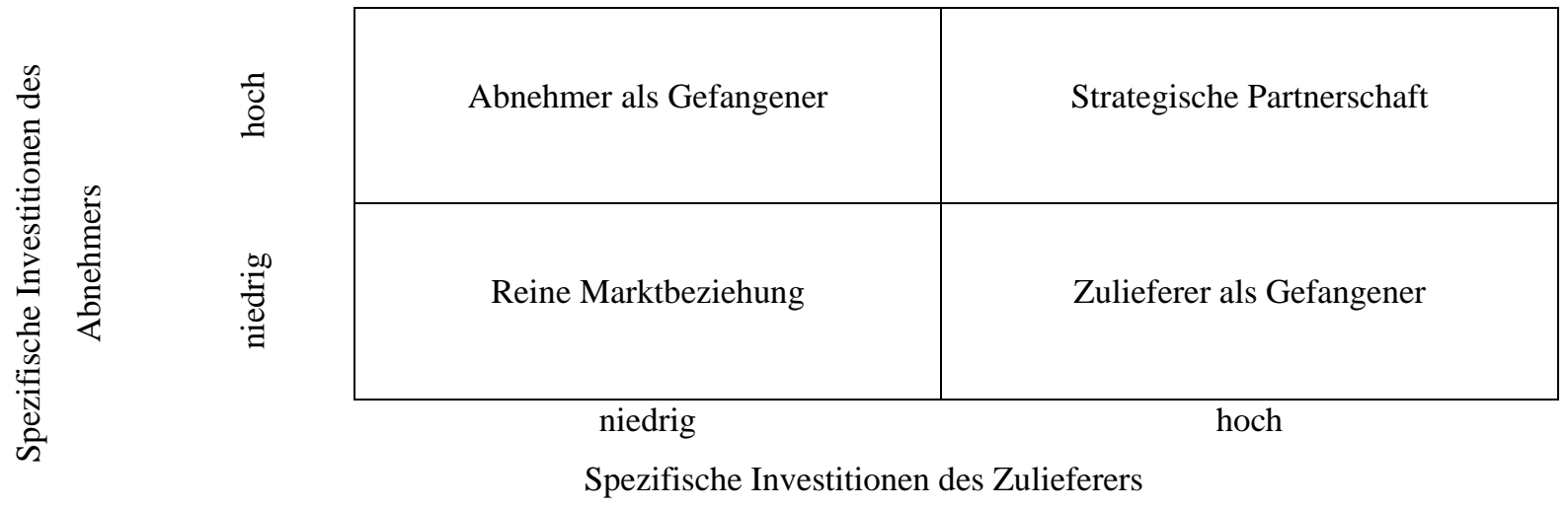

Quelle: Stölzle/Heusler 2003: 173

Das Beziehungsmanagement hat, wie im vorigen Abschnitt erläutert, die strategischen Partnerschaften im Fokus. Dabei ist nicht nur der ökonomische Erfolg, sondern auch Beziehungsgerechtigkeit von großer Bedeutung. Eine Konkretisierung des Beziehungsmanagements ist allerdings nur zum Teil vorhanden. Dabei sind die Konstrukte Vertrauen und Commitment für die Steuerung von Geschäftsbeziehungen maßgeblich (Wilson 1995: 337). Vertrauen und Commitment werden jeweils unterschiedlich definiert und operationalisiert. 
Beispiele für Vertrauen finden sich bei Moorman et al. 1992 („,...a willingness to rely on an exchange partner in whom one has confidence“), Hansen et al. 2002: 42 („Trust is the extent to which one believes that the other will not act to exploit one's vulnerabilities“), Schurr/Oyanne 1985; Dwyer et al. 1987 („Vertrauen ist der Glaube, dass der Geschäftspartner in seinen Zusagen und Versprechen verlässlich ist, seinen Verpflichtungen nachkommt und seine gesamte Kraft in die Geschäftsbeziehung legt“), Ganesan 1993; Doney/Cannon 1997; Batt/Rexha 1999 („Vertrauen ist eine wichtige Determinante langfristiger Geschäftsbeziehungen, die opportunistisches Verhalten und Transaktionskosten reduziert"). Commitment bzw. die innere Verpflichtung wird von Dwyer et al. (1987: 19) als „an implicit or explicit pledge of relational continuity between exchange partners“ definiert. Moormann et al. (1992: 316) verstehen darunter „... ein beständiges Verlangen, eine geschätzte Geschäftsbeziehung aufrechtzuerhalten“. Die Operationalisierungen der Konstrukte müssen an die spezifischen Geschäftsbeziehungen angepasst werden. Problematisch ist eher, dass das Beziehungsmanagement bislang noch keine institutionelle Umsetzung erfahren hat. Allerdings werden erste Ansätze, z. B. mit Beziehungspromotoren etc., diskutiert (Stölzle/Heusler 2003: 187; Walter 1998).

Maßgeblich für den Wechsel vom Beeinflussungs- zum Beziehungsmarketing und damit auch einen Paradigmenwechsel in der Marketingwissenschaft waren zum einen die Sättigung vieler Märkte und die Erkenntnis, dass es u. U. lohnender ist, vorhandene Kundenbeziehungen auszubauen als neue Kunden zu gewinnen (Grönroos 2000: 20). Teilweise reduzierten sich die Kundenzahlen durch Konzentrationsprozesse selbst, wodurch die Abhängigkeit vom einzelnen Kunden stieg. Zudem ist durch einen steigenden Qualitätswettbewerb eine Orientierung an den Kundenwünschen im Sinne des Total Quality Managements erforderlich. Aber auch neue Datenbank- und Kontakttechnologien ermöglichen die quasi-individuelle Kundenbeziehung auch in Massenmärkten (Diller 2001: 164). Tabelle 2 stellt die Unterschiede im Beeinflussungs- und Beziehungsmarketing im Überblick dar. 
TABELLE 2: VERGLEICH BEEINFLUSSUNGS- VERSUS BEZIEHUNGSMARKETING

\begin{tabular}{|c|c|}
\hline Beeinflussungsmarketing & Beziehungsmarketing \\
\hline Orientierung am kurzfristigen & Orientierung am langfristigen \\
\hline Transaktionserfolg & Beziehungserfolg \\
\hline o Priorität der kurzfristigen & o Priorität der langfristigen Ausschöpfung \\
\hline Kundenabschöpfung & aller Kundenpotenziale \\
\hline o Wachstum durch neue Kunden & o Wachstum durch Kundenbindung \\
\hline $\begin{array}{l}\text { o Transaktionsorientierte Sicht der } \\
\text { Kundenbeziehung }\end{array}$ & $\begin{array}{l}\text { o Evolutorisches Verständnis der } \\
\text { Kundenbeziehung }\end{array}$ \\
\hline Priorität des Produkterfolgs & Priorität des Kundenerfolges \\
\hline o Umsatz und Marktanteil als & o Kundennähe, -zufriedenheit und \\
\hline Marketingoberziele & Kundenbindung als Marketingoberziele \\
\hline $\begin{array}{l}\text { o Gesamtmarkt- oder Segmentbetrachtung } \\
\text { im Marketing-Management }\end{array}$ & $\begin{array}{l}\text { o Individuelle Steuerung von } \\
\text { Kundenbeziehungen }\end{array}$ \\
\hline $\begin{array}{l}\text { O Kontrolle der Vorteilhaftigkeit von } \\
\text { Transaktionen }\end{array}$ & $\begin{array}{l}\text { O Vertrauen in Fairness der } \\
\text { Geschäftsprozesse }\end{array}$ \\
\hline Aktionistische Marketingprozesse & Interaktive Marketingprozesse \\
\hline o Broadcasting-Kommunikation & o Dialog-Kommunikation \\
\hline o Standardisierte Marketingaktivitäten & o Individualisierte Marketingaktivitäten \\
\hline o Anonymes Massenmarketing & o Aktive Förderung der Interaktion \\
\hline o Klare Grenzen zum Kunden & o Integration des Kunden \\
\hline
\end{tabular}

Quelle: Diller 1991: 162

Zwischenfazit: Das Relationship Management ist durch einen Paradigmenwechsel vom Beeinflussungs- zum Beziehungsmarketing geprägt. Damit stehen langfristige Beziehungen und nicht nur einzelne Transaktionen im Blickpunkt, die die Prioritäten des Unternehmens strategisch verschieben. Besonders verhaltenswissenschaftliche Kategorien wie Vertrauen und Commitment spielen eine herausragende Rolle.

\subsection{Blickrichtung Kunde: Customer Relationship Management}

Die Entwicklung des Relationship Managements war zunächst auf das Investitionsgütermarketing fokussiert. Hier stehen langfristige Verträge aufgrund der stärkeren Bedeutung von Systemlieferanten bzw. Single Sourcing eine traditionelle Rolle. Damit trat verstärkt der Umgang mit langfristigen Verträgen und den daraus resultierenden Vor- und Nachteilen in den Vordergrund. Das Konsumgütermarketing hat die Ideen des Investitionsgütermarketings mit dem Konzept des Customer Relationship Managements erst geraume Zeit später übernommen. Auslöser war die Diskussion um Kundenzufriedenheit. Mit dem Servqual-Konzept (Service Quality) wurde ein standardisiertes Verfahren entwickelt, das die Qualität von Dienstleistungen als Differenz zwischen erwarteter und erhaltener Dienstleistung misst (Zeithaml et al. 1988). 
Die Analyse der Geschäftsbeziehung zum Kunden werden unter dem Konzept Customer Relationship Management (CRM) (synonym wird von einigen Autoren auch der Begriff Kundenbindungsmanagement verwendet) und allerdings wieder bezogen auf gewerbliche Abnehmer - unter dem Begriff Key Account Management diskutiert (siehe Abbildung 3) (Plinke 1997: 19; Stölzle/Heusler 2003: 178). Ziel des CRM ist es, die Kundenbearbeitung ganzheitlich an den Kundenbedürfnissen auszurichten (Dangelmaier et al. 2002: 5). Das Key Account Management, ursprünglich im Business-to-Business Bereich (B-to-B) aus der Bearbeitung für den Unternehmenserfolg bedeutender Industriekunden entstanden, ist heute auch im Konsumgütervertrieb weit verbreitet (Kleinaltenkamp/Rieker 1997: 164). Dabei wird nicht der Verbraucher als Kunde angesprochen, sondern bedeutende Einzelhändler, die eine hohe Absatzrelevanz haben.

AbBiLdung 3: Praktische ERsCheinungsFormen DEs Business-TO-Business Marketings

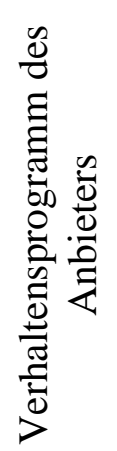

\begin{tabular}{|c|c|c|}
\hline \multirow[b]{3}{*}{$\begin{array}{l}\text { Transaction } \\
\text { Marketing }\end{array}$} & \multicolumn{2}{|c|}{ Anbieterfokus } \\
\hline & Markt(segment) & Einzelkunde \\
\hline & Markt(segment)-Management & Projekt-Management \\
\hline $\begin{array}{c}\text { Relationship } \\
\text { Marketing }\end{array}$ & $\begin{array}{c}\text { Kundenbindungs-Management } \\
\text { Customer Relationship } \\
\text { Management }\end{array}$ & Key Account Management \\
\hline
\end{tabular}

Quelle: leicht verändert nach Plinke 1997: 19

Beim Customer Relationship Management (CRM) steht der Endkunde im Fokus der Managementaktivitäten. Dieses Konzept umfasst „die Planung, Durchführung, Kontrolle sowie die Anpassung aller Unternehmensaktivitäten, die zur Erhöhung der Profitabilität der Kundenbeziehung“ beitragen (Homburg/Sieben 2000: 475). Folgende Prinzipien sind charakteristisch:

- Eine über alle Unternehmensaktivitäten konsequent ausgerichtete Kundenorientierung.

- Eine differenzierte Bearbeitung des Kunden in Abhängigkeit vom Kundenwert und damit eine Wirtschaftlichkeitsorientierung.

- Eine langfristige Orientierung der Kundenbearbeitung über den gesamten Kundenlebenszyklus und damit eine Systematisierung der Kundenbeziehung. 
- Die Ausrichtung aller Aktivitäten des Unternehmens gezielt auf einzelne Kundensegmente (Individualisierung).

- Eine systematische Aufnahme und Verarbeitung von Markt- und Kundeninformationen durch IT-Anwendungen, insbesondere Database-Marketing.

Eine Steigerung des Unternehmenswertes soll durch höhere Kundenzufriedenheit und -bindung erreicht werden (Dangelmaier et al. 2002: 5). Die Kundenzufriedenheit ist ein sehr wichtiges Element für ein erfolgreiches CRM (Sieben 2001: 298). Darunter wird im Allgemeinen die emotionale Reaktion eines Kunden auf die von ihm vorgenommene „kognitive Beurteilung eines Objektes“ verstanden (Henning-Thurau/Hansen 2001: 878). Zu Messung von Kundenzufriedenheit und ihrer Einflussgrößen gibt es eine ausgedehnte wissenschaftliche Debatte, die hier nicht näher aufgegriffen werden soll (Homburg et al. 1999: 174 f.) (vgl. Kap. 2.2). Interessanter ist der Einfluss von zufriedenen bzw. unzufriedenen Kunden. Kundenzufriedenheit beeinflusst demnach die Einstellungsebene des Verbrauchers, die auf der Verhaltensebene zu Kundenloyalität und dem Kauf weiterer Produkte des Herstellers führt (Cross Selling) und auf der Kommunikationsebene negative bzw. positive Mund-zu-Mund Werbung auslöst (Henning-Thurau/Hansen 2001: 878). Für das Beziehungsmanagement kann gezeigt werden, dass der Einfluss von Kundenzufriedenheit auf die Kundenloyalität sehr komplex ist und auch zufriedene Kunden wechseln (Spiller et al. 2005b).

Insgesamt ist das CRM ein etablierter Ansatz, der durch seine technische Umsetzung in entsprechenden Softwarelösungen eine weite Verbreitung gefunden hat. Bei eigenen Arbeiten wurden exemplarisch die Kundenzufriedenheit und -bindung und deren Einfluss auf das Wechselverhalten von Bio-Intensivkäufern untersucht (Spiller et al. 2005b, Gerlach et al. 2005b). Als Ergebnis zeigt sich, dass Kundenzufriedenheit zwar ein notwendiger, aber kein hinreichender Faktor für eine langfristige Kundenbindung ist. Variety Seeking, aber auch kostengünstige Konkurrenzangebote lassen selbst zufriedene Kunden ihre Geschäftsstätte wechseln. Bei sehr stabilen Kundenbeziehungen spielen vor allem nicht-ökonomische Aspekte wie die persönliche Bindung und Überzeugungen eine herausragende Rolle. Im Zuge eines Customer Relationship Managements gilt es daher, diese Aspekte systematisch zu erfassen und auszubauen. 


\subsection{Blickrichtung Lieferanten: Supplier Relationship Management}

Das Supplier Relationship Management (SRM) ist eine spiegelbildliche Übertragung des CRM auf die Beschaffungsseite (Koppelmann 2003: 79). Dabei stehen Aufbau und Pflege von Lieferantenbeziehungen im Vordergrund (Stölzle/Heusler 2003: 181). Insgesamt hat die strategische Betrachtung des Lieferantenmanagements bisher in der betrieblichen Praxis nur geringe Relevanz. Besonders im Agribusiness wird die Auseinandersetzung mit diesem Thema erst sehr randständisch vorgenommen (Gerlach et al. 2005a; Gerlach et al. 2005b, Berendson 2005, Spiller et al. 2005a). Der geringe Stellenwert liegt darin begründet, dass der klassische Einkauf durch eine Transaktionsorientierung mit einem starken Fokus auf den Einkaufspreis geprägt ist und eine strategische Betrachtung der Lieferantenbeziehung lange unterblieben ist (Eßig 2001: 24). Durch steigenden Wettbewerbsdruck und zunehmende Qualitätsanforderungen wird aber die langfristige Bedeutung der Beschaffung stärker virulent (Arnold 1997). Eine Prozessoptimierung kann zum Beispiel nur in Zusammenarbeit mit Lieferanten geschehen, was letztlich zum Supplier Relationship Management führt (Bogaschewsky 2003: 37). Primär steht im SRM zwar die Lieferantenbeziehung im Mittelpunkt, dennoch findet die Optimierung der gesamten Wertschöpfungskette Berücksichtigung (Eßig 2003: 327).

Die längerfristige Zusammenarbeit im Agribusiness bietet gegenüber ungebundenen Geschäftsbeziehungen in Fragen der Qualitätssicherung, Markenführung und Innovationspolitik Vorteile (Bogetoft/Olesen 2004). Dabei ist ein aktives Lieferantenmanagement, das auf langfristige und vertrauensvolle Zusammenarbeit setzt, u. a. für Unternehmen aus dem Qualitätssegment sinnvoll. In der Langfristigkeit und partnerschaftlichen Betrachtung der Lieferantenbeziehungen werden die Wurzeln des Relationship Management deutlich. Eine enge Lieferantenbindung hat folgende Vorteile (siehe Tabelle 3). 
TABELLE 3: VORTEILE EINER ENGEN LIEFERANTENBINDUNG

$>$ Höhere Zufriedenheit beider Parteien

$>$ Längerfristige Planungssicherheit durch geringere Wechselbereitschaft

> Entschärfung von opportunistischem Verhalten bei Verteilungs- und Zielkonflikten/ kooperativere Preisverhandlungen

$>$ Flexibilität und Geschwindigkeit im Wettbewerb durch bessere Abstimmung und höhere Kommunikationsintensität

$>$ Senkung von Transaktionskosten durch Wegfall von Neuakquisition und Vertragsverhandlungen

$>$ Senkung von Prozesskosten durch Abstimmung von (EDV-) Schnittstellen

$>$ Ermöglichung von Just-in-Time-Konzepten und Efficient Consumer Response

$>$ Anpassung von Losgrößen

$>$ Besseres Qualitätsmanagement durch vertrauensvollen Informationsaustausch

$>$ Entwicklungspartnerschaften mit Lieferanten (simultaneous engineering)

$>$ Commitment erhöht die Investitionsbereitschaft der Lieferanten

$>$ Senkung von Koordinationskosten (z. B. bei Reklamationen, Streitigkeiten usf.)

Quelle: Gerlach et al. 2004: 7

Die langfristige und partnerschaftliche Orientierung, gemäß den Prinzipien des Relationship Marketing, ist eine zentrale Prämisse des Relationship Marketing (Stölzle/Helm 2003: 287). Zudem wird die Notwendigkeit der Betrachtung der Lieferantenbeziehung auch vor dem Hintergrund der Optimierung der Supply Chain gesehen (Wathne/Heide 2004: 74 f.). So können z. B. durch langfristige und partnerschaftliche Zusammenarbeit zwischen Verarbeiter und Kunde erreichte Vorteile durch Probleme der Verarbeiter mit ihren Lieferanten, bspw. mangelhafte Qualitäten, empfindlich gestört werden. Auch ein Abbruch der Geschäftsbeziehung zu dem Kunden ist im Extremfall als Folge denkbar. Es reicht also im Sinne des SCM nicht aus, nur die Geschäftsbeziehung zu den Kunden zu optimieren; vielmehr muss auch die Lieferantenbeziehung mit einbezogen werden.

Im Agribusiness wurden die Geschäftsbeziehungen zwischen Landwirten und abnehmender Industrie bislang nur in wenigen Studien untersucht. $\mathrm{Zu}$ den Beiträgen zählt eine Studie zur Beziehung zwischen Traubenanbauern und Winzern in West-Australien (Batt and Wilson 2001), eine ähnliche Untersuchung beschäftigte sich mit der Beziehung zwischen kleinen landwirtschaftlichen Betrieben und ihren Abnehmern in Indonesien (Gusti et al. 2004). Clare et al. (2005) evaluierten die Beziehung zwischen Landwirten, Viehhändlern und Schlachthäusern in Neuseeland im Rindfleischmarkt. Um dieses Feld weiter zu beleuchten, wurden eigene Studien zur Geschäftsbeziehung zwischen Zuckerproduzenten und Zuckerfabrik in Norddeutschland (Gerlach et al. 2005a) und Milchbauern und Molkereien in Nordwestdeutschland (Gerlach et al 2005b) durchgeführt. Die Geschäftsbeziehung zwischen Schweine- 
produzenten und Schlachthöfen untersuchten Spiller et al. (2005a) ebenfalls in Nordwestdeutschland.

Als Ergebnis der Studien zur Milch- und Zuckerwirtschaft zeigt sich, dass vermeintlich „weichen Faktoren“, wie Beschwerdemöglichkeiten und das Vertrauen der Lieferanten, einen erheblichen Einfluss auf die Zufriedenheit mit der Geschäftsbeziehung haben. Die Preiszufriedenheit hat zwar einen Einfluss, ist aber in beiden Studien nicht der wichtigste Faktor. Als Ergebnis kann festgehalten werden, dass es sich lohnt im Agribusiness zufriedene Landwirte zu haben, denn diese sind eher bereit, Kapitalerhöhungen mitzutragen und sich den strukturellen Erfordernissen anzupassen. Sie informieren sich außerdem intensiver über die Anforderungen des Abnehmers. In der Studie zur Molkereiwirtschaft konnte gezeigt werden, dass zufriedene Lieferanten weniger dazu tendieren, ihre Molkerei zu wechseln und eine Gegenmacht zur Molkerei zu bilden (z. B. BDM-Mitgliedschaft).

Insgesamt bietet das strategische SRM für viele Unternehmen des Agribusiness Chancen vor allem in Hinblick auf die sich abzeichnende Strukturanpassung in der Landwirtschaft. Letztlich sollten auch Abnehmer von Standardware interessiert sein, leistungsfähige Lieferanten an sich zu binden, da der Wettbewerb zunehmend über die gesamte Wertschöpfungskette ausgetragen wird.

Wie eigene Studien und zahlreiche Praxisberichte zeigen, ist die Ernährungsindustrie zurzeit in vielen Fällen durch ein antagonistisches Verhältnis zu ihren Lieferanten charakterisiert. Kurzfristige Geschäftsbeziehungen, geringes Vertrauen und eine Tendenz zu opportunistischem Verhalten erweisen sich als Barrieren eines Relationship Managements. Auf Langfristigkeit ausgelegte Lieferantenbeziehungen erleichtern es dagegen dem Hersteller, strategische Richtungswechsel bei den landwirtschaftlichen Lieferanten durchzusetzen. Insgesamt führt ein erfolgreiches SRM zu höherer Flexibilität, Stabilität, Qualität und Innovationskraft (Stölzle 2000: 17). Dem stehen die Kosten der Lieferantenpflege gegenüber, die nicht nur die direkten Maßnahmen (z. B. verstärkte Kommunikation), sondern auch die geringeren Möglichkeiten des Preisdrucks umfassen.

Das Supplier Relationship Management hat bislang eine sehr geringe Relevanz im Agribusiness. Aufgrund der hohen Plausibilität eines systematischen Lieferanten- 
managements vor allem bei den skizzierten Rahmenbedingungen ist dieses Konzept aber für weite Teile des Agribusiness sinnvoll.

\subsection{Blickrichtung Stakeholder: Stakeholder Relationship Management}

In den vorherigen Ausführungen wurde die Bedeutung des Geschäftsbeziehungsmanagements mit den spezifischen Blickwinkeln auf Kunden und Lieferanten erläutert. Damit sind ausschließlich marktliche Akteure in die Betrachtung des Relationship Managements eingeschlossen. Aber auch externe Anspruchsgruppen haben Einfluss auf den Unternehmenserfolg. Ein bekanntes Beispiel hierfür war die Auseinandersetzung zwischen Shell und Greenpeace um die Ölplattform Brent Spar (Dyllick 1990), aber auch die beschriebenen Beispiele im Agribusiness.

Gesellschaftliche Auseinandersetzungen wie z. B. um die Rolle der Ernährungswirtschaft für eine gesunde Ernährung oder die grüne Gentechnologie zeigen, dass es auch hier um den Aufbau langfristiger Vertrauenspotenziale geht. Eine Vielzahl von Studien zeigen, dass die Ernährungswirtschaft insgesamt über ein ausgesprochen niedriges Vertrauen in der Bevölkerung verfügt (siehe Abbildung 4) (Kafka 1999: 56). 
AbBILDUnG 4: GRAd DES VeRTRAuens in BEZUG AUf LEBENSMITTELSKANDALE

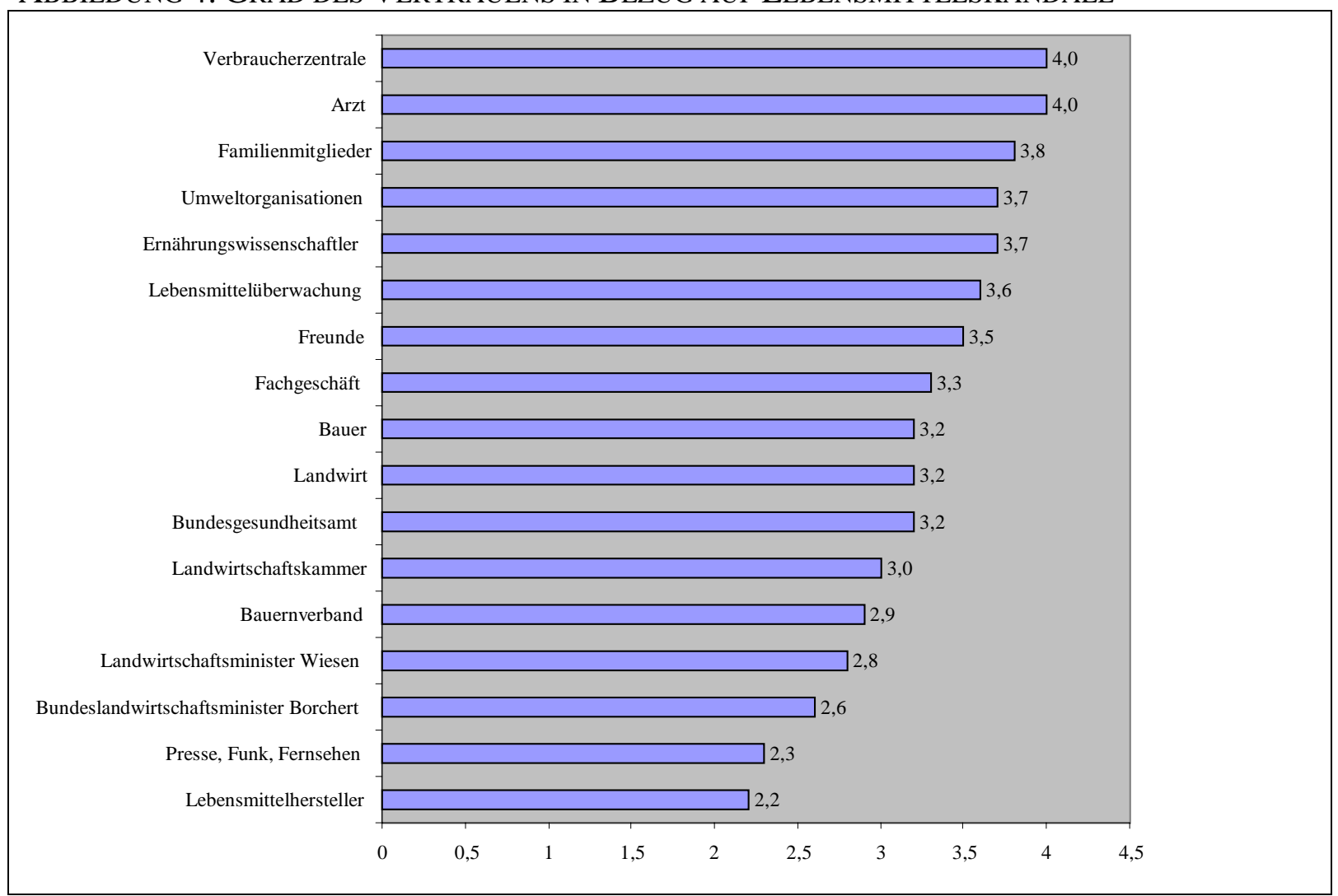

arith. Mittel (1 = starkes Misstrauen, 5 = starkes Vertrauen)

Quelle: Kafka 1999: 56

Daher soll das Relationship Management an dieser Stelle um Beziehungen zu nichtmarktlichen Akteuren erweitert werden. Wie im Kapitel 2.3 ausgearbeitet wurde, fällt es Unternehmen des Agribusiness schwer, sich auf die veränderten gesellschaftlichen Ansprüche einzustellen. Aufgrund der potenziellen Relevanz dieser Ansprüche und der zunehmenden öffentlichen Bedeutung des Agribusiness ist eine Einbeziehung dieser nicht-marktlichen Akteure nötig. Im Folgenden sollen die theoretischen Ursprünge in der Auseinandersetzung mit gesellschaftlichen Anspruchsgruppen dargestellt werden.

Die Beschäftigung mit gesellschaftlichen Ansprüchen an Unternehmen ist seit jeher Gegenstand der ökonomischen Forschung. Sie lässt sich bis in die Gründungsphasen von Volks- und Betriebswirtschaftslehre zurückverfolgen (Wieland 1997). Dabei lassen sich vier zentrale Forschungslinien identifizieren. In der allgemeinen Managementforschung spiegelt sich Gesellschaftsorientierung in der Debatte um Unternehmensethik und Corporate Social Responsibility auf der einen und - stärker umsetzungsorientiert - Stakeholdermanagement sowie Strategische Frühaufklärung auf der anderen Seite. Eine ähnliche Zweiteilung in eine grundsätzlich normative Analyse und eine handlungsorientierte Variante findet sich in der 
Marketing- und Kommunikationsforschung mit der Debatte um Social Marketing einerseits und neuen Formen der Public Relations andererseits.

Wichtige Beiträge für die unternehmensethische Debatte gingen von der diskursorientierten Gesellschaftstheorie von Habermas aus (1983). Hier wird in normativer Hinsicht eine grundlegende Dialogausrichtung der Unternehmen eingefordert, die sich in vielfältigen demokratischen Verständigungsprozessen zwischen Unternehmen und ihren Anspruchsgruppen niederschlagen soll (Ulrich 1998). Die neuere Debatte um Corporate Social Responsibility bzw. Corporate Citizenship spiegelt dagegen im Kern eine verantwortungsethische Position und betont die Notwendigkeit, die Unternehmenspolitik immer wieder auf ihre globale gesellschaftliche Verträglichkeit zu überprüfen (Saiia/Cyphert 2003; De Geer 2004).

Als prominenter Ansatz zur Einbindung gesellschaftlicher Ansprüche in die Unternehmensführung gilt i. A. der Stakeholderansatz (Freeman 1984). Er wird zumeist erfolgsstrategisch aufgefasst, d. h. Anspruchsgruppen sind soweit zu berücksichtigen, wie von ihnen ein realistisches Drohpotenzial ausgeht (Liebl 1996: 102 f.). Während der Stakeholderansatz akteurfokussiert vorgeht, richtet sich die Strategische Frühaufklärung (Ansoff 1976) auf Themenlebenszyklen. Hauptkritikpunkt an diesen Ansätzen ist ihre geringe Implementierung in der betrieblichen Praxis, die im auffallenden Kontrast zur Diffusion der Konzepte in der Managementtheorie steht (Zühlsdorf 2002: 127 ff.).

Institutionell liegt die Verantwortung für den Umgang mit Anspruchsgruppen im Unternehmen i. d. R. bei der Marketing- oder PR-Abteilung. Es verwundert daher nicht, dass sich diese Disziplinen seit längerer Zeit mit der Schnittstelle zur Gesellschaft beschäftigen. Die Marketinglehre tat dies in den 70er Jahren zunächst in Form des Social Marketing (Kotler 1988) bzw. des Human Concept of Marketing (Dawson 1969), indem sie eine Erweiterung des unternehmenspolitischen Zielkatalogs um außerökonomische Gesichtspunkte diskutierte. Seit dieser Zeit sind insbesondere unter verbraucher- und umweltpolitischen Gesichtspunkten eine Vielzahl weiterer Varianten eines gesellschaftsorientierten Marketings (Wiedmann 1993) postuliert worden. In der PR-Forschung findet sich in den 90er Jahren eine ähnliche Diskussion unter dem Begriff der dialogorientierten Öffentlichkeitsarbeit, die insbesondere auf die viel beachteten Arbeiten von Grunig/Hunt (1984) zurückgeht. 
Im Gegensatz zu diesen eher abstrakten Diskussionen gibt es in der neueren PR-Theorie Ansätze, die auf eine stärkere praktische Fundierung unter Einbezug kommunikationswissenschaftlicher Erkenntnisse und speziell der Medienforschung setzen. Die Medienforschung hat unter dem Begriff Nachrichtenwert (Galtung/Ruge 1965) und besonders in systemtheoretischen Ansätzen die hohe Selektivität des Mediensystems herausgearbeitet, da immer nur ein sehr kleiner Teil des realen Geschehens Beachtung finden kann (Luhmann 1996). Diese Scheinwerferfunktion macht die Medienberichterstattung insbesondere in Krisensituationen für die Unternehmen unberechenbar, da sie einer spezifischen Eigenlogik folgt. Welche Themen besonders in den Vordergrund rücken und wie sie frühzeitig identifiziert und beeinflusst werden können, ist Gegenstand des Issues-Managements (Liebl 2000). Mit Bezug auf Entwicklungen in der politischen Landschaft wird dabei in den letzten Jahren die besondere Rolle von strategisch konzipierten Themenkampagnen zur Beeinflussung der öffentlichen Meinung hervorgehoben (Röttger 1997; Zühlsdorf 2002). Besonders NGOs wie Greenpeace haben die Möglichkeiten der Mediengesellschaft in der Auseinandersetzung um öffentliche Aufmerksamkeit frühzeitig aufgegriffen (Hecker 1997).

Im Folgenden soll das Stakeholder Management - aufgrund seines Akteursfokus - als ein Baustein des erweiterten Relationship Managements vorgestellt werden. Die Stakeholder Theorie sieht die Beziehung zwischen Unternehmen und externen Gruppen aus Sicht der Anspruchsgruppen. Als Anspruchsgruppe werden alle Gruppen innerhalb und außerhalb eines Unternehmens bezeichnet, die zur Leistungserstellung beitragen. Ein Unternehmen kann erst dann funktionieren, wenn alle Anspruchsgruppen ihren Beitrag leisten. Die Gruppen erwarten eine Gegenleistung des Unternehmens, sodass es zu Zielkonflikten zwischen den verschiedenen Stakeholdern kommen kann. Eine wichtige Fragestellung der StakeholderTheorie ist die Frage nach der Auswahl der Anspruchsgruppen. Dyllick (1984: 75) nennt sieben Gruppen, die aus seiner Sicht untersucht werden müssen (vgl. Tabelle 4). Dazu zählen die Eigentümer, das Management und die Mitarbeiter als interne Anspruchsgruppen. Als externe Anspruchsgruppen sind Lieferanten, Kunden, Staat und Gesellschaft wichtig. 
TABELLE 4: DiE LEISTUNGEN DER ANSPRUCHSGRUPPEN FÜR DIE UNTERNEHMUNG UND DIE DAFÜR ERWARTETEN GEGENLEISTUNGEN

\begin{tabular}{|c|c|c|c|}
\hline & \begin{tabular}{|l|} 
Anspruchsgruppen \\
\end{tabular} & Leistungen & Gegenleistungen \\
\hline \multirow{3}{*}{ 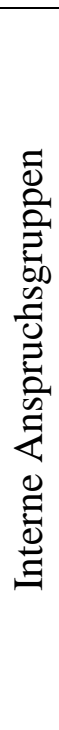 } & Eigentümer & Eigenkapital & $\begin{array}{l}\text { Einkommen, Erhaltung, } \\
\text { Verzinsung, Wertsteigerung des } \\
\text { investierten Kapitals, } \\
\text { Mitgestaltung }\end{array}$ \\
\hline & Management & $\begin{array}{l}\text { Kompetenz, } \\
\text { Engagement, } \\
\text { Leistung }\end{array}$ & $\begin{array}{l}\text { Einkommen, Macht, Einfluss, } \\
\text { Prestige, Entfaltung eigener Ideen } \\
\text { und Fähigkeiten, Arbeit = } \\
\text { Lebensinhalt }\end{array}$ \\
\hline & Mitarbeiter & $\begin{array}{l}\text { Arbeitskraft, } \\
\text { Fähigkeiten }\end{array}$ & $\begin{array}{l}\text { Einkommen (Arbeitsplatz), soziale } \\
\text { Sicherheit, sinnvolle Betätigung, } \\
\text { Entfaltung der eigenen Fähig- } \\
\text { keiten, zwischenmenschliche Kon- } \\
\text { takte (Gruppenzugehörigkeit), } \\
\text { Status, Anerkennung, Prestige } \\
\text { (ego-needs) }\end{array}$ \\
\hline \multirow{4}{*}{ 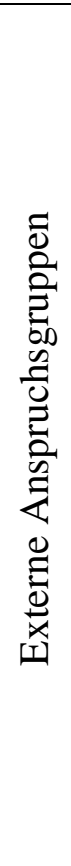 } & Fremdkapitalgeber & Fremdkapital & $\begin{array}{l}\text { Sichere Kapitalanlage, } \\
\text { befriedigende Verzinsung, } \\
\text { Vermögenszuwachs }\end{array}$ \\
\hline & Lieferanten & $\begin{array}{l}\text { Termingerechte } \\
\text { Leistung, hoch- } \\
\text { wertige Güter }\end{array}$ & $\begin{array}{l}\text { Stabile Liefermöglichkeiten, } \\
\text { günstige Konditionen, Zahlungs- } \\
\text { fähigkeit der Abnehmer }\end{array}$ \\
\hline & Kunden & $\begin{array}{l}\text { Kauf der } \\
\text { Produkte, } \\
\text { Markentreue }\end{array}$ & $\begin{array}{l}\text { Qualitativ und quantitativ be- } \\
\text { friedigende Marktleistung zu } \\
\text { günstigen Preisen, Service, } \\
\text { günstige Konditionen usw. }\end{array}$ \\
\hline & $\begin{array}{l}\text { Staat und } \\
\text { Gesellschaft } \\
\text { (Allgemeinheit) }\end{array}$ & $\begin{array}{l}\text { Öffentliche } \\
\text { Sicherheit und } \\
\text { Ordnung, } \\
\text { Infrastruktur, } \\
\text { Legitimität }\end{array}$ & $\begin{array}{l}\text { Steuern, Sicherung der Arbeits- } \\
\text { plätze, Sozialleistungen, positive } \\
\text { Beiträge an die Infrastruktur, Ein- } \\
\text { halten von Rechtsvorschriften und } \\
\text { Normen, Teilnahme an der poli- } \\
\text { tischen Willensbildung, Beiträge } \\
\text { an kulturelle, wissenschaftliche } \\
\text { und Bildungsinstitutionen }\end{array}$ \\
\hline
\end{tabular}

Quelle: Dyllick 1984: 75

Die Frage, welche Stakeholder relevant für ein Unternehmen sind, wird sehr kontrovers diskutiert. Mitchel et al. (1997: 865 ff.) plädieren dafür, die Kriterien Macht, Legitimität und Dringlichkeit zu nutzen (vgl. Tabelle 5). 
TABELLE 5: STAKEHOLDERIDENTIFIKATION ANHAND VON MACHT, LEGITIMITÄT UND DRINGLICHKEIT

\begin{tabular}{|l|l|l|}
\hline Identifikationsmerkmal & \multicolumn{1}{|c|}{ Definition } & \multicolumn{1}{c|}{ Ausprägung } \\
\hline Macht & $\begin{array}{l}\text { Durchsetzung der eigenen } \\
\text { Ziele auch gegen die } \\
\text { Widerstände anderer }\end{array}$ & $\begin{array}{l}\text { Ressourcen in Form von Geld, } \\
\text { Informationen, Know-how, } \\
\text { Rechten, Persönlichkeits- } \\
\text { merkmalen }\end{array}$ \\
\hline Legitimität & $\begin{array}{l}\text { Legitimität wird denjenigen } \\
\text { Handlungen zugesprochen, } \\
\text { die vom sozialen System als } \\
\text { angemessen und richtig } \\
\text { bezeichnet werden }\end{array}$ & $\begin{array}{l}\text { Regulative Legitimität } \\
\text { Einhaltung von Gesetzen } \\
\text { Normative Legitimität: } \\
\text { Werte und Normen } \\
\text { Kognitive Legitimität } \\
\text { Orientierung an zugewiesenen } \\
\text { Handlungsrollen }\end{array}$ \\
\hline Dringlichkeit & $\begin{array}{l}\text { Der Grad mit welchem } \\
\text { Stakeholder Anspruch auf } \\
\text { sofortige Aufmerksamkeit } \\
\text { stellt. }\end{array}$ & $\begin{array}{l}\text { O Geringe Dringlichkeit } \\
\text { Mittlere Dringlichkeit } \\
\text { Hohe Dringlichkeit }\end{array}$ \\
\hline
\end{tabular}

Quelle: Eigene Zusammenstellung nach Mitchell, et al. 1997: 866 ff; Theuvsen 2001: 7 ff;

Mit Macht besteht die Möglichkeit, innerhalb einer sozialen Beziehung die eigenen Ziele auch gegen die Widerstände anderer durchzusetzen (Weber 1956: 28). Salancik und Pfeffer (1973) sagen: „Macht ist vielleicht schwierig zu definieren, aber nicht schwer zu erkennen.“ Bei Stakholdern kann sich Macht auf ökonomische und außerökonomische Ressourcen beziehen, z. B. die Möglichkeiten zum Konsumboykott, soziale Isolation des Unternehmens/Unternehmers oder Beschädigung des Images. Legitimität wird denjenigen zugesprochen, die aus Sicht der Mitglieder eines sozialen Systems angemessen und richtig handeln (Suchmann 1995: 574; zitiert nach Theuvsen 2001: 7). Ob die Ansprüche eines Stakeholders als legitim akzeptiert werden, ist wiederum eine Machtfrage, da Legitimitätsurteile durch andere soziale Gruppen in Frage gestellt werden können. Die Legitimitätsgrundlage wird unterschieden in regulative, normative und kognitive Legitimität. Die legitimsten Stakeholder sind diejenigen, die auf unumstrittenen Legitimitätsbasen stehen. Eine hohe Dringlichkeit der Stakeholderansprüche ist dann gegeben, wenn es sich um einen zeitkritischen Moment mit aus Sicht der Anspruchsgruppe hoher Bedeutung handelt (Theuvsen 2001: 9). Aus diesen drei Komponenten ergeben sich nach Mitchell et al. (1997) sieben Stakeholdertypen, die unterschiedlich zu behandeln sind (siehe Abbildung 5). 


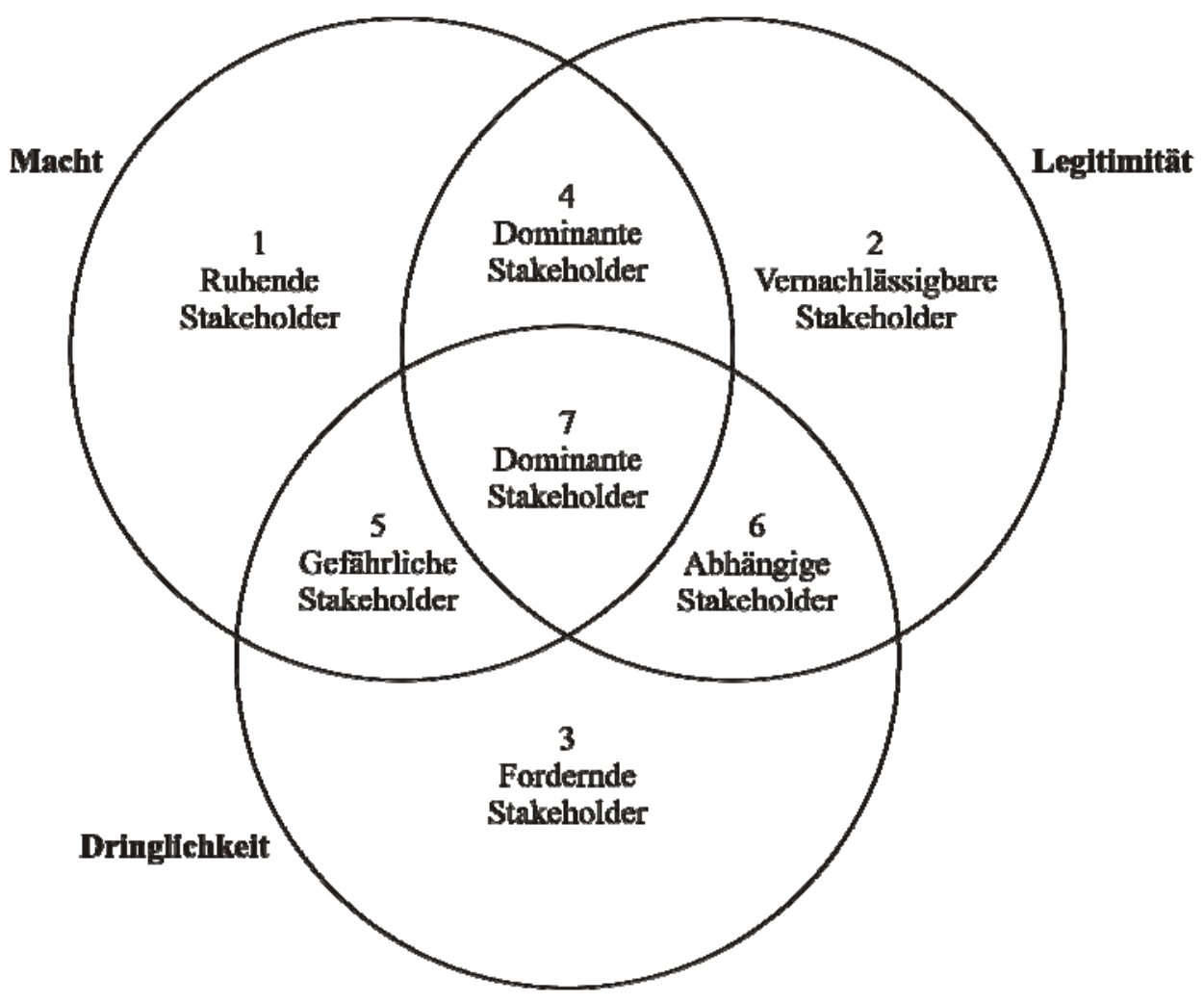

Quelle: Mitchell et al. 1997: 872, Theuvsen 2001: 18

Andere Autoren plädieren für ein dreistufiges Vorgehen bei der Stakeholderanalyse. Zunächst werden alle relevanten Stakeholder aufgeführt, wobei vor allem in der Praxis vielfältige Abgrenzungsprobleme aufkommen. Hier hat sich vor allem das checklistenbezogene Scanning durchgesetzt (Zühlsdorf 2001: 153). Im nächsten Schritt werden die Gruppen im Hinblick auf ihre Ansprüche und Leistungen sowie auf die Relevanz für die Unternehmenspolitik bewertet (Liebl 1996: 103 ff).

Neben der Identifikation von Stakeholdern ist der Umgang mit diesen ein weiterer Schwerpunkt der wissenschaftlichen Auseinandersetzung. Dabei reichen die Strategien von einer Verminderung der Abhängigkeit von der Anspruchsgruppe über Diversifikation, Herstellung besonderer Beziehungen zu Anspruchsgruppen und die Beeinflussung der Machtbasis von Stakeholdern bis hin zur Verminderung der „Kosten der Abhängigkeit“ durch Gestaltung der eigenen Organisation (Dyllick 1984: 76). Auch kommunikative Verfahren werden diskutiert (Roloff 2002: 78). An dieser Stelle sei auf die verschiedenen Strategien nicht weiter eingegangen, da die Strategiewahl sehr stark vom Einzelfall abhängt und letztlich 
ein empirischer Beweis, dass bestimmte Strategien erfolgsversprechender sind als andere, nicht zu erbringen ist.

Insgesamt ist ein strategisches Stakeholdermanagement bislang im Agribusiness die Ausnahme. Aber auch anderen Wirtschaftsbereichen fällt aufgrund der schwierigen institutionellen Umsetzung ein strategisches Stakeholdermanagement schwer. Für das Agribusiness ist aber aus Sicht der Autorin weniger die institutionelle Umsetzung, die vor allem für landwirtschaftliche Betriebe nicht möglich ist, wichtig, als die Erweiterung des betrieblichen Fokus auf nicht-marktliche Akteure. Der Einfluss von NGOs und anderen Stakeholdern scheint nur im politischen Bereich voll erkannt zu sein. Auch vermeintlich „harmlose“ Anspruchsgruppen wie Nachbarn können sich stark auf das Unternehmenshandeln auswirken. Dies zeigt eine eigene Untersuchung zur Akzeptanz von Tierhaltung in viehschwachen Regionen. Selbst aus landwirtschaftlicher Sicht kleine Ställe werden von der nicht-landwirtschaftlichen Bevölkerung als Massentierhaltung und Bedrohung wahrgenommen. Kommunikationsprobleme und unterschiedliche Ziele lassen schnell Konflikte entstehen, die teilweise richterlich entschieden werden müssen. Bei verschiedenen Unternehmensentscheidungen kann die Erweiterung des Blickwinkels auf nicht-marktliche Akteure Konflikte vermeiden, allerdings auch nicht garantiert ausschließen.

Ein strategisches Stakeholdermanagement sollte in erster Linie dazu dienen, dass die Ansprüche anderer systematisch erfasst, verstanden und ein Umgang mit diesen geplant werden kann. Wie dieser im Einzelfall aussehen kann, ist nicht generalisierbar. Das viele Unternehmen (Heidemark, Landwirte, Müller-Milch) aber letztlich überrascht sind, verdeutlicht die Notwendigkeit der Erweiterung des Blickwinkels. Da besonders landwirtschaftliche Betriebe schnell überfordert sind, ist eine Vernetzung der relevanten Akteure im Agribusiness (DBV, Raiffeisenverband, Landfrauen, CMA, AID) anzustreben.

\section{Relationship Management im Agribusiness}

In dieser Arbeit wurden zunächst die Ursachen für eine mangelnde Markt-, Lieferanten- und Gesellschaftsorientierung aufgezeigt und anschließend mit dem erweiterten Relationship Management-Ansatz ein Konzept vorgestellt, das mit einem langfristigen Fokus auf (Geschäfts-) Beziehungen neue Impulse für die skizzierten Herausforderungen gibt. Die dargestellten Blickwinkel und Ansätze sind in Abbildung 6 schematisch zusammengefasst. 
ABBILDUNG 6: BLICKWINKEL DES ERWEITERTEN RELATIONSHIP MANAGEMENTS

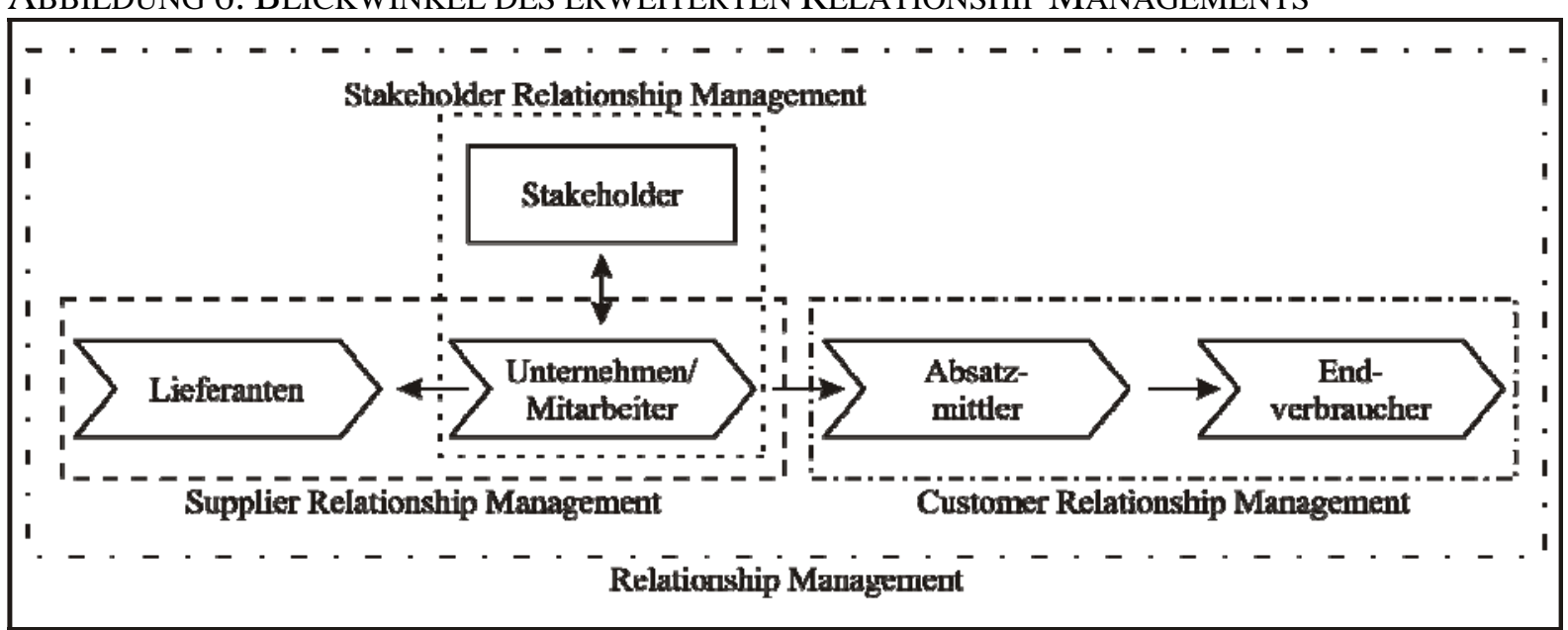

Quelle: Eigene Darstellung

Tabelle 6 gibt das Konzept des Relationship Managements im Überblick wieder. Letztlich kann dieses Konzept nicht die gesamten Probleme der Branche lösen. Einen Beitrag für innovative Ideen liefert es aber durch den spezifischen Fokus auf die grundlegende langfristige und eher partnerschaftliche Orientierung. Es geht - etwas provokant formuliert um die Öffnung der Wagenburg, d. h. die Steigerung der Sensibilisierung für marktliche und gesellschaftliche Prozesse. Dem Relationship Management liegt die Grundphilosophie zugrunde, dass es in vielen Fällen eine Interaktion mit Beziehungspartnern und die aktive Einbindung externer Interessen in die eigenen Entscheidungen ökonomisch sinnvoll sein kann. Diese These gilt sicherlich nicht überall (vgl. z. B. Gerlach/Spiller 2006), entsprechende Defizite sind aber im Agribusiness unverkennbar. Bisher fehlt es jedoch häufig an der systematischen Planung und Steuerung der Aktivitäten. Damit rücken neuere Steuerungsgrößen wie z. B. die Lieferantenzufriedenheit (Gerlach et al. 2004) in den Vordergrund. 
TABELLE 6: GEGENÜBERSTELLUNG DER VERSCHIEDENEN RELATIONSHIP-KONZEPTE

\begin{tabular}{|c|c|c|c|c|}
\hline Merkmal & $\begin{array}{l}\text { Relationship } \\
\text { Management }\end{array}$ & $\begin{array}{c}\text { Customer } \\
\text { Relationship } \\
\text { Management }\end{array}$ & $\begin{array}{c}\text { Supplier } \\
\text { Relationship } \\
\text { Management }\end{array}$ & $\begin{array}{l}\text { Stakeholder- } \\
\text { Relationship } \\
\text { Management }\end{array}$ \\
\hline Blickrichtung & $\begin{array}{l}\text { Dyade in Form } \\
\text { gleichbe- } \\
\text { rechtigter Partner }\end{array}$ & Abnehmer & Zulieferer & Stakeholder \\
\hline $\begin{array}{l}\text { Betrachtungs- } \\
\text { objekt }\end{array}$ & $\begin{array}{l}\text { (Geschäfts-) } \\
\text { Beziehung im } \\
\text { Sinne einer } \\
\text { strategischen } \\
\text { Partnerschaft }\end{array}$ & $\begin{array}{l}\text { Geschäftbeziehu } \\
\text { ngen mit } \\
\text { (Schlüssel-) } \\
\text { Kunden }\end{array}$ & $\begin{array}{l}\text { Geschäftsbe- } \\
\text { ziehung mit } \\
\text { (Schlüssel-) } \\
\text { Lieferanten }\end{array}$ & $\begin{array}{l}\text { Beziehung mit } \\
\text { relevanten } \\
\text { Anspruchs- } \\
\text { gruppen }\end{array}$ \\
\hline $\begin{array}{l}\text { Fristigkeit der } \\
\text { Beziehung }\end{array}$ & langfristig & langfristig & langfristig & langfristig \\
\hline $\begin{array}{l}\text { Entscheidungs- } \\
\text { orientierung }\end{array}$ & $\begin{array}{l}\text { Analyse, } \\
\text { Planung, } \\
\text { Steuerung, } \\
\text { Kontrolle und } \\
\text { Entwicklung von } \\
\text { Geschäfts- } \\
\text { beziehungen }\end{array}$ & $\begin{array}{l}\text { Analyse, } \\
\text { Planung, } \\
\text { Steuerung, } \\
\text { Kontrolle und } \\
\text { Entwicklung } \\
\text { sämtlicher } \\
\text { (kunden- } \\
\text { orientierter) } \\
\text { Marketing- } \\
\text { aktivitäten }\end{array}$ & $\begin{array}{l}\text { Analyse, } \\
\text { Planung, } \\
\text { Steuerung, } \\
\text { Kontrolle und } \\
\text { Entwicklung } \\
\text { sämtlicher } \\
\text { (lieferanten- } \\
\text { orientierter) } \\
\text { Beschaffungs- } \\
\text { aktivitäten }\end{array}$ & $\begin{array}{l}\text { Analyse von } \\
\text { Issues, Planung, } \\
\text { Steuerung und } \\
\text { Kontrolle und } \\
\text { Entwicklung } \\
\text { sämtlicher } \\
\text { Stakeholder- } \\
\text { aktivitäten }\end{array}$ \\
\hline $\begin{array}{l}\text { Nutzen- } \\
\text { orientierung }\end{array}$ & $\begin{array}{l}\text { Beziehungserfolg } \\
\text { (-spotenzial) und } \\
\text { Beziehungsge- } \\
\text { rechtigkeit }\end{array}$ & $\begin{array}{l}\text { Beziehungserfolg } \\
\text { des Zulieferers } \\
\text { über Kundenzu- } \\
\text { friedenheit und } \\
\text { Kundenbindung; } \\
\text { Customer } \\
\text { Lifetime Value }\end{array}$ & $\begin{array}{l}\text { Beziehungserfolg } \\
\text { des Abnehmers } \\
\text { über Effektivität } \\
\text { und Effizienz; } \\
\text { Supplier Lifetime } \\
\text { Value }\end{array}$ & $\begin{array}{l}\text { Beziehungserfolg } \\
\text { (-spotenzial) über } \\
\text { Krisenabwehr, } \\
\text { Aufbau } \\
\text { langfristiger } \\
\text { Vertrauens- } \\
\text { potenziale }\end{array}$ \\
\hline $\begin{array}{l}\text { Zeitraum- } \\
\text { orientierung }\end{array}$ & $\begin{array}{l}\text { Geschäfts- } \\
\text { beziehungszyklus }\end{array}$ & $\begin{array}{l}\text { Kundenbe- } \\
\text { ziehungszyklus }\end{array}$ & $\begin{array}{l}\text { Lieferan- } \\
\text { tenbeziehungs- } \\
\text { lebenszyklus }\end{array}$ & $\begin{array}{l}\text { Themen- } \\
\text { lebenszyklus }\end{array}$ \\
\hline $\begin{array}{l}\text { Organisa- } \\
\text { torische } \\
\text { Verankerung }\end{array}$ & $\begin{array}{l}\text { z. B. in Form } \\
\text { interorga- } \\
\text { nisationaler } \\
\text { Teams, } \\
\text { Relationship } \\
\text { Groups, } \\
\text { Beziehungs- } \\
\text { promotoren }\end{array}$ & $\begin{array}{l}\text { Infolge der } \\
\text { Forderung nach } \\
\text { Bildung } \\
\text { dezentraler } \\
\text { Einheiten und } \\
\text { verstärkter } \\
\text { Prozessorientieru } \\
\text { ng des gesamten } \\
\text { Unternehmens } \\
\text { betroffen; } \\
\text { Vorschläge zur } \\
\text { Organisation des } \\
\text { Key Account } \\
\text { Management }\end{array}$ & $\begin{array}{l}\text { z. B. in Form } \\
\text { inter- } \\
\text { organisationaler } \\
\text { Teams, } \\
\text { Relationship } \\
\text { Groups, } \\
\text { vereinzelt } \\
\text { Vorschläge zur } \\
\text { Organisation des } \\
\text { Key Supplier } \\
\text { Management }\end{array}$ & $\begin{array}{l}\text { z. B. in } \\
\text { Integration in der } \\
\text { PR-Abteilung, } \\
\text { Dialogansätze }\end{array}$ \\
\hline
\end{tabular}

Quelle: Eigene Darstellung in Anlehnung an Stölzle/Heusler 2003: 183 
Fazit: Das Agribusiness ist aufgrund der langjährigen und hohen Relevanz der Agrarpolitik immer noch sehr produktionsorientiert. Für die Mehrzahl der Unternehmen ist eine mangelnde Markt-, Lieferanten- und Gesellschaftsorientierung zu konstatieren. Da Subventionen langfristig noch mehr an Bedeutung verlieren werden, ist eine Anpassung an die sich ändernden Rahmenbedingungen zwingend erforderlich. Eine Unternehmensstrategie, die im Sinne eines Kostenführers weiterhin auf das Niedrigpreissegement setzt, ist aufgrund der vergleichsweise hohen Produktionskosten in vielen Bereichen nicht konkurrenzfähig. Hier müssen Alternativen erarbeitet werden.

Das Relationship Management als Grundphilosophie bildet den Rahmen der folgenden Studien, die in unterschiedlicher Form verschiedene Facetten des Themas empirisch ausleuchten. Dabei sind die Fallbeispiele auch durch die unterschiedlichen (Drittmittel-) Projekte und die sich daraus ergebenden verschiedenen Fragestellungen geprägt, die von der Verfasserin im Laufe der Promotionszeit bearbeitet wurden. 


\section{LITERATUR}

Ansoff, H. I. (1976): Managing Surprise and Discontinuity - Strategic Response to Weak Signals. In: Zeitschrift für betriebswirtschaftliche Forschung, 28. Jg., Heft 3, S. 129152.

Arnold, U. (1997): Beschaffungsmanagement, 2. Aufl., Stuttgart.

Backhaus, K. (1997): Entwicklungspfade im Investitionsgütermarketing, in: Backhaus, K. (Hrsg.): Marktleistung und Wettbewerb: strategische und operative Perspektiven der marktorientierten Leistungsgestaltung; Festschrift für Werner H. Engelhardt zum 65. Geburtstag, Wiesbaden, S. 33-62.

Batt, P. J.; Rexha, N. (1999): Building Trust in Agribusiness Supply Chains: A Conceptual Model of Buyer-Seller Relationships in the Seed Potato Industry in Asia, in: Journal of International Food \& Agribusiness Marketing, 11. Jg., Heft 1, S. 1-17.

Batt, P. J.; Wilson, H. (2001): Exploring the nature of long-term buyer-seller relationships in the Western Australian wine industry, in: Australia New Zealand Wine Industry Journal, 16. Jg., Heft 6, S. 87-96.

Becker, H. (1996): Ländliche Lebensverhältnisse im Wandel 1952, 1972, 1993/1994 Verhandlungen der Öffentlichen Arbeitstagung am 16. November 1995, Bonn.

Benecke, A.; Vogel, H. (2004): Übergewicht und Adipositas - Gesundheitsberichterstattung des Bundes, Heft 16. Berlin, Robert Koch-Institut (RKI).

Berry, L. L. (1983): Relationship Marketing, in: Berry, L. L. et al. (Hrsg.): Emerging Perspectives on Services Marketing, Chicago, S. 236-245.

Berendson, H. (2005): Beschaffungsmarketing von Unternehmen in der Ernährungswirtschaft: eine empirische Analyse am Beispiel der Obst- und Gemüseverarbeitung in Nordrhein-Westfalen, Göttingen.

Blois, K. J. (1996): Relationship Marketing in Organizational Markets: When is it Appropriate? in: Journal of Marketing Management , 12. Jg., Heft 1-3, S. 161-173.

BMELV (2006a): Agrarpolitischer Bericht 2006 der Bundesregierung, Berlin.

BMELV (2006b): Die EU-Agrarreform - Umsetzung in Deutschland, Ausgabe 2006, Berlin.

BMELV (2006c): Wir über uns: Das BMELV stellt sich vor, unter: http://www.bmelv.de/cln_045/nn_754188/DE/14-WirUeberUns/_WirUeberUns_node.html_nnn=true; Abrufdatum: 11.03.2006.

BMVEL (2005): Zukunft der Nutztierhaltung: Gutachten des Wissenschaftlichen Beirats Agrarpolitik, nachhaltige Landbewirtschaftung und Entwicklung ländlicher Räume beim BMVEL, Berlin.

Bogaschewsky, R. (2003): Integrated Supply Management - Zukunftskonzept für die Beschaffung, in: Bogaschewsky, R. (Hrsg.): Integrated Supply Management - Einkauf und Beschaffung: Effizienz steigern, Kosten senken, Köln, S. 23-54.

Bogetoft, P.; Olesen, H. B. (2004): Quality Incentives and Supply Chains: Managing Salmonella in Pork Production, in: American Journal of Agricultural Economics, 86. Jg., Heft 3, S. 829-834.

Bonus, H. (1986): The Cooperative Association as a Business Enterprise: A Study in the Economics of Transactions, in: Journal of Institutional and Theoretical Economics, 142. Jg., Heft 2, S. 310-339. 
Bonus, H. (1987a): Die Genossenschaft im Jahr 2000, in: Genossenschaftswissenschaftliche Beiträge, Heft 13, Institut für Genossenschaftswesen der Universität Münster.

Bonus, H. (1987b): Die Genossenschaft als modernes Unternehmenskonzept, in: Genossenschaftswissenschaftliche Beiträge, 10, Institut für Genossenschaftswesen der Universität Münster.

BUND (Hrsg.) (2004): Gegen die Errichtung von Massentierhaltungsanlagen, Köln.

Chaddad, F. R., Cook, M. L. (2004): Understanding New Cooperative Models: An Ownership-Control Rights Typology, in: Review of Agricultural Economics, 26. Jg., Heft 3, S. 348-360.

Chwalleck, A. (2003): Nordzucker Konzern forciert die Diversifizierung, unter: www.lznet.de/archives/lznet/mylenet.... Abrufdatum: 20.03.2006.

Clare, B. G. et al. (2005): Supply base relationships in the New Zealand red meat industry: A case study. Paper presented to 15th annual world forum, symposium and case conference of the International Food and Agribusiness Management Association, Chicago, June.

Cook, M. L. et al. (2004): Advances in Cooperative Theory since 1990: A Review of Agricultural Economics Literature, in: Hendrikse, G. W. J. (Hrsg.): Restructuring Agricultural Cooperatives, Rotterdam, S. 65-90.

Dangelmaier, W. et al. (2002): Grundrahmen des Customer Relationship Management Ansatzes, in: Uebel, M. F. et al. (Hrsg.): Praxis des Customer Relationship Management: Branchenlösungen und Erfahrungsberichte, Wiesbaden, S. 3-16.

Dawson, L. M. (1969): The Human Concept: New Philosophy for Business, in: Business Horizons, 12. Jg., Heft 6, S. 29-38.

DBV (Hrsg.) (2005): Situationsbericht 2004: Trends und Fakten zur Landwirtschaft, Bonn.

De Geer, H. (2004): Business and Society, in: Zsolnai, L. (Hrsg.): Ethics in the Economy: Handbook of Business Ethics, Oxford et al., S. 59-80.

Diller, H. (1997): Beziehungsmanagement, in: Die Betriebswirtschaft, 57. Jg., Heft 4, S. 572575.

Diller, H. (2001): Beziehungsmanagement, in: Diller, H. (Hrsg.): Vahlens Großes Marketing Lexikon, 2. Aufl. München, S. 162-163.

Diller, H., Kusterer, M. (1988): Beziehungsmanagement - Theoretische Grundlagen und explorative Befunde, Hamburg.

Dohms, H. (2002): Ein interregionaler Vergleich der Regelungen zur zwischenbetrieblichen Übertragung von Rübenlieferrechten sowie der Pacht- und Kaufpreise dieser Rechte in Deutschland, Masterarbeit, Göttingen.

Doney, P. M., Cannon, J. P. (1997): An Examination of the Nature of Trust in Buyer-Seller Relationships, in: Journal of Marketing, 61. Jg., Heft. 2, S. 35-51.

Dorsch, K. (2004): Flugblatt-Hetze gegen Schweinemäster, in: top agrar, 32. Jg., Heft 6, S. 14-15.

Dyllick, T. (1984): Das Anspruchsgruppen-Konzept: Eine Methodik zum Erfassen der Umweltbeziehungen der Unternehmung, in: Management Zeitschrift io, 53. Jg., Heft 2, S. 74-78. 
Dyllick; T. (1990): Management der Umweltbeziehungen: öffentliche Auseinandersetzungen als Herausforderung, Wiesbaden.

Dwyer, F. R. et al. (1987): Developing Buyer-Seller Relationships, in: Journal of Marketing, 51. Jg., Heft 2, S. 11-27.

Engels, W. et al. (Hrsg.) (1985): Verordnete Verschwendung? Für eine neue Agrarordnung in Europa, Stuttgart.

Eßig, M. (2001): Lieferantenbeziehungen im Wandel: Eine Analyse von Kooperationsformen in der Beschaffung, in: Der Betriebswirt, 42. Jg., Heft 4, S. 21-27.

Eßig, M. (2003): Supplier Lifetime Value als Ansatz zur Neubewertung von Lieferantenbeziehungen, in: Bogaschewsky, R. (Hrsg.): Integrated Supply Management - Einkauf und Beschaffung: Effizienz steigern, Kosten senken, Köln, S. 323-346.

FAZ-NET (2005): Schweizer stimmen klar gegen Gentechnik. In: http://www.faz.net/s/Rub8E1390D3396F422B869A49268EE3F15C/Doc E2285A70C11A94129B4F10D4 02B547A3B ATpl Ecommon Scontent.html. Abrufdatum 03.12.2005.

Feindt, P. H. et al. (2004): Konflikte des Agrarsektors - eine Landkarte: empirische Ergebnisse einer konflikttheoretischen Fundierung der Nachhaltigkeitsforschung, Biogum Forschungsbericht/ FG Landwirtschaft Nr. 12, Hamburg.

Fiddelke, T. (2001): Vom Assistenten zum Vorstandssprecher - Manager im Portrait, unter: http://www.welt.de/daten/2001/02/01/0201brw219594.htx\#wwwlinks, vom 01.02.2001, Abrufdatum: 20.03.2006.

Folmer, C. et al. (1995): The common agricultural policy beyond the MacSharry reform, Amsterdam.

Freeman, F. E. (1984): Strategic Management: A Stakeholder Approach, Boston.

Frewer, L. (1998): Methodological approaches to assessing risk perceptions associated with food-related hazards, in: Risk Analysis, 18. Jg., Heft 1, S. 95-102.

Freisberg, E. (1965): Die Grüne Hürde Europas, Köln und Opladen.

Ganesan, S. (1994): Determinants of Long-Term Orientation in Buyer-Seller Relationships, in: Journal of Marketing, 58 Jg., Heft. 2, S. 1-19.

Galtung, J., Ruge, M. H. (1965): The Structure of Foreign News. The Presentation of the Congo, Cuba and Cyprus crises in Four Norwegian Newspapers, in: Journal of Peace Research, 2. Jg., Heft 1, S. 64-91.

Gerlach, S. et al. (2004): Supplier Relationship Management im Agribusiness: Ein Konzept zur Messung der Geschäftsbeziehungsqualität, Diskussionsbeitrag Nr. 0406 des Instituts für Agrarökonomie, Georg-August-Universität Göttingen.

Gerlach, S. et al. (2005a): Landwirte als Liefanten und Unternehmenseigner: Zum Management von Supplier- und Investor-Relations im Agribusiness, in: Darnhofer, K., et al. (Hrsg.): Jahrbuch der Österreichischen Gesellschaft für Agrarökonomie „Standards in der Agrar- und Ernährungswirtschaft - Lokale und globale Herausforderungen, Band 14, S. 221-233.

Gerlach, S. et al. (2005b): Supplier Relationship Management in der Milchwirtschaft: ein Regressionsmodell zur Erklärung der Geschäftsbeziehungsqualität, erscheint in: v. Cramon-Taubadel, S. et al. (Hrsg.): Tagungsband der 45. Gewisola Jahrestagung „Unternehmen im Agrarbereich vor neuen Herausforderungen, Göttingen, im Druck. 
Gerlach, S. et al. (2005c): Die Agrarwende - Neustrukturierung eines Politikfeldes, Diskussionspapier Nr. 10 des BMBF-Projekts „Von der Agrarwende zur Konsumwende?“ unter: www.konsumwende.de.

Gerlach, S., Spiller, A. (2006): Anwohnerkonflikte bei landwirtschaftlichen Stallbauten: Hintergründe und Einflussfaktoren - Ergebnisse einer empirischen Analyse, Diskussionsbeitrag 0206 des Instituts für Agrarökonomie der Universität Göttingen, Göttingen.

Greenpeace (Hrsg.) (2001): Jahresrückblick 2001, Hamburg.

Grönroos, C. (2005): Service management and marketing: a customer relationship management approach, 2. Aufl., Chichester, West Sussex.

Grönroos, C. (2000): Service management and marketing: A Customer Relationship Management Approach, New York.

Grönroos, C. (1994): From Marketing Mix to Relationship Marketing: Towards a Paradigm Shift in Marketing, in: Management Decisions, 32. Jg. Heft. 2, S. 4-20.

Grunig, J. E., Hunt, T. (1984): Managing Public Relations, Fort Worth u. a.

Gusti, I. et al. (2004): Factors affecting supply chain participants on choosing their preferred trading partners, Agriculture Congress 2004, Innovation Towards Modernised Agriculture, 4-7 October, Mines Resort City, University Putra Malaysia.

Habermas, J. (1983): Diskursethik - Notizen zu einem Begründungsprogramm, in: Habermas, J. (Hrsg.): Moralbewußtsein und kommunikatives Handeln, Frankfurt am Main, S. 53125.

Hansen, M. H. et al. (2002): The impact of trust on cooperative membership retention, performance, and satisfaction: an exploratory study, in: International Food and Agribusiness Management Review, 5. Jg., Heft 4, S. 41-59.

Hagedorn, K. (Hrsg.) (1996): Institutioneller Wandel und politische Ökonomie von Landwirtschaft und Agrarpolitik. Festschrift zum 65. Geburtstag von Günther Schmitt. Frankfurt a. M.

Hagenhoff, V. (2003): Analyse der Printmedien-Berichterstattung und deren Einfluss auf die Bevölkerungsmeinung: Eine Fallstudie der Rinderkrankheit BSE 1990 - 2001, Hamburg.

Hamm, U. (1991): Landwirtschaftliches Marketing, Wiesbaden.

Harris, L. C. (2000): The organizational barriers to developing market orientation, in: European Journal of Marketing, 34. Jg., Heft 5/6, S. 598-624.

Hartenstein, L. (1997): Vom großen Mißverständnis der modernen Agrarpolitik, in: Hartenstein et al. (Hrsg.): Braucht Europa seine Bauern noch? Über die Zukunft der Landwirtschaft, Baden-Baden, S. 11-18.

Hartmann, H.-B. (2005): Bioenergie boomt: Neue Chancen für Landwirte als Energiewirte, in: AgrarBündnis e. V. (Hrsg.): Der kritische Agrarbericht 2005, Rheda-Wiedenbrück, Hamm, S. 76-81.

Hecker, S. (1997): Kommunikation in ökologischen Unternehmenskrisen: Der Fall Shell und Brent Spar, Wiesbaden.

Heissenhuber, A., Lippert, C. (2000): Multifunktionalität und Wettbewerbsverzerrungen, in: Agrarwirtschaft, 49. Jg., Heft 7, S. 249-252. 
Henning, C. H. C. A. et al. (2004): Auswirkungen der Mid-Term-Review-Beschlüsse auf den Agrarsektor und das Agribusiness in Schleswig-Holstein und MecklenburgVorpommern, Bergen/Dumme.

Henning-Thurau, T., Hansen, U. (2001): Kundenzufriedenheit, in: Diller, H. (Hrsg.): Vahlens großes Marketinglexikon, S. 879-881.

Henrichsmeyer, W., Witzke, H. P. (1994): Agrarpolitik, Bd. 2. Bewertung und Willensbildung, Stuttgart.

Heseker, H., Schmidt, A. (2000): Epidemiology of obesity, in: Therapeutische UmschauRevue therapeutique 2000, 57. Jg., Heft 8, S. 478-481.

Homburg, C.; Krohmer, H. (2003): Marketingmanagement, Wiesbaden.

Homburg, C.; Sieben, F. G. (2000): Customer Relationship Management (CRM) Strategische Ausrichtung statt IT-getriebenem Aktivismus, in: Bruhn, M.; Homburg, C. (Hrsg.): Handbuch Kundenbindungsmanagement, 3. Aufl., Wiesbaden, S. 473-501.

Homburg, C. et al. (1999): Der Zusammenhang zwischen Kundenzufriedenheit und Kundenbindung, in: Die Betriebswirtschaft, 59. Jg., Heft 2, S. 174-195.

Huth, J., Prinz, C. (2005): Cross Compliance - Irrungen und Wirrungen, in: Agrar- und Umweltrecht, 35. Jg., Heft 4, S. 121-122.

Isermeyer, F. (2005): Ökonomische Rahmenbedingungen und Perspektiven landwirtschaftlicher Produktion in den nächsten Jahrzehnten, Arbeitsberichte Nr. 02/2005 des Bereichs Agrarökonomie Bundesforschungsanstalt für Landwirtschaft, Braunschweig.

Isermeyer, F. (1989): Landwirtschaft und Agrarpolitik in der Krise - Entwicklungen, Hintergründe, internationale Verflechtungen, in: Thomas-Morus-Akademie (Hrsg.): Subventionierte Unvernunft?: Agrarpolitik und Überschußposition der EG, Bergisch Gladbach, S. 9-42.

Jäckel, K., Spiller, A. (2005): Public Orientation im Agribusiness: Eine empirische Studie zur Interaktion von Unternehmen und Gesellschaft, erscheint in: v. Cramon-Taubadel, S. et al. (Hrsg.): Tagungsband der 45. Gewisola Jahrestagung „Unternehmen im Agrarbereich vor neuen Herausforderungen, Göttingen, im Druck.

Jackson, B. B. (1985): Build customer relationships that last, in: Harvard Business Review, 63. Jg., Heft November-December, S. 120 - 128.

Jenner, B. (2002): Greenpeace - vom Kritiker zum größten Werbepartner der Firma Heidemark, unter: wwww.tiernotruf-111.de/tvg25.html., Abrufdatum: 20.03.2006.

Kaas, K. P. (1995): Marketing zwischen Markt und Hierarchie, in: Kaas, K. P. (Hrsg.): Kontrakte, Geschäftsbeziehungen, Netzwerke: Marketing und Neue Institutionenökonomik, Düsseldorf, S. 1-17.

Kafka, C. (1998): Risikowahrnehmung und -kommunikation bei Lebensmitteln, Lehrstuhl für Agrarmarketing. Arbeitsbericht Nr. 13, Kiel.

Kemper, K. (2005): Tomaten statt Weizen: Plädoyer für eine Neuorientierung in der Agrarökonomie, Frankfurt a. M.

Klee, A. (2000): Strategisches Beziehungsmanagement: Ein integrativer Ansatz zur strategischen Planung und Implementierung des Beziehungsmanagements, Aachen. 
Kleinaltenkamp, M., Rieker, S. A. (1997): Kundenorientierte Organisation, in: Kleinaltenkamp, M., Plinke, W. (Hrsg.): Geschäftsbeziehungsmanagement, Berlin, Heidelberg, S. 161-215.

Kleinschmit, D., Feindt, P. H. (2004): Verursacher, Opfer und Helfer: BSE und Agrarpolitik in deutschen Zeitungen. In: Neue Soziale Bewegungen, 17. Jg. Heft 3, S. 93-98.

Kluge, U. (1989): Vierzig Jahre Agrarpolitik in der Bundesrepublik Deutschland, Hamburg.

Kohli, A., Jaworski, B. (1990): Market Orientation: The Construct, Research Propositions, and Managerial Implications, in: Journal of Marketing, 54. Jg., Heft 2, S. 1-18.

Kommission der Europäischen Gemeinschaft (Hrsg.) (2002): Bericht über die Milchquoten, Arbeitsdokument der Kommission, unter: http://europa.eu.int/comm/agriculture/capreform/milkrep/text_de.pdf, Abrufdatum: 20.03.2006.

Kotler, P. (1988): Principles of Marketing, 6th ed., Prentice-Hall, Englewood Cliffs, NJ.

Koppelmann, U. (2003): Vertrauen oder Misstrauen als Grundlage für Beschaffungsverhandlungen, in: Bogaschewsky, R., Götze, U. (Hrsg.): Management und Controlling von Einkauf und Logistik: Festschrift für Jürgen Bloech, Gernsbach, S. 67-80.

Kromeyer-Hausschild, K., Wabitsch, M. (2004): Aktuelle Sicht der Prävalenz und Epidemiologie von Übergewicht und Adipositas bei Kindern und Jugendlichen in Deutschland. Arbeitsgemeinschaft Adipositas im Kindes- und Jugendalter (AGA) der Deutschen Gesellschaft für Kinderheilkunde und Jugendmedizin (DGKJ). Unter: www.a-g-a.de/aga_content.html, Abrufdatum: 01.03.2006.

Krönert, A. (2003): Fette Tatsachen, vom 10.06.2003 unter: www.lz-net.de/archives/lznet/mylznet/pages... Abrufdatum: 20.03.2006.

Lacroix, E. L. de (Hrsg.) (2003): Überblick über die Gap-Reform, Newsletter Sonderausgabe der Europäischen Kommission Generaldirektion Landwirtschaft, Brüssel.

Langelüddeke, P., Deichmann T. (2004): Was Konsumenten wollen müssen. In: http://www.novo-magazin.de/71/novo7124.htm, Abrufdatum 02.12.2005.

Liebl, F. (1996): Strategische Frühaufklärung: Trends, Issues, Stakeholders, München, Wien.

Liebl, F. (1997) „Up and Down with Stakeholder Management“ - Ein Plädoyer für eine strategische Sichtweise; in: Baecker, D. (Hrsg.): Wittener Jahrbuch für Ökonomische Literatur 1997; Marburg 1997; S. 61-81.

Liebl, F. (2000): Der Schock des Neuen. Entstehung und Management von Issues, München.

Luhmann, N. (1996): Die Realität der Massenmedien, 2. Aufl., Opladen.

LZ-Net (2005): Tegut verkauft Milch „ohne Gentechnik“. In: http://www.lz-net.de/news/topnews/pages/protected/showPrint.prl?id=46629. Abrufdatum 02.12.2005.

Moorman, C. et al. (1992): Relationships Between Providers and Users of Marketing Research: The Dynamics of Trust Within and Between Organizations, in: Journal of Marketing Research, 29. Jg., Heft 3, S. 314-329.

Mitchell, R. et al. (1997): Toward a theory of stakeholder identification, in: The Academy of Management Review, 22. Jg., Heft 4, S. 853-886.

Narver, J. C., Slater, S. F. (1990): The effect of a market orientation on business profitability, in: Journal of Marketing, 54. Jg., Heft 4, S. 20-36. 
Neumann, H. (2001): Eine Region mit dem Rücken an der Wand, in: top agrar, 29. Jg., Heft 8, S. 40-43.

OECD (2004): OECD Agricultural Policies 2004: At A Glance, Paris.

Oberbeck, H., Oppermann, R. (1994): Agrarwirtschaft und Dörfer am Scheideweg: Erfahrungen von Landwirten mit dem Wandel gesellschaftlicher Akzeptanz mit der landwirtschaftlichen Intensivproduktion, in: Soziale Welt, 45. Jg., Heft 3, S. 259 278.

Odening, M., Bokelmann, W. (1999): Agrarmanagement, Stuttgart.

Österreichische Milch- \& Lebensmittelwirtschaft (2005): „Gentechnikfrei“ und die Sorge um die Folgen, in: Deutsche Milchwirtschaft, 56. Jg., Heft 20, S. 877-878.

o. V. (2006a): Nordmilch wird Aktiengesellschaft, unter: www.lz-net.de/archives/Lznet.... vom 26.01.2006, Abrufdatum 20.03.2006.

o. V. (2006b): Jens Fokuhl tritt zurück, unter: www.lz-net.de/archives/Lznet.... vom 09.03.2006, Abrufdatum: 20.03.2006.

o. V. (2005): Goetz von Engelbrechten zum Aufsichtsratsmitglied bestellt, unter: http://www.kws.de/aw/KWS/home/ueber_kws_3238196/presse-...; vom 10.11.2005, Abrufdatum: 20.03.2006.

o. V. (2004a): Neuer Vorsitz, unter: www.lz-net.de/archives/lznet..... vom 17.06.2004, Abrufdatum: 20.03.2006.

o. V. (2004b): Rufmordkampagne gegen Schweinemäster, in: dlz, 10. Jg., Heft 6, S. 97-98.

o. V. (2001): Putenstreit: Unilever zieht Klage gegen Greenpeace zurück, vom 27.09.2001, unter: www.123recht.net/printarticle.asp?a=1812; Abrufdatum 01.03.2006.

Parasuraman, A. et al. (1988): SERVQUAL. A Multiple-Item Scale for Measuring Consumer Perceptions of Service Quality, in: Journal of Retailing, 64. Jg., Heft 1, S. 12-40.

Piel, E. (2003): Wie werden Landwirte von der Gesellschaft gesehen? In Deutsche Landwirtschafts-Gesellschaft (Hrsg.): Wege zu besserem Image und Ansehen - Landwirte in der Gesellschaft: Analysen, Erfahrungen, Perspektiven, Frankfurt am Main, S. 13-28.

Plinke, W. (1997): Grundlagen des Geschäftsbeziehungsmanagements, in: Kleinaltenkamp, M., Plinke, W. (Hrsg.): Geschäftsbeziehungsmanagement, Berlin, Heidelberg, S. 1-61.

Plinke, W. (1989): Die Geschäftsbeziehung als Investition, in: Specht, G. et al. (Hrsg.): Marketing-Schnittstellen: Herausforderungen für das Management, Stuttgart, S. 305325.

Pohlabeln, H. et al. (2004): Möhre statt Big Mac, Apfel statt Schokoriegel, Vollkornbrot statt Pizza?, in: Bundesgesundheitsblatt - Gesundheitsforschung - Gesundheitsschutz, 46. Jg. Heft 3, S. 211-212.

Porter, M. E. (1989): Wettbewerbsvorteile, Frankfurt am Main.

Priebe, H. (1985): Die subventionierte Unvernunft, Berlin.

Pitschmann, T. (2005): Prüfen Sie das Umfeld, in: DLG-Mitteilungen, 30. Jg., Heft 10, S. 1315.

Reinehr, T., Wabitsch, M. (2003) Strukturierte Erfassung der Therapieangebote für adipöse Kinder und Jugendliche, in: Monatsschrift Kinderheilkunde, 151. Jg., Heft 7, S. 757761. 
Reisch, L. (2006): Food Chain Politik - Elemente einer strategischen Neuorientierung der Agrarpolitik, erscheint in: Agrarwirtschaft.

Roloff, J. (2002): Stakeholdermanagement: ein monologisches oder dialogisches Verfahren? in: Zeitschrift Wirtschafts- und Unternehmensethik: zfwu, 3. Jg., Heft 1, S. 77-95.

Röttger, U. (Hrsg.) (1997): PR-Kampagnen. Über die Inszenierung von Öffentlichkeitsarbeit, Opladen.

Saiia, D. H., Cyphert, D. (2003): The Public Discourse of the Corporate Citizen, in: Corporate Reputation Review, 6. Jg., Heft 1, S. 47-57.

Salancik, G. R., Pfeffer, J. (1974): The bases and use of power in organizational decisionmaking: The case of universities, in: Administrative Science Quarterly, 19. Jg., Heft 4, S. 453-473.

Schramm, M. et al. (2004): Brand Orientation in der Ernährungsindustrie, Wiesbaden.

Schmidhuber, J. (2003): The outlook for long-term changes in food consumption pattern: Concerns and policy options, Paper Prepared for the FAO Scientific Workshop on Globalization of the Food System: Impacts on Food Security and Nutrition, FAO, Rome, October 8-10, 2003, unter: http://www.fao.org/es/ESD/Schmidhuberdiets.pdf, Abrufdatum: 10.03.2006.

Schulz, J. (2001): Issues Management im Rahmen der Risiko- und Krisenkommunikation. in: Röttger, U. (Hrsg.): Issues Management, Opladen, S. 217-234.

Schurr, P. H., Ozanne, J. L. (1985): Influences on Exchange Process: Buyers' Preconceptions of a Seller's Trustworthiness and Bargaining Toughness, in: Journal of Consumer Research, 11. Jg., Heft 3, S. 939-953.

Sieben, F. G. (2001): Customer Relationship Management als Schlüssel zur Kundenzufriedenheit, in: Homburg, C. (Hrsg.): Kundenzufriedenheit, 4. Aufl., Wiesbaden, S. 295-314.

Spiller, A. (2004): Qualitätssicherung in der Wertschöpfungskette: Vor- und Nachteile unterschiedlicher Organisationskonzepte, in: Dachverband Agrarforschung (Hrsg.): Lebensmittelqualität und Qualitätssicherungssysteme, Frankfurt.

Spiller, A. et al. (2005a): Sicherstellung der Wertschöpfung in der Schweineerzeugung: Perspektiven des Nordwestdeutschen Modells, Münster-Hilltrup.

Spiller, A., et al. (2005b): Zur Zukunft des Bio-Fachhandels: Eine Befragung von BioIntensivkäufern. Diskussionspapier Nr. 6 des BMBF-Forschungsprojekts „Von der Agrarwende zur Konsumwende?“, Georg-August Universität Göttingen.

Staatz, J. M. (1989): Farmer Cooperative Theory: Recent Developments. ACS Research Report Nr. 84, Washington D. C.

Stölzle, W. (1999): Industrial Relationships, München.

Stölzle, W., Heusler, K. F. (2003): Supplier Relationship Management, in: Bogaschewsky, R., Götze, U. (Hrsg.): Management und Controlling von Einkauf und Logistik, Gernsbach, S. 169-194.

Stölzle, W., Helm, R. (2003): Der Einfluss elektronischer Märkte auf die Beziehungsqualität, in: Bogaschwesky, R. (Hrsg.): Integrated Supply Management: Einkauf und Beschaffung: Effizienz steigern, Kosten senken, Köln, S. 285-322. 
Strecker, O. et al. (1996): Marketing in der Agrar- und Ernährungswirtschaft: - Grundlagen, Strategien, Maßnahmen, 3. Aufl., Frankfurt a. M. et al.

Sturen, R. (1998): Effiziente Lobbies - Fluch oder Segen? in: Scheff, J., Gutschelhofer, A. (Hrsg.): Chancen und Risiken vernetzter Machtstrukturen im Wirtschaftsgefüge, S. 3748.

Theuvsen, L. (2001): Stakeholder Management: Möglichkeiten des Umgangs mit Anspruchsgruppen, Münsteraner Diskussionspapiere zum Nonprofit-Sektor, Nr. 16, Münster.

Tracy, M. (1993): Food and Agriculture in a Market Economy, Tonbridge.

Tracy, M. (1989): Government and Agriculture in Western Europe 1880-1988, Herfordshire.

Ulrich, P. (1998): Integrative Wirtschaftsethik: Grundlagen einer lebensdienlichen Ökonomie, 2. Aufl., Bern et al.

Voss, J., Spiller, A. (2006): Zur Akzeptanz von gentechnisch verändertem SaatgutErgebnisse einer empirischen Studie bei deutschen Landwirte, erscheint als Diskussionspapier des Instituts für Agrarökonomie 0603, Göttingen.

Wabitsch, M. (2004): Kinder und Jugendliche mit Adipositas in Deutschland - Aufruf zum Handeln. In: Bundesgesundheitsblatt, 47. Jg., S. 251-255.

Walenda, I. (2004): Der Landwirt als Energiewirt, in: AgrarBündnis e. V. (Hrsg.): Der kritische Agrarbericht 2004, Rheda-Wiedenbrück, Hamm, S. 178-182.

Walter, A. (1998): Der Beziehungspromotor, Wiesbaden.

Waskow, F., Rehaag, R. (2004): Ernährungspolitik nach der BSE-Krise, ein Politikfeld in Transformation, Diskussionspapier Nr. 6 des BMBF-Projekts „Ernährungswende“, unter: http://www.ernaehrungswende.de/fr_ver.html, Abrufdatum: 27.01.2006.

Wathne, K. H., Heide, J. B. (2004): Relationship Governance in a Supply Chain Network, in: Journal of Marketing, 68. Jg., Heft 1, S. 73-89.

Weber, M. (1956): Wirtschaft und Gesellschaft. Grundriß der verstehenden Soziologie, 4. Aufl., 1. Halbband, Tübingen.

Weindlmaier, H. (2005): Entwicklung der Erzeugerpreise: Welche Chancen bietet eine aktive Marktbeeinflussung. Vortrag beim 1. Nordmilch-Unternehmerforum in Oldenburg, 6. Dezember 2005.

Wiedmann, K. - P. (1993 ): Rekonstruktion des Marketingansatzes und Grundlagen einer erweiterten Marketingkonzeption, Stuttgart.

Wieland, J. (1997): Die langen Wellen des institutionalistischen Wandels - Ökonomische Theorie und Theorie der Gesellschaft. In: Held, M. (Hrsg.): Normative Grundfragen der Ökonomik: Folgen für die Theoriebildung, Frankfurt am Main/New York, S. 238261.

Wildner, S. (2002): Der Einfluss der BSE-Berichterstattung auf die Nachfrage nach Fleisch und Fisch, in: Berichte über Landwirtschaft, 80. Jg. Heft 1, S. 40-52.

Wilson, D. T. (1995): An Integrated Model of Buyer-Seller Relationships, in: Journal of Academy of Marketing Science, 23. Jg., Heft 4, S. 335-345.

Williamson, O. E. (1979): Transaction Cost Economics: The Governance of Contractual Relations, in: Journal of Law and Economics, 22 Jg., Heft 2, S. 233-261.

Wocken, C. (2004): Die Geschäftsbeziehung zwischen Milcherzeugern und Molkerei - Eine empirische Analyse zum Supplier Relationship Management, Masterarbeit, Göttingen. 
Zühlsdorf, A. (2002): Gesellschaftsorientierte Public Relations: eine strukturationstheoretische Analyse der Interaktion von Unternehmen und kritischer Öffentlichkeit, Wiesbaden. 


\section{Anhang}

TABELLE 1: UNTERSCHIEDE IN DER UNTERNEHMERPERSÖNLICHKEIT: MILCH- VERSUS SCHWEINEPRODUZENTEN

\begin{tabular}{|c|c|c|c|c|c|}
\hline $\begin{array}{l}\text { Milch- bzw. } \\
\text { Schweineerzeuger }\end{array}$ & & $\begin{array}{l}\text { Ich kenne mich bei } \\
\text { verschiedenen } \\
\text { agrarpolitischen } \\
\text { Förderungsmöglichk } \\
\text { eiten gut aus. } \\
\end{array}$ & $\begin{array}{l}\text { Ich versuche } \\
\text { möglichst viele } \\
\text { Subventionen } \\
\text { mitzunehmen. }\end{array}$ & $\begin{array}{l}\text { Für mich ist die Zeit } \\
\text { am Schreibtisch } \\
\text { genauso sinnvoll wie } \\
\text { im Schweinestall. }\end{array}$ & $\begin{array}{l}\text { Als Landwirt habe } \\
\text { ich nur noch wenige } \\
\text { unternehmerische } \\
\text { Entscheidungs- } \\
\text { freiheiten. }\end{array}$ \\
\hline \multirow[t]{3}{*}{ Milcherzeuger } & Mittelwert & 0,88 & 1,32 & 0,69 & 0,45 \\
\hline & $\mathrm{N}$ & 209 & 209 & 209 & 209 \\
\hline & Standardabweichung & 1,229 & 1,315 & 1,488 & 1,667 \\
\hline \multirow[t]{3}{*}{ Schweineerzeuger } & Mittelwert & 0,41 & 0,73 & 1,15 & $-0,47$ \\
\hline & $\mathrm{N}$ & 354 & 355 & 355 & 354 \\
\hline & Standardabweichung & 1,270 & 1,555 & 1,297 & 1,416 \\
\hline \multirow[t]{3}{*}{ Insgesamt } & Mittelwert & 0,58 & 0,95 & 0,98 & $-0,13$ \\
\hline & $\mathrm{N}$ & 563 & 564 & 564 & 563 \\
\hline & Standardabweichung & 1,274 & 1,496 & 1,387 & 1,577 \\
\hline
\end{tabular}

Quelle: Spiller et al. 2005; Wocken 2004 


\section{KAPITEL I}

Customer Relationship Management 


\section{KAPITEL I.1}

Zur Zukunft des Biofachhandels:

Eine Befragung von Bio-Intensivkäufern 


\section{Zur Zukunft des Biofachhandels: Eine Befragung von Bio-Intensivkäufern*}

(mit Achim Spiller und Julia Engelken)

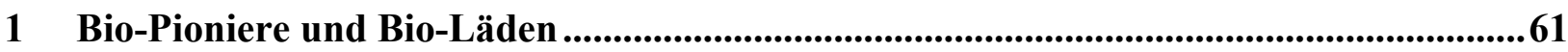

2 Absatzwege für Bio-Lebensmittel im Überblick........................................................62

3 Zielgruppen für Bio-Produkte: Intensiv- versus Gelegenheitskäufer und ihre Einkaufsstättenpräferenzen ..................................................................................65

4 Untersuchungsdesign der Online-Befragung..............................................................69

5 Einkaufsstättentreue der Bio-Intensivkäufer ..............................................................72

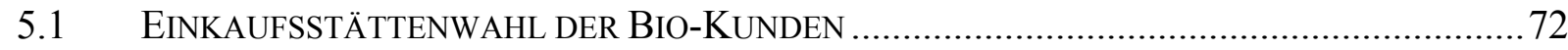

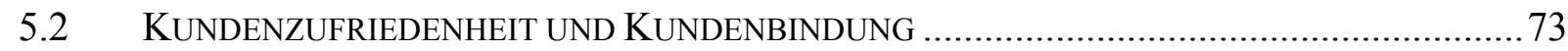

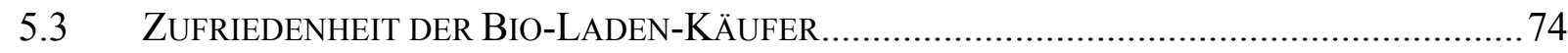

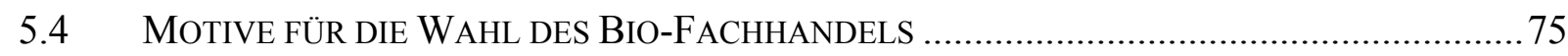

5.5 VERGLEICHENDE BEWERTUNG VON Bio-LADEN UND BIO-SUPERMARKT ..................... 81

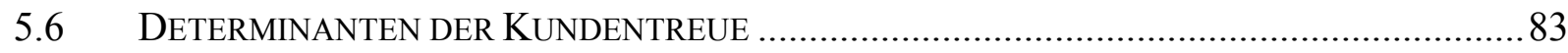

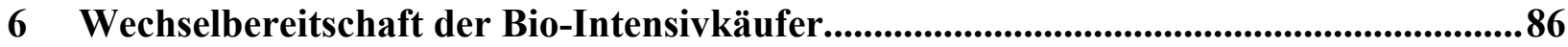

7 Perspektiven der Bio-Läden ..........................................................................................................93

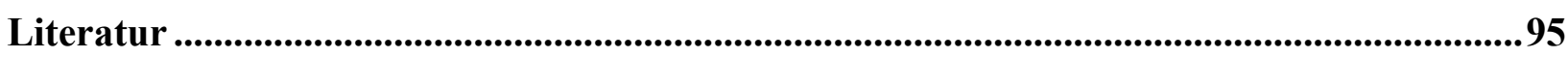

* Veröffentlicht als Diskussionsbeitrag 0501 des Instituts für Agrarökonomie 


\section{Abbildungsverzeichnis}

Abbildung 1: Absatzwege und Ausgabenanteile für Biolebensmittel........................................63

Abbildung 2: Käufergruppen für Bio-Lebensmittel im Einzelhandel

Abbildung 3: Globalzufriedenheit mit dem Naturkostfachhandel bei Stammkunden: Wie zufrieden sind Sie mit Ihrem Naturkostfachhändler? (in \%).

Abbildung 4: Vertrauen: Ich vertraue Herstellern, die nur Bio-Produkte produzieren mehr als solchen, die zusätzlich auch konventionelle Ware haben (in \%).

Abbildung 5: Informationsnachfrage zur Naturkost: Wie häufig informieren Sie sich über Naturkost? (z. B. in Schrot \& Korn, Eve, Naturkost.de) (in \%).

Abbildung 6: Variety Seeking: Den Einkauf im Bio-Laden finde ich interessant, weil es dort viele neue Produkte und Marken zu entdecken gibt (in \%).

Abbildung 7: Einkaufsstättenpräferenz und gesellschaftliche Protesthaltung: Wenn ich im Bioladen einkaufe, zeige ich, dass ich gegen die industrielle Herstellung von

Lebensmitteln und gegen Agrarfabriken bin (in \%).

Abbildung 8: Wahrgenommene soziale Kontrolle im Bio-Laden: Mir ist unangenehm, dass man im Bio-Laden nicht in Ruhe schauen kann, da fühle ich mich wie auf dem Prüfstand (in \%).

Abbildung 9: Vergleich Bio-Supermärkte und Bio-Läden ..................................................... 82

Abbildung 10: Regressionsmodell Kundenbindung Bio-Laden. .85

\section{Tabellenverzeichnis}

Tabelle 1: Struktur der Betriebsformen des Naturkostfachhandels..........................................64

Tabelle 2: Merkmale und Besonderheiten von Bio-Intensivkäufern..........................................69

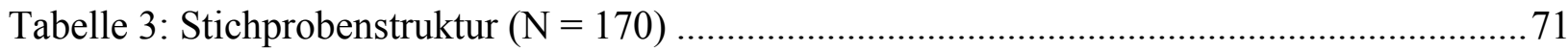

Tabelle 4: Einkaufsstätten der Bio-Kunden.......................................................................... 73

Tabelle 5: Einkaufsatmosphäre und grundsätzliche Unterstützung der Naturkostläden.............. 75

Tabelle 6: Kaufmotive der Bio-Fachhandelskunden (Konstantsummenskala mit 100 Punkten).. 76

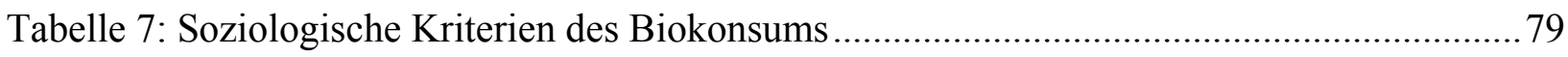

Tabelle 8: Ökologischer Konsum im Freundes- und Bekanntenkreis ....................................... 81

Tabelle 9: Faktorenanalyse Vergleich Bio-Laden - Bio-Supermarkt........................................83

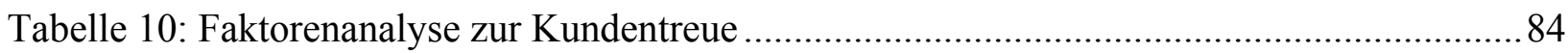

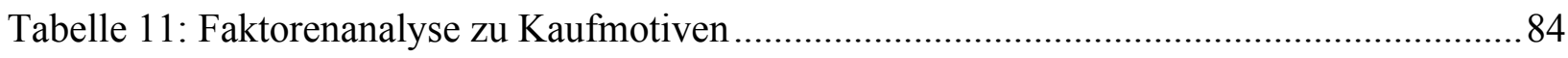

Tabelle 12: Auswahlexperiment mit realen Produktpreisen für vier Betriebsformen.................. 88

Tabelle 13: Kundencluster nach Einkaufsstättenwahl ............................................................. 90

Tabelle 14: Multinominales Regressionsmodell zur Wechselbereitschaft................................91 


\section{Bio-Pioniere und Bio-Läden}

Die Entwicklung des biologischen Landbaus und die Distribution seiner Produkte sind eng verknüpft mit dem Bio-Fachhandel als Pionier der Biovermarktung (Spahn 2002: 8). Die

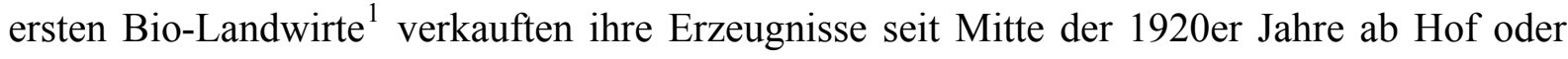
über Reformhäuser. Da die Verbraucher meist lange Anfahrtswege zu den wenigen BioBetrieben in Kauf nehmen mussten, gründeten sich in den 70er Jahren verstärkt Bio-Läden. Diese waren z. T. als Einkaufsgemeinschaften von konsum- und kapitalismuskritischen Kunden organisiert. Verbraucher nutzten die Bio-Läden nicht nur zum Bezug ökologisch erzeugter Lebensmittel, sondern auch als Treffpunkte der alternativen Szene, zur politischen Diskussion und Information. Kunden, die dieser Szene nicht angehörten, fanden den Weg in den Bio-Laden nur selten, da der Kauf von Bio-Produkten neben dem Gesundheitsaspekt vor allem Ausdruck einer politischen Grundhaltung war. Zudem waren die Bio-Läden der ersten Stunde häufig in ungünstigen Lagen, z. T. sogar in Kellerräumen, untergebracht, so dass entsprechende Einschränkungen in der Verfügbarkeit nur von engagierten Konsumenten in Kauf genommen wurden (Spahn 2002: 27).

Im Zuge der Umweltbewegung der 1980er Jahre und nach der Reaktorkatastrophe in Tschernobyl wurde die Biobranche von einer breiteren Kundenschicht wahrgenommen und erlebte einen starken Wachstumsschub. Kundenstudien aus dieser Zeit demonstrieren allerdings, dass immer noch im Kern die Gruppe der politisch interessierten Konsumenten mit links-alternativem Bewusstsein angesprochen wurde, auch wenn sich erste Ausweitungen in gesundheitsbewusst-hedonistische und konservativ-etablierte Milieus zeigten (SinusSociovision 2002). Fördernd auf den Absatz wirkten sich in dieser Phase die Festlegung von Basisrichtlinien durch die Anbauverbände und die zunehmende Verbreitung der entsprechenden Label aus, die für den Verbraucher größere Klarheit und Qualitätssicherheit schufen. Hinzu kam in dieser Phase allerdings auch zum ersten Mal Konkurrenz durch den konventionellen Lebensmitteleinzelhandel (LEH). Der Markteinstieg der Tengelmann-Gruppe und die Verbreiterung der Käuferschicht hatten eine Professionalisierung der Bio-Läden zur Folge, was sich zum einen in einer stärkeren betriebswirtschaftlichen Orientierung, aber auch in einem moderneren Ladenbau zeigte (Kreuzer 1996:114). Mit der Etablierung neuer Vertriebstypen - in den 90er Jahren entstanden die ersten Bio-Supermärkte - hält der Professionalisierungstrend weiterhin an.

\footnotetext{
${ }^{1}$ In diesem Beitrag wurde zur besseren Lesbarkeit bei Personenangaben nicht durchgängig die männliche und weibliche Form gewählt, auch wenn natürlich in jedem Fall Personen beider Geschlechter gemeint sind.
} 
Heute zählen die Bio-Supermärkte zu den am schnellsten wachsenden Absatzkanälen für BioWare und erwirtschafteten im Jahr 2002 bereits ein Fünftel des Gesamtumsatzes im Naturkosthandel (Bahrdt et al. 2003).

Der zunehmende Erfolg von Bio-Supermärkten, aber auch die Ausweitung des BioSortiments im konventionellen LEH bis in den Discountbereich charakterisiert das Marktwachstum des Bio-Segments und die Erschließung neuer Käuferschichten. Vor diesem Hintergrund wird im folgenden Beitrag die Frage aufgeworfen, welche Perspektiven der BioFachhandel heute hat. Wird sich der traditionelle Bio-Fachhandel in Zeiten von Discountboom und Zeitknappheit gegen den konventionellen LEH und neue Fachhandelskonzepte behaupten können? Zur Beantwortung dieser Fragen werden im Rahmen der vorliegenden Studie zunächst die unterschiedlichen Distributionswege von Bio-Lebensmitteln skizziert und die Zielgruppe der Biokonsumenten charakterisiert. Kern der Untersuchung ist eine Befragung von Bio-Intensivkäufern zu ihren Einkaufsstättenpräferenzen und ihrer Wechselbereitschaft. In der Nachfolge der BSE-Krise und der Agrarwende tragen eine Reihe von Faktoren (z. B. das Bio-Siegel) dazu bei, dass die Wettbewerbsposition des BioFachhandels fragil werden könnte.

\section{Absatzwege für Bio-Lebensmittel im Überblick}

Die Distribution von Bio-Lebensmitteln verläuft über verschiedene Absatzwege (siehe Abbildung 1). Mit 31,2\% der Ausgaben für Öko-Lebensmittel ist der Naturkostfachhandel (Bio-Läden, Bio-Supermärkte) der wichtigste Vertriebskanal, gefolgt vom konventionellen LEH mit $28 \%$ Umsatzanteil. Auch die Direktvermarktung ist mit $16 \%$ für Bio-Lebensmittel von großer Bedeutung. 


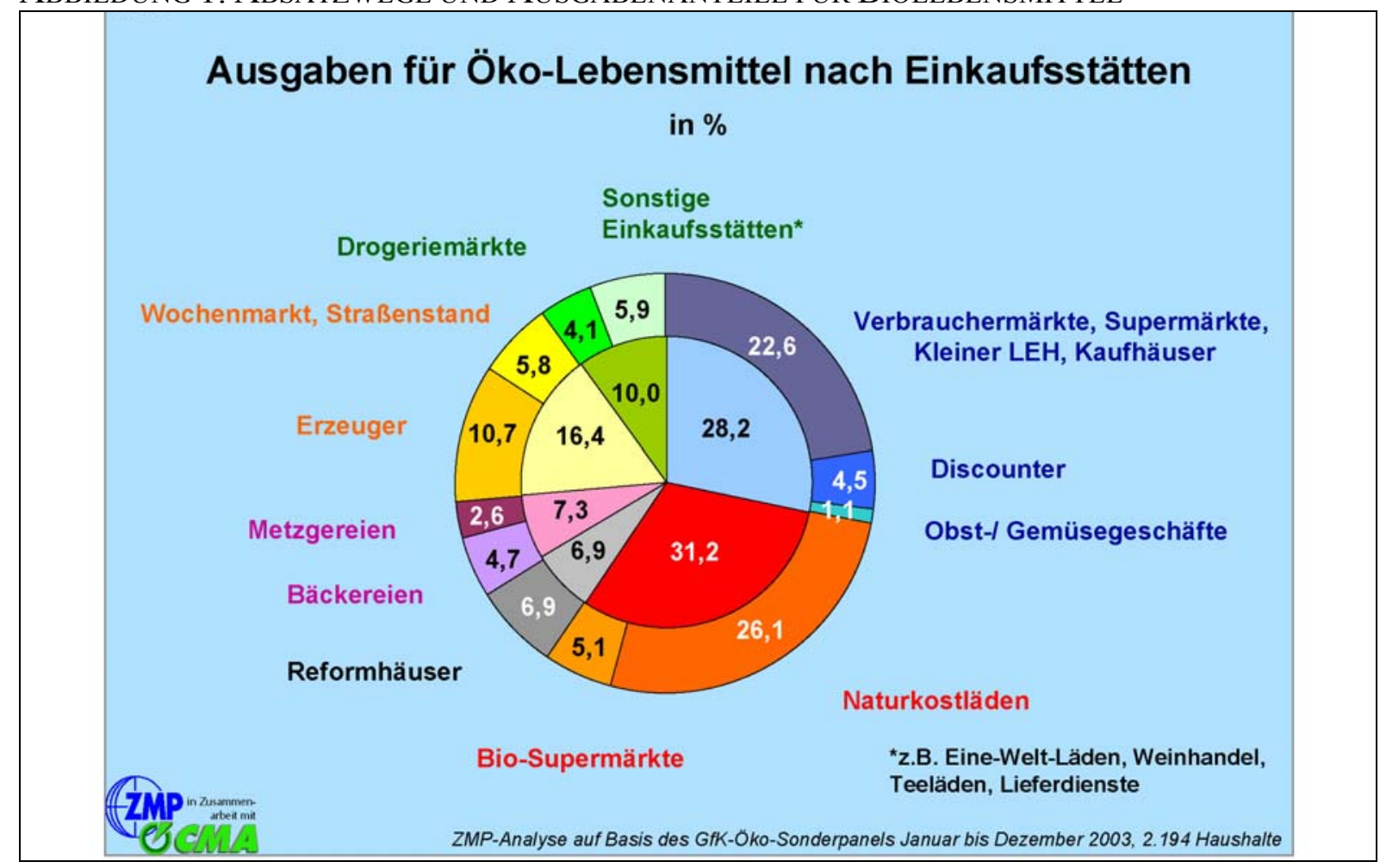

Quelle: Michels et al. 2004: 8

Besonders interessant ist der große Erfolg der Bio-Supermärkte. Während im Jahr 2000 erst 50 Bio-Supermärkte existierten, sind es nur drei Jahre später bereits 180 Geschäftsstätten, die einen Umsatzanteil von 5,1 \% ausmachen (Michels et al. 2004: 6). Mit nur $9 \%$ der Läden erwirtschaften die Bio-Supermärkte $17 \%$ des Umsatzes des Naturkostfachhandels (Bahrdt et al. 2003: 13). Das Wachstum der Bio-Supermärkte war auch im Jahr 2004 sehr stark, so dass ihre Zahl inzwischen auf 250 angestiegen ist (Kreuzer/Offeney 2005). Im Fachhandelsbereich agieren darüber hinaus Reformhäuser, die nicht ausschließlich Bio-Waren führen, häufig aber im Zuge ihrer ganzheitlichen Gesundheitsorientierung das Naturkostsegment ausgedehnt haben.

Bei der Abgrenzung der Formen des Naturkostfachhandels sind vor allem die unterschiedliche Ladengröße und damit einhergehend auch die Artikelanzahl maßgeblich (siehe Tab. 1). Die Naturkostfachgeschäfte unterscheiden sich vom Bio-Supermarkt weniger in der grundsätzlichen Sortimentsgestaltung. Bei beiden ist der Frischebereich ähnlich wichtig. Die gelisteten Marken sind häufig identisch. Die größere Artikelanzahl und der Fokus auf SBWaren verlangen allerdings eine erhebliche Ausweitung der Ladengröße, auch wenn BioSupermärkte immer noch deutlich kleiner als konventionelle Supermärkte sind (dort liegt die Wachstumsschwelle, ab der heute neue Geschäfte eröffnet werden, zzt. bei rund 1.000 qm). 
TABELLE 1: STRUKTUR DER BETRIEBSFORMEN DES NATURKOSTFACHHANDELS

\begin{tabular}{|c|c|c|c|}
\hline & $\begin{array}{l}\text { Naturkostfach- } \\
\text { geschäfte }\end{array}$ & Bio-Supermärkte & Reformhäuser \\
\hline $\begin{array}{l}\text { Umsatzanteil } \\
\text { am Bio-Markt }\end{array}$ & $26,1 \%$ & $5,1 \%$ & $6,9 \%$ \\
\hline Outlet-Zahl & 2.000 & 250 & 2.300 \\
\hline $\begin{array}{l}\text { Ladengröße in } \\
\mathrm{qm}\end{array}$ & ca. $100-200$ & ca. $200-1.000$ & ca. 70 \\
\hline $\begin{array}{l}\text { Artikelanzahl } \\
\text { im Sortiment }\end{array}$ & $\begin{array}{l}\text { ca. } 6.000 \\
\varnothing 3.000 \\
\end{array}$ & $\begin{array}{c}\text { bis } 10.000 \\
\varnothing 5.500 \\
\end{array}$ & Keine Angaben \\
\hline $\begin{array}{l}\text { Umsatzver- } \\
\text { teilung }\end{array}$ & $\begin{array}{ll}\text { Frische } & 50 \% \\
\text { Trocken- } & 37 \% \\
\text { produkte } & \\
\text { Non-Food } & 11 \%\end{array}$ & $\begin{array}{ll}\text { Frische } & 53 \% \\
\text { Trocken- } & 37 \% \\
\text { produkte } & \\
\text { Non-Food } & 10 \%\end{array}$ & $\begin{array}{ll}\text { Frische } & \\
\text { Trocken- } & 68,5 \% \\
\text { produkte } & \\
\text { Non-Food } & 31,5 \% \\
\end{array}$ \\
\hline Kernkompetenz & $\begin{array}{l}\text { Inhabergeführt, } \\
\text { Kundenbindung, } \\
\text { Verbrauchervertrauen, } \\
\text { Sortimentsklarheit }\end{array}$ & $\begin{array}{l}\text { Sortimentsbreite und - } \\
\text { tiefe, Neukunden- } \\
\text { gewinnung, attraktive } \\
\text { Standorte, moderne } \\
\text { Outlets }\end{array}$ & $\begin{array}{l}\text { Inhabergeführt, } \\
\text { Beratung im Bereich } \\
\text { Gesundheit und } \\
\text { Ernährung, } \\
\text { Qualitätsstandards }\end{array}$ \\
\hline Kernsortimente & $\begin{array}{l}\text { Obst/Gemüse, } \\
\text { Molkereiprodukte, } \\
\text { Trockenprodukte }\end{array}$ & $\begin{array}{l}\text { Obst/Gemüse, } \\
\text { Trockenprodukte, SB- } \\
\text { Ausrichtung }\end{array}$ & $\begin{array}{l}\text { Vegetarische } \\
\text { Lebensmittel, } \\
\text { freiverkäufliche } \\
\text { Naturarzneimittel, } \\
\text { Körperpflege }\end{array}$ \\
\hline
\end{tabular}

Quelle: Eigene Zusammenstellung nach Kreuzer/Offeney 2005, Spahn 2002: 26; Bahrdt et al. 2003: 12, Michels et al. 2004: 8

Auch wenn damit die Grenzen zwischen den beiden Betriebsformen Bio-Laden und BioSupermarkt nicht immer trennscharf sind, so trägt doch die Geschäftsflächenausweitung, der SB-Fokus und die i. d. R. einheitlichere und weniger traditionelle Inneneinrichtung zu einer moderneren Anmutung bei, was zugleich die Barrieren bei der Neukundengewinnung senkt. Bio-Supermärkte erreichen möglicherweise leichter Bio-Erstkunden als der Naturkostfachhandel, letzterer weist dafür gegebenenfalls Vorteile in der Kundenbindung auf (Spahn 2002: 26).

Neben dem klassischen Naturkostfachhandel spielen der konventionelle LEH und hier besonders die qualitätsorientierten Vertriebstypen in der Biovermarktung mit 28 \% Umsatzanteil eine wichtige Rolle. Das durchschnittliche Sortiment an Bioprodukten je Outlet beläuft sich je nach Anbieter (Edeka, Metro, Rewe, Tengelmann, Karstadt) auf 200 bis 800 Artikel. Eine herausragende Stellung nimmt Tegut mit ca. 1.200 Artikeln im Sortiment ein. Aber auch 
die selbstständigen Lebensmitteleinzelhändler (SEH) in den Kooperationsgruppen Edeka und Rewe sind z. T. besonders erfolgreich in der Biovermarktung und bauen ihr Biosortiment weiter aus (Bahrdt et al. 2003: 12). Inzwischen haben auch einige Discounter (z. B. Plus und Aldi) erste Bioartikel gelistet. Der Umsatzanteil am Biosegment ist allerdings noch relativ gering und beträgt etwa 4,5\%, der Discountanteil am gesamten Lebensmittelmarkt dagegen fast $40 \%$ (Michels et al. 2004: 8).

\section{Zielgruppen für Bio-Produkte: Intensiv- versus Gelegenheitskäufer und ihre Einkaufsstättenpräferenzen}

Während der vergangenen Jahre wurden zahlreiche Studien zum Konsumverhalten bei BioLebensmitteln erstellt (z. B. Kropp/Brunner 2004; Lüth et al. 2004; Michels et al. 2003; Bruhn 2002; ZMP 2002; Richter 2001; Schaer 2001; ZMP 2001; Thompson/Kidwell 1998). Insgesamt zeigt sich durchgängig, dass Frauen häufiger und mehr Bio-Produkte kaufen als Männer (Bruhn 2002; ZMP 2001; Jung 1998: 88). Der Einfluss der klassischen Schichtenkriterien (Einkommen, Bildung, Beruf) ist ausgesprochen groß (Kropp/Sehrer 2004). Betrachtet man den Familienlebenszyklus, der verschiedene demographische Merkmale wie Haushaltsform, Familienstand und Zahl der Kinder zu unterschiedlichen Lebensphasen zusammenfasst (Moser 2002; Bodenstein/Spiller 1998), so fällt auf, dass Single-Haushalte die geringste Kaufhäufigkeit aufweisen, Zwei-Personen-Haushalte bereits mehr Bio-Produkte konsumieren und Familien mit Kindern einen besonders hohen Verwenderanteil aufweisen (Ziemann/Thomas 2003: 22; ZMP 2001; Jung 1998: 96).

Die Studien decken weiterhin klare Unterschiede zwischen den verschiedenen Kundengruppen und ihren jeweiligen Einkaufsstättenpräferenzen auf. So zeigt sich, dass jeweils bestimmte Kundensegmente ökologische Lebensmittel in unterschiedlichen Absatzkanälen kaufen. Auffällig ist dabei meist eine deutliche Präferenz der Käufer für einen der Absatzkanäle, so dass Fachhandelskäufer selten im großbetrieblichen konventionellen LEH und umgekehrt Kunden des LEH selten im Naturkostfachhandel kaufen (Lüth/Spiller 2004).

Eine wichtige Rolle bei der Differenzierung der Bio-Käufer spielt die Kaufintensität (siehe Abbildung 2). Selten- und Gelegenheitskäufer unterscheiden sich deutlich von den Intensivkäufern. Während die meisten Bio-Kunden des Fachhandels zu den Intensivkäufern zählen, spaltet sich die Gruppe der Bio-Kunden des LEH in Selten- und Gelegenheitskäufer einerseits sowie Intensivkäufer andererseits. Jedoch dominieren bei den Käufern des LEH die 
Selten- und Gelegenheitskäufer stark (Lüth et al. 2004), während der Intensivkäuferanteil geringer ist. Die Besonderheiten dieser Kundensegmente geben Aufschluss über die Anforderungen an den Handel und werden daher im Folgenden näher betrachtet.

ABBILDUNG 2: KÄUFERGRUPPEN FÜR BIO-LEBENSMITTEL IM EINZELHANDEL

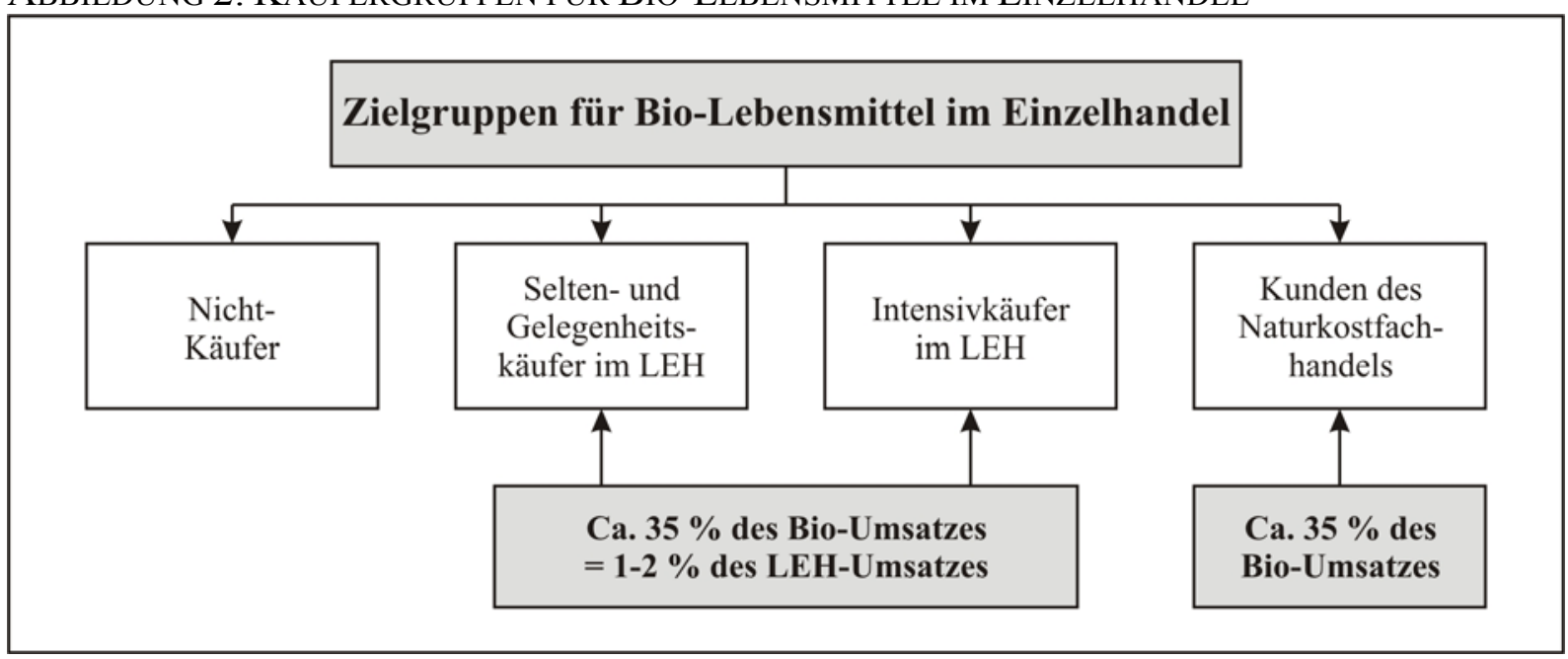

Quelle: Eigene Darstellung

\section{Selten- und Gelegenheitskäufer:}

Diese Gruppe der Konsumenten ist soziodemographisch schwer abzugrenzen und weist nur geringe Unterschiede zum Durchschnitt der Lebensmittelkäufer insgesamt auf. Bio-Produkte werden vorwiegend im Vollsortimenter des konventionellen LEH sowie im Discounter gekauft, z. T. auch im Bio-Supermarkt (ISOE 2003: 29). Es wird seltener und in geringeren Mengen Bio gekauft als von den Intensivkäufern (Michels et al. 2003: ff.). Laut ZMP (2001) liegt in dieser Gruppe der Anteil von Bio-Produkten am Gesamtlebensmittelverbrauch zwischen 5 und $10 \%$ bei den Gelegenheitskäufern bzw. unter $5 \%$ bei den Seltenkäufern, wobei diese Zahlen methodenbedingt noch überschätzt sein dürften. Das Wissen über BioProdukte, -Marken und -Label ist gering. Ungestützt erreichten die Bio-Eigenmarken des LEH im Jahr 2003 eine Bekanntheit von deutlich weniger als $5 \%$, Anbauverbände wie Bioland und Demeter näherten sich 10 \% Bekanntheitsgrad (Lüth et al. 2004). Im Gegensatz zu den Kaufpräferenzen der Intensivkäufer werden vorwiegend Trockenprodukte und Kartoffeln in Bio-Qualität gekauft, selten hingegen Molkereiprodukte und Frischfleisch. Dies ist einerseits durch die geringere Auswahl im Bio-Bereich des konventionellen LEH begründet, die in direkter Konkurrenz zu einer großen Auswahl an konventionellen Alternativen steht. Andererseits reicht die Mehrpreisbereitschaft der Käufer häufig nicht an die tatsächlichen Aufschläge heran (Bruhn 2002). Lediglich bei risikobehafteten Produkten wie Eiern und Fleisch ist eine höhere Mehrpreisbereitschaft zu erkennen (Spiller 2002). Diese 
Tatsache zeigt deutlich die geringere Relevanz altruistischer Kaufmotive in dieser Käufergruppe. Häufig stehen vor allem Gesundheit, Genuss und Sicherheitsmotive, also der individuelle Nutzen durch die Steigerung bzw. den Erhalt der eigenen Lebensqualität im Vordergrund des Kaufs (Lüth et al. 2004; Kuhnert et al. 2002: 5).

\section{Intensivkäufer:}

Die Bio-Intensivkäufer teilen sich auf in die Gruppe der Intensivkäufer des konventionellen LEH und die des Fachhandels, die sich z. T. deutlich unterscheiden, teilweise jedoch auch einheitliche Merkmale aufweisen. Im Folgenden werden daher Gemeinsamkeiten und Unterschiede beschrieben (siehe auch Tabelle 2, die Unterschiede sind durch Schattierung gekennzeichnet).

Intensivkäufer kennzeichnet in erster Linie, dass sie regelmäßig und in sehr viel höheren Anteilen Bio-Produkte konsumieren als Selten- und Gelegenheitskäufer. Letztere zeichnen sich durch unregelmäßige und in größeren Zeitabständen getätigte Bio-Käufe aus, während Intensivkäufer kontinuierlich einen Teil ihres täglichen Bedarfs durch Bio-Produkte decken. Obgleich die Gruppe der Intensivkäufer relativ klein ist, macht sie doch einen großen Anteil des Umsatzes aus. Daten des GfK-Haushaltspanels 2002 zeigen, dass der Anteil der Intensivkäufer im gesamten Biomarkt bei lediglich etwa $8 \%$ aller Bio-Käufer liegt, die jedoch etwa $66 \%$ des Umsatzes tätigen (Michels et al. 2003).

Im Hinblick auf die Altersstruktur dieser Gruppe gibt es unterschiedliche Studienergebnisse. Einige Studien kommen zu dem Schluss, dass leichte Schwerpunkte bei älteren Käufern liegen (Lüth et al. 2004; ISOE 2003). Die Intensivkäufer des LEH sind dabei in den Altersgruppen unter 30 deutlich geringer und in der Altersgruppe zwischen 40 und 49 Jahren deutlich stärker vertreten als die des Naturkostfachhandels (Michels et al. 2003). Auch im Familienlebenszyklus zeigen sich Unterschiede. Während Familien mit Klein- oder Schulkindern häufig Intensivkäufer des LEH sind, handelt es sich bei den Fachhandelskäufern eher um junge Paare oder Singles ohne Kinder (Michels et al. 2003).

Im Hinblick auf das Bildungsniveau unterscheiden sich die Gruppen der Intensivkäufer wiederum. Die Heavy User im LEH zeigen ein ähnliches Bildungsniveau wie der Durchschnitt der Bevölkerung, während die Kunden des Naturkostfachhandels sich durch einen weit überdurchschnittlich hohen Akademikeranteil auszeichnen (Michels et al 2003). Das Ein- 
kommen ist in beiden Gruppen deutlich höher als beim Durchschnitt der Konsumenten (Lüth et al. 2004; Michels et al. 2003; Ziemann/Thomas 2003).

Zusammenhänge mit der Wohnortgröße konnten, wenn überhaupt, nur schwach festgestellt werden. Michels et al. (2003) sehen bei beiden Gruppen leichte Tendenzen zu größeren Städten von 100.000 und mehr Einwohnern. Unter denjenigen, die in kleineren Orten wohnen, leben die Intensivkäufer des LEH eher in Kleinstädten (5.000 - 20.000 Einwohner), die des Naturkostfachhandels eher in Dörfern (unter 5.000 Einwohner).

Intensivkäufer tendieren zu einem stärkeren Ernährungsinvolvement mit einer Präferenz für gesunde, vollwertige und geschmackvolle sowie fair gehandelte Lebensmittel und weisen eine kritische Einstellung gegenüber Fast Food, einen geringeren Fleischkonsum und ein höheres Regionalbewusstsein auf. Dieses Charakteristikum ist bei den Fachhandelskunden meist noch etwas stärker ausgeprägt als bei denen des LEH (Lüth et al. 2004; Michels et al. 2003).

Obgleich Intensivkäufer sehr markenbewusst sind, den Fachhandel bevorzugen und Discountern skeptischer gegenüberstehen, sind sie dennoch preisbewusst und bei BioProdukten nicht unbedingt markentreu (Hamm/Wild 2004). 
TABELLE 2: MERKMALE UND BESONDERHEITEN VON BIO-INTENSIVKÄUFERN

\begin{tabular}{|c|c|c|}
\hline & Intensivkunden des LEH & $\begin{array}{l}\text { Intensivkunden des } \\
\text { Fachhandels } \\
\end{array}$ \\
\hline Einkaufsintensität & $\begin{array}{l}\text { Regelmäßig (ein- bis mehrmals } \\
\text { pro Woche) }\end{array}$ & $\begin{array}{l}\text { Regelmäßig (ein- bis mehrmals } \\
\text { pro Woche) }\end{array}$ \\
\hline Alter & $\begin{array}{l}\text { Schwerpunkt bei mittleren und } \\
\text { höheren Altersgruppen }\end{array}$ & $\begin{array}{l}\text { Alle Altersgruppen, leichter } \\
\text { Überhang der jüngeren } \\
\text { Altersgruppen im Vergleich zu } \\
\text { Biokunden allgemein }\end{array}$ \\
\hline Familienlebenszyklus & $\begin{array}{l}\text { Vor allem Familien mit Klein- } \\
\text { und Schulkindern }\end{array}$ & $\begin{array}{l}\text { Leichter Überhang bei jungen } \\
\text { Singles und Paaren }\end{array}$ \\
\hline Bildung & $\begin{array}{l}\text { Durchschnittliches } \\
\text { Bildungsniveau }\end{array}$ & $\begin{array}{l}\text { Deutlich gehobenes } \\
\text { Bildungsniveau }\end{array}$ \\
\hline Einkommen & $\begin{array}{l}\text { Deutlich gehobenes } \\
\text { Einkommen }\end{array}$ & $\begin{array}{l}\text { Deutlich gehobenes } \\
\text { Einkommen }\end{array}$ \\
\hline Wohnortgröße & $\begin{array}{l}\text { Tendenz zu Städten } \\
\geq 100.000 \text { Einwohner, in kleinen } \\
\text { Orten eher kleinstädtisch }\end{array}$ & $\begin{array}{l}\text { Tendenz zu Städten } \\
\geq 100.000 \text { Einwohner, in kleinen } \\
\text { Orten eher dörflich }\end{array}$ \\
\hline Ernährungsinvolvement & $\begin{array}{l}\text { Relativ hohes } \\
\text { Ernährungsinvolvement }\end{array}$ & Hohes Ernährungsinvolvement \\
\hline Markenbewusstsein generell & hoch & hoch \\
\hline Markentreue bei Bio & gering & gering \\
\hline
\end{tabular}

\section{Untersuchungsdesign der Online-Befragung}

Vor dem Hintergrund der zuvor skizzierten Markt- und Käuferstudien fokussiert die folgende Befragung auf die Kunden des Bio-Fachhandels, um dessen „Überlebenschancen“ im Wettbewerb der Vertriebsformen $\mathrm{zu}$ analysieren. Bisher haben sich die meisten BioIntensivkäufer als relativ fachhandelstreu erwiesen. In der Folge von BSE-Krise und Agrarwende bauen aber die Unternehmen des konventionellen LEH ihr Bio-Sortiment langsam aus. Der Markteintritt der Discounter verstärkt zudem den Preiswettbewerb, der Preisabstand zwischen den Discountern wie Plus und dem Bio-Fachhandel ist deutlich größer als im Fall der Supermärkte wie Edeka (vgl. unten). Aufgrund der strukturellen Kostennachteile wird der Fachhandel preispolitisch nur begrenzt reagieren können. Schließlich hat das staatliche Bio-Siegel die Vergleichbarkeit der Produkte erhöht und die Qualitätsunsicherheit für Käufer im LEH reduziert. Angesichts der zunehmenden Wettbewerbsintensität fehlen aktuelle Studien, die auf die Wettbewerbsposition des Fachhandels und seine Zukunftsperspektiven abheben.

Die Befragung richtet sich auf die Beweggründe für den Kauf im Fachhandel, auf die Kundenzufriedenheit sowie die Wechselbereitschaft. Durchgeführt wurde die Erhebung im Herbst 2004 in Zusammenarbeit mit Naturkost.de. Hierbei handelt es sich um eine Internet- 
plattform der Bio Verlags GmbH. Diese ist mit durchschnittlich 180.000 Besuchern pro Monat (Mediadaten Naturkost.de 2002) eines der führenden Internet-Portale für die deutsche Naturkostfachwirtschaft (Bio-Läden, ökologische Produzenten, Öko-Großhandel). Das selbst definierte Ziel des Verlages ist, „, [...] gute und kostengünstige Medien anzubieten [und] über Ökolebensmittel zu informieren [...]““ (Naturkost.de 2002). Genutzt wird Naturkost.de hauptsächlich von Kunden des Naturkostfachhandels, so dass die User der angestrebten Zielgruppe der Befragung entsprechen.

In die Auswertung konnten insgesamt 170 gültige Antworten einbezogen werden, weitere 50 Antworten mussten wegen unvollständiger Angaben ausgesondert werden. ${ }^{2}$ Durch eine vorgeschaltete Gabelfrage wurde sichergestellt, dass nur Kunden mit Bio-Fachhandelserfahrung befragt wurden. Tabelle 3 fasst die Stichprobenstruktur zusammen. Die Befragung dauerte im Durchschnitt 13 Minuten, was für eine Online-Befragung sicherlich eher die Obergrenze darstellt.

In dieser Befragung fällt der mit $70 \%$ hohe Frauenanteil auf, was die reale Situation beim Einkauf und die höhere Biopräferenz von Frauen widerspiegelt. Auch der sehr hohe Bildungsstand, $70 \%$ der Probanden verfügt über Abitur, ein gutes Drittel sogar über einen Hochschulabschluss, repräsentiert den typischen Bio-Konsumenten (siehe Kap. 3).

\footnotetext{
${ }^{2}$ Durch die Erfassung der Beantwortungszeit war es möglich, alle Probanden mit sehr niedriger Antwortzeit auszusondern, da hier von unreflektierten Antworten auszugehen ist. Ebenso wurden alle Befragten mit auffällig einheitlichem Antwortverhalten (z. B. durchgehend immer nur einen Skalenwert genannt) ausgefiltert.
} 
TABELLE 3: STICHPROBENSTRUKTUR $(\mathrm{N}=170)$

\begin{tabular}{|c|c|c|c|}
\hline Geschlecht & 30\% Männer & \multicolumn{2}{|c|}{$70 \%$ Frauen } \\
\hline Altersgruppen & $\begin{array}{l}\text { Stichprobe } \\
\text { (in \%) }\end{array}$ & $\begin{array}{c}\text { Naturkostfach- } \\
\text { geschäfte (in \%) }\end{array}$ & $\begin{array}{l}\text { Bevölkerungsanteil } \\
\text { Haushalte (in \%) }\end{array}$ \\
\hline bis 34 Jahre & 38,2 & 18 & 22 \\
\hline 35-44 Jahre & 34,7 & 30 & 20 \\
\hline 45-54 Jahre & 18,2 & 16 & 17 \\
\hline 55-64 Jahre & 4,7 & 24 & 18 \\
\hline über 65 Jahre & 0,6 & 12 & 24 \\
\hline keine Angaben & 3,5 & & \\
\hline Schulbildung & $\begin{array}{l}\text { Stichprobe } \\
\text { (in \%) }\end{array}$ & $\begin{array}{l}\text { Naturkostfach- } \\
\text { geschäfte (in \%) }\end{array}$ & $\begin{array}{l}\text { Bevölkerungsanteil } \\
\text { Haushalte (in \%) }\end{array}$ \\
\hline Haupt-/Volksschule & 4,1 & 14 & 28 \\
\hline mittlere Reife/Realschule & 21,8 & 17 & 27 \\
\hline Abitur/Fachabitur & 32,4 & $21^{2}$ & $23^{2}$ \\
\hline Hochschulabschluss & 36,5 & 48 & 22 \\
\hline sonstige & 2,4 & & \\
\hline keine Angaben & 2,9 & & \\
\hline Wohnortgröße & $\begin{array}{c}\text { Stichprobe (in } \\
\% \text { ) }\end{array}$ & \multicolumn{2}{|c|}{ Bundesdurchschnitt $^{3}$} \\
\hline $\begin{array}{l}\text { weniger als } 1.000 \\
\text { Einwohner }\end{array}$ & 7,6 & \multicolumn{2}{|c|}{3,3} \\
\hline 1.000 - 5.000 Einwohner & 9,4 & \multicolumn{2}{|c|}{15,1} \\
\hline $5.000-10.000$ Einwohner & 7,1 & \multicolumn{2}{|c|}{11,0} \\
\hline $\begin{array}{l}10.000-50.000 \\
\text { Einwohner }\end{array}$ & 19,4 & \multicolumn{2}{|c|}{32,7} \\
\hline $\begin{array}{l}50.000-100.0000 \\
\text { Einwohner }\end{array}$ & 9,4 & \multicolumn{2}{|c|}{8,7} \\
\hline $\begin{array}{l}100.000-500.000 \\
\text { Einwohner }\end{array}$ & 24,1 & \multicolumn{2}{|c|}{16,3} \\
\hline $\begin{array}{l}\text { mehr als } 500.000 \\
\text { Einwohner }\end{array}$ & 19,4 & \multicolumn{2}{|c|}{14,4} \\
\hline
\end{tabular}

Quelle: Eigene Erhebung; ${ }^{1}$ Michels et al. 2004: 18 f.; ${ }^{2}$ Abitur und Fach-/Berufsfachschule addiert; ${ }^{3}$ Statistisches Bundesamt 2004: 38

Die Altersstreuung liegt zwischen 28 und 66 Jahren, das durchschnittliche Alter beträgt 38 Jahre. Vergleicht man die Alterklassen mit der Verteilung der Fachhandelskunden, zeigt sich, dass die Probanden unserer Stichprobe jünger sind als die typischen Bio-Fachhandelskunden, was sicherlich mit der Onlinebefragung zusammenhängt. Die Verteilung der Probanden auf die Wohnortgrößenklassen ist gegenüber dem Bundesdurchschnitt insoweit verzerrt, als dass großstädtische Wohnregionen überrepräsentiert sind. Dies entspricht der o. g. Situation bei Bio-Intensivkäufern und war insofern zu erwarten.

Im Durchschnitt geben die Probanden an, dass $64 \%$ ihres Lebensmittelkonsums auf BioLebensmittel entfallen. 10 der 170 Probanden kaufen sogar ausschließlich Bio-Lebensmittel. 
Knapp $70 \%$ bekunden, mehr als $50 \%$ ihrer Lebensmittel in Bio-Qualität einzukaufen. Vergleicht man diese Zahlen mit den von der ZMP publizierten Daten zum generellen BioKonsum, die nur $10 \%$ der Haushalte ausweisen, in denen mindestens zweimal wöchentlich Bio gekauft wird und deren Ausgabenanteil für Bio bei 35 \% liegt (Michels et al. 2004: 14 f.), wird deutlich, dass es tatsächlich gelungen ist, die Kerngruppe der Bio-Intensivkäufer zu erfassen.

Insgesamt handelt es sich damit um eine Sondierungsstudie, die jedoch einen relativ aussagekräftigen Einblick in die Konsumgewohnheiten der intendierten Zielgruppe verspricht.

\section{Einkaufsstättentreue der Bio-Intensivkäufer}

\subsection{Einkaufsstättenwahl der Bio-Kunden}

Die befragten Probanden bevorzugen bisher beim Einkauf ihrer Bio-Produkte sehr eindeutig den Bio-Laden. Gut 60 \% kaufen hier häufig oder sehr häufig ein, nur $3 \%$ nie (14\% selten). Die zweitwichtigste Einkaufsstätte für Bio-Waren ist der Bio-Supermarkt (38 \% häufig oder sehr häufig). An dritter Stelle folgt der konventionelle Supermarkt (35 \% häufig bzw. sehr häufig), vor dem Wochenmarkt, dem Reformhaus und dem Direkteinkauf beim Landwirt. Nur $14 \%$ der Befragten kaufen häufiger Bio-Waren beim Discounter. Lieferdienste werden von gut $18 \%$ der Befragten präferiert, wobei aufgrund der häufig vorhandenen Abokonzepte in diesen Fällen eine sehr regelmäßige Einkaufsfrequenz vorliegt. Food-Coops spielen bei den befragten Intensivkäufern keine größere Rolle. 
TABELLE 4: EINKAUFSSTÄTTEN DER BIO-KUNDEN

\begin{tabular}{|l|c|c|c|c|c|c|c|}
\hline & $\boldsymbol{\mu}$ & $\boldsymbol{\sigma}$ & nie & selten & $\begin{array}{c}\text { manch- } \\
\text { mal }\end{array}$ & häufig & $\begin{array}{c}\text { sehr } \\
\text { häufig }\end{array}$ \\
\hline Bio-Laden & 0,84 & 1,20 & $2,9 \%$ & $13,5 \%$ & $22,9 \%$ & $18,2 \%$ & $42,4 \%$ \\
\hline Bio-Supermarkt & $-0,40$ & 1,47 & $22,4 \%$ & $20 \%$ & $20 \%$ & $14,7 \%$ & $22,9 \%$ \\
\hline $\begin{array}{l}\text { Normaler Supermarkt } \\
\text { (z. B. Edeka) }\end{array}$ & $-0,25$ & 1,17 & $17,1 \%$ & $25,3 \%$ & $31,2 \%$ & $18,8 \%$ & $7,6 \%$ \\
\hline Discounter (z. B. Plus) & $-0,91$ & 1,13 & $38,2 \%$ & $31,8 \%$ & $15,9 \%$ & $10,6 \%$ & $3,5 \%$ \\
\hline Wochenmarkt & $-0,46$ & 1,29 & $25,3 \%$ & $30,6 \%$ & $18,8 \%$ & $15,3 \%$ & $10,0 \%$ \\
\hline Reformhaus & $-0,58$ & 1,07 & $19,4 \%$ & $40 \%$ & $23,5 \%$ & $12,9 \%$ & $4,1 \%$ \\
\hline Lieferdienst & $-1,21$ & 1,42 & $72,4 \%$ & $5,9 \%$ & $3,5 \%$ & $7,1 \%$ & $11,2 \%$ \\
\hline Food-Coop & $-1,86$ & 0,60 & $93,5 \%$ & $2,9 \%$ & $1,2 \%$ & $1,2 \%$ & $1,2 \%$ \\
\hline beim Bauern & $-0,75$ & 1,28 & $37,1 \%$ & $25,9 \%$ & $21,2 \%$ & $6,5 \%$ & $9,4 \%$ \\
\hline \multicolumn{7}{|l|}{-1} \\
\hline
\end{tabular}

Quelle: Eigene Erhebung

\subsection{Kundenzufriedenheit und Kundenbindung}

Die Bindung der Kunden an ihren Naturkostfachhändler stellt eine zentrale Voraussetzung für dessen langfristige Wettbewerbsfähigkeit dar. Zufriedene Kunden geben ihre positiven Erfahrungen an andere Verbraucher weiter und tragen damit zur Imagebildung bei. Unzufriedenheit führt dagegen zu imageschädlichen Kundenäußerungen, wobei empirische Studien gezeigt haben, dass Unzufriedenheit deutlich häufiger als Zufriedenheit kommuniziert wird (Homburg et al. 1999: 177).

In den ersten Forschungsarbeiten zur Kundenbindung wurde die Kundenzufriedenheit als eine hinreichende Bedingung für treue Kunden gesehen. Die neuere Kundenzufriedenheitsforschung hat allerdings gezeigt, dass Kundenzufriedenheit nur eine notwendige, nicht aber die hinreichende Bedingung für Kundenbindung ist. Neben der Suche nach Neuerungen und Abwechslung (Variety Seeking) sind es gute Konkurrenzangebote, die auch einen grundsätzlich zufriedenen Verbraucher zum Marken- oder Einkaufsstättenwechsel bewegen können (Peter 1997: 100). Umgekehrt gibt es auch unzufriedene treue Kunden, z. B. mangels relevanter Alternativen (Müller 1998). Die folgende Studie überprüft daher die Zukunftsfähigkeit des traditionellen Bio-Fachhandels in zweifacher Hinsicht:

a) Im ersten Teil wird die Kundenzufriedenheit detailliert mittels klassischer Zufriedenheitsfragen und mehrstufiger Likert-Skalen erfasst. 
b) Teil zwei der Studie untersucht anhand verschiedener hypothetischer Wahlentscheidungen, wie groß die Abwanderungsgefahr von Bio-Laden-Kunden zu Wettbewerbern ist (Wechselbereitschaft). Die Kunden werden bei vorgegebenen realen Preisen für verschiedene Produkte nach der jeweils bevorzugten Vertriebsform befragt.

\subsection{Zufriedenheit der Bio-Laden-Käufer}

Die Kundenzufriedenheit wurde im Fragebogen durch drei Fragen operationalisiert. Abbildung 3 skizziert zunächst die Ergebnisse der allgemeinen Kundenzufriedenheitsfrage (Globalzufriedenheit). Der Mittelwert von 1,66 auf einer Schulnotenskala von 1-5 repräsentiert die ausgesprochen hohe Kundenzufriedenheit, die deutlich über dem Wert anderer Branchen liegt. Der im Deutschen Kundenmonitor (einer repräsentativen Kundenbefragung für Deutschland) ausgewiesene beste Wert liegt bei 1,95 für Optiker, der schlechteste bei 2,73 für Paket- und Expressdienste (Kundenmonitor 2004).

ABBILDUNG 3: GLOBALZUFRIEDENHEIT MIT DEM NATURKOSTFACHHANDEL BEI STAMMKUNDEN: WIE ZUFRIEDEN SIND SIE MIT IHREM NATURKOSTFACHHÄNDLER? (IN \%).

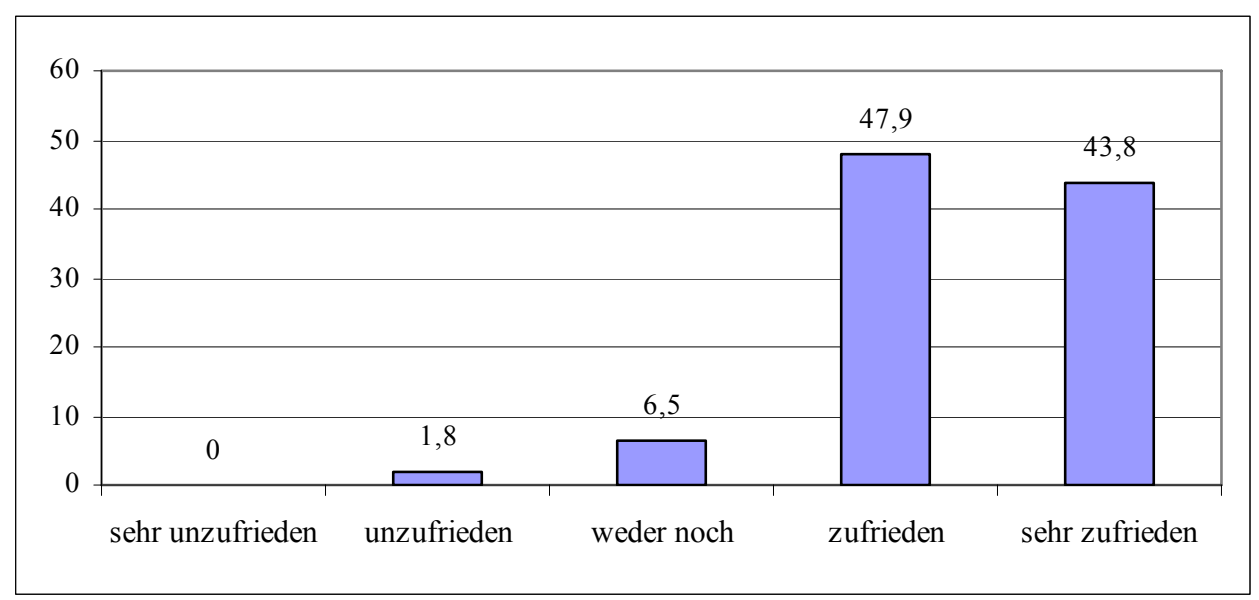

Quelle: Eigene Erhebung

Relativ positiv fallen auch die Antworten auf zwei weitere Fragen aus, die sich auf die Einkaufsatmosphäre im Vergleich zu konventionellen Supermärkten und auf die grundsätzliche Unterstützung für diesen Vertriebstyp beziehen. Diese beiden Fragen sind eng mit der generellen Kundenzufriedenheit verknüpft, da sie zum einen die übergreifende Leistungsdimension und zum anderen die prinzipielle Unterstützung dieser Vertriebsform umfassen (vgl. unten). Mehr als $70 \%$ der Befragten empfinden die Einkaufsatmosphäre im Vergleich zum klassischen LEH als besser (53,5 \% stimmen voll und ganz zu). Diese Zustimmung findet ihren 
Ausdruck im grundsätzlichen Interesse am Fortbestehen dieser Betriebsform (51,2 \% stimmen voll und ganz zu, 29,4 \% stimmen zu). Neben der persönlichen Zufriedenheit deutet sich hier auch eine politisch-gesellschaftliche Motivation der Biofachhandelstreue an. Es zeigt sich aber auch, dass fast ein Viertel mit der Geschäftsstättenatmosphäre eher unzufrieden ist.

TABELLE 5: EINKAUFSATMOSPHÄRE UND GRUNDSÄTZLICHE UNTERSTÜTZUNG DER NATURKOSTLÄDEN

\begin{tabular}{|l|c|c|c|c|c|c|}
\hline & $\begin{array}{c}\text { lehne voll } \\
\text { und ganz } \\
\text { ab }\end{array}$ & lehne ab & teils, teils & stimme zu & $\begin{array}{c}\text { stimme } \\
\text { voll und } \\
\text { ganz zu }\end{array}$ & fehlend \\
\hline $\begin{array}{l}\text { Die Einkaufsatmosphäre } \\
\text { gefällt mir besser als im } \\
\text { Supermarkt. }\end{array}$ & $1,8 \%$ & $2,9 \%$ & $19,4 \%$ & $20 \%$ & $53,5 \%$ & $2,4 \%$ \\
\hline $\begin{array}{l}\text { Mir ist es wichtig, dass } \\
\text { die kleinen Bio-Läden } \\
\text { überleben können. }\end{array}$ & $1,8 \%$ & $2,4 \%$ & $12,4 \%$ & $29,4 \%$ & $51,2 \%$ & $2,9 \%$ \\
\hline
\end{tabular}

Quelle: Eigene Erhebung

\subsection{Motive für die Wahl des Bio-Fachhandels}

Die ausgesprochen hohe Kundenzufriedenheit der Bio-Intensivkäufer ist angesichts der Zielgruppe der Befragung nicht überraschend. Ohne eine entsprechende Zufriedenheit wäre die notwendige hohe Mehrpreisbereitschaft für den langjährigen Einkauf im Bio-Laden wohl nicht vorhanden. Im folgenden Kapitel geht es daher um die Identifikation der Faktoren, die diese Kundenzufriedenheit bewirken. Hierzu wurden auf der Grundlage bereits vorliegender Studien verschiedene potenzielle Kaufmotive evaluiert, die den Probanden dann vorgelegt wurden und auf Basis einer Likert-Skala bewertet werden sollten (Lüth et al. 2004). Dabei wurden sowohl individuelle Faktoren wie Vertrauen, Motivation und Involvement als auch soziologische Kategorien wie gesellschaftliche Protesthaltung und soziale Bindung einbezogen. Auf Basis dieser Fragen wurde dann im nächsten Schritt mittels einer Regressionsanalyse überprüft, welche Kaufmotive die Kundenzufriedenheit besonders stark beeinflussen und damit als Treiber der Kundenbindung dienen.

Kaufmotive: Mit Hilfe einer Konstantsummenskala, bei der die Probanden insgesamt 100 Punkte verteilen konnten, wurden verschiedene potenzielle Kaufmotive bewertet. Gefragt wurde, welche der vorgegebenen Gründe für den Einkauf im Bio-Laden besonders wichtig sind. Häufigkeitsauszählungen sowie entsprechende Korrelationsrechnungen zeigen, dass drei Bereiche zu unterscheiden sind. An erster Stelle steht die spezifische Bio-Kompetenz im 
Sortiment. Insbesondere die große Bio-Auswahl sowie die entsprechende Beratung, aber auch Erzeugnisse mit speziellen Eigenschaften (z. B. ohne Zusatz von Aromastoffen) und von besonderen Herstellern (z. B. Demeter) prägen die Kompetenz eines Bio-Anbieters. Diese Kompetenz sowie die Glaubwürdigkeit sind Kriterien, die hinter dem Produktangebot stehen. Zusammen umfassen diese hoch korrelierten Kriterien fast $90 \%$ der verteilten Punkte. Die Einkaufsstättenatmosphäre ist mit knapp $12 \%$ ebenfalls noch relevant, während die soziale Bindung an andere Kunden von vollkommen untergeordneter Bedeutung ist. Insgesamt wird deutlich, dass der wichtigste Leistungsvorteil des Bio-Fachhandels im Sortimentsvorsprung liegt.

TABELLE 6: KAUFMOTIVE DER BIO-FACHHANDELSKUNDEN (KONSTANTSUMMENSKALA MIT 100 PUNKTEN)

\begin{tabular}{|l|c|c|c|c|c|c|c|}
\hline & $\begin{array}{c}\text { große } \\
\text { Bio- } \\
\text { Auswahl }\end{array}$ & $\begin{array}{c}\text { gute } \\
\text { Atmos- } \\
\text { phäre }\end{array}$ & $\begin{array}{c}\text { spezielle } \\
\text { Produkte } \\
\text { (z. B. ohne } \\
\text { Zusatz von } \\
\text { Aroma- } \\
\text { stoffen) }\end{array}$ & $\begin{array}{c}\text { Produkte } \\
\text { spezieller } \\
\text { Anbauver- } \\
\text { bände (z. B. } \\
\text { Demeter) }\end{array}$ & $\begin{array}{c}\text { Kompe- } \\
\text { tente Bera- } \\
\text { tung }\end{array}$ & $\begin{array}{c}\text { glaub- } \\
\text { würdiger }\end{array}$ & $\begin{array}{c}\text { Leute } \\
\text { treffen }\end{array}$ \\
\hline Mittelwert & 34,17 & 11,90 & 16,08 & 12,42 & 11,89 & 10,97 & 1,99 \\
\hline $\begin{array}{l}\text { Standard- } \\
\text { abweichung }\end{array}$ & 20,32 & 9,14 & 11,89 & 10,38 & 9,80 & 9,83 & 4,97 \\
\hline
\end{tabular}

Quelle: Eigene Erhebung

Vertrauen: In informationsökonomischer Hinsicht handelt es sich bei Bio-Produkten um Vertrauensgüter mit hoher Informationsasymmetrie und entsprechenden Glaubwürdigkeitsproblemen (Jahn et al. 2004). Umgekehrt ist es gerade das durch vielfältige Lebensmittelkrisen geförderte Misstrauen in die traditionelle Lebensmittelwirtschaft, das den Bio-Konsum vorantreibt. Abbildung 4 zeigt deutlich das relativ große Misstrauen der Kerngruppe der Bio-Käufer gegenüber der konventionellen Lebensmittelwirtschaft. Nur knapp $4 \%$ der Befragten lehnen das u. g. Statement ab. 
AbBildung 4: Vertrauen: ICH Vertraue Herstellern, die nuR Bio-Produkte PRODUZIEREN MEHR ALS SOLCHEN, DIE ZUSÄTZLICH AUCH KONVENTIONELLE WARE HABEN (IN \%).

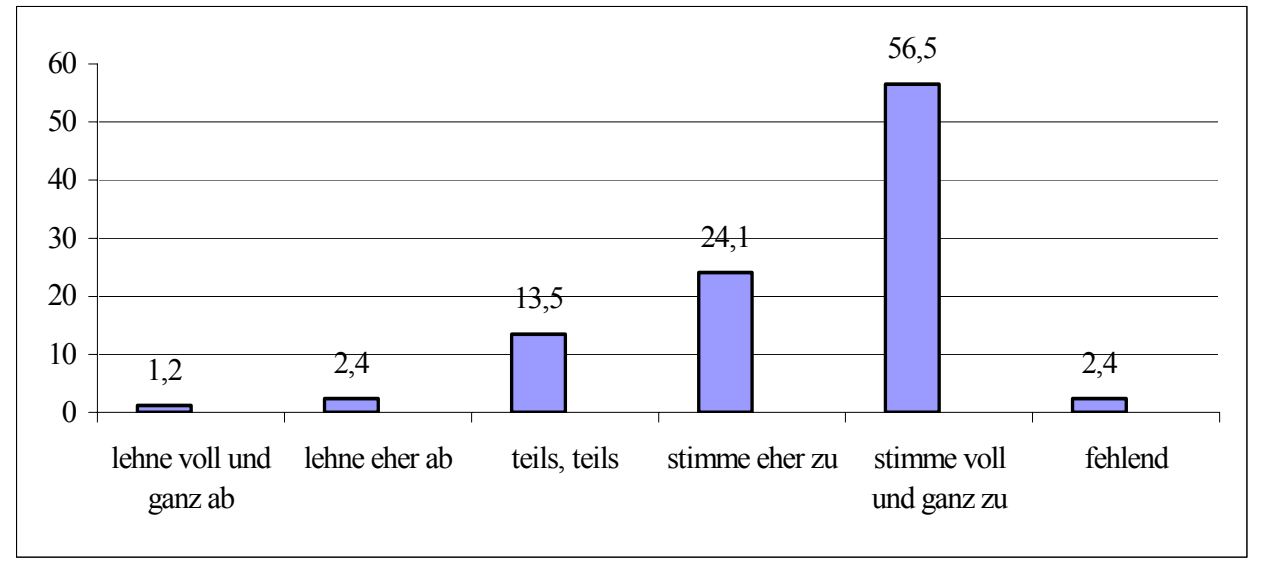

Quelle: Eigene Erhebung

Involvement: Der Begriff Involvement umfasst die Bereitschaft, sich mit einem Produkt intensiv auseinander $\mathrm{zu}$ setzen und beschreibt damit die Relevanz des Gutes für einen Konsumenten. Ein hohes Involvement schlägt sich in erster Linie in ausgeprägter Informationssuche und größeren kognitiven Anstrengungen nieder. Im vorliegenden Fall ist die Informationsnachfrage sehr groß. 48 \% der Befragten informieren sich ein- oder mehrmals pro Woche über Naturkost, 8,3 \% sogar täglich. Für den Naturkostfachhandel bedeutet dies, dass ein wesentlicher Teil der Kunden über ein vertieftes Hintergrundwissen verfügt.

ABBILDUNG 5: INFORMATIONSNACHFRAGE ZUR NATURKOST: WIE HÄUFIG INFORMIEREN SIE Sich ÜBER NATURKOST? (Z. B. IN SCHROT \& KorN, EVE, NATURKOST.DE) (IN \%).

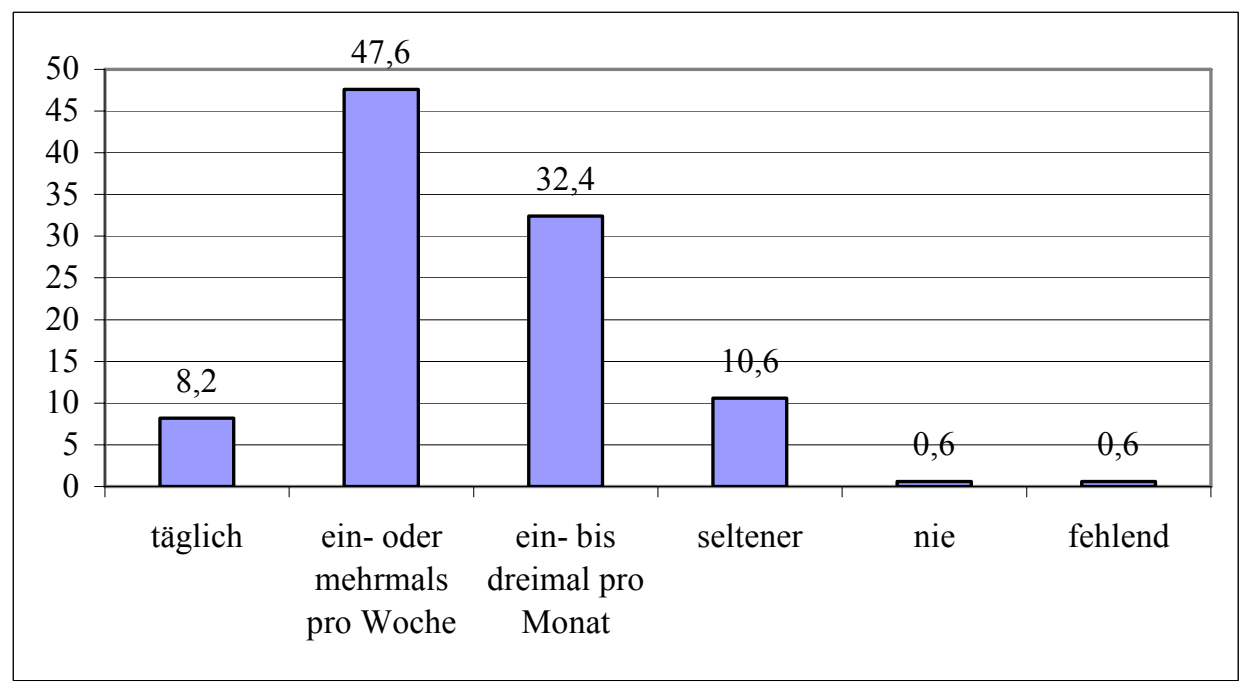

Quelle: Eigene Erhebung 
Variety Seeking: Unter Variety Seeking wird der Wunsch des Kunden nach Abwechslung verstanden. Dieser kann zu einem Einkaufsstättenwechsel führen, ohne dass Unzufriedenheit vorliegen muss (Peter 1997, Kuß 2001). Die Zustimmung zu dem Statement, welches den Innovationsgrad der Bio-Läden überprüfen soll, fällt mit $60 \%$ etwas geringer aus. Hierzu mag die begrenzte Sortimentsvielfalt aufgrund der Flächenknappheit vieler Bio-Läden beitragen.

ABBILDUNG 6: VARIETY SEEKING: DEN EINKAUf IM BIO-LADEN FINDE ICH INTERESSANT, WEIL ES DORT VIELE NEUE PRODUKTE UND MARKEN ZU ENTDECKEN GIBT (IN \%).

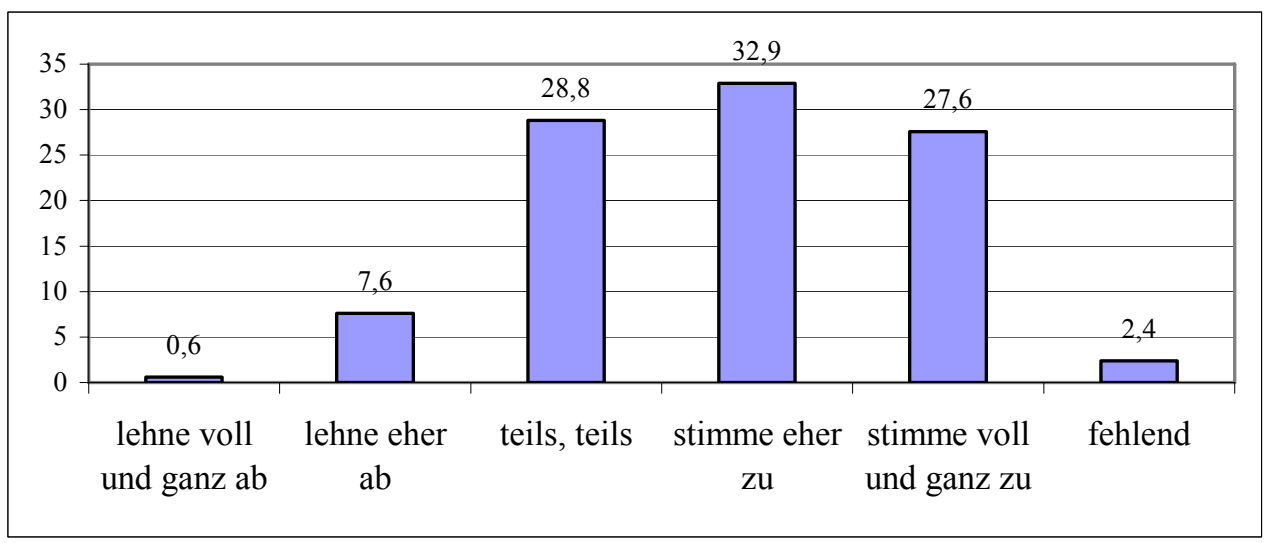

Quelle: Eigene Erhebung

Während die bisherigen Fragen im Wesentlichen auf die individuellen Einstellungen und Motive der Probanden gerichtet waren, fokussiert der folgende Block (siehe Tabelle 7) auf die sozialen und politischen Motive des Bio-Konsums. 
TABELLE 7: SOZIOLOGISCHE KRITERIEN DES BIOKONSUMS

\begin{tabular}{|l|c|c|c|c|c|c|}
\hline & $\begin{array}{c}\text { lehne } \\
\text { voll } \\
\text { und } \\
\text { ganz ab }\end{array}$ & $\begin{array}{c}\text { lehne } \\
\mathbf{a b}\end{array}$ & $\begin{array}{c}\text { teils, } \\
\text { teils }\end{array}$ & $\begin{array}{c}\text { stimme } \\
\text { zu }\end{array}$ & $\begin{array}{c}\text { stimme } \\
\text { voll } \\
\text { und } \\
\text { ganz zu }\end{array}$ & fehlend \\
\hline $\begin{array}{l}\text { Im Bio-Laden kaufen Menschen, } \\
\text { die wirklich konsequent sind. }\end{array}$ & $5,9 \%$ & $12,4 \%$ & $45,9 \%$ & $24,7 \%$ & $8,8 \%$ & $2,4 \%$ \\
\hline $\begin{array}{l}\text { Im Bio-Laden sind viele Leute, } \\
\text { die so denken wie ich. }\end{array}$ & $0,6 \%$ & $5,9 \%$ & $30,0 \%$ & $47,1 \%$ & $13,5 \%$ & $2,9 \%$ \\
\hline $\begin{array}{l}\text { Wenn ich Fragen habe, finde ich } \\
\text { im Bio-Laden/Internet/der Com- } \\
\text { munity auf Naturkost.de immer } \\
\begin{array}{l}\text { Menschen, die mir weiterhelfen } \\
\text { können. }\end{array}\end{array}$ & $5,5 \%$ & $13.5 \%$ & $46,5 \%$ & $25,3 \%$ & $6,5 \%$ & $2,9 \%$ \\
\hline $\begin{array}{l}\text { Ich mache mir Gedanken über } \\
\text { die Umwelt und unsere/meine } \\
\text { Gesundheit, deswegen kaufe ich } \\
\text { im Bio-Laden. }\end{array}$ & $0,6 \%$ & $1,2 \%$ & $6,5 \%$ & $17,6 \%$ & $71,8 \%$ & $2,9 \%$ \\
\hline
\end{tabular}

Quelle: Eigene Erhebung

Interessant ist das Ergebnis der Frage, die sich auf das Gemeinschaftsgefühl richtet, das ggf. durch das Zusammentreffen von Käufern aus relativ ähnlichen soziologischen Milieus entstehen kann (Im Bio-Laden sind viele Leute, die so denken wie ich). Tabelle 7 zeigt zwar eine überwiegende Zustimmung, die allerdings im Vergleich $\mathrm{zu}$ anderen Fragen etwas geringer ausfällt. Eine sehr deutliche Bejahung erfährt das Statement, das sich auf Demonstration gesellschaftlichen Engagements und einer entsprechenden Protesthaltung richtet (siehe Abbildung 7). 
ABBILDUNG 7: EINKAUFSSTÄTTENPRÄFERENZ UND GESELLSCHAFTLICHE PROTESTHALTUNG: WENN ICH IM BIOLADEN EINKAUFE, ZEIGE ICH, DASS ICH GEGEN DIE INDUSTRIELLE HERSTELLUNG VON LEBENSMITTELN UND GEGEN AGRARFABRIKEN BIN (IN \%).

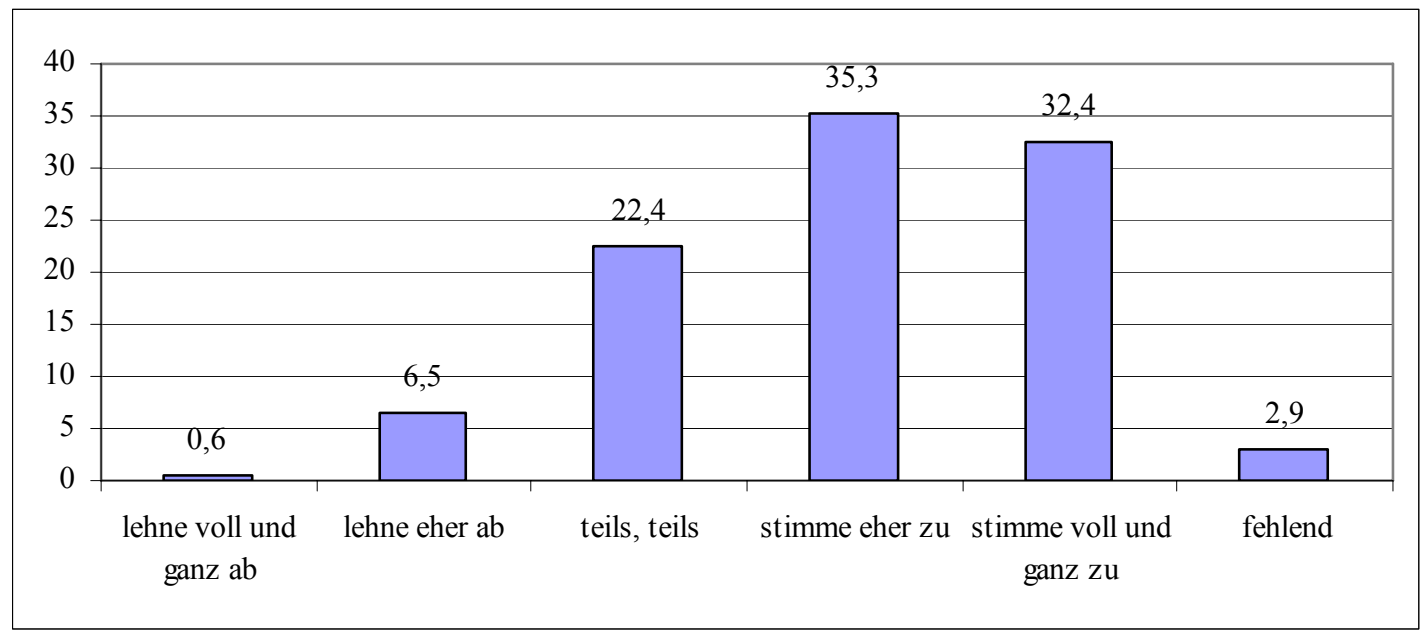

Quelle: Eigene Erhebung

Die politische Haltung ist für Bio-Intensivkäufer offensichtlich immer noch ausgesprochen wichtig und der Biokonsum Ausdruck einer politischen Grundhaltung. Die in der Literatur zunehmend populäre These, dass Bio kaum noch aus altruistischen Motiven heraus gekauft wird, scheint in dieser Pauschalität für die Intensivkäufer nicht zuzutreffen.

Ein bekanntes Problem von Fachgeschäften ist, dass die soziale Kohäsion auf neue Kunden oder Personen aus anderen Milieus ausgrenzend wirken kann und als unangenehm empfunden wird. Bei den von uns Befragten lehnten 75,8 \% der Probanden das Statement ab, dass man sich im Bio-Laden beobachtet fühlt und einem Kaufdruck ausgesetzt sieht. Allerdings handelt es sich bei unserer Studie um Bio-Intensivkäufer. Die Aussagen von Selten- und Gelegenheitskäufern dürften wohl negativer ausfallen. Zudem zeigt sich an späterer Stelle, dass die hier zustimmenden Probanden deutlich geringere Kaufneigungen aufweisen. 
ABBiLdung 8: WAHRgENOMMENE SOZIALE KONTROLle IM BIO-LAdEN: MiR IST UNANGENEHM, DASS MAN IM BIO-LADEN NICHT IN RUHE SCHAUEN KANN, DA FÜHLE ICH MICH WIE AUF DEM PRÜFSTAND (IN \%).

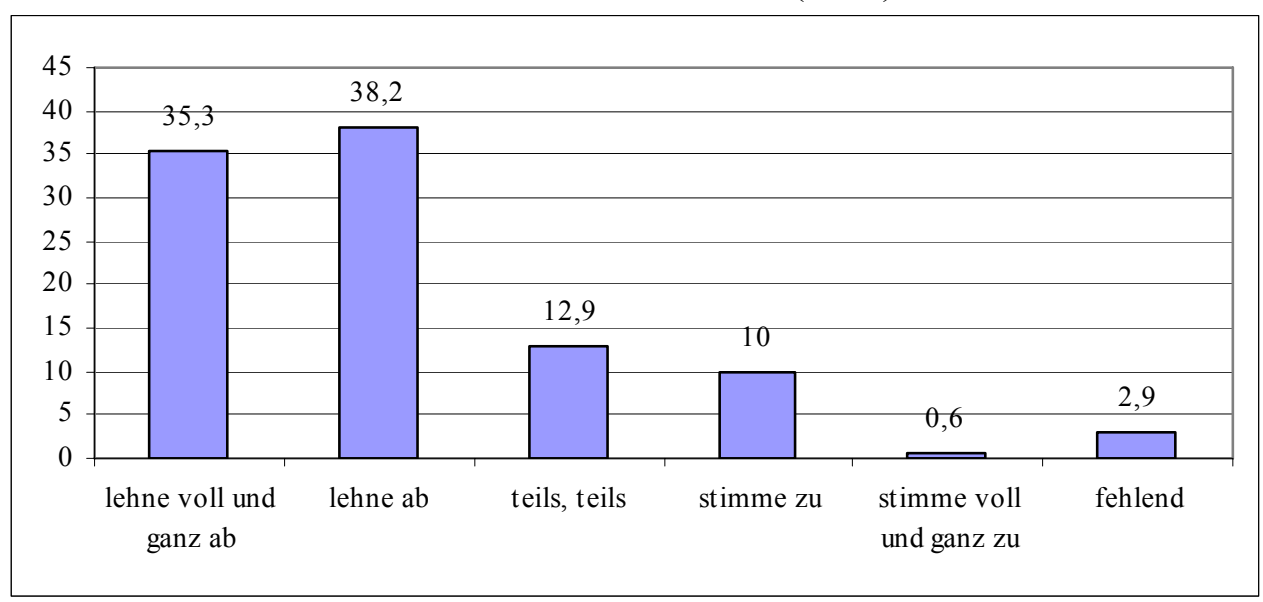

Quelle: Eigene Erhebung

In einer letzten Frage wurde erhoben, wie die Position zu Bio-Produkten in der Peer-Group der Probanden ausfällt. Hier zeigten sich überraschende Ergebnisse. Nur in knapp $20 \%$ der Fälle kaufen Freunde oder Bekannte in größerem Umfang ökologische Lebensmittel. 56 \% der Befragten geben an, dass sie mit ihrem Bio-Konsum eher eine Außenseiterposition in ihrem Freundes- und Bekanntenkreis einnehmen.

TABELLE 8: ÖKOLOGISCHER KONSUM IM FREUNDES- UND BEKANNTENKREIS

\begin{tabular}{|l|c|c|}
\hline & $\begin{array}{c}\text { Zustimmung } \\
\text { in \% }\end{array}$ & $\begin{array}{c}\text { Kumulierte } \\
\text { Prozente }\end{array}$ \\
\hline Meine Freunde kaufen fast alle Bio & $0,6 \%$ & $0,6 \%$ \\
\hline Viele Freunde kaufen auch Bio & $17,6 \%$ & $18,2 \%$ \\
\hline Hält sich die Waage & $26,1 \%$ & $44,2 \%$ \\
\hline Einige wenige kaufen auch Bio & $33,3 \%$ & $77,6 \%$ \\
\hline Ich stehe ziemlich alleine dar mit meinem Bio-Kauf & $22,4 \%$ & $100 \%$ \\
\hline
\end{tabular}

Quelle: Eigene Erhebung

\subsection{Vergleichende Bewertung von Bio-Laden und Bio-Supermarkt}

In einem weiteren Teil des Fragebogens wurden die Probanden gebeten, traditionelle BioLäden und Bio-Supermärkte miteinander auf Basis eines semantischen Differentials zu vergleichen. Die folgende Übersicht visualisiert die Mittelwerte der fünfstufigen Skala und gibt zusätzlich die Standardabweichungen an. 
Bei einer Reihe von Kriterien erkennen die Probanden im Durchschnitt nur geringe Unterschiede, z. B. bei der wahrgenommenen Sicherheit, dem Geschmack der Produkte, der Qualität der Waren und den Inhaltsstoffen. Hier spiegelt sich die Überschneidung im Sortiment wider.

ABBILDUNG 9: VERGLEICH BIO-SUPERMÄRKTE UND BIO-LÄDEN

\begin{tabular}{|c|c|c|c|c|c|c|c|}
\hline & & & $\begin{array}{l}\text { Bio- } \\
\text { viel }\end{array}$ & $\begin{array}{l}\mathrm{rma} \\
\mathrm{r}\end{array}$ & & & $\begin{array}{l}\text { den } \\
\text { sser }\end{array}$ \\
\hline & $\mu$ & $\sigma$ & -2 & -1 & 0 & 1 & 2 \\
\hline Regionalität & 0,94 & 1,01 & : & : & : & : & : \\
\hline Geschmack & 0,21 & 0,66 & : & : & .0 & : & $\dot{5}$ \\
\hline Beratungsqualität & 0,90 & 0,92 & : & : & $:$ & : & : \\
\hline Auswahl & $-1,11$ & 1,10 & $:$ & : & : & : & $:$ \\
\hline Sicherheit & 0,28 & 0,77 & $:$ & : & : & : & $:$ \\
\hline Qualität der Ware & 0,13 & 0,83 & : & : & . & : & $:$ \\
\hline Inhaltsstoffe & 0,18 & 0,51 & : & $:$ & $: 0$ & • & : \\
\hline Atmosphäre & 0,75 & 1,15 & : & : & $:$ & & : \\
\hline Preisgünstig & $-0,91$ & 0,98 & : & . & & . & $:$ \\
\hline
\end{tabular}

Quelle: Eigene Erhebung

Erwartungsgemäß werden Bio-Supermärkte als preisgünstiger wahrgenommen, sie bieten zudem eine deutlich bessere Auswahl. Regionalität und Beratungsqualität sind Stärken des Bio-Ladens. Hinzu kommt - und dies war nicht unbedingt zu erwarten - die bessere Einkaufsatmosphäre in den kleineren Fachgeschäften.

Die Items zum Vergleich von Bio-Laden und Bio-Supermarkt können in einem nächsten Schritt weiter verdichtet werden, indem durch eine Faktorenanalyse diejenigen Fragen zusammengefasst werden, die aus Sicht der Probanden eine ähnliche Aussage haben und daher relativ einheitlich beantwortet wurden. Eine Faktorenanalyse auf Basis des Polaritätenprofils zeigt drei Entscheidungsbereiche (vgl. Tabelle 9). 
TABELLE 9: FAKTORENANALYSE VERGLEICH BIO-LADEN - BIO-SUPERMARKT

\begin{tabular}{|l|c|}
\hline \multicolumn{1}{|c|}{ Faktoren/Statements } & Faktorladung \\
\hline \multicolumn{2}{|c|}{ Faktor 1: Kognitive Bewertung } \\
\hline Auswahl KMO: 0,69; Cronbachs Alpha: 0,7; erklärte Varianz 67,4 \%) \\
\hline Sicherheit & 0,758 \\
\hline Inhaltsstoffe & 0,857 \\
\hline \multicolumn{2}{|c|}{ Faktor 2: Emotionale und sensorische Qualität } \\
\hline Regionalität 0,82; Cronbachs Alpha 0,81; erklärte Varianz 59,3 \%) \\
\hline Geschmack \\
\hline Beratungsqualität & 0,846 \\
\hline Qualität der Ware & 0,893 \\
\hline Atmosphäre & 0,777 \\
\hline Einzelkriterium: Preisgünstigkeit & 0,819 \\
\hline
\end{tabular}

Quelle: Eigene Berechnungen

Auswahl, Sicherheit und Inhaltsstoffe beziehen sich aus Sicht der Befragten eher auf die indirekt erfahrbaren und stärker kognitiv geprägten Leistungskriterien, während die Variablen des zweiten Faktors stärker auf die qualitativen Aspekte des Einkaufs abheben. Die Preisgünstigkeit bleibt ein Einzelstatement, wird also nicht mit den anderen Kriterien verbunden.

\subsection{Determinanten der Kundentreue}

Die folgende Analyse beruht auf den o. g. Kaufmotiven sowie dem Polaritätenprofil und versucht, den Einfluss dieser Größen auf die Kundenbindung zu bestimmen. Dazu wurde zunächst eine weitere Faktorenanalyse durchgeführt. Anschließend wurden dann mit Hilfe einer Regressionsrechnung die wichtigsten Einflussfaktoren auf die Kundenzufriedenheit ermittelt.

$\mathrm{Zu}$ einem Faktor zusammengefasst werden konnten vier Fragen, die sich auf Kundenbindung und Commitment beziehen: Kaufhäufigkeit im Bio-Laden, Kundenzufriedenheit, Bewertung der Einkaufsatmosphäre und die Unterstützung der Bio-Läden im Wettbewerb. Diese Statements erfassen zusammen die unterschiedlichen Facetten der Kundenzufriedenheit, wobei auffällt, dass die wahrgenommene Relevanz der Betriebsform sehr eng mit der Kundenzufriedenheit verbunden ist. Dieser Faktor bildet die abhängige Variable des folgenden Regressionsmodells. 
TABELLE 10: FAKTORENANALYSE ZUR KUNDENTREUE

\section{Kundenbindung und Commitment}

(KMO: 0,75; Cronbachs Alpha: 0,74; erklärte Varianz 57,2 \%)

\begin{tabular}{|l|c|}
\hline \multicolumn{1}{|c|}{ Statements } & Faktorladung \\
\hline Mir ist es wichtig, dass die kleinen Bio-Läden überleben können. & 0,824 \\
\hline Kaufhäufigkeit im Bio-Laden. & 0,791 \\
\hline Die Einkaufsatmosphäre im Bio-Laden gefällt mir besser als im Supermarkt. & 0,776 \\
\hline Wie zufrieden sind Sie mit Ihrem Naturkostfachhändler? & 0,616 \\
\hline
\end{tabular}

Quelle: Eigene Berechnungen

Ein weiterer Faktor ergibt sich aus insgesamt fünf Fragen, die sich auf die gesellschaftspolitische Grundhaltung des Bio-Konsums beziehen. Die etwas geringeren Gütewerte der Faktorlösung (insbesondere die niedrigere erklärte Varianz) zeigen an, dass die Fragen durchaus unterschiedliche Nuancen der Bewertung erfassen, dass aber insgesamt politisches Engagement, Vertrauen und die Einbindung in ein soziales Milieu eng miteinander verknüpft sind.

TABELLE 11: FAKTORENANALYSE ZU KAUFMOTIVEN

\section{Gesellschaftlicher Protest und Vertrauen}

(KMO 0,73; Cronbachs Alpha 0,71; erklärte Varianz 46,6 \%)

\begin{tabular}{|l|c|}
\hline \multicolumn{1}{|c|}{ Statements } & Faktorladung \\
\hline Im Bio-Laden kaufen Menschen, die wirklich konsequent sind. & 0,741 \\
\hline $\begin{array}{l}\text { Wenn ich im Bio-Laden einkaufe, zeige ich, dass ich gegen die industrielle } \\
\text { Herstellung von Lebensmitteln und gegen Agrarfabriken bin. }\end{array}$ & 0,726 \\
\hline $\begin{array}{l}\text { Ich vertraue Herstellern, die nur Bio-Produkte produzieren mehr als solchen, } \\
\text { die zusätzlich auch konventionelle Ware haben. }\end{array}$ & 0,654 \\
\hline Im Bio-Laden sind viele Leute, die so denken wie ich. & 0,651 \\
\hline $\begin{array}{l}\text { Ich mache mir Gedanken über die Umwelt und unsere/meine Gesundheit, } \\
\text { deswegen kaufe ich im Bio-Laden. }\end{array}$ & 0,636 \\
\hline
\end{tabular}

Quelle: Eigene Berechnungen

Ziel der multiplen Regressionsanalyse ist die Identifikation der Faktoren bzw. Variablen, die eine zu erklärende Größe (abhängige Variable) besonders stark beeinflussen. Im vorliegenden Fall geht es um die Bindung der Befragten an den Bio-Laden. Als erklärende Variablen kommen die o. g. Einstellungskriterien in Betracht. Weiterhin werden die Faktoren aus dem Polaritätenprofil einbezogen. Soziodemographische Determinanten haben keine Erklärungskraft. 
Die folgende Abbildung zeigt nur die tatsächlich relevanten Einflussfaktoren. Die sehr hohe Modellgüte von 57 \% erklärter Varianz zeigt an, dass wesentliche Variablen einbezogen sind und Kundenbindung und Commitment gut erfasst wird (korr. $\left.\mathrm{R}^{2}=0,57 ; \mathrm{F}=41,24 * * *\right)$.

\section{ABBILDUNG 10: REGRESSIONSMODELL KUNDENBINDUNG BIO-LADEN}

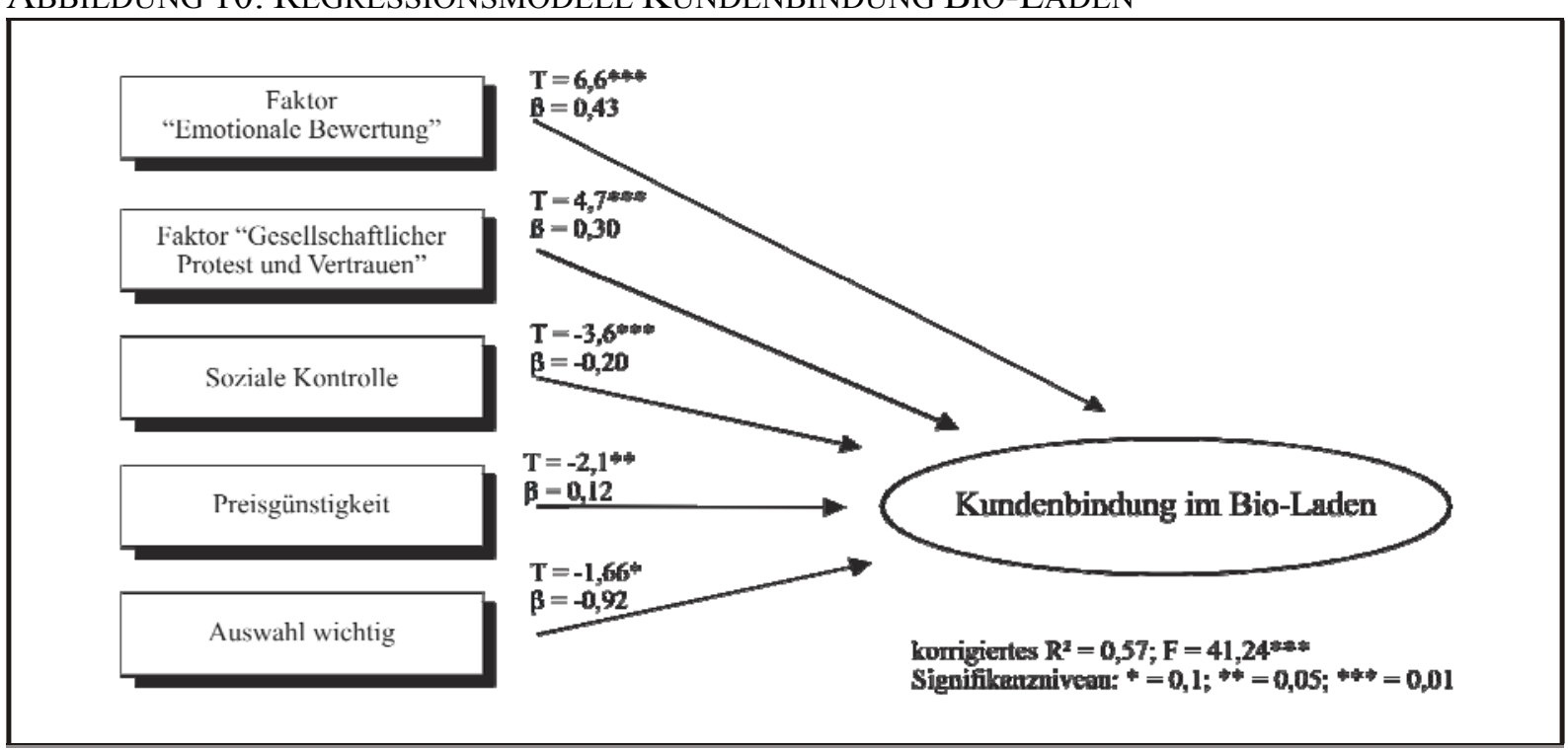

Quelle: Eigene Darstellung

Der zentrale Faktor zur Erklärung der Kundenbindung ist die emotional-sensorische Bewertung des Bio-Ladens und seiner Produkte im Vergleich zum Bio-Supermarkt. Befragte, die bei diesen Fragen (vgl. Tab. 9) den Bio-Laden gut bewertet haben, kaufen deutlich häufiger im Bio-Laden ein, sind zufriedener und befürworten das weitere Überleben dieser Betriebsform.

Einen ähnlich großen Einfluss hat der Faktor „Gesellschaftlicher Protest und Vertrauen“. In diesem Wert bündeln sich die politischen Dimensionen des Bio-Konsums. Die Kerngruppe der Bio-Käufer ist ganz offensichtlich immer noch in beachtlichem Maße durch politische Kaufmotive geprägt.

Groß ist auch die Wirkung, die von der Wahrnehmung einer sozialen Kontrolle ausgeht. Das negative Vorzeichen zeigt, dass Probanden, die sich im Bio-Laden aufgrund der persönlichen Bedienung eher unwohl fühlen, deutlich unzufriedener sind und eine geringere Einkaufsintensität aufweisen. 
Eine weitere wichtige Variable ist die wahrgenommene Preisgünstigkeit des Bio-Ladens. Probanden, die diesen im Vergleich zu Bio-Supermärkten für unwesentlich teurer halten, weisen eine deutlich höhere Kundenbindung auf. Die letzte, nur knapp signifikante Einflussgröße bezieht sich auf die Angebotskompetenz. Es wird deutlich, dass die Sortimentsbreite für einen Teil der Kunden nicht ausreicht.

Zusammenfassend kann gesagt werden, dass die Warenqualität und der Geschmack der Produkte sind, wesentlich zur Kundenbindung beitragen. Darüber hinaus zieht der Bio-Laden immer noch eine bestimmte, politisch interessierte oder engagierte Klientel an, deren Konsumverhalten auch Ausdruck der persönlichen Haltung ist. Das Kundenmilieu ist entgegen anders lautenden Auffassungen in der Literatur relativ homogen.

Die negativ wirkenden Variablen „Preis“, „soziale Kontrolle“ und „Relevanz der Produktauswahl“" zeigen an, welche Kundengruppen von Bio-Läden nicht angesprochen werden bzw. wechselbereit sind.

\section{Wechselbereitschaft der Bio-Intensivkäufer}

Die bisherige Analyse weist eine beachtliche Zustimmung der Bio-Intensivkäufer zum BioFachhandel aus. Dies ist jedoch noch nicht hinreichend, um eine langfristige Kundenbindung zu prognostizieren. Neben der Kundenzufriedenheit beeinflusst - wie die o. g. Regressionsanalyse verdeutlicht - selbstverständlich auch die Preisdifferenz zu Wettbewerbern die Wechselbereitschaft. Auch zufriedene Kunden wandern ggf. ab, wenn der Preisunterschied zu groß wird. Diese Gefahr soll im Folgenden aus Sicht von Bio-Läden erhoben werden.

In der Forschung werden verschiedene Möglichkeiten zur Analyse der Abwanderungsbereitschaft diskutiert. Liegen Haushaltspaneldaten vor, so kann z. B. aus dem tatsächlichen Wechselverhalten mittels Markoff-Modellen auf die Kundenbindung geschlossen werden (Kaas 2001: 1031). Wenn Paneldaten wie im vorliegenden Fall nicht vorhanden sind, kann die Wechselbereitschaft direkt erfragt werden. Eine solche Frage bleibt aber relativ abstrakt und kann insbesondere keine Einsichten in das Preis-Reaktionsverhalten der Probanden liefern. Letzteres leisten Wahlexperimente auf Basis der Conjoint- oder Discrete ChoiceAnalyse (Hahn 1997: 47), die allerdings bei Online-Befragungen schwierig einzusetzen sind (Conjoint) bzw. extrem große Stichproben verlangen (Discrete Choice) (Enneking et al. 2003: 275). 
Im vorliegenden Fall wurde deshalb ein einfaches Wahlexperiment genutzt. Den Befragten wurde eine hypothetische Einkaufssituation vorgegeben. Sie wurden aufgefordert, sich für den von ihnen präferieren Einkaufsort zu entscheiden unter der Voraussetzung, dass dort BioProdukte angeboten werden und alle Geschäfte gleich weit entfernt wären. Da Analysen zum Bio-Konsum erhebliche produktspezifische Unterschiede im Kaufverhalten aufgezeigt haben (Bodenstein/Spiller 2001), wurde diese Frage für mehrere Produkte gestellt. Dabei wurden die jeweils realen Preise vorgegeben. Auf Basis der Wahlentscheidungen können anschließend mittels Clusteranalyse Probandengruppen identifiziert werden. Im nächsten Schritt werden diese Cluster dann mittels eines Regressionsmodells erklärt, d. h. es werden diejenigen Faktoren identifiziert, die einen Bio-Ladenkunden zum Wechsel der Betriebsform veranlassen.

Die in Tabelle 12 für sieben Artikel genannten Produktpreise wurden den Marktdaten der ZMP sowie, für die dort nicht ausgewerteten Bio-Supermärkte, eigenen Recherchen in mehreren Märkten entnommen. Der Soft-Discounter Plus ist bei den von uns analysierten sieben Produkten in sechs Fällen Preisführer. In einem Fall ist es der Bio-Supermarkt, der insgesamt deutlich günstiger ist als Supermarktfilialisten wie Edeka und Rewe. Letztere sind mit einem Preisindex von 96,8 kaum preiswerter als der Bio-Laden (Preisindex =100). Eine aktuelle und breitere Erhebung von Reuter et al. (2005) zeigt, dass das den Befragten vorgespielte Preisniveau ebenso wie die wechselnde Preisführerschaft die reale Marktsituation sehr gut wiedergibt. Die in der folgenden Tabelle aufgeführten Prozentwerte für die Auswahlentscheidung spiegeln damit die bevorzugten Einkaufsstätten wider. In der Tabelle ist für alle Produkte zunächst der den Probanden vorgegebene Preis genannt. Die zweite Zeile drückt diesen dann als Preisindex aus. Die jeweils dritte Zeile weist das Befragungsergebnis aus, wobei den Probanden auch die Möglichkeit gegeben wurde, anzugeben, dass sie dieses Produkt nicht verwenden (No-Choice-Option). Die beiden letzten Zeilen der Gesamttabelle geben den simulierten Marktanteil über alle befragten Produkte bei der vorgegebenen Preisdifferenz wieder. 
TABelle 12: AuswahleXPeriment MIT REALEN ProduktPreisen FÜR VIER BETRIEBSFORMEN

\begin{tabular}{|c|c|c|c|c|c|}
\hline & Plus & Edeka & $\begin{array}{c}\text { Bio- } \\
\text { Supermarkt }\end{array}$ & Bio-Laden & $\begin{array}{c}\text { verwende ich } \\
\text { nicht }\end{array}$ \\
\hline Preis Eier in Euro $(\mathrm{M} / 10)$ & 2,36 & 3,02 & 3,10 & 2,95 & - \\
\hline Preisindex $($ Bio-L. $=100)$ & 80 & 102,4 & 105,1 & 100 & - \\
\hline Wahlverhalten & $13,3 \%$ & $1,8 \%$ & $7,2 \%$ & $69,9 \%$ & $7,8 \%$ \\
\hline Preis Äpfel kg & 2,03 & 2,61 & 2,49 & 3,02 & - \\
\hline Preisindex $($ Bio-L. $=100)$ & 67,2 & 86,4 & 82,5 & 100 & - \\
\hline Wahlverhalten & $15,7 \%$ & $1,8 \%$ & $51,2 \%$ & $26,5 \%$ & $4,8 \%$ \\
\hline Preis Möhren kg & 1,13 & 1,67 & 0,94 & 1,48 & - \\
\hline Preisindex $($ Bio-L. $=100)$ & 76,4 & 112,8 & 63,5 & 100 & - \\
\hline Wahlverhalten & $3,6 \%$ & $1,2 \%$ & $57 \%$ & $33,9 \%$ & $4,2 \%$ \\
\hline Preis Kartoffeln kg & 1,31 & 1,62 & 1,34 & 1,66 & - \\
\hline Preisindex $($ Bio-L. $=100)$ & 78,9 & 97,6 & 80,7 & 100 & - \\
\hline Wahlverhalten & $8,4 \%$ & $0,6 \%$ & $50,6 \%$ & $33,7 \%$ & $6,6 \%$ \\
\hline Preis Vollmilch Pfandfl. & 0,91 & 1,06 & 0,96 & 1,05 & - \\
\hline Preisindex (Bio-L. $=100)$ & 86,7 & 101 & 91,4 & 100 & - \\
\hline Wahlverhalten & $7,9 \%$ & $3,0 \%$ & $41,2 \%$ & $33,3 \%$ & $14,5 \%$ \\
\hline Preis Käse/Gouda kg & 9,36 & 10,95 & 9,90 & 11,18 & - \\
\hline Preisindex (Bio-L. = 100) & 83,7 & 97,9 & 88,6 & 100 & - \\
\hline Wahlverhalten & $9,6 \%$ & $1,8 \%$ & $47,6 \%$ & $28,9 \%$ & $12,0 \%$ \\
\hline Preis Roggen-Vollkorn-Brot & 1,96 & 2,74 & 2,97 & 3,44 & - \\
\hline Preisindex (Bio-L. = 100) & 57,0 & 79,6 & 86,3 & 100 & - \\
\hline Wahlverhalten & $10,2 \%$ & $0,6 \%$ & $39,2 \%$ & $41,0 \%$ & $9,0 \%$ \\
\hline Gesamtpreisindex 7 Artikel & 75,7 & 96,8 & 85,4 & 100 & - \\
\hline Absatzanteil insgesamt & 10,6 & 1,6 & 45,7 & 41,6 & - \\
\hline
\end{tabular}

Quelle: Eigene Erhebung

Marktführer wäre bei den genannten 7 Artikeln der Bio-Supermarkt mit einem Absatzanteil von 45,7 \%, knapp vor dem Bio-Laden. Supermärkte wie Edeka sind ohne deutlichen Preisvorteil keine relevante Kaufalternative für Bio-Intensivkunden. Die erheblichen Preisvorteile des Soft-Discounters Plus führen mit gut $10 \% \mathrm{zu}$ einem etwas größeren Marktanteil. Dieser ist hauptsächlich auf die Produkte mit deutlichem Preisvorsprung zurückzuführen.

Im Ergebnis zeigt sich, dass die Wechselbereitschaft zum konventionellen Handel bei den Bio-Intensivkäufern relativ gering ist. Der härteste Konkurrent des Bio-Ladens ist der BioSupermarkt, der, ökologisch ähnlich konsequent wie der Bio-Laden, eine größere Auswahl mit angenehmer Atmosphäre und häufig günstigeren Preisen verbindet. Tabelle 12 zeigt aber am Beispiel Eier auch, dass die befragten Intensivkäufer den Bio-Supermarkt ohne 
Preisvorteil nicht durchgängig bevorzugen. Zum einen gibt es eine Kerngruppe, die auch bei deutlicher Preisdifferenz dem traditionellen Bio-Laden treu bleibt (Beispiel Möhren), zum anderen werden produktspezifische Unterschiede deutlich. So ist der Marktanteil des BioLadens bei Brot trotz beachtlicher Preisdifferenzen hoch, was möglicherweise auf vermutete Qualitätsvorteile (z. B. besondere Bio-Bäcker als Lieferanten) zurückzuführen ist, während hier z. B. der Discounter Plus auch bei ausgeprägtem Preisvorteil nur wenige Kunden überzeugen kann.

Insgesamt macht die Analyse deutlich, dass die Bio-Intensivkäufer ausgesprochen fachhandelstreu sind. Allerdings wird auch deutlich, dass nur wenige Probanden auf den klassischen Bio-Laden festgelegt sind. Eine Auszählung zeigt, dass nur 19 Probanden $(11,2 \%)$ bei allen Artikeln den Bio-Laden gewählt haben. 10 Befragte haben in allen Fällen den Bio-Supermarkt bevorzugt.

In einer anschließenden Clusteranalyse wurden die Befragten nach ihrem Wahlverhalten bei dem Auswahlexperiment gruppiert, speziell danach, wie häufig sie sich jeweils für BioLäden, Bio-Supermärkte und Discounter entschieden haben. ${ }^{3}$ Drei Gruppen lassen sich demnach unterscheiden (vgl. Tabelle 13). Die Preiskäufer aus Cluster 1 haben eine ganz eindeutige Präferenz für die jeweils günstigste Einkaufsstätte, was sich auch an ihrem tatsächlichen Einkaufsverhalten nachweisen lässt. Sie nutzen den Fachhandel auch jetzt schon deutlich unterproportional. Die beiden großen Fachhandelscluster dagegen stehen dem LEH weitgehend ablehnend gegenüber.

\footnotetext{
3 In der weiteren Analyse werden diejenigen Probanden, die sich bei den Wahlexperimenten für Edeka entschieden haben, aufgrund der geringen Fallzahl ausgeblendet.
} 
TABELLE 13: KUNDENCLUSTER NACH EINKAUFSSTÄTTENWAHL

\begin{tabular}{|l|c|c|c|}
\hline Cluster & $\begin{array}{c}\text { (1) } \\
\text { Discountorientierte } \\
\text { Bio-Käufer } \\
\text { (Lost Customers) }\end{array}$ & $\begin{array}{c}\text { (2) } \\
\text { Bio-Laden-Kunden } \\
\text { (Safe Customers) }\end{array}$ & $\begin{array}{c}\text { (3) } \\
\text { Bio-Supermarkt- } \\
\text { Kunden } \\
\text { (Switching Customers) }\end{array}$ \\
\hline $\begin{array}{l}\text { Clustergröße } \\
\text { (absolut) }\end{array}$ & 19 & 60 & 85 \\
\hline $\begin{array}{l}\text { Clustergröße } \\
\text { (in Prozent) }\end{array}$ & 12 & 36 & 52 \\
\hline $\begin{array}{l}\text { Auswahlhäufigkeit } \\
\text { Bio-Laden Ø }\end{array}$ & 0,5 & 5,3 & 1,3 \\
\hline $\begin{array}{l}\text { Auswahlhäufigkeit } \\
\text { Bio-Supermarkt } \varnothing\end{array}$ & 1,1 & 1,0 & 4,8 \\
\hline $\begin{array}{l}\text { Auswahlhäufigkeit } \\
\text { Discounter } \varnothing\end{array}$ & 4,2 & 0,2 & 0,3 \\
\hline
\end{tabular}

Quelle: Eigene Berechnungen

Mit Hilfe eines multinomialen Logit-Modells wurden im Anschluss diejenigen Einstellungskriterien identifiziert, die die Wechselbereitschaft $\mathrm{zu}$ Bio-Supermärkten und Discountern bestimmen. Das folgende Modell weist die Schätzkoeffizienten (B) für BioSupermarkt und discountorientierte Käufer aus. Bio-Ladenkunden bilden die Referenzgruppe. ${ }^{4}$

\footnotetext{
${ }^{4}$ Im multinomialen Logit-Modell sind die Schätzkoeffizienten immer im Vergleich aller übrigen Gruppen zu einer Referenzgruppe angegeben. In diesem Fall wurden die Kunden mit Bio-Ladenpräferenz als Referenzgruppe gewählt, da deren Weschelbereitschaft im Vordergrund steht.
} 
TABELLE 14: MultinOMINALES REGRESSIONSMODELL ZUR WECHSELBEREITSCHAFT

\begin{tabular}{|c|c|c|c|c|c|}
\hline & & B & $\begin{array}{l}\text { Standard- } \\
\text { fehler }\end{array}$ & Wald & Signifikanz \\
\hline \multirow{10}{*}{ 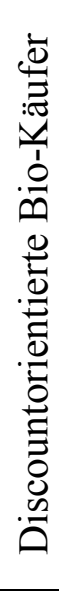 } & Konstante & 13,728 & 4,708 & 8,504 & 0,004 \\
\hline & $\begin{array}{l}\text { Faktor „Emotionale und } \\
\text { sensorische -Qualität“" }\end{array}$ & 0,906 & 0,765 & 1,400 & 0,237 \\
\hline & $\begin{array}{l}\text { Faktor „Kunden- } \\
\text { bindung/Commitment““ }\end{array}$ & $-4,246$ & 1,151 & 13,616 & 0,000 \\
\hline & Preisgünstigkeit Bio-Laden & 0,769 & 0,569 & 1,827 & 0,176 \\
\hline & Relevanz Auswahl bei Bio-Kauf & $-0,071$ & 0,028 & 6,316 & 0,012 \\
\hline & Anteil Bio-Lebensmittel & $-0,053$ & 0,025 & 4,436 & 0,035 \\
\hline & Bio im Freundeskreis & $-0,737$ & 0,484 & 2,320 & 0,128 \\
\hline & Relevanz Glaubwürdigkeit & $-0,144$ & 0,071 & 4,180 & 0,041 \\
\hline & Nutzung Homepage Naturkost.de & 0,379 & 0,509 & 0,554 & 0,457 \\
\hline & Nutzung Virtuelle Community & $-1,699$ & 0,675 & 6,340 & 0,012 \\
\hline \multirow{10}{*}{ 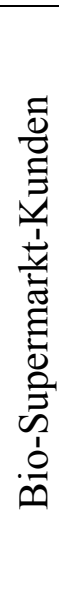 } & Konstante & 0,432 & 2,301 & 0,035 & 0,851 \\
\hline & $\begin{array}{l}\text { Faktor „Emotionale und } \\
\text { sensorische Qualität““ }\end{array}$ & $-1,200$ & 0,370 & 10,521 & 0,001 \\
\hline & $\begin{array}{l}\text { Faktor } \\
\text { „Kundenbindung/Commitment““ }\end{array}$ & $-0,437$ & 0,446 & 0,958 & 0,328 \\
\hline & Preisgünstigkeit Bio-Laden & -0372 & 0,291 & 1,631 & 0,202 \\
\hline & Relevanz Auswahl bei Bio-Kauf & $-0,016$ & 0,013 & 1,476 & 0,224 \\
\hline & Anteil Bio-Lebensmittel & $-0,005$ & 0,010 & 0,207 & 0,649 \\
\hline & Bio im Freundeskreis & $-0,390$ & 0,222 & 3,075 & 0,080 \\
\hline & Relevanz Glaubwürdigkeit & 0,012 & 0,026 & 0,204 & 0,651 \\
\hline & Nutzung Homepage Naturkost.de & 0,536 & 0,270 & 3,957 & 0,047 \\
\hline & Nutzung Virtuelle Community & 0,142 & 0,372 & 0,146 & 0,703 \\
\hline \multicolumn{6}{|c|}{ Referenzkategorie: Bio-Laden-Kunden } \\
\hline \multicolumn{6}{|c|}{$\begin{array}{l}\text { Chi-Quadrat }=115,970 * * * ; \text { Pseudo-R2: Cox } / \text { Snell }=0,551 \text {, Nagelkerke }=0,648 \text {, } \\
\text { McFadden }=0,421 ; \text { zutreffend klassifiziert: } 75,9 \%\end{array}$} \\
\hline
\end{tabular}

Die Analyse zeigt, dass sich die Discount-Kunden durch die geringste Einkaufsintensität bei Bio-Lebensmitteln auszeichnen, während es keine Unterschiede zwischen den beiden Fachhandelskundentypen gibt. Probanden mit Präferenz für die preiswerten Bio-Artikel von Plus sind durch eine signifikant geringere Zufriedenheit mit Bio-Läden und ein geringeres Commitment charakterisiert. Ihre bekundete Zufriedenheit liegt z. B. bei 2,2 im Gegensatz zu 1,66 in der Gesamtstichprobe und 1,47 bei den Bio-Laden-Kunden ( $1=$ sehr zufrieden, $5=$ sehr unzufrieden). Die Discount-Kunden finden die Einkaufsatmosphäre im konventionellen Supermarkt ähnlich gut wie im Bio-Fachhandel. Zudem ist diesen Kunden Auswahl bei Bio weniger wichtig. Gleiches trifft für das Kriterium Glaubwürdigkeit zu, das Vertrauen in konventionelle Hersteller ist offensichtlich ausgeprägter. Schließlich zeigt sich ihr insgesamt 
geringeres Involvement in der Ablehnung von speziellen Informationsinstrumenten wie der Virtuellen Community von Naturkost.de.

Drei Bereiche sind es, die die Wechselbereitschaft des Clusters 3 zum Bio-Supermarkt erklären. Befragte, die sehr häufig den Bio-Supermarkt gewählt haben, beurteilen diesen im Hinblick auf Regionalität, Geschmack, Beratungsqualität, Qualität der Ware und Atmosphäre deutlich besser als Bio-Laden-Kunden. Dass die emotionale und sensorische Qualität den größten Einfluss ausübt, zeigt, dass hier der zentrale Faktor zur Verhinderung von Abwanderung liegt. Die Supermarkt-Kunden stehen den beiden Fachhandelsbetriebsformen indifferent gegenüber (z. B. in Hinblick auf Geschmack und Qualität der Produkte), z. T. sehen sie sogar leichte Vorteile für den Bio-Laden (Regionalität, Beratungsqualität, Atmosphäre). Diese leicht positive Einschätzung der Qualität reicht jedoch offensichtlich nicht aus, die Preisnachteile zu kompensieren. Kunden, die sich bei der Wahlentscheidung für den klassischen Bio-Laden entscheiden, sehen dagegen bei Regionalität, Beratungsqualität und Atmosphäre durchgängig deutliche Vorteile für ihren Bio-Laden. Größere Unterschiede in der Einkaufshäufigkeit und in der Kundenzufriedenheit finden sich dagegen erstaunlicherweise nicht. Eine weitere signifikante Trennvariable stellt das Verhalten der Peer Group dar. Bio-Supermarkt-Kunden finden hier weniger Unterstützung als die Käufer im klassischen Bio-Laden. Schließlich zeigen die Supermarkt-Kunden eine signifikant höhere Affinität zur Nutzung des Internets als Informationsquelle.

Fazit: Nur ein gutes Drittel der Bio-Intensivkäufer ist nachhaltig auf den klassischen BioLaden fokussiert. Nur bei ihnen ist von einer gesicherten Stammkundenbindung auszugehen. Der größere Teil der Kunden schwenkt bei einem entsprechenden Angebot jedoch auf BioSupermärkte um, zumindest dann, wenn Preisdifferenzen, wie derzeit im Markt vorfindlich bestehen bleiben. Rund $40 \%$ der Probanden, die in der Befragung Bio-Supermärkte präferieren, verfügen heute noch nicht über entsprechende Einkaufsmöglichkeiten in ihrer Umgebung. Sie werden dem Fachhandel wohl mit der Neueröffnung entsprechender Standorte verloren gehen. Dies wird bei vielen klassischen Bio-Läden zu merklichen Kundenverlusten führen und aller Voraussicht nach das Ladensterben deutlich forcieren.

Das Regressionsmodell verdeutlicht zudem, dass Kundenzufriedenheits- und Commitmentfragen allein nicht zur Erklärung der Wechselbereitschaft ausreichen (Keller et al. 2002: 549). Es gibt keine signifikanten Unterschiede in der Kundenzufriedenheit zwischen Bio- 
Laden- und Bio-Supermarkt-Kunden. Sehr deutlich sind dagegen die Abweichungen bei der Kundenzufriedenheit zwischen denjenigen Käufern, die den Discounter Plus präferieren, und den übrigen Probanden. Ganz offensichtlich führt die insgesamt hohe Kundenzufriedenheit der heutigen Bio-Ladenkäufer zu einer ausgeprägten Fachhandelsbindung, die jedoch den Bio-Supermarkt mit einschließt.

Der entscheidende Unterschied zwischen den Bio-Laden- und den Bio-Supermarkt-Kunden liegt vielmehr in den Punkten Regionalität, Beratungsqualität und Atmosphäre. Kann der BioLaden hier deutliche Vorteile kommunizieren, kann er sich auch gegen preiswertere BioSupermärkte behaupten.

Aus methodischer Sicht hat sich das Konzept der produktspezifischen Wahlentscheidungen als Analysemethode zur Prognose der Betriebsformenwahl bewährt. Es zeigen sich hochsignifikante und plausible Ergebnisse. Zugleich ist das Befragungskonzept relativ einfach und fehlerunempfindlich, so dass es sich für Online-Befragungen eignet.

\section{Perspektiven der Bio-Läden}

Die befragten Bio-Intensivkäufer haben sich als ausgesprochen fachhandelstreu erwiesen. Dies bestätigen die einleitend skizzierten Erfahrungen der Panelforschung und deutet damit auf eine relativ geringe Konkurrenzintensität zwischen dem Fachhandel und dem konventionellen LEH hin. Der Fachhandel spricht eine stark politisch motivierte Zielgruppe an, aus deren Sicht das eher randständige Bio-Angebot der Supermärkte und Discounter keine glaubwürdige Alternative darstellt. Diese Stärke gilt es auszubauen, z. B. durch die Gewinnung neuer Bündnispartner wie Attac, um junge politisch motivierte Zielgruppen anzusprechen.

In politischer Hinsicht kann daraus die Schlussfolgerung gezogen werden, dass von der Förderung des Bio-Sortiments im großbetrieblichen Bereich wenige Verdrängungseffekte auf das Fachhandelssegment ausgehen. Die im Zuge der Agrarwende vom Bundesministerium propagierte und durch das Bio-Siegel geförderte Ausweitung der Distribution in den konventionellen LEH geht bisher nur wenig zu Lasten des Fachhandels.

Deutlich stärker ist die Wechselbereitschaft der Bio-Laden-Kunden zu Bio-Supermärkten. Hier spielt die Preispolitik eine starke Rolle. Die Entwicklung der Bio-Supermärkte verlief in 
den letzten Jahren vergleichsweise dynamisch. Nach Expertenschätzung werden jährliche Steigerungsraten von durchschnittlich $6 \%$ erwartet, so dass im Jahr 2007 ca. 600 Mio. $€$ Umsatz sowie 350 Bio-Supermärkte erwartet werden (Bahrdt et al. 2003: 30). Als Vorteile der Bio-Supermärkte sind sicherlich im Vergleich zum Bio-Laden das größere Sortiment sowie die günstigere Kostenstruktur zu nennen. Zudem können bei filialisierten Unternehmen Marketingkosten eingespart werden. Auch der modernere Ladenbau sowie die häufig besseren Standorte der Bio-Supermärkte ermöglichen eine erfolgreichere Neukundengewinnung.

Aus Sicht der klassischen Bio-Läden müssen die Wettbewerbsvorteile in Hinblick auf die Wahrnehmung von Regionalität, Beratungsqualität und Atmosphäre gegenüber den BioSupermärkten verteidigt werden. Regionalität ist z. B. für Filialbetriebe systembedingt deutlich schwieriger zu gewährleisten. Beratungsqualität verlangt gut ausgebildete und erfahrene Fachkräfte. Atmosphäre wird entscheidend bestimmt durch Servicequalität (Freundlichkeit, Sauberkeit, Lebensstil-Fit usf.).

Insgesamt sind aber die Perspektiven des Bio-Ladens selbst bei weiterem Gesamtmarktwachstum nicht besonders positiv. Die Konkurrenz der Bio-Supermärkte ist nicht nur für potenzielle Neukunden attraktiv, sondern auch für bisherige Bio-Laden-Käufer. In der Analyse zur Wechselbereitschaft konnte gezeigt werden, dass nur ein gutes Drittel der BioIntensivkäufer nachhaltig dem klassischen Bio-Laden treu bleibt. Bei den Kunden, die bislang keine Bio-Supermärkte als Alternative haben, ist eine Abwanderung bei Neueröffnung zu befürchten. Der Bio-Supermarkt gilt als preisgünstiger, zudem wird die Auswahl besser bewertet. Angesichts der bereits heute prekären Finanzlage vieler Bio-Läden können diese eine größere Kundenabwanderung kaum verkraften. Sie werden der Konkurrenz durch neue Bio-Supermärkte nur dann standhalten, wenn sie durch eigene massive Neukundengewinnung zum Gesamtwachstum des Segmentes beitragen. Dazu ist es wichtig, die skizzierten Schwellenängste (empfundener sozialer Druck, Preisbarriere) durch neue Präsentationskonzepte und eine variablere Preispolitik anzugehen. Zudem sollten sie Möglichkeiten zu eigenem Wachstum durch Vergrößerung der Geschäftsflächen überprüfen. Schließlich können zur Verbesserung der Kostensituation noch erhebliche Kooperationspotenziale in der Branche erschlossen werden. 


\section{Literatur}

Bahrdt, K. et al. (2003): Bio-Supermärkte in Deutschland - Chancen und Entwicklungen 2003, Frankfurt a. M.

Bodenstein, G., Spiller, A. (2001): Preispolitik des deutschen Lebensmitteleinzelhandels und Preisbereitschaft der Konsumenten bei ökologischen Lebensmitteln, in: Schrader, U., Hansen, U. (Hrsg.), Nachhaltiger Konsum: Forschung und Praxis im Dialog, Frankfurt a. M., S. 189208.

Bruhn, M. (2002): Die Nachfrage nach Bioprodukten: Eine Langzeitstudie unter besonderer Berücksichtigung von Verbrauchereinstellungen, Frankfurt am Main u. a.

Enneking, U. et al. (2003): Ein Weg aus der Nische? Eine Analyse von Selten- und Gelegenheitskäufern ökologischer Lebensmittel mittels Discrete Choice Analyse, in: Dabbert, S. (Hrsg.): Perspektiven in der Landnutzung - Regionen, Landschaften, Betriebe - Entscheidungsträger und Instrumente. 43. Jahrestagung der Gesellschaft für Wirtschafts- und Sozialwissenschaften des Landbaus (GEWISOLA) 2003 in Hohenheim, Münster-Hiltrup, S. 273-281.

Hahn, C. (1997): Conjoint und Discrete-Choice Analyse als Verfahren zur Abbildung von Präferenzstrukturen und Produktauswahlentscheidungen - Ein theoretischer und computergestützter empirischer Vergleich, Münster.

Hamm, U.; Wild, S. (2004): Der Preis bestimmt den Absatz, in: BioHandel, 4, H. 1, S. 8-13.

Homburg, C. et al. (1999): Der Zusammenhang zwischen Kundenzufriedenheit und Kundenbindung, in: DBW, 59. Jg., Nr. 2, S. 174-195.

ISOE (Institut für sozialökologische Forschung) (2003): „bio+pro“- Zielgruppen für den Bio-Lebensmittelmarkt, Ergebnisbericht der empirischen Forschung des ISOE GmbH im Auftrag der Geschäftsstelle Bundesprogramm Ökologischer Landbau, Frankfurt a. M.

Jahn, G., Schramm, M., Spiller, A. (2004): Trust in Certification procedures: An Institutional Economics Approach Investigating the Quality of Audits within Food Chains. Conference Proceeding presented at the 14th World Food and Agribusiness Forum, June 12-15, 2004, Montreux, Switzerland.

Jung, A. (1998): Qualitätsunsicherheit auf dem Markt für Lebensmittel aus ökologischem Anbau Erklärungsansätze für träges Umweltverhalten unter besonderer Berücksichtigung informationsökonomischer Erkenntnisse, Frankfurt a. M.

Kaas, K. P. (2001): Markoff-Modelle, in: Diller, H. (Hrsg.): Vahlens Großes Marketinglexikon, 2. Aufl., München; Sp. 1032-1033.

Keller, B., Krause, J., Siek, M. (2002): Kundenbindung als Instrument des Marketing-Controlling, in: Die Bank, Nr. 8, S. 548-553.

Kreuzer, K., Offeney, C. (2005): 40 neue Bio-Supermärkte in Deutschland, unter: www.biomarkt.info/druck..... Abrufdatum: 01.02.2005.

Kreuzer, K. (1996): Bio-Vermarktung, Vermarktungswege für Lebensmittel aus ökologischer Erzeugung, Lauterbach.

Kropp, C., Brunner, K.-M. (2004): Ökologisierungspotentiale der privaten Konsum- und Ernährungsmuster, Diskussionspapier Nr. 1 des BMBF-Forschungsprojektes „Von der Agrarwende zur Konsumwende?"،, München.

Kropp, C., Sehrer, W. (2004): Die Nachfrage nach Bio-Lebensmitteln in München und Leipzig sozialdemographische Hintergründe, Einkaufsstättenpräferenzen und Ernährungshaltungen, Diskussionspapier Nr. 2 des BMBF-Forschungsprojektes „Von der Agrarwende zur Konsumwende?", München. 
Kundenmonitor (Hrsg.) (2004): Globalzufriedenheit Kundenmonitor Deutschland 2004, unter: http://www.kundenmonitor.de/, Abrufdatum: 01.02.2005

Kuhnert, H. et al. (2002): Nachfrage nach Öko-Lebensmitteln - Veränderungen durch BSE? BIOGUM-Forschungsbericht FG Landwirtschaft, H. 1 (2002), Universität Hamburg.

Kuß, A. (2001): Variety Seeking, in: Diller, H. (Hrsg.): Vahlens Großes Marketing Lexikon, 2. Aufl., München, S. 1721.

Lüth, M., Spiller, A. (2004): Käuferverhalten, in: Leitzmann, C. et al. (Hrsg.): Praxishandbuch BioLebensmittel, Hamburg, Kap. V, 2.2.1, S. 1-18.

Lüth, M.; Spiller, A.; Enneking, U. (2004): Analyse des Kaufverhaltens von Selten- und Gelegenheitskäufern und ihrer Bestimmungsgründe für/gegen den Kauf von Öko-Produkten, Projektabschlussbericht für das BMVEL im Rahmen des Bundesprogramms ökologischer Landbau, Göttingen.

Michels, P. et al. (2003): Bio-Frische im LEH: Fakten zum Verbraucherverhalten, Materialien zur Marktberichterstattung der ZMP, Band 45, Bonn.

Moser, K. (2002): Markt- und Werbepsychologie, Göttingen.

Müller, S. (1998): Die Unzufriedenheit der „eher zufriedenen“ Kunden, in: Müller, S., Strothmann, H. (Hrsg.): Kundenzufriedenheit und Kundenbindung: Strategien und Instrumente von Finanzdienstleistern, München, S. 197-218.

Naturkost.de (2005) : Mediadaten, unter: http://www.naturkost.de/mediadaten/naturkost/index.htm, Abrufdatum 01.02.2005.

Peter, S. I. (1997): Kundenbindung als Marketingziel: Identifikation und Analyse zentraler Determinanten, Wiesbaden.

Reuter, K. et al. (2005): Wo Kunden am billigsten Bio kaufen können, in: BioHandel, Heft 1, S. 6-7.

Richter, T. (2001): Kaufverhalten, Einstellungen und Kenntnisse der Konsumenten in der "RegioTrirhena" in Bezug auf regionale und umweltgerecht erzeugte Nahrungsmittel, Frick, Forschungsinstitut für Biologischen Landbau.

Schaer, B. (2001): Regionales Gemeinschaftsmarketing für Öko-Lebensmittel: dargestellt am Beispiel der Konzeption des Zeichens "Öko-Qualität garantiert aus Bayern", Hamburg.

SinusSociovision (2002), Strategische Zielgruppenanalyse für den Öko-Ernährungs-Markt, Untersuchung im Auftrag der CMA, unveröffentlichte Studie, Heidelberg.

Spahn, M. (2002): Der Bio-Fachhandel in Europa, Bad Wildbad.

Spiller, A. (2002): Preispolitik für ökologische Lebensmittel: Eine neoinstitutionalistische Analyse. Agrarwirtschaft, 50, H. 7, S. 451-461.

Statistisches Bundesamt (Hrsg.) (2004): Statistisches Jahrbuch 2004, Wiesbaden.

Thompson, G. D.; Kidwell, J. (1998): Explaining the Choice of Organic Produce: Cosmetic Defects, Prices and Consumer Preferences, in: American Journal of Agricultural Economics, 80, H. 2, S. 277-287.

Ziemann, M.; Thomas, S. (2003): Wer kauft Bio-Handelsmarken, in: Ernährungs-Umschau, 50, H. 6, S. B 21-B 24 .

ZMP (Hrsg.) (2001): Einstellung und Käuferprofile bei Bio-Lebensmitteln, Bonn.

ZMP/CMA (Hrsg.) (2002): Wie viel Bio wollen die Deutschen? Bonn. 
KAPITEL I.2

Kundenbindung und Wechselbereitschaft im Bio-Fachhandel: Ein multinomiales Logit-Modell 


\section{Kundenbindung und Wechselbereitschaft im Bio-Fachhandel: Ein multinomiales Logit-Modell*}

(mit Achim Spiller und Julia Engelken)

1 Wettbewerbsintensität im Bio-Fachhandel ..............................................................99

2 Distributionskanäle für Bio-Lebensmittel ..............................................................100

3 Kundenzufriedenheit und Abwanderungsbereitschaft .............................................102

4 Studiendesign der Online-Erhebung.........................................................................................103

5 Ergebnisse eines Wahlexperiments zur Bestimmung der Wechselbereitschaft........... 105

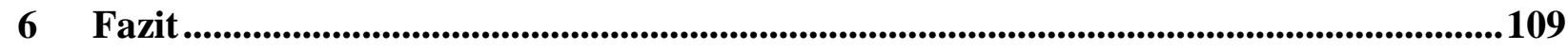

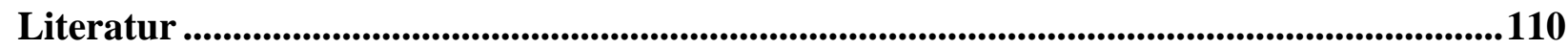

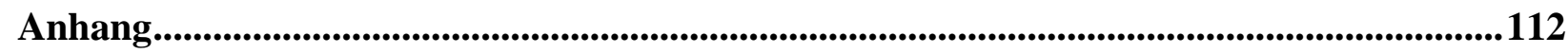

\section{Tabellenverzeichnis}

Tabelle 1: Absatzwege und Ausgabenanteile für Biolebensmittel 2004 in Deutschland (in \%). 100 Tabelle 2: Struktur der Betriebsformen des Naturkostfachhandels Deutschland........................101

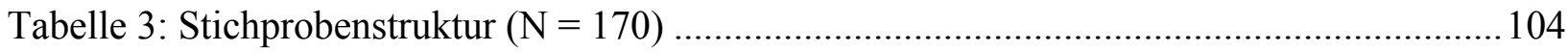

Tabelle 4: Auswahlexperiment mit realen Produktpreisen für vier Betriebsformen.................. 106

Tabelle 5: Kundencluster nach Einkaufsstättenwahl.......................................................... 107

Tabelle 6: Multinominales Regressionsmodell zur Wechselbereitschaft................................ 108

* Erscheint in: Bahrs, E. et al (Hrsg.): Tagungsband der 45. Gewisola Jahrestagung "Unternehmen im Agrarbereich vor neuen Herausforderungen", Göttingen, im Druck. 


\section{Zusammenfassung}

In den letzten Jahren haben Bio-Läden verstärkt Konkurrenz durch Bio-Supermärkte und den konventionellen Lebensmitteleinzelhandel bekommen. Kern der Untersuchung ist eine Befragung von Bio-Intensivkäufern zu ihren Einkaufsstättenpräferenzen und ihrer Wechselbereitschaft zu anderen Handelsbetriebsformen. Auf Basis eines Wahlexperimentes wurden Kundencluster analysiert und mit Hilfe eines multinominalen Logit-Modells die Abwanderungsgefahren und Kundenbindungsfaktoren bestimmt. Als Ergebnis zeigt sich, dass nur 1/3 der bisherigen Kunden einkaufsstättentreu sind, der größere Teil dagegen bei entsprechenden Preisvorteilen zum Bio-Supermarkt abwandert. Der Wechsel in den konventionellen LEH spielt dagegen nur eine geringere Rolle. Über den konkreten Fall hinaus präsentiert die Studie ein einfaches Modell zur Modellierung des Betriebsformenwettbewerbs, das sich auch für eine Online-Befragung eignet.

Keywords: Kundenbindung, Geschäftsstättentreue, Wahlexperiment, Clusteranalyse, multinomiales Logit-Modell

\section{Wettbewerbsintensität im Bio-Fachhandel}

Die Vermarktung von ökologischen Lebensmitteln fand $\mathrm{zu}$ Beginn des ökologischen Landbaus vornehmlich über Direktverkauf und Reformhäuser statt. In den 1970er Jahren gründeten sich die ersten Bio-Läden, die sich schnell zu einem wichtigen Distributionskanal entwickelten (Spahn 2002: 8). Mit der Umweltbewegung der 80er Jahre erlebten die BioLäden einen Wachstumsschub. Hinzu kam in dieser Phase allerdings auch erstmals Konkurrenz durch den konventionellen Lebensmitteleinzelhandel (LEH). In jüngerer Zeit nimmt die Wettbewerbsintensität aus Sicht des traditionellen Bio-Fachhandels noch einmal deutlich zu. Zum einen weiten die Filialunternehmen des LEH ihr Bio-Angebot kontinuierlich aus, auch Discounter wie Plus und Aldi sind in den Markt eingestiegen. Zum anderen kommt es im Fachhandelsbereich zu einer Betriebsformenkonkurrenz durch die Neugründung von Bio-Supermärkten. Diese zählen zu den am schnellsten wachsenden Absatzkanälen für BioWare und erwirtschafteten im Jahr 2002 bereits ein Fünftel des Gesamtumsatzes im Naturkosthandel (Bahrdt et al. 2003: 13).

Vor diesem Hintergrund wird die Frage aufgeworfen, wie die Perspektiven des Bio-Fachhandels zu beurteilen sind. Kern der Untersuchung ist eine Befragung von Bio-Intensivkäufern zu ihren Einkaufsstättenpräferenzen und ihrer Wechselbereitschaft. Es handelt sich 
damit um einen Beitrag zur Messung des Inter-Betriebsformenwettbewerbs im Handel. Die Basis bildet ein relativ einfaches Wahlexperiment, bei dem die Probanden auf Basis realer Preise Einkaufsstättenpräferenzen für verschiedene Produkte offenbaren. Mit Hilfe einer Clusteranalyse und eines multinomialen Logit-Modells werden daraus Abwanderungsgefahren und Kundenbindungsfaktoren berechnet. Aufgrund der transparenten und leicht nachvollziehbaren Aufgabenstellung eignet sich das vorgeschlagene Modell - wie im vorliegenden Fall - auch für Online-Erhebungen.

\section{Distributionskanäle für Bio-Lebensmittel}

Die Distribution von Bio-Lebensmitteln verläuft über verschiedene Absatzwege (siehe Tab. 1). Mit 31,2 \% der Ausgaben für Öko-Lebensmittel ist der Naturkostfachhandel (BioLäden, Bio-Supermärkte) der wichtigste Vertriebskanal, gefolgt vom LEH mit 28 \% Umsatzanteil. Ein weiterer wichtiger Absatzkanal ist die Direktvermarktung mit 16,5\% (Michels et al. 2004: 8).

Tabelle 1: Absatzwege und Ausgabenanteile für Biolebensmittel 2004 in Deutschland (in \%)

\begin{tabular}{|c|c|c|c|c|c|c|c|c|c|}
\hline $\begin{array}{c}\text { Natur- } \\
\text { kost- } \\
\text { läden }\end{array}$ & $\begin{array}{c}\text { Bio- } \\
\text { Super- } \\
\text { märkte }\end{array}$ & $\begin{array}{c}\text { Refor } \\
\mathrm{m}- \\
\text { häuser }\end{array}$ & $\begin{array}{c}\text { Bäck- } \\
\text { ereien }\end{array}$ & $\begin{array}{c}\text { Metz- } \\
\text { gereien }\end{array}$ & Erzeuger & $\begin{array}{c}\text { Wochen- } \\
\text { markt, } \\
\text { Straßen- } \\
\text { stand }\end{array}$ & $\begin{array}{c}\text { Verbraucherm.; } \\
\text { Supermärkte, } \\
\text { kleiner LEH, } \\
\text { Kaufhäuser }\end{array}$ & $\begin{array}{c}\text { Dis- } \\
\text { counter }\end{array}$ & $\begin{array}{c}\text { Drogerie- } \\
\text { märkte }\end{array}$ \\
\hline 26,1 & 5,1 & 6,9 & 4,7 & 2,6 & 10,7 & 5,8 & 22,6 & 4,1 & 4,1 \\
\hline
\end{tabular}

Quelle: Michels et al. 2004: 8

Besonders auffällig ist der Erfolg der Bio-Supermärkte. Während im Jahr 2000 erst 50 BioSupermärkte existierten, sind es drei Jahre später bereits 180 Geschäftsstätten, die einen Umsatzanteil von 5,1 \% am Gesamtmarkt ausmachen (MiCHELS et al. 2004: 6). Mit nur $9 \%$ der Betriebe erwirtschaften die Bio-Supermärkte $17 \%$ des Umsatzes des Naturkostfachhandels (Bahrdt et al. 2003: 13). Inzwischen ist ihre Zahl auf 250 angestiegen (Kreuzer/Offeney 2005).

Bei der Abgrenzung der Formen des Naturkostfachhandels sind vor allem die unterschiedliche Ladengröße und damit einhergehend auch die Artikelanzahl maßgeblich (siehe Tab. 2). Die Bio-Läden unterscheiden sich vom Bio-Supermarkt weniger in der grundsätzlichen Sortimentsgestaltung. Bei beiden ist der Frischebereich ähnlich wichtig. Die gelisteten Marken sind häufig identisch. Die größere Artikelanzahl und der Fokus auf SB-Waren verlangen allerdings eine Ausweitung der Ladengröße, auch wenn Bio-Supermärkte immer noch deutlich kleiner als konventionelle Supermärkte sind. Diese werden als Betriebe 
zwischen 400 und 1.500 qm definiert (Metro Group 2004: 123), wobei die Wachstumsschwelle, ab der heute neue konventionelle Supermärkte eröffnet werden, zzt. bei rund 1.000 qm liegt (Spahn 2002: 54; Bahrdt et al. 2003: 13). Viele Bio-Supermärkte fallen damit bezogen auf die Verkaufsfläche eigentlich in die Kategorie der SB-Geschäfte. Der höhere Filialisierungsgrad und die umfangreichen Ladenbauinvestitionen weisen aber auf die deutlichen Unterschiede zum klassischen Naturkostfachhandel hin.

TABELLE 2: STRUKTUR DER BETRIEBSFORMEN DES NATURKOSTFACHHANDELS DEUTSCHLAND

\begin{tabular}{|l|c|c|c|}
\hline & Naturkostfachgeschäfte & Bio-Supermärkte & Reformhäuser \\
\hline Umsatzanteil am Bio-Markt & $26,1 \%$ & $5,1 \%$ & $6,9 \%$ \\
\hline Outlet-Zahl & 2.000 & 250 & 2.300 \\
\hline Verkaufsfläche in qm & ca. $100-200$ & ca. $200-1.000$ & ca. 70 \\
\hline Artikelanzahl im Sortiment & ca. 6.000 & bis 10.000 & Keine Angaben \\
\hline Filialisierungsgrad & $\varnothing 3.000$ & $\varnothing 5.500$ & sehr gering \\
\hline
\end{tabular}

Quelle: Eigene Zusammenstellung nach MiCHELS et al. 2004: 8; BAHRDT et al. 2003: 13

Neben dem Naturkostfachhandel spielt der LEH in der Biovermarktung mit $28 \%$ Umsatzanteil eine wichtige Rolle. Das durchschnittliche Sortiment an Bioprodukten je Outlet beläuft sich hier auf 200 bis 800 Artikel. Eine herausragende Stellung nimmt Tegut mit ca. 1.200 Artikeln ein. Aber auch die selbstständigen Lebensmitteleinzelhändler in den Kooperationsgruppen Edeka und Rewe sind z. T. besonders erfolgreich in der Biovermarktung und bauen ihr Biosortiment weiter aus (Bahrdt et al. 2003: 12). Inzwischen haben auch einige Discounter (z. B. Plus und Aldi) erste Bioartikel gelistet. Ihr Umsatzanteil am Biosegment ist allerdings noch relativ gering (Michels et al. 2004: 8).

Die Konsumentenzielgruppen der verschiedenen Absatzkanäle unterscheiden sich relativ deutlich. Im Bio-Fachhandel kaufen überwiegend Intensivkäufer ein, die sich durch lange Einkaufserfahrung, hohes Involvement, ausgeprägte Preisbereitschaft und einen hohen BioAnteil an den Lebensmittelausgaben auszeichnen (Lüth et al. 2004). Im LEH ist dagegen der Anteil der Selten- und Gelegenheitskäufer deutlich größer, obwohl Panelstudien auch hier gezeigt haben, dass $2 / 3$ des Bio-Absatzes auf eine kleine Teilgruppe von rund $8 \%$ der Käufer entfällt (Michels et al. 2003: 23). Die Überschneidungen zwischen den beiden Intensivkäufergruppen sind aber gering. 


\section{Kundenzufriedenheit und Abwanderungsbereitschaft}

Die folgende Befragung fokussiert auf die Kunden des Bio-Fachhandels, um dessen „Überlebenschancen“ im Wettbewerb der Vertriebsformen zu analysieren. In der Folge der BSE-Krise bauen die Unternehmen des konventionellen LEH ihr Bio-Sortiment weiter aus. Der Markteintritt der Discounter verstärkt zudem den Preiswettbewerb. So ist der Preisabstand zwischen den Discountern wie Plus und dem Bio-Fachhandel deutlich größer als zu Supermärkten wie Edeka (vgl. unten). Aufgrund der strukturellen Kostennachteile wird der Fachhandel preispolitisch nur begrenzt reagieren können. Schließlich hat das staatliche BioSiegel die Vergleichbarkeit der Produkte erhöht und die Qualitätsunsicherheit für Käufer im LEH reduziert. Vor diesem Hintergrund wächst die Gefahr von Kundenabwanderungen.

Im Marketing gibt es unterschiedliche Ansätze zur Messung der Kundenbindung. Kundenzufriedenheit wurde zunächst als eine hinreichende Bedingung für treue Kunden gesehen. Die neuere Kundenzufriedenheitsforschung hat allerdings gezeigt, dass Kundenzufriedenheit nur eine notwendige, nicht aber die hinreichende Bedingung für Kundenbindung ist. Neben der Suche nach Neuerungen und Abwechslung (Variety Seeking) sind es gute Konkurrenzangebote, die auch einen grundsätzlich zufriedenen Verbraucher zum Marken- oder Einkaufsstättenwechsel bewegen können (Peter 1997: 100). Umgekehrt gibt es auch unzufriedene treue Kunden, z. B. mangels relevanter Alternativen (Müller 1998). Die folgende Studie überprüft daher die Zukunftsfähigkeit des traditionellen Bio-Fachhandels in zweifacher Hinsicht: Im ersten Teil wird die Kundenzufriedenheit detailliert mittels klassischer Zufriedenheitsfragen und mehrstufiger Likert-Skalen erfasst. Teil zwei der Studie untersucht verhaltensbezogen, wie groß die Abwanderungsgefahr von Bio-Laden-Kunden zu Wettbewerbern ist.

In der Forschung werden zur Analyse der Wechselbereitschaft verschiedene Varianten diskutiert. Liegen Haushaltspaneldaten vor, so kann z. B. aus dem tatsächlichen Wechselverhalten mittels Markoff-Modellen auf die Kundenbindung geschlossen werden (Tang et al. 2001: 60). Wenn Paneldaten wie im vorliegenden Fall nicht vorhanden sind, kann die Wechselbereitschaft direkt erfragt werden. Eine solche Frage bleibt aber relativ abstrakt und kann insbesondere keine Einsichten in das Preis-Reaktionsverhalten der Probanden liefern. Letzteres leisten Wahlexperimente auf Basis der Conjoint- oder Discrete ChoiceAnalyse (Großmann et al. 2002), die allerdings bei Online-Befragungen schwierig einzu- 
setzen sind (Conjoint) bzw. extrem große Stichproben verlangen (Discrete Choice) (Enneking et al. 2003: 275).

Im vorliegenden Fall wurde deshalb ein einfaches Wahlexperiment genutzt. Den Befragten wurde eine hypothetische Einkaufssituation vorgegeben. Sie wurden aufgefordert, sich für den von ihnen präferierten Einkaufsort zu entscheiden unter der Voraussetzung, dass dort BioProdukte angeboten werden und alle Geschäfte gleich weit entfernt wären (Wechselkosten werden insofern ausgeblendet). Da Analysen zum Bio-Konsum erhebliche produktspezifische Unterschiede im Kaufverhalten aufgezeigt haben (Bodenstein/Spiller 2001), wurde diese Frage für mehrere Produkte gestellt. Dabei wurden die jeweils realen Preise vorgegeben. Auf Basis der Wahlentscheidungen können anschließend mittels Clusteranalyse Probandengruppen identifiziert werden. Im nächsten Schritt werden diese Cluster dann mittels eines multinomialen Regressionsmodells erklärt.

\section{Studiendesign der Online-Erhebung}

Die Befragung richtet sich auf die Kundenzufriedenheit sowie die Wechselbereitschaft der Stammkunden des klassischen Bio-Fachhandels. Durchgeführt wurde die Erhebung deshalb im Herbst 2004 in Zusammenarbeit mit Naturkost.de, einem führenden Internet-Portal für die deutsche Naturkostfachwirtschaft mit durchschnittlich 180.000 Besuchern pro Monat (Naturkost.de 2005). Genutzt wird Naturkost.de hauptsächlich von Kunden des Naturkostfachhandels, so dass die User der angestrebten Zielgruppe der Befragung entsprechen. In die Auswertung konnten insgesamt 170 gültige Antworten einbezogen werden. Durch eine Gabelfrage wurde sichergestellt, dass nur Kunden mit Bio-Fachhandelserfahrung befragt wurden. Tabelle 3 fasst die Stichprobenstruktur zusammen. Die Befragung dauerte durchschnittlich 13 Minuten, was für eine Online-Befragung eher die Obergrenze darstellt.

In der Befragung fällt der mit $70 \%$ hohe Frauenanteil auf, was die reale Situation beim Einkauf und die höhere Biopräferenz von Frauen widerspiegelt. Auch der sehr hohe Bildungsstand, $70 \%$ der Probanden verfügen über Abitur, ein gutes Drittel sogar über einen Hochschulabschluss, repräsentiert den typischen Bio-Konsumenten. Die Altersstreuung liegt zwischen 28 und 66 Jahren, das durchschnittliche Alter beträgt 38 Jahre. Hier gibt es einen für Online-Befragungen typischen Bias durch die geringere Beteiligung älterer Probanden. Im Durchschnitt geben die Befragten an, dass $64 \%$ ihres Lebensmittelkonsums auf Bio-Lebens- 
mittel entfallen, so dass es tatsächlich gelungen ist, die Kerngruppe der Bio-Intensivkäufer zu erfassen. Aufgrund der dargestellten Verzerrungen handelt es sich um eine erste Sondierungsstudie.

TABELLE 3: STICHPROBENSTRUKTUR $(\mathrm{N}=170)$

\begin{tabular}{|c|c|c|c|}
\hline Geschlecht & \multicolumn{2}{|c|}{$30 \%$ Männer } & $70 \%$ Frauen \\
\hline Altersgruppen & Stichprobe (in \%) & $\begin{array}{c}\text { Käufer in } \\
\text { Naturkostfachgeschäften } \\
\text { (in \%) }\end{array}$ & $\begin{array}{c}\text { Bevölkerungsanteil } \\
\text { Haushalte (in \%) }\end{array}$ \\
\hline bis 34 Jahre & 39,6 & 18 & 22 \\
\hline 35-44 Jahre & 36,0 & 30 & 20 \\
\hline 45-54 Jahre & 18,9 & 16 & 17 \\
\hline 55-64 Jahre & 4,9 & 24 & 18 \\
\hline über 65 Jahre & 0,6 & 12 & 24 \\
\hline Schulbildung & Stichprobe (in \%) & $\begin{array}{c}\text { Käufer in } \\
\text { Naturkostfachgeschäften } \\
\text { (in \%) }^{1} \\
\end{array}$ & $\begin{array}{c}\text { Bevölkerungsanteil } \\
\text { Haushalte (in \%) }\end{array}$ \\
\hline Haupt-/Volksschule & 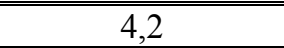 & 14 & 28 \\
\hline Mittlere Reife/Realschule & 22,4 & 17 & 27 \\
\hline Abitur/Fachabitur & 33,3 & 21 & $23^{2}$ \\
\hline Hochschulabschluss & 37,6 & 48 & 22 \\
\hline Sonstige & 2,4 & & \\
\hline Wohnortgröße & Stichprobe (in \%) & Bundesdu & schnitt $^{2}$ \\
\hline "weniger als 1.000 Einwohner & 7,6 & & \\
\hline $1.000-5.000$ Einwohner & 9,4 & & \\
\hline $5.000-10.000$ Einwohner & 7,1 & & \\
\hline $10.000-50.000$ Einwohner & 19,4 & & \\
\hline $50.000-100.000$ Einwohner & 9,4 & & \\
\hline $100.000-500.000$ Einwohner & 24,1 & & \\
\hline mehr als 500.000 Einwohner & 19,4 & & \\
\hline
\end{tabular}




\section{Ergebnisse eines Wahlexperiments zur Bestimmung der Wechselbereitschaft}

Die befragten Probanden bevorzugen bisher beim Einkauf ihrer Bio-Produkte sehr eindeutig den Bio-Laden. Gut 60 \% kaufen hier nach eigenen Angaben häufig oder sehr häufig ein, nur $3 \%$ nie. Die zweitwichtigste Einkaufsstätte für Bio-Waren ist der Bio-Supermarkt (38 \% häufig oder sehr häufig). An dritter Stelle folgt der konventionelle Supermarkt (35\% häufig bzw. sehr häufig), vor dem Wochenmarkt, dem Reformhaus und dem Direkteinkauf beim Landwirt. Nur 14 \% der Befragten kaufen häufiger Bio-Waren beim Discounter.

Kundenbindung und Commitment wurden durch vier Fragen erfasst und konnten per Faktorenanalyse $\mathrm{zu}$ einem Faktor verdichtet werden: Kaufhäufigkeit im Bio-Laden, Kundenzufriedenheit, Bewertung der Einkaufsatmosphäre und die Unterstützung der BioLäden im Wettbewerb. Die Erfassung der Wechselbereitschaft erfolgt über das bereits grundsätzlich skizzierte Wahlexperiment. Die in Tabelle 4 für sieben Artikel genannten Produktpreise wurden den Marktdaten der ZMP sowie, für die dort nicht ausgewerteten BioSupermärkte, eigenen Recherchen in mehreren Märkten entnommen. Der Soft-Discounter Plus ist bei den von uns analysierten sieben Produkten in sechs Fällen Preisführer. In einem Fall ist es der Bio-Supermarkt, der insgesamt deutlich günstiger ist als Supermarktfilialisten wie Edeka und Rewe. Letztere sind mit einem Preisindex von 96,8 kaum preiswerter als der Bio-Laden (Preisindex = 100). Eine aktuelle und breitere Erhebung von Reuter et al. (2005) zeigt, dass das den Befragten vorgespielte Preisniveau ebenso wie die wechselnde Preisführerschaft die reale Marktsituation sehr gut wiedergibt.

Die in der Tabelle 4 aufgeführten Prozentwerte zeigen den Anteil der Konsumenten, die sich für die jeweilige Einkaufsstätte entschieden haben (Wahlverhalten). Es ist für alle Produkte zunächst der den Probanden vorgegebene Preis genannt. Die zweite Zeile drückt diesen dann als Preisindex aus. Die jeweils dritte Zeile weist das Befragungsergebnis ink1. No-ChoiceOption aus. Die beiden letzten Zeilen der Gesamttabelle geben den simulierten Marktanteil über alle befragten Produkte bei der vorgegebenen Preisdifferenz wieder. 
TABELLE 4: AUSWAHLEXPERIMENT MIT REALEN PRODUKTPREISEN FÜR VIER BETRIEBSFORMEN

\begin{tabular}{|c|c|c|c|c|c|}
\hline & Plus & Edeka & $\begin{array}{c}\text { Bio- } \\
\text { Supermarkt }\end{array}$ & Bio-Laden & $\begin{array}{c}\text { verwende ich } \\
\text { nicht }\end{array}$ \\
\hline Preis Eier in Euro $(\mathrm{M} / 10)$ & 2,36 & 3,02 & 3,10 & 2,95 & - \\
\hline Preisindex (Bio-L. $=100)$ & 80 & 102,4 & 105,1 & 100 & - \\
\hline Wahlverhalten & $13,3 \%$ & $1,8 \%$ & $7,2 \%$ & $69,9 \%$ & $7,8 \%$ \\
\hline Preis Äpfel kg & 2,03 & 2,61 & 2,49 & 3,02 & 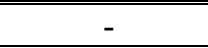 \\
\hline Preisindex (Bio-L. $=100)$ & 67,2 & 86,4 & 82,5 & 100 & - \\
\hline Wahlverhalten & $15,7 \%$ & $1,8 \%$ & $51,2 \%$ & $26,5 \%$ & $4,8 \%$ \\
\hline Preis Möhren kg & 1,13 & 1,67 & 0,94 & 1,48 & - \\
\hline Preisindex $($ Bio-L. $=100)$ & 76,4 & 112,8 & 63,5 & 100 & - \\
\hline Wahlverhalten & $3,6 \%$ & $1,2 \%$ & $57 \%$ & $33,9 \%$ & $4,2 \%$ \\
\hline Preis Kartoffeln kg & 1,31 & 1,62 & 1 & $1,1,66$ & - \\
\hline Preisindex (Bio-L. $=100)$ & 78,9 & 97,6 & 80,7 & 100 & - \\
\hline Wahlverhalten & $8,4 \%$ & $0,6 \%$ & $50,6 \%$ & $33,7 \%$ & $6,6 \%$ \\
\hline Preis Vollmilch Pfandfl. & 0,91 & 1,06 & 0,96 & 1,05 & - \\
\hline Preisindex (Bio-L. $=100)$ & 86,7 & 101 & 91,4 & 100 & - \\
\hline Wahlverhalten & $7,9 \%$ & $3,0 \%$ & $41,2 \%$ & $33,3 \%$ & $14,5 \%$ \\
\hline Preis Käse/Gouda kg & 9,36 & 10,95 & 9,90 & 11,18 & - \\
\hline Preisindex (Bio-L. $=100)$ & 83,7 & 97,9 & 88,6 & 100 & - \\
\hline Wahlverhalten & $9,6 \%$ & $1,8 \%$ & $47,6 \%$ & $28,9 \%$ & $12,0 \%$ \\
\hline $\begin{array}{l}\text { Preis Roggen-Vollkorn- } \\
\text { Brot }\end{array}$ & 1,96 & 2,74 & 2,97 & 3,44 & - \\
\hline Preisindex (Bio-L. $=100)$ & 57,0 & 79,6 & 86,3 & 100 & - \\
\hline Wahlverhalten & $10,2 \%$ & $0,6 \%$ & $39,2 \%$ & $41,0 \%$ & $9,0 \%$ \\
\hline $\begin{array}{l}\text { Gesamtpreisindex } 7 \\
\text { Artikel }\end{array}$ & 75,7 & 96,8 & 85,4 & 100 & - \\
\hline Marktanteil insgesamt & 10,6 & 1,6 & 45,7 & 41,6 & - \\
\hline
\end{tabular}

Quelle: Eigene Erhebung

„Marktführer“ wäre bei den genannten 7 Artikeln der Bio-Supermarkt mit einem Absatzanteil von 45,7 \%, knapp vor dem Bio-Laden. Supermärkte wie Edeka sind ohne deutlichen Preisvorteil keine relevante Kaufalternative für Bio-Intensivkunden. Die erheblichen Preisvorteile des Soft-Discounters Plus führen mit gut $10 \%$ zu einem etwas größeren Marktanteil. Dieser ist hauptsächlich auf die Produkte mit deutlichem Preisvorsprung zurückzuführen. Im Ergebnis zeigt sich, dass die Wechselbereitschaft zum konventionellen Handel bei den BioIntensivkäufern relativ gering ist. Der härteste Konkurrent des Bio-Ladens ist der BioSupermarkt, der, ökologisch ähnlich positioniert, eine größere Auswahl mit angenehmer Atmosphäre und häufig günstigeren Preisen verbindet.

Insgesamt macht die Analyse deutlich, dass die Bio-Intensivkäufer ausgesprochen fachhandelstreu sind. Allerdings wird auch deutlich, dass nur wenige Probanden auf den klassischen Bio-Laden festgelegt sind. Eine Auszählung zeigt, dass nur 19 Probanden $(11,2 \%)$ bei allen Artikeln den Bio-Laden gewählt haben. 10 Befragte haben in allen Fällen den Bio-Supermarkt bevorzugt. 
In einer anschließenden Clusteranalyse wurden die Befragten nach ihrem Wahlverhalten bei dem Auswahlexperiment gruppiert, speziell danach, wie häufig sie sich jeweils für BioLäden, Bio-Supermärkte und Discounter entschieden haben. ${ }^{1}$ Drei hoch-signifikant unterschiedliche Gruppen lassen sich demnach identifizieren (vgl. Tabelle 5). Die Preiskäufer aus Cluster 1 haben eine ganz eindeutige Präferenz für die jeweils günstigste Einkaufsstätte, was sich auch an ihrem an anderen Stellen im Fragebogen bekundeten Einkaufsverhalten nachweisen lässt. Sie nutzen den Fachhandel auch jetzt schon deutlich unterproportional. Die beiden großen Fachhandelscluster dagegen stehen dem LEH weitgehend ablehnend gegenüber.

TABELLE 5: KUNDENCLUSTER NACH EINKAUFSSTÄTTENWAHL

\begin{tabular}{|l|c|c|c|}
\hline Cluster & $\begin{array}{c}\text { (1) } \\
\text { Discountorientierte } \\
\text { Bio-Käufer }\end{array}$ & $\begin{array}{c}\text { (2) } \\
\text { Bio-Laden-Kunden }\end{array}$ & $\begin{array}{c}\text { (3) } \\
\text { Bio-Supermarkt- } \\
\text { Kunden }\end{array}$ \\
\hline Clustergröße (absolut) & 19 & 60 & 85 \\
\hline Clustergröße (in Prozent) & 12 & 36 & 52 \\
\hline Auswahlhäufigkeit Bio-Laden Ø & 0,5 & 5,3 & 1,3 \\
\hline $\begin{array}{l}\text { Auswahlhäufigkeit Bio- } \\
\text { Supermarkt Ø }\end{array}$ & 1,1 & 1,0 & 4,8 \\
\hline Auswahlhäufigkeit Discounter Ø & 4,2 & 0,2 & 0,3 \\
\hline
\end{tabular}

Das Ergebnis der Clusteranalyse wurde mittels Diskriminanzanalyse zu 96,3 \% bestätigt.

Die Mittelwerte unterscheiden sich nach den F-Werten signifikant (F-Werte siehe Anhang).

Quelle: Eigene Berechnungen

Mit Hilfe eines multinomialen Logit-Modells wurden im Anschluss diejenigen Einstellungskriterien identifiziert, die die Wechselbereitschaft zu Bio-Supermärkten und Discountern bestimmen. Dazu wurden in der Befragung Kaufmotive, Images des Bio-Ladens im Vergleich zum Bio-Supermarkt und Einstellungen gegenüber den verschiedenen Vertriebsformen und Anbietern erhoben und soweit möglich durch eine Faktorenanalyse verdichtet (vgl. Anhang). Das folgende Modell (Tab. 6) weist die signifikanten Schätzkoeffizienten (B) für BioSupermarkt-Kunden und discountorientierte Käufer aus; das Cluster der Bio-Laden-Kunden bildet die Referenzgruppe.

\footnotetext{
1 In der weiteren Analyse werden diejenigen Probanden, die sich bei den Wahlexperimenten für Edeka entschieden haben, aufgrund der geringen Fallzahl ausgeblendet.
} 


\section{TABELLE 6: MultinOMINALES REGRESSIONSMODELL ZUR WECHSELBEREITSCHAFT}

\begin{tabular}{|c|c|c|c|c|}
\hline & & B & Standardfehler & Signifikanz \\
\hline \multirow{5}{*}{ 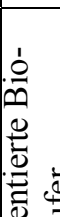 } & Konstante & 13,728 & 4,708 & 0,004 \\
\hline & Faktor „Emotionale und sensorische Qualität“ & 0,906 & 0,765 & 0,237 \\
\hline & Faktor „Kundenbindung/Commitment“ & $-4,246$ & 1,151 & 0,000 \\
\hline & Preisgünstigkeit Bio-Laden & 0,769 & 0,569 & 0,176 \\
\hline & Relevanz Auswahl bei Bio-Kauf & $-0,071$ & 0,028 & 0,012 \\
\hline \multirow{5}{*}{$\underline{n}$} & Anteil Bio-Lebensmittel & $-0,053$ & 0,025 & 0,035 \\
\hline & Bio im Freundeskreis & $-0,737$ & 0,484 & 0,128 \\
\hline & Relevanz Glaubwürdigkeit & $-0,144$ & 0,071 & 0,041 \\
\hline & Nutzung Homepage Naturkost.de & 0,379 & 0,509 & 0,457 \\
\hline & Nutzung Virtuelle Community & $-1,699$ & 0,675 & 0,012 \\
\hline \multirow{10}{*}{ 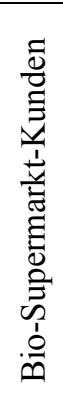 } & Konstante & 0,432 & 2,301 & 0,851 \\
\hline & Faktor „Emotionale und sensorische Qualität“ & $-1,200$ & 0,370 & 0,001 \\
\hline & Faktor „Kundenbindung/Commitment“ & $-0,437$ & 0,446 & 0,328 \\
\hline & Preisgünstigkeit Bio-Laden & -0372 & 0,291 & 0,202 \\
\hline & Relevanz Auswahl bei Bio-Kauf & $-0,016$ & 0,013 & 0,224 \\
\hline & Anteil Bio-Lebensmittel & $-0,005$ & 0,010 & 0,649 \\
\hline & Bio im Freundeskreis & $-0,390$ & 0,222 & 0,080 \\
\hline & Relevanz Glaubwürdigkeit & 0,012 & 0,026 & 0,651 \\
\hline & Nutzung Homepage Naturkost.de & 0,536 & 0,270 & 0,047 \\
\hline & Nutzung Virtuelle Community & 0,142 & 0,372 & 0,703 \\
\hline \multicolumn{5}{|c|}{ o-Laden-Kunden } \\
\hline \multicolumn{5}{|c|}{$\begin{array}{l}\text { Chi-Quadrat }=115,970^{* * *}(* * * \leq 0,01 \text { signifikant }) ; \text { Pseudo- } \mathrm{R}^{2}: \text { Cox } / \text { Snell }=0,551, \text { Nagelkerke }=0,648, \text { McFadden }=0,421 \text {; } \\
\text { zutreffend klassifiziert: } 75,9 \%\end{array}$} \\
\hline
\end{tabular}

Die Analyse zeigt (siehe Tabelle 6), dass die discountorientierten Käufer sich besonders im Bereich „Kundenbindung/Commitment“ von den Bio-Laden-Kunden unterscheiden. Diese Kundengruppe fühlt sich an den Bio-Laden weniger gebunden und ist deutlich unzufriedener als die Bio-Laden-Kunden. Auch die Produktauswahl ist für diese Kundengruppe weniger wichtig. Der Anteil von Bio-Lebensmitteln ist bei den Discountkunden am geringsten. Diese Kundengruppe vertraut zudem den Herstellern, die sowohl konventionelle als auch BioLebensmittel produzieren, stärker als die beiden fachhandelstreuen Cluster. Zudem nutzen die Discount-Kunden die virtuelle Community auf der Plattform Naturkost.de weniger, wodurch insgesamt das geringe Involvement in Öko-Lebensmittel deutlich wird.

Schaut man sich die Gruppe der Bio-Supermarkt-Kunden an (siehe Tabelle 6), so sind es drei Bereiche, die den Unterschied zu den Bio-Ladenkunden ausmachen. Die Gruppe der BioLaden-Kunden differenziert sich von den Bio-Supermarkt-Kunden dadurch, dass die BioSupermärkte hinsichtlich des Faktors „emotionale und sensorische Qualität“ (vgl. Anhang) besser beurteilt werden als der Bio-Laden. Hinter diesem Faktor verbergen sich die Einschätzung über Regionalität, Geschmack, Beratungsqualität, Qualität der Ware und Atmosphäre des Geschäfts. Eine weitere signifikante Trennvariable stellt das Verhalten der Peer Group dar. Bei der Gruppe der Bio-Supermarkt-Kunden findet sich weniger Unterstützung für Bio-Lebensmittel im Freundeskreis als bei der der Bio-Ladenkunden. Schließlich 
zeigen die Bio-Supermarkt-Kunden eine signifikant höhere Affinität zur Nutzung des Internets als Informationsquelle für Bio-Lebensmittel. Größere Unterschiede in der Einkaufshäufigkeit und der Kundenzufriedenheit finden sich dagegen nicht.

\section{Fazit}

Nur ein gutes Drittel der Bio-Intensivkäufer ist nachhaltig auf den klassischen Bio-Laden fokussiert. Nur bei ihnen ist von einer gesicherten Stammkundenbindung auszugehen. Der größere Teil der Kunden schwenkt bei einem entsprechenden Angebot auf Bio-Supermärkte um, zumindest bei den derzeitigen Preisdifferenzen. Rund $40 \%$ der Probanden, die in der Befragung Bio-Supermärkte präferieren, verfügen heute noch nicht über entsprechende Einkaufsmöglichkeiten in ihrer Umgebung. Sie werden dem traditionellen Fachhandel wohl mit der Neueröffnung entsprechender Standorte verloren gehen. Dies wird bei vielen klassischen Bio-Läden zu merklichen Kundenverlusten führen und aller Voraussicht nach das Ladensterben deutlich forcieren.

Das Regressionsmodell verdeutlicht zudem, dass Kundenzufriedenheit und Commitment allein nicht zur Erklärung der Wechselbereitschaft ausreichten (Keller et al. 2002: 549). Es gibt keine signifikanten Unterschiede in der Kundenzufriedenheit zwischen Bio-Laden- und Bio-Supermarktkunden. Deutlich sind dagegen die Abweichungen bei der Kundenzufriedenheit zwischen denjenigen Käufern, die den Discounter Plus präferieren, und den übrigen Probanden. Offensichtlich führt die hohe Kundenzufriedenheit der heutigen BioLadenkäufer zu einer ausgeprägten Fachhandelsbindung, die jedoch den Bio-Supermarkt mit einschließt.

Aus methodischer Sicht hat sich das Konzept der produktspezifischen Wahlentscheidungen als Analysemethode zur Prognose der Betriebsformenwahl bewährt. Es zeigen sich hochsignifikante und plausible Ergebnisse. Zugleich ist das Befragungskonzept relativ einfach und fehlerunempfindlich, so dass es sich für Online-Befragungen eignet. 


\section{Literatur}

Bahrdt, K. et al. (2003): Bio-Supermärkte in Deutschland - Chancen und Entwicklungen 2003. Unternehmensberatung Synergie, Frankfurt a. M.

Bodenstein, G. und A. Spiller (2001): Preispolitik des deutschen Lebensmitteleinzelhandels und Preisbereitschaft der Konsumenten bei ökologischen Lebensmitteln, in: Schrader, U., Hansen, U. (Hrsg.), Nachhaltiger Konsum: Forschung und Praxis im Dialog, Frankfurt a. M.: 189-208.

Enneking, U. et al. (2003): Ein Weg aus der Nische? Eine Analyse von Selten- und Gelegenheitskäufern ökologischer Lebensmittel mittels Discrete Choice Analyse. In: Dabbert, S. (Hrsg.): Perspektiven in der Landnutzung - Regionen, Landschaften, Betriebe - Entscheidungsträger und Instrumente. 43. Jahrestagung der Gesellschaft für Wirtschafts- und Sozialwissenschaften des Landbaus (GEWISOLA) 2003 in Hohenheim. Schriften der Gesellschaft für Wirtschafts- und Sozialwissenschaften des Landbaues e.V.; (39): 273-281.

Großmann, H. et al. (2002): Advances in optimum experimental design for conjoint analysis and discrete choice models. In: Econometric models in marketing, 16: 93-117.

Keller, B. et al. (2002): Kundenbindung als Instrument des Marketing-Controlling. In: Die Bank 28 (8): 548-553.

Kreuzer, K. und C. Offeney (2005): 40 neue Bio-Supermärkte in Deutschland. In: www.biomarkt.info/druck..... Abrufdatum: 01.02.2005.

Lüth, M. et al. (2004): Analyse des Kaufverhaltens von Selten- und Gelegenheitskäufern und ihrer Bestimmungsgründe für/gegen den Kauf von Öko-Produkten. Göttingen. In: http://orgprints.org/4201/.

Metro Group (Hrsg.): Metro Handelslexikon 2004/2005: Daten, Fakten und Adressen zum Handel in Deutschland, Europa und weltweit, Düsseldorf.

Michels, P. et al. (2004): Strukturen der Nachfrage nach ökologischen Nahrungsmitteln in Deutschland. ZMP, Bonn.

Michels, P. et al. (2003): Bio-Frische im LEH: Fakten zum Verbraucherverhalten. ZMP, Bonn.

Müller, S. (1998): Die Unzufriedenheit der „eher zufriedenen“ Kunden. In: Müller, S. und H. Strothmann (Hrsg.): Kundenzufriedenheit und Kundenbindung: Strategien und Instrumente von Finanzdienstleistern. Beck, München: 197-218.

Naturkost.de (2005): Mediadaten. In: www.naturkost.de/mediadaten/naturkost/index.htm, Abrufdatum 01.02.2005.

Peter, S. I. (1997): Kundenbindung als Marketingziel: Identifikation und Analyse zentraler Determinanten. Gabler, Wiesbaden.

Reuter, K. et al. (2005): Wo Kunden am billigsten Bio kaufen können. In: BioHandel 5 (1): 67.

Spahn, M. (2002): Der Bio-Fachhandel in Europa. Unternehmensberatung Synergie, Bad Wildbad.

Statistisches Bundesamt (Hrsg.) (2004): Statistisches Jahrbuch 2004. Statistisches Bundesamt, Wiesbaden. 
Tang, C. S. et al. (2001): Marketing - Store Choice and Shopping Behaviour. How Price Format Works. In: California management review 43 (winter): 56-74. 


\section{Anhang}

Faktoren und Variablen des Regressionsmodells

\begin{tabular}{|l|c|}
\hline \multicolumn{1}{|c|}{ Statements } & Faktorladung \\
\hline \multicolumn{2}{|c|}{ Kundenbindung und Commitment (KMO: 0,75; Cronbachs Alpha: 0,74; erklärte Varianz } \\
$57,2 \%)$
\end{tabular}

Emotionale und sensorische Qualität (KMO 0,82; Cronbachs Alpha 0,81; erklärte Varianz $59,3 \%)$

Semantisches Differential im Vergleich Bio-Laden - Bio-Supermarkt:

Regionalität

Semantisches Differential im Vergleich Bio-Laden - Bio-Supermarkt:

Geschmack

Semantisches Differential im Vergleich Bio-Laden - Bio-Supermarkt:

Beratungsqualität

\begin{tabular}{l|l} 
& 0,693 \\
\hline$t:$ & 0,824 \\
\hline$t:$ & 0,777 \\
\hline$t:$ & 0,819 \\
\hline
\end{tabular}

Semantisches Differential im Vergleich Bio-Laden - Bio-Supermarkt:

Qualität der Ware

Semantisches Differential im Vergleich Bio-Laden - Bio-Supermarkt:

Atmosphäre

Einzelstatements

Preisgünstigkeit Bio-Laden: Semantisches Differential im Vergleich Bio-Laden - BioSupermarkt

Relevanz Auswahl bei Bio-Kauf: Semantisches Differential im Vergleich Bio-Laden - BioSupermarkt

Anteil der Bio-Lebensmittel: Wie viel Prozent Ihrer gesamten Lebensmitteleinkäufe entfallen auf Bio-Lebensmittel?

Bio im Freundeskreis: Uns würde noch interessieren, wie Bio in Ihrem Bekannten- und Freundeskreis bewertet wird (von $1=$ meine Freunde kaufen fast alle Bio bis $5=$ ich stehe ziemlich alleine da mit meinem Bio-Kauf).

Relevanz Glaubwürdigkeit: Ich vertraue Herstellern, die nur Bio-Produkte produzieren, mehr als solchen, die zusätzlich auch konventionelle Ware haben.

Nutzung Homepage Naturkost.de: Sie sind auf unsere Befragung über die Internetseite von Naturkost.de gekommen. Wie häufig nutzen Sie diese Seite?

Nutzung Virtuelle Community: Wenn ich Fragen habe, finde ich im Bioladen/Internet/der Community auf Naturkost.de immer Menschen, die mir weiterhelfen können. 
KAPITEL I.3

Die Zukunft des Bio-Großhandels in der Wertschöpfungskette 


\section{Die Zukunft des Bio-Großhandels in der Wertschöpfungskette*}

(mit Raphael Kennerknecht und Achim Spiller)

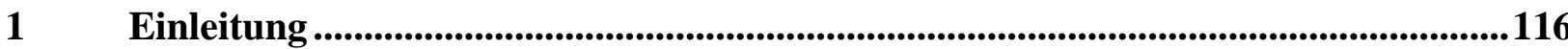

2 Die Struktur des Bio-Marktes in Deutschland ....................................................117

2.1 WiCHTIGE ENTWICKLUNGEN IM DEUTSCHEN BIOMARKT .........................................117

2.2 WERTSCHÖPFUNGSKETTE FÜR BIO-LEBENSMITTEL …...........................................119

3 Die Rolle des Großhandels in der Wertschöpfungskette ...........................................126

3.1 TYPOLOGISIERUNG DER GROßHANDELSBETRIEBSFORMEN ….......................................126

3.2 BEDEUTUNG DES GROßHANDELS IN DER WERTSCHÖPFUNGSKETTE ...........................129

$4 \quad$ Distributionsstrategien in der Bio-Branche ................................................................... 130

4.1 ABSATZWEGE IN DER BIO-WERTSCHÖPFUNGSKETTE .................................................130

4.2 Vertikale SeleKtion: Tendenzen Zur Ausschaltung Des Bio-Großhandels ..132

4.3 VERTIKALE BINDUNG: INTEGRATION ODER KOOPERATION ENTLANG DER SUPPLY

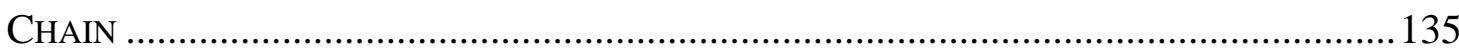

$5 \quad$ Primäre Kompetenzfelder des Großhandels in der Bio-Branche..............................136

5.1 DISKUSSION DER GROßHANDELSFUNKTIONEN …..................................................136

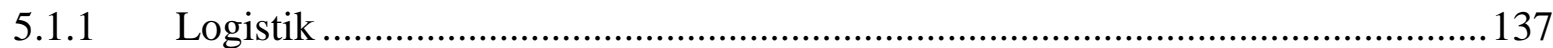

5.1.2 Sortimentsbildung und Transaktionskostenreduktion........................................138

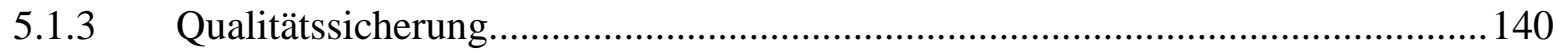

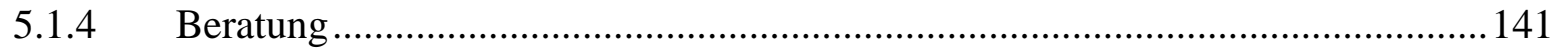

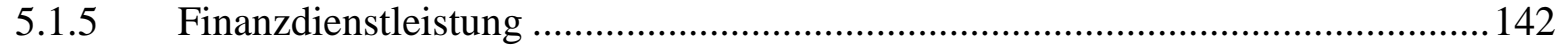

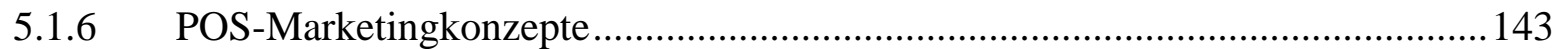

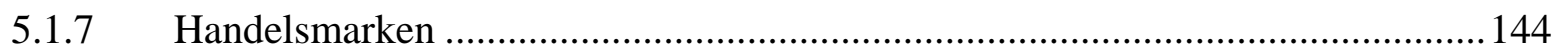

5.2 ZUKUNFT DES GROßHANDELS AUS EXPERTENSICHT ...............................................145

5.3 THEORIEN ZU FUNKTIONEN BZW. AUSSCHALTUNG DES GROßHANDELS .......................147

6 Fazit: Zur Zukunft des Großhandels in der Bio-Wertschöpfungskette....................159

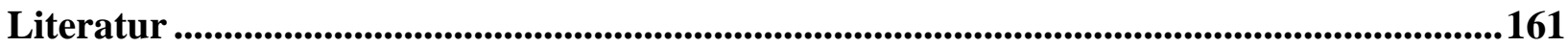

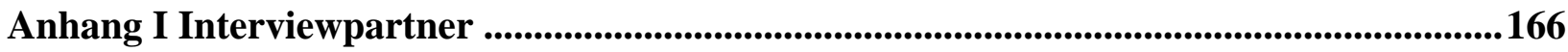

Anhang II Interviewleitfaden für das Experteninterview .............................................167

* Veröffentlicht als Diskussionsbeitrag 0505 des Instituts für Agrarökonomie 


\section{Abbildungsverzeichnis}

Abbildung 1: Der Öko-Lebensmittelumsatz in Deutschland (in Mrd. €).................................119

Abbildung 2: Großhandelsumsatz mit Öko-Lebensmitteln (in Mio. €) ..................................... 122

Abbildung 3: Umsatzanteile der verschiedenen Einkaufsstätten (2003)..................................123

Abbildung 4: Absatzwege in der Bio-Wertschöpfungskette ................................................... 131

Abbildung 5: Absatzstrukturen in der Biowertschöpfungskette .............................................. 132

Abbildung 6: Zentrale Warenverteilung über einen Großhändler.............................................139

Abbildung 7: Einflussfaktoren auf die Einzelhandelsentwicklung im Biomarkt......................158

\section{Tabellenverzeichnis}

Tabelle 1: Öko-Landbau in den einzelnen Bundesländern (Stand 31.12.2003) .......................... 120

Tabelle 2: Struktur der Betriebsformen des Naturkostfachhandels.......................................... 124

Tabelle 3: Betriebstypen gegliedert nach ihren Funktionen ................................................... 128

Tabelle 4: Zusammenfassung der Vor- und Nachteile beim Absatz über den Großhandel aus

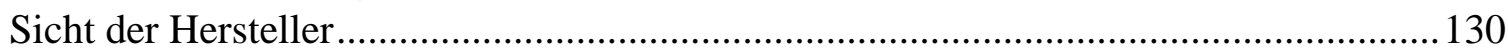

Tabelle 5: Voraussetzungen einer Direktbelieferung ............................................................ 138

Tabelle 6: Anforderungen an den Großhandel ...................................................................... 146 


\section{Einleitung}

Das Forschungsprojekt „Von der Agrarwende zur Konsumwende?“ beschäftigt sich mit den Effekten der Agrarwende auf die Wertschöpfungskette. Im Mittelpunkt der Analyse steht die Frage, wie sich die „Agrarwende“ mit dem erklärten Ziel, bis zum Jahr 2010 den Anteil der ökologisch genutzten Landwirtschaftsfläche auf 20 \% zu erhöhen (Künast 2001), auf die verschiedenen Wertschöpfungsstufen auswirkt. Die Maßnahmen im Rahmen der Agrarwendepolitik zielen darauf ab, nicht nur das Angebot, sondern auch die Nachfrage nach Bio-Produkten zu steigern. Eingesetzt werden klassische Instrumente der Subventionspolitik, aber auch weiche Politikinstrumente wie die Einführung des Biosiegels, die Ausweitung der Forschung sowie die Bereitstellung von Beratungsangeboten. Mit solchen weichen Politikinstrumenten sollen vor allem die Akteure der Wertschöpfungskette unterstützt werden, die mit der traditionellen Subventionspolitik nicht erreicht werden können, also insbesondere Handels- und Verarbeitungsunternehmen von Bio-Produkten.

In Deutschland ist der Markt für Bio-Produkte von 2000 bis 2004 um fast 70 \% gestiegen, von 2,1 Mrd. € im Jahr 2000 auf 3,5 Mrd. € im Jahr 2004 (Hamm 2005: 65). Auch im Jahr 2005 zeichnet sich weiterhin eine dynamische Ausweitung ab. In welchem Ausmaß die politischen Maßnahmen zum starken Wachstum beigetragen haben, ist dabei unklar. Deutlich ist jedoch, dass sich hinter der durch das Gesamtwachstum ausgelösten positiven Marktstimmung eine Reihe latenter Konflikte abzeichnen, die zzt. durch die allgemein guten wirtschaftlichen Erwartungen überdeckt werden.

In erster Linie ist dabei auf den Konflikt zwischen dem großbetrieblichen - konventionellen Lebensmitteleinzelhandel (LEH) und den mittelständischen Strukturen des spezialisierten Bio-Fachhandels zu verweisen. Der LEH hat in den letzten Jahren an Marktanteilen gewonnen, wenngleich die Marketingkonzepte hier in den meisten Fällen immer noch wenig ambitioniert sind. Aber auch innerhalb des Bio-Fachhandels zeichnen sich Strukturbrüche und wirtschaftliche Interessengegensätze ab. So werden derzeit neue großflächigere Fachgeschäfte (Bio-Supermärkte) forciert, die nicht selten angestammte Fachhändler verdrängen (Gerlach et al. 2005; Ambros 2005; Völkner 2005: 4). 
Der Fokus der vorliegenden Arbeit richtet sich allerdings auf den Bio-Großhandel, der in der Supply Chain eine relativ große Relevanz hat und bisher in der Forschung kaum beachtet wurde. Die Entwicklungen im konventionellen Lebensmittelhandel haben in den letzten Jahrzehnten zu einem starken Bedeutungsverlust des dortigen Großhandels geführt. Dies deutet darauf hin, dass Marktwachstum und Konzentration nicht ohne Einfluss auf die Struktur des Großhandels bleiben und dieser ggf. durch Ausschaltungstendenzen bedroht ist. Die Direktbelieferung von Rapunzel an Naturkostläden unterstreicht exemplarisch diese These (o. V. 2003a). Aus diesem Grund stellt sich die Frage, welche Entwicklung die BioBranche nehmen wird und wie die heutige und die zukünftige Situation des Großhandels in der Biowertschöpfungskette zu beurteilen ist. Welche Funktionen hat der Bio-Großhandel und welche wird er durch die veränderten Marktgegebenheiten an andere Marktteilnehmer abgeben müssen? Um die Fragen erläutern zu können, werden in dieser Arbeit nicht nur der Großhandel und seine betriebswirtschaftlichen Funktionen diskutiert, sondern zunächst generell auf die Struktur des Biomarktes in Deutschland und auf die Distributionspolitik der Bio-Branche eingegangen.

Da bislang nur wenige Veröffentlichungen zur Wertschöpfungskette der Bio-Branche (Bahrdt et al. 2003) vorliegen, wurde neben Praxiszeitschriften auch auf Einschätzungen von Branchenexperten zurückgegriffen. Aus diesem Grund wurden vier Großhändler und zwei Vertreter von Bio-Supermärkten zu den Funktionen des Großhandels befragt. Die Experteninterviews wurden Anfang März 2005 in Stuttgart, Tübingen und München durchgeführt.

\section{Die Struktur des Bio-Marktes in Deutschland}

\subsection{Wichtige Entwicklungen im deutschen Biomarkt}

Mit Beginn der Reformbewegung am Anfang des 20. Jahrhunderts entstand in der Bevölkerung ein Bewusstsein für eine alternative Ernährungsweise. Im Zuge dieser Bewegung bildeten sich in Deutschland landwirtschaftliche Betriebe, die ökologisch wirtschafteten. Zur selben Zeit wurden auch die ersten Reformhäuser gegründet. Obwohl ökologische Lebensmittel auf eine lange Tradition zurückblicken können, führten sie bis in die 1980er Jahre ein Schattendasein. Vor allem die Vermarktung fand an ungünstigen Standorten und in nur wenigen, kleinen Naturkostläden statt. Aufgrund des gestiegenen Umweltbewusstseins in den 80er Jahren wurde die Bevölkerung auch für eine ökologische Ernährung sensibilisiert. 
Durch diese Entwicklung erhielt der Biomarkt einen wesentlichen Wachstumsschub. Auch im Zuge der BSE-Krise stieg die Nachfrage nach Bio-Lebensmitteln stark an, so dass der Biomarkt in Deutschland mit einem Umsatz von 5 Mrd. € im Jahr 2004 mit Abstand der größte in Europa war (Hamm 2005: 65).

Die Entwicklung des Biomarktes ist hauptsächlich durch folgende Punkte gekennzeichnet:

- In der zweiten Hälfte der 1990er Jahre kommt es zu verstärkten Markteintritten von konventionellen Einzelhändlern in die Bio-Vermarktung, was dazu führt, dass die Nachfrage mit dem steigenden Angebot wächst.

- Durch die BSE-Krise erlebt der Biomarkt im Jahr 2001 einen Boom. Der Absatz wächst im Jahr 2001 im Vergleich zum Jahr 2000 von 2,1 Mrd. € auf 2,7 Mrd. €, was einem relativen Zuwachs von 30 \% entspricht. Damit ist der Anteil der BioLebensmittel am gesamten Lebensmittelumsatz auf 2,1\% gestiegen (siehe Abb. 1).

- Aufgrund von Nitrofen in Öko-Rohstoffen gehen die Nachfragezuwächse im Jahr 2002 zunächst deutlich zurück. Nachdem der Nitrofen-Skandal in der ÖkoBranche aufgeklärt worden ist, erholt sich die Nachfrage wieder. Es wird noch ein Umsatzplus von 10 \% im Jahr 2002 erreicht. Der Umsatzzuwachs wird vor allem auf die größere Distributionsdichte von Öko-Produkten zurückgeführt (Schaer 2001: 4 f.).

- Wegen der Kaufzurückhaltung in Folge der rezessiven Tendenz der Weltwirtschaft stagniert der Öko-Markt in 2003. Es wird nur ein leichter Zuwachs von ca. 2 \% für das Jahr 2003 verzeichnet (Brzukalla 2003: 14).

- Im Jahr 2004 ist die Nachfrage nach Bio-Produkten deutlich angestiegen. Sowohl im Lebensmitteleinzelhandel (LEH) als auch im Naturkostfachhandel liegen die Zuwachsraten im Vergleich zu 2003 zwischen 5 \% und 10 \%. Die Sortimentsausweitung im LEH und breitere Werbekampagnen sind Zeichen für ein gewachsenes Interesse der Handelsunternehmen an Öko-Produkten (Schaer 2001: 4 f.). 


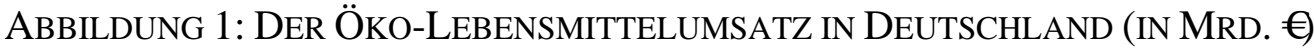

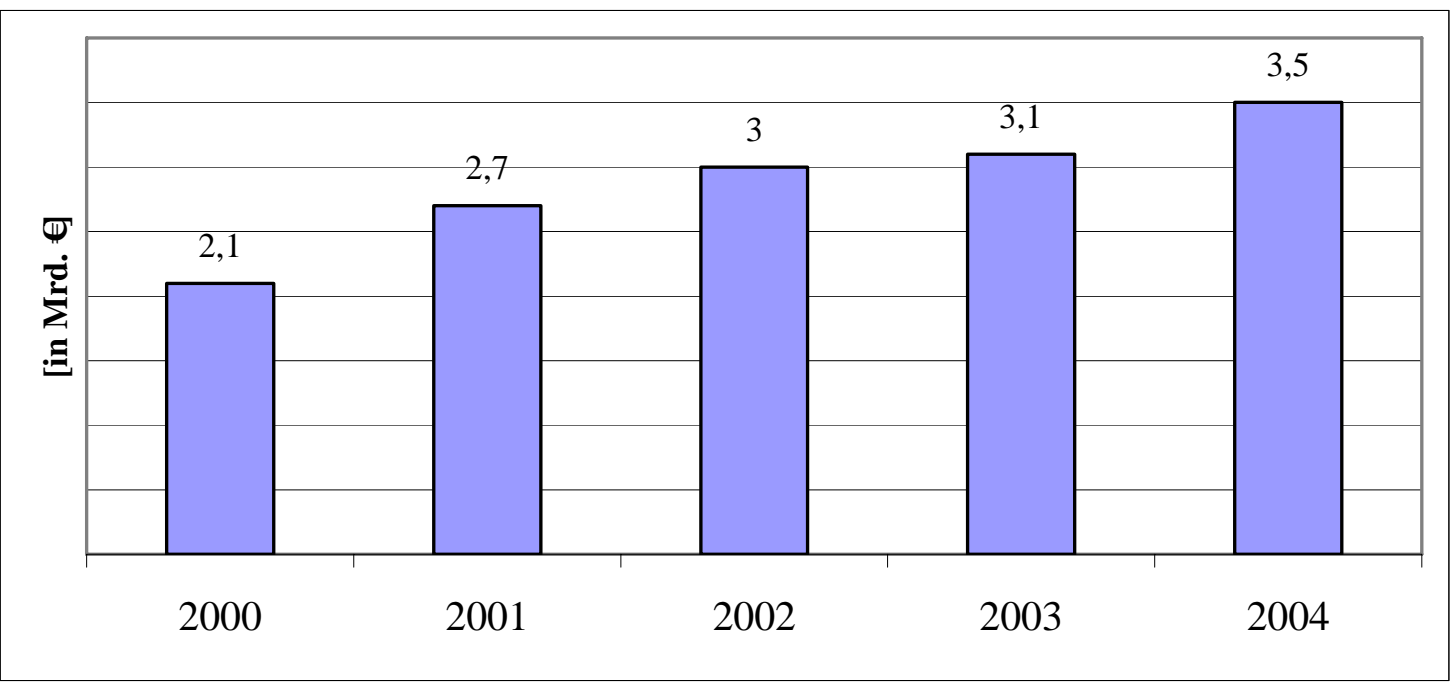

Quelle: Hamm 2005: 65

\subsection{Wertschöpfungskette für Bio-Lebensmittel}

\section{Ökologische Landwirtschaft}

In Deutschland sind Ende 2003734.027 ha landwirtschaftliche Fläche von 16.476 Betrieben nach den EU-weiten Regelungen des ökologischen Landbaus bewirtschaftet worden. Durch die Expansion des ökologischen Anbaus erhöht sich die Anzahl der Öko-Betriebe im Vergleich zum Vorjahr um 5,4 \% und die nach EG-Öko-Verordnung bewirtschaftete Fläche um 5,3 \%. Der Anteil der Öko-Betriebe an der Gesamtzahl der Betriebe in Deutschland liegt 2003 bei 4,0 \% und der Anteil an der Gesamtfläche bei 4,1 \% (Yussefi et al. 2004: 1). 
TABELLE 1: ÖKO-LANDBAU IN DEN EINZELNEN BUNDESLÄNDERN (STAND 31.12.2003)

\begin{tabular}{|l|r|r|r|}
\hline & $\begin{array}{c}\text { Öko-Fläche in } \\
\text { ha }\end{array}$ & \multicolumn{1}{|c|}{ Öko-Betriebe } & $\begin{array}{c}\text { Ø Fläche in ha } \\
\text { je Betrieb }\end{array}$ \\
\hline Baden-Württemberg & 85.825 & 5.004 & 17,1 \\
\hline Bayern & 127.151 & 4.622 & 27,5 \\
\hline Berlin & 106 & 10 & 10,6 \\
\hline Brandenburg & 119.270 & 559 & 213,4 \\
\hline Bremen & 372 & 9 & 41,3 \\
\hline Hamburg & 859 & 29 & 29,6 \\
\hline Hessen & 56.578 & 1.481 & 38,2 \\
\hline Mecklenburg-Vorpommern & 107.412 & 619 & 173,5 \\
\hline Niedersachsen & 55.959 & 1.052 & 53,2 \\
\hline Nordrhein-Westfalen & 47.579 & 1.297 & 36,7 \\
\hline Rheinland-Pfalz & 18.604 & 540 & 34,5 \\
\hline Saarland & 4.691 & 63 & 74,5 \\
\hline Sachsen & 20.342 & 277 & 73,4 \\
\hline Sachsen-Anhalt & 34.855 & 257 & 135,6 \\
\hline Schleswig-Holstein & 27.765 & 423 & 65,6 \\
\hline Thüringen & 26.659 & 234 & 113,9 \\
\hline Summe & 734.027 & 16.476 & \\
\hline
\end{tabular}

Quelle: Bundesanstalt für Landwirtschaft und Ernährung, zitiert nach Yussefi et al. 2004: 24

In der Tabelle 1 wird deutlich, dass die ökologische Erzeugung in Deutschland ihren Schwerpunkt in den Bundesländern Baden-Württemberg, Bayern, Brandenburg und MecklenburgVorpommern hat. Die in den einzelnen Bundesländern bewirtschaftete Fläche je Öko-Betrieb variiert beträchtlich. Das zurzeit flächenstärkste Land ist Bayern mit 127.151 ha, die von 4.622 Betrieben bewirtschaftet (27,5 ha/Betrieb) werden, gefolgt von Brandenburg mit 119.270 ha Öko-Fläche. In Brandenburg ist der Flächenanteil pro Betrieb mit einem Durchschnitt von 213 ha am größten in Deutschland. Die meisten Öko-Betriebe befinden sich dagegen in Baden-Württemberg (5.004) (Yussefi et al. 2004: 24). Insgesamt zeichnet sich in der Landwirtschaft eine zunehmende Polarisierung zwischen produktionsorientierten Großbetrieben, spezialisiert auf den überregionalen Absatz, und kleinbetrieblichen, vornehmlich auf das Regionalmarketing fokussierten Bio-Landwirten ab. ${ }^{1}$

\section{Die Verarbeitungsunternehmen}

Da die Struktur der Verarbeitungsunternehmen in keiner Statistik vollständig erfasst ist, können über diese Wertschöpfungsstufe nur ungenaue Angaben gemacht werden. Eine Quelle für die Anzahl und die Strukturen der Verarbeiter sind die Verbände, in denen sich die

\footnotetext{
${ }^{1}$ Eine sehr differenzierte Typisierung von landwirtschaftlichen Betrieben ist im Teilprojekt 1 „Bewertungskriterien und Entwicklungsszenarien für eine nachhaltige Nahrungserzeugung - regionale Fallstudien“ unter www.konsumwende.de nachzulesen.
} 
Unternehmen zusammengeschlossen haben, um ihre wirtschaftlichen und politischen Interessen $\mathrm{zu}$ vertreten. So sind beim BNN, dem Bundesverband Naturkost Naturwaren Herstellung und Handel e. V., 56 Großhändler und Verarbeiter von Bio-Lebensmitteln aus verschiedenen europäischen Ländern registriert (BNN 2005). Die Assoziation ökologischer Lebensmittelhersteller e. V. (AoeL), weist 57 Verarbeitungsunternehmen der Lebensmittelwirtschaft, die ökologische Lebensmittel herstellen, auf. Sie haben im Jahr 2004 zusammen einen Umsatz von ca. 900 Mio. € erwirtschaftet (AoeL 2005). Eine weitere Quelle, aus der eine ungefähre Zahl der Verarbeiter von Bio-Produkten abgeleitet werden kann, ist die Informationsstelle Biosiegel, bei der sich insgesamt 375 Verarbeitungsunternehmen im Jahr 2004 für die Nutzung des Biosiegels registriert haben. Es lässt sich aber hier nicht genau erkennen, ob es sich um reine Ökoverarbeitungsunternehmen handelt oder um Unternehmen, die im Wesentlichen Handelsfunktionen ausüben (Informationsstelle Biosiegel 2004).

In den letzten Jahren zeichnet sich die Herstellerseite durch eine wachsende Professionalisierung und die Übernahme klassischer Marketingkonzepte aus. Vertriebsbemühungen, Markenwerbung und Verkaufsförderung werden ausgebaut. Aus „Garagenbetrieben“ sind mittelständische Hersteller entstanden, die z. T. beachtliche Innovationsleistungen erbringen. Gleichwohl sind nur wenige Marken bisher so stark bei den Bio-Kunden verankert, dass eine größere Markenbindung entsteht (Hamm/Wild 2004). Aus diesem Grund finden sich in den letzten Jahren erste Bio-Handelsmarkenkonzepte, bei denen Hersteller für Naturkostgroßhändler oder Einzelhandelsfilialisten Eigenmarken produzieren.

Neben den Bio-Spezialisten gibt es eine Reihe von konventionellen Herstellern, die in den letzten Jahren ergänzende Bio-Linien in ihr Produktionsprogramm aufgenommen haben. Teilweise geschieht dies unter der Traditionsmarke (Beispiel: Kölln-Flocken), z. T. werden neue Bio-Marken aufgebaut (Beispiel: Frosta mit Elbetal). Diese Gruppe von Herstellern konzentriert sich im Vertrieb auf den LEH.

\section{Der Naturkostgroßhandel}

Nicht viel besser als bei den Verarbeitern sieht die statistische Erfassung der Anzahl und der Strukturen der Biogroßhändler in Deutschland aus. Aus diesem Grund ist auch hier der BNN, der ca. 56 Unternehmen aus den Bereichen Lebensmittelhandwerk, -verarbeitung, Import und Handel repräsentiert, die wichtigste Quelle. Mit rund 25 Großhandelsmitgliedern vertritt der 
Verband nach eigenen Angaben ungefähr 90 \% der Großhändler im deutschen Naturkostmarkt (Reich 2003: 1).

Trotz allgemein schlechter Konjunkturdaten im Bereich Lebensmittelhandel und Verarbeitung verbesserte sich im Jahr 2004 der Gesamtumsatz um 9,9 \% auf 477,3 Mio. € (siehe Abbildung 2).

AbBildung 2: Großhandelsumsatz Mit ÖKo-Lebensmitteln (In Mio. €)

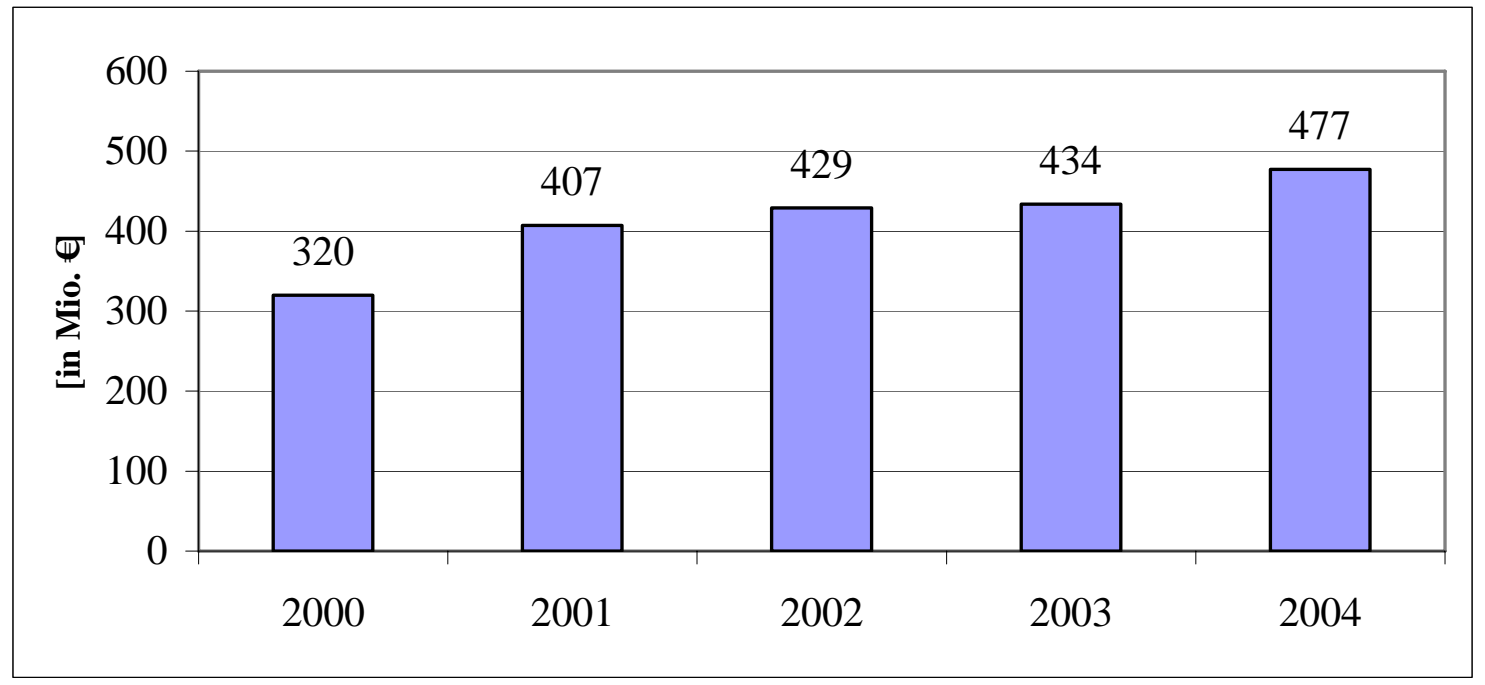

Quelle: Eigene Darstellung in Anlehnung an BNN Herstellung und Handel, verschiedene Jahrgänge

Im Jahr 2001 verzeichneten die Großhändler die stärkste Umsatzsteigerung. Der kräftige Anstieg ist vor allem mit der starken Nachfrage nach Öko-Lebensmittel im Zuge der BSEund MKS- Krise zu erklären. So konnten einzelne Großhandelsunternehmen Umsatzzuwächse von bis zu 115 \% aufweisen. Bei diesen Dimensionen wird deutlich, dass sich die Anforderungen an die Branche stark ändern (Brzukalla 2002: 20). Zudem zeigt sich, dass die Umsatzentwicklung im Naturkostgroßhandel relativ nachhaltig verläuft und allein zwischen 2000 bis 2003 fast 40 \% Wachstum zu verzeichnen sind (o. V. 2003b: 4).

\section{Der Naturkost-Einzelhandel}

In Deutschland erfolgt der Verkauf von Bio-Produkten über unterschiedliche Einkaufsstätten (siehe Abbildung 3). Der wichtigste Absatzweg für Öko-Produkte war im Jahr 2003 mit 31,2 \% der Naturkostfachhandel. Die Anzahl seiner Verkaufsstellen lag im Jahr 2002 bei ca. 2.000. Von den $31 \%$ des Gesamtumsatzes entfallen $25 \%$ auf die kleinen und mittleren Naturkostläden und 6 \% auf Biosupermärkte (Michels et al. 2004: 7). 
ABBILDUNG 3: UMSATZANTEILE DER VERSCHIEDENEN EINKAUFSSTÄTTEN (2003)

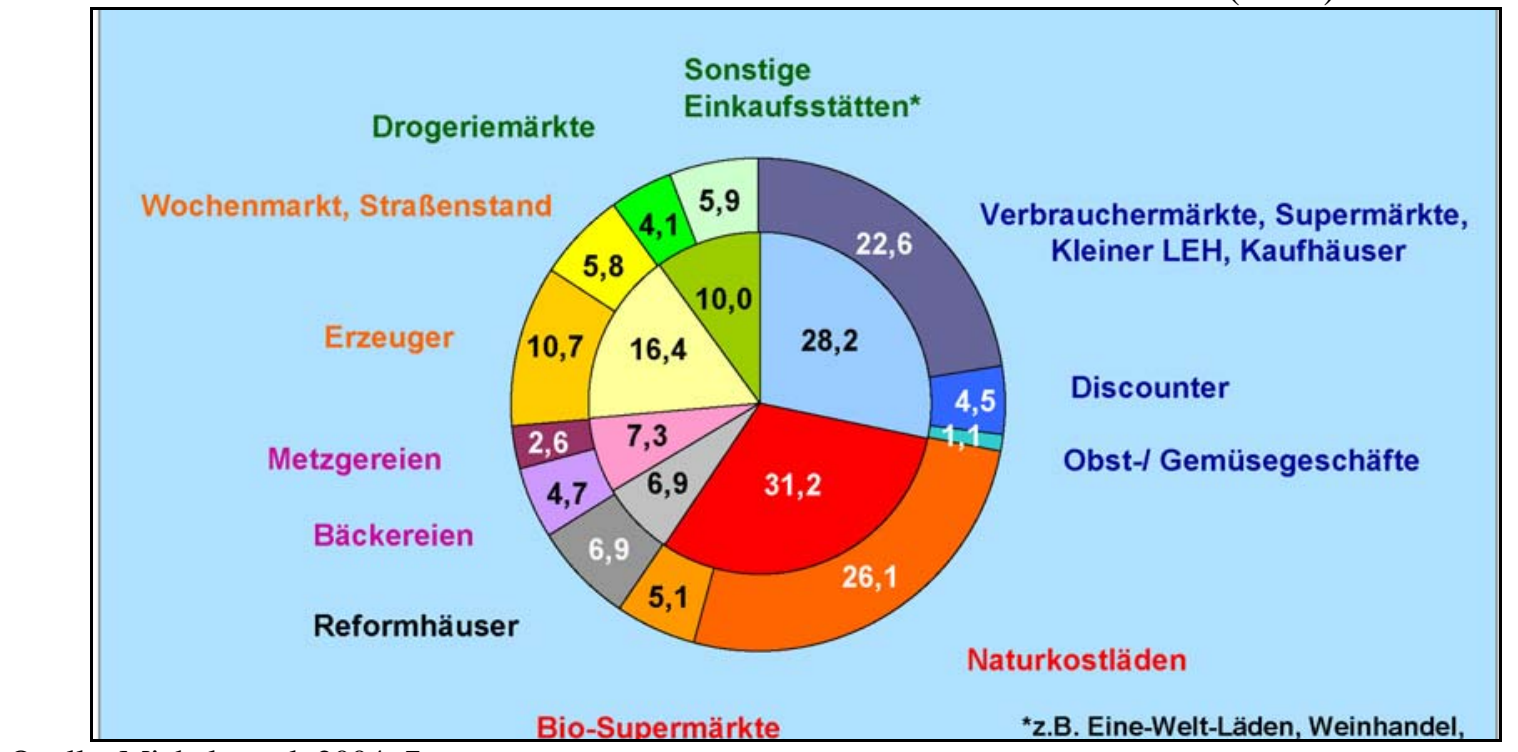

Quelle: Michels et al. 2004: 7

Bio-Supermärkte

Bei der Abgrenzung der Formen des Naturkostfachhandels sind vor allem die unterschiedliche Ladengröße und damit einhergehend auch die Artikelanzahl maßgeblich (siehe Tabelle 2). Die Naturkostfachgeschäfte unterscheiden sich vom Bio-Supermarkt weniger in der grundsätzlichen Sortimentsgestaltung. Bei beiden ist der Frischebereich ähnlich wichtig. Die gelisteten Marken sind häufig identisch. Die größere Artikelanzahl und der Fokus auf SBWaren verlangen allerdings eine erhebliche Ausweitung der Ladengröße, auch wenn BioSupermärkte immer noch deutlich kleiner als konventionelle Supermärkte sind (dort liegt die Wachstumsschwelle, ab der heute neue Geschäfte eröffnet werden, zzt. bei rund 1.000 qm). 
TABELLE 2: STRUKTUR DER BETRIEBSFORMEN DES NATURKOSTFACHHANDELS

\begin{tabular}{|c|c|c|c|}
\hline & $\begin{array}{l}\text { Naturkostfach- } \\
\text { geschäfte }\end{array}$ & Bio-Supermärkte & Reformhäuser \\
\hline $\begin{array}{l}\text { Umsatzanteil } \\
\text { am Bio-Markt }\end{array}$ & $26,1 \%$ & $5,1 \%$ & $6,9 \%$ \\
\hline Outlet-Zahl & 2.000 & 250 & 2.300 \\
\hline $\begin{array}{l}\text { Ladengröße in } \\
\text { qm }\end{array}$ & са. $100-200$ & са. 200-1.000 & са. 70 \\
\hline $\begin{array}{l}\text { Artikelanzahl } \\
\text { im Sortiment }\end{array}$ & $\begin{array}{c}\text { ca. } 6.000 \\
\varnothing 3.000 \\
\end{array}$ & $\begin{array}{c}\text { bis } 10.000 \\
\varnothing 5.500 \\
\end{array}$ & Keine Angaben \\
\hline $\begin{array}{l}\text { Umsatzver- } \\
\text { teilung }\end{array}$ & $\begin{array}{ll}\text { Frische } & 50 \% \\
\text { Trocken- } & 38 \% \\
\text { produkte } & \\
\text { Non-Food } & 12 \% \\
\end{array}$ & $\begin{array}{ll}\text { Frische } & 53 \% \\
\text { Trocken- } & 37 \% \\
\text { produkte } & \\
\text { Non-Food } & 10 \% \\
\end{array}$ & $\begin{array}{ll}\text { Frische } & \\
\text { Trocken- } & 68,5 \% \\
\text { produkte } & \\
\text { Non-Food } & 31,5 \% \\
\end{array}$ \\
\hline Kernkompetenz & $\begin{array}{l}\text { Inhabergeführt, } \\
\text { Kundenbindung, } \\
\text { Verbraucherver- } \\
\text { trauen, } \\
\text { Sortimentsklarheit }\end{array}$ & $\begin{array}{l}\text { Sortimentsbreite und - } \\
\text { tiefe, Neukunden- } \\
\text { gewinnung, attraktive } \\
\text { Standorte, moderne } \\
\text { Outlets }\end{array}$ & $\begin{array}{l}\text { Inhabergeführt, Beratung } \\
\text { im Bereich Gesundheit } \\
\text { und Ernährung, } \\
\text { Qualitätsstandards }\end{array}$ \\
\hline Kernsortimente & $\begin{array}{l}\text { Obst/Gemüse, } \\
\text { Molkereiprodukte, } \\
\text { Trockenprodukte }\end{array}$ & $\begin{array}{l}\text { Obst/Gemüse, } \\
\text { Trockenprodukte, SB- } \\
\text { Ausrichtung }\end{array}$ & $\begin{array}{l}\text { Vegetarische } \\
\text { Lebensmittel, } \\
\text { freiverkäufliche } \\
\text { Naturarzneimittel, } \\
\text { Körperpflege }\end{array}$ \\
\hline
\end{tabular}

Quelle: Eigene Zusammenstellung nach Kreuzer/Offeney 2005; Synergie 2002: 26; Bahrdt et al. 2003: 12;

Michels et al. 2004: 8

Auch wenn damit die Grenzen zwischen den beiden Betriebsformen Bio-Laden und BioSupermarkt nicht immer trennscharf sind, so trägt doch die Geschäftsflächenausweitung, der SB-Fokus und die i. d. R. einheitlichere und weniger traditionelle Inneneinrichtung zu einer moderneren Anmutung bei, was zugleich die Barrieren bei der Neukundengewinnung senkt. Bio-Supermärkte erreichen möglicherweise leichter Bio-Erstkunden als der Naturkostfachhandel, letzterer weist dafür gegebenenfalls Vorteile in der Kundenbindung auf (Synergie 2002: 26).

Den mit 24 \% zweitgrößten Anteil am Öko-Markt nimmt der Lebensmitteleinzelhandel ein. Im Vordergrund stehen die serviceorientierten Betriebsformen Supermarkt, Verbrauchermarkt und SB-Warenhaus. Die Discounter haben lediglich einen Anteil von $4 \%$ am Gesamtumsatz (Michels et al. 2004: 8). Das durchschnittliche Sortiment an Bio-Produkten je Outlet umfasst 
je nach Filialunternehmen (Edeka, Tengelmann, Karstadt) zwischen 200 und 800 Artikel. Eine herausragende Stellung nimmt Tegut mit etwa 1.800 Artikeln im Sortiment und mehr als 10 \% Umsatzanteil ein (Bahrdt et al. 2003: 12).

An dritter Stelle stehen mit einem Anteil von insgesamt $16 \%$ am Gesamtumsatz die landwirtschaftlichen Erzeuger, die über Direktvermarktung ab Hof (10 \% Anteil) sowie über den Wochenmarkt bzw. Straßenstände (6 \% Anteil) ihre Öko-Ware verkaufen. Hofläden weisen unterschiedlich große Verkaufsflächen auf und führen variable Sortimente. Hier spielt die Sortimentsbildung durch Zukauf von Ware eine steigende Rolle, so dass einige professionelle Hofvermarkter inzwischen eher Handelsfunktionen einnehmen. Je 7 \% entfallen auf das Lebensmittelhandwerk und die Reformhäuser. Der Rest wird in Drogeriemärkten und Lieferdiensten erwirtschaftet (Michels et al. 2004: 8).

Insgesamt ist der Bio-Einzelhandel weiterhin durch eine strikte Trennung der Wertschöpfungsketten gekennzeichnet. Der konventionelle LEH setzt im Kern auf seine Handelsmarkenkonzepte (z. B. Bio-Wertkost/Edeka, Grünes Land/Metro, BioBio/Tengelmann), wobei die Waren entweder von größeren Bio-Herstellern oder von spezialisierten Anbietern direkt geliefert werden. Der Bio-Fachhandel einschließlich Direktvermarktung und Reformhäuser ist immer noch sehr kleinbetrieblich strukturiert und bezieht seine Produkte i. d. R. über den spezialisierten Großhandel. An den Schnittstellen dieser beiden Wertschöpfungsketten, z. B. bei Herstellern, die Waren für beide Bereiche liefern, sowie an den dynamischen Wachstumspunkten (z. B. Bio-Supermärkten) kommt es in wachsendem Umfang zu brancheninternen Konflikten.

\section{Perspektiven des Biomarktes}

Der deutsche Biomarkt ist traditionell durch die starke Stellung der Fachgeschäfte wie Naturkostläden und Reformhäuser geprägt. In den letzten Jahren konnte der LEH vom Umsatzwachstum profitieren und seine Umsatzanteile an Bio-Produkten erhöhen (o. V. 2004a: 3). Die zunehmende Vermarktung der Bio-Produkte über den LEH wird durch die Pioniere des Ökolandbaus teilweise kritisch beurteilt. Sie befürchten, dass die traditionellen Absatzwege in der Bio-Branche verdrängt werden und sich die Landwirte mit niedrigen Auszahlungspreisen zufrieden geben müssen (Hamm/Rippin 2005: 122 f.). Wie sich die Umsatzanteile in Zukunft entwickeln werden, hängt zum großen Teil vom Engagement und den Strategien einzelner Marktteilnehmer ab. Eine besondere Rolle spielen dabei 
konventionelle Handelsfilialisten und ihr konsequenter Einstieg in die Vermarktung von BioProdukten. Aber auch die Investitionen von Rewe in bislang zwei Bio-Supermärkte zeigen, dass der Biomarkt auch für konventionelle Händler ein interessanter Wachstumsmarkt ist (Großkinsy 2005: 22).

Eine eigene Studie zum Wechselverhalten von Bio-Intensivkäufern verdeutlicht, dass trotz Wachstums des Biomarktes das Überleben vor allem kleiner Naturkostläden zunehmend schwieriger wird (Gerlach et al. 2005). Die Bio-Supermärkte konnten hingegen ihren Anteil am Umsatz in den vergangenen Jahren deutlich ausbauen. So wurden im Jahr 2002 in den 180 Bio-Supermarkt-Verkaufsstätten (9 \% der Verkaufsstätten im Naturkosthandel) 220 Mio. € (17\% des Naturkosthandelumsatzes) umgesetzt. Vergleicht man den prozentualen Anteil von Umsatz und Betriebszahlen im Naturkosthandel, dann ist festzustellen, dass in diesen $9 \%$ aller Verkaufsstätten bereits knapp ein Fünftel des Naturkosthandelsumsatzes (Naturkosthandelsumsatz liegt bei 1,3 Mrd. €) erbracht wird (Bahrdt et al. 2003: 12).

Insgesamt macht die Struktur der Bio-Wertschöpfungskette deutlich, dass es sich um einen noch sehr fragmentierten Markt handelt, in dem wenig größere Unternehmen agieren. Die Wachstumsraten der ersten filialisierten Bio-Supermärkte zeigen aber die Dynamik des Marktes. Im Ausland deutet der große Erfolg von WholeFoods an, welche Perspektiven das gesundheitsorientierte Bio-Segment bietet.

Im Folgenden werden daher vor allem mögliche Veränderungen des Biomarktes und deren Auswirkungen auf den Großhandel diskutiert. Dem Großhandel kommt als Bindeglied zwischen Produktion und verbrauchsnahem Einzelhandel derzeit eine zentrale Scharnierfunktion zu. Er nimmt nicht nur Logistik-, sondern auch vielfältige Vermarktungsfunktionen ein. Da jedoch im konventionellen Bereich Sortimentsgroßhändler mit breitem Angebot letztlich fast komplett aus dem Markt verdrängt wurden, stellt sich auch im BioBereich die Frage nach den Überlebensperspektiven.

\section{Die Rolle des Großhandels in der Wertschöpfungskette}

\subsection{Typologisierung der Großhandelsbetriebsformen}

Unter dem Großhandel wird ein Absatzmittler verstanden, der auf eigene oder fremde Rechnung (Kommissionsware) seine Handelsware an Abnehmer wie andere Handelsunter- 
nehmen (vor allem Einzelhändler), Weiterverarbeiter (Industrie, Handwerk) oder gewerbliche Verbraucher (Großverbraucher, Gastronomie), jedoch nicht an den Endverbraucher, verkauft. Unter Handelswaren sind Güter zu verstehen, die ohne wesentliche Verarbeitung weiter verkauft werden (Tietz 1993: 9 ff.). Groß- und Einzelhandel gleichen die bestehenden Differenzen zwischen Herstellerangebot und Konsumentennachfrage in zeitlicher, qualitativ und quantitativ variierender Hinsicht aus (Barth/Köhler 2001: 551).

Eine Einteilung des Großhandels in einzelne Betriebsformen ist mittels verschiedener Segmentierungsmerkmale möglich. Im Folgenden wird eine Typologisierung anhand der zentralen wahrgenommenen Funktionen vorgenommen (Specht 1992: 54 f.), da diese Systematik am besten der Situation des Bio-Großhandels in Deutschland gerecht wird. Danach können folgende Großhandelstypen unterschieden werden (siehe Tabelle 3):

- Zustell- bzw. Liefergroßhändler liefern die Waren auf Bestellung an den Einzelhändler aus. Diese Form des Großhandels steht in der Bio-Distribution im Vordergrund. Einer leistungsfähigen Logistik kommt hier eine zentrale Rolle zu.

- Streckengroßhändler sind Großhändler, die sich auf die Transaktionsfunktion konzentrieren und sich nicht mit dem physischen Warenfluss beschäftigen. In der Bio-Branche kann diese Betriebsform den Großhändlern zugeschrieben werden, die am Markt als Agenten im Aus- und Inland tätig sind und ihre Ware durch Speditionen über große Entfernungen verteilen lassen.

- Rack Jobber sind Großhändler, die im Einzelhandel das Absatzrisiko für ihre Produkte übernehmen und eigenständig für den Regalservice zuständig sind. In der Regel betreuen sie als Warenspezialisten eine Sortimentsgruppe. Die Betriebsform ist selten im Bio-Großhandel zu finden.

- Sortimentsgroßhändler sind durch ein breites und flaches Sortiment gekennzeichnet. Viele von ihnen sind Bio-Vollsortimenter mit einem Sortiment von ca. 5.000 Artikeln. Sie liefern im Regelfall die Ware an.

- Spezialgroßhändler unterscheiden sich von den Sortimentsgroßhändlern in Bezug auf ihre hohe Sortimentstiefe bei Konzentration auf eine Warengruppe. $\mathrm{Zu}$ dem Betriebstyp zählen die Frischespezialisten (Obst, Gemüse und Molkereiprodukte).

- Cash und Carry (C \& C) Betriebe sind durch die Art der Bedienungsform gekennzeichnet. In C \& C Märkten besteht für den Kunden die Möglichkeit, sich die Ware selber auszusuchen und anschließend zu zahlen. Wichtigster Vertreter dieses Betriebstyps im konventionellen Bereich ist die Metro. 
TABELLE 3: BETRIEBSTYPEN GEGLIEDERT NACH IHREN FUNKTIONEN

\begin{tabular}{|c|c|c|c|c|c|c|}
\hline $\begin{array}{l}\text { Funktionen } \\
\text { Betriebstyp }\end{array}$ & $\begin{array}{l}\text { Trans- } \\
\text { aktions- } \\
\text { funktion }\end{array}$ & Lagerung & Transport & $\begin{array}{l}\text { Finanzie- } \\
\text { rung }\end{array}$ & $\begin{array}{l}\text { Qualitäts- } \\
\text { sicherung }\end{array}$ & Beratung \\
\hline $\begin{array}{l}\text { Zustell- bzw. } \\
\text { Liefergroßhandel }\end{array}$ & $X$ & $\mathrm{X}$ & $\mathrm{X}$ & $\mathrm{O}$ & $\mathrm{O}$ & $\mathrm{O}$ \\
\hline Rack Jobber & $X$ & $X$ & $X$ & $X$ & $X$ & $\mathrm{O}$ \\
\hline Strecken-GH & $X$ & -- & -- & -- & -- & $\mathrm{O}$ \\
\hline Sortiments-GH & $X$ & $\mathrm{O}$ & $\mathrm{O}$ & $\mathrm{O}$ & $\mathrm{O}$ & $\mathrm{X}$ \\
\hline Spezial-GH & $X$ & $\mathrm{O}$ & $\mathrm{O}$ & $\mathrm{O}$ & $\mathrm{O}$ & $\mathrm{O}$ \\
\hline $\begin{array}{l}\text { Cash und Carry } \\
\text { GH }\end{array}$ & $X$ & $X$ & -- & -- & $\mathrm{O}$ & $\mathrm{O}$ \\
\hline $\begin{array}{l}X \\
-- \\
O\end{array}$ & $\begin{array}{l}\text { ezifische } \\
\text { nktion w } \\
\text { nktion ka }\end{array}$ & $\begin{array}{l}\text { tion der B } \\
\text { on dieser } \mathrm{B} \\
\text { yernomme }\end{array}$ & $\begin{array}{l}\text { riebsform } \\
\text { triebsform } \\
\text { werden }\end{array}$ & nicht übe & men & \\
\hline
\end{tabular}

Quelle: Eigene Darstellung in Anlehnung an Specht 1992: 54

In der Bio-Branche selbst ist eine etwas andere Typisierung der Großhändler üblich, die sich nicht mit der Literatur deckt. Hier wird der Spezialgroßhandel noch einmal in zwei Untergruppen, den Warengruppenspezialisten und den Frischespezialisten, unterteilt. Aus diesem Grund wird in der Bio-Branche insgesamt in Vollsortimenter, Warengruppen- und Frischespezialisten differenziert. Unter die Warengruppenspezialisten fallen Großhändler, die sich unter anderem auf den Handel mit Weinen oder Kosmetika spezialisiert haben. Zu den Frischespezialisten gehören vor allem die Obst- und Gemüsegroßhändler (Schrade 2005). Eine weitere Form des Großhandels sind die so genannten „Vorlieferanten“, die ähnliche Aufgaben wie die Streckengroßhändler übernehmen und eine besonders hohe Bedeutung bei Produkten aus dem Ausland haben. Da die Strukturen der ausländischen Hersteller für die deutschen Großhändler oft zu klein sind, nutzen sie die Bündelungsfunktion der Vorlieferanten im In- und Ausland (Römer 2005).

Die Vollsortimenter, Warengruppen- und Frischespezialisten können in räumlicher Hinsicht nochmals unterteilt werden in national und regional agierende Absatzmittler. Die Anzahl der national agierenden Großhändler beschränkt sich nach Schätzungen der Experten in Deutschland auf einige wenige Großhändler: Dazu zählen die Vollsortimenter Dennree und Biogarten. Ihr Umsatz beträgt zusammen ca. 240 Mio. € jährlich. Der Gesamtumsatz der ca. 
25 regional $^{2}$ tätigen Großhändler (90 \% aller Großhändler) beläuft sich jährlich auf ca. 235 Mio. €. An den 240 Mio. € Umsatz der nationalen Großhändler hat Dennree den größten Anteil mit ungefähr 200 Mio. € jährlich. Unter den regionalen Großhändlern ist eine große Streuung der Umsatzgrößen zu finden. Viele Großhändler erwirtschaften einen Jahresumsatz von 5 bis 8 Mio. €. Mit 57 Mio. € Umsatz im Jahr 2004 ist Weilling der größte Regionalgroßhändler (Fiedler 2005a). Nur wenige der regionalen Großhändler wie z. B. Naturkost Elkershausen und Ökoring können einen Umsatz von 20 bis 30 Mio. € realisieren (Michaelidis 2005).

\subsection{Bedeutung des Großhandels in der Wertschöpfungskette}

Ein Unterschied der Bio-Wertschöpfungskette gegenüber der konventionellen Wertschöpfungskette ist die hohe ökonomische Relevanz des klassischen Bio-Großhandels, der völlig unabhängig von Hersteller und Einzelhandel wirtschaftet und zwischen beiden Akteuren als Schnittstelle arbeitet. Eine solche Form des Großhandels hat im konventionellen Lebensmittelhandel stark an Bedeutung verloren, da die Hersteller dazu tendieren, den Großhandel auszuschalten, indem sie die Einzelhändler direkt beliefern und die großen Handelsfilialisten in ihrer Zentrale größere Bündlungseffekte und Einkaufspreisvorteile generieren. Der filialisierten LEH hat zudem durch eigene Zentral- und Regionalläger die logistischen Funktionen des Großhandels integriert. Die Folge ist, dass es abgesehen von einigen Ausnahmen (z. B. EDEKA, Frischespezialisten) zwischen dem Hersteller und dem Einzelhandel keine selbständige Handelsstufe mehr gibt.

Für Hersteller haben der einstufige bzw. der mehrstufige Absatz verschiedene Vor- und Nachteile. Zu den Vorteilen einer Distribution über den Großhandel gehören unter anderem der geringere Aufwand für den Hersteller bei der Bearbeitung kleinerer Aufträge sowie die Verteilung der Ware an räumlich weit verstreute Abnehmer. Diese Vorzüge nehmen entsprechend mit wachsender Einzelhandelskonzentration ab. Für Hersteller, die neu am Markt agieren, besteht die Möglichkeit, die vorhandenen Kundenkontakte des Großhandels zu nutzen, um einen eigenen, fixkostenintensiven Außendienst einzusparen. Mit dem mehrstufigen Absatz ist es für viele Hersteller möglich, sich auf ihre Kernkompetenzen in der Produktion zu konzentrieren.

\footnotetext{
${ }^{2}$ Regional agierender Großhändler bezieht sich auf den Umkreis des Liefergebiets. Regional sind neben den kleinen Liefergebieten auch Liefergebiete, die sich auf ganz Nord- oder Süddeutschland beziehen.
} 
Die Nachteile einer mehrstufigen Distribution liegen auf den ersten Blick in der zusätzlichen Handelsspanne. Dem stehen allerdings die geringeren Logistikkosten gegenüber, so dass im Einzelfall in Abhängigkeit von der Dichte der zu beliefernden Einzelhändler und dem zu distribuierenden Volumen über die kostengünstigste Lösung zu entscheiden ist. Außerdem birgt der Absatz über den Großhandel die Gefahr der Abhängigkeit, indem der Großhandel in erster Linie seine eigenen Ziele verfolgt, bevor er denen des Herstellers nachgeht (Pepels 1995a: 23 f.). Schließlich ist es für die Industrie schwieriger, eigene POS-Marketingkonzepte zu realisieren.

\section{TABelLe 4: ZusAmMENFASSUNG DER VOR- Und NACHTEILE BEIM ABSATZ ÜBER DEN} GROßHANDEL AUS SICHT DER HERSTELLER

\begin{tabular}{|cl|}
\hline $\begin{array}{c}\text { Vorteile : } \\
-\end{array}$ & Zusätzlicher Außendienst zur Akquisition \\
- & Rationelle Abwicklung von Kleinaufträgen \\
- & Schnelle Markterschließung aus vorhandenen Kundenbeziehungen \\
- & Versorgung weit verteilter Abnehmer \\
- & Reduktion der Transaktionszahl \\
- & Konzentration auf Kernkompetenzen \\
Nachteile: & \\
- & Konkurrenzverhältnis im Sortiment \\
- & Zielkonflikte zwischen Hersteller und Großhandel \\
- & Geringer Einfluss auf das Einzelhandelsmarketing \\
- & Gefahr der Abhängigkeit von bedeutenden Großhändlern \\
- & Einbehalten der Distributionsspanne \\
\hline
\end{tabular}

Quelle: Eigene Zusammenstellung in Anlehnung an Pepels 1995a

\section{Distributionsstrategien in der Bio-Branche}

\subsection{Absatzwege in der Bio-Wertschöpfungskette}

In der Bio-Branche ist, im Gegensatz zum konventionellen Lebensmittelhandel, ein Großteil der mittelständischen Hersteller von Bio-Produkten auf die Vermarktung über Zwischenhändler und Weiterverarbeiter angewiesen. Der direkte Absatz, bei dem Hersteller ihre Produkte ohne selbständige Absatzmittler an den Endkunden vertreiben, spielt nur eine äußerst geringe Rolle. Der indirekte Absatz kann noch einmal unterteilt werden in einstufigen und mehrstufigen Absatz. Unter einstufigem Absatz wird der Warenfluss über den 
Einzelhandel und unter mehrstufigem der Absatz über mindestens zwei Absatzmittler wie z. B. Großhandel und Einzelhandel verstanden (Spiller/Zühlsdorf 2002: 123) (siehe Abbildung 4).

ABBILDUNG 4: ABSATZWEGE IN DER BIO-WERTSCHÖPFUNGSKETTE

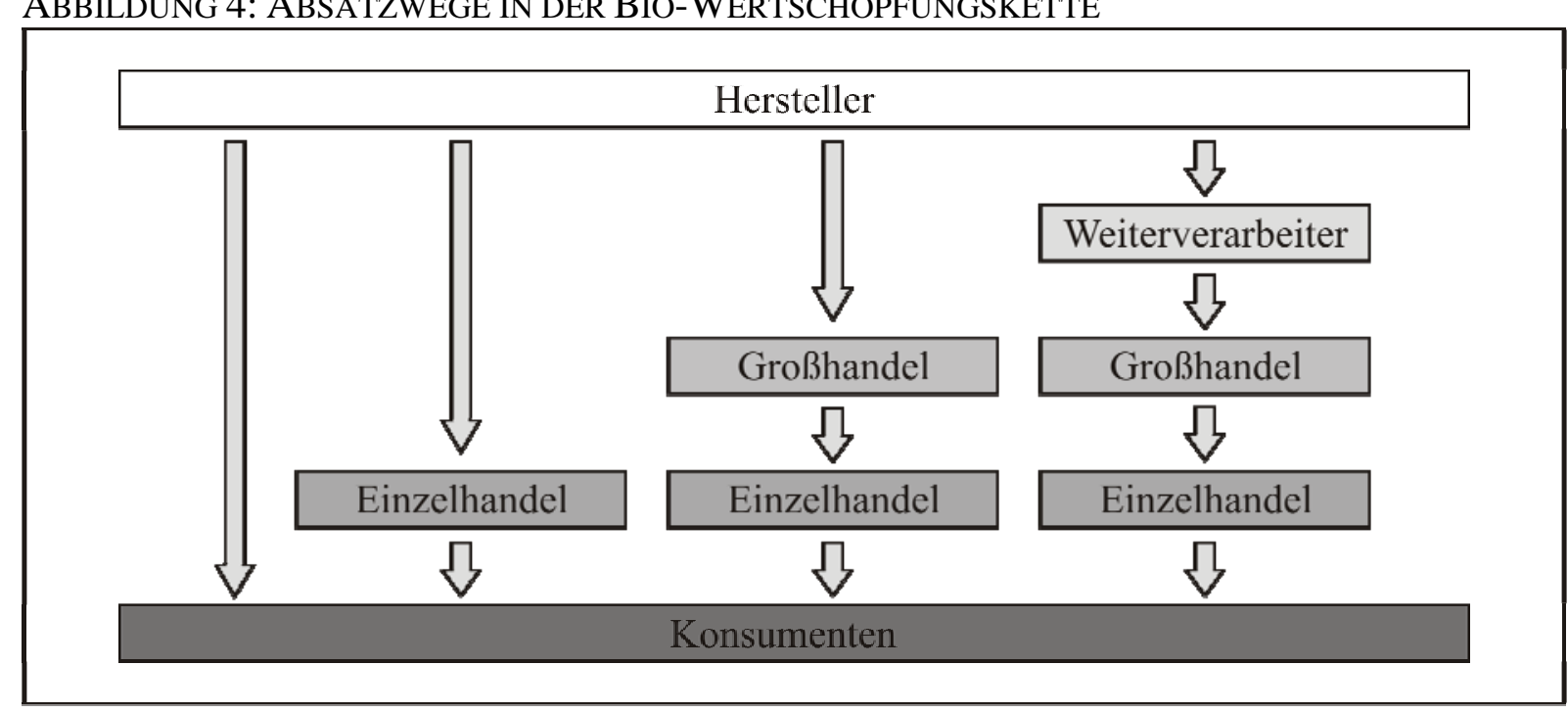

Quelle: Eigene Darstellung in Anlehnung an Richter 2004: 1

Der Einkauf des Naturkostfachhandels erfolgt in Deutschland, wie beschrieben, zum Großteil über den regional oder den national agierenden Großhandel. Neben dem Bezug der Ware über den Großhandel nutzt der Einzelhandel auch die Möglichkeit, regionale Produkte direkt bei inländischen Herstellern oder Landwirten zu beziehen (siehe Abbildung 5). Ein Direktbezug von ausländischer Ware ist für den Einzelhandel, ausgenommen für den großbetrieblichen LEH, schwer zu realisieren (Römer 2005). Trotz einiger Versuche ausländischer Produzenten, den Handel in Deutschland direkt zu beliefern, ist es dem Großhandel gegenwärtig gelungen, sich als wichtigster Lieferant für den Einzelhandel zu behaupten (Michaelidis 2005). 
ABBILDUNG 5: ABSATZSTRUKTUREN IN DER BIOWERTSCHÖPFUNGSKETTE

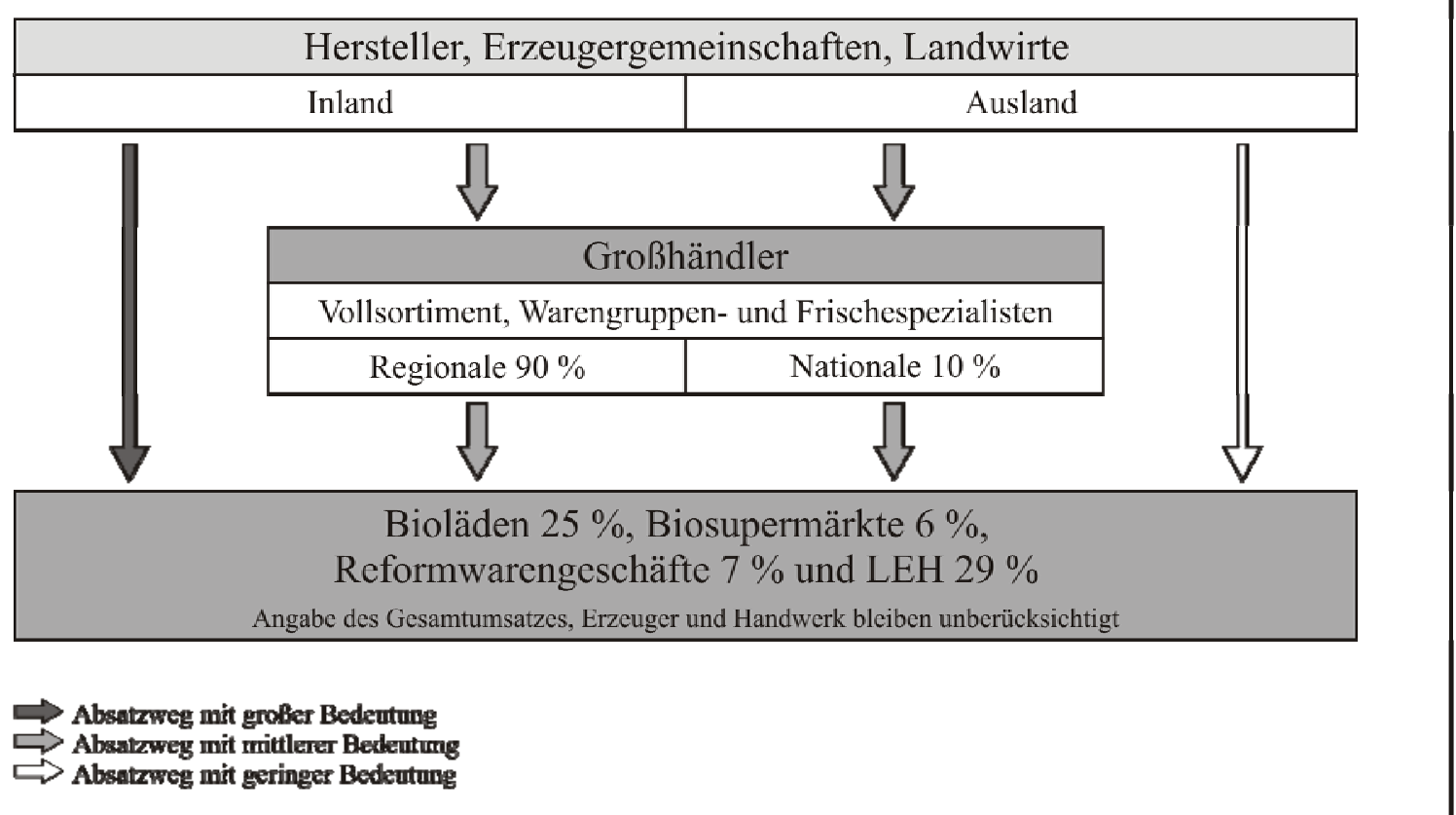

Quelle: Eigene Darstellung, in Anlehnung an die Experteninterviews

Für den Bio-Großhandel spielt der Absatz über den konventionellen LEH bislang kaum eine Rolle. Aus Rücksichtnahme auf den Naturkostfachhandel (Stichwort Fachhandelstreue) wird der LEH bislang nur sehr eingeschränkt beliefert. Diese Art des selektiven Vertriebs ist allerdings sehr brüchig.

\subsection{Vertikale Selektion: Tendenzen zur Ausschaltung des Bio-Großhandels}

Die Struktur der Wertschöpfungskette ist u. a. ein Ergebnis des bestehenden Wettbewerbsdruckes. Ein aggressiver Preiswettbewerb wie im konventionellen Lebensmittelbereich war für die Bio-Branche bis vor kurzem kein zentrales Thema. Gründe dafür waren zum einen der ungesättigte Biomarkt, zum anderen die Motivation und Überzeugung der Akteure, eine angemessene Entlohnung der ganzen Kette zu gewährleisten. Seit den Lebensmittelkrisen und der intendierten Agrarwende im Jahr 2001 ist die Bio-Branche stark in Bewegung geraten. Die Nachfrage nach Bio-Produkten ist in Deutschland deutlich gewachsen, was dazu geführt hat, dass neue Akteure in den Markt eingedrungen sind. Mit einem verstärkten Einstieg des konventionellen LEHs (z. B. Plus „BioBio“) ist u. a. auch die Wettbewerbsintensität gestiegen mit der Folge, dass die Preispolitik auch in der Bio-Branche an Priorität gewonnen hat (Spiller 2004: 244 ff.). 
Vergleicht man die Handelsspannen des konventionellen LEH und des Naturkostfachhandels, werden gravierende Unterschiede deutlich. ${ }^{3}$ Die Gesamthandelsspanne beträgt beim Discounter Aldi z. B. ca. 15 \% und bei konventionellen Supermärkten zwischen $20 \%$ und 25 \%. Im Vergleich dazu beläuft sich in der Bio-Branche die Handelsspanne des Naturkostfachhandels auf ca. 40 \% und nochmals ca. 30 \% für den Großhandel (Spiller 2004: 244 ff.). Durch die Addition der 30 \% Großhandelsspanne auf den Herstellerpreis und die auf diese Summe aufzuschlagende 40 \%ige Einzelhandelsspanne, entsteht in der Bio-Branche eine Gesamthandelsspanne von rund 80 \%. ${ }^{4}$ Im konventionellen Lebensmittelhandel übernimmt der Einzelhandel selbst, wie Rewe oder Aldi, die Funktionen des Großhandels. Aufgrund der Größenvorteile ist die gesamte Wertschöpfungskette erheblich kostengünstiger als die der Bio-Branche.

Diese Unterschiede in den Handelsspannen verdeutlichen zweierlei: Zum einen hat der konventionelle LEH erhebliche Kostenvorteile gegenüber dem Naturkostfachhandel, die an den Endverbraucher weitergegeben werden können. Zum anderen wird deutlich, dass auch im Bereich der Bio-Distribution mit zunehmendem Wachstum erhebliche Kosteneinsparungen möglich sind.

Um den hohen Endverbraucherpreis in der Bio-Branche, der sich u. a. auch durch die Distributionsspanne des Großhandels erklärt, zu reduzieren, kann der Hersteller den Großhandel durch vertikale Selektion ausschalten bzw. der Einzelhandel direkt beim Hersteller einkaufen (Pepels 1995b: 112). Der Hersteller trifft mit der vertikalen Selektion eine Auswahl darüber, ob er seine Produkte an den Großhändler, an den Einzelhändler oder direkt an den Konsumenten absetzen soll (Ahlert 1981: 49 f.).

Die vertikale Selektion hat im konventionellen Lebensmittelhandel zu einem sehr deutlichen Machtverlust des Großhandels geführt. Heutige Schätzungen gehen davon aus, dass ca. 80 \% der Einzelhandelsunternehmen direkt vom Hersteller beziehen (Bodenstein/Spiller 1998: 194). In der Bio-Branche hingegen ist, abgesehen von wenigen Ausnahmen (Rapunzel),

\footnotetext{
${ }^{3}$ Die folgenden Zahlen beruhen auf Schätzungen von Branchenexperten und eigenen Erfahrungen, sie sind als Näherungslösungen zu interpretieren.

${ }^{4}$ Die Erklärung der Gesamthandelsspanne an einem Zahlenbeispiel: Der Herstellerpreis für ein Produkt beträgt $1,40 €$. Auf diesen schlägt der Großhandel eine Spanne von $30 \%$ auf und verkauft damit das Produkt für 1,82 € an den Einzelhändler. Dieser schlägt auf die 1,82 € wiederum seine Einzelhandelsspanne von ca. 40 \% auf, so dass der Abgabepreis im Laden 2,55 € beträgt. Gegenüber dem Herstellerpreis $(1,40 € €)$ verteuert sich das Produkt also um $82 \%$.
} 
bisher noch kein vergleichbarer Trend zu erkennen, da eine der Schwierigkeiten die große räumliche Verteilung der Einzelhandelsunternehmen ist (Spiller/Zühlsdorf 2002: 123).

Der Hersteller Rapunzel ist eines der wenigen Beispiele aus der Praxis für eine vollständige Ausschaltung des Großhandels durch den Hersteller. Rapunzel hat seit Oktober 2003 die Belieferung der Großhändler eingestellt und vertreibt seine Produkte ausschließlich über Speditionen und Paketdienste an die Einzelhändler. Dieser Schritt wurde vor allem von Großhandelsseite, aber auch von kleinen Naturkostläden stark kritisiert. Befürchtet werden neben Entlassungen bei kleineren Großhändlern, die teilweise 20 \% ihres Umsatzes mit Rapunzel-Artikel erwirtschaften, auch ein deutlicher Mehraufwand für Bestellungen, Warenannahme und Überweisungen bei kleineren Läden (o. V. 2003c). Der BNN wirft dem Unternehmen mangelnde „Fachhandelstreue“ vor und fordert für die Zukunft „wieder mehr gemeinschaftliches Handeln, anstelle eines gnadenlosen Wettlaufs um die Marktführerschaft“ (o. V. 2003a). Gegenüber den kleinen Naturkostläden verhält sich die Rapunzel AG hingegen entgegenkommend, indem sie die Mindestbestellmenge um $50 \%$ von $250 €$ auf $125 €$ gesenkt hat (o. V. 2003d).

Insgesamt ist in der Naturkostbranche umstritten, ob die vertikale Selektionsstrategie von Rapunzel Beispielcharakter für die Marktentwicklung hat. Die Rapunzel AG ist deutlich marktstärker als der Großteil der übrigen Lieferanten und verfügt über ein relativ breites Produktionsprogramm. Zudem werden exklusiv Produkte zweier weiterer Firmen (Bioforce und Lima) sowie - nicht exklusiv - weite Teile des Allos-Sortiments vertrieben (o. V. 2005a). Obwohl viele kleine Hersteller zzt. nicht in der Lage sein werden, ein eigenständiges Distributionssystem aufzubauen, deuten solche Entwicklungen auf das grundsätzliche Potenzial der Direktbelieferung hin. Auch aus der konventionellen Lebensmitteldistribution sind Beispiele kooperativen Warenvertriebs oder der Auslagerung der Logistik an Speditionen bekannt, die auch für kleinere Anbieter rentabel sein können.

Zwischenfazit: Die vertikale Selektion spielt bislang in der Bio-Branche nur eine geringe Rolle. Da bislang nur wenige Hersteller starke Bio-Marken aufgebaut haben und über ein breiteres Angebotsprogramm verfügen, sind die Großhändler bisher gegenüber den Herstellern in einer besseren Position. 


\subsection{Vertikale Bindung: Integration oder Kooperation entlang der Supply Chain}

Zur Steigerung der Effizienz in der Bio-Wertschöpfung besteht die Möglichkeit, die Zusammenarbeit im Absatzkanal zu verbessern. Es gibt zwischen unterschiedlichen Marktstufen der gleichen Branche zum einen die vertikale Kooperation und zum anderen die vertikale Integration, unter der eine Vorwärts- oder Rückwärtsintegration im Absatzkanal zu verstehen ist. Vertikale Integration bedeutet die eigentumsrechtliche Zusammenfassung aufeinander folgender Wertschöpfungsstufen unter einheitlicher Unternehmensführung (Azzam/Pagoulatos 1999: 7 f.). Während die Unternehmen bei einer Kooperation ihre wirtschaftliche und rechtliche Selbständigkeit erhalten, verliert bei der vertikalen Integration (im Fall von zwei Unternehmen) ein Unternehmen seine Autonomie (Pepels 1995a: 48 f.).

Ausgehend von der Fragestellung, welche Chancen der Großhandel zukünftig in der Wertschöpfungskette hat, ist neben der Kooperation insbesondere die Vorwärtsintegration von Bedeutung. Vorwärtsintegration findet statt, wenn entweder der Hersteller Eigentümer des Großhandels oder der Großhandel Eigentümer des Einzelhandels wird (Stern et al. 1989: 293).

Ein Beispiel für eine Vorwärtsintegration in der Bio-Branche ist Dennree, der als Großhändler seit Juli 2003 Einzelhandelsgeschäfte unter dem Namen Denn`s Bio Discount betreibt. Durch den Verkauf seiner Ware zum Großhandelsabgabepreis an den Endkunden erntet Dennree scharfe Proteste aus Einzel- und Großhändlerkreisen. Der Großhändler Bodan schreibt in einem Mitteilungsblatt an seine Kunden: „Ihr Lieferant von heute ist der Untergang von morgen“ (Fiedler 2003a). Aber auch andere Großhändler haben eigene Bio-Läden. Naturkost Elkershausen betreibt vier Bio-Läden, die z. T. von zuvor insolventen Einzelhändlern übernommen wurden. Auch der Großhändler Kornkraft verfügt über einen eigenen Bio-Laden, in dem aber vor allem neue Sortimente getestet werden. Diese Beispiele machen deutlich, dass die Vorwärtsintegration auf Großhändlerebene außer bei Dennree nicht als strategische Option zum Verbleib in der Wertschöpfungskette dient, sondern nur gelegentlich erfolgt.

Neben der Vorwärtsintegration könnten aber auch stärkere Kooperationen von Großhändlern und Einzelhandel zu einer Stärkung des Großhandels beitragen. Durch den Ausbau der Beratung für Bio-Läden und das Angebot von ausgearbeiteten Marketingkonzepten könnten franchiseähnliche Systeme aufgebaut werden. Ein Beispiel für diese Art von Kooperation zeigt sich bei dem Bio-Großhändler Weilling, der mit seinem „Bioladen“-Konzept für 
kleinere Händler ein professionelles Marketingkonzept ausgearbeitet hat. Ein weiteres Beispiel sind „die Regionalen“, ein Zusammenschluss von 12 regionalen Großhändlern aus dem gesamten Bundesgebiet, die mit einer gemeinsamen Kampagne „[echt bio.]“ ihren Einzelhändlern ein Konzept für die Verbraucheransprache vor Ort bereitstellen (Die Regionalen 2005).

Eine andere Option des Großhandels zur Festigung der Position in der Kette ist der Aufbau von Handelsmarkenkonzepten. Durch beim Konsumenten verankerte Handelsmarken kann zum einen die Bindung des Einzelhändlers an den Großhändler gefestigt werden. Zum anderen bietet die Option den Vorteil, dass der Großhändler seine Position gegenüber den Herstellerunternehmen festigt. Bislang spielen Handelsmarken bei Bio-Lebensmitteln eine noch sehr untergeordnete Rolle. Ihr Anteil lag nach den Zahlen des Biovista-Handelspanels im Jahr 2004 bei nur 5,1 \%. Dennoch deutet die Wachstumsrate von 30 \% auf die Dynamik in diesem Bereich hin (o. V. 2005b).

Zwischenfazit: Die Vorwärtsintegration des Großhandels spielt in Teilbereichen (Denn's Bio) eine Rolle. Insgesamt steht diese Entwicklung allerdings noch am Anfang. Im Gegensatz zur vertikalen Selektion sind die Bedingungen für die relativ kapitalstarken Großhändler, in den Einzelhandel zu investieren, jedoch günstig.

Es bleiben damit drei zentrale Fragen für die Zukunft des Bio-Großhandels offen:

- Werden Hersteller wie Rapunzel oder größere Einzelhändler wie z. B. BioSupermarktfilialisten den Großhandel verstärkt umgehen, um die Wertschöpfungskette zu rationalisieren?

- Werden Großhändler - nicht zuletzt als Reaktion auf die o. g. Herausforderungen - verstärkt Einzelhandelsfunktionen übernehmen?

- Werden Großhändler zur Bindung der Fachhandelskunden und zur Gegenmachtbildung gegen die Industrie Handelsmarken forcieren?

\section{Primäre Kompetenzfelder des Großhandels in der Bio-Branche}

\subsection{Diskussion der Großhandelsfunktionen}

Wie in den vorherigen Ausführungen deutlich wurde, bedroht eine Direktbelieferung des Herstellers die Großhandelsstellung. Aus diesem Grund bietet der Großhandel, ergänzend zu 
den klassischen Leistungen wie Bündelung der Ware und Logistik, weitere Serviceleistungen an, um sich im Absatzkanal zu behaupten. Die wichtigsten Funktionen des Großhandels in der Bio-Branche werden in diesem Kapitel erklärt und anhand einer Expertenbefragung im Hinblick auf ihre Relevanz bewertet.

\subsubsection{Logistik}

Die Logistikfunktion des Großhandels besteht darin, dem Einzelhandel die Ware über Raum (durch Transport) und Zeit (durch Lagerhaltung) zur Verfügung zu stellen. Damit übernimmt der Großhandel die Aufgaben und Kosten der Lagerhaltung und des Transports für den Einzelhändler. Lagerhaltung ist notwendig, wenn die Nachfrage temporär unterschiedlich ist und wenn die Produktion nicht mit der Nachfrage übereinstimmt (Delfmann/Arzt 2001: 993 f.). Der Großhandel überbrückt die räumlichen Differenzen zwischen Produktion und Einzelhandel durch einen eigenen Fuhrpark oder durch fremde Transporteure. Zu den fremden Transporteuren gehören nicht nur Speditionen, sondern auch Paketdienste, wie das Beispiel Rapunzel zeigt, die während der letzten Jahre in der Bio-Branche an Bedeutung gewonnen haben.

Um die Bedeutung der Großhandelslogistik beurteilen zu können, müssen die Probleme in Bezug auf Lagerung und Transport aufgezeigt werden, die durch den Direktbezug des Einzelhandels beim Hersteller entstehen. Eines der grundlegenden Probleme ist, dass nur wenige Einzelhändler eigene Lager besitzen und aus diesem Grund auf eine häufige Warenanlieferung angewiesen sind. Die Belieferung kann durch den Hersteller oder den Großhandel erfolgen. Bei einer Belieferung durch den Hersteller muss der Einzelhandel aufgrund der geringen Abnahmemenge mit maximal zwei Anlieferungstagen in der Woche auskommen, was dazu führt, dass zum einen die Frische der Ware leidet, zum anderen größere Lager bereit gestellt werden müssen. Dies erfordert wiederum eine Lagerhaltung des Einzelhandels. Große Bio-Supermarktketten wie Alnatura oder Basic müssen bei der Direktbelieferung mehrere Regionallager in Deutschland verteilt betreiben. Ein Zentrallager würde nicht ausreichen, um Filialen in ganz Deutschland zu versorgen, da die Entfernung zu den einzelnen Filialen zu groß und als Folge die Distributionskosten zu hoch wären. Bisher sind die wenigen Filialen der Bio-Supermarktfilialisten jedoch so weit räumlich voneinander getrennt, dass ein Regionallagerkonzept ausscheidet. Erst bei einer erheblich weiter fortgeschrittenen Filialdichte kommt für Bio-Supermärkte ein eigenes Regionallagerkonzept in Frage. Andere Probleme des Direktbezugs sind die Anforderungen an den Transport und 
die spätere Lagerung. Produkte mit langer Haltbarkeit und geringen Anforderungen an Transport und Lagerung sind leicht handelbare Produkte wie Wein und Trockenprodukte. Sie können einfacher direkt vom Hersteller bezogen werden, im Gegensatz zu Frische- (Obst, Gemüse) oder Tiefkühlprodukten, da letztere einen wesentlich höheren Anspruch an die Logistik stellen (z. B. optimale Kühlketten), die nur von wenigen Akteuren erfüllt werden können. Aus diesem Grund gilt: „Je einfacher ein Produkt ist, desto eher ist eine Direktbelieferung möglich“ (Raff 2005).

\section{TABELLE 5: VORAUSSETZUNGEN EINER DiREKTBELIEFERUNG}

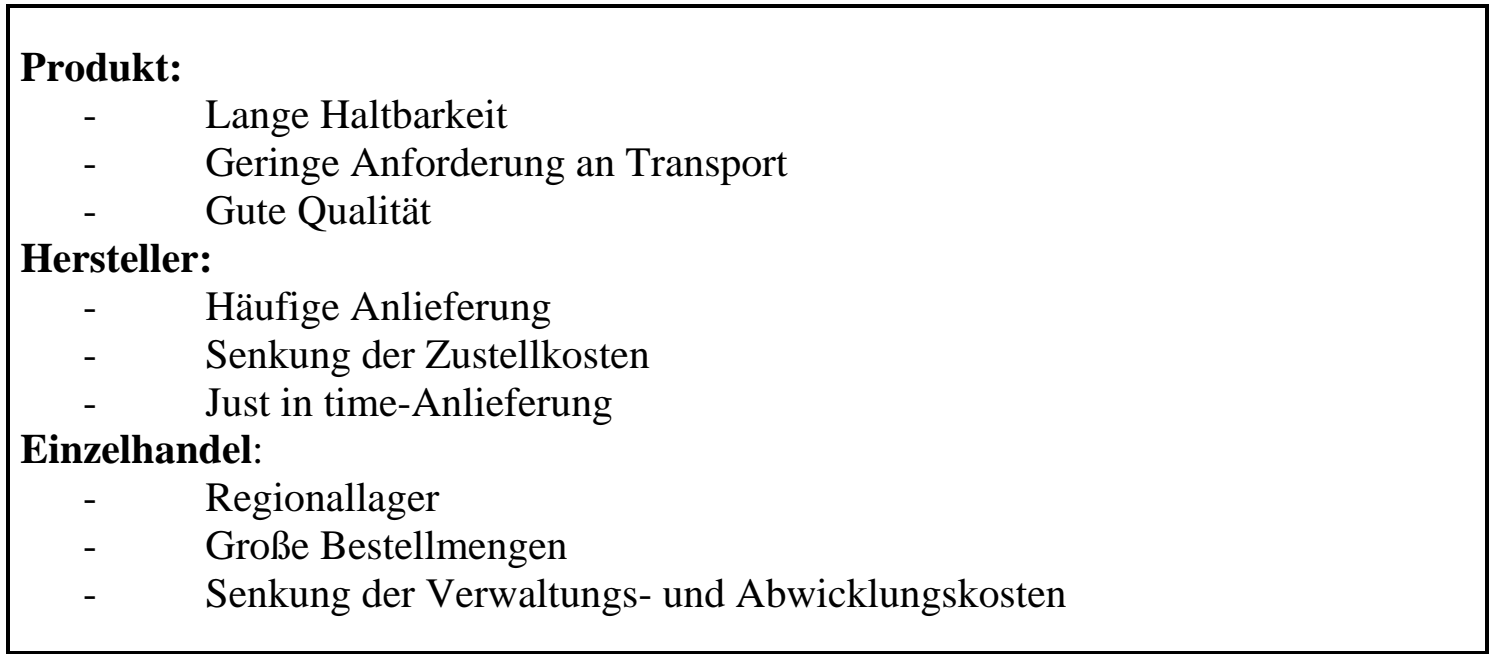

Quelle: Eigene Zusammenstellung in Anlehnung an die Experteninterviews

Wesentliche Voraussetzungen einer Direktbelieferung bzw. eines Regionallagerkonzeptes des Einzelhandels sind derzeit nicht erfüllt, so dass die Entwicklung einer angemessenen Logistik in den nächsten Jahren eine der wichtigsten Aufgaben des Großhandels bleiben wird. Die Logistik kann wegen der genannten Bedingungen und Mengen bislang nur schwer von anderen Akteuren übernommen werden.

\subsubsection{Sortimentsbildung und Transaktionskostenreduktion}

Die Ware der verschiedenen Lieferanten wird beim Großhandel gebündelt, bevor sie weiter an die Einzelhändler verteilt wird. In diesem Fall spricht man von einer zentralen Verteilung. Diese Art der Warendistribution hat gegenüber einer dezentralen Verteilung den Vorteil, dass sich die Anzahl der Kontaktlinien zwischen Einzelhandel und Hersteller verringert, welches zu einer Senkung der Transaktionskosten ${ }^{5}$ führt (siehe Abbildung 6) (Stern et al. 1989: 8).

\footnotetext{
${ }^{5}$ Unter Transaktionskosten werden Kosten verstanden, die bei der Beschaffung von Gütern und Dienstleistungen über den Markt entstehen. Dazu zählen Such- und Informationskosten, Verhandlungs- und Entscheidungskosten, die sich bei einem unvollkommenen Markt und unvollkommener Information ergeben (Coase 1937: 386 ff.).
} 
ABBILDUNG 6: ZENTRALE WARENVERTEILUNG ÜBER EINEN GROßHÄNDLER

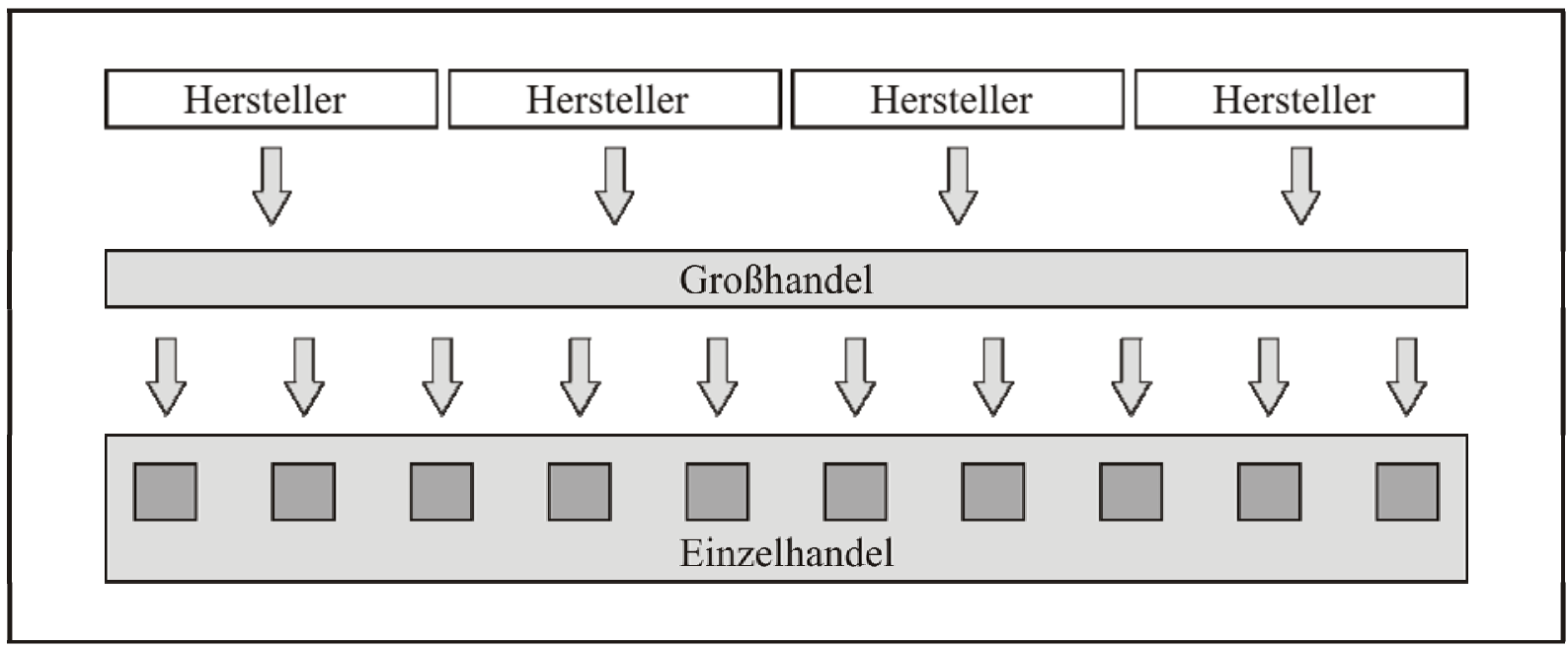

Quelle: Stern et al. 1989: 9

Im Falle einer dezentralen Distribution müsste jeder der vier Hersteller mit den beispielhaft in Abbildung 6 skizzierten zehn verschiedenen Einzelhändlern kommunizieren. Damit würden anstelle von 14 Kontakten 40 entstehen. Allgemein formuliert erklärt dieser so genannte Baligh/Richartz-Effekt die Kontaktkosten-Reduktion und ermöglicht die mathematische Berechnung für die Anzahl der Handelsstufen (Schenk 1991: 70). In der Bio-Branche ist die Bedeutung der zentralen Verteilung über den Großhandel die mit Abstand gängigste Methode, da durch die hohe Anzahl und weite Streuung der Bioläden eine dezentrale Verteilung zu aufwändig wäre. Die wachsende Größe des Einzelhandels stellt diese zentrale Verteilung aber zunehmend in Frage.

Wie schon im Abschnitt Logistik angesprochen wurde, verfügt nur ein kleiner Teil der Einzelhändler über größere Lager. Bio-Einzelhändler sind aus diesem Grund, neben dem täglichen Bedarf an Frischware, von einer häufigen Warenanlieferung abhängig. Ein weiterer Vorteil des Großhandels ist die zentrale Verteilung. Im Gegensatz zum Hersteller kann der Großhändler das volle Sortiment anliefern, da er nicht wie der Hersteller nur eine eng begrenzte Anzahl an Produkten anbietet. Das hat zur Folge, dass die Produktbündelung des Großhandels die Nachfrage des Einzelhandels fördert und der Großhandel dadurch mehrmals wöchentlich Warenanlieferung anbieten kann und muss. Würde der Hersteller einen Weg finden, die Einzelhändler trotz geringer Nachfrage beliefern zu können (dezentrale Verteilung), dann käme es zu einem erheblich größeren Verwaltungsaufwand für den Einzelhandel: „Hätte der Einzelhandel mehrere Lieferanten, weil er versucht, soviel wie möglich bei den Herstellern zu beziehen, dann würden an einem Tag anstatt einiger weniger Warenannahmen, viele, vielleicht bis zu 20 LKWs, an dem Bioladen vorfahren und man 
bräuchte allein einen Mitarbeiter, der nichts anderes macht als die Ware anzunehmen“ (Schrade 2005). Da diese Praxis eine Erhöhung der Verwaltungs- und Personalkosten bedeutet, wird weiterhin der Großhandel diese Bündelungsfunktion übernehmen (Schrade 2005).

Neben den Transaktionskosten spielt der Einkaufspreis eine zentrale Rolle für die Frage der optimalen Warenbündlung. Solange der Einzelhandel klein strukturiert ist und sich nicht zu Einkaufsgemeinschaften zusammenschließt, hat er nur begrenzt Möglichkeiten, Marktmacht gegenüber dem Hersteller auszuüben. Der Großhandel hat hingegen durch seine großen Bestellmengen eine wesentlich bessere Position, um die Produzenten unter Druck zu setzen und einen günstigen Einkaufspreis zu erlangen (Schrade 2005).

Bei den jetzigen Marktgegebenheiten ergeben sich keine relevanten Vorteile der Direktbelieferung, weder für den Hersteller noch für den Einzelhandel. Die Situation kann sich in Zukunft durch die zunehmende Bedeutung der Biosupermarktfilialisten ändern. Mit wachsender Relevanz der Biosupermarktketten kann die Marktmacht des Einzelhandels so ansteigen, dass die höheren Personal- und Verwaltungskosten durch einen niedrigeren Einkaufspreis kompensiert werden. Insgesamt ist die Bündelungsfunktion des Großhandels in starkem Maße von der Marktstruktur auf Lieferanten- und Abnehmerseite abhängig. Mit steigendem Konzentrationsgrad wächst die Wahrscheinlichkeit einstufiger Strukturen.

\subsubsection{Qualitätssicherung}

Zur Aufgabe des Großhandels in der Qualitätssicherung gehört vor allem die Qualitätsprüfung im Wareneingang, bei der durch Stichprobenprüfung die inneren und äußeren Qualitätsmerkmale kontrolliert werden (Pfeifer 2001: 460). In der Bio-Branche kommt außerdem noch die Kontrolle über die Einhaltung der Öko-Verordnungen durch das Einsenden der Proben an unabhängige Labore hinzu, um die Produkte auf Rückstände untersuchen zu lassen. Ein aktuelles Beispiel für die Kontrollen ist das vom Bundesverband Naturkost Naturwaren eingeführte Monitoringsystem für Obst und Gemüse im Naturkosthandel. An diesem Projekt nehmen 28 Naturkostgroßhändler und Importeure des deutschen Biomarktes teil, mit dem Ziel, die Qualität im Naturkostmarkt zu sichern und den Absatzmarkt für Bio-Produkte in Europa vor Betrugsversuchen zu schützen (Niedzwezky 2004). 
Aufgrund der „Flaschenhalsfunktion“ des Großhandels ist dies ein effektiver Ort für Qualitätskontrollen in Form von Laboruntersuchungen. In diesem Punkt sind sich die Experten einig. Aber sobald die Bio-Supermarktketten in eigene Zentrallager investieren, können dort genauso einfach und effektiv die Kontrollen durchgeführt werden (Michaelidis 2005). Nur bis dahin gilt, dass für den Einzelhandel Qualitätssicherung, bezogen auf die Stückkosten, einen zu großen Aufwand ausmacht und „der Großhandel als Sieb für den Einzelhandel“ (Raff 2005) dient.

\subsubsection{Beratung}

In vielen Einzelhandelsbereichen bietet der Großhandel heute Beratung für den Einzelhandel an. Die Bedeutung der Großhandelsberatung wird deutlich, wenn man einen Blick auf die Homepages der bedeutendsten Großhändler wirft. So bietet Weilling beispielsweise in einer

eigens gegründeten Weilling-Akademie verschiedene Schulungsmaßnahmen für Einzelhändler an.

Die Bedeutung der Beratung wird unter den Experten kontrovers diskutiert. Vor allem die Einzelhändler unter den befragten Experten stufen die Bedeutung des Großhandels in der Beratungsfunktion als sehr gering ein, da die Großhändler bei relevanten Fragen wie zur Sortimentsgestaltung häufig enttäuscht haben. Einen weiteren Nachteil sehen die Einzelhändler darin, dass die Großhändler die Produkte in den Vordergrund stellen, bei denen ihre Handelsspanne am größten ist (Tenta 2005). Aus Sicht der Großhändler wird die Bedeutung der Beratungsfunktion anhand der Einzelhandelsgröße festgemacht. Große Einzelhandelsfilialisten, die über eigene Fachkompetenz verfügen, nutzen nur selten das Angebot des Großhandels. Sie haben sich durch den „Einkauf“ von Personal aus dem konventionellen LEH entsprechendes Know-how angeeignet. Für kleinere Bioläden hingegen ist das Produktberatungsangebot sowie Warenkunde von großer Bedeutung.

Allerdings nehmen auch Hersteller wie Rapunzel die Beratung der Einzelhändler selbst in die Hand, um den Großhandel, der seit einiger Zeit verstärkt für seine Eigenmarken wirbt, zu umgehen (Schrade 2005).

Obwohl der Großhandel durch verschiedene Beratungsangebote versucht hat, seine Stellung in der Wertschöpfungskette zu festigen, könnten diese Aufgaben auch von anderen Akteuren übernommen werden. Bislang wird noch nicht das spezifische Wissen weitergegeben, das 
dem Einzelhändler vor Ort zusammen mit seinen Standortkenntnissen das Know-how zur Verfügung stellt, das ihn dauerhaft an den Großhandel bindet.

\subsubsection{Finanzdienstleistung}

Unter Finanzdienstleistungen sind Dienstleistungen des Großhandels an die Einzelhändler wie die Vergabe von Krediten, Rabatten, Ladenausstattungen und verlängerte Zahlungsziele zu verstehen. Die hohe Relevanz des Services ist an dem Beispiel des Bio-Großhandels Weilling zu erkennen, der seinen Kunden bei einer Neueröffnung eines Ladens ein Finanzierungsmodell in Form einer Bürgschaft von 20 \% über drei Jahre anbietet (o. V. 2004b).

Die Finanzdienstleistungen, die der Großhandel dem Einzelhandel anbietet, haben stark an Bedeutung gewonnen. Das liegt einerseits daran, dass es für die Einzelhändler aufgrund von Basel II schwer geworden ist, Kredite von den Banken zu bekommen, und andererseits an den hohen Kosten, die für die Neueröffnung eines Bio-Ladens entstehen. Aus diesem Grund sind viele Einzelhändler auf die finanzielle Unterstützung des Großhandels in Form von Zahlungszielen, Bürgschaften und Krediten angewiesen (Römer 2005). Im Gegenzug verpflichtet sich der Einzelhandel, über einen längeren Zeitraum eine bestimmte Menge an Ware bei dem unterstützenden Großhandel zu beziehen.

Kleine Bioläden werden es hingegen auch bei den Großhändlern schwer haben, finanzielle Unterstützung zu bekommen. Auch Großhändler haben, ebenso wie Banken, kein Interesse daran, in Bioläden zu investieren, deren wirtschaftliche Aussichten ungewiss sind (Schrade 2005). Letztlich ist die Frage der Finanzierung von Bio-Läden aber weniger eine des Kapitalgebers, sondern vielmehr eine von Größe und Professionalisierung. Bei funktionierenden Finanzmärkten steht Risikokapital für aussichtsreiche Geschäftsmodelle zur Verfügung.

Aufgrund der unterschiedlichen Aussagen kann an dieser Stelle nicht mit Sicherheit festgestellt werden, ob die Finanzierung durch den Großhandel an Bedeutung gewinnt oder verliert. Sie wird in den Bereichen zunehmen, in denen die Kredite der Großhändler deutlich günstiger sind als die der Banken oder in denen die Einzelhändler, aufgrund von schlechten Betriebsergebnissen in der Vergangenheit, keine Kredite von Banken bekommen. Dass zumindest ein Teil des Biohandels Probleme mit Krediten von Banken hat, zeigt eine Studie, in der die Bio-Lebensmittelwirtschaft nach ihren Erfahrungen mit Finanzierungsmodellen von Hausbanken befragt wurde. Hier geben 20 \% der Unternehmen des Biohandels an, dass 
Kreditanträge abgelehnt wurden. Insgesamt kommt diese Studie zu dem Ergebnis, dass Kredite über Hausbanken zunehmend schwieriger werden (Mercabio 2003).

\subsubsection{POS-Marketingkonzepte}

Die Naturkostbranche wird zu einem Großteil durch Marketingkonzepte des Großhandels bedient. Die Marketingkompetenzen und das Marketingbudget der Naturkostfachhändler sind vielfach gering, so dass der Großhandel hier zentrales Know-how bereit stellt und economies of scope ermöglicht. So benutzen ca. 350 Naturkostfachgeschäfte ein von 12 Regionalgroßhändlern erarbeitetes Werbekonzept unter dem Slogan „Echt Bio“ (o. V. 2004c). Dazu sagt Ronald Mikus, einer der Verantwortlichen dieses Konzepts: „Wir wollen den selbständigen Einzelhändlern genügend Platz für Eigeninitiativen lassen, ihnen aber gleichzeitig kompetente Marketinghilfen anbieten. Das ist uns unter dem Kampagnendach 'Echt Bio’ gut gelungen“ (Mikus 2004). Der Ansatz wurde in Zusammenarbeit von mehreren Großhändlern und dem BNN erstellt und wird nun dem Einzelhandel angeboten.

Der Vorteil für die Einzelhändler ist, dass sie sich nicht unter hohem Aufwand die Marketingkonzepte selber erarbeiten müssen, sondern die Option haben, Konzepte preiswert bei den Großhändlern einzukaufen. Das gilt nicht nur für kleinere Bioläden, sondern auch für kleinere Großhändler, für die es ebenso schwierig ist, in Marketingaktivitäten zu investieren. Die einzigen, die außer den umsatzstarken Großhändlern investieren können, sind größere Biosupermarktketten, die finanziell und personell besser ausgestattet sind. So haben sie die Möglichkeit, ihre eigenen Konzeptionen zu entwickeln und sie regionenspezifisch durchzuführen (Michaelidis 2005).

Eine weitere wichtige Rolle im Marketing spielen die Hersteller, die sich insbesondere auf das POS-Marketing spezialisiert haben (Müller 2005). Für die Zukunft gehen die Prognosen dahin, dass sich „der Großhandel im Verbund mit dem Hersteller verstärkt um das Marketing kümmern wird“ (Römer 2005). Angesichts des zunehmenden Verdrängungswettbewerbs im Bio-Einzelhandel wird die Funktion des Marketings durch die Großhändler weiter an Bedeutung gewinnen, da sie durch Zusammenschlüsse mit anderen Großhändlern oder Herstellern die preisgünstigsten Konzepte am Markt für die Einzelhändler anbieten können. Alternativ dazu könnten Einzelhändler zur Erarbeitung von Marketingkonzepten auch kooperieren, dann könnten sie die Kosten senken und die Bedeutung der Marketingkonzepte der Großhändler reduzieren. 


\subsubsection{Handelsmarken}

Die Relevanz von Handelsmarken für das Einzelhandelsmarketing ist im Lebensmittelmarkt unbestritten. Im konventionellen Bereich liegt ihr Anteil inzwischen bei ca. $30 \%$ des Umsatzes (Gerhardt 2005). In der Bio-Branche lag der Umsatzanteil der Handelsmarken im Jahr 2004 mit 5,1 \% im Trockensortiment und 15,5 \% im Frischesortiment deutlich niedriger, allerdings mit deutlich steigender Tendenz. Im Jahr 2003 nahm der Anteil der Handelsmarken um ca. 30 \% zu (BioVista 2005).

Der Großhandel ist der wichtigste Akteur in der Bio-Branche, der in Handelsmarken investiert. Bekannte Beispiele sind Dennree, Bioladen und Green. Die Folge ist, dass Naturkosthersteller dem Großhandel vorwerfen, mit ihren Handelsmarken die Branche in einen ruinösen Preiswettbewerb zu treiben, da die Gewinnspannen aller Beteiligten, vom Landwirt bis zum Einzelhändler, geschmälert werden (Fiedler 2003b).

Über die Bedeutung der Handelsmarken in der Bio-Branche sind sich die Experten uneinig. Ihre Stellungnahmen reichen von „keine große Bedeutung“ (Michaelidis 2005) bis zu „spielen eine sehr große Rolle“ (Schrade 2005). Die Einzelhändler unter den Befragten messen den Handelsmarken, im Gegensatz zu den Herstellermarken wie z. B. Rapunzel, keine große Bedeutung zu. Nur bei relativ einfachen Produkten wie beispielsweise Nudeln oder Milch sehen auch sie einen Trend zu den Handelsmarken, deren Preis in den meisten Fällen unter denen der Herstellermarken liegt. Neben den Großhändlern versuchen derzeit nur wenige BioSupermarktfilialisten am Markt ihre Eigenmarke zu positionieren. Ein Beispiel dafür ist die Handelsmarke von Basic (Tenta 2005).

Ziel einer Handelsmarke ist die stärkere Bindung der Einzelhändler an den Großhändler (Römer 2005), die durch Gewöhnungseffekte und Markenbindungen der Kunden seinerseits für den Biofachhändler unverzichtbar wird. Hinzu kommt, dass Handelsmarkenkonzepte den Hersteller unter Druck setzen (Tenta 2005) und Preisspielräume erhöhen.

In den unterschiedlichen Positionen zu Marken und den daraus resultierenden Machtfragen in der Bio-Branche wird deutlich, dass das Thema Handelsmarken noch ausführlicher diskutiert werden muss, bis sich eine eindeutige Stellung herauskristallisiert hat. Trotz der unterschiedlichen Vorstellungen der Experten ist ein Trend zu den Handelsmarken sichtbar. 
Bedeutende Akteure, die in Zukunft verstärkt in die Implementierung von Marken investieren werden, sind neben dem Großhandel auch finanzstarke Einzelhändler. Insgesamt ist die Markenpolitik im Biobereich derzeit noch eher unterentwickelt, so dass sich hier für Hersteller wie Großhändler erhebliche Potenziale bieten.

\subsection{Zukunft des Großhandels aus Expertensicht}

Die Entwicklung im Einzelhandel und damit des Großhandels hängt überwiegend davon ab, wie sich LEH und Bio-Supermärkte in Zukunft verhalten. Nach der bisherigen Entwicklung des LEHs zu urteilen, sehen die Fachhändler den LEH nicht als direkte Gefahr im Wettbewerb um Marktanteile, da er nicht annähernd die Beratung und Sortimentsleistung des Bio-Fachhandels bieten kann. Sie sehen Bio-Produkte im konventionellen LEH als Chance für sich, da Neukunden dort „auf den Geschmack von Bio kommen“ und später das größere Sortiment des Bio-Fachhandels nachfragen werden (Tenta 2005). Die Expansion der BioSupermärkte und Bio-Discounter wird wegen der niedrigen Preise wesentlich kritischer beurteilt. Der Fachhandel befürchtet, dass Bio-Läden die Kunden informieren und beraten und diese anschließend die Bio-Produkte in den günstigeren Betriebsformen einkaufen werden (Müller 2005). Eine eigene Studie über die Kundenbindung von Bio-Intensivkäufern im BioFachhandel bestätigt die Einschätzung der Abwanderungsgefahr. Nur ein kleiner Teil der Kunden bleibt dem Bio-Laden unabhängig von Preisdifferenzen treu, bei dem überwiegenden Teil ist die Gefahr des Wechsels in den Bio-Supermarkt bei entsprechendem Angebot sehr wahrscheinlich (Gerlach et al. 2005).

Neben dem erhöhten Preisdruck, den alle Akteure in den letzen Jahren zu spüren bekommen haben, ist der zunehmende Einzug eines ökonomischen Denkens in der Bio-Branche zu erkennen. Dies führt zu einer stärkeren Professionalisierung dieser Branche. Damit wird auch die klassische kleinbetriebliche Wertschöpfungskette für Bio-Lebensmittel, die ihren Hintergrund in der alternativen Wirtschaftsstruktur hat, und in der Produktivitätsgesichtspunkte nicht im Vordergrund stehen sollten, in Frage gestellt. Der zunehmende Wettbewerbsdruck auf der einen und die stärkere Professionalisierung der Anbieter auf der anderen Seite führen jedoch dazu, dass ökonomische Kalküle an Relevanz gewinnen und Strukturen hinterfragt werden (Lautermann/Pfriem 2005: 15 ff.). 
Die vertikale Integration, vor allem die Vorwärtsintegration und die vertikale Selektion, spielen in der Bio-Branche eine immer wichtigere Rolle, da sie die Veränderung und Optimierung des Absatzkanals widerspiegeln. Für die Vorwärtsintegration des Großhandels nennen die Experten eine ausreichende Kapitalausstattung als wichtigste Voraussetzung. Da aber nur wenige Großhändler über genügend Kapital verfügen, um ein breites Filialnetz aufzubauen, ist in der Vergangenheit nur von wenigen Fällen zu berichten (Raff 2005). Ein Beispiel ist Dennree, „der eine separate $\mathrm{GmbH}$ für die Führung eigener Bio-Supermärkte gegründet hat und marode Läden aufkauft und daraus zukunftsfähige Bio-Supermärkte macht“ (Schrade 2005). Der Nachteil eines solchen Vorgehens ist, dass einige BioFachhändler den Einkauf bei Dennree boykottieren und ihre Ware von anderen Großhändlern beziehen (Römer 2005).

Vertikale Selektion hingegen kann zu einer Existenzgefährdung der Großhändler führen, da sie ihre Position in der Wertschöpfungsstufe verlieren. Um dies zu verhindern, sind die Experten der Meinung, dass der Großhandel Funktionen übernehmen muss, die von keinem anderen Marktakteur übernommen werden können. Dazu gehören die Kernleistungen Logistik, Sortimentsbündelung und Transaktionskostenreduktion. Neben der Qualität der Ware hat die Flexibilität der Großhändler für den Einzelhandel eine große Bedeutung. Aus diesem Grund haben die Großhändler solange keine Konkurrenz zu befürchten, wie die Hersteller den Kunden nicht genauso flexibel wie die Großhändler beliefern können. Eine andere Strategie, um sich in der Bio-Branche unentbehrlich zu machen, ist die Spezialisierung auf eine bestimmte Warengruppe. Insbesondere die Spezialisierung auf Obst und Gemüse hat sehr gute Zukunftsperspektiven. Bei einem Blick auf die konventionelle Lebensmittelbranche wird die Wichtigkeit der Spezialisierung des Großhandels deutlich, da selbst Aldi seine Frischeprodukte (Obst und Gemüse) auf dem Großmarkt und nicht direkt bei den Herstellern bezieht (Schrade 2005).

\section{TABELLE 6: ANFORDERUNGEN AN DEN GROßHANDEL}

\begin{tabular}{|cl|}
\hline - & Bereitstellung qualitativ hochwertiger Ware \\
- & Pünktliche Anlieferung \\
- & Vorab-Beratung am Telefon \\
- & Tohe Flexibilität (z. B. spätmöglichster Bestellzeitpunkt) \\
- & Spezialisierung auf eine Warengruppe \\
\hline
\end{tabular}

Quelle: Eigene Zusammenstellung in Anlehnung an die Experteninterviews 
Wenn der Hersteller Lösungen findet, wie die Schwierigkeiten einer Direktbelieferung überwunden und wichtige Funktionen des Großhandels übernommen werden können, dann wird der Großhandel nur wenige Möglichkeiten haben, dieses Vorgehen zu unterbinden. Handelt es sich auf der Lieferantenseite des Großhandels um einen bedeutenden Hersteller mit einer hohen Marktmacht, dann wird der Großhandel so gut wie keine Möglichkeiten haben, den Hersteller durch Auslistung zu sanktionieren. Weniger bekannte Hersteller, die durch alternative Lieferanten leicht zu ersetzen sind, müssen dagegen eher mit einer Auslistung des Großhandels rechnen. Auf der Abnehmerseite des Großhandels bleiben die Einzelhändler in der Regel unbestraft (Schrade 2005).

Zwischenfazit: Analysiert man die verschiedenen Möglichkeiten der Vorwärts- und Rückwärtsintegration in der Kette, sind verschiedene Entwicklungsmöglichkeiten denkbar. Diese können zum einen nach der Form der Zusammenarbeit gruppiert werden, zum anderen danach, von welcher Wertschöpfungsstufe die Initiative ausgeht. Die Aussagen der Experten deuten wichtige Entwicklungsparameter an, eine klare Tendenzaussage fehlt jedoch ebenso wie eine strukturierte Analyse der potenziellen Optionen der Wertschöpfungskettengestaltung. Im folgenden Abschnitt sollen die verschiedenen Entwicklungsmöglichkeiten sowie deren theoretischen Potenziale am Biomarkt daher näher mit Bezug auf die neuere Managementforschung untersucht werden.

\subsection{Theorien zu Funktionen bzw. Ausschaltung des Großhandels}

Die Entwicklung des Großhandels muss im Zusammenhang mit der Entwicklung des Einzelhandels, als Hauptkunde des Großhandels, gesehen werden. Nicht zuletzt die Entwicklungen im konventionellen LEH haben gezeigt, dass die Struktur auf Einzelhandelsebene entscheidend für die Perspektiven des Großhandels ist. Daher steht im Folgenden die Marktentwicklung des Bio-Handels insgesamt im Mittelpunkt. Aufgrund der dynamischen Marktprozesse sind allerdings keine einfachen Prognosen möglich. Wie immer in ökonomischen Fragen ist es letztlich das Handeln der Akteure in den gegebenen, aber nicht unveränderlichen Strukturen, die die Prognosegenauigkeit verringern.

Eine der wichtigsten und für den Großhandel relevantesten Entwicklungen im Bereich des Bio-Handels ist die Filialisierung von Einzelhandelsgeschäften, i. d. R. in Form von BioSupermärkten. Unter Filialisierung wird die Vervielfachung eines bestehenden, standardisierten Geschäftstyps verstanden. Vorteile der Filialisierung sind Kostenersparnisse 
durch Zentralisierung des Einkaufs und Ausnutzung von Größeneffekten im Marketing. Nachteile ergeben sich aus der Vernachlässigung lokaler Standortparameter, z. B. von Konsumentenzielgruppen und insbesondere von lokalen Wettbewerbern (Hansen 1990: 562). In der Biobranche sind verschiedene Filialisierungskonzepte denkbar bzw. vorhanden. Dazu gehören:

- Filialisierungen ausgehend vom Großhandel (bzw. Verbundgruppen) („Regiemodell“): In der konventionellen Lebensmittelwirtschaft wird diese Filialisierungsform als „Regiemodell“ bezeichnet, da Einzelhandelsgeschäfte vom Großhandel „in eigener Regie geführt“ werden. Beispiele für diese Filialisierungsform sind im konventionellen Bereich Edeka, Rewe und SPAR (Geßner 2001a: 1479), im Biomarkt Dennree mit seinen derzeit zwölf Märkten (Fiedler 2005b).

- Einzelhändler mit eigenen Filialen („Alnatura-Modell“): Das Beispiel Alnatura zeigt, wie erfolgreich Filialisten im Einzelhandel agieren können. Alnatura ist mit 21 Bio-Supermärkten der größte und auch erste Bio-Filialist (Heinze 2002). Neben den eigenen Filialen werden die etwa 635 Produkte der Eigenmarke „Alnatura“ aber auch über den qualitätsorientierten konventionellen Handel bei Tegut, dm, Budnikowsky, Hit, Feneberg und Famila angeboten (o. V. 2005c). Ein weiteres bekanntes Beispiel für diese Filialisierungsstrategie ist Basic. Basic begann 1997 mit einem Bio-Supermarkt in Schwabing und hat inzwischen die Zahl der Filialen auf insgesamt 14 in 10 Städten erhöht. Dieses Filialisierungsmodell ist das typische im konventionellen Lebensmitteleinzelhandel, besonders im Discountund Großflächenbereich (z. B. Aldi, Kaufland, Real). Ein bestehendes, standardisiertes Ladenkonzept wird auf einen neuen Standort ausgeweitet. Im BioMarkt finden sich neben Basic auch andere Filialisten. Dazu gehört „SuperBioMarkt“ mit neun Filialen in Nordrhein-Westfalen (Heinze 2002), Erdkorn, ein Filialist der bislang sieben Filialen vor allem in Norddeutschland unterhält, aber bundesweit expandieren will (Fiedler 2005c), der bislang finanziell nicht erfolgreiche Filialist SuperNatural mit fünf Standorten (o. V. 2005d) und die Rewe-Tochter Vierlinden mit bislang zwei Filialen (Großinsky 2005: 22).

- Hersteller mit eigenen Filialen („Tchibo-Modell“): Auch Hersteller können im Zuge einer Vorwärtsintegration als Filialisten im Markt auftreten. Ein prominentes Beispiel dafür ist Tchibo. Im Bio-Bereich gibt es bisher keinen derartigen Hersteller. Allerdings finden sich keine Beispiele für Herstellerfilialen mit breitem 
Sortiment, da bei hoher Sortimentsbreite offensichtlich die Produktkompetenzen eines einzelnen Herstellers nicht ausreichend sind. Herstellerfilialen finden sich deshalb schwerpunktmäßig bei spezialisierten Fachhändlern.

Neben Filialisierungskonzepten sind verschiedene Formen von Franchisesystemen denkbar. Auch hier wird ein standardisiertes Konzept auf die Fläche übertragen, allerdings werden die neuen Geschäftsstätten vom Franchisenehmer selbständig geführt und nicht von einem angestellten Filialleiter. Unter Franchising wird allgemein ein Systemverbund einer Franchisezentrale und selbständigen Kaufleuten verstanden, das am Markt einheitlich auftritt. Der Franchisegeber stellt ein Beschaffungs-, Absatz- und Organisationskonzept zur Verfügung, ebenso das Nutzungsrecht an Schutzrechten (z. B. Firmenname, Vertrieb von Waren etc.). Der Franchisenehmer arbeitet im eigenen Namen und auf eigene Rechnung (Tietz/Zentes 2001a: 493), er bezahlt eine umsatzabhängige Franchisegebühr sowie ggf. eine Eintrittsgebühr und Werbekostenbeteiligungen. Im Gegensatz $\mathrm{zu}$ kooperativen Handelssystemen besteht der Unterschied in Franchisesystemen in der Intensität der Zusammenarbeit und weniger in den Kostenstrukturen. Bislang sind am deutschen Bio-Markt nur wenige Franchisekonzepte vorzufinden, obwohl diese zeitweise intensiv diskutiert wurden (Kreuzer 2000). Folgende Konstellationen für Franchising sind denkbar:

- Franchising ausgehend vom Großhandel (abgewandeltes „denn's-BioModell“): Wenn ein einheitliches Laden-Design, Beschaffungs- und Handelsmarken zur Verfügung gestellt werden, so kann dies auch über unterschiedlich intensive Formen mittels Franchisesystem vom Großhandel bereitgestellt werden. Der Großhändler Dennree denkt z. B. darüber nach, sein Discount-Filialkonzept „denn’s-bio“ bei gelungener Markteinführung als Franchisekonzept anzubieten (Fiedler 2005b), zunächst wird ein für das Jahr 2005 geplanter Markt mit einem selbstständigen Einzelhändler eröffnet (Gutting 2005).

- Franchising ausgehend vom Einzelhandel („1000 Körner Markt-Modell“): Franchise-Geber können auch Einzelhandelsunternehmen sein. Ein in der Branchen-Presse dargestelltes Beispiel ist die Franchise-Idee des 1000 Körner Marktes. Bisher wird allerdings erst eine Geschäftsstätte im Franchisekonzept geführt. Die vormals angestrebten 50 bis 100 Franchisepartner sind bislang nicht erreicht worden (Kreuzer 2000). In anderen europäischen Ländern haben allerdings Franchisekonzepte (mit unterschiedlicher Intensität in der Zusammenarbeit) relativ große Verbreitung. So gibt es z. B. in Frankreich 210 
Läden im Biocoop-System, in den Niederlanden werden im Franchisekonzept von Natuurwinkel 120 Läden geführt (Kreuzer 2000).

Unter Kooperation wird die gemeinsame Erfüllung betrieblicher Aufgaben durch wirtschaftlich und rechtlich selbständige Unternehmen verstanden. Im Handelsbereich spielen Kooperationen im Bereich Marktforschung, Werbung, Vertrieb und insbesondere in der Beschaffung eine Rolle. Der Kooperationsgrad, also die Intensität der Zusammenarbeit, kann von losen Rahmenvereinbarungen bis zum Kontraktvertrieb reichen. Im Handel sind vor allem horizontale Kooperationen des Einzelhandels, die so genannten Verbundgruppen mit einer gemeinsamen Einkaufszentrale, relevant. Daneben gibt es zweistufige Kooperationen des Großhandels, bei denen sich Großhandelsunternehmen verschiedener Regionen zusammenschließen und Einzelhandelsgeschäfte an sich binden. Dieses Organisationsmodell wird als „freiwillige Kette“ bezeichnet (Tietz/Zentes 2001b: 825). Häufig zielen Kooperationen im Handel darauf ab, im Wareneinkauf Synergieeffekte zu nutzen. Inzwischen werden aber auch weitere Funktionen zunehmend wichtig, so dass sich so genannte FullService-Organisationen entwickelt haben, die u. a. auch Aufgaben im Bereich des Marketings übernehmen (Geßner 2001b: 1742). Im Bio-Handel sind folgende Modelle denkbar:

- Einzelhandelskooperationen („Edeka-Modell“): Durch den Zusammenschluss verschiedener Naturkostfachgeschäfte können Größeneffekte vor allem im Einkauf erschlossen werden. Die erfolgreiche Entwicklung der Kooperationsgruppen Edeka und Rewe kann hier ebenso als Beispiel dienen wie Neuform im Reformwarenhandel.

- Filialisierte Einzelhändler bzw. Supermärkte schließen Kooperationen („Markant-Modell“): Kooperationen sind auch zwischen filialisierten Einzelhandelsgeschäften denkbar, wenn die einzelnen Filialunternehmen für sich noch nicht die kritische Größe am Markt erreichen. Hier sind aufgrund der Größe deutliche Skaleneffekte zu erwarten, die Intensität der Zusammenarbeit ist allerdings regelmäßig geringer.

- Großhandel schließt Kooperationen mit dem Einzelhandel (freiwillige Kette „Spar Modell“/Partnerschaftskonzepte Bodan): Das europaweit bekannteste Beispiel einer freiwilligen Kette ist die inzwischen in Deutschland nicht mehr vertretene Spar-Gruppe. Auch im Biomarkt sind ausgehend von Großhändlern bereits einige Kooperationsmodelle mit unterschiedlicher Intensität der Zusammenarbeit zu finden. Der regionale Großhändler Bodan bietet 
beispielsweise ein Partnerschaftsmodell an, in dem dem Einzelhändler vor Ort neben der Beratung zur Optimierung der Sortimente und der Warenpräsentation auch Unterstützung bei der Auswertung der Betriebsergebnisse sowie Mitarbeiterschulungen angeboten werden. Zudem werden verschiedene Maßnahmen zur Verkaufsförderung und Kommunikation vom Großhändler durchgeführt. Im Gegenzug verpflichtet sich der Fachhändler, „den Bedarf so weit wie möglich“ über Bodan zu decken (o. V. 2005e).

Die dargestellten Optionen deuten auf die Vielzahl von Entwicklungsmöglichkeiten im Biomarkt hin. Bisher sind der horizontale und der vertikale Organisationsgrad in der Branche eher gering. Die aufgezeigten Modelle finden sich erst ansatzweise wieder.

Aus theoretischer Sicht ist es schwierig, die verschiedenen Optionen mit einem einzelnen Ansatz zu bewerten, da es keine geschlossene Theorie gibt, die der Fragestellung umfassend gerecht wird. Den bisherigen Ausführungen lag im Kern der traditionelle absatzwirtschaftliche Ansatz der Handelsfunktionenlehre zugrunde (Schenk 1991). Dieser ist wichtig zur Systematisierung der komplexen betrieblichen Realität, zugleich ist er aber eher deskriptiver und statischer Natur und vermag die Veränderungsdynamik der Märkte nur begrenzt einzufangen. Historisch gewachsene Aufgabenverteilungen sind in einer Wettbewerbswirtschaft nicht schutzfähig. Im Folgenden soll aus Sicht neuerer betriebswirtschaftlicher Theorien eine zusammenfassende Beurteilung der Perspektiven des Großhandels vorgenommen werden.

Relativ klare Aussagen sind auf transaktionskostentheoretischer Basis möglich. Die Transaktionskostentheorie in ihrer klassischen Variante beschäftigt sich mit der Reduktion von Kontaktkosten durch die Einschaltung eines Handelsbetriebs (siehe Kap. 5.1.2). Demnach reduzieren Handelsbetriebe bei wachsender Anzahl von Produzenten und Konsumenten, im Falle des Großhandels zwischen Herstellern und Einzelhändlern, die Transaktionskosten (Baligh/Richartz-Effekt). Der Großhandel trägt in der Kette zu einer Kostenersparnis bei, solange viele kleinere Einzelhändler auf der abnehmenden Seite vorhanden sind. Im Falle größerer Einheiten verringert sich die Kostenersparnis, und diese Handelstufe wird sich Ausschaltungstendenzen ausgesetzt sehen. Bei der derzeitigen Struktur der Wertschöpfungskette ist es zurzeit noch unwahrscheinlich, dass durch Ausschalten des Großhandels die Transaktionskosten gesenkt werden können. Die Logistik- und Bündlungs- 
funktion müssten selbst organisiert werden, was erst bei starkem Wachstum vor allem der filialisierten Bio-Supermärkte rentabel wäre. Damit wird aber auch deutlich, dass für einen Großteil der Bio-Großhändler der Verbleib im Markt verknüpft ist mit der Entwicklung der Bio-Läden. Nur bei einer Vielzahl von relativ kleinen selbständigen Lebensmitteleinzelhändlern trägt der Großhandel zu einer Transaktionskostenreduktion bei und festigt bzw. verteidigt seine Stellung in der Wertschöpfungskette. Bei zunehmender Marktmacht filialisierter Bio-Supermärkte, Franchisesystemen oder einem Zusammenschluss der Fachhändler zu Kooperationsgruppen trifft dies nur noch auf Spezial- bzw. Frischegroßhändler zu.

Der Resource-based View des Strategischen Managements hebt auf die Unternehmensbesonderheiten als zentrale Prämisse der Strategiewahl ab (Prahalad/Hamel 1990; Theuvsen 2001). Es gibt Kernkompetenzen, die ein Unternehmen unverwechselbar machen und auf die bei der Strategieselektion geachtet werden muss. Kernkompetenzen sind gegenüber der Konkurrenz herausragende Fähigkeiten, die den erfolgreichen Leistungen des Unternehmens zugrunde liegen, schwer imitierbar bzw. substituierbar sind und potenziell den Zugang zu neuen Märkten eröffnen. Zur Systematisierung hat sich eine Einteilung in physische (z. B. Technologie, Rohstoffe, Standort), intangible (z. B. Humankapital, Unternehmenskultur, Außendienststärke, Kundendaten, Reputation) und finanzielle Ressourcen (z. B. Cash-flow, Finanzierungsmöglichkeiten) durchgesetzt (Rasche 2004).

Es stellt sich aus Sicht des ressourcenorientierten Ansatzes die Frage, welche Kernkompetenzen der Großhandel hat oder aufbauen muss, um einen Verbleib in der Wertschöpfungskette zu gewährleisten. Bislang sind es vor allem die erwähnten Logistik- und Bündlungsfunktionen, die die Stärke dieser Wertschöpfungsstufe ausmachen. Die Stärke der Großhandelsunternehmen in Konkurrenz zu anderen Organisationsformen der Kette wird dann durch die jeweilige logistische Leistungsfähigkeit bestimmt. Diese Funktionen können allerdings auch von größeren Filialunternehmen übernommen werden, so dass diese Aufgabe imitierbar ist und nur dann einen langfristigen strategischen Vorteil verspricht, wenn hier Leistungen aufgebaut werden können, die über den Marktstandard von z. B. Speditionsunternehmen hinausgehen. Ähnliches trifft für die Sortimentsbündlungsfunktion zu, die nur dann langfristige Wettbewerbsvorteile verspricht, wenn außergewöhnliche Beschaffungsoptionen erschlossen werden, die von einem Filial- oder Franchiseunternehmen nicht leicht zu imitieren sind. 
Die Beratungsfunktion, die der Großhandel besonders für kleinere Einzelhändler übernimmt, wird von den Experten zurzeit noch nicht als essentiell eingeschätzt. Bislang scheint der Großhandel wenig Beratungs- und Marketing Know-how aufgebaut zu haben. Allerdings unterscheiden sich die einzelnen Großhandelsunternehmen hier wohl deutlich. Da eine Reihe von Großhändlern durch eigene Fachhandelsgeschäfte sowie die Auswertung von Umsatzzahlen über wichtige Marktdaten verfügt, besteht zwar grundsätzlich die Möglichkeit, aus diesen Informationen eine Kernkompetenz zu generieren. Fraglich ist aber, ob zum einen dafür entsprechende personelle Ressourcen vorhanden sind, und zum anderen, ob dieses Wissen nicht auch von filialisierten Einzelhandelsunternehmen aufgebaut werden kann.

Insgesamt lässt der ressourcenorientierte Ansatz keine übergreifenden Aussagen für alle Großhändler zu. Vielmehr hängt die Zukunft des Großhandels aus dieser Sicht von der erfolgreichen Generierung und Verteidigung der jeweils spezifischen Kernkompetenzen ab. Fehlen Unternehmen einzelne, im Wettbewerb relevante Kernkompetenzen, so sollte diese Lücke z. B. durch die Akquisition von Unternehmen oder durch Personaleinstellungen geschlossen werden. Es deutet einiges darauf hin, dass eine zu starke Fokussierung auf Logistik- und Sortimentsbündelung im Wettbewerb mit stärker konzentrierten Einzelhandelsunternehmen problematisch wird. Ergänzende, marktnahe Kernkompetenzen erscheinen insbesondere für die Vollsortimenter wichtig, während Warengruppenspezialisten ihre Kernkompetenzen in der Beschaffung ausbauen sollten.

Der wissensbasierte Ansatz unterscheidet grundsätzlich zwischen generellem und damit leicht weiterzugebendem sowie spezifischem und entsprechend schwer übertragbarem Wissen (Bonus/Wessels 1998). Die Form des Wissens, die in einem bestimmten Markt wichtig für den Erfolg einer Unternehmung ist, wirkt sich auch auf die Organisationsstruktur aus. Eine besondere Art des spezifischen Wissens, das auch plastisches Wissen genannt wird, sind z. B. Kenntnisse über lokale oder regionale Besonderheiten. Die Nutzung dieser Informationen kann vertraglich nicht festgeschrieben werden, da sie von außen bzw. für einen Auftraggeber nicht beobachtbar ist. Es kann nicht unterschieden werden, ob es Glück war, welches einen Ladenbesitzer zum Erfolg geführt hat, oder das durch Lebenserfahrung erworbene Fingerspitzengefühl eines Akteurs. In Märkten oder Geschäftsfeldern, in denen die Erfolgsfaktoren nicht mehr zentral kontrolliert werden können, da sie vor allem auf plastischem Wissen beruhen, bilden sich dezentrale Entscheidungsstrukturen. Handelt es sich 
dagegen um ein Geschäft, in dem das entscheidende Wissen durch generelle Managementfähigkeiten oder technische Systeme geprägt wird, lassen sich zentrale Organisationsstrukturen wie ein Filialsystem erfolgreich installieren. Beispielhaft verdeutlicht: Das Management eines Discounters ist sehr gut zu zentralisieren, da es entscheidend auf Standardisierungsvorteile im Einkauf und eine ausgefeilte zentrale Logistik ankommt, während lokale Verbraucherpräferenzen systembedingt und damit beabsichtigt keine Berücksichtigung finden. Discounter werden daher als strikt zentral geführte Filialsysteme organisiert. Supermärkte dagegen, so zeigt die Erfahrung der letzten 20 Jahre, verlangen aufgrund ihres breiteren und tieferen Sortiments sowie der hohen Bedeutung der Kundenzufriedenheit lokale Kenntnisse und können daher - trotz entsprechender Nachteile im Einkauf - erfolgreicher durch selbständige Kaufleute innerhalb einer Verbundgruppe geführt werden. Nicht ohne Grund privatisieren Edeka und Rewe seit geraumer Zeit ihre (kleineren) Regiebetriebe. Großflächenmärkte wie SB-Warenhäuser dagegen sind für Einzelkaufleute zu komplex, hier wird das zentrale System-Know-how wieder wichtiger, so dass sich kaum selbständige Kaufleute finden. Mit diesem Ansatz kann auch die Bedeutung von Franchisesystemen erklärt werden. Der Franchisegeber bietet ein leicht vermittelbares, auf generellem Wissen basiertes Konzept an. Dieses wird vom Franchisenehmer mit dem plastischen Wissen verbunden, um das generelle Konzept vor Ort erfolgreich umzusetzen (Bonus/Wessels 1998). Franchisesysteme eignen sich besonders für Märkte mit gleichzeitig hohen Zentralisierungs- und Lokalisierungsvorteilen.

Die Situation im konventionellen LEH ist insgesamt durch das deutliche Überwiegen zentraler und hoch standardisierter Filialsysteme charakterisiert, mit Ausnahmen bei den wohnortnahen Supermärkten. Bei den Großflächen gibt es sowohl stark zentralisierte Filialkonzepte (z. B. Kaufland) als auch losere Systeme wie bei Globus, die den einzelnen Filialleitern mehr Freiräume für lokale Anpassungen bieten. Letztere finden sich eher bei qualitätsorientiert positionierten Händlern. Aufgrund der Marktstrukturentwicklung lässt sich aber zusammenfassend eindeutig die hohe Relevanz der Zentralisierung für den Geschäftserfolg ablesen.

Der Vergleich von konventionellem LEH und Biohandel deutet darauf hin, dass sich der Biobereich in wachsendem Maße in die Rolle eines spezialisierten Feinkosthändlers mit hoher Beratungskompetenz entwickelt. In diesem Geschäft kommt dem lokalen Wissen insgesamt eine höhere Bedeutung zu, was gegen eine uneingeschränkte Filialisierung spricht. Einzel- 
händler vor Ort kennen ihre Zielgruppe, die sich auch bei grundsätzlich ähnlichen Größenstrukturen der jeweiligen Städte deutlich unterscheiden kann. Sogar zwischen Stadtteilen sind deutliche Unterschiede zu finden. Neben der genauen Kenntnis der Zielgruppe und deren Bedürfnisse weiß der lokale Händler auch um die Konkurrenzsituation und kann auf diese flexibel eingehen. So kann z. B. auf Werbeaktionen von Mitbewerbern flexibel reagiert werde. Auch an örtlichen Aktionen, z. B. im Rahmen von Stadt- und Straßenfesten etc., kann sich der Einzelhändler vor Ort einfacher beteiligen und eine zielgruppenspezifische Ansprache gewährleisten. Schließlich ist es durch die persönliche Kenntnis seiner Kunden möglich, Meinungsführer zu identifizieren und damit positive Mund-zu-Mund-Werbung zu initiieren. Für Händler in einem kleinen Marktsegment wie dem Biomarkt sind diese Kenntnisse insgesamt deutlich relevanter als z. B. im Discountgeschäft.

Gleichwohl gibt es auch im Biohandel generalisierbares Wissen, und dessen Stellenwert wächst tendenziell an. Neben Produkt- und Prozesswissen gehört die Ladengestaltung, Sortimentsanordnung sowie betriebswirtschaftliches Grundwissen zum generellen Wissen, das für alle Bio-Händler gleichermaßen gilt. Ladenkonzepte, Regalplatzierungen, Sortimentsanordnungen etc. können generalisierbar und übertragbar gemacht werden. Mit steigendem Professionalisierungsgrad des Marketings im Naturkostmarkt wächst auch der Stellenwert dieser Faktoren, so dass langfristig ein Trend zu etwas zentralistischeren Strukturen zu erkennen ist.

Neben der Nutzung von generellem und spezifischem Wissen spielen motivationale Erklärungsansätze bei der Einschätzung der Entwicklung des Biomarktes eine Rolle. Die Prinzipal-Agenten-Theorie geht davon aus, dass es sinnvoll ist, anreizkompatible finanzielle Anreize zu setzen und dadurch die Motivation zu erhöhen. In Bezug auf den Handel bedeutet dies, dass ein angestellter Filialleiter mit fixem Gehalt den geringsten materiellen Anreizen unterliegt, während ein selbständiger Kaufmann die höchste Motivation aufweist. Zwischenformen sind dann variable, erfolgsabhängige Vergütungen oder finanzielle Beteiligungen für Filialleiter. Franchising ist aus Sicht dieses Ansatzes besonders Erfolg versprechend, da hier Selbständigkeit mit Weisungsbindung gekoppelt wird. Der Vorteil von Selbständigen kommt allerdings nur dann besonders zum Tragen, wenn das o. g. lokale Wissen und die Personalführung im Vordergrund stehen. In den Fällen, wo es um komplexe Tätigkeiten geht und Kundenorientierung im Vordergrund steht, erreichen Selbständige mehr als Angestellte. Im umgekehrten Fall überwiegen die Vorteile der Standardisierung. 
Die neuere ökonomische Forschung hat zudem gezeigt, dass verschiedene Arten der Motivation zu unterscheiden sind. Grundsätzlich kann die Motivation von Menschen intrinsischer oder extrinsischer Natur sein. Intrinsisch motivierte Menschen erledigen die Arbeit um ihrer selbst willen (Becker 1995: 37; Wolff/Lazear 2001: 13); zum Beispiel auf Grund von Freude an der Tätigkeit, dem Wunsch nach Anerkennung der Leistung oder aus altruistischen Zielen. Diese Motivation spielt vor allem in der Naturkostbranche eine sehr große Rolle und erklärt, warum z. B. sehr viele kleine Läden mit einer geringen finanziellen Entlohnung am Markt existent sind. Die extrinsische Motivation zielt hingegen auf eine indirekte Nutzenerfüllung ab. Die Tätigkeit wird ausgeführt, um dadurch etwas anderes zu erreichen (z. B. Gelderwerb). Bei der Ausgestaltung von Arbeitsverträgen hat sich gezeigt, dass es zu Crowding-Out-Effekten kommen kann. Intrinsische werden ggf. durch extrinsische Motive verdrängt, wenn finanzielle Anreize eingeführt werden (Frey et al. 2001: 563 ff). Wenn Menschen erkennen, dass sich bestimmte Formen des Engagements auszahlen, werden sie ihre Fähigkeiten auf diese Tätigkeiten konzentrieren und nicht entlohnte Arbeiten reduzieren. Es kann zu einem sich verstärkenden Prozess der Verdrängung von intrinsischer Motivation kommen.

Die Gefahr eines Verdrängungseffektes ist besonders bei Personen groß, für die finanzielle Anreize für ihre Tätigkeit bisher von untergeordneter Bedeutung waren und die über ein hohes Maß an eigenständiger Motivation verfügen (Theuvsen 2003: 489). Die Präferenzstruktur der Mitarbeiter ist folglich von großer Relevanz für die Anreizwirkung des Systems. Im Biohandel kann davon ausgegangen werden, dass durch die hohe intrinsische Motivation der dort Tätigen eine Umstellung auf ein stärker extrinsisch orientiertes Organisationskonzept (z. B. Filialsystem) erhebliche Crowding-Out-Effekte mit sich bringen könnte. BioLadenbesitzer und viele Mitarbeiter sind „Überzeugungstäter“. Der Ersatz dieser Motivation durch finanzielle Anreize in einem Filialsystem ist schwierig. Dieser Gesichtspunkt erklärt sicherlich einen Teil der Probleme, die bisher Filialkonzepte in der Branche haben.

Die unterschiedlichen Einflussfaktoren sollen anhand eines einfachen Schaubildes dargestellt werden. Dabei bilden die unterschiedlichen Pole zum einen Filialbetriebe eines Konzerns, zum anderen die unabhängigen Lebensmitteleinzelhändler (siehe Abbildung 7). Dazwischen finden sich gestaffelt nach Intensität der Zusammenarbeit die unterschiedlichen Kooperationsformen. Die relative Vorzüglichkeit dieser Handelsformen wird durch verschiedene, teilweise 
gegensätzliche Effekte geprägt. Dazu gehört der Einfluss der intrinsischen Motivation der Kaufleute. Mit zunehmender Eigenverantwortlichkeit des Händlers nimmt die intrinsische Motivation zu. Gerade im Biohandel spielt die Beratung und die Freundlichkeit des Personals eine große Rolle und ist damit bei der Handelsentwicklung von Bedeutung. Zudem zeigen aktuelle Beispiele aus dem konventionellen Handel, dass kleinere Geschäftsstätten oftmals in die Hände von selbständigen Kaufleuten gegeben werden, da diese, teilweise auch unter Selbstausbeutung, auf den Flächen eine höhere Rendite erzielen. Diese Beispiele verdeutlichen, dass neben einem geeigneten Ladenkonzept auch und besonders die Motivation des Personals für den Erfolg von Handelsgeschäften wichtig sind.

Warum selbständige Einzelhändler auf kleineren Flächen höhere Renditen erzielen, kann neben motivationalen Gründen auch auf der Kenntnis von lokalem Wissen begründet sein. Der Händler vor Ort kennt seine Zielgruppe und die örtliche Konkurrenzsituation, so dass Marketinginstrumente gezielter eingesetzt werden können. Auch kann auf lokale Aktionen von Konkurrenten besser reagiert werden. Dass Zusammenspiel von intrinsischer Motivation und der Einbeziehung von lokalem Wissen kann demnach zu Vorteilen gegenüber filialisierten Betriebsformen führen.

Neben den Managementeinflüssen tragen aber auch Effekte des Systemwissens sowie Größenvorteile zu der Entwicklung der Bio-Handelsstruktur bei. Unter Systemwissen kann im Handelsbereich z. B. die Ladengestaltung, das Sortiments-Know-how und die massenmediale Verbraucheransprache gefasst werden. Dieses Wissen ist leicht systematisierbar und transferierbar und kann demnach auf viele Einkaufsstätten übertragen werden. Die angesprochenen Größenvorteile sind dann besonders wichtig, wenn economies of scale eine große Bedeutung haben. Beim Einzelhandel sind dies natürlich die Wareneinstandskosten, aber auch Logistik und Marketing spielen eine wichtige Rolle. Wie in den vorangegangen Ausführungen verdeutlicht wurde, können Filialisten, Verbundgruppen oder Franchisesysteme hier ein großes Rationalisierungspotenzial erschließen. 


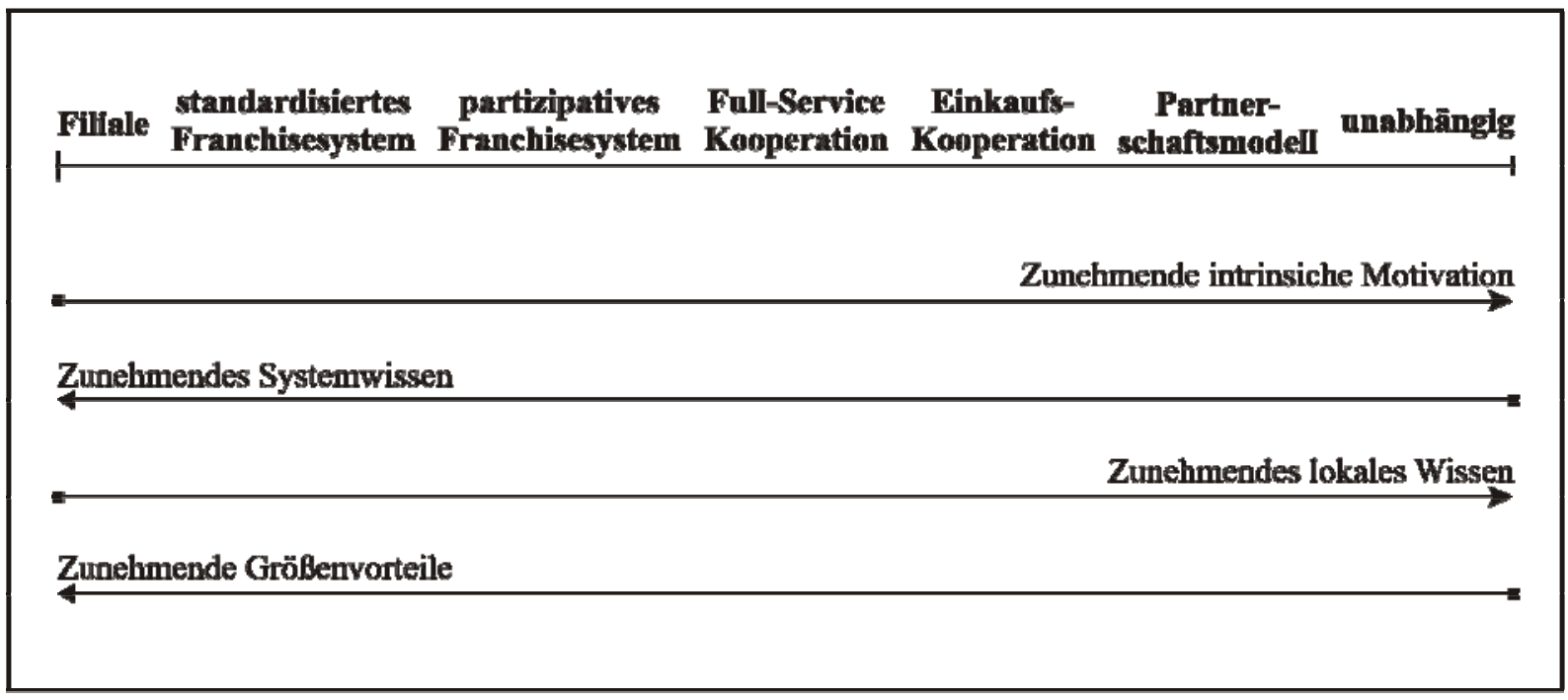

Quelle: Eigene Darstellung

Die dargestellten Einflussfaktoren verdeutlichen, dass die verschiedenen Handelssysteme unterschiedliche Vor- und Nachteile mit sich bringen. Welche dieser Einflussfaktoren besonders wichtig und vielleicht sogar ausschlaggebend für die Entwicklungen der Betriebsformen ist, kann an dieser Stelle nicht eindeutig festgestellt werden. Die schon angesprochene Dynamik des Marktes macht eine einfache „wenn - dann“ - Betrachtung aufgrund der zahlreichen Einflussfaktoren unmöglich. Hinzu kommen Pfadabhängigkeiten, da die historisch gewachsenen Strukturen Beharrungstendenzen aufweisen.

Bewertet man die vorgestellten Konzepte nach ihrer Auswirkung auf die Strukturentwicklung des Biomarktes, zeigen sich zwei wichtige Einflussfaktoren. Zum einen ist die Generierung von Größendegressionseffekten in Einkauf und Marketing besonders wichtig, vor allem wenn der zurzeit herrschende Preisfrieden zwischen den Betriebsformen brüchig wird und/oder die Bio-Discounter eine stärkere Verbreitung finden. Zum anderen scheint die Kombination aus der Nutzung von lokalem und generellem Wissen, in Kombination von intrinsisch hoch motivierten Händlern mit zentralem Marketing-Know-how, sehr wichtig zu sein, um an dem jeweiligen Standort ein Maximum zu erreichen. Diese Argumente sprechen für Franchiseoder Verbundsysteme, die generelle Konzepte bereitstellen, Größeneffekte generieren und gleichwohl dem Einzelhändler vor Ort genug Raum bietet, um sich an den lokalen Gegebenheiten anzupassen. 
Angesichts der potenziellen Vorteile einer stärkeren horizontalen wie vertikalen Kooperation bleibt zu fragen, warum Zentralisierungsvorteile bisher relativ geringe Beachtung erfahren haben. Eine wichtige - und in vielen ökonomischen Ansätzen zu wenig beachtete - Rolle dürfte hier die Branchenkultur spielen. Die Akteure der Biobranche sind in starkem Maße auf Individualität und Selbständigkeit bedacht. Dies steht einem Franchisekonzept entgegen und erklärt auch, warum bislang Franchisekonzepte wenig erfolgreich waren. Vielleicht haben Kooperationsmodelle wie das Konzept der „Regionalen Großhändler“ mehr Erfolg, da sie größere unternehmerische Freiräume bieten. Generell ist aber ein Ansatz, der versucht, Größen-, Wissens- und Motivations-Effekte zu kombinieren, sinnvoll. Welche Rolle der Großhandel in solchen Modellen spielen wird, hängt entscheidend davon ab, welches Wissen er bereitstellen kann und ob die Logistik- und Bündlungsfunktion von anderen Akteuren durch Größenwachstum übernommen wird.

\section{Fazit: Zur Zukunft des Großhandels in der Bio-Wertschöpfungskette}

Der konventionelle Lebensmittelhandel hat in Folge der Optimierung der Absatzwege den Großhandel weitgehend ausgeschaltet. Aus den Aussagen der Experten und theoretischen Überlegungen ist bei der Betrachtung der Logistikfunktion zu sehen, dass zum jetzigen Zeitpunkt der Großhandel in der Bio-Wertschöpfungskette nicht zu ersetzen ist. Mit Ausnahme weniger großer Hersteller, die den Einzelhandel direkt beliefern können, haben weder der Bio-Laden noch der Bio-Supermarkt aktuell die Möglichkeit, diese Funktion des Großhandels zu übernehmen. Ähnlich sieht es bei der Bündlungsfunktion des Großhandels aus. Aufgrund der bislang noch geringen Mengen werden an dieser Stelle (Transaktions-)Kosten verringert. Damit wird aber auch ersichtlich, dass die Rolle des Großhandels abhängig von der Einzelhandelsentwicklung ist.

Die dargestellten Entwicklungsmöglichkeiten der Handelsstruktur hängen dabei im Wesentlichen von vier Effekten ab: der Relevanz von lokalem, Wissen im Vergleich zum Systemwissen und deren Verknüpfung, der Realisation von Größeneffekten sowie der Motivation der Mitarbeiter bzw. der Händler. Da die beschriebenen Effekte nicht einheitlich wirken und die Entwicklung des Marktes Dynamiken und Branchenkulturen unterliegt, ist eine eindeutige Aussage nicht zu treffen. Für den Großhandel stellt sich aber insgesamt die Frage, welche Rolle er in den unterschiedlichen Systemen spielt, welche Kernkompetenzen vorhanden sind und wie die Stellung innerhalb der Wertschöpfungskette gesichert werden 
kann. Aus unserer Sicht spricht hinsichtlich der Sortimentsgroßhändler vieles dafür, den Ausbau der logistischen Kernkompetenzen mit einem stärkeren Investment in MarketingKnow-how zu bündeln.

Für die Agrarpolitik folgt daraus, dass sie es mit einem unübersichtlichen und in seiner Komplexität von politischer Seite kaum prognostizierbaren System zu tun hat. Interventionen wie das Bio-Siegel oder finanzielle Förderung von Beratungs- oder Qualitätssicherungsmaßnahmen im Rahmen des Bundesprogramms Ökolandbau bleiben nicht ohne Folgen für die Branchenstruktur, können allerdings von politischer Seite kaum abgeschätzt werden. Insgesamt dürften sie zu einer stärkeren Zentralisierung im Biohandel beigetragen haben. 


\section{Literatur}

Ahlert, D. (1981): Absatzkanalstrategien des Konsumgüterherstellers auf der Grundlage Vertraglicher Vertriebssysteme mit dem Handel, in: Ahlert, D. (Hrsg.): Vertragliche Vertriebssysteme zwischen Industrie und Handel, Wiesbaden: 45-96.

Ambros, G. (2005): Wenn plötzlich ein Großer kommt, in: BioHandel 8/2005, unter: www.naturkost.de/biohandel/HTML/aktuelles/ak20050806.shtml. Abrufdatum: 01.11.2005.

AoeL (Assoziation ökologischer Lebensmittel Hersteller) (2005): Assoziation ökologischer Lebensmittel Hersteller, unter www.aoel.org; Abrufdatum: 05.05.2005.

Azzam, M., Pagoulatos, E. (1999): Vertical Relationships: Economic Theory an Empirical Evidence, in: Galizzi, G. et al. (Hrsg.): Vertical Relationships and Coordination in the Food System, Heidelberg: 7-20.

Bahrdt, K. et al. (2003): Bio-Supermärkte in Deutschland - Chancen und Entwicklungen 2003, Frankfurt a. M.

Barth, K., Köhler, R. (2001): Großhandel, in: Diller, H. (Hrsg.): Vahlens Großes Marketing Lexikon, 2. Aufl. München: 551-554.

Becker, F. G. (1995): Anreizsysteme als Führungsinstrumente, in: A. Kieser: Handwörterbuch der Führung, Stuttgart: 34-45.

BioVista (2005): BioVista-Studie - Handelsmarken schwächer als gedacht, in: Newsletter Biohandel am 21.04.2005, unter: www.naturkost.de/-biohandel/public/200504.htm, Abrufdatum: 24.04.2005.

BNN (Bundesverband Naturkost Naturwaren Herstellung und Handel e. V.) (2005): BNN Herstellung und Handel, unter: www.nbnn.de/seiten/-herstellung_gh/verband/verband_gh_fs.htm; Abrufdatum: 05.05.2005.

Bodenstein, G., Spiller, A. (1998): Marketing: Strategien, Instrumente und Organisation, Landsberg/Lech.

Bonus, H., Wessels, A. M. (1998): Genossenschaften und Franchising, Arbeitspapiere Nr. 14 des Instituts für Genossenschaftswesen der westfälischen Wilhelms-Universität, Münster.

Bruhn, M. (1996): Handelsmarken im Wettbewerb: Entwicklungstendenzen und Zukunftsperspektiven der Handelsmarkenpolitik, Frankfurt a. M.

Brzukalla, H. J. (2002): Naturkostgroßhandel mit gut 30 Prozent Umsatzplus, in: BNN Nachrichten, 19. Jg., Ausgabe März 2002, unter: www.n-bnn.de/phpserve/input/bnnnachrichten/bnn-19.pdf; Abrufdatum: 24.11.2004.

Brzukalla, H. J. (2003): Naturkost Großhandel trotzt Konjunkturflaute, in: BNN-Nachrichten, 23. Jg., Heft 8: 13-14.

Coase, R. H. (1937): The Nature of the Firm, in: Economica, Vol. 4 (1937): 386-400.

Delfmann, W., Arzt, R. (2001): Marketing-Logistik, in: Diller, H. (Hrsg.): Vahlens Großes Marketing Lexikon, 2. Aufl., München: 993-998.

Die Regionalen (2005): Echt Bio im Überblick, unter: www.die-regionalen.de/cm/re/echtbio/kamp.php?objectID=3687, Abrufdatum 02.11.2005. 
Fiedler, H. (2005a): Weilling verdoppelt Lagerkapazität, in: BioHandel, 10/2005, unter: www.biohandel-online.de/HTML/aktuelles/ak20051011.shtml, Abrufdatum: 02.11.2005.

Fiedler, H. (2005b): Dennree sucht festere Partnerschaften, in: BioHandel, 4/2005, unter: www.naturkost.de/biohandel/HTML/aktuelles/ak20050415.shtml.

Abrufdatum 02.11.2005.

Fiedler, H. (2005c): Erdkorn kündigt zügige Expansion an, in: BioHandel 8/2005, unter: www.naturkost.de/biohandel/HTML/perspektiven/pp20050801.shtml, Abrufdatum: 05.11.2005.

Fiedler, H. (2003a): Nützlich, verzichtbar, gegen die Philosophie, in: BioHandel, 02/2003, unter: http://www.naturkost.de/biohandel/-HTML/branche/br20030204.htm; Abrufdatum: 25.04.2005.

Fiedler, H. (2003b): Der Kunde entscheidet: in: BioHandel, 09/2003, unter: www.naturkost.de/biohandel/HTML/-branche/br20030901.htm; Abrufdatum: 25.04.2005.

Frey, B. S. et al. (2001): Grenzen variabler Leistungslöhne - Die Rolle intrinsischer Motivation, in: Jost, P.-J.: Die Prinzipal-Agenten-Theorie in der Betriebswirtschaftslehre, Stuttgart: 561-577.

Gerhardt: (2005): ACNielsen: Trend zu Handelsmarken weltweit ungebrochen, unter: http://www.acnielsen.de/news/pr20050930.shtml, Abrufdatum: 15.10.2005.

Gerlach:, Spiller, A., Engelken, J. (2005): Kundenbindung und Wechselbereitschaft im BioFachhandel: Ein multinomiales Logit-Modell, erscheint in: Unternehmen der Agrarwirtschaft vor neuen Herausforderungen, Tagungsband der 45. GewisolaJahrestagung, Göttingen.

Geßner, H.-J. (2001a): Regiebetrieb im Einzelhandel, in: Diller, H. (Hrsg.): Vahlens Großes Marketing Lexikon, 2. Aufl., München: 1476-1479.

Geßner, H.-J. (2001b): Verbundgruppen des Einzelhandels, in: Diller, H. (Hrsg.): Vahlens Großes Marketing Lexikon, 2. Aufl., München: 1741-1744.

Greim, T. (2004): Logistiker, Moderator oder Einzelhandelspartner, in: Biohandel Ausgabe 04/04, unter: www.naturkost.de/biohandel/-HTML/branche/br20040404.htm; Abrufdatum: 28.04.2005.

Großkinsy, A. (2005): Weitere Vierlinden gepflanzt, in: BioPress, 5. Jg., Heft 12: 22-23.

Gutting, P. (2005): Dennree-Kurs stößt auf Kritik, in BioHandel, 5/2005, unter: www.biohandel-online.de/HTML/aktuelles/ak20050505.shtml, Abrufdatum: 27.11.2005.

Hansen, U. (1990): Absatz- und Beschaffungsmarketing des Einzelhandels: eine Aktionsanalyse, Göttingen.

Hamm, U. (2005): Handel im Wandel, in: BioPress, 5. Jg., Heft 8: 64-65.

Hamm, U., Rippin, M. (2005): Ungleiches Wachstum, in: AgrarBündnis (Hrsg.): Der kritische Agrarbericht, Rheda-Wiedenbrück: 120-125.

Hamm, U., Wild: (2004): Der Preis bestimmt den Absatz, in: BioHandel, 01/2004, unter: www.biohandel-online.de/HTML/branche/br20040102.htm; Abrufdatum: 31.08.2005.

Heinze, K. (2002): Ketten im Kommen, in: BioHandel, 12/2002, unter: www.biohandelonline.de/HTML/branche/br20021202.htm, Abrufdatum: 05.05.2005. 
Informationsstelle Biosiegel (2004): Marktimplementierung des Biosiegels, unter: www.biosiegel.de/download/mib.pdf; Abrufdatum: 05.05.2005.

Künast, R. (2001): Regierungserklärung zur neuen Verbraucherschutz- und Landwirtschaftspolitik, unter: www.verbraucherministerium.de/-pressedienst/pd2001-0607.htm, Abrufdatum: 08.01.2004.

Kreuzer, K., Offeney, C. (2005): 40 neue Bio-Supermärkte in Deutschland, unter: www.biomarkt.info/druck..... Abrufdatum: 01.02.2005.

Kreuzer, K. (2000): 1000-Körner-Markt: Franchise als Zukunftsmodell, in: BioHandel 11/2000, unter: www.biohandel-online.de/HTML/menschen/me200011.htm, Abrufdatum: 05.05.2005

Lautermann, C., Pfriem, R. (2005): Die Machbarkeitsstudie, in: Lautermann et al. (Hrsg.): Ethikmanagement in der Naturkostbranche, Marburg, Teil 1: S. 17-108.

Mercabio Consulting \& Financing (2003): Wachstumsfinanzierung in der Branche für BioLebensmittel, Polling.

Michels, P., Müller, H., Schmanke, A. (2004): Strukturen und Nachfrage nach ökologischen Nahrungsmitteln in Deutschland, Bonn.

Mikus, R. (2004): Marketingkonzept mit neuem Auftritt, in: BioHandel, 2/2004 unter: www.naturkost.de/biohandel/-HTML/branche/br20040204.htm;

Abrufdatum: 28.04.2005.

Niedzwezky, K. (2004): BNN-Monitoring: Qualitätsvorsprung von Naturkost bewiesen, in: Pressemeldung des BNN vom 18.11.04, unter: www.n-bnn.de/phpserve/input/pdf/PM_BNN_Obst_Gemuese.pdf; Abrufdatum: 06.05.2005.

o. V. (2003a): Ausstieg der Rapunzel AG aus Großhandelsbelieferung, in: Pressemeldung des BNN 02.10.03, unter: http://www.n-bnn.de/phpserve/input/pdf/Rapunzel.pdf; Abrufdatum: 29.04.2005.

o. V. (2003b): Indikator der Marktentwicklung im Naturkostgroßhandel, in: BNN Trendbericht 2003, unter: www.n-bnn.de/phpserve/input/downloads/-BNN-Trendbericht.pdf; Abrufdatum: 28.11.2004.

o. V. (2003c): Rapunzel erntet bei Vortrag zum Lieferstopp vorwiegend Kritik, in: BioHandel, 10/2003, unter: www.naturkost.de/biohandel/-HTML/branche/br20031002.htm; Abrufdatum: 24.04.2005.

o. V. (2003d): Segen für die Branche? Rapunzel will Großhandel nicht mehr beliefern, in: BioHandel, 09/2003, unter: www.biohandel-online.de/HTML/meldungen/m20030901.htm, Abrufdatum: 25.04.2005.

o. V. (2004a): Der Markt für Ökolebensmittel steht vor großen Herausforderungen, in: Ausgabe 30/04 (26.07.2004); Sonderbeilage.

o. V. (2004b): Weiling vergrößert Betrieb und erweitert Einzugsgebiet, in: BioHandel, 11/2004, unter: www.naturkost.de/biohandel/-HTML/meldungen/m20041006.htm; Abrufdatum: 29.04.2005.

o. V. (2004c): Marketingkonzept mit neuem Auftritt, in: BioHandel, 02/2004, unter: www.naturkost.de/biohandel/HTML/-branche/br20040204.htm;

Abrufdatum: 28.04.2005.

o. V. (2005a): Rapunzel vertreibt Bioforce, in: BioHandel, 05/2005, unter: www.biohandelonline.de/HTML/hintergrund/hg20050505.shtml, Abrufdatum: 01.11.2005. 
o. V. (2005b): Weniger Erfolg als erwartet, in: BioHandel, 6/2005, unter: http://www.biohandel-online.de/HTML/hintergrund/hg20050603.shtml, Abrufdatum 01.11.2005.

o. V. (2005c): Alnatura mit 26 Prozent Plus, in: BioHandel, 5/2005, unter: www.biohandelonline.de/HTML/hintergrund/hg20050509.shtml, Abrufdatum: 01.11.2005.

o. V. (2005d): Vorstand geht - Verluste bleiben, in: BioHandel, 7/2005, unter: http://www.naturkost.de/biohandel/HTML/aktuell/20050706a.shtml, Abrufdatum 01.11.2005

o. V. (2005e): Bodan mit neuem Partnerschaftskonzept, in: BioHandel, 2/2005, unter: www.biohandel-online.de/HTML/meldungen/m20050201.htm, Abrufdatum: 27.11.2005.

Pepels, W. (1995a): Praxis der Unternehmensführung: Handelsmarketing, Wiesbaden.

Pepels, W. (1995b): Handels-Marketing und Distributionspolitik: das Konzept des Absatzkanalmanagements, Stuttgart.

Pfeifer, T. (2001): Qualitätsmanagement: Strategien, Methoden, Techniken, 3. Auflage, München.

Prahalad, C., Hamel, G. (1990): The Core Competence of the Corporation, in: Harvard Business Review, 68. Jg., Nr. 3: 79-91.

Rasche, C. (2004): Wettbewerbsvorteile durch Kernkompetenzen. Ein ressourcenorientierter Ansatz. Wiesbaden.

Reich, C. (2003): Editorial, in: Verbandsportrait 2003 des BNN, Köln

Richter, T. (2004): Distributionspolitik, in: Leitzmann, C. et al. (Hrsg.): Praxishandbuch BioLebensmittel, Hamburg, Kap. VI.

Schaer, B. (2001): Regionales Gemeinschaftsmarketing für Öko-Lebensmittel: dargestellt am Beispiel der Konzeption des Zeichens „Öko-Qualität aus Bayern“, Hamburg.

Schenk, H.-O. (1991): Marktwirtschaftslehre des Handels, Wiesbaden.

Specht, G. (1992): Distributionsmanagement, 2. Auflage Stuttgart.

Spiller, A., Zühlsdorf, A. (2002): Öko-Marketing, FernUniversität - Gesamthochschule Hagen, Oberhausen.

Spiller, A. (2004): Preiskrieg oder Schlafmützenwettbewerb, in: AgrarBündnis e. V. (Hrsg.): Der kritische Agrarbericht 2004, Rheda-Wiedenbrück: 244-248.

Stern, L., Ansary, A., Brown, J. (1989): Management in Marketing Channels, New Jersey.

Synergie (2002): Der Fachhandel für Bio-Produkte in Europa, Bad Wildbad: 25-40.

Theuvsen, L. (2001): Kernkompetenzorientierte Unternehmensführung: Grundzüge und Bewertung. In: Das Wirtschaftsstudium, 30. Jg.: 1644-1650.

Theuvsen, L. (2003): Erfolgsbedingungen leistungsorientierter Entgeltsysteme, in: Die Verwaltung, Band 36, Heft 4: 483-500.

Tietz, B. (1993): Großhandelsperspektiven für die Bundesrepublik Deutschland bis zum Jahre 2010, Frankfurt a. M.

Tietz, B., Zentes, J. (2001a): Franchising, in: Diller, H. (Hrsg.): Vahlens Großes Marketing Lexikon, 2. Aufl., München: 493-494. 
Tietz, B., Zentes, J. (2001b): Kooperationen im Handel, in: Diller, H. (Hrsg.): Vahlens Großes Marketing Lexikon, 2. Aufl., München: 824-827.

Völkner, M. (2005): Tante-Emma-Geschichte wiederholt sich in unschöner Weise, in: BioHandel, Oktober 2005: 4-5.

Wolff, B. und Lazear, E. P. (2001): Einführung in die Personalökonomik; Stuttgart.

Yussefi, M. et al. (2004): Öko-Landbau in Deutschland, unter: www.soel.de/oekolandbau/deutschland_ueber.html, Abrufdatum: 28.11.2004. 


\section{Anhang I Interviewpartner}

Schrade, H., Geschäftsführer der Ecofit GmbH in Stuttgart,

Befragungsdatum: 09.03.2005

Geschäftstyp: Großhandel

Sortiment: Frische (Obst, Gemüse)

Art des Kundenkontakts: Belieferung, Abholmarkt

Tenta, C., Inhaber des Biosupermarktes Organix in Stuttgart,

Befragungsdatum: 09.03.2005

Geschäftstyp: Einzelhandel

Verkaufsfläche: $300 \mathrm{~m}^{2}$

Artikelanzahl: 3.000

Müller, A., Verkaufsleiter des Biosupermarktes Marktladen in Tübingen,

Befragungsdatum: 09.03.2005

Geschäftstyp: Einzelhandel

Verkaufsfläche: $350 \mathrm{~m}^{2}$

Artikelanzahl: 2.800

Römer, V., Geschäftsführer der Ökoring Handels GmbH in Mammendorf, (bei München), Befragungsdatum: 10.03.2005

Geschäftstyp: Großhandel

Sortiment: Vollsortiment mit 7.000 Artikeln

Art des Kundenkontakts: Belieferung, Abholmarkt

Michaelidis:, Geschäftsführer der Bio-Ilios GmbH in Tübingen,

Befragungsdatum: 04.03.2005

Geschäftstyp: Großhandel (Streckengroßhandel)

Liefergebiet: Deutschland, Griechenland, Italien und Niederlande

Sortiment: Frische (Gemüse, Obst)

Art des Kundenkontakts: Belieferung

Raff, M., Geschäftsführer der Allecos GmbH in Filderstadt,

Befragungsdatum: 04.03.2005

Geschäftstyp: Großhandel

Sortiment: Frische (Gemüse, Obst)

Art des Kundenkontakts: Belieferung, Abholmarkt 


\section{Anhang II Interviewleitfaden für das Experteninterview}

Für die Expertengespräche wurden zwei unterschiedliche Interviewleitfäden entworfen. Einer für die Experten aus dem Einzelhandel und einer für die Experten des Großhandels. Die Interviewleitfäden bestehen aus Fragen, die von den Experten nacheinander beantwortet wurden. Die Experten des Großhandels haben neben den Fragen außerdem noch ein von mir erstelltes Schaubild über die Absatzstrukturen in der Bio-Branche diskutiert.

\section{Fragen an Einzelhandel:}

1. Welche Aufgaben übernimmt für Sie der Bio-Großhandel:

a. Diskussion der Logistikfunktion: Ab wann macht eine Direktbelieferung seitens des Herstellers für ihr Unternehmen Sinn? Bei welchen Warengruppen ist dies möglich (unterscheiden Sie zwischen Frisch-, Trocken und Herkunft)? Ab wann lohnt es sich für Sie direkt beim Hersteller seine Ware zu beziehen (Mengen, Margen)?

b. Diskussion der Beratungsfunktion: Der GH berät auch Einzelhändler. Lassen Sie sich auch von Ihrem GH beraten? Oder durch einen Hersteller? Denken Sie insgesamt, dass die Beratung für Ihr Unternehmen/Geschäft sinnvoll ist?

c. Diskussion der (Handels/Hersteller)-Marken: Wer hat die Möglichkeit Marken beim Endverbraucher zu profilieren (z. B. Rapunzel, Alnatura Dennree etc.)? Wer hat die Möglichkeit, verstärkt ins Marketing zu investieren? Wie hoch ist die Bedeutung von Marken als verkaufsförderndes Instrument (z. B. hat Dennrees Markeneinführung zu Verschiebungen der Marktanteile geführt)?

d. Diskussion der Finanzdienstleistung: Werden Sie vom GH in Bezug auf Expansion oder Verkaufsförderungsmaßnahmen finanziell unterstützt? Wie wichtig sehen Sie die Finanzdienstleistung der GH für die gesamte BioBranche (bzw. Bioläden)?

e. Diskussion um Marketingkonzepte von Einkaufsstätten: z. B. Durchführung von Kommunikationsmaßnahmen, Point of Sale-Marketing etc. Liegen die Kernkompetenzen beim Großhandel? Wer in der Wertschöpfungskette wird sich in Zukunft verstärkt um das Marketing kümmern / Kundenansprache? 
f. Diskussion Qualitätssicherung: Kontrolle der Bio-Zertifizierung, Qualitätsmanagement, der GH als „Sieb“, das schlechte Ware aus dem Verkehr zieht?

2. Wie sehen Sie als Händler die zukünftige Funktion des Großhandels?

3. Würde es sich für Sie lohnen (Kosteneinsparung) direkt beim Hersteller zu kaufen oder wäre der Aufwand zu groß? Oder gibt es andere Probleme beim Direkteinkauf?

4. Glauben Sie, dass sich die Bio-Vermarktung dem konventionellen LEH-Verhalten annähern wird (Das heißt, was unterscheidet die Bio-Vermarktung in 10 Jahren noch von der konventionellen)?

\section{Fragen an Großhandel:}

1. Typisierung und die Abatzstrukturen im Biohandel diskutieren

a. Diskussion der Logistikfunktion: Ab wann macht eine Direktbelieferung seitens des Herstellers Sinn? Wann fällt Bündlerfunktion weg? Bei welchen Warengruppen ist es wichtig bzw. möglich?

b. Diskussion der Beratungsfunktion: Welche Betriebsformen müssen/können von Seiten des GH beraten werden? Haben Bio-Supermärkte eine eigene Beratung? Können Bio-Läden auch von Herstellern beraten werden? Oder ist die Beratung so gut implementiert, dass andere keinen Marktzutritt haben?

c. Diskussion der (Handels/Hersteller)-Marken: Wer hat die Möglichkeit Marken beim Endverbraucher zu profilieren? (z. B. Rapunzel? Dennree? etc.).

d. Diskussion der Finanzdienstleistung: Wer übernimmt die Finanzierung? Banken, Hersteller, Franchise-Konzepte oder wie bisher der GH? Was aber, wenn kleine Bio-Läden es zunehmend schwerer haben?

e. Diskussion um Marketingkonzepte von Einkaufsstätten: Konzeption und Durchführung von Kommunikationsmaßnahmen, Point of Sale Marketing etc.

f. Kernkompetenz des GH?

g. Wer wird besser: GH oder Franchise Bio-Supermärkte oder Hersteller?

h. Diskussion um Qualitätssicherung: Kontrolle der Bio-Zertifizierung; Qualitätsmanagement (Unterschiede in Sortimenten beachten).

2. Wie viele Hersteller liefern direkt an den Bio-Fachhandel (Bio-Läden und BioSupermärkte) und/oder an den konv. LEH? Haben Sie als GH Sanktionsmöglichkeiten, wenn ja welche? 
3. Können Sie sich vorstellen, dass der Großhandel verstärkt selbst Bio-Supermärkte eröffnet (bevor es andere tun)?

4. Wie schafft es der GH unentbehrlich zu werden? Welche Dienstleistungen können Sie dem Bio-Handel anbieten, die sie unverzichtbar machen?

5. Glauben Sie, dass sich die Bio-Vermarktung dem konventionellen LEH-Verhalten annähern wird (Das heißt, was unterscheidet die Bio-Vermarktung in 10 Jahren noch von der konventionellen)? 


\section{KAPITEL II}

Supplier Relationship Management 


\section{KAPITEL II.1}

Geschäftsbeziehungsqualität als Schlüssel zu einem effizienten Supply Chain Management 


\section{Geschäftsbeziehungsqualität als Schlüssel zu einem effizienten Supply Chain Management*}

(mit Berit Köhler, Achim Spiller und Christian Wocken)

$1 \quad$ Supply Chain Management als Herausforderung................................................177

2 Lieferantenmanagement als Teil einer Differenzierungsstrategie............................. 179

3 Lieferantenzufriedenheit und Lieferantenbindung als Erfolgsfaktor im

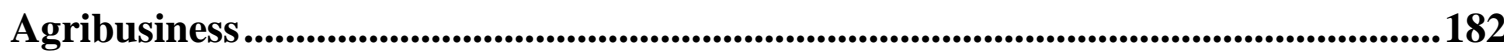

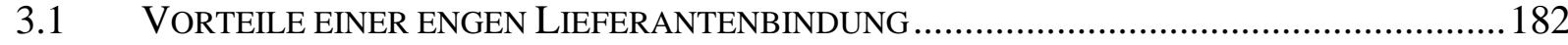

3.2 ZUM STATUS QUO DES LIEFERANTENMANAGEMENTS IM AGRIBUSINESS......................183

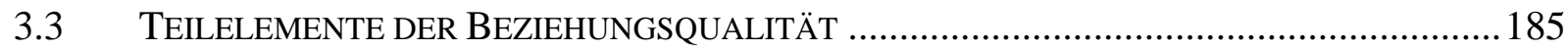

3.4 EINFLUSSFAKTOREN AUF DIE BEZIEHUNGSQUALITÄT .............................................. 188

$4 \quad$ SRQ: Ein Instrument zur Messung der Lieferantenbindung .....................................192

$5 \quad$ Einbindung der Lieferantenbefragung in einen Benchmarking-Prozess ................. 195

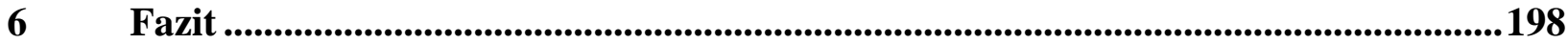

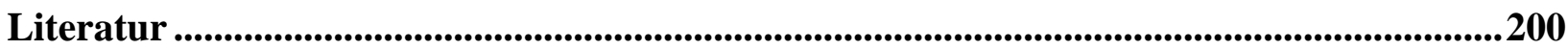

\section{Abbildungsverzeichnis}

Abbildung 1: Messmodell zur Überprüfung der Geschäftsbeziehungsqualität - „SRQ“ ...........175

Abbildung 2: Rolle des Einkaufs im Supply Chain Management...........................................178

Abbildung 3: Transaktionskostentheoretische Analyse der Geschäftsbeziehungsqualität..........181

Abbildung 4: Basiselemente der Geschäftsbeziehungsqualität...............................................187

Abbildung 5: Zusammenhang zwischen Geschäftsbeziehungsqualität und

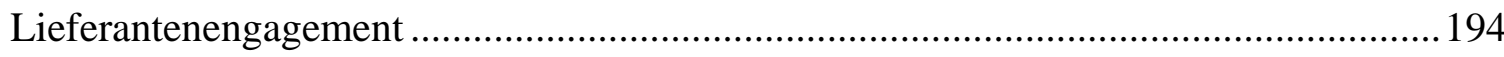

Abbildung 6: Messmodell zur Überprüfung der Geschäftsbeziehungsqualität - „SRQ“ ...........195

Abbildung 7: Zusammenhang zwischen Kundenzufriedenheit und Ausgaben in dem jeweiligen Geschäft.

\section{Tabellenverzeichnis}

Tabelle 1: Vorteile einer engen Lieferantenbindung.....

* Veröffentlicht als Diskussionsbeitrag 0406 des Instituts für Agrarökonomie 


\section{Management Summary}

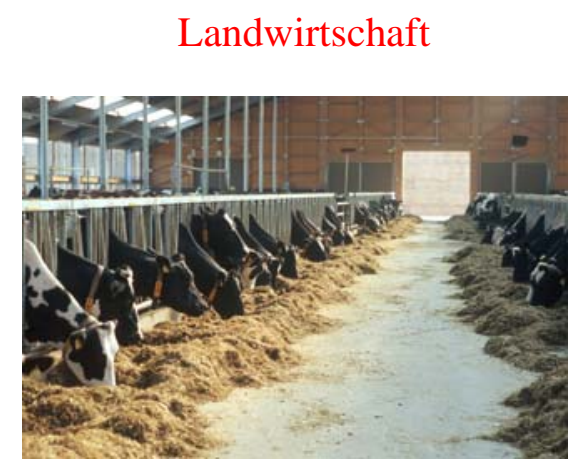

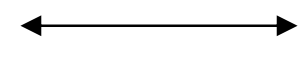

Vertrauen

Lieferzufriedenheit

Commitment

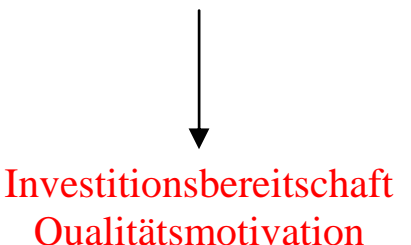

Qualitätsmotivation

Geringe Wechselbereitschaft

\section{Lebensmittelindustrie}

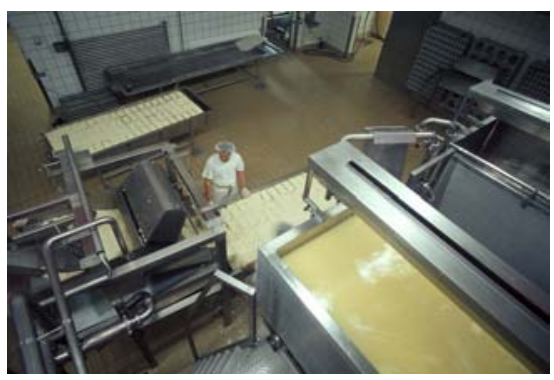

Supply Chain Management bzw. das Denken in Wertschöpfungsketten ist eine neue Herausforderung für die deutsche Ernährungswirtschaft. Aktuell wird dies deutlich bei der Implementierung von Qualitätsmanagementsystemen und der Rückverfolgbarkeit von Lebensmitteln nach EU Verordnung Nr. 178/2002. Insbesondere diejenigen Unternehmen, die sich im Wettbewerb durch besondere Qualitäten und Innovationen differenzieren, benötigen motivierte und leistungsfähige landwirtschaftliche Unternehmen als Lieferanten. Der strategischen Einbindung der landwirtschaftlichen Betriebe in die Supply Chain kommt daher eine stärkere Rolle zu.

Diese Herausforderung kann nur mit einem konsequenten Lieferantenmanagement gemeistert werden - ein Ansatz, der in der neueren Forschung als Supplier Relationship Management bezeichnet wird (Stölzle/Heusler 2003). Die Vorteile von engen Lieferantenbeziehungen sind dabei vielfältig und reichen von höherer Zufriedenheit beider Parteien, einer längerfristigen Planungssicherheit und Entschärfung von opportunistischem Verhalten, der Implementierung von Just-in-Time-Konzepten bis zur Erhöhung der Investitionsbereitschaft in eine Lieferbeziehung. Zufriedene Lieferanten investieren schneller in neue EDV-Schnittstellen, sind motivierter, Qualität zu produzieren, verursachen geringere Überwachungskosten und wechseln seltener den Abnehmer.

Welche Defizite im Gegensatz dazu eine unzureichende Bindung der landwirtschaftlichen Lieferanten hervorruft, lässt sich in vielen Warengruppen der Ernährungswirtschaft nachweisen. Ein Beispiel sind die vielen misslungenen Versuche deutscher Schlachtunternehmen, ein funktionierendes Salmonellenmonitoring aufzubauen. Die Molkereien 
kämpfen derzeit gegen die Versuche landwirtschaftlicher Kooperationen und neuer Verbände, die Vertragsbeziehungen kurzfristiger zu gestalten und noch stärker auf den Auszahlungspreis zu fokussieren. In der Gemüseproduktion ist die Geschäftsbeziehung wohl vertrauensvoller, aber auch hier gelingt es nicht immer, die Landwirte zu Investitionen in neue Kulturen oder andere Anbautechniken zu überzeugen. Kurz: In der Geschäftsbeziehung zwischen Lebensmittelproduzenten und landwirtschaftlichen Lieferanten sind derzeit viele Friktionen anzutreffen, die eine schnelle Reaktion der Supply Chain auf marktliche Herausforderungen erschweren. Im Gegensatz zu anderen Branchen wie etwa der Automobilindustrie gibt es im Agribusiness noch zu wenig Verständnis dafür, dass sich der Wettbewerb nicht nur zwischen Unternehmen auf einer Wertschöpfungsstufe, sondern zwischen Supply Chains abspielt - und dass eine vertrauensvolle Zusammenarbeit entscheidende Voraussetzung in einem Wettbewerb ist, in dem „Economies of Speed“ über den Erfolg entscheiden.

Der vorliegende Beitrag thematisiert vor diesem Hintergrund die Elemente eines erfolgreichen Beschaffungsmanagements und analysiert die Determinanten einer effizienten Geschäftsbeziehung. Dazu wird die internationale Literatur aus den Bereichen Supply Chain Management, Geschäftsbeziehungsmanagement und Customer Relationship Management aufgearbeitet. Kern der Studie ist die Entwicklung eines innovativen Messinstrumentes („Supplier Relationship Quality/SRQ“), das Unternehmen ermöglicht, den Status quo der Geschäftsbeziehung empirisch zu erfassen und daraus Handlungsempfehlungen für das Supplier Relationship Management abzuleiten.

Das Messinstrument „Supplier Relationship Quality“ umfasst zentrale Dimensionen der Geschäftsbeziehung: die Zufriedenheit der Lieferanten, ihr Vertrauen in den Abnehmer und das Commitment in die Geschäftsbeziehung (vgl. Abb. 1). Hinter der Geschäftsbeziehungsqualität stehen eine Reihe von Einflussfaktoren (z. B. die wahrgenommene Abhängigkeit, die Intensität und Qualität der Kommunikation usf.). Diese sind die Treiber der Geschäftsbeziehung und bilden die Ansatzpunkte für ein Supplier Relationship Management. Sie werden in der Befragung erfasst und in Form von Kennzahlen verdichtet. Ziel des Supplier Relationship Managements sind motivierte Lieferanten, die sich durch eine geringe Wechselbereitschaft auszeichnen und in eine kooperative Geschäftsbeziehung investieren.

In einem ersten Pretest von „SRQ“ bei einem Großunternehmen des Agribusiness konnte die prinzipielle Eignung des Instruments dargelegt werden. Auf dieser Basis erfolgen derzeit weitere Befragungen, u. a. von Lieferanten in der Milchwirtschaft. 
ABBILDUNG 1: MESSMODELL ZUR ÜBERPRÜFUNG DER GESCHÄFTSBEZIEHUNGSQUALITÄT „SRQ“

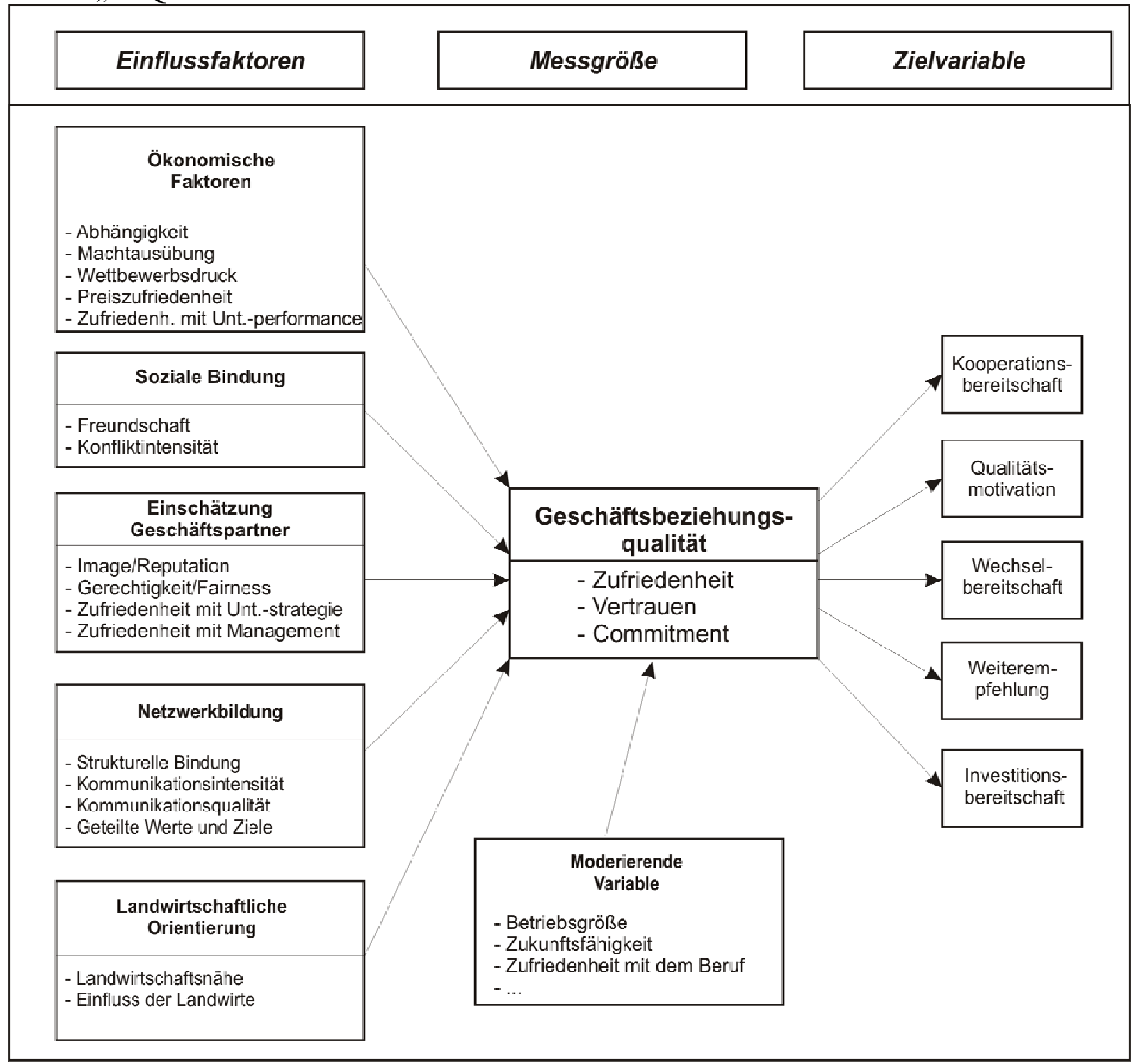

Quelle: Eigene Darstellung

Supplier Relationship Management (SRM) ist eines der wichtigsten Themen der aktuellen Managementdiskussion. Das vorliegende Instrument ermöglicht eine qualitative Einschätzung der Lieferanten und ergänzt so die von der Softwareindustrie entwickelten Methoden, wie z. B. mySAP SRM, die auf die elektronische Unterstützung des Transaktionsprozesses gerichtet sind. Die Befragung ihrer Lieferanten auf Basis eines standardisierten Fragebogens ist für große Unternehmen des Agribusiness, die z. T. mehrere tausend landwirtschaftliche Zulieferer haben, ein leistungsfähiges Werkzeug zum Monitoring der Lieferantenbeziehungen.

Auf Basis der bereits vorliegenden ersten Befragungen können diese Werte in einem Benchmarking-Prozess mit den führenden Unternehmen innerhalb und außerhalb der Branche 
sowie mit dem Branchendurchschnitt verglichen werden. Im Zeitreihenvergleich ermöglicht eine kontinuierliche Erhebung im zwei- bis dreijährigen Rhythmus ein systematisches Controlling der Lieferantenbeziehung. Im Zusammenspiel mit anderen Instrumenten des Beschaffungscontrollings (z. B. Prozesskostenrechnung, Einkaufs-Portfolioanalyse, Performance-Measurement-Systeme, Qualitätskostenrechnung) wird so ein professionelles Lieferantenmanagement möglich. 


\section{Supply Chain Management als Herausforderung}

Supply Chain Management ist seit geraumer Zeit ein wichtiges Thema für die deutsche Ernährungswirtschaft (Simchi-Levi et al. 2003; Bourlakis/Weightman 2004). Viele Unternehmen sind in den letzten Jahren mit unterschiedlichen Herausforderungen konfrontiert worden, die auf neue Modelle der Wertschöpfungskoordination zielen. Im Bereich des Qualitätsmanagements geht es z. B. um Rückverfolgbarkeit, einen verbesserten Informationsfluss und integrative Qualitätsmanagementkonzepte - Ansätze, die insgesamt auf eine stärkere Einbindung der Lieferanten setzen (Allinson 2004). Dies wird auch durch die zahlreichen Lebensmittelkrisen der letzten Jahre deutlich, die nicht zuletzt auf eine unzureichende Sicherstellung der Warenqualität im Einkauf zurückzuführen waren.

Ein verwandtes, seit Mitte der 90er Jahre diskutiertes Thema für die Struktur der Geschäftsbeziehungen in der Ernährungswirtschaft ist Efficient Consumer Response (Seifert 2001). Unter diesem Begriff werden neue Modelle für Logistik und Marketing entwickelt, die die Reibungsverluste entlang der Supply Chain vermindern. Es geht um ein verbessertes Schnittstellenmanagement im Hinblick auf die EDV-technische Anbindung, gemeinsame Datenstandards und -nutzung, organisatorische Abstimmungen, normierte Logistikeinheiten, ein kooperatives Sortimentsmarketing usf. Collaborative Planning, Forecasting and Replenishment bezeichnet Konzepte zur Weitergabe von Planungsinformationen in der Logistik. Solche Modelle werden nur durch den Aufbau von Netzwerkstrukturen gelingen und schließen entsprechend die bessere Kooperation mit vor- und nachgelagerten Unternehmen ein.

Im Kern beschäftigen sich Supply Chain Management und Efficient Consumer Response, aber auch neue Ansätze des Innovations- und Qualitätsmanagements mit der Steuerung der gesamten Wertschöpfungskette. Dies gelingt nicht durch einzelbetriebliche Optimierung, sondern setzt auf Effizienz in der gesamten Kette mit anschließender „Verteilung des größeren Kuchens“. Es geht um „totales Kosten- und Effizienzdenken“ auf der einen und eine effektivere Form des Managements von vertikalen Unternehmensnetzwerken auf der anderen Seite. Der letztgenannte Punkt, die veränderte Rolle des Einkaufs im Unternehmen im Rahmen eines Supply Chain Managements, zeigt die folgende Abbildung im Überblick. 
ABBILdUng 2: Rolle DES EINKAUfS IM SUPPLy CHAin MANAGEMENT

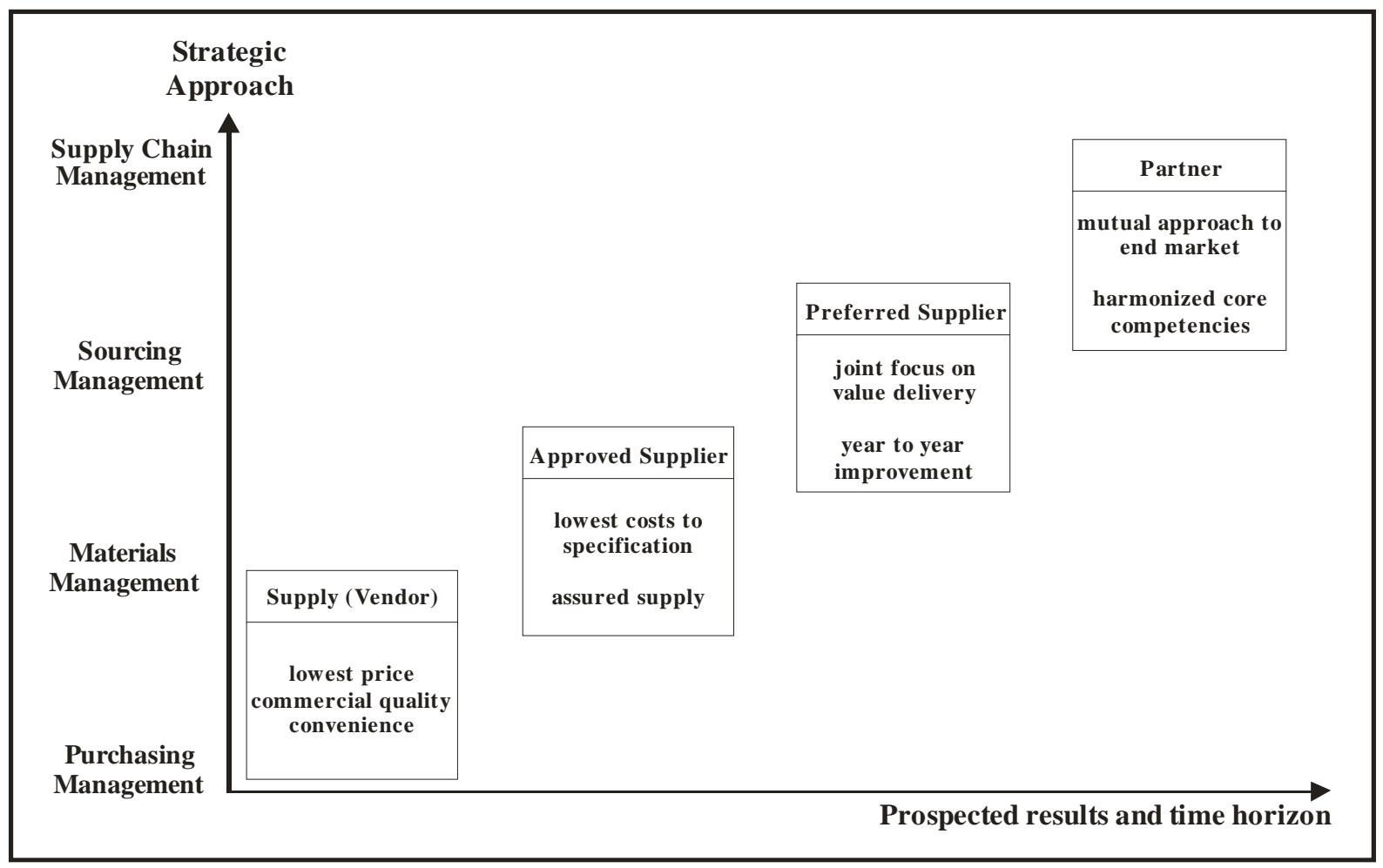

Quelle: Wagner 2001: 80

Die strategische Funktion des Einkaufs setzt auf kooperative Beziehungen sowie eine längerfristige Ausrichtung der Zusammenarbeit und damit auf den Aufbau von Vertrauen. An die Stelle eines kurzfristigen Lieferantenwettbewerbs mit dem Fokus auf Preise soll die integrative Ausschöpfung von Effizienzpotenzialen entlang der Wertschöpfungskette treten (Stölzle/Heusler 2003: 173). In diesem Sinne bezeichnet Supplier Relationship Management den systematischen Aufbau, die Pflege und das Controlling der Geschäftsbeziehung mit den Lieferanten - es ist damit das Gegenstück zum Business-to-Business-Marketing der Zulieferindustrie und gewinnt besonders in Geschäftsbeziehungen an Relevanz, in denen der Abnehmer die ökonomisch dominierende Position in der Wertschöpfungskette einnimmt.

Die sich damit wandelnde Rolle der Beschaffungsabteilung vom operativen Einkauf zum strategischen Lieferantenmanagement verlangt neue Instrumente. Ein besonders wichtiger, in der Praxis aber stark vernachlässigter Bereich ist die Überprüfung der Geschäftsbeziehungsqualität. Die vorliegende Studie entwickelt ein Modell zur empirischen Überprüfung der Zusammenarbeit, das wichtige Kenngrößen zur Bewertung der Lieferantenbeziehungen ermittelt. Diese können zur Steuerung des Supply Chain Management eingesetzt werden und z. B. in ein Controllingkonzept wie die Balanced Scorecard einfließen. 
Während es zahlreiche Studien zur Kundenzufriedenheit gibt, finden sich in der Unternehmenspraxis keine (veröffentlichten) Befragungen zur Qualität der Lieferbeziehung. Die vorliegenden Forschungsarbeiten entstammen anderen Forschungsgebieten wie dem Absatzkanalmanagement, sind nicht auf die Bedürfnisse der Unternehmen zugeschnitten und haben entsprechend zu keiner Umsetzung in der Wirtschaft geführt. Die regelmäßige Erhebung der Kundenbindung ist heute ein Standardtool in der Konsumgüterindustrie. Im Gegensatz dazu wird die Zusammenarbeit mit den Lieferanten, die in Zeiten des Outsourcing essentiell für Wirtschaftlichkeit und Produktqualität ist, nicht überprüft und deshalb auch nicht systematisch gemanagt.

Die Vernachlässigung der empirischen Überprüfung der Geschäftsbeziehungsqualität in der Unternehmenspraxis mag vordergründig dadurch $\mathrm{zu}$ erklären sein, dass die Lieferantenstruktur in vielen Branchen sehr heterogen ist. Ein Automobilproduzent hat zwar mehrere tausend Lieferanten, die aber durch sehr unterschiedliche Größe und Branchenherkunft gekennzeichnet sind. Die unterschiedliche Struktur der Lieferanten erschwert zwar in der Tat eine Erhebung, dies ließe sich aber durch eine geeignete Konzeption des Messinstrumentes beheben.

Im Weiteren betrachten wir jedoch eine Branche, die durch ausgesprochen viele und homogene Zulieferer charakterisiert ist. Für Unternehmen des Agribusiness ist das Supplier Relationship Management von besonderer Bedeutung, da Molkereien, Schlachtunternehmen, Zuckerhersteller oder Tiefkühlproduzenten nicht nur über sehr viele, sondern auch über homogene Lieferanten verfügen. Außerdem prägt in der Ernährungswirtschaft die Qualität der Rohprodukte ganz entscheidend die Endproduktbeschaffenheit. Die meisten Defizite auf landwirtschaftlicher Ebene lassen sich später in der Wertschöpfungskette kaum noch kompensieren. Motivierte und leistungsfähige Lieferanten können hier einen zentralen Wettbewerbsvorteil darstellen.

\section{Lieferantenmanagement als Teil einer Differenzierungsstrategie}

Der Nutzen einer engen Zusammenarbeit mit den Lieferanten und einer vertrauensvollen Geschäftsbeziehung trifft insbesondere auf diejenigen Bereiche der Ernährungswirtschaft zu, in denen längerfristige Geschäftsbeziehungen bestehen. Werden Produkte über Spotmärkte wie z. B. Auktionen gehandelt oder in einer vollständig integrierten Wertschöpfungskette von nur einem Unternehmen produziert (wie in einigen Geflügelunternehmen), stellt sich die 
Fragestellung nicht. Die folgenden Ausführungen verdeutlichen daher zunächst den Anwendungsbereich eines langfristig orientierten Lieferantenmanagements.

Wichtige Hinweise auf die Frage, in welchen Fällen partnerschaftliche Geschäftsbeziehungen zu Lieferanten wichtig sind, gibt die Transaktionskostentheorie. Diese verweist auf Vorteile einer längerfristigen Bindung bei ausgeprägter Spezifität der Investitionen und hoher Qualitätsunsicherheit (Williamson 1979; Spiller 2004). Immer dann, wenn auf Seiten des Lieferanten umfangreiche partnerspezifische Investitionen notwendig sind, um in eine Geschäftsbeziehung zu einem bestimmten Weiterverarbeiter eintreten zu können (z. B. in bestimmte Stallanlagen oder Anbaumethoden), wird es eine Bereitschaft zur langfristigen Zusammenarbeit geben (Lawrence/Hayenga 2002). Ohne vertragliche Absicherungen droht ein Abhängigkeitsverhältnis, da Sunk Costs Spielraum für opportunistisches Verhalten der Marktgegenseite bieten. Solche spezifischen Investitionen existieren z. B. in der Geflügelwirtschaft durch das knappe Zeitfenster bei der Vermarktung vor dem Hintergrund einer oligopolistischen Verarbeitungsstruktur. Es gibt sie auch in speziellen Qualitätssegmenten, z. B. der biologischen Landwirtschaft oder bei Markenfleischprogrammen. Hohe Qualitätsunsicherheit existiert für industrielle Nachfrager oder den Einzelhandel, wenn diese Gefahr laufen, durch Fehlentscheidungen beim Wareneinkauf in die öffentliche Kritik zu geraten. In diesem Fall steigen die Transaktionskosten zur Überwachung ungebundener Lieferanten erheblich an, so dass im Vergleich striktere Bindungen kostengünstiger werden (Hobbs 1996). Da die Qualitätsunsicherheit in den letzten Jahren durch neue Verbraucheranforderungen zugenommen hat, steigt in der Ernährungswirtschaft die Bindungsintensität tendenziell an (Lawrence et al. 2001).

Letztlich zeigt die Transaktionskostentheorie, dass es im Kern eine Frage der Wettbewerbsstrategie ist, ob kurzfristiges Einkaufsmanagement oder langfristiges Geschäftsbeziehungsmanagement dominieren sollte (vgl. Abb. 3). Unternehmen, die ausschließlich die Strategie der Kostenführerschaft verfolgen und damit eine konsequente Kostenminimierung in allen Geschäftsbereichen etabliert haben, werden im Zweifelsfalle eine lose Bindung an ihre Lieferanten anstreben. Sie treffen die Auswahl des Lieferanten in erster Linie nach dem Preis und werden entsprechend versuchen, über geeignete Beschaffungsinstrumente wie z. B. internetgestützte Reverse-Auctions Druck auf die Zulieferer auszuüben (Porter 1989: 34). 
Im Gegensatz dazu werden im Rahmen einer Differenzierungsstrategie Faktoren wie die Produktion herausragender Qualitäten, die Qualitätssicherung und der Innovationsgrad wichtig, die zu erheblichen Teilen mit spezifischen Investitionen der Lieferanten verknüpft sind. Der Preis steht hier nicht länger im Vordergrund der Lieferantenauswahl. Mögliche Differenzierungsvorteile können z. B. die Qualität, die längere Haltbarkeit, die Flexibilität bei der Lieferung, fortschrittliche Technologien, neue Anbaukulturen oder spezielle genetische Eigenschaften der Tiere sein. Durch den höheren Preis, den die Lieferanten für ihre Ware erhalten, entwickeln sie Loyalität und Vertrauen zum abnehmenden Unternehmen. Zudem müssen mit höheren Auszahlungspreisen zwangsläufig höhere Kosten entstehen. Oftmals können an anderer Stelle Transaktionskosten (z. B. Kontrollkosten) gesenkt werden. Dadurch wird eine langfristige Verbindung initiiert (Porter 1989: 35).

ABBILDUNG 3: TRANSAKTIONSKOSTENTHEORETISCHE ANALYSE DER GESCHÄFTSBEZIEHUNGSQUALITÄT

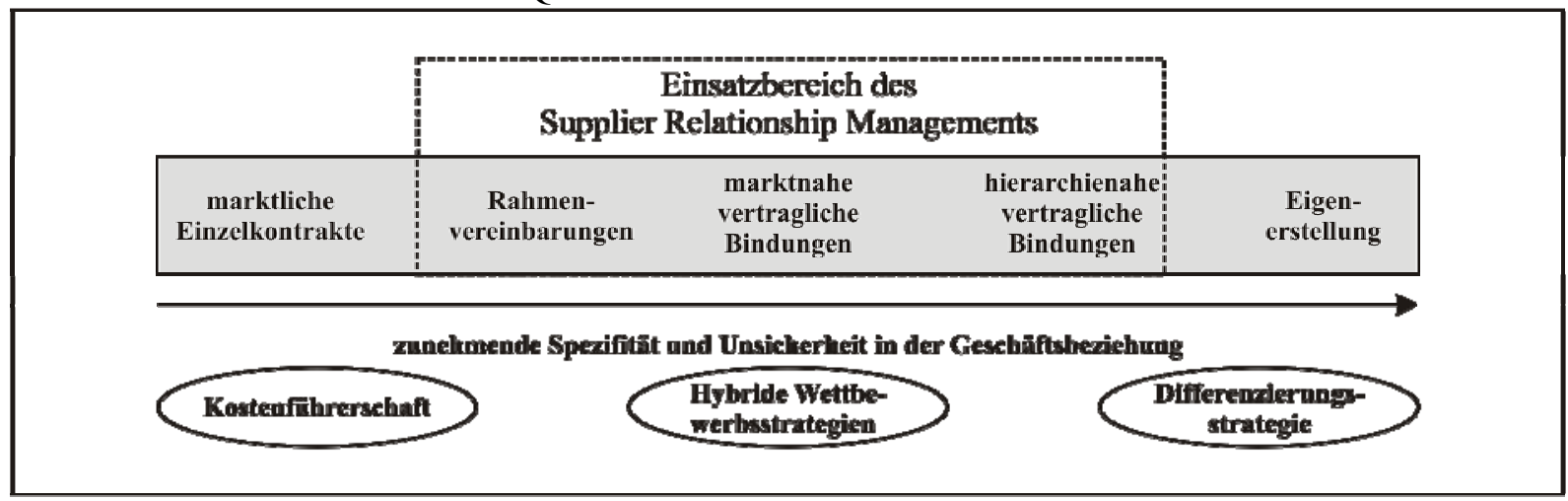

Quelle: Eigene Darstellung

Insgesamt gewinnt die längerfristige Zusammenarbeit in der Wertschöpfungskette des Agribusiness ökonomisch weiter an Bedeutung. Sie bietet Vorteile gegenüber der ungebundenen Geschäftsbeziehung in Fragen der Qualitätssicherung, der Markenführung und der Innovationspolitik, vermeidet aber die Flexibilitätsdefizite einer vollständigen Eigenproduktion (Bogetoft/Olesen 2004). Damit steigt die Relevanz des Supplier Relationship Managements.

Anders ist die Situation nur für diejenigen Unternehmen zu beurteilen, die eine strikte Kostenorientierung verfolgen. Ein zu starker Preisdruck könnte hier einem kooperativen Lieferantenmanagement entgegenstehen (Cannon/Perreault 1999: 457). Durch die Drohung mit Lieferantenwechsel kann der Preis ggf. bis an die Grenzkosten des Lieferanten gedrückt werden. Dies steht einer vertrauensvollen Zusammenarbeit ganz offensichtlich entgegen. Gleichwohl gibt es selbst im Bereich der Niedrigpreisproduktion Argumente, die für 
längerfristige Geschäftsbeziehungen sprechen, z. B. große homogene Produktionsmengen, Belieferungssicherheit, Vermeidung des Bullwhip-Effektes, abgestimmte EDV-Schnittstellen, hohe Reaktionsgeschwindigkeit und verstärkte Kommunikationsintensität (Christopherson/ Coath 2002; Windhorst 2002). Insgesamt ist nur im Einzelfall in Abhängigkeit von den genannten Variablen zu entscheiden, ob die Vorteile einer längerfristigen Lieferantenintegration den geringeren Preisdruck überwiegen.

Im Ergebnis zeigt sich, dass ein aktives Lieferantenmanagement, das auf eine langfristige und vertrauensvolle Zusammenarbeit setzt, für Unternehmen aus dem Qualitätssegment sinnvoll ist. Kostenorientierte Anbieter müssen im Einzelfall entscheiden, ob aus ihrer Sicht die Qualität der Geschäftsbeziehung wettbewerbsrelevant ist. Im folgenden Kapitel werden die positiven Implikationen zufriedener Lieferanten näher vorgestellt.

\section{Lieferantenzufriedenheit und Lieferantenbindung als Erfolgsfaktor im Agribusiness}

\subsection{Vorteile einer engen Lieferantenbindung}

Ein kooperativ ausgerichtetes Lieferantenmanagement ist für Unternehmen im Qualitätssegment eine zunehmend wichtigere Quelle von Wettbewerbsvorteilen. Die Potenziale, die solche Unternehmen durch eine feste Verbindung an ihre Lieferanten erreichen können, sind vielfältig (Stölzle/Helm 2003: 294 ff.). Die folgende Aufzählung stellt diese im Überblick zusammen. 


\section{TABELLE 1: VORTEILE EINER ENGEN LIEFERANTENBINDUNG}

$>$ Höhere Zufriedenheit beider Parteien

$>$ Längerfristige Planungssicherheit durch geringere Wechselbereitschaft

> Entschärfung von opportunistischem Verhalten bei Verteilungs- und Zielkonflikten/ kooperativere Preisverhandlungen

$>$ Flexibilität und Geschwindigkeit im Wettbewerb durch bessere Abstimmung und höhere Kommunikationsintensität

$>$ Senkung von Transaktionskosten durch Wegfall von Neuakquisition und Vertragsverhandlungen

$>$ Senkung von Prozesskosten durch Abstimmung von (EDV-) Schnittstellen

$>$ Ermöglichung von Just-in-Time-Konzepten und Efficient Consumer Response

$>$ Anpassung von Losgrößen

$>$ Besseres Qualitätsmanagement durch vertrauensvollen Informationsaustausch

$>$ Entwicklungspartnerschaften mit Lieferanten (simultaneous engineering)

$>$ Commitment erhöht die Investitionsbereitschaft der Lieferanten

$>$ Senkung von Koordinationskosten (z. B. bei Reklamationen, Streitigkeiten usf.)

Quelle: Eigene Zusammenstellung

Neben diesen grundsätzlichen Vorteilen gibt es im Agribusiness eine Vielzahl von Genossenschaften, die aufgrund ihrer Rechtsstruktur unmittelbar an der Zufriedenheit ihrer Lieferanten interessiert sein müssen. Lebensmittelproduzenten mit genossenschaftlicher oder genossenschaftsähnlicher Struktur befinden sich im Eigentum der Landwirte. Diese haben hier eine Doppelrolle als Lieferant und Anteilseigner zugleich. Wichtige Großunternehmen aus Milch-, Fleisch- und Zuckerwirtschaft sollten daher schon aus Gründen der Investor Relations ihren Lieferanten besondere Aufmerksamkeit schenken. Beispielsweise werden in Deutschland rund drei Viertel aller Milchprodukte in genossenschaftlich strukturierten Unternehmen verarbeitet (Schramm et al. 2004). Genossenschaftliche Hersteller benötigen für zentrale unternehmenspolitische Weichenstellungen die Unterstützung der Landwirte, so dass das Management auf die Akzeptanz seiner Strategien bei den Lieferanten angewiesen ist. Das Lieferantenmanagement dient hier dem Management von Unterstützungspotenzialen in einer Zeit, in der die Geschwindigkeit von Entscheidungsprozessen zum Erfolgsfaktor der Unternehmenspolitik wird.

\subsection{Zum Status quo des Lieferantenmanagements im Agribusiness}

Im Agribusiness ist das Lieferantenmanagement in einzelnen Teilsegmenten, abhängig vom Endprodukt und gesetzlichen Vorgaben, sehr unterschiedlich ausgeprägt. In vielen Branchen wie der Getreideerzeugung, der Produktion von Obsterzeugnissen und vor allem in der Schweine- und Rindfleischproduktion ist nur eine geringe Bindung zwischen Verarbeitungsunternehmen und Landwirt vorhanden. Beispielhaft sei das sogenannte „Springerverhalten“ von Landwirten genannt, die zwischen einzelnen Schlachthöfen kurzfristige Preisunterschiede 
ausnutzen und sich nur selten (z. B. in der Markenfleischproduktion) auf einen Abnehmer festlegen (Traupe 2002: 34). Durch die in diesem Segment überwiegend fehlende Lieferantenbindungen sind vor allem kooperative Qualitätsmanagementsysteme nur sehr schwer zu implementieren. Dies zeigt sich z. B. am Salmonellenmonitoring, das einen Datenfluss über die verschiedenen Wertschöpfungsstufen gewährleisten muss, und dessen Einführung in den vergangenen Jahren wiederholt gescheitert ist.

Im Gegensatz zur Fleischproduktion ist die Molkereiwirtschaft durch eine etwas längerfristige Bindung der Marktseiten gekennzeichnet, die bereits durch die logistischen Besonderheiten notwendig ist. So wird die Milch i. d. R. zweitägig abgeholt und die Molkereien zahlen größtenteils monatlich das Milchgeld an die Landwirte aus. Entsprechend finden sich längerfristige Verträge. Trotz der langjährigen Zusammenarbeit und der stark genossenschaftlich geprägten Struktur hat sich allerdings kein umfassendes Lieferantenmanagement entwickelt. Zwar gibt es vielfach eine Erzeugerberatung, eine umfassende Einbindung z. B. in Form von Qualitätszirkeln ist jedoch selten. Im Gegenteil: Die Landwirte drängen zurzeit eher auf Flexibilität und den Abbau von Verträgen. Ein Beispiel ist die Gründung eines neuen Interessenverbandes der Milcherzeuger, des Bundesverbandes deutscher Milchviehhalter (BDM). Vor dem Hintergrund der schlechten Ertragslage der Milchproduzenten angesichts niedriger Milchpreise spiegelt sich hier der Unmut der Landwirte wider. Der BDM macht insbesondere die genossenschaftlichen Molkereien für die schlechte Vermarktung der Milch und Milchprodukte verantwortlich. Daraus hat sich das Ziel entwickelt, durch Kündigung der Lieferverträge möglichst große Milchmengen zu bündeln und so Druck auf die Molkereiunternehmen auszuüben (BDM 2004). Dies zeigt die hohe Wechselbereitschaft der Landwirte und damit die geringe Bindung an die Molkereien.

Etwas kooperativer und vertrauensvoller ist die Geschäftsbeziehung in Teilen der Kartoffelund Gemüseproduktion (Grimsdell 1996). So haben z. B. die großen Tiefkühlproduzenten längerfristige Verträge mit ihren Erzeugern abgeschlossen. Wiederum andere Strukturen finden sich in der Geflügelwirtschaft mit einem hohen vertikalen Integrationsgrad, eng gebundenen landwirtschaftlichen Lohnmästern und einer intensiven Kommunikation zwischen den Stufen (z. B. in „Mästerkreisen“).

Insgesamt lässt sich aber im Agribusiness eine eher geringe Kommunikationsintensität beobachten. Das Vertrauen der Geschäftspartner ist nur rudimentär ausgeprägt. Die 
Unzufriedenheit hat beispielsweise in der Milchwirtschaft solche Ausmaße angenommen, dass sich selbst bei genossenschaftlichen Unternehmen neue Formen der Gegenmachtbildung durch den Zusammenschluss von Landwirten entwickeln. Trotz Vertragslandwirtschaft sind in vielen Bereichen der Ernährungswirtschaft die Potenziale einer engen Zusammenarbeit nicht annähernd erschlossen. Ohne ein aktives Geschäftsbeziehungsmanagement fehlt in kritischen Situationen wie z. B. bei der Einführung neuer Qualitätsmanagementsysteme die Unterstützung durch Lieferanten. Vergleicht man das Agribusiness mit der Automobilwirtschaft, so werden erhebliche Defizite in der systematischen Anwendung von leistungsfähigen Tools des Beschaffungs- und Lieferantenmanagements deutlich (Ryder/Fearne 2003). In einer durch Outsourcing geprägten Wirtschaft, in der die Lieferanten zu wesentlichen Teilen für das Endprodukt verantwortlich sind, ist dies kontraproduktiv.

\subsection{Teilelemente der Beziehungsqualität}

In der Forschung wird relativ einhellig die Zufriedenheit mit der Geschäftsbeziehung als zentrale Variable der Beziehungsqualität hervorgehoben. Ähnlich wie im Konsumgütermarketing gilt die Zufriedenheit als umfassendes Konstrukt und grundlegende Voraussetzung, um die Bereitschaft für eine engere Verbindung zu erzeugen. Daneben werden Vertrauen und Commitment als weitere Kernelemente der Geschäftsbeziehungsqualität betont (Klee 2000; Diller/Ivens 2004).

Zufriedenheit entsteht aus dem Vergleich der tatsächlichen Erfahrung bei der Inanspruchnahme einer Leistung (Ist-Leistung) mit einem bestimmten Vergleichsstandard (Soll-Leistung) (Homburg/Krohmer 2003: 102). Das Niveau, das als Erwartung angesetzt wird, wird zum einen durch den Verlauf der speziellen Geschäftsbeziehung geprägt. Zum anderen werden Vorinformationen von anderen Geschäftspartnern, alternative Erfahrungen und Qualitätsurteile der Bewertung zu Grunde gelegt (Homburg/Stock 2001: 20 f.). Allerdings basiert dieser Bewertungsprozess nicht auf einer einzigen Transaktion, vielmehr werden alle Geschäftsvorgänge kumulativ betrachtet und $\mathrm{zu}$ einem Gesamtbild zusammengefasst (Herrmann/Johnson 1999: 582; Stölzle 2000: 6 ff.; Van Weele 2002: 165 f.). Auf dieses dauerhafte Verhältnis können kritische Ereignisse einwirken. Dies geschieht, wenn eine Situation eintritt, die sich im Gedächtnis des Lieferanten verankert. Dieses Ereignis wird in der Gesamtbeurteilung ggf. besonders stark berücksichtigt (Bauer 2000: 32 ff.). 
Eine herausgehobene Rolle spielt die Preiszufriedenheit, d. h. die langfristige Auskömmlichkeit des Verkaufspreises aus Sicht des Lieferanten und kurzfristige Preistendenzen. Daneben können alle Teilbereiche der Kooperation (Logistik, Qualitätsmanagement, Entgeltpolitik usf.) zufriedenheitsrelevant sein. Ein zufriedener Lieferant wird sich besser mit dem Abnehmer identifizieren, so dass sein Verantwortungsgefühl z. B. in Fragen des Qualitätsmanagements steigt (Keebingate 2003: 174).

Aus Zufriedenheit kann sich im Laufe der Zeit Vertrauen entwickeln. "While seemingly intangible, trust refers to the belief in the character, ability, strength, or truth of another party“ (Monczka et al. 2001: 132). Gegenseitiges Vertrauen trägt dazu bei, dass der Gewinn, den beide Partner aus der Beziehung ziehen, vergrößert wird. Es wirkt als „Schmiermittel“ der Geschäftsbeziehung, da es auch riskantere Vorleistungen ermöglicht, z. B. Investitionen in neue Kulturen oder in neue Stalltechnologien auf Seiten der Landwirte, die für den Hersteller wichtig sind.

Dabei setzt sich Vertrauen aus zwei Komponenten zusammen. Zum einen aus der gegenseitigen Glaubwürdigkeit, die zur Reduktion opportunistischen Verhaltens führt, und zum anderen aus dem sicheren Willen der beiden Seiten, die Partnerschaft aufrechtzuerhalten, was langfristig wiederum zu einer Senkung der Transaktionskosten führt (Ganesan 1994: 2; Plöttner 1995: 36). Das gegenseitige Vertrauen führt zu einem Verhältnis, in dem auf permanente gegenseitige Kontrolle verzichtet werden kann, da die Partner von selbst bemüht sind, zusammenzuarbeiten. Allerdings hat Vertrauen neben Verlässlichkeit zwangsläufig den Nebeneffekt, dass der Partner verletzlich wird. Ferner ist die Dauer der gemeinsamen Beziehung ungewiss, so dass die strategische Bedeutung zuvor abgeschätzt werden muss (Batt/Rexha 1999: 3 f.; Walter 1998: 151). In Beziehungen, in denen Vertrauen herrscht, treten weniger Konflikte auf (Doney/Cannon 1997: 35). Vertrauen kann beispielsweise durch den Abschluss langfristiger Verträge signalisiert werden. Dadurch wird der Lieferant ermutigt, in die Beziehung zu investieren, z. B. indem er neue Technik erwirbt (Monczka et al. 2001: 132). Außerdem führt diese durch Vertrauen initiierte Langfristigkeit zu einem Aufbau von Commitment (Doney/Cannon 1997: 35).

Commitment ist ein weiterer wesentlicher Bestandteil kooperativer Beziehungen. Sie kennzeichnet die Überzeugung eines Geschäftspartners, dass ein Fortbestehen der Geschäftsbeziehung wichtig ist und einen hohen (materiellen und immateriellen) Einsatz 
rechtfertigt (Dwyer et al. 1987; Morgan/Hunt 1994; Werani 1999). Es handelt sich mithin um eine subjektiv empfundene Bindung, demzufolge sich die Partner verpflichtet fühlen, den Anforderungen des anderen gerecht zu werden (Walter 1998: 154). Commitment besteht in verbreiteter Definition aus drei Teilkonstrukten. Die erste Komponente ist die instrumentelle Dimension, die Bereitschaft zur Erbringung von kurzzeitigen Opfern für den Fortbestand der Transaktionsbeziehung. Als zweiter Teilbereich wird die Langfristorientierung beschrieben (Heide/Miner 1992; Ganesan 1994). Die Einstellungsdimension ist schließlich durch den Willen der Partner zum Aufbau einer stabilen Beziehung geprägt (Giering 2000: 19). Förderlich ist Commitment für den Aufbau einer intensiveren Geschäftsbeziehung, da die Partner nicht für jede Leistung unmittelbar eine Gegenleistung fordern und bemüht sind, die Geschäftsbeziehung langfristig aufrecht zu erhalten (Walter 1998: 154). Dabei kommt es besonders auf die Ausgeglichenheit des Commitments zwischen den Geschäftsparteien an, da eine einseitige Verteilung zu Opportunismus anleitet (Anderson/Weitz 1992). Beispiele für die erfolgreiche Generierung von Commitment sind z. B. Formen der Vertragslandwirtschaft, in denen Abnehmer ihren Landwirten bei drastischen Veränderungen des Marktpreises auch dann entgegenkommen, wenn dies vertraglich nicht zwingend ist. Hieraus können sich erhebliche emotionale Bindungseffekte ergeben.

Die drei skizzierten Elemente führen, wenn sie zusammenwirken, zu hoher Beziehungsqualität (Rudolph 1998: 51; Hennig-Thurau/Bornemann 2003: 113). Abbildung 4 veranschaulicht diesen Zusammenhang.

\section{ABBILDUNG 4: BASISELEMENTE DER GESCHÄFTSBEZIEHUNGSQUALITÄT}

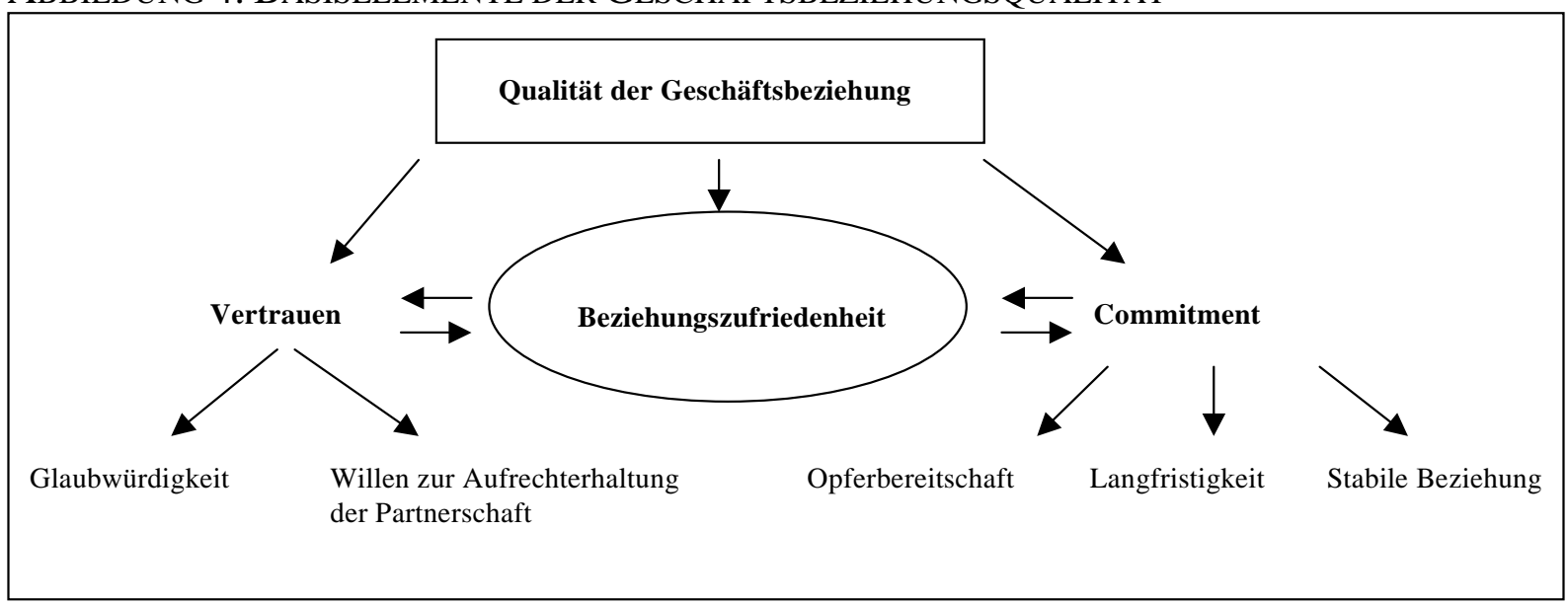

Quelle: Eigene Darstellung 


\subsection{Einflussfaktoren auf die Beziehungsqualität}

Die verhaltenswissenschaftliche Managementforschung hat in den letzten Jahren in einer Reihe von Studien empirisch überprüft, welche Faktoren zu Zufriedenheit, Vertrauen und Commitment führen. Diese Studien wurden allerdings nicht wie hier aus Sicht eines Herstellers durchgeführt, der seine Lieferanten befragt, sondern richten sich schwerpunktmäßig auf die Geschäftsbeziehung zwischen Industrie und Handel im Rahmen des Absatzkanalmanagements (Heide 1994; Wilson 1995; Kumar 1996; Fearne et al. 2004). Sie liefern gleichwohl wichtige Anregungen für das Controlling der Lieferantenzufriedenheit.

Folgende Faktoren können Einfluss auf die Qualität einer Geschäftsbeziehung nehmen:

- Abhängigkeit: Ausmaß der wechselseitigen oder einseitigen Ressourcenabhängigkeit. Eine symmetrische Beziehung bindet beide Partner aneinander und stabilisiert damit die Geschäftsbeziehung (Andaleeb 1995; Andaleeb 1996; Ganesan 1994; Heide/John 1988). Fehlende Ausweichmöglichkeiten führen ggf. zu erzwungenermaßen stabilen Beziehungen, die aber aufgrund von Reaktanzeffekten besonders negativ beurteilt werden. In der Transaktionskostentheorie wird besonders die Relevanz spezifischer Investitionen hervorgehoben, die sich außerhalb der jeweiligen Geschäftsbeziehung nicht mehr vollständig amortisieren und deshalb lock-in-Effekte verursachen (Claro et al. 2004).

- Machtausübung: Die Fähigkeit zur Durchsetzung von Druckmitteln zur Absicherung der eigenen Interessen. Ein deutliches Machtübergewicht erleichtert die Initiierung der Geschäftsbeziehung, verschärft aber tendenziell die Konflikte im weiteren Verlauf (Brown et al. 1995; Anderson/Narus 1990; Dwyer et al. 1987; Frazier 1983).

- Wahrgenommener Wettbewerbsdruck bzw. Unternehmenserfolg: Es gibt einen deutlichen Zusammenhang zwischen Erfolgsdruck und Opportunismusneigung. Als situativer Faktor beeinflusst der wahrgenommene Wettbewerbsdruck daher die Wahrscheinlichkeit von Konflikten (Dwyer/Oh 1987).

- Preiszufriedenheit: Die Bewertung der Fairness und der Auskömmlichkeit des Verkaufspreises (bzw. der Konditionen) ist für den Lieferanten essentiell. Dabei ist zwischen kurz- und langfristiger Preiszufriedenheit zu unterscheiden.

- Zufriedenheit mit den Geschäftsprozessen: Die Ausgestaltung der operativen Geschäftsbeziehung und der Grad der interorganisationalen Verknüpfung (z. B. 
Logistik, EDV-Systeme usf.) wird auf die Bewertung der Geschäftsbeziehung Einfluss nehmen (Cannon/Perreault 1999: 442), wobei zwischen einzelnen kritischen Ereignissen und den kontinuierlichen Erfahrungen zu unterscheiden ist.

- Strukturelle Bindung: Das Vorhandsein und die Bewertung längerfristiger vertraglicher Bindungen prägt die Handlungsoptionen der Geschäftspartner (Wilson 1995: 339; Cannon/Perreault 1999: 443).

- Soziale Bindung bzw. Freundschaft: Enge, auch private Kontakte zwischen den Repräsentanten der Unternehmen können als Unterstützungspotenzial der Geschäftsbeziehungen fungieren (Wilson/Mummalaneni 1986).

- Konfliktintensität: Ziel-, Verteilungs-, Kommunikations- und Rollenauseinandersetzungen zwischen den Geschäftspartnern (Steffenhagen 1975; Stern et al. 2001) sind zum Teil auf strukturelle Faktoren zurückzuführen, sie können aber personalen Charakter haben. Bei ausgeprägten Konflikten sind Konfliktmanagementsysteme notwendig, speziell um die nicht-strukturell angelegten Problemfelder wie z. B. Kommunikationsdifferenzen zu überbrücken.

- Image bzw. Reputation: Subjektive Wahrnehmung und Bewertung des Abnehmers, die eine relativ konsistente Verhaltensbereitschaft auslöst (Franke 1997). Das Image des Abnehmers als vertrauenswürdiger Geschäftspartner wird über einen längeren Zeitraum aufgebaut und ist kurzfristig kaum veränderbar.

- Gerechtigkeit bzw. Fairness: Der Umgang der Partner einer Geschäftsbeziehung miteinander (prodzeduale Gerechtigkeit) und das Ergebnis (distributive Gerechtigkeit), das beide Partner aus der Beziehung erzielen, haben Einfluss auf die wahrgenommene Fairness. Dabei spielt vor allem der Umgang innerhalb einer Geschäftsbeziehung eine wichtige Rolle, ob sich der schwächere Partner gerecht bzw. fair behandelt fühlt (Fearne et al. 2004: 7).

- Kommunikationsintensität: Frequenz der Kontakte zwischen den Geschäftspartnern. Diese kann sich positiv auf das Vertrauen, auf den Informationsstand und die Opportunismusgefahr auswirken (Morgan/Hunt 1994; Böhme 1999: 83).

- Kommunikationsqualität: Ausmaß, in dem innerhalb der Geschäftsbeziehung relevante Informationen an den Geschäftspartner weitergeleitet werden (Anderson/Weitz 1992; Matanda/Schroder 2004). Im Rahmen kontinuierlicher Verbesserungsprozesse kommt der Qualität des Informationsaustausches eine zentrale Rolle zu. 
- Geteilte Werte bzw. gemeinsame Ziele: Übereinstimmende Überzeugungen, welche Ziele und Verhaltensweisen richtig, wichtig und angemessen sind (Morgan/Hunt 1994; Heide/John 1992). Das Ausmaß der wahrgenommenen Zielharmonie bzw. der Zielkonflikte beeinflusst Vertrauen und Commitment.

- Gemeinsame berufliche Normen: Ähnlicher beruflicher Werdegang oder gleicher akademischer Hintergrund. Diese wirken positiv auf das Vertrauen zwischen den Geschäftspartnern und erleichtern Kooperationen (Husted 1994). Im konkreten Fall ist hierunter die Landwirtschaftsnähe des Verarbeitungsunternehmens zu verstehen. Es geht um das Verständnis für die spezifischen Probleme und die wettbewerbliche Situation der Agrarbetriebe. Wir bezeichnen dieses Konstrukt im Weiteren als „Landwirtschaftliche Orientierung“ bzw. Landwirtschaftsnähe.

Eine weitere Besonderheit des Agribusiness ist die hohe Verbreitung genossenschaftlicher Verarbeitungsunternehmen, in denen die landwirtschaftlichen Lieferanten zugleich Unternehmenseigner sind. Das skizzierte Grundmodell muss für genossenschaftliche oder genossenschaftsähnliche Unternehmen um den Aspekt der Investor Relations ergänzt werden. Landwirte sind zum einen an einem möglichst hohen Auszahlungspreis, zum anderen als Anteilseigner an der Zukunft ihres Unternehmens interessiert. ${ }^{1}$ Hierzu wurden auf Basis der einschlägigen Forschung (Kirchhoff/Piwinger 2001; Janik 2002) sowie durch qualitative Interviews mit landwirtschaftlichen Unternehmern folgende Kriterien extrahiert:

- Zufriedenheit mit der Unternehmensperformance des Abnehmers: Die Unternehmensperformance ist geprägt durch die „harten Fakten“ eines Unternehmens, also Rentabilität und Wachstumsziele. Diese Größen stehen für die Richtigkeit einer eingeschlagenen Strategie (Meier-Pfister/Thommen 2002: 53).

- Zufriedenheit mit den Unternehmensstrategien: Die vom Unternehmen gewählte Strategie muss für die Landwirte plausibel sein, um sie auch bei längeren Amortisationsfristen mitzutragen.

- Zufriedenheit mit dem Management: Als Anteilseigner wie als vertraglich gebundener Lieferant hängt der eigene Erfolg in erheblichem Umfang von der Fähigkeit des Managements ab. Da die Landwirte aufgrund von Informationsasymmetrien die Qualität der Unternehmensführung nur teilweise

\footnotetext{
${ }^{1}$ Da in Deutschland aufgrund des Genossenschaftsrechts (§ 73 Abs. 3 GenG) die Anteilseigner nur sehr eingeschränkt an der Unternehmenswertsteigerung partizipieren, tritt diese Zielsetzung bisher in der Unternehmenspraxis deutlich hinter die Auszahlungspreismaximierung zurück (Schramm et al. 2004).
} 
beurteilen können, gewinnt hier auch die persönliche Einschätzung der Führungskräfte an Bedeutung.

- Bewertung der Rechtsform der Genossenschaft: Genossenschaften haben im Agribusiness nach wie vor eine hohe Relevanz, gleichwohl ist ihre Zukunftsfähigkeit als solidarisches Modell umstritten.

- Einfluss und Vertrauen der Anteilseigner: Landwirten, die nicht nur Anteilseigner, sondern auch Lieferanten eines Unternehmens sind, ist es wichtig, Einfluss auf die Unternehmensstrategie nehmen zu können und Vertrauen in das Unternehmen zu haben. Oftmals ist die Lieferbeziehung (z. B. Milch-, Zuckerproduktion) für die landwirtschaftlichen Erzeuger die Haupteinnahmequelle des Betriebes.

Die einzelnen Aspekte sind - wie bei solchen verhaltenswissenschaftlichen Konstrukten zu erwarten - nicht gänzlich überschneidungsfrei. Sie lassen sich aber relativ klar in folgende übergeordnete Bereiche einteilen (Diller/Ivens 2004):

- Ökonomisch determinierte Faktoren: Machtausübung, Abhängigkeit, wahrgenommener Wettbewerbsdruck, Zufriedenheit mit der Unternehmensperformance.

- Einschätzung des Geschäftspartners: Image/Reputation, Gerechtigkeit/Fairness, Zufriedenheit mit der Unternehmensstrategie und dem Management.

- Soziale Bindung: Freundschaft, Konfliktintensität.

- Netzwerkbildung: Kommunikationsintensität, Kommunikationsqualität, gemeinsame berufliche Normen, geteilte Werte.

- Landwirtschaftliche Orientierung: Nähe des Verarbeiters zu Landwirtschaft und Einfluss bzw. Vertrauen der Anteilseigner.

Die Vielzahl der potenziellen Einflussfaktoren verdeutlicht die Komplexität einer Messung der Geschäftsbeziehungsqualität. ${ }^{2}$ Eine solche Messung ist jedoch unumgänglich: „If you can’t measure it, you can’t manage it”. Ohne verlässliche Steuerungsgrößen gleicht das Lieferantenmanagement einem Blindflug und wird im betrieblichen Alltag nur allzu häufig gegenüber kurzfristigen Kosten- und Preiszielen unterliegen. Die oben skizzierten Erfahrungen aus der Fleisch- und Milchwirtschaft zeigen dies sehr deutlich.

\footnotetext{
${ }^{2}$ Neben diesen hier als wichtig erachteten Größen werden in der Forschung weitere Konstrukte diskutiert, z. B. wahrgenommener Formalisierungsgrad (Mohr/Nevin 1994), Beziehungsfähigkeit (Pfohl/Buse 1999), Autonomiestreben (Robicheaux/Coleman 1994), Opportunismusneigung (Böhme 1999), Flexibilität (Homburg et al. 2002; Matanda/Schroder 2004), Kontrollverhalten, Solidarität, Rollenintegrität und Planungsverhalten (Diller/Ivens 2004). Die oben getroffene Auswahl erfolgt im Hinblick auf die Besonderheiten des Agribusiness.
} 


\section{SRQ: Ein Instrument zur Messung der Lieferantenbindung}

Für Unternehmen des Agribusiness, die nicht selten über mehrere tausend landwirtschaftliche Lieferanten verfügen, erscheint eine kontinuierliche und valide Messung der Geschäftsbeziehungsqualität sinnvoll. Je nach Unternehmensgröße sollten zwischen 50 und 200 landwirtschaftliche Betriebe befragt werden. Hierzu schlagen wir auf Grundlage der theoretischen Vorarbeiten ein Standardmodell vor, das die wesentlichen Teilbereiche der Geschäftsbeziehung erfasst. Auf Basis der Befragung werden verschiedene Kennzahlen berechnet, die die Geschäftsbeziehungsqualität spiegeln und eine Steuerung der Relationship Quality ermöglichen.

Im Marketing haben sich standardisierte Befragungskonzepte bewährt, da sie für die Unternehmenspraxis eine einfache und entsprechend preisgünstige Umsetzung ermöglichen. Besonders prominent ist das von Parasuraman/Berry/Zeithaml (1985) entwickelte Tool zur Messung der Kundenzufriedenheit im Dienstleistungsbereich SERVQUAL, das in zahlreichen Verbraucherbefragungen weltweit verwendet wurde. In Anlehnung daran bezeichnen wir das hier entwickelte Konzept als „Supplier Relationship Quality/SRQ“.

Die Erfassung der Geschäftsbeziehungsqualität ist kein Selbstzweck, sondern dient ökonomisch der Optimierung des Beschaffungsprozesses und der besseren Einbindung der Lieferanten (Hansen et al. 2002). Folgende Ziele sind im Agribusiness besonders relevant:

- Die Geschäftsbeziehungsqualität soll sich zunächst in einer gesteigerten Loyalität gegenüber dem Abnehmer niederschlagen (Foscht 2002: 85; Homburg/Krohmer 2003: 102). Ob dieses Ziel erreicht wird, lässt sich valide an der Wechselbereitschaft ablesen. Im Wettbewerb um qualitativ hochwertige Rohwaren ist die Gewinnung liefertreuer Landwirte ein wichtiger Faktor.

- Eine weitere Zielvariable ist die Investitionsbereitschaft der Lieferanten. Viele Maßnahmen des Qualitätsmanagements oder der Neuproduktentwicklung verlangen parallele Investitionen von Hersteller und Lieferanten. Die Bereitschaft, auch in risikobehafteten Situationen in die Geschäftsbeziehung zu investieren, ist ein zentraler Vorteil eines erfolgreichen Lieferantenmanagements.

- Ein zunehmend wichtiges Ziel einer vertrauensvollen Geschäftsbeziehung ist die Steigerung der intrinsischen Qualitätsmotivation der Lieferanten. Im positiven Fall entwickeln diese ein Verständnis für die Herausforderungen eines modernen 
Qualitätsmanagements mit seiner Betonung des kontinuierlichen Verbesserungsprozesses. Die Probleme, die z. B. derzeit die Molkereiwirtschaft bei der Einführung des QM-Konzeptes oder die Fleischwirtschaft bei QS haben, weisen auf die derzeitigen Schwierigkeiten hin.

- Weiterhin wird als Zielvariable die Weiterempfehlungsbereitschaft in das Modell integriert. Sie erfasst, ob der Lieferant seinen Abnehmer an Berufskollegen weiterempfiehlt. Diese Form der Mund-zu-Mund-Kommunikation spielt eine wichtige Rolle für das Beschaffungsmarketing, wenn es um die Akquisition neuer Lieferanten geht. Aber auch für die Durchsetzung von neuen, bei den Landwirten unpopulären Maßnahmen kann eine positive Kommunikation von Meinungsführern unter den Lieferanten unterstützend wirken.

- Schließlich kann ein positives Geschäftsbeziehungsklima dazu beitragen, dass Versuche der Gegenmachtbildung unter den Lieferanten unterbleiben und die Kooperationsbereitschaft steigt. Versuche einer countervailing power zeichnen sich derzeit z. B. in der Milchwirtschaft durch die Bildung neuer landwirtschaftlicher Verkaufskooperationen und des Bundesverbandes Deutscher Milchviehhalter (BDM) ab. Sie stehen einem Supplier Relationship Management diametral entgegen.

Bei Unternehmen der Ernährungsindustrie, an denen Landwirte als Aktionäre oder Genossen beteiligt sind, kommt als weiterer Faktor die Bereitschaft zur Kapitalerhöhung hinzu. Die Fähigkeit, in den Reihen der landwirtschaftlichen Anteilseigner kurzfristig Kapitalerhöhungen durchsetzen zu können, kann ein wichtiger Erfolgsfaktor bei Mergers \& Akquisitions sein.

Der Zusammenhang zwischen der Einschätzung der Lieferbeziehung durch die Landwirte und den o. g. Verhaltenswirkungen kann unterschiedlich ausgeprägt sein. In der Forschung wird häufig ein umgekehrt S-förmiger Zusammenhang unterstellt (Hennig-Thurau et al. 1999; Mittal/Kamakura 2001), d. h. ein besseres Lieferklima führt zunächst zu deutlich steigender Loyalität, Investitionsbereitschaft und Qualitätsmotivation. Nach dem Erreichen eines gewissen Mindestniveaus der Zufriedenheit steigen die genannten Größen nur noch langsam an. Bei ausgesprochen guter Geschäftsbeziehungsqualität nimmt das Engagement der Landwirte dann wieder deutlich zu. Die Verhaltenswirkungen sind mithin an den Endbereichen bei besonders guter und besonders schlechter Geschäftsbeziehung ausgeprägter. Abbildung 5 zeigt einen solchen Funktionsverlauf (Modell A). Es sind aber auch linear 
steigende (Modell B) oder S-förmige Zusammengänge (Modell C) möglich. Die S-KurvenHypothese weist einen Sättigungspunkt auf, ab dem steigende Lieferantenbindung keinen positiven Nutzen mehr bringt, hier kommt es hauptsächlich auf die Absicherung einer mittleren Geschäftsbeziehungsqualität an. Legt man dagegen einen umgekehrt S-förmigen Funktionsverlauf zugrunde, so würde erst die außergewöhnliche Zufriedenheit der Landwirte $\mathrm{zu}$ einem herausragenden Engagement führen. Es bleibt empirisch in den verschiedenen Branchen zu prüfen, wie sich die landwirtschaftlichen Lieferanten tatsächlich verhalten.

\section{ABBILDUNG 5: ZUSAMMENHANG ZWISCHEN GESCHÄFTSBEZIEHUNGSQUALITÄT UND} LIEFERANTENENGAGEMENT

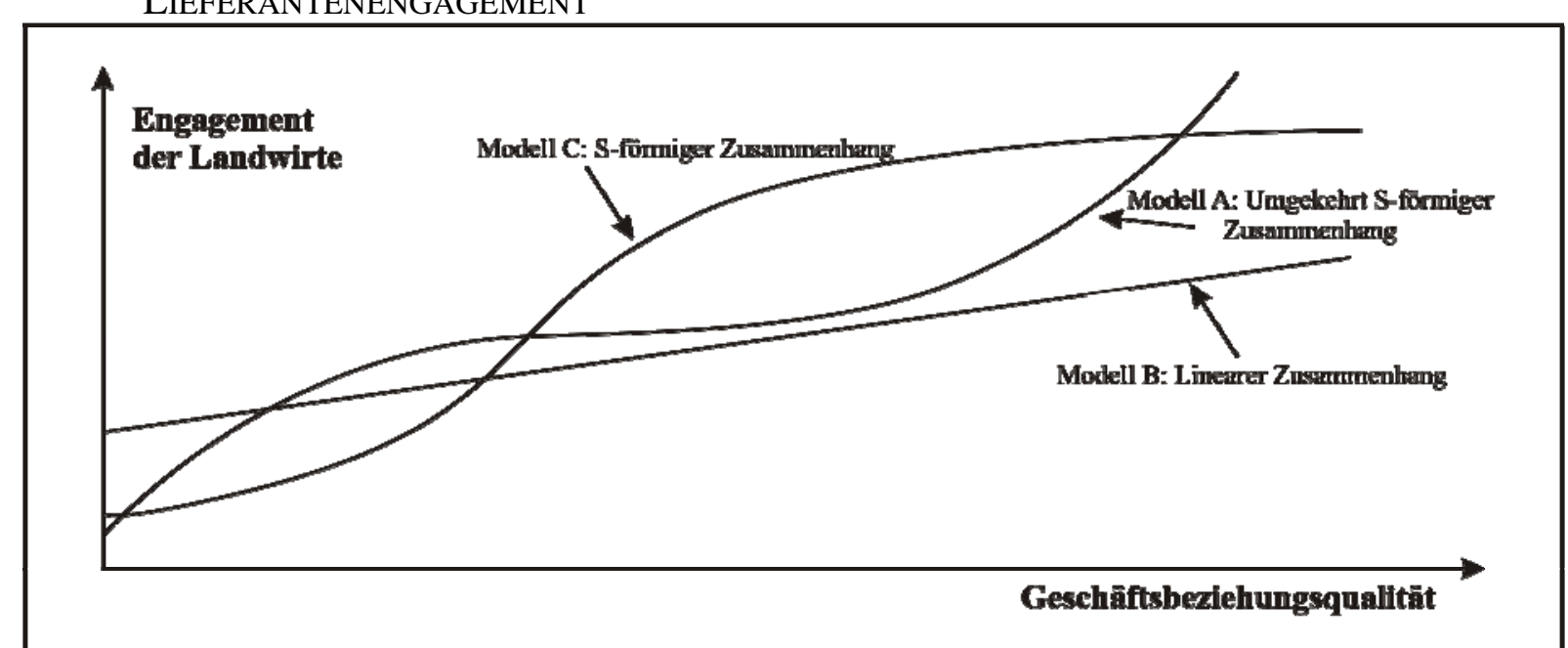

Quelle: Eigene Darstellung

Das Modell lässt Raum, um ggf. weitere branchen- und unternehmensspezifische Besonderheiten zu beachten. So kann die Bindung an einen Lieferanten noch andere Ursachen als Zufriedenheit und Vertrauen haben, z. B. rechtliche Wechselbarrieren oder fehlende Ausweichmöglichkeiten (Herrmann/Johnson 1999: 580). Im Rahmen von Vertragslandwirtschaft kann die Ausgestaltung des Kontraktes eine wichtige Rolle spielen. Es ist daher sinnvoll, neben dem verallgemeinerungsfähigen Kern von $S R Q$ weitere, auf die Spezifika der Branche jeweils zugeschnittene Variable zu verwenden. Insgesamt ergibt sich das in Abbildung 6 skizzierte Kausalmodell, das als Grundkonzept zur Überprüfung der Geschäftsbeziehungsqualität im Agribusiness dienen kann. 
ABBILDUNG 6: MESSMODELL ZUR ÜBERPRÜFUNG DER GESCHÄFTSBEZIEHUNGSQUALITÄT „SRQ“

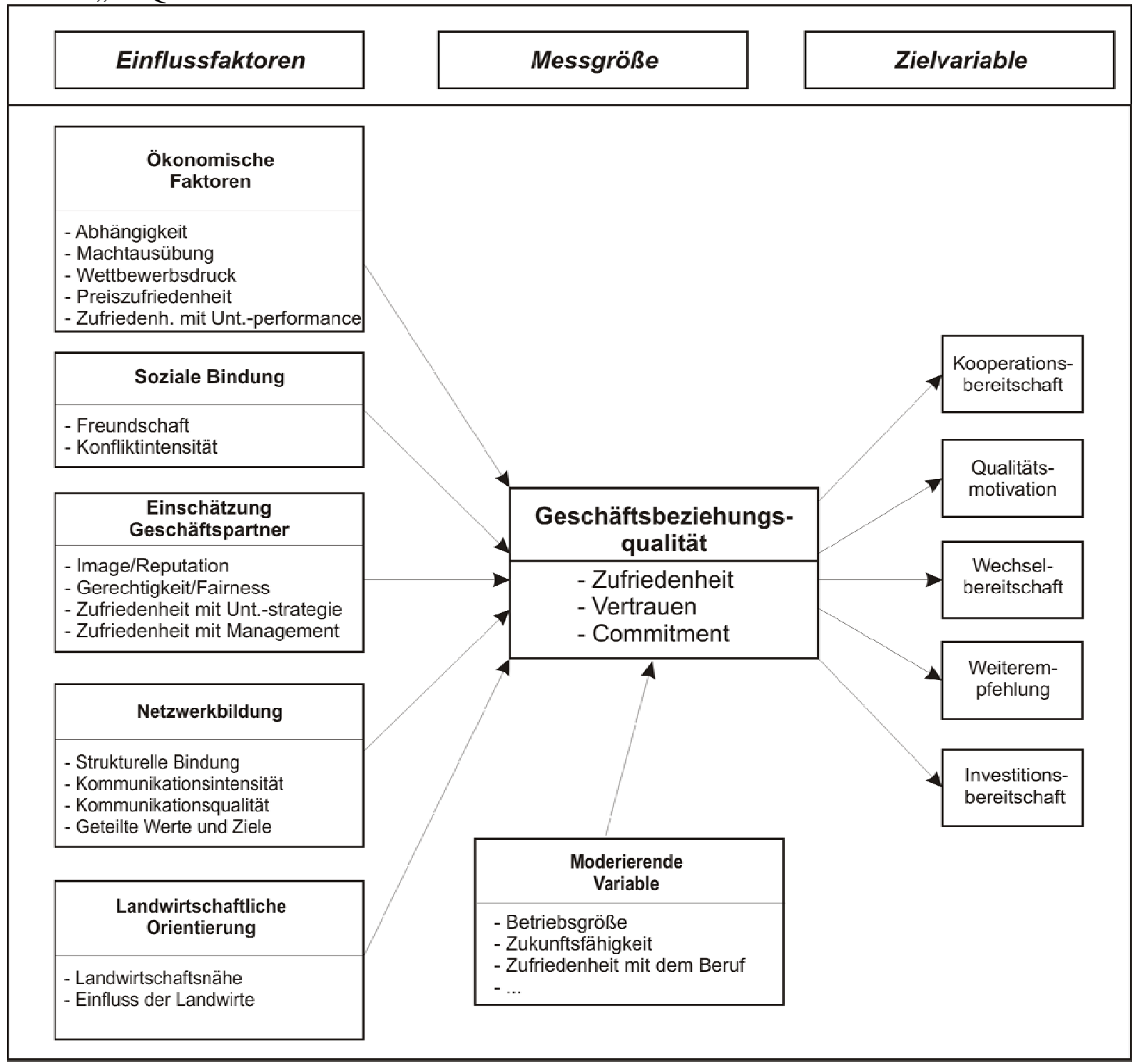

Quelle: Eigene Darstellung

Neben den Faktoren, die sich aus der Geschäftsbeziehung selbst heraus ergeben, nehmen externe Rahmenbedingungen und betriebsstrukturelle Merkmale Einfluss auf die Bewertung des Abnehmers. So werden erfolgreiche landwirtschaftliche Betriebe ggf. zufriedener sein als weniger erfolgreiche. Auch dem Branchenwachstum kann eine moderierende Funktion zukommen. Entsprechend werden die Betriebsmerkmale und personale Faktoren des Landwirts (z. B. Berufszufriedenheit) in die Befragung integriert.

\section{Einbindung der Lieferantenbefragung in einen Benchmarking-Prozess}

Eine Messung der Supplier Relationship Quality ist aufgrund der Komplexität der Wirkungsbeziehungen nicht einfach und verlangt multivariate Analysemethoden wie die Regressions- 
oder Kausalanalyse. Das vorgestellte Instrument gewinnt zudem an Nutzen, wenn die resultierenden Zahlenwerte in einen systematischen Controlling-Prozess eingebunden werden. Selbstverständlich liefern auch ad-hoc-Studien interessante Ergebnisse. Die Einordnung der Daten wird jedoch aussagekräftiger, wenn - vergleichbar zum Deutschen Kundenmonitoring (www.servicebarometer.de), in dem seit 1992 branchenübergreifend Kundenzufriedenheitswerte erhoben und in einem Benchmarkingverfahren analysiert werden - Vergleichsgrößen verschiedener Unternehmen und Produktgruppen vorliegen. Mit dieser Zielrichtung wird zurzeit am Lehrstuhl für Agrar- und Lebensmittelmarketing der Universität Göttingen eine Datenbank entwickelt, die in anonymisierter Form Branchen- und Betriebsvergleiche ermöglicht.

Das Beispiel Kundenzufriedenheit zeigt auch, welche ökonomischen Konsequenzen solche auf den ersten Blick „weiche“ Faktoren der Geschäftsbeziehung haben. In Abbildung 7 wird die Gesamtzufriedenheit von Verbrauchern mit Lebensmittelhandelsgeschäften in Verbindung zu ihren jeweiligen Einkaufsausgaben in diesen Geschäften gesetzt. Der Zusammenhang ist statistisch ausgesprochen deutlich. 
ABBILDUNG 7: ZUSAMMENHANG ZWISCHEN KUNDENZUFRIEDENHEIT UND AUSGABEN IN DEM JEWEILIGEN GESCHÄFT

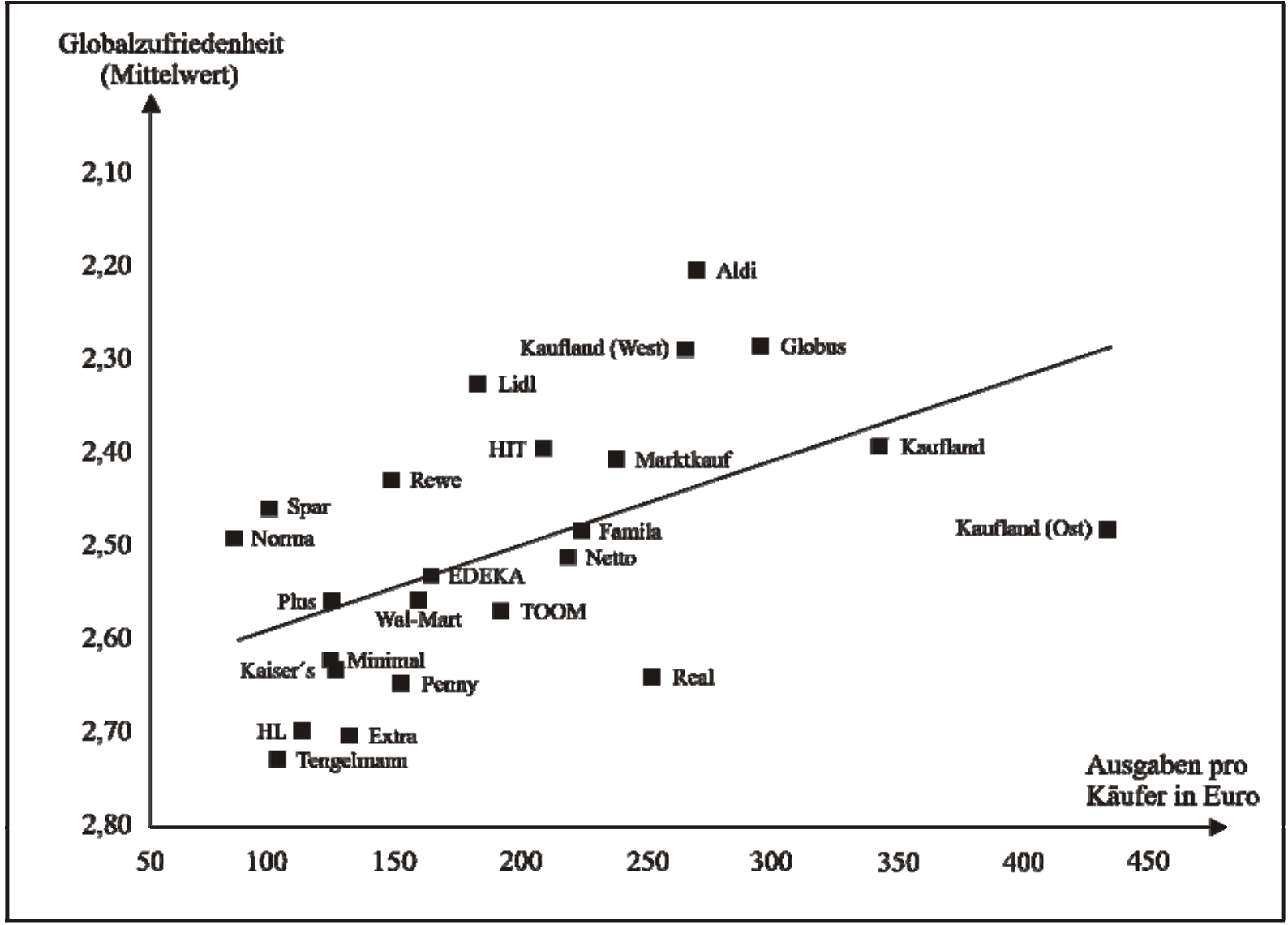

Quelle: Twardawa 2004

Über den Ausweis der Geschäftsbeziehungsqualität insgesamt und den darin inkorporierten Größen (Gesamtzufriedenheit, Commitment, Vertrauen) hinaus ermöglicht das Konzept der Lieferantenbefragung „SRQ“ die Analyse von unternehmensspezifischen RelationshipTreibern. Mittels Regressions- und Kausalanalyse können diejenigen Faktoren ermittelt werden, die im konkreten Fall die Geschäftsbeziehungsqualität besonders stark beeinflussen. Zudem können Zusammenhänge zwischen der Unternehmensgröße u. a. betriebsstrukturellen Merkmalen der Lieferanten und ihrer jeweiligen Einschätzung des Abnehmers aufgedeckt werden. Auf diese Weise werden z. B. diejenigen Einflussgrößen identifiziert, mit denen die landwirtschaftlichen Zukunftsbetriebe angesprochen werden können. Schließlich ermöglicht ein Zeitreihenvergleich auf Basis einer kontinuierlichen Erhebung im zwei- bis dreijährigen Rhythmus ein systematisches Controlling der Lieferantenbeziehung.

Die im Benchmarking sowie im Zeitreihenvergleich ermittelten Kennzahlen können anschließend in die Balanced Scorecard (Procurement Scorecard) eines Unternehmens einfließen. Dies ermöglicht die Verknüpfung der Kennwerte mit dem übergreifenden 
Controllingprozess des Unternehmens und kann z. B. zur Leistungsbewertung von Einkaufsabteilung und - falls vorhanden - landwirtschaftlicher Beratung herangezogen werden.

Ziel des hier skizzierten Projektes ist es somit insgesamt, Daten für unterschiedliche Unternehmen und Branchen des Agribusiness zu erheben, um Vergleichsgrößen im Sinne des Benchmarking zu erfassen und den Industrieunternehmen eine Einordnung ihres Status quo zu ermöglichen. In einer ersten Pilotstudie mit einem großen Unternehmen der Zuckerwirtschaft wurde das oben skizzierte Modell getestet und weiterentwickelt. Die überarbeitete und hier präsentierte Fassung des SRQ-Modells wird derzeit in einem weiteren Pilotprojekt für ausgewählte Unternehmen der deutschen Milchwirtschaft realisiert. Anschließend soll dann eine verdichtete und für Online- und schriftliche Befragungen geeignete Version zur Verfügung stehen, die eine kostengünstige Erhebung ermöglicht.

\section{Fazit}

Die deutsche Ernährungsindustrie ist in vielen Fällen durch ein antagonistisches Verhältnis zu ihren Lieferanten charakterisiert. Kurzfristige Geschäftsbeziehungen, geringes Vertrauen und eine Tendenz zu opportunistischem Verhalten erweisen sich als Barrieren eines qualitätsorientierten Supply Chain Managements.

Die Vorteile, die ein Unternehmen aus einem guten Verhältnis zu seinen Abnehmern zieht, sind vielfältig. Alle Beteiligten sind bemüht, Qualität zu produzieren sowie den Leistungserstellungsprozess kontinuierlich zu verbessern und Informationen rechtzeitig auszutauschen. Kooperative Lieferantenbeziehungen erleichtern es dem Hersteller, strategische Richtungswechsel bei den landwirtschaftlichen Lieferanten durchzusetzen. Insgesamt führt ein erfolgreiches Supplier Relationship Management zu höherer Flexibilität, Stabilität, Qualität und Innovationskraft (Stölzle 2000: 17). Dem stehen die Kosten der Lieferantenpflege gegenüber, die nicht nur die direkten Maßnahmen wie z. B. Qualitätszirkel entlang der Kette, sondern auch die geringeren Möglichkeiten des Preisdrucks umfassen. Supplier Relationship Management eignet sich aus diesem Grund besonders für Unternehmen mit einer Differenzierungsstrategie.

Als Ergänzung der bisher in der Forschung diskutierten Instrumente des Lieferantenmanagements wurde in der vorliegenden Arbeit ein Messkonzept zur kontinuierlichen Überprüfung der Geschäftsbeziehungsqualität vorgeschlagen. Die ersten Erfahrungen mit 
diesem Instrument deuten darauf hin, dass es sich zum validen und kontinuierlichen Monitoring der Geschäftsbeziehungsqualität eignet und in Controllingsysteme einbinden lässt. Durch die Erhebung in weiteren Branchen und Unternehmen könnten zukünftig Vergleichswerte erhoben werden, die in anonymisierter Form die Bewertung der jeweiligen Leistung erleichtert. Im Zusammenspiel mit anderen Instrumenten des Beschaffungscontrollings (z. B. Prozesskostenrechnung, Einkaufs-Portfolioanalyse, Performance-Measurement-Systeme, Qualitätskostenrechnung) wird so ein professionelles Lieferantenmanagement möglich (Pampel 1999; Seuring 2001). 


\section{Literatur}

Allinson, J. (2004): Procurement in the Food and Drink Industry in the early $21^{\text {st }}$ Century, in: Bourlakis, M. A.; Weightman, P. W. H. (Hrsg.) (2004): Food Supply Chain Management, Oxford, S. 49-61.

Andaleeb, S. S. (1995): Dependence relations and the moderating role of trust: implications for behavioral intentions in marketing channels, in: International Journal of Research in Marketing, 12. Jg., Heft 2, S. 157-172.

Andaleeb, S. S. (1996): An Experimental Investigation of Satisfaction and Commitment in Marketing Channels: The Role of Trust and Dependence, in: Journal of Retailing, 72. Jg., Heft 1, S. 77-94.

Anderson, E.; Weitz, B. (1992): The Use of Pledges to Build and Sustain Commitment in Distribution Channels, in: Journal of Marketing Research, 29. Jg., S. 18-34.

Anderson, J. C.; Narus, J. A. (1990): A Model of Distributor Firm and Manufacturer Firm Working Partnerships, in: Journal of Marketing, 54. Jg., Heft 1, S. 42-58.

Batt, J.; Rexha, N. (1999): Building Trust in Agribusiness Supply Chains: A Conceptual Model of Buyer-Seller Relationships in the Seed Potato Industry in Asia, in: Journal of International Food \& Agribusiness Marketing, 11 Jg., Heft 1, S. 1-17.

Bauer, M. (2000): Kundenzufriedenheit in industriellen Geschäftsbeziehungen: kritische Ereignisse, nichtlineare Zufriedenheitsbildung und Zufriedenheitsdynamik, Wiesbaden.

BDM (Hrsg.) (2004): Internetseiten des Bundesverband Deutscher Milchviehhalter Nord e.V., http://www.milchviehhalter-nord.de, Abrufdatum: 26.07.2004.

Bodenstein, G.; Spiller, A. (1998): Marketing: Strategien, Instrumente, Organisation, Landsberg/Lech.

Bogetoft, P.; Olesen, H. B. (2004): Quality Incentives and Supply Chains: Managing Salmonella in Pork Production, in: American Journal of Agricultural Economics. 86. Jg., Heft 3, S. 829-834.

Böhme, A. (1999): Die Ausgestaltung von Abnehmer-Zulieferer-Beziehungen, Lohmar, Köln.

Bourlakis, M. A.; Weightman, P. W. H. (Hrsg.) (2004): Food Supply Chain Management, Oxford.

Brown, J. R. et al. (1995): Power and Relationship Commitment: Their Impact on Marketing Channel Member Performance, in: Journal of Retailing, 71. Jg., Heft 4, S. 363-392.

Cannon, J. P. et al. (1999): Buyer-Seller-Relationships in Business Markets, in: Journal of Marketing Research, 36 Jg., November, S. 439-460.

Christopherson, G.; Coath, E. (2002): Collaboration or control in food supply chains: who ultimately pays the price?, Proceedings of the Fifth International Conference on Chain and Network Management in Agribusiness and the Food Industry, in: Trienekens, J.; Omta, S. (Hrsg.), Wageningen Academic Publishers, The Netherlands.

Claro, D. P. et al. (2004): How to manage a relationship and be successful: A study of the network and buyer-supplier relationship in the Dutch Potted Flower and Plant Industry, in: Bremmers, H. J.; Omta, S. W. F.; Trienekens, J. H.; Wubben, E. F. M. (Hrsg.): Dynamics in Chains and Networks, Wageningen, S. 203-210. 
Diller, H.; Ivens, B. S. (2004): Beziehungsstile im Business-to-Business-Geschäft, in: Zeitschrift für Betriebswirtschaft, 74. Jg., Heft 3, S. 249-271.

Doney, P. M.; Cannon, J. P. (1997): An Examination of the Nature of Trust in Buyer-Seller Relationships, in: Journal of Marketing, 61. Jg., Heft 4, S. 35-51.

Dwyer, F. R.; Oh, S. (1987): Output Sector Munificence Effects on the Internal Political Economy of Marketing Channels, in: Journal of Marketing Research, 24. Jg., S. 347358.

Dwyer, F. R. et al. (1987): Developing Buyer-Seller Relationships, in: Journal of Marketing, 51. Jg., Heft 2, S. 11-27.

Fearne, A. et al. (2004): Measuring Distributive and Procedural Justice in Buyer/Supplier Relationship: An Empirical Study of UK Supermarket Supply Chain, Paper presented at the 88th Seminar of the European Association of Agricultural Economics, Paris, May 5-6 2004.

Foscht, T. (2002): Kundenloyalität: Integrative Konzeption und Analyse der Verhaltens- und Profitabilitätswirkungen, Wiesbaden.

Franke, N. (1997): Das Image des Herstellers im Handel. Theoretische Konzeption eines allgemeinen Modells und kausalanalytische Überprüfung im Taschenbuchmarkt, in: Marketing ZFP Zeitschrift für Forschung und Praxis, 19. Jg., Nr. 4, S. 209-219.

Frazier, G. L. (1983): On the Measurement of Interfirm Power in Channels of Distribution, in: Journal of Marketing Research, 20. Jg., Heft 5, S. 158-166.

Ganesan, S. (1994): Determinants of Long-Term Orientation in Buyer-Seller Relationships, in: Journal of Marketing, 58. Jg., Heft 4, S. 1-19.

Giering, A. (2000): Der Zusammenhang zwischen Kundenzufriedenheit und Kundenloyalität: eine Untersuchung moderierender Effekte, Mannheim.

Grimsdell, K. (1996): The supply chain for fresh vegetables: what it takes to make it work, in: Supply Chain Management: An International Journal, 1. Jg., Heft 1, S. 11-14.

Hansen, M. H. et al. (2002): The impact of trust on cooperative membership retention, performance and satisfaction: an exploratory study, in: International Food and Agribusiness Management Review, 5. Jg., S. 41-59.

Heide, J. B. (1994): Interorganizational governance in Marketing Channels, in: Journal of Marketing, 58. Jg., Heft 1, S. 71-85.

Heide, J. B.; John, G. (1988): The Role of Dependence Balancing in Safeguarding Transaction-Specific Assets in Conventional Channels, in: Journal of Marketing, 52. Jg., Heft 1, S. 20-35.

Heide, J. B.; John, G. (1992): Do Norms Matter in Marketing Relationships?, in: Journal of Marketing, 56. Jg., Heft 2, S. 32-44.

Heide, J. B.; Miner, A. S. (1992): The Shadow of the Future: Effects of anticipated Interaction and Frequency of Contact on Buyer-Seller Cooperation, in: Academy of Management Journal, 35. Jg., Nr. 2, S. 265-291.

Hennig-Thurau, T.; Bornemann, D. (2003): Return on Relationship Quality, oder: Lohnen sich Investitionen in die Qualität von Geschäftsbeziehungen, in: Payne, A.; Rapp, R. (Hrsg.): Handbuch Relationship Marketing - Konzeption und erfolgreiche Umsetzung, 2. Aufl., München. 
Herrmann, A.; Johnson, D. (1999): Die Kundenzufriedenheit als Bestimmungsfaktor der Kundenbindung, in: Zeitschrift für betriebswirtschaftliche Forschung (zfbf), 51. Jg., Heft 6, S. 579-599.

Hobbs, J. E. (1996): Transaction Costs and Slaughter Cattle Procurement: Processors Selection of Supply Channels, in: Agribusiness, 12. Jg., Nr. 6, S. 509-523.

Homburg, C.; Krohmer H. (2003): Marketingmanagement: Strategie - Instrumente Umsetzung - Unternehmensführung, Wiesbaden.

Homburg, C.; Stock R. (2001): Theoretische Perspektiven zur Kundenzufriedenheit, in: Homburg, C. (Hrsg.): Marktforschung, Wiesbaden.

Husted, B. W. (1994): Transaction Costs, Norms and Social Networks, in: Business \& Society, 33 Jg., Heft 1, S. 30-57.

Janik, A. (2002): Investor Relations in der Unternehmenskommunikation: Kommunikationswissenschaftliche Analysen und Handlungsempfehlungen, Wiesbaden.

Keebingate, F. (2003): Triadische Strategieausrichtung förderwirtschaftlich tätiger Unternehmen, Hamburger Schriften zum Genossenschaftswesen, Bd. 15, Göttingen.

Kirchhoff, K. R.; Piwinger, M. (Hrsg.) (2001): Die Praxis der Investor Relations, 2. Aufl., Neuwied.

Klee, A., Strategisches Beziehungsmanagement, Aachen.

Kumar, N. (1996): The power of trust in manufacturer-retailer relationship, in: Harvard Business Review, 74. Jg., Nov./Dec., S. 92-106.

Lawrence, J. D.; Schroeder, T. C.; Hayenga, M. L. (2001): Evolving Producer-PackerCustomer Linkages in the Beef and Pork Industries, in: Review of Agricultural Economics, 23. Jg., Nr. 2, S. 370-385.

Lawrence, J. D., Hayenga, M. L. (2002): The U.S. Pork and Beef Sectors: Divergent Organization Patterns, Paradoxes and Conflicts, in: Trienekens, J. H.; Omta, S. W. F. (Hrsg.): Paradoxes in Food Chains and Networks, Wageningen, S. 512-521.

Matanda, M. J.; Schroder, B. (2004): Business-to-Business Relationships by Categories of Suppliers in the Marketing Channel, in: Bremmers, H. J.; Omta, S. W. F.; Trienekens, J. H.; Wubben, E. F. M. (Hrsg.): Dynamics in Chains and Networks, Wageningen, S. 532-537.

Meier-Pfister, M.; Thommen, A. A. (2002): Erfolgsfaktor Investor Relations? Finanzkommunikation in der Schweiz, Zürich.

Mittal, V.; Kamakura, W. (2001): Satisfaction, Repurchase Intent, and Repurchase Behaviour: Investigating the Moderating Effects of Customer Characteristics, in: Journal of Marketing Research, 38 Jg., February, S. 131-142.

Monczka, R. M. et al. (2001): Purchasing and supply chain management, 2. Aufl., Cincinnati, Ohio.

Mohr, J.; Nevin, J. R. (1994): Communication Strategies in Marketing Channels: A Theoretical Perspective, in: Journal of Marketing, 58. Jg., October, S. 36-53.

Morgan, R. M.; Hunt, S. D. (1994): The Commitment-Trust Theory of Relationship Marketing, in: Journal of Marketing, 58. Jg., Heft 3, S. 20-38. 
Pampel, J. R. (1999): Instrumente für das kooperationsbezogene Beschaffungscontrolling Steuerung von Produktions- und Transaktionskosten, in: Hahn, D.; Kaufmann, L. (Hrsg.): Handbuch Industrielles Beschaffungsmanagement, Wiesbaden, S. 549-575.

Parasuraman, A. et al. (1985): A conceptual model of service quality and its implications for future research, in: Journal of Marketing, 49. Jg., Heft 4, S. 41-50.

Pfohl, H.-C.; Buse, H. P. (1999): Organisationale Beziehungsfähigkeit in komplexen kooperativen Beziehungen, in: Engelhard, J.; Sinz, E. (Hrsg.): Kooperation im Wettbewerb: Neue Formen und Gestaltungskonzepte im Zeichen von Globalisierung und Informationstechnologie, Wiesbaden, S. 269-300.

Plöttner, O. (1995): Das Vertrauen des Kunden - Relevanz, Aufbau und Steuerung auf industriellen Märkten, Wiesbaden.

Porter, M. E. (1989): Wettbewerbsvorteile, Frankfurt am Main.

Riemer, K.; Klein, S. (2002): Supplier Relationship Management - Supplier Relationships im Rahmen des Partner Relationship Managements, in: HMD: Praxis der Wirtschaftsinformatik, 39 Jg., Heft 228, S. 5-22.

Robicheaux, R. A.; Coleman, J. E. (1994): The Structure of Marketing Channel Relationships, in: Journal of the Academy of Marketing Science, 22 Jg., Nr. 1, S. 38-51.

Rudolph, B. (1998): Kundenzufriedenheit im Industriegüterbereich, Wiesbaden.

Ryder, R.; Fearne, A. (2003): Procurement best practice in the food industry: supplier clustering as a source of strategic competitive advantage, in: Supply Chain Management: An International Journal, 8. Jg., Heft 1, S. 12-16.

Schramm, M. et al. (2004): Brand Orientation in der Ernährungsindustrie: Erfolgsdeterminanten der Markenführung am Beispiel genossenschaftlicher Hersteller, Wiesbaden.

Seifert, D. (2001): Efficient Consumer Response: Supply Chain Managment (SCM), Category Management (CM) und Collaborative Planing, Forecasting and Replenishment (CPFR) als neue Strategieansätze, 2. Aufl., München.

Seuring, S. (2001): Supply Chain Costing, München.

Simchi-Levi, D. et al. (2003): Designing \& Managing the Supply Chain, Concepts, Strategies \& Case Studies, 2. Aufl., Mc Graw Hill.

Spiller, A. (2004): Qualitätssicherung in der Wertschöpfungskette: Vor- und Nachteile unterschiedlicher Organisationskonzepte, in: Dachverband Agrarforschung (Hrsg.): Lebensmittelqualität und Qualitätssicherungssysteme, Frankfurt.

Steffenhagen, H. (1975): Konflikt und Kooperation in Absatzkanälen, Wiesbaden.

Stern, L.W.; El-Ansary, A.I.; Coughlan, A. T. (2001): Marketing Channels, 6. Aufl., London.

Stölzle, W. (2000): Beziehungsmanagement - Konzeptverständnis und Implikationen für die Beschaffung, in: Hildebrandt, H.; Koppelmann, U. (Hrsg.): Beziehungsmanagement mit Lieferanten: Konzepte, Instrumente, Erfolgsnachweise, Stuttgart, S. 1-23.

Stölzle, W.; Helm, R. (2003): Der Einfluss elektronischer Märkte auf die Beziehungsqualität - Theoretische Grundlagen und empirische Ergebnisse, in: Bogaschewsky, R. (Hrsg.): Integrated Supply Chain Management, Köln, S. 285-322. 
Stölzle, W.; Heusler, K. F. (2003): Supplier Relationship Management - Entstehung, Konzeptverständnis und methodisch-instrumentelle Anwendung, in: Bogaschewsky, R., Götze, U. (Hrsg.): Management und Controlling von Einkauf und Logistik, Gernsbach, S. 168-194.

Traupe, C. (2002): Schlachtschweinevermarktung in Niedersachsen: Stand, Defizite, Entwicklungsmöglichkeiten, Göttingen.

Twardawa, W. (2004): Vom “Wollen” und "Walten” der Konsumenten, http://www.servicebarometer.de/kundenmonitor2004/bestpractice/gfk.php, Abrufdatum: 20.08.2004.

Van Weele, A. J. (2002): Purchasing and Supply Chain Management: Analysis, Planning and Practice, 3. Aufl., Padstow, Cornwall.

Wagener, S. M. (2001): Strategisches Lieferantenmanagement in Industrieunternehmen, Frankfurt a. M.

Walter, A. (1998): Der Beziehungspromotor: Ein personaler Gestaltungsansatz für erfolgreiches Relationship Marketing, Wiesbaden.

Werani, T. (1999): Die Stabilität kooperativer Geschäftsbeziehungen in industriellen Märkten: Ergebnisse einer empirischen Untersuchung unter besonderer Berücksichtigung des Beziehungswertkonzeptes, in: Engelhard, J.; Sinz, E. (Hrsg.): Kooperation im Wettbewerb: Neue Formen und Gestaltungskonzepte im Zeichen von Globalisierung und Informationstechnologie, Wiesbaden, S. 325-345.

Williamson, O. E. (1979): Transaction Cost Economics: The Governance of Contractual Relations, in: Journal of Law and Economics, 22 Jg., 233-261.

Wilson, D. T. (1995): An Integrated Model of Buyer-Seller Relationships, in: Journal of the Academy of Marketing Science, 23. Jg., Heft 4, S. 335-345.

Wilson, D. T.; Mummalaneni, V. (1986): Bonding and Commitment in Supplier Relationship: A Preliminary Conceptualization, in: Industrial Marketing and Purchasing, 16 Jg., Heft 3, S. 44-58.

Windhorst, H.-W. (2002): Strukturen der US-amerikanischen Schweinehaltung und Schweinefleischproduktion, Heft 49 des Instituts für Strukturforschung und Planung in agrarischen Intensivgebieten der Hochschule Vechta, Vechta. 


\section{KAPITEL II.2}

Landwirte als Lieferanten und Unternehmenseigner: Zum Management von Supplier- und Investor-Relations im Agribusiness 


\section{Landwirte als Lieferanten und Unternehmenseigner: Zum Management von Supplier- und Investor-Relations im Agribusiness*}

Farmers as Suppliers and Investors: Management of Supplier- and Investor-Relations in the Agribusiness

(mit Berit Köhler und Achim Spiller)

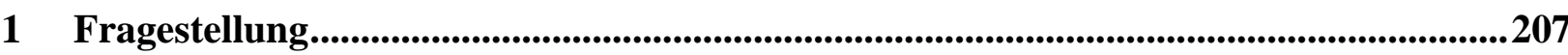

2 Supplier Relationship Management als Herausforderung für die Ernährungsindustrie .....................................................................................................................208

3 Zur besonderen Situation von Marketing Cooperatives .............................................209

4 Entwicklung eines Messmodells für die Zufriedenheit einer Lieferbeziehung..............210

5 Fallstudie: Beziehungsqualität in einem genossenschaftlich strukturierten

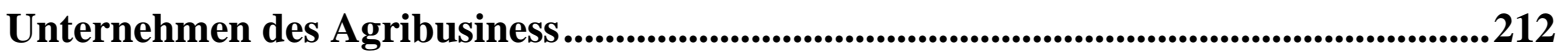

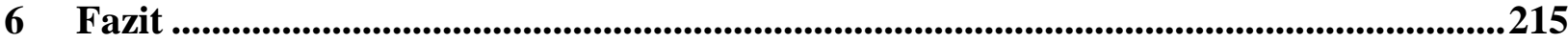

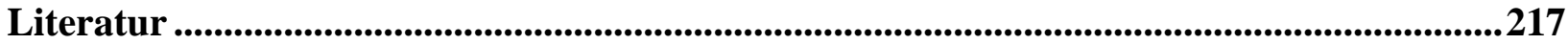

\section{Tabellenverzeichnis}

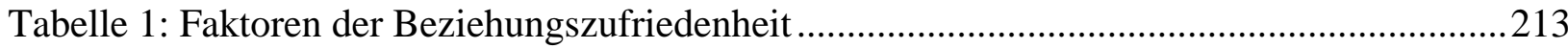

Tabelle 2: Regressionsmodell der zufriedenheitsrelevanten Dimensionen ............................... 214

Tabelle 3: Zusammenhang zwischen Zufriedenheit und Outputvariablen ...............................215

Tabelle 4: Zusammenhang zwischen relativer ökonomischer Bedeutung des Betriebszweigs und Outputvariablen

* in: Darnhofer, K., Pöchtrager, S. und Schmid, E. (Hrsg.): Jahrbuch der Österreichischen Gesellschaft für Agrarökonomie "Standards in der Agrar- und Ernährungswirtschaft - Lokale und globale Herausforderungen, Band 14, S. 221-223. 


\section{Zusammenfassung}

Im Agribusiness haben genossenschaftliche Industrieunternehmen, in denen Landwirte zugleich Lieferanten und Unternehmenseigner sind, eine herausgehobene Position. Hier ist die Zufriedenheit der Landwirte eine wichtige Voraussetzung für ein kooperatives Supply Chain Management. Der vorliegende Beitrag stellt ein Modell zur empirischen Messung der Zufriedenheit der Landwirte vor und überprüft verschiedene Einflussfaktoren in einer Regressionsanalyse. Deutlich wird die Bedeutung der systematischen Beziehungspflege zu den Lieferanten, die über die genossenschaftliche Pflichtkommunikation hinausgeht.

Schlagworte: Supply Chain Management, Lieferantenzufriedenheit, Genossenschaften, Investor Relations, Regressionsanalyse

\section{Summary}

Marketing cooperatives, in which farmers are both suppliers and investors, play an important role in modern agribusiness. Satisfaction of farmers is a necessary condition for a cooperative supply chain management. This paper provides a model for measuring the satisfaction of the farmer suppliers. Furthermore a regression analysis verifies the different influence factors on the basis of a survey, which included 271 farmers. As a result the importance of strategic relationship management comes to the fore. Such communication processes go far beyond the traditional compulsory instruments of cooperative management.

Keywords: supply chain management, supplier satisfaction, marketing cooperatives, investor relations, regression analysis

\section{Fragestellung}

Die Beziehung zwischen Landwirten und der verarbeitenden Industrie ist durch eine Reihe von Besonderheiten geprägt. Aus Sicht der abnehmenden Unternehmen liegen diese in der Vielzahl der Lieferanten und der großen Bedeutung der Rohproduktqualität begründet. Für die Landwirtschaft kann die Geschäftsbeziehung wesentliche Auswirkungen auf das Betriebsergebnis haben. Hinzu kommt, dass in einigen Warengruppen der Wechsel zu anderen Abnehmern nur schwer bzw. gar nicht möglich ist. Bei genossenschaftlichen Unternehmen bestehen schließlich nicht nur Lieferbeziehungen, sondern der Landwirt ist zugleich Unternehmenseigner und verfolgt daher Kapitalinteressen. 
Im Fokus des vorliegenden Beitrags stehen die Einflussfaktoren auf diese Geschäftsbeziehung. Welche Elemente beeinflussen die Zufriedenheit der Lieferanten und welche Relevanz hat die Geschäftsbeziehungsqualität für die Zusammenarbeit? Diese Fragestellungen werden anhand einer Studie, in der Lieferanten eines großen norddeutschen Agribusinessunternehmens befragt wurden, beantwortet.

\section{Supplier Relationship Management als Herausforderung für die Ernährungsindustrie}

Nicht nur die vielen Lebensmittelkrisen der vergangenen Jahre, sondern auch die im Qualitätsmanagement geführte Diskussion um Rückverfolgbarkeit nach EU VO 178/2002 machen deutlich, dass Supply Chain Management ein zunehmend wichtigeres Thema für die Ernährungswirtschaft ist (Simchi-Levi et al. 2003). Insgesamt wird eine stärkere Einbindung der Lieferanten gefordert (Allinson 2004).

Diese Herausforderung kann nur mit einem konsequenten Lieferantenmanagement gemeistert werden. Die Vorteile von engen Lieferantenbeziehungen sind dabei vielfältig und reichen von höherer Zufriedenheit beider Parteien, einer längerfristigen Planungssicherheit und Entschärfung von opportunistischem Verhalten, der Implementierung von Just-in-TimeKonzepten bis zur Erhöhung der Investitionsbereitschaft in eine Lieferbeziehung. Zufriedene Lieferanten investieren schneller in neue EDV-Schnittstellen, sind motivierter Qualität zu produzieren, verursachen geringere Überwachungskosten und wechseln seltener den Abnehmer (Stölzle/Helm 2003: 294 ff.).

Welche Defizite im Gegensatz dazu eine unzureichende Bindung der landwirtschaftlichen Lieferanten hervorruft, lässt sich in vielen Warengruppen der Ernährungswirtschaft nachweisen. Ein Beispiel sind die misslungenen Versuche deutscher Schlachtunternehmen, ein funktionierendes Salmonellenmonitoring aufzubauen. Die deutschen Molkereien kämpfen derzeit gegen die Anstrengungen neuer landwirtschaftlicher Kooperationen, die Vertragsbeziehungen kurzfristiger zu gestalten und noch stärker auf den Auszahlungspreis zu fokussieren. In der Geschäftsbeziehung zwischen Lebensmittelproduzenten und landwirtschaftlichen Lieferanten sind heute insgesamt viele Friktionen anzutreffen, die eine schnelle Reaktion der Supply Chain auf marktliche Herausforderungen erschweren. 


\section{Zur besonderen Situation von Marketing Cooperatives}

Die beschriebenen Problemfelder innerhalb von Wertschöpfungsketten treffen nicht nur auf unabhängige Verarbeitungsunternehmen, sondern auch auf genossenschaftliche Hersteller zu, die sich im Eigentum der Lieferanten befinden. Der genossenschaftliche Bereich spielt eine überragende Rolle in der Ernährungsindustrie, z. B. werden rund drei Viertel der in Deutschland produzierten Milchmenge von genossenschaftlichen Herstellern verarbeitet (Schramm et al. 2004). Wie vielfältige Beispiele aus der Fleisch- und Milchwirtschaft deutlich machen, ist auch diese Geschäftsbeziehung nicht per se vertrauensvoller. Der viel beschworene Genossenschaftsgeist reicht zur Lieferantenbindung nicht aus, da in modernen Großgenossenschaften Sozialkapital nicht mehr allein durch personalisiertes Vertrauen entsteht (Steding 2002).

In Genossenschaften sind die Landwirte nicht nur Lieferanten, sondern zugleich als Anteilseigner an der Geschäftsentwicklung ihres Abnehmers interessiert. Wir bezeichnen diese spezifische Form der Zusammenarbeit auf Liefer- und Aktionärsebene als duale Geschäftsbeziehung. Beide Ebenen der Geschäftsbeziehung stehen in einem interdependenten Verhältnis, weil zumindest kurzfristig Zielkonflikte zwischen der Perspektive der Lieferanten (Auszahlungspreismaximierung) und der Sichtweise des Anteilseigners (Unternehmenswertsteigerung, Kapitalrendite) bestehen. Dies insbesondere deshalb, weil viele kleinere landwirtschaftliche Betriebe oder solche, die kurz vor dem Marktaustritt stehen, kein Interesse an langfristigen Investitionen haben (Cook/Iliopoulos 1999). Inwieweit in langfristiger Sicht Zielharmonie herrscht, wird entscheidend von der Rechtsform mitbestimmt. Das deutsche Genossenschaftsrecht unterbindet die Partizipation der Landwirte an der Unternehmenswertsteigerung (Großkopf 2001) und verstärkt damit die Fokussierung auf den Auszahlungspreis. Für die langfristige Wettbewerbsfähigkeit der Industrieunternehmen sind aber Kapitalbildung und langfristige Investitionen (z. B. in den Aufbau von Marken, in F\&E usf.) notwendig. Empirisch lässt sich nachweisen, dass genossenschaftliche Verarbeitungsunternehmen hier entscheidende Schwächen aufweisen, da es an der notwendigen Zustimmung der Landwirte mangelt (Hendrikse 2004). Sie weisen eine geringere Innovationstätigkeit auf, verfügen selten über starke Marken und produzieren bisweilen schlechtere Qualitäten (Frick 2004). Eine vertrauensvolle Geschäftsbeziehung zu den Landwirten im Sinne des Supplier Relationship Managements (SRM) (Stölzle/Heusler 2003) erhöht - so die Hypothese der weiteren Arbeit - die Bereitschaft der Landwirte zu 
risikobehafteten, langfristigen Investitionen und verbessert gleichzeitig die operative Lieferbeziehung.

\section{Entwicklung eines Messmodells für die Zufriedenheit einer Lieferbeziehung}

Ziel der Arbeit ist die Identifikation der Beziehungszufriedenheit und deren Auswirkung auf das Verhalten der Landwirte. In der Forschung wird relativ einhellig die Zufriedenheit des Geschäftspartners als zentrale Variable der Geschäftsbeziehungsqualität hervorgehoben. Ähnlich wie im Konsumgütermarketing gilt Zufriedenheit als umfassendes Konstrukt, um Bereitschaft für eine kooperative Zusammenarbeit zu erzeugen (Diller/Ivens 2004). Zufriedenheit entsteht aus dem Vergleich der tatsächlichen Erfahrung bei der Inanspruchnahme einer Leistung (Ist-Leistung) mit einem bestimmten Vergleichsstandard (Soll-Leistung). Das Niveau, das als Erwartung angesetzt wird, wird zum einen durch den Verlauf der speziellen Geschäftsbeziehung geprägt. Zum anderen werden Vorinformationen von anderen Geschäftspartnern, alternative Erfahrungen und Qualitätsurteile der Bewertung zu Grunde gelegt (Homburg/Stock 2001: 20 f.). Allerdings basiert dieser Bewertungsprozess nicht auf einer einzigen Transaktion, vielmehr werden die Geschäftsvorgänge kumulativ betrachtet und zu einem Gesamtbild zusammengefasst (Herrmann/Johnson 1999: 582).

Während für das Konsumgütermarketing viele empirische Studien zu den relevanten Einflussfaktoren vorliegen (Parasuramanet al. 1985), gibt es zur Lieferantenzufriedenheit keine vergleichbaren Arbeiten. Es ist jedoch von einer herausgehobnen Rolle der Preiszufriedenheit auszugehen. Daneben können alle Teilbereiche der Kooperation (Logistik, Beratung usf.) zufriedenheitsrelevant sein.

Neben der Lieferzufriedenheit ist im zweiten Schritt die Zufriedenheit als Anteilseigner zu erfassen, vergleichbar zur klassischen Investor Relations (IR). Die Ziele der IR liegen in der Senkung der Kapitalkosten sowie der Steigerung des Aktienkurses und damit des Unternehmenswerts. Dazu ist die Generierung von Vertrauen bei den Investoren notwendig (Hank 1999: 32). Im Agribusiness sind zwar wenig börsennotierte Unternehmen zu finden, dennoch gelten auch hier die gleichen Grundsätze, da durch Beziehungspflege und Dialog mit den Anteilseignern mehr Akzeptanz für Unternehmensentscheidungen erreicht werden soll (Rolke/Wolff 2000: 37). Dies ist besonders bedeutend für Landwirte, deren Einkommen stark 
von der Unternehmenspolitik des Verarbeitungsunternehmens abhängt. Um Akzeptanz und Vertrauen für Unternehmensentscheidungen zu generieren, sind Offenheit und Transparenz besonders wichtig (Hank 1999: 63 ff.). Die Vorteile, die ein Unternehmen sich von klassischen IR-Tätigkeiten erhofft, sind Umsatz- und Imageverbesserung, MitarbeiterMotivation und Kosteneinsparung (Rolke/Wolff 2000: 43).

In empirischen Forschungsarbeiten zu IR wurde im Laufe der letzten Jahre herausgearbeitet, dass über die Unternehmensperformance hinaus auch „weiche“ Faktoren den Unternehmenswert und das Verhalten der Anteilseigner bestimmen. Bedeutsam ist dabei die ausführliche Kommunikation der Werttreiber des Unternehmens: Unternehmenskennzahlen, Kommunikationsstärke des Managements und das Marktumfeld (Meier-Pfister/Thommen 2002: 20). Eine kontinuierliche Information ist hierbei von besonderer Relevanz. Dies gilt auch bei negativen Entwicklungen, um nicht an Glaubwürdigkeit zu verlieren (Günther/Otterbein 1996: 395).

Um der Besonderheit der dualen Geschäftsbeziehung mit dem Nebeneinander von Auszahlungspreis und Anlegerperspektive gerecht zu werden, wurde im Untersuchungsmodell zunächst zwischen Lieferanten- und Aktionärszufriedenheit unterschieden. Die Einflussfaktoren entstammen der Kundenzufriedenheits- sowie der IR-Forschung. Da sich bislang keine Studie mit den Besonderheiten des Agribusiness beschäftigt hat, wurde das Modell durch Konstrukte, die aus acht qualitativen Interviews mit Landwirten und Verarbeitungsunternehmen gewonnen wurden, ergänzt. In das Ursprungsmodell sind für die Lieferantenzufriedenheit folgende Konstrukte eingeflossen:

- Zufriedenheit mit dem Auszahlungspreis und den Konditionen,

- Quantität und Qualität des Informationsflusses,

- Zufriedenheit mit Beratungsangeboten des Verarbeiters,

- Zufriedenheit mit der Beschwerdebearbeitung,

- Einschätzung und Verhalten der Mitarbeiter des Abnehmers sowie

- Bewertung der Zusammenarbeit im Bereich Logistik.

Für den Bereich Aktionärszufriedenheit sind relevant:

- Zufriedenheit mit der Unternehmensstrategie,

- Zufriedenheit mit der Unternehmensperformance,

- Zufriedenheit mit dem Managementhandeln, 
- Informationsqualität und -quantität aus Aktionärssicht,

- Einschätzung der Möglichkeiten zur Einflussnahme auf Unternehmensentscheidungen sowie die

- Bewertung der Gesellschaftsform.

Hinzu kommt die Hypothese, dass sowohl die Lieferanten- als auch die Aktionärszufriedenheit entscheidend durch die wahrgenommene landwirtschaftliche Nähe des Verarbeiters bestimmt wird. Daneben wurde die Bewertung der Lobbyarbeit des Verarbeiters erfasst, da es sich bei dem im Weiteren skizzierten Fall um einen politisch regulierten und im Umbruch befindlichen Markt handelt.

Die Gesamtzufriedenheit der Lieferanten soll sich in einer gesteigerten Loyalität gegenüber dem Abnehmer niederschlagen (Foscht 2002: 85). Die Zielerreichung lässt sich valide an der Wechselbereitschaft ablesen. Im Wettbewerb um hochwertige Rohwaren ist die Gewinnung liefertreuer Landwirte wichtig. Weitere Ziele des SRM-Managements liegen u. a. in einer erhöhten Investitionsbereitschaft der Landwirte und einem kooperativeren Verhältnis, so dass auch unangenehme Entscheidungen eher mitgetragen werden (Gerlach et al. 2004).

\section{Fallstudie: Beziehungsqualität in einem genossenschaftlich strukturierten Unternehmen des Agribusiness}

Im Rahmen eines Forschungsprojektes wurden die o. g. Zusammenhänge in Zusammenarbeit mit einem Großunternehmen aus dem Agribusiness erstmals getestet. Das Unternehmen firmiert zwar als Aktiengesellschaft, ist aber genossenschaftlich strukturiert, da der Aktienbesitz fast vollständig in bäuerlicher Hand ist. Es weist mehr als 10.000 Lieferanten auf, die fast alle Anteilseigner sind. Aufgrund der Bindung der Lieferanten an den Abnehmer auf Basis der EU-Marktordnung konnte allerdings keine Wechselbereitschaft erfasst werden.

Befragt wurden im Frühjahr 2004 nach einer Zufallsauswahl insgesamt 271 Landwirte aus dem gesamten Liefergebiet, die gleichzeitig Aktien besitzen. Die ca. 45-minütigen Interviews erfolgten persönlich auf Basis eines standardisierten Fragebogens durch studentische Interviewer. 
Die Modellkonzeption erwies sich grundsätzlich als geeignet. Die wesentlichen zufriedenheitsrelevanten Bereiche konnten erfasst werden. Zur Überprüfung der Einflussfaktoren wurde zunächst eine Verdichtung der Statements über eine Faktorenanalyse (vgl. Tab.1) vorgenommen. Die extrahierten Faktoren wurden anschließend einer Reliabilitätsanalyse unterworfen und gegebenenfalls modifiziert. So zeigt sich, dass „Auszahlungspreis“ und „Zufriedenheit mit den Konditionen“ aufgrund eines unbefriedigenden Cronbachs AlphaWertes nicht zu einem Faktor zusammengefasst werden sollten.

TABELLE 1: FAKTOREN DER BEZIEHUNGSZUFRIEDENHEIT

\begin{tabular}{|l|r|}
\hline \multicolumn{1}{|c|}{ Faktoren/Statements } & \multicolumn{1}{|c|}{ Faktorladung } \\
\hline Möglichkeiten zur Beschwerde. & 0,802 \\
\hline Wenn ich unzufrieden bin, finde ich sofort einen Ansprechpartner. & 0,799 \\
\hline Kooperatives Verhältnis zum Unternehmen. & 0,771 \\
\hline Rechtzeitige Informationen bei auftretenden Problemen. & 0,667 \\
\hline \multicolumn{1}{|c|}{ Einfluss/Vertrauen der Anteilseigner (KMO: 0,813; Cronbachs A.: 0,792) } \\
\hline Meine Stimme zählt beim Unternehmen etwas. & 0,822 \\
\hline Das Unternehmen nimmt auch Kleinaktionäre ernst. & 0,758 \\
\hline Das Unternehmen sichert den Anbau langfristig. & 0,729 \\
\hline Ich bin gerne Aktionär des Unternehmens. & 0,719 \\
\hline Bei Kapitalerhöhungen wird umfassend über deren Zweck informiert. & 0,665 \\
\hline \multicolumn{2}{|c|}{ Zufriedenheit mit dem Management (KMO: 0,913; Cronbachs Alpha: 0,889) } \\
\hline Die Unternehmensführung ist kompetent. & 0,831 \\
\hline Das Unternehmen ist profitabel. & 0,813 \\
\hline Das Unternehmen ist innovativ. & 0,746 \\
\hline Das Unternehmen ist langfristig erfolgreich. & 0,734 \\
\hline Qualität des Managements. & 0,717 \\
\hline Das Unternehmen ist ein Trendsetter. & 0,715 \\
\hline Das Unternehmen ist bodenständig. & 0,697 \\
\hline Das Unternehmen ist sparsam. & 0,685 \\
\hline Mit dem Geschäftserfolg des Unternehmens bin ich zufrieden. & 0,636 \\
\hline
\end{tabular}

Quelle: Eigene Erhebung

Auf Basis der identifizierten Faktoren und zwei Einzelstatements wurde eine Regressionsrechnung mit dem Faktor Gesamtzufriedenheit als abhängige Variable durchgeführt. Anders als im Ausgangmodell angenommen, trennen Landwirte die Lieferanten- und Aktionärsperspektive bisher nicht allzu stark, so dass das Modell direkt für die Gesamtzufriedenheit geschätzt wurde (vgl. Tab. 2). 
TABELLE 2: REGRESSIONSMODELL DER ZUFRIEDENHEITSRELEVANTEN DIMENSIONEN

\begin{tabular}{|c|c|c|c|}
\hline Einflussfaktoren & Beta & T-Wert & Signifikanz \\
\hline Konstante & & 0,217 & 0,829 \\
\hline Faktor Beschwerde und Dialog & 0,322 & 5,358 & 0,000 \\
\hline Faktor Einfluss und Vertrauen & 0,341 & 4,653 & 0,000 \\
\hline Preiszufriedenheit & 0,149 & 2,712 & 0,007 \\
\hline Bewertung der Gesellschaftsform & 0,120 & 2,383 & 0,018 \\
\hline Faktor Zufriedenheit mit dem Management & 0,126 & 1,818 & 0,071 \\
\hline
\end{tabular}

Quelle: Eigene Erhebung

Wie die Ergebnisse verdeutlichen, beeinflussen fünf Bereiche die Zufriedenheit der Lieferanten und erklären rund 53 \% der Varianz. Der Aspekt „Beschwerde und Dialog“ hat den größten Einfluss auf die Gesamtzufriedenheit mit der Geschäftsbeziehung. Der zweitstärkste Einfluss geht von dem Bereich „Einfluss und Vertrauen“ aus, gefolgt von der „Preiszufriedenheit“, der „Bewertung der Gesellschaftsform“ und der „Zufriedenheit mit dem Management“.

Insgesamt variiert die Qualität der Geschäftsbeziehung derzeit unter dem Schutz der EUMarktordnung nur begrenzt. Die Marktregulation mit hohen Renditen ist auch der Grund für die relativ geringe Relevanz der Preiszufriedenheit. In anderen Branchen würde dieser Faktor sicherlich an Bedeutung gewinnen. Im vorliegenden Fall sind vielmehr vermeintlich „weiche“ Faktoren ausschlaggebend für die Zufriedenheit in der Geschäftsbeziehung aus Sicht der Landwirte. Dazu gehört ein funktionierendes Beschwerdemanagement ebenso wie die rechtzeitige Kommunikation von Seiten des Unternehmens bei Problemen im operativen Ablauf. Hinzu kommt die wahrgenommene Managementkompetenz.

Im zweiten Schritt wurde der Einfluss der Gesamtzufriedenheit auf verschiedene Handlungsparameter mittels Korrelationsanalyse überprüft. Es zeigt sich, dass zwischen der Gesamtzufriedenheit und verschiedenen Zielvariablen Zusammenhänge bestehen (siehe Tab. 3). 
TABELLE 3: ZUSAMMENHANG ZWISCHEN ZUFRIEDENHEIT UND OUTPUTVARIABLEN

Gesamtzufriedenheit

\begin{tabular}{|l|l|}
\hline Ich lese den Geschäftsbericht. & $0,138^{*}$ \\
\hline Ich lese die Unternehmenszeitschrift. & $0,134^{*}$ \\
\hline Ich nehme an der Hauptversammlung teil. & 0,009 n. s. \\
\hline Ich lese die Rundschreiben des Unternehmens. & $0,294^{* *}$ \\
\hline Ich bin bereit, mich den wirtschaftlichen Erfordernissen anzupassen. & $0,211^{* *}$ \\
\hline Ich bin bereit, auch in Zukunft in Technik zu investieren. & 0,100 n. s. \\
\hline Kapitalerhöhungen stehe ich aufgeschlossen gegenüber. & $0,313^{* *}$ \\
\hline
\end{tabular}

$*$ : Die Korrelation ist auf dem Niveau von $<=0,05$ signifikant;

**: Die Korrelation ist auf dem Niveau von $<=0,01$ signifikant

Quelle: Eigene Erhebung

Interessant aus Sicht der Verarbeitung ist, dass zufriedene Landwirte Kapitalerhöhungen signifikant stärker mittragen (0,313**). Zudem informieren sie sich über Entwicklungen und Anforderungen ihres Abnehmers (Lesen von Rundschreiben/0,294** und Unternehmenszeitung/0,134*) und sind eher bereit, sich den wirtschaftlichen Erfordernissen in der Produktion anzupassen $\left(0,211^{* *}\right)$. Keinen Einfluss hat die Zufriedenheit auf den Besuch der Hauptversammlung.

Die mäßige Korrelationshöhe weist allerdings auf die Bedeutung weiterer Variablen hin. Ein wichtiges Element ist z. B. die relative monetäre Bedeutung des hier erfassten Betriebzweiges für den gesamten landwirtschaftlichen Betrieb. Tab. 4 zeigt etwa, dass die Investitionsbereitschaft in neue Technik sehr stark zunimmt $(0,402 * *)$, wenn der Betriebszweig für den landwirtschaftlichen Betrieb essentiell ist.

TABELLE 4: ZUSAMMENHANG ZWISCHEN RELATIVER ÖKONOMISCHER BEDEUTUNG DES BETRIEBSZWEIGS UND OUTPUTVARIABLEN

\begin{tabular}{|l|l|}
\hline \multicolumn{2}{|c|}{ Bedeutung des Betriebszweiges } \\
\hline Ich lese den Geschäftsbericht. & $0,165^{* *}$ \\
\hline Ich lese die Unternehmenszeitschrift. & $0,172^{* *}$ \\
\hline Ich nehme an der Hauptversammlung teil. & $0,334^{* *}$ \\
\hline Ich lese die Rundschreiben des Unternehmens. & $0,173^{* *}$ \\
\hline Ich bin bereit, mich den wirtschaftlichen Erfordernissen anzupassen. & 0,007 n. s. \\
\hline Ich bin bereit, auch in Zukunft in Technik zu investieren. & $0,402^{* *}$ \\
\hline Kapitalerhöhungen stehe ich aufgeschlossen gegenüber. & $0,128^{*}$ \\
\hline
\end{tabular}
Quelle: Eigene Erhebung

\section{Fazit}

Die Ernährungsindustrie ist zurzeit in vielen Fällen durch ein antagonistisches Verhältnis zu ihren Lieferanten charakterisiert. Kurzfristige Geschäftsbeziehungen, geringes Vertrauen und eine Tendenz zu opportunistischem Verhalten erweisen sich als Barrieren eines qualitäts- 
orientierten Supply Chain Managements. Kooperative Lieferantenbeziehungen erleichtern es dagegen dem Hersteller, strategische Richtungswechsel bei den landwirtschaftlichen Lieferanten durchzusetzen. Insgesamt führt ein erfolgreiches SRM zu höherer Flexibilität, Stabilität, Qualität und Innovationskraft (Stölzle 2000: 17). Dem stehen die Kosten der Lieferantenpflege gegenüber, die nicht nur die direkten Maßnahmen (z. B. verstärkte Kommunikation), sondern auch die geringeren Möglichkeiten des Preisdrucks umfassen.

Im vorliegenden Fall wurde erstmals ein umfassendes Messinstrument für ein Controlling des SRM entwickelt. Im Ergebnis zeigen vermeintlich „weiche Faktoren“, wie Beschwerdemöglichkeiten und das Vertrauen der Lieferanten, einen erheblichen Einfluss auf die Zufriedenheit. Zudem macht der relativ geringe Einfluss der Preiszufriedenheit deutlich, dass die Kommunikation mit den Landwirten umfassender angelegt und z. B. auch im Bereich der IR verstärkt werden muss. Die genossenschaftliche Pflichtkommunikation reicht hier nicht aus.

Zufriedene Lieferanten sind eher bereit, Kapitalerhöhungen mitzutragen, sich den strukturellen Erfordernissen anzupassen und sie informieren sich intensiver über die Anforderungen des Abnehmers. Inwieweit sich die Lieferantenzufriedenheit auf die Abnehmertreue und die Bereitschaft zu spezifischen Investitionen in diese Geschäftsbeziehung auswirken, konnte für diese Untersuchung aufgrund der bestehenden EU-Marktordnung nicht erhoben werden, ist aber für andere Bereiche des Agribusiness zentral.

In Hinblick auf die Dualität der Geschäftsbeziehung in Genossenschaften lässt sich konstatieren, dass die Beziehung des Landwirts zu seinem Abnehmer sowohl durch die Lieferbeziehung, als auch durch die Kapitalseite bestimmt wird: Beide Bereiche sind relevant, allerdings trennt der Landwirt in seiner Bewertung diese Felder kaum, sondern kommt zu einem zusammenfassenden Gesamturteil. Entsprechend umfassend muss ein Supplier Relationship Management angelegt sein. 


\section{Literatur}

Allinson J. (2004): Procurement in the Food and Drink Industry in the early $21^{\text {st }}$ Century, in: Bourlakis, M. A.; Weightman, P. W. H. (Hrsg.) (2004): Food Supply Chain Management, Oxford: Blackwell, S. 49-61.

Cook, M. L., Iliopoulos, C. (1999): Beginning to Inform the Theory of the Cooperative Firm: Emergence of the New Generation Cooperative, Finnish Journal of Business Economics, 48. Jg., Heft 4, S. 525-535.

Diller, H., Ivens, B. S. (2004): Beziehungsstile im Business-to-Business-Geschäft, in: Zeitschrift für Betriebswirtschaft, 74. Jg., Heft 3, S. 249-271.

Foscht, T. (2002): Kundenloyalität: Integrative Konzeption und Analyse der Verhaltens- und Profitabilitätswirkungen, Wiesbaden: DUV.

Frick, B. (2004): Does Ownership Matter? Empirical Evidence from the German Wine Industry, KYKLOS, 57. Jg., Heft 3, S. 357-386.

Gerlach, S. et al. (2004): Supplier Relationship Management im Agribusiness: Ein Konzept zur Messung der Geschäftsbeziehungsqualität, Diskussionsbeitrag des Instituts für Agrarökonomie der Universität Göttingen Nr. 0406, Göttingen.

Großkopf, W. (2001): Die Mitgliederbindung, in: Großkopf, W. (Hrsg.): Hohenheimer Genossenschaftsforschung 2001, Stuttgart-Hohenheim.

Günter, T., Otterbein, S. (1996): Die Gestaltung der Investor Relations am Beispiel führender deutscher Aktiengesellschaften, Zeitschrift für Betriebswirtschaft, 66. Jg., Heft 4, S. 389-417.

Hank, B. (1999): Informationsbedürfnisse von Kleinaktionären: zur Gestaltung von Investor Relations, Frankfurt a. M.: Lang.

Hendrikse, G. (Hrsg.) (2004): Restructuring Agricultural Cooperatives, Rotterdam.

Herrmann, A., Johnson, D. (1999): Die Kundenzufriedenheit als Bestimmungsfaktor der Kundenbindung, Zeitschrift für betriebswirtschaftliche Forschung (zfbf), 51. Jg., Heft 6, S. 579-599.

Homburg, C., Stock, R. (2001): Theoretische Perspektiven zur Kundenzufriedenheit, in: Homburg, C. (Hrsg.): Marktforschung, Wiesbaden: Gabler.

Meier-Pfister, M., Thommen, A. S. (2002): Erfolgsfaktor Investor Relations? Finanzkommunikation in der Schweiz, Zürich: Verlag Neue Züricher Zeitung.

Parasuraman, A. et al. (1985): A conceptual model of service quality and its implications for future research, Journal of Marketing, 49. Jg., Heft 4, S. 41-50.

Rolke, L., Wolf, V. (2000): Finanzkommunikation - Kurspflege durch Meinungspflege. Die neuen Spielregeln am Aktienmarkt, Frankfurt a. M.: FAZ.-Inst. Für Management-, Markt- und Medieninformationen.

Schramm, M. et al. (2004): Brand Orientation in der Ernährungsindustrie: Erfolgsdeterminanten der Markenführung am Beispiel genossenschaftlicher Hersteller, Wiesbaden: DUV.

Simchi-Levi, D. et al. (2003): Designing \& Managing the Supply Chain, Concepts, Strategies \& Case Studies, 2. Aufl., Boston: Mc Graw Hill. 
Steding, R. (2002): Das Recht der eingetragenen Genossenschaft: Ein Überblick. Berliner Beiträge zum Genossenschaftswesen, Institut für Genossenschaftswesen an der Humboldt-Universität zu Berlin, Berlin: Institut für Genossenschaftswesen.

Stölzle, W. (2000): Beziehungsmanagement - Konzeptverständnis und Implikationen für die Beschaffung, in: Hildebrandt, H., Koppelmann, U. (Hrsg.): Beziehungsmanagement mit Lieferanten: Konzepte, Instrumente, Erfolgsnachweise, Stuttgart: SchäfferPoeschel, S. 1-23.

Stölzle, W.; Helm, R. (2003): Der Einfluss elektronischer Märkte auf die Beziehungsqualität - Theoretische Grundlagen und empirische Ergebnisse, in: Bogaschewsky, R. (Hrsg.): Integrated Supply Chain Management: Einkauf und Beschaffung: Effizienz steigern, Kosten senken, Köln: Dt. Wirtschaftsdienst, S. 285-322.

Stölzle, W., Heusler, K. F. (2003): Supplier Relationship Management - Entstehung, Konzeptverständnis und methodisch-instrumentelle Anwendung, in: Bogaschewsky, R., Götze, U. (Hrsg.): Management und Controlling von Einkauf und Logistik, Gernsbach: Dt. Betriebswirte Verlag, S. 168-194. 


\section{KAPITEL II.3}

Supplier Relationship Management in der Milchwirtschaft: Ein Regressionsmodell zur Erklärung der Geschäftsbeziehungsqualität 


\title{
Supplier Relationship Management in der Milchwirtschaft: Ein Regressionsmodell zur Erklärung der Geschäftsbeziehungsqualität*
}

\author{
(mit Achim Spiller und Christian Wocken)
}

1 Spot-Markt oder Contract-Farming...........................................................................................2221

2 Supplier Relationship Management zur Verbesserung der Geschäftsbeziehung .......222

3 Studiendesign und Modelloperationalisierung ................................................................224

4 Zur Relevanz ökonomischer und verhaltenswissenschaftlicher Einflussfaktoren auf die Geschäftsbeziehungsqualität................................................................................................222

4.1 UNTERSCHIEDE IN DER GESCHÄFTSBEZIEHUNG BEI VERSCHIEDENEN MOLKEREIEN ....227

4.2 DETERMINANTEN DER GESCHÄFTSBEZIEHUNGSQUALITÄT ........................................228

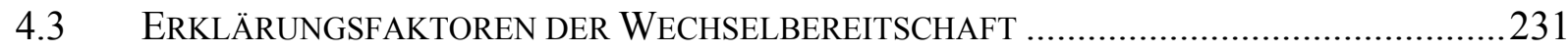

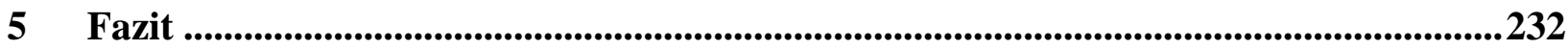

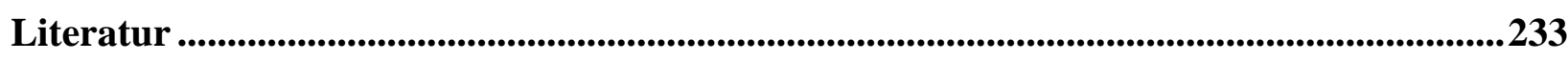

\section{Abbildungsverzeichnis}

Abbildung 1: Modell zur Messung der Geschäftsbeziehung ...............................................226

Abbildung 2: Zufriedenheit mit den Molkereien im Vergleich..............................................228

\section{Tabellenverzeichnis}

Tabelle 1: Potenziale einer engen Lieferantenbindung im Agribusiness ................................223

Tabelle 2: Faktorenanalyse und Reliabilität ......................................................................229

Tabelle 3: Regressionsmodell zur Erklärung der Geschäftsbeziehungsqualität.........................230

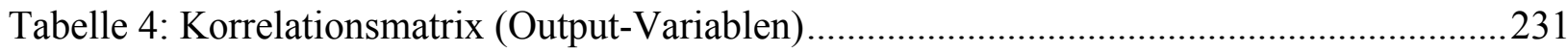

Tabelle 5: Regressionsmodell der Einflussfaktoren auf die Wechselbereitschaft.....................232

* Erscheint in: Bahrs, E. et al. (Hrsg.): Tagungsband der 45. Gewisola Jahrestagung "Unternehmen im Agrarbereich vor neuen Herausforderungen", Göttingen, im Druck. 


\section{Zusammenfassung}

Die Geschäftsbeziehung zwischen Milcherzeugern und Molkereien ist zwar durch die große Bedeutung genossenschaftlicher Molkereien relativ langfristig und stabil, aber die Unzufriedenheit vieler Landwirte mit dieser Geschäftsbeziehung steigt, was sich nicht nur an der Wechselbereitschaft, sondern auch an der Gründung neuer Interessenverbände ablesen lässt. Im Mittelpunkt dieses Beitrags steht die empirische Überprüfung der Einflussfaktoren auf die Geschäftsbeziehungsqualität aus Sicht der Landwirte. Als Ergebnis zeigt sich, dass weniger die Preiszufriedenheit, als vielmehr die landwirtschaftliche Orientierung der Molkerei sowie die Zufriedenheit mit dem Management die Geschäftsbeziehungsqualität beeinflusst. Zudem wird deutlich, dass die Geschäftsbeziehungsqualität Einfluss auf die Wechselbereitschaft, Gegenmachtbildung und Weiterempfehlung der Molkerei hat.

Keywords: Geschäftsbeziehungsqualität, Milchwirtschaft, Lieferantenmanagement, Regressionsanalyse

\section{Spot-Markt oder Contract-Farming}

Traditionell ist der Milchmarkt durch relativ langjährige und stabile Geschäftsbeziehungen sowie die hohe Relevanz genossenschaftlicher Verarbeitungsunternehmen charakterisiert (Schramm et al.: 2004). Derzeit nimmt jedoch die Unzufriedenheit vieler Landwirte mit dieser Struktur zu, und es kommt zur Gründung von neuen Interessenverbänden wie bspw. dem Bundesverband deutscher Milchviehhalter Nord (BDM). Ein zentrales Ziel des Verbandes ist der Zusammenschluss möglichst großer Milchmengen, um eine Gegenmacht zu den Molkereien zu schaffen. Aber auch unabhängig vom BDM versuchen derzeit viele und gerade leistungsfähige Landwirte, sich in neuen Vermarktungskooperationen gegen die Abnehmerseite zu organisieren. Diese Tendenzen finden sich nicht nur in Deutschland. Auch in den Niederlanden, Österreich und Großbritannien gibt es Bestrebungen zur Gründung zentraler Vermarktungsagenturen auf landwirtschaftlicher Seite (Lebensmittelzeitung 2004: 25). Die Bereitschaft der Landwirte, die Molkerei zu wechseln, wird mit dieser Entwicklung wesentlich verstärkt. Bindungen an den Abnehmer werden lockerer und der Milchauszahlungspreis tritt immer mehr in den Vordergrund.

Die skizzierten Ansätze sind aus ökonomischer Sicht der Versuch, durch countervailing power den Wertschöpfungsanteil der Landwirtschaft zu erhöhen. Sollte sich diese Tendenz 
fortsetzen, würde sich der Milchmarkt in Richtung Spot-Markt entwickeln, wie er heute z. B. für weite Teile der Fleischwirtschaft charakteristisch ist. Trotz großer genossenschaftlicher Unternehmen dominieren hier kurzfristige Marktbeziehungen. Spotmärkte bieten für gut informierte und leistungsstarke Akteure durchaus Chancen. Sie können allerdings zu einer stärkeren Preisdifferenzierung bei den Auszahlungspreisen führen und den Strukturwandel in der Landwirtschaft - aber auch in der Industrie - vorantreiben. Probleme liegen zudem in der geringen vertikalen Koordination, wie z. B. an den zahlreichen Qualitätsproblemen im Fleischmarkt abgelesen werden kann.

Vor diesem Hintergrund ist es das Ziel der vorliegenden Arbeit, aus Sicht der Molkereien Ansatzpunkte für eine Verbesserung der Geschäftsbeziehung zu entwickeln. $\mathrm{Zu}$ diesem Zweck wurde ein Modell zur Erklärung der Geschäftsbeziehungsqualität entwickelt und empirisch durch eine Befragung von 209 Milchlandwirten überprüft. In theoretischer Hinsicht wird damit ein Beitrag zur Messung von Marktprozessen in hybriden vertikalen Marktstrukturen und zum Supply Chain Management geleistet.

\section{Supplier Relationship Management zur Verbesserung der Geschäftsbeziehung}

Konzepte des Lieferantenmanagements, die auf eine leistungsfähige Zusammenarbeit zwischen rechtlich und wirtschaftlich unabhängigen Unternehmen zielen, werden in der neueren Managementtheorie als Supplier Relationship Management bezeichnet (Stölzle/Heusler 2003). Stabile Geschäftsbeziehungen bieten nicht nur Planungssicherheit, sondern erlauben eine vertrauensvollere, besser abgestimmte Zusammenarbeit. In Branchen wie der Automobilindustrie wird eine solche Lieferantenentwicklung und Geschäftsbeziehungsoptimierung inzwischen lebhaft diskutiert. Die potenziellen Vorteile enger Lieferantenbindung sind in Tabelle 1 dargestellt. 


\section{TABELLE 1: PotenZIALE EINER ENGEN LIEFERANTENBINDUNG IM AGRIBUSINESS}

$>$ Höhere Zufriedenheit von Landwirten und Molkereien

$>$ Längerfristige Planungssicherheit der Molkereien durch geringere Wechselbereitschaft der Landwirte

$>$ Entschärfung von Konflikten

$>$ Flexibilität und Geschwindigkeit im Wettbewerb durch bessere Abstimmung

> Senkung von Transaktionskosten durch Wegfall von Neuakquisition und Vertragsverhandlungen

$>$ Senkung von Prozesskosten durch Abstimmung von (EDV-) Schnittstellen

> Senkung von Koordinationskosten (z. B. bei Qualitätsproblemen, Streitigkeiten usf.)

$>$ Besseres Qualitätsmanagement durch vertrauensvollen Informationsaustausch

$>$ Erhöhung der Investitionsbereitschaft der Landwirte durch ein stärkeres Commitment (Wir-Gefühl)

Quelle: Eigene Zusammenstellung

Supplier Relationship Management ist damit ein Managementkonzept, das die Verantwortung des Herstellers für die Leistungs- und Innovationsfähigkeit der gesamten Wertschöpfungskette betont und damit den Fokus vom Einkaufspreis auf Lieferantenentwicklung verschiebt (Lemke et al. 2000: 34). Es geht darum, als Wertschöpfungskette besser als die Wettbewerber zu werden und damit den Total Chain Value zu erhöhen, in der Hoffnung, dass damit die Auseinandersetzung um die Verteilung des (dann größeren) Kuchens langfristig etwas an Härte verliert (Wathne/Heide 2004: 74 f.). Supplier Relationship Management gliedert sich damit ein in eine Reihe von neueren Ansätzen des Geschäftsbeziehungsmanagements: So beinhaltet Customer Relationship Management die systematische Steuerung der Kundenbeziehungen mit dem Ziel der Steigerung des Unternehmens- und Kundenwerts (Rapp 2003: 61; Sieben 2001: 297 ff.). Etwas spezieller befasst sich das Key Account Management mit einzelnen Großkunden, deren ökonomische Bedeutung eine individuelle Vertriebsplanung rechtfertigt (Plinke 1997). Auch das seit Mitte der 90er Jahre verstärkt diskutierte Efficient Consumer Response richtet sich auf die Verbesserung der Geschäftsbeziehung in der Ernährungswirtschaft, speziell zwischen Industrie und Handel (Seifert 2001).

Im Gegensatz zu früheren auf die Abnehmer gerichteten Downstream-Konzepten der Marketinglehre fokussiert das Supplier Relationship Management auf die Lieferanten eines Unternehmens und damit auf das Beschaffungsmanagement. Es ist geeignet für Unternehmen, in denen die Beschaffungsabteilung über den operativen Einkauf hinaus ein strategisches Lieferantenmanagement intendiert. Die strategische Funktion des Einkaufs setzt auf kooperative 
Beziehungen sowie eine längerfristige Ausrichtung der Zusammenarbeit und damit auf den Aufbau von Vertrauen. An die Stelle eines kurzfristigen Lieferantenwettbewerbs mit dem Fokus auf dem Preis soll die integrative Ausschöpfung von Effizienzpotenzialen entlang der Wertschöpfungskette treten (Stölzle/Heusler 2003: 173). In diesem Sinne bezeichnet Supplier Relationship Management den systematischen Aufbau, die Pflege und das Controlling der Geschäftsbeziehung mit den Lieferanten - es ist damit das Gegenstück zum Business-toBusiness-Marketing der Zulieferindustrie und gewinnt besonders in Geschäftsbeziehungen an Relevanz, in denen der Abnehmer die ökonomisch dominierende Position in der Wertschöpfungskette einnimmt. Für das Agribusiness ist die Idee von besonderer Brisanz, da Molkereien, Schlachtunternehmen, Zuckerhersteller oder Tiefkühlproduzenten nicht nur über sehr viele, sondern auch über homogene Lieferanten verfügen. Außerdem prägt in der Ernährungswirtschaft die Qualität der Rohprodukte ganz entscheidend die Endproduktbeschaffenheit. Die meisten Defizite auf landwirtschaftlicher Ebene lassen sich später in der Wertschöpfungskette kaum noch kompensieren. Motivierte und leistungsfähige Lieferanten können hier einen zentralen Wettbewerbsvorteil darstellen.

Hintergrund des Lieferantenmanagements ist aus Sicht der Molkereien das Ziel, leistungsfähigere Lieferanten als der Konkurrent zu haben und damit als Supply Chain im Wettbewerb zu bestehen. Dies hebt die Verteilungskonflikte und damit die Relevanz des Auszahlungspreises nicht auf. Ob Landwirte und Molkereien gut zusammenarbeiten, hängt aber möglicherweise nicht nur von der Höhe des Milchgeldes ab. Gelingt eine Verbesserung der Geschäftsbeziehungsqualität, dann sinkt die Wechselbereitschaft der Lieferanten, so dass die Molkereien ein Instrument zur Sicherung ihrer Rohstoffbasis an der Hand haben.

\section{Studiendesign und Modelloperationalisierung}

Bislang liegen keine empirischen Daten zur Entwicklung der Geschäftsbeziehung in der Milchwirtschaft und zum Vergleich der unterschiedlichen Molkereien vor. Im Frühjahr 2004 wurden daher 209 Milchviehhalter aus Nordwestdeutschland zu ihrer Einschätzung der Geschäftsbeziehungsqualität befragt. Dabei standen zukunftsorientierte Betriebe im Mittelpunkt. Die durchschnittliche Anzahl Milchkühe pro Betrieb ist mit 73,2 in der Stichprobe wesentlich größer als im deutschen Durchschnitt, gleiches gilt für die Fläche mit 97 ha, die Milchquote von $600.000 \mathrm{~kg} / \mathrm{Jahr}$ und die durchschnittliche Milchleistung von $9.006 \mathrm{~kg} /$ Laktation. Die Studie ist aus diesem Grund und wegen des Verzichts auf eine Zufallsauswahl nicht repräsentativ, durch die Stichprobengröße und die Berücksichtigung unterschiedlichster 
Molkereien (insb. Nordmilch $(n=73)$, Humana $(n=50)$, Campina $(n=31))$ erlaubt sie aber erste aussagekräftige Angaben.

Kern des im Weiteren vorgestellten Modells ist die Hypothese, dass es einen relativ engen Zusammenhang gibt zwischen der Qualität der Geschäftsbeziehung (speziell: Zufriedenheit, Vertrauen und Commitment) und der Struktur bzw. Intensität der Zusammenarbeit. Faktoren wie Bindungsbereitschaft und Motivation zur Qualitätsproduktion sollten bei guter Geschäftsbeziehung zunehmen (siehe Abb. 1). Eine solche positive Korrelation ist vor einem anderen Hintergrund in Studien zum Absatzkanalmanagement und in der BusinessNetzwerkforschung vielfach nachgewiesen worden (Diller/Ivens 2004). Sollte sich diese Hypothese bestätigen, so wäre es im zweiten Schritt interessant zu erfahren, welche Faktoren eine gute Geschäftsbeziehungsqualität fördern. Auch hierzu kann im Analogieschluss auf die Forschungsergebnisse der Marketing Channel- und Business Network-Forschung zurückgegriffen werden. Folgende potenzielle Treiber der Geschäftsbeziehungsqualität liegen dem Modell zugrunde:

- Landwirtschaftsnähe und Einfluss der Landwirte: In einer Analyse der Geschäftsbeziehung zwischen Landwirten und der Zuckerindustrie erwies sich die bäuerliche Verwurzelung als zentrale Einflussgröße (GERLACH et al. 2005).

- Machtasymmetrie und Abhängigkeit: Fehlende Ausweichmöglichkeiten führen zu erzwungenermaßen stabilen Beziehungen, die aber aufgrund von Reaktanzeffekten besonders negativ beurteilt werden (Brown et al. 1995; Anderson/Narus, 1990; Dwyer et al. 1987; Frazier 1983).

- Soziale Bindung: "[...] the degree of mutual personal friendship and liking shared by the buyer and seller" (Wilson 1995: 339). Geschäftsbeziehungen, in denen ein großes Maß an sozialer Bindung bis hin zu Freundschaft vorhanden ist, werden leichter aufrechterhalten (Rodríguez/Wilson 2002: 55).

- Strukturelle Bindung: "Structural bonds reflect irretrievable investments in the relationship, social pressures to maintain it, and contractual barriers" (Rodriguez/Wilson 2002: 55). Strukturelle Bindungen führen dazu, dass eine Beendigung der Geschäftsbeziehung erschwert wird (Cannon/Perreault, 1999: 443).

- Kommunikation: Diese wird geprägt durch die Kommunikationsintensität, also die Frequenz der Kontakte zwischen den Geschäftspartnern, und die Kommunika- 
tionsqualität, d. h. das Ausmaß der Informationsweitergabe (Matanda/Schroder 2004: 534).

- Emotionale Bewertung des Managements: Der ökonomische Erfolg des Lieferanten hängt u. U. von der Fähigkeit des Managements des Kunden ab. Aufgrund von Informationsasymmetrien gewinnt die persönliche Einschätzung der Führungskräfte durch die Landwirte an Bedeutung (Gerlach et al. 2005).

- Zufriedenheit mit der Unternehmensstrategie und der Unternehmensperformance: Die vom Unternehmen gewählte Strategie muss für die Landwirte plausibel sein, um sie auch bei längeren Amortisationsfristen mitzutragen (MeierPfister/Thommen 2002: 53; Stölzle/Karrer 2004: 240).

- Gemeinsame Ziele: "[...] The degree to which partners share goals that can only be accomplished through joint action and the maintenance of the relationship" (Wilson 1995: 338). Intendiert sind übereinstimmende Überzeugungen, welche Ziele und Verhaltensweisen richtig, wichtig und angemessen sind (Morgan/Hunt 1994; Heide/John 1992).

- Preiszufriedenheit: Die Preiszufriedenheit steht in ökonomisch schwierigen Zeiten besonderes im Fokus der Milcherzeuger. Das Konstrukt wird i. d. R. mehrdimensional operationalisiert (Matzler/Pramhas 2004: 183 f.), hier als kurzfristige (aktuelle) Preiszufriedenheit, (langfristige) Preiszufriedenheit der letzten fünf Jahre und (relative) Preiszufriedenheit im Vergleich $\mathrm{zu}$ anderen Molkereiunternehmen

\section{ABBILDUnG 1: Modell ZUR MESSUNG DER GeSChÄFTSBEZIEHUNG}

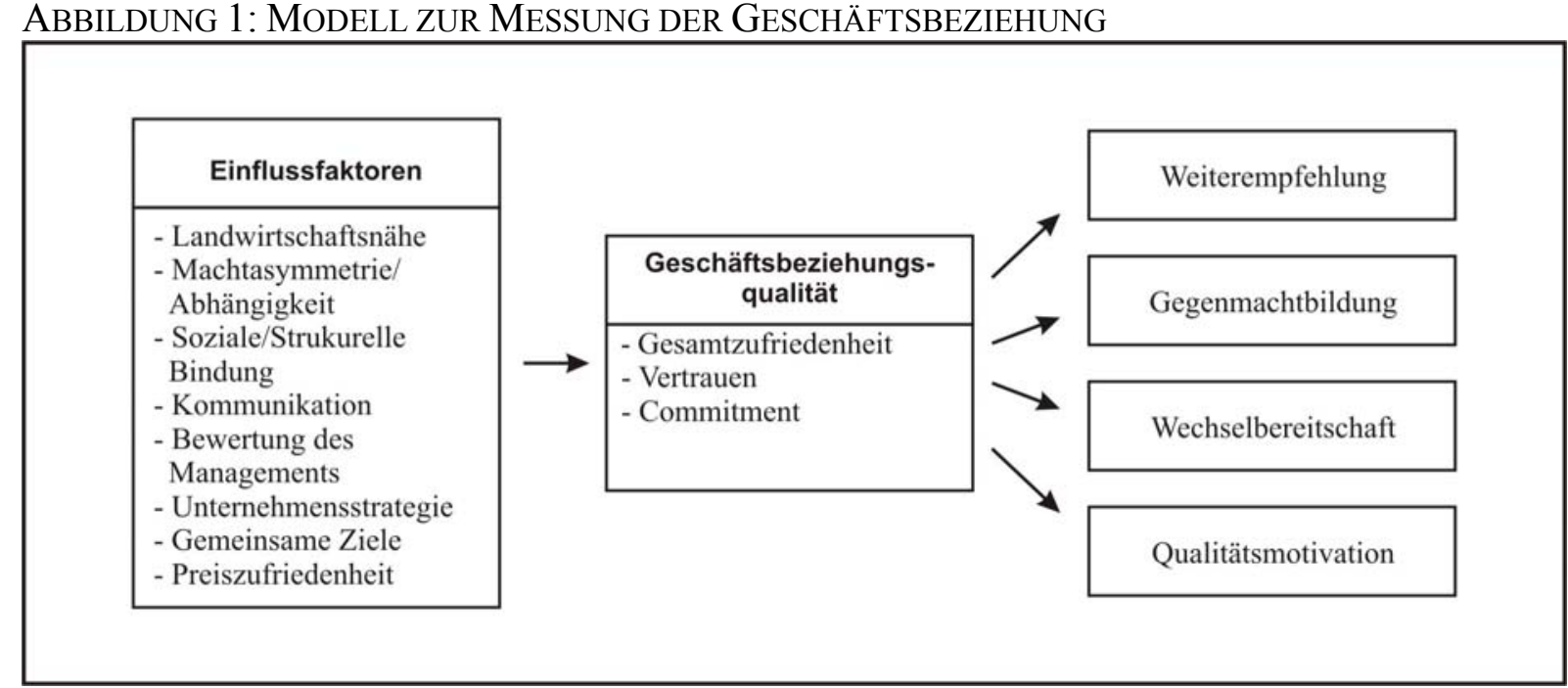

Quelle: Eigene Darstellung 
Besonders interessant ist die Frage, welchen Einfluss die zuletzt genannte Preiszufriedenheit ausübt. In einem einfachen ökonomischen Modell sollte sie die Geschäftsbeziehungsqualität und die Anreizwirkung weitestgehend erklären. Auch in der betrieblichen Praxis findet sich vielfach die Hypothese, dass der Auszahlungspreis letztlich allein entscheidend für das (Wechsel-)Verhalten der landwirtschaftlichen Lieferanten ist.

\section{Zur Relevanz ökonomischer und verhaltenswissenschaftlicher Einflussfaktoren auf die Geschäftsbeziehungsqualität}

\subsection{Unterschiede in der Geschäftsbeziehung bei verschiedenen Molkereien}

Das folgende Kapitel gibt einen knappen Überblick über das Antwortverhalten der Landwirte im Hinblick auf die o. g. Konstrukte, die überwiegend durch 7-stufige Likertskalen erfasst wurden. Die Gesamteinschätzung der Geschäftsbeziehung zu den Molkereien ist von einer eher skeptischen Haltung gekennzeichnet. Die Gesamtzufriedenheit liegt im mittleren Bereich $(\mu=1,40 ; \sigma=1,369)$ (vgl. Abb. 2, alle Befragten). Deutliche Defizite zeigen sich bei Vertrauen $(\mu=0,52 ; \sigma=1,641)$ und Commitment $(\mu=0,47 ; \sigma=1,575)$, die den Molkereien entgegengebracht werden. Besonders gering sind die wahrgenommene Landwirtschaftsnähe $(\mu=-0,40 ; \sigma=1,757)$ der Molkereien und das Ausmaß der empfundenen Zielharmonie $(\mu=$ 0,02; $\sigma=1,547)$. Der Bezug zur landwirtschaftlichen Basis geht bei den zumeist genossenschaftlichen Industrieunternehmen nach Einschätzung der Lieferanten verloren. Aus dieser eher negativen Einschätzung der Geschäftsbeziehung folgt eine hohe Wechselbereitschaft ( $\mu=1,26 ; \sigma=1,695) .68,8 \%$ der Betriebe geben an, bei höheren Auszahlungspreisen den Abnehmer wechseln zu wollen. Insgesamt sind Bindungen an die Molkereien damit gering ausgeprägt und eher instabil. Die hohen Standardabweichungen $(\sigma)$ weisen allerdings auf abweichende Positionen bei den befragten Milcherzeugern hin. Die skizzierten Mittelwerte $(\mu)$ zeigen somit nur den generellen Trend auf. 
ABBILDUNG 2: ZUFRIEDENHEIT MIT DEN MOLKEREIEN IM VERGLEICH

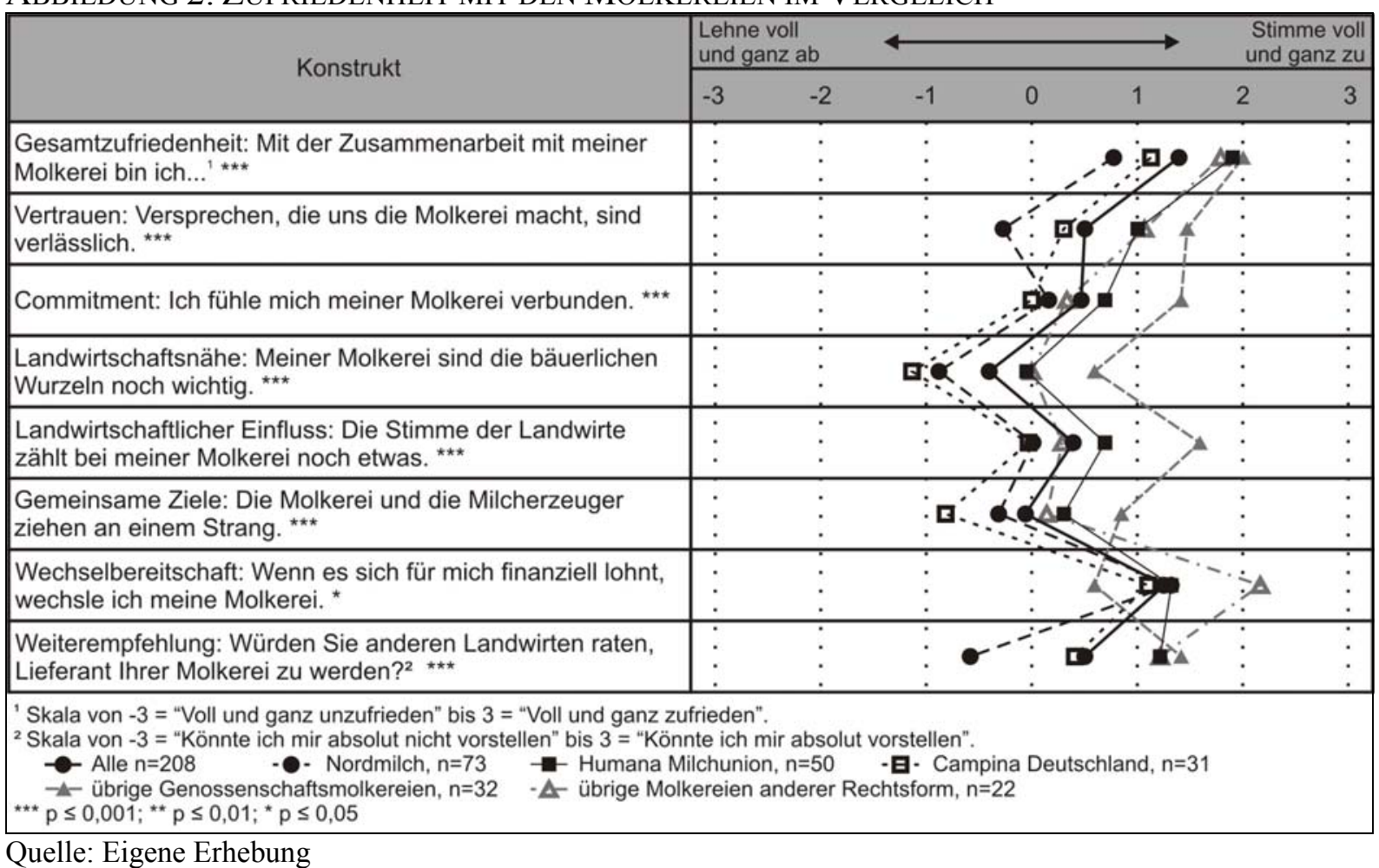

Ein Vergleich der verschiedenen Molkereien zeigt signifikante Mittelwertunterschiede (vgl. Abb. 2). Aufgrund der Stichprobengröße liefern die dargestellten Werte allerdings nur erste Anhaltspunkte und sind nicht repräsentativ. Die Lieferanten von Nordmilch und Campina sind insgesamt deutlich unzufriedener. Möglicherweise spiegeln sich hier die Erfahrungen der schwierigen Unternehmenszusammenschlüsse. Eine höhere Lieferantenbindung weisen kleinere Genossenschaftsmolkereien und die Humana Milchunion auf. Dies kann zum einen auf Managementfaktoren zurückzuführen sein, zum anderen lässt sich hier die Aussage der Genossenschaftsforschung belegen, dass sich Sozialkapital leichter in kleineren Gruppen bildet. Interessant ist schließlich, dass sich in den kleineren Privatmolkereien die deutlich wechselbereiteren Landwirte finden, hier mithin schon Tendenzen in Richtung kurzfristige Marktbeziehungen bestehen.

\subsection{Determinanten der Geschäftsbeziehungsqualität}

In der folgenden multivariaten Analyse wurden zunächst die oben skizzierten Erklärungskonstrukte, die i. d. R. durch mehrere Fragen operationalisiert wurden, soweit möglich per Faktorenanalyse verdichtet. Die zuvor theoretisch abgeleiteten Einflussfaktoren mussten z. T. modifiziert werden. So laden auf den Faktor „Landwirtschaftliche Orientierung“ die Items zur Landwirtschaftsnähe, zum Einfluss der Landwirte auf das Unternehmen, zur Machtasymmetrie und zur wahrgenommenen Zielharmonie. Die Items zur Gesamtzufriedenheit, zum 
Vertrauen und zum Commitment ließen sich wie intendiert zu einem Faktor Geschäftsbeziehungsqualität zusammenfassen. Ebenfalls einen Faktor bilden erwartungsgemäß die Items zur Zielvariable Wechselbereitschaft. Tabelle 2 zeigt die extrahierten Faktoren, deren Statements und Faktorladungen sowie Cronbachs Alpha als Maß zur Beurteilung der Zuverlässigkeit der Faktoren.

TABELLE 2: FAKTORENANALYSE UND RELIABILITÄT

Faktor und Statements

Faktorladung

Landwirtschaftliche Orientierung (KMO: 0,906; Cronbachs Alpha: 0,886)

Meiner Molkerei sind die bäuerlichen Wurzeln noch wichtig.

Meine Molkerei nimmt die Landwirte ernst, wenn Probleme auftreten.

0,615

0,744

Die Molkerei und die Milcherzeuger ziehen an einem Strang.

0,801

Wir Milcherzeuger und die Molkerei verfolgen häufig unterschiedliche Ziele. $\quad-0,730$

Die Stimme der Landwirte zählt bei meiner Molkerei noch etwas.

0,772

$-0,790$

Auf Milcherzeuger wird von Seiten der Molkerei keine Rücksicht genommen.

$-0,746$

Ich habe das Gefühl, dass die Molkerei mit den Milcherzeugern machen kann, was sie will.

0,766

Ich fühle mich dem Management meiner Molkerei verbunden.

Zufriedenheit mit Management und Kommunikation $\quad$ (KMO: 0,885; Cronbachs Alpha: 0,861)
0,549

Meine Molkerei informiert mich schlecht.

$-0,684$

Ich fühle mich über die Geschäftspolitik meiner Molkerei ausreichend informiert.

Das Management meiner Molkerei halte ich für: offen - verschlossen.

$-0,756$

Das Management meiner Molkerei halte ich für: von oben herab - wie ein Partner.

0,725

Das Management meiner Molkerei halte ich für: unkooperativ - kooperativ.

0,805

Das Management meiner Molkerei halte ich für: ehrlich - unehrlich.

$-0,775$

Das Management meiner Molkerei halte ich für: unfair - fair.

0,838

Mit dem Milchauszahlungspreis bin ich..

0,705

Und jetzt im Vergleich zu anderen Molkereien bin ich mit dem Auszahlungspreis meiner $\quad 0,834$

Molkerei...

Wenn Sie über den Milchpreis nachdenken, den Ihnen Ihre Molkerei in den letzten 5 Jahren

0,815 ausgezahlt hat, wo würden Sie Ihre Zufriedenheit damit auf einer Skala von $0=$ existenzgefährdend bis $100=$ sehr zufriedenstellend einordnen?

(Un-)Zufriedenheit mit der Unternehmensperformance (KMO: 0,664; Cronbachs Alpha: 0,714)

Meine Molkerei müsste profitabler sein.

Ich finde, die Molkerei erlöst zu wenig aus unserer Milch.

0,833

Meine Molkerei müsste noch stärker rationalisieren.

Das Genossenschaftsprinzip ist mir wichtig.

0,753

Die Rechtsform der Genossenschaft ist überholt.

Wenn meine Molkerei keine Genossenschaft wäre, stände Sie im Wettbewerb besser da.

$-0,663$

Der Genossenschaftsgedanke ist auch in Zukunft noch ein Vorteil im Wettbewerb.

$-0,785$

Geschäftsbeziehungsqualität (KMO: 0,768; Cronbachs Alpha: 0,840)

Mit der Zusammenarbeit mit meiner Molkerei bin ich insgesamt...

0,841

Wenn Sie an die Zusammenarbeit mit Ihrer Molkerei denken und 100 Punkte verteilen

könnten (100 wenn alles zu Ihrer vollen Zufriedenheit ist), wie viele Punkte würden Sie

Ihrer Molkerei geben?

Versprechen, die uns die Molkerei macht, sind verlässlich.

0,894

Wenn wir Schwierigkeiten in der Zusammenarbeit haben, kommt mir die Molkerei entgegen.

Ich fühle mich meiner Molkerei verbunden.

Wenn es sich für mich finanziell lohnt, wechsle ich meine Molkerei.

0,707

Haben Sie sich schon einmal mit einem Wechsel der Molkerei beschäftigt?

0,762

Ohne die (längerfristige) vertragliche Bindung würde ich meine Molkerei eher wechseln.

0,797

Extraktionsmethode: Hauptkomponentenanalyse

Quelle: Eigene Berechnung 
In einer anschließenden Regressionsanalyse wurde die Geschäftsbeziehungsqualität als abhängige Variable definiert. Die in Tabelle 2 oberhalb der Geschäftsbeziehungsqualität aufgeführten Faktoren wurden als unabhängige Variable in die Regressionsanalyse einbezogen. Zusätzlich wurden weitere Einzelstatements mit in die Analyse aufgenommen, die sich zu keinem Faktor verdichten ließen. Die Geschäftsbeziehungsqualität wird zu erheblichen Teilen (korr. $\quad \mathrm{R}^{2}=0,681, \quad \mathrm{~F}-\mathrm{Wert}=86,365^{* * *}$ ) durch die Faktoren „Landwirtschaftliche Orientierung“, „Zufriedenheit mit Management und Kommunikation“ und „Preiszufriedenheit" sowie das Item zur Unternehmensperformance und den Anteil der Milchproduktion am Gesamteinkommen des Betriebes erklärt. Die übrigen Faktoren und Items leisten keinen signifikanten Erklärungsbeitrag. Daneben bleibt festzuhalten, dass kein Einfluss von betriebsstrukturellen und anderen moderierenden Variablen wie z. B. Größe und Zukunftsfähigkeit des Betriebs, Ausbildung des Betriebsleiters, Investitionsbereitschaft oder landwirtschaftliche Gremientätigkeit des Befragten auf die Geschäftsbeziehungsqualität nachzuweisen ist.

TABELLE 3: REGRESSIONSMODELL ZUR ERKLÄRUNG DER GESCHÄFTSBEZIEHUNGSQUALITÄT

\begin{tabular}{|c|c|c|}
\hline Unabhängige Variablen & $\begin{array}{l}\text { Standardisierter B- } \\
\text { Koeffizient }\end{array}$ & t-Wert \\
\hline Landwirtschaftliche Orientierung & 0,432 & $6,754 * * *$ \\
\hline $\begin{array}{l}\text { Einzelstatement: „Ich halte meine Molkerei für langfristig } \\
\text { erfolgreich.“(Unternehmenserfolg) }\end{array}$ & 0,193 & $4,521 * * *$ \\
\hline Preiszufriedenheit & 0,199 & $4,448 * * *$ \\
\hline Zufriedenheit mit Management und Kommunikation & 0,247 & $3,943 * * *$ \\
\hline $\begin{array}{l}\text { Einzelstatement: „Welchen Anteil hat die Milchproduktion an Ihrem } \\
\text { Gesamteinkommen?“(relative Wichtigkeit der Milchproduktion) }\end{array}$ & 0,068 & 1,658 \\
\hline $\begin{array}{l}\text { Methode: Einschluss } \\
\text { Abhängige Variable: Geschäftsbeziehungsqualität } \\
\text { Korr. } \mathrm{R}^{2}=0,681 ; \mathrm{F}-\text { Wert }=86,365^{* * *} ; * * * \mathrm{p} \leq 0,001 ; * * \mathrm{p} \leq 0,01 ; * \\
\mathrm{p} \leq 0,05\end{array}$ & & \\
\hline
\end{tabular}

Inhaltlich ist überraschend, dass der Milchauszahlungspreis aus Sicht der Landwirte nicht der wichtigste Faktor ist. Vielmehr kommt eher emotionalen Kriterien und der wahrgenommenen Managementkompetenz eine ausgesprochen hohe Bedeutung zu. Das Verständnis für die landwirtschaftlichen Lieferanten und ihre Probleme sowie eine ausgebaute Lieferantenkommunikation sind für die Qualität der Geschäftsbeziehung relevanter als der Preis. Daneben spielt die Bewertung des Unternehmenserfolgs für die Milcherzeuger eine wichtige Rolle. Wird eine Molkerei für langfristig erfolgreich gehalten, verbessert dies die Einschätzung der Geschäftsbeziehungsqualität beachtlich. 


\subsection{Erklärungsfaktoren der Wechselbereitschaft}

Der postulierte Zusammenhang zwischen der Geschäftsbeziehungsqualität und den intendierten Zielvariablen wurde im nächsten Schritt zunächst mittels Korrelationsanalyse untersucht. Die Korrelationskoeffizienten bestätigen einen signifikanten Zusammenhang zwischen der Geschäftsbeziehungsqualität und den aus Sicht der Molkereien wichtigen Zielgrößen Wechselbereitschaft, Gegenmachtbildung und Weiterempfehlung (Tabelle 4). Bei einer guten Geschäftsbeziehung zu Milcherzeugern ist insbesondere die Wechselbereitschaft $\left(\mathrm{r}=-0,464^{* * *}\right)$, aber auch die Neigung zur Gegenmachtbildung $\left(\mathrm{r}=-0,233^{* * *}\right)$ deutlich geringer ausgeprägt. Es zeigt sich zudem, dass Molkereien bei hoher Geschäftsbeziehungsqualität von den Lieferanten weiterempfohlen werden $(r=0,692 * * *)$.

TABELLE 4: KoRRELATIONSMATRIX (OUTPUT-VARIABLEN)

\begin{tabular}{lcccc}
\hline & 1 & 2 & 3 & 4 \\
\hline 1 Geschäftsbeziehungsqualität & 1 & & & \\
2 Wechselbereitschaft & $-0,464 * * *$ & 1 & & \\
3 Gegenmachtbildung & $-0,233^{* * *}$ & $0,446^{* * *}$ & 1 & \\
4 Weiterempfehlung & $0,692^{* * *}$ & $-0,459 * * *$ & $-0,160 *$ & 1 \\
\hline$* * * \mathrm{p} \leq 0,001 ; * * \mathrm{p} \leq 0,01 ; * \mathrm{p} \leq 0,05$ & & & & \\
Quelle: Eigene Berechnungen & & & &
\end{tabular}

Insgesamt bestätigt sich die Annahme, dass eine hohe Geschäftsbeziehungsqualität die Lieferantenbindung fördert. Hinsichtlich der Qualitätsmotivation kann für die vorliegenden Daten kein signifikanter Zusammenhang festgestellt werden. Dies resultiert möglicherweise aus den spezifischen Gegebenheiten der deutschen Milchwirtschaft, die insgesamt sehr hohe Qualitätsvorgaben hat und durch hoheitliche Regeln wenig Unterschiede aufweist. In anderen Branchen wie bspw. in der Fleischproduktion ist jedoch zu vermuten, dass durch die Art der Geschäftsbeziehung auch die Qualitätsmotivation der Landwirte positiv beeinflusst werden könnte.

Die bisherige Argumentation zeigt einen geringen Einfluss des Faktors Preiszufriedenheit. Die mehrstufige Form der Analyse kann jedoch nicht ausschließen, dass es ggf. eine direkte Wirkung des Preises auf die Wechselbereitschaft gibt. Ergänzend wurde deshalb ein zweites Regressionsmodell mit der abhängigen Variable Wechselbereitschaft geschätzt (vgl. Tabelle 5). Auch hier erweist sich die Preiszufriedenheit als nicht signifikant, neben den „weichen“ Variablen „Landwirtschaftsorientierung der Molkerei“, „Unzufriedenheit mit der Unternehmensperformance“ der Molkerei und „Geschäftsbeziehungsqualität“" zeigt sich allerdings ein beachtlicher Einfluss der Betriebsgröße (Anzahl Milchkühe) sowie der 
Leistungsfähigkeit des landwirtschaftlichen Betriebs (durchschnittliche Laktationsleistung). Relevant, wenn auch nur schwach signifikant, ist schließlich noch die Einstellung zum Genossenschaftsprinzip.

TABELLE 5: REGRESSIONSMODELL DER EINFLUSSFAKTOREN AUF DIE WECHSELBEREITSCHAFT

\begin{tabular}{lcc}
\hline Unabhängige Variablen & $\begin{array}{c}\text { Standardisierter } \\
\text { B-Koeefizient }\end{array}$ & t-Wert \\
\hline Landwirtschaftliche Orientierung & $-0,301$ & $-3,288^{* *}$ \\
(Un-)Zufriedenheit mit der Unternehmensperformance & 0,211 & $3,077^{* *}$ \\
"Wie viele Milchkühe halten Sie?“ & 0,147 & $2,442^{*}$ \\
Geschäftsbeziehungsqualität & $-0,221$ & $-2,375^{*}$ \\
"Welche durchschnittliche Laktationsleistung haben & 0,132 & $2,233^{*}$ \\
Ihre Kühe?“ & $-0,114$ & $-1,811$ \\
Bewertung des Genossenschaftsprinzips &
\end{tabular}

Methode: Blockweise Regressionsanalyse

Abhängige Variable: Faktor Wechselbereitschaft

Korr. $\mathrm{R}^{2}=0,423 ; \mathrm{F}-$ Wert $=20,788^{* * *} ; * * * \mathrm{p} \leq 0,001 ; * * \mathrm{p} \leq 0,01 ; * \mathrm{p} \leq 0,05$

Quelle: Eigene Berechnungen

\section{Fazit}

Insgesamt zeigt die Befragung eher konfliktäre Geschäftsbeziehungen. Auch die Genossenschaften werden von den Landwirten nicht als ,ihr“ Unternehmen wahrgenommen. Bei größer werdenden Molkereien mit z. T. mehr als 10.000 Lieferanten stellt dieses Ergebnis die Unternehmen vor neue Herausforderungen. Problematisch ist die Unzufriedenheit gerade der größeren, leistungsstarken Betriebe, die zudem häufig eine Meinungsführerposition bei ihren Berufskollegen einnehmen. Ein systematisches Management der Lieferantenbeziehungen (Supplier Relationship Management) und eine regelmäßige Analyse der Geschäftsbeziehungsqualität sind zumindest für diejenigen Molkereien wichtig, die nicht auf Spotmärkten agieren wollen. Dabei erweisen sich die „Landwirtschaftliche Orientierung“ und die Kommunikation unternehmerischer Leistungsfähigkeit als zentrale Ansatzpunkte zur Optimierung der Geschäftsbeziehung. Dies verweist auf den Ausbau der Lieferantenkommunikation, bei Genossenschaften auch auf verstärkte Investor Relations. 


\section{Literatur}

Anderson, J. C. und J. A. Narus (1990): A Model of Distributor Firm and Manufacturer Firm Working Partnerships. In: Journal of Marketing 54 (1): 42-58.

Brown, J. R. et al. (1995): Power and Relationship Commitment: Their Impact on Marketing Channel Member Performance. In: Journal of Retailing 71 (4): 363-392.

Cannon, J. P. und W. D. Jr. Perreault (1999): Buyer-Seller-Relationships in Business Markets. In: Journal of Marketing Research 36 (November): 439-460.

Diller, H. und B. S. Ivens (2004): Beziehungsstile im Business-to-Business-Geschäft. In: Zeitschrift für Betriebswirtschaft 74 (3): 249-271.

Dwyer, F. R. et al. (1987): Developing Buyer-Seller Relationships. In: Journal of Marketing $51(2): 11-27$.

Frazier, G. L. (1983): On the Measurement of Interfirm Power in Channels of Distribution. In: Journal of Marketing Research 20 (5): 158-166.

Gerlach, S. et al. (2005): Landwirte als Lieferanten und Unternehmenseigner: Zum Management von Supplier- und Investor-Relations im Agribusiness. In: Darnhofer, I., S. Pöchtrager und E. Schmid (Hrsg.): Dokumentation der 14. ÖGA-Jahrestagung am 23. und 24. September 2004 in Wien. Facultas Verlag, Wien (in Druck).

Heide, J. B. und G. John (1992): Do Norms Matter in Marketing Relationships? In: Journal of Marketing 56 (2): 32-44.

Lebensmittelzeitung (2004): Dutch Dairy Board soll helfen. In: Lebensmittelzeitung, (41): 25.

Lemke, F., R. Pfeifer, M. Szwejczewski, K. Goffin, C. New und B. Lohmüller (2000): Mit leistungsfähigen Gleichgesinnten verbünden. In: Beschaffung Aktuell 8 (2):34-37.

Matanda, M. J. und B. Schroder (2004): Business-to-Business Relationships by Categories of Suppliers in the Marketing Channel. In: Bremmers, H.J., S.W.F. Omta, J.H. Trienekens und E.F.M. Wubben (Hrsg.): Dynamics in Chains and Networks, Proceeding of the sixth International Conference on Chain and Network Management in Agribusiness and Food Industry. Wageningen Acad. Pub., Wageningen: 532-537.

Matzler, K. und N. Pramhas (2004): Preiszufriedenheit - Prospect Theory oder Kano Modell. In: Hinterhuber, H. H. und K. Matzler (Hrsg.): Kundenorientierte Unternehmensführung, 4. Aufl., Gabler, Wiesbaden: 181-193.

Meier-Pfister, M. und A. A. Thommen (2002): Erfolgsfaktor Investor Relations? Finanzkommunikation in der Schweiz, Verlag Neue Züricher Zeitung, Zürich.

Morgan, R. M. und S. D. Hunt (1994): The Commitment-Trust Theory of Relationship Marketing. In: Journal of Marketing 58 (3): 20-38.

Plinke W. (1997): Grundlagen des Geschäftsbeziehungsmanagement. In: Kleinaltenkamp, P. und W. Plinke (Hrsg.): Geschäftsbeziehungsmanagement. Springer-Verlag. Berlin, Heidelberg: 1-61.

Rapp, R. (2003): Relationship Marketing und Customer Relationship Management. In: Payne, A. und R. Rapp (Hrsg.): Handbuch Relationship Marketing, 2. Aufl., Vahlen, München: 59-72.

Rodríguez, C. M. und D. T. Wilson (2002): Relationship Bonding and Trust as a Foundation for Commitment in U.S.-Mexican Strategic Alliances: A Structural Equation Modeling Approach. In: Journal of International Marketing 10 (4): 53-76. 
Schramm, M. et al. (2004): Brand Orientation in der Ernährungsindustrie. Wiesbaden, Deutscher Universitäts-Verlag.

Seifert, D. (2001): Efficient Consumer Response: Supply Chain Managment (SCM), Category Management (CM) und Collaborative Planing, Forecasting and Replenishment (CPFR) als neue Strategieansätze. 2. Aufl. Hamp, München.

Sieben, F. G. (2001): Customer Relationship Management als Schlüssel zur Kundenzufriedenheit. In: Homburg, C. (Hrsg.): Kundenzufriedenheit, 4. Aufl., Gabler, Wiesbaden: 295-314.

Stölzle, W. und K. F. Heusler (2003): Supplier Relationship Management - Entstehung, Konzeptverständnis und methodisch-instrumentelle Anwendung. In: Bogaschewsky, R. und U. Götze (Hrsg.): Management und Controlling von Einkauf und Logistik. Dt. Betriebswirte-Verlag, Gernsbach: 168-194.

Stölzle, W. und M. Karrer (2004): Von der Unternehmens- zur Supply Chain Performance ein konzeptioneller Beitrag für das Management von Supply Chains. In: Sprengler, T., S. Voß und H. Kopfer (Hrsg.): Logistik Management: Prozesse, Systeme, Ausbildung, Physica-Verlag, Heidelberg: 235-254.

Wathne, T. und J. B. Heide (2004): Relationship Governance in a Supply Chain Network. In: Journal of Marketing 68 (1): 73-89.

Wilson, D. T. (1995): An Integrated Model of Buyer-Seller Relationships. In: Journal of the Academy of Marketing Science 23 (4): 335-345. 
KAPITEL II.4

Supplier Relationship Management in the German Dairy Industry 


\section{Supplier Relationship Management in the the \\ German Dairy Industry*}

(with Achim Spiller and Christian Wocken)

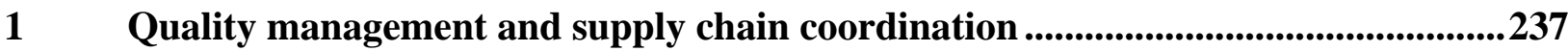

2 Relationship quality: A precondition of quality management .................................237

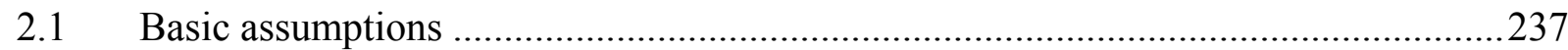

2.2 Introduction of a new quality management system to the German dairy business. ....239

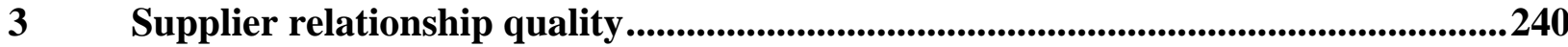

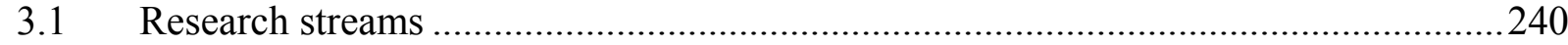

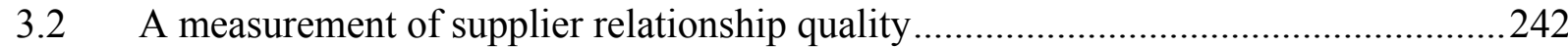

4 The relevance of economic and behavioural factors on the quality of business

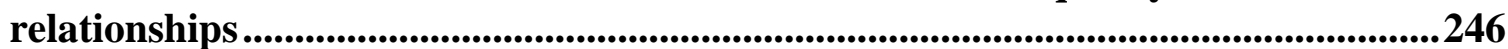

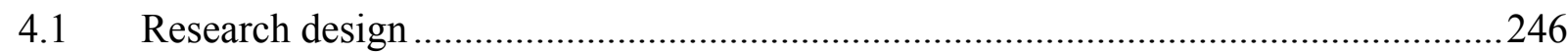

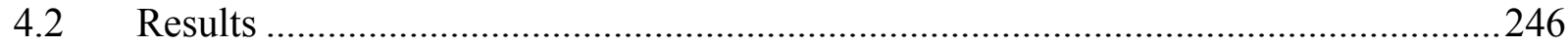

4.3 Factors influencing the quality of the business relationship..................................247

4.4 Implications of supplier relationship management towards food quality...................249

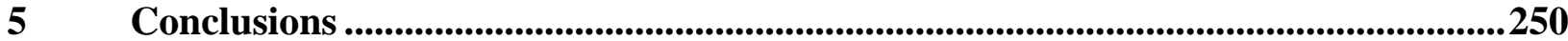

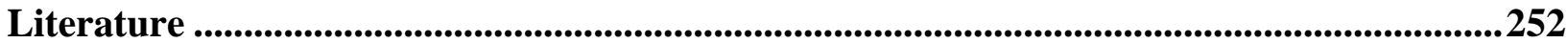

\section{List of figures}

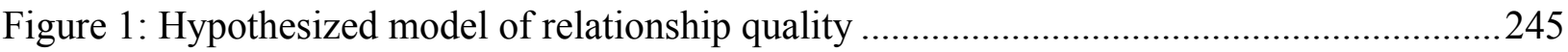

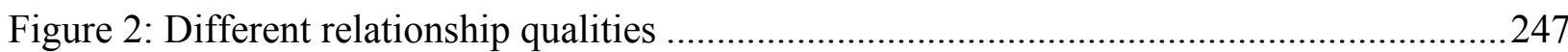

\section{List of tables}

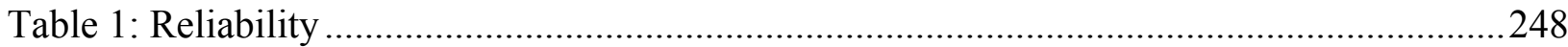

Table 2: Regression model to explain the quality of the business relationship........................248

Table 3: Correlation matrix (Output variables) .............................................................................249

Table 4: Correlation matrix without Humana Milchunion suppliers (Output variables) ............250

Table 5: Potential advantages of a closed supplier relationship in the agribusiness ..................251

* Konferenzbeitrag zum 92nd EAAE Seminar "Quality Management and Quality Assurance in Food Chains", 2.-

4. März 2005, Göttingen. 


\section{Quality management and supply chain coordination}

Quality Management in agribusiness encompasses different facets; from a company's internal management system to metasystems like the growing certification concepts, and from business to state run programs. One of the most common assumptions of the modern quality approach is the advantage of a supply chain perspective. The overall quality of a product is determined through the weakest link in the chain. However, the concepts of quality management in supply chains are not equally discussed. Whereas there is detailed debate about the options for vertical integration and contract farming, the possibilities of chain coordination in arm-length markets and weak vertical coordinated structures are rarely discussed.

The following paper analyses relationship quality in the German dairy sector in order to evaluate opportunities to enhance product quality through better supply chain coordination. The underlying hypothesis is the role that trust, commitment and satisfaction play in determining sustainable business relationships, chain wide information flow and quality motivation. We develop a measurement concept of supplier relationship quality which allows new insights into the critical success factors of supplier development. The analysis is based on different research streams, mainly network science, channel management and sourcing theory. A survey involving 209 German farmers constituted the empirical basis.

\section{Relationship quality: A precondition of quality management}

\subsection{Basic assumptions}

Traditionally sourcing management plays an important role in quality assurance concepts. Statistical quality control and inspection systems ensure the quality of direct and indirect materials in a business environment which is characterized through an increase in outsourcing. But the role sourcing plays in management theory has changed through the last decades from procurement to supply chain management. The buyer-supplier relationship tends from price focus towards a portfolio model in which key vendors act as partners bonded through mutual investments and trust (Han et al. 1993).

This development of sourcing theory is not well reflected in the discussion about quality management in the agribusiness. Here two recent trends can be found: The first opportunity is quality management as part of a vertical coordinated chain. In this case a predominant 
company - mainly the processor - develops standards for production and logistics depending on its own quality objectives and marketing requirements (examples can be found in the poultry sector). The second is that of certification in arms-length relationships. Through third party control, resulting in a generally accepted certificate (e. g., Eurepgap, ISO 9000), suppliers are enforced to follow general quality standards.

In both cases, whenever independent firms are involved in the supply chain, it is not always assured that the intentions of the supply chain leader or the customer are fulfilled. Detection of any opportunistic behaviour on the part of the supplier depends on the quality of controlling procedures. Control systems tend to be static in nature. In the positive sense they lead to a given standard, but there are no incentives to go beyond this. Moreover, certification systems show a tendency to build up bureaucratic structures for example various checklist controls, thus missing out on a real quality driven process. Basically, without intrinsic motivation the dangers of short falls are appreciable.

These problems are rarely discussed in the literature because of relatively new developments. Jahn et al. (2005) explain findings from the auditing theory in order to secure the validity of certification procedures. Theuvsen (2005: 175) argues that quality management systems could lead to more bureaucracy. On the one hand, there is "good bureaucracy" that leads for example to precision, speed, unambiguity and knowledge of files. On the other hand "bad bureaucracy" can cause inflexible work and progress conservatism. Finally, there are some empirical indications that the recent quality management approaches may be inadequate if they are not able to motivate suppliers as to their own quality.

Another more theoretical contribution to our problem comes from economic psychology, especially that of motivational crowding effects (Frey/Jegen 2001; Frey/Oberholzer-Gee 1997). The theory suggests that external intervention via financial incentives or control pressure reduce intrinsic motivation, the effect of this trade-off may result in a quality below that of the initial motivation level. This effect is well known to every employer who uses monetary incentives to motivate agents. On the one hand, they higher the overall output level. This holds true due to the extrinsic motivational effect of a higher payment. On the other hand, they undermine intrinsic motivation and thus jeopardise the quality of the work. Under particular conditions the negative crowding effect outweighs the positive effect of higher payment. In general, the initial amount of intrinsic motivation, the perceived fairness of the 
incentive and the opportunities to control the agents' work are factors which determine the occurrence of crowding effects. The same trade-off applies to external pressure or control, so the described relationship between internal and external motivation may appear in the field of quality motivation. As a result, after introducing a control oriented quality management, the loss of internal quality motivation can be larger than the amount added by the increased external pressure (Jahn et al. 2004).

The described problems stand in high contrast to major requirements of total quality management. For example the basic tool of kaizen (continual improvement) is based on creativity and, thus, mainly on intrinsic motivation. Although the net effect of the above mentioned crowding effect may be not negative in all cases, quality management will be clearly more effective if suppliers are intrinsically motivated. Overall, there are some well founded reasons for the basic hypotheses of this article, that suitable business relationships with a high amount of trust and commitment lead to stable and long-term networks allowing better quality management along the whole supply chain. This is especially true for the agribusiness, where processors have a high number of small suppliers.

In the following paper we demonstrate with the example of the German dairy business, that new tools of supplier relationship management can be useful in improving the relationship between processors, trying to build up new quality approaches, and thus enhancing farmerdairy relationships. In the following section, new quality developments in this industry are discussed, emphasising the obstacles when introducing new quality schemes to business relationships with low trust.

\subsection{Introduction of a new quality management system to the German dairy business.}

The German dairy business is highly fragmented with a concentration ratio of CR10 from $58 \%$ in 2003 (own calculation, based on MIV 2004). For the last few years price competition has been increasing through changes in agricultural policy and a higher number of private labels, launched by growing numbers of discount retailers. In the year 2002 nearly all German dairies began with the introduction of a joint approach to a farmer oriented quality management system. Because of the high level of consumer confidence in the quality of milk, the industry was relatively late in introducing a third party control structure. 
Coming into this equation, the so called "Qualitaetsmanagement Milch" (QM Milk) should ensure the basic requirements of milk, fodder, documentation, environment and animal welfare, enclosing the farmer in a chain wide control concept. Up to this, no independent verification was carried out on farms. QM Milk is an attempt to enhance the established statistical raw material control system through a process management approach. However, the introduction of QM Milk has been postponed due to a low level of acceptance by farmers.

Although QM Milk is easy to carry out for most farmers as it is based on existing legal requirements, there is a lot of resistance. A nationwide farmer's association is resisting the concept, threatening milk boycotts. In a recent study (Jahn/Spiller 2005) it could be demonstrated that most dairy farmers are not convinced of the advantages QM Milk will bring in addition to the existing analytical product control of the dairy. The authors show that most farmers do not see quality improvements but bureaucratic "paper control". For that reason the amount of intrinsic motivation is not enhanced. Even the more successful farmers, with a high degree of commitment to quality production, tend to reject the new concept.

Jahn and Spiller (2005) also reveal great differences in the ability of the dairies in communicating the necessity of QM Milk. Some processors fail completely in convincing their farmers of the possible advantages and the general trend towards third party control. This demonstrates how critical a good relationship is in chain wide quality management. For that reason the following study tries to analyze the antecedents of farmer-processor relationships.

\section{Supplier relationship quality}

\subsection{Research streams}

The first attempts to measure relationship quality go back to the marketing channel literature. With a special focus on manufacturer-retailer dyads, channel research highlights conflict between supplier and retailer, the emphasis was placed on exploring sick rather than healthy relationships (Young/Wilkinson 1989: 109). In the nineties the focus changed towards cooperation in general and trust and commitment in particular (Morgan/Hunt 1994). All in all, marketing channel research highlights the potential benefits of co-operative relationships, building the theoretical background for the huge efforts manufactures and retailers undertake to improve collaboration through, for example "Efficient Consumer Response". Relationship quality is also analysed in the sales and service management literature, where a people-based 
approach dominate and relationship quality is defined as the ability of a customer to rely on the sales person's integrity (Crosby et al. 1990; Lagace et al. 1991).

Another research stream depends on industrial marketing. The well-known Scandinavian approach (IMP Group 1982) concentrated on long-term network relationships in business-tobusiness marketing. In initial studies, the focus was on the ongoing interaction process, in which single transactions are embedded. Later on the attention shifted towards a network approach (Hakansson/Snehota 1995). Based on the IMP interaction model, Woo and Ennew (2004) offer a conceptualization of business-to-business relationship quality and explain the connection between relationship quality and service quality.

Similarly, in consumer marketing, the relationship perspective attracted great interest which led to new business approaches, such as customer relationship management (CRM). The measurement of customer satisfaction was first conceptualized through the work of Parasuraman et al. (1988), who developed the SERVQUAL-scale for customer satisfaction analysis. A review of selected approaches explaining relationship quality in consumer behaviour was presented by Hennig-Thurau et al. (2002). The ongoing work reveals that satisfaction is a necessary, but not a sufficient requirement for customer bonding.

Previous studies on relationship quality in the context of procurement were undertaken by Leuthesser (1997), Dorsch et al. (1998) and Naudé and Buttle (2000). Dorsch et al. (1998) highlighted the relevance of trust, satisfaction, commitment, opportunism, customer satisfaction, and ethical profile. Naudé and Buttle (2000) proposed five attributes of relationship quality: trust, power, integration, mutual understanding of needs, and profit. A measurement scale of relationship quality was developed by Lages et al. (2005), who focused on the relationship between exporting firms and the importer. Their RELQUAL scale tried to define elements of successful export relationships by questioning export managers of UK companies. They revealed the amount of information sharing, communication quality, longterm orientation and satisfaction with the relationship as elements of the multi-item scale. RELQUAL is positively related to export performance.

In the agribusiness literature, a growing number of studies dealing with relationship management can be found. Most studies discuss selected constructs, such as trust, power, and dependency (Morgan/Hunt 1994). Means of collaboration beyond contracts and vertical 
integration are revealed in Hobbs and Young (2001). Several empirical studies were conducted by Batt and co-authors. The role of trust in supply chains is discussed in Batt and Rexha (1999) and Batt (2003). Batt and Wilson (2001) studied the relationship between grape growers and wine makers in Western Australia. Gusti et al. (2004) conducted a similar survey with small farmers and their intermediaries in Indonesia. In all studies Batt et al. identified factors affecting the respective buyer-seller relationship and accentuated the role of collaboration and trust in various agricultural supply chains (Batt 2003; Batt/Purchase 2004). Hansen et al. (2002) suggested that trust between members of a co-op and the co-op management is an important variable to enhance group cohesion. Matanda and Schroder (2004) analysed buyer-seller-relationships in Zimbabwean horticulture with a comprehensive behavioural approach, focussing on a broad model of relational constructs. They elaborated differences between small and large primary producers in terms of satisfaction, dependency, conflict frequency, long-term orientation, commitment and social bonding. Clare et al. (2005) evaluated the relationship between farmers, livestock buyers and slaughterhouses in the New Zealand red meat industry, and found that buyers have a far closer relationship with farmersuppliers than both groups have with slaughterhouses.

On the whole, the literature review provides evidence for the growing importance of a behavioural approach towards the relationship between primary producers and processors in the agribusiness. In the following part, elements of the research streams described are used to develop an approach for the measurement of relationship quality between farmers and processors. Thus, the impact of relationship quality on quality management is analysed.

\subsection{A measurement of supplier relationship quality}

The starting point for the following discussion is the assumption that quality management systems in the agri chain can be improved by enhancing the relationship between the farmer and the processor. Therefore the next step is working out a valid and reliable concept of measuring this supplier-customer dyad. Because of the unequal nature of this relationship with one processor, dealing with numerous small farmer-suppliers, the empirical analysis is concentrated on the farmer's perception.

To develop a scale of relationship quality, the experience of the research streams described above is transferred to the industry researched. In addition, qualitative interviews with 
managers and farmers were carried out to identify more sector specific topics. After these considerations, a first draft of items was discussed with managers of an agribusiness company (sugar industry). This first draft was again tested with 271 suppliers of sugar processors in Germany (Gerlach et al. 2005). The study already showed important similarities to following surveys, especially concerning the importance of farmer orientation and the low significance of prices for supplier satisfaction. After reviewing items, wording, testing validity, clarity and redundancy, the second step was to apply this study to the German dairy industry.

In line with past research (Smith 1998; Lages et al. 2005), we define relationship quality as a higher-order concept, composed of three different, though related elements. Relationship quality is the overall assessment of the strength of a business relationship, combining satisfaction, trust and commitment. A basic element for nearly all relationship models is the outstanding importance of customer satisfaction or, in our case, supplier satisfaction (Gerlach et al. 2004: 9). As with consumer marketing, satisfaction reflects comprehensive experience with a business partner as a necessary but not sufficient condition for an ongoing relationship (van Weele 2002: 165). In addition to own experiences, information from other business partners and other cues build the basis of satisfaction (Homburg/Stock 2001: 20). According to the disconfirmation model, satisfaction in supplier relationship quality is the result of a comparison between a buyer's performance and the supplier's expectations.

Other elements of relationship quality are trust and commitment (Crosby et al. 1990; Bejou et al. 1996; Naudé/Buttle 2000; Batt 2003): Trust is defined as “(...) a willingness to rely on an exchange partner in whom one has confidence“ (Moorman et al. 1993: 82). It is combined with the belief that others will not act to exploit one's vulnerabilities (Hansen et al. 2002: 42). Trust reduces opportunistic behaviour and transaction costs (Ganesan 1994; Doney/Cannon 1997; Batt/Rexha 1999) thus it is relevant if information asymmetries are present.

Commitment "(...) is an implicit or explicit pledge of relational continuity between exchange partners" (Dwyer et al. 1987: 19). It is seen as an outcome of trust and defined variously in the literature as the belief of a supplier that the relationship with a processor is so important that it warrants maximum effort to maintain it even if problems occur (Morgan/Hunt 1994). Satisfaction, trust, and commitment are common variables in relationship quality research. However there is a lack of consensus about additional parameters. Other authors add variables, such as communication quality or information sharing (Naudé/Buttle 2000; Lages 
et al. 2005). From our viewpoint, these are not integral elements of relationship strength, but management instruments and thus determinants of relationship quality and not ingredients. In the following section possible determinants of relationship quality are presented.

To improve relationship quality, it is necessary to identify the crucial influencing variables. Price satisfaction appears to be particularly important. Price satisfaction refers to several relationship studies that state that the economic outcome is important for the evaluation of that relationship (Jaervelin 2001) and, thereby, positively affects the development of trust. The parameters include short- and long-term price satisfaction as well as relative price satisfaction when comparing the own price received with the price paid by other dairies/slaughterhouses. Furthermore, often used variables in relationship management are shared values (Heide and John 1992; Morgan and Hunt 1994), perceived performance of the partner, communication quality and quantity (Matanda/Schroder 2004: 534) and friendships between partners (Wilson 1995: 339; Rodriguez/Wilson 2002: 55). As the dairy industry is facing an increasing concentration at the processor and retail level, the effects of power asymmetries and coercion also have to be considered as important for relationship perception (Anderson/Narus 1990; Dwyer et al. 1987).

One particular factor influencing supplier relationship quality in agribusiness is the processor's orientation towards farming. Due to the importance of co-operatives, farmers are used to having some influence on the manufacturer (Gerlach et al. 2005). Possible elements of farmer orientation are farmers' influence, the processor's proximity to agricultural problems, competence of farm advisory service etc. The parameter farmer orientation is also closely related to "the degree to which partners share goals that can only be accomplished through joint action and the maintenance of the relationship" (Wilson 1995: 338).

The economic success of a farmer ultimately depends on the performance of the processor. This is especially true for those farmers who are shareholders and bound by contracts. Therefore perceived management competences are probably an important factor for assessing the buyer. The management strategy of the manufacturer should be comprehensible for the farmers because their prices depend on it.

Aiming at more than a simple "feel-good-approach" (Dyer/Chu 2000), the potential outcomes of an improved relationship with the suppliers also have to be measured. As output variables, 
the intention to switch the buyer, recommendation of the farmer, and the absence of countervailing power are defined. Regarding quality management, we measure the impact of relationship quality on the acceptance of the recently introduced QM-concept. Figure 1 describes the revealed elements of the farmer-processor relationship.

FIGURE 1: HYPOTHESIZED MODEL OF RELATIONSHIP QUALITY

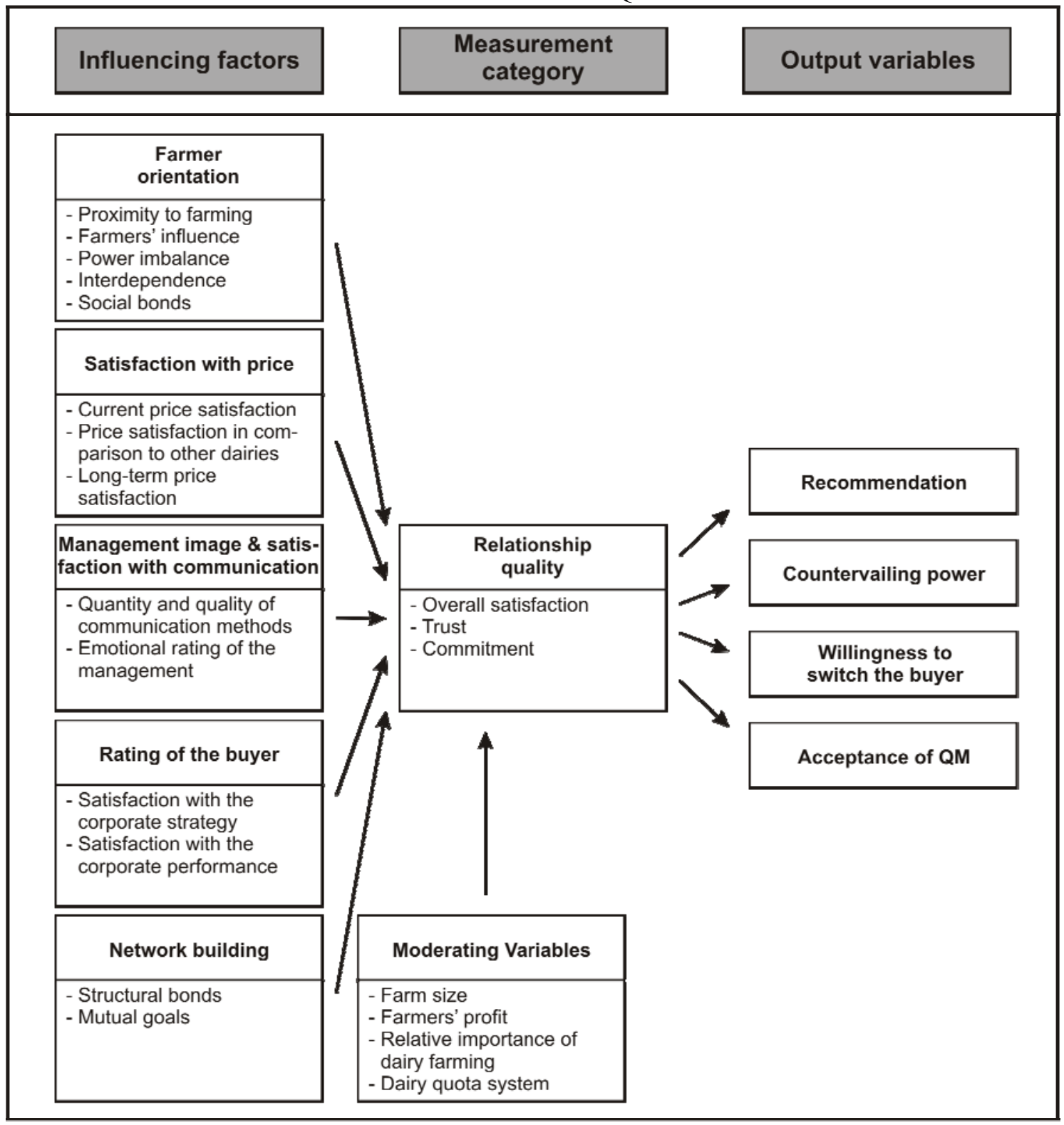

Source: Own 


\section{The relevance of economic and behavioural factors on the quality of business relationships}

\subsection{Research design}

The analysis detailed in this paper was conducted on data obtained from a sample of 209 dairy farmers in Northern Germany. In summer 2004 the farmers were questioned in face-to-face interviews. The average interview took about 45 minutes. The sample includes larger sized farms (97 ha, 73 cows per farm) than the average ones in Germany (35 cows per farm, Eurostat 2004). The average milk quota per farm is comparatively high (600 $000 \mathrm{~kg} \mathrm{p}$. a.) and the milk quality is much higher than the requested minimum standards of the official regulation.

The respondents are on average 42 years old and well-educated (only $3.4 \%$ have no agricultural education). The majority of these farmers $(60.6 \%)$ are active members in agricultural associations. Therefore, the sample includes presumably more farmers with firm viewpoints. $84.1 \%$ of the respondents intend to continue milk production in the future. The others are not sure, but only two of them have so far decided to give up their farm.

The farmers interviewed delivered their milk to 22 different dairies of which "Nordmilch e.G. (Nordmilch)" receives 35.4\%, "Humana Milchunion e.G. (Humana)" 22.5\% and "Campina GmbH Deutschland (Campina)" 14.8\%. Humana is the biggest dairy in Germany (sales volume: 2.444 Mio. $€$, milk production 2.175 Mio t p.a.) followed by Nordmilch. Campina is in fourth place (MIV 2004). The remaining farmers (27.3\%) deliver to smaller companies.

\subsection{Results}

The following chapter provides a short overview on the farmers' responses regarding the above-mentioned parameters, which have been modelled with 7-point Likert scales. Overall satisfaction with the relationship to the dairy industry is rather mixed, hence its position in mid-range. There are clear deficits in trust and commitment. It is notable that farmer orientation and common purpose is perceived very low. From the farmers' point of view, most of the cooperative industries lose their agrarian basis. Consequently, the willingness to change the buyer is $68.8 \%$ if another dairy pays a higher milk price. On the whole, the strength of the relationship between farmer and dairy is low and unstable. However, the high standard deviations show different positions by the farmers. 
A comparison between the different dairies shows clear differences (Figure 2). In general, suppliers of Nordmilch and Campina show more dissatisfaction. Some difficulties with recent mergers may provide a possible explanation. Smaller co-operatives and the Humana Milchunion show higher supplier commitments. Research on co-operatives provides another possible explanation besides management factors: in small groups social capital can be built easier. It is also interesting to note, that suppliers of small private dairies show a higher willingness to change. Hence, a tendency towards spot markets can be identified.

FIGURE 2: DIFFERENT RELATIONSHIP QUALITIES

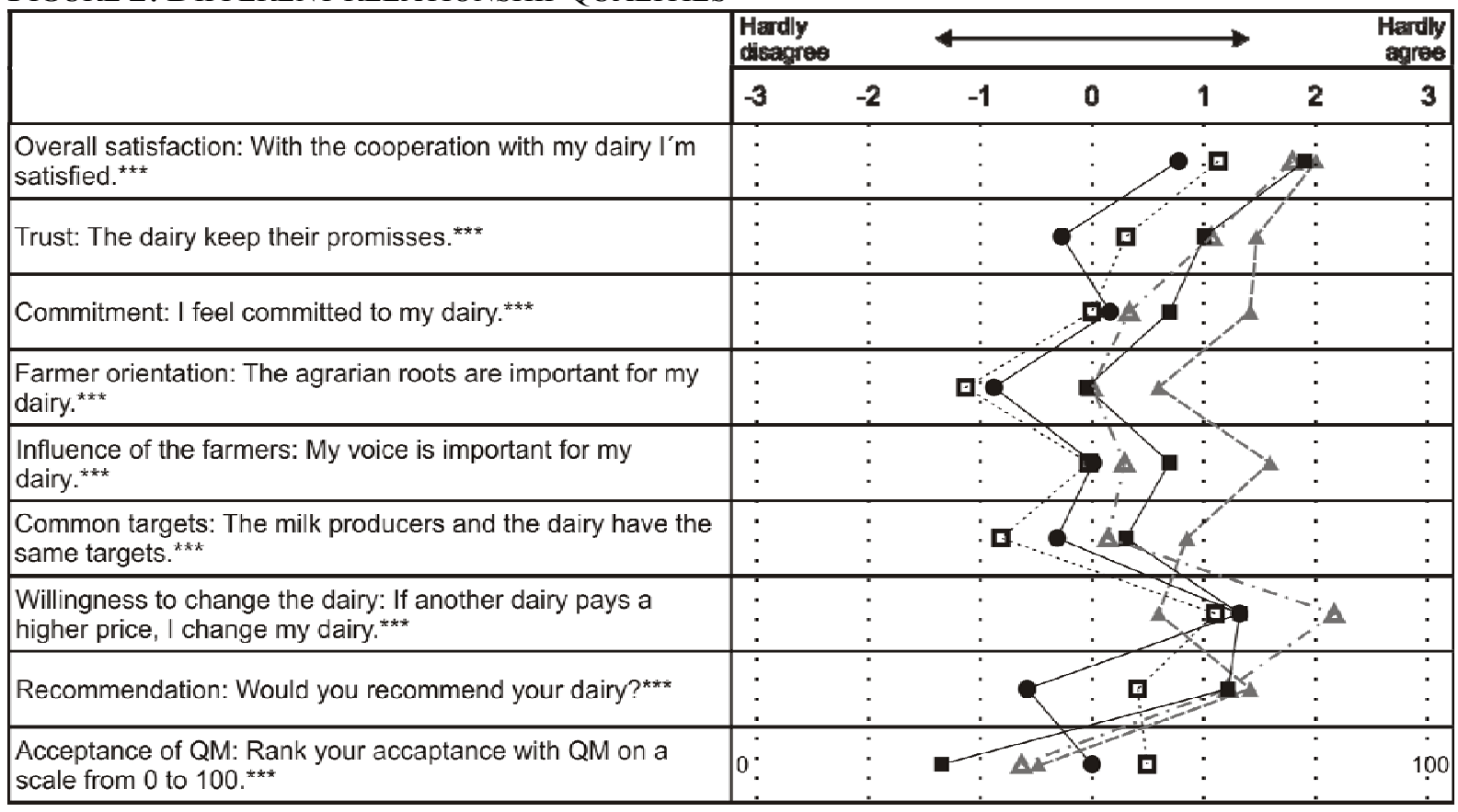

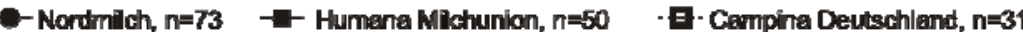

- other co-operative dairies, $n=32 \quad-A$ - other dairies with different forms of organization, $n=22$

Source: Own survey

\subsection{Factors influencing the quality of the business relationship}

The described model of business relationship quality was verified using factor analysis. Some parameters had to be modified: The factor "farmer orientation" comprises items which primarily are related to agrian proximity influence of the farmers, power asymmetry and the perception of trade offs between farmers and the dairy. The items constituting global satisfaction, trust and commitment were reduced to the factor "quality of business relationship". The factor "willingness to change" however was maintained. Table 1 shows Cronbachs Alpha as a measure of the reliability of the extracted factors. 
TABLE 1: RELIABILITY

\begin{tabular}{lc}
\hline Factor & Alpha \\
\hline Relationship quality & .840 \\
\hline Farmer orientation & .886 \\
Management image and satisfaction with communication & .661 \\
Price satisfaction & .674 \\
\hline Willingness to switch the dairy (Output variable) & \\
\hline
\end{tabular}

Source: Own survey

The impact of the factors on the quality of the business relationship was then measured using linear regression analysis. In addition some single statements were entered, i.e. those asking for satisfaction with business performance. The quality of the business relationship (satisfaction, trust, commitment) is to a great extent determined (adjusted $\mathrm{R}^{2}=0.681, \mathrm{~F}=$ $86.365^{* * *}$ ) through the factors farmer orientation (1), management image and satisfaction with communication (2), price satisfaction (3), business performance (4), and the relative importance of dairy farming on the farmers' income (5). All other factors as well as other moderating variables such as farm size, the farmers' education, and their willingness to invest or engage in agrarian organisations have no significant impact on the perceived quality of the business relationship.

TABLE 2: REGRESSION MODEL TO EXPLAIN THE QUALITY OF THE BUSINESS RELATIONSHIP

\begin{tabular}{lcc}
\hline Independent Variables & $\begin{array}{c}\text { Standardized } \\
\text { Beta Coefficient }\end{array}$ & $\begin{array}{c}\mathrm{t} \text {-Value } \\
\text { Farmer orientation }\end{array}$ \\
Management image and satisfaction with communication & .432 & $6.754^{* * *}$ \\
Price satisfaction & .247 & $3.943^{* * *}$ \\
Performance satisfaction (one Item) & .199 & $4.448^{* * *}$ \\
Relative importance of dairy farming (Moderating Variable) & .193 & $4.521^{* * *}$ \\
\hline
\end{tabular}

Depending variable: Relationship quality

Adj. $\mathrm{R}^{2}=0.681 ; \mathrm{F}-$ Value $=86.365^{* * *} ; * * * \mathrm{p} \leq 0.001 ; * * \mathrm{p} \leq 0.01 ; * \mathrm{p} \leq 0.05$

Source: Own survey

Surprisingly, price satisfaction does not have the strongest impact. Emotional criteria and the perception of management competence are much more important. The understanding of farmers' problems as well as communication with the supplier are much more relevant than the price perception. When farmers believe that a dairy is more successful than others, the quality of the relationship is better from the farmer's view. 


\subsection{Implications of supplier relationship management towards food quality}

Correlation analysis was used to check the correlation between relationship quality and different output variables. The coefficients indicate a highly significant link between business relationship quality and the output variables - willingness to change, building countervailing power and recommendation - which are from the dairy point of view very important (see table 3 ). In a good business relationship, willingness to change is lower ( $\left.r=0.464^{* *}\right)$, just as it is for the willingness to build countervailing power $\left(\mathrm{r}=0.233^{* * *}\right)$. A means comparison between those who are members of the Bund Deutscher Milchviehhalter (an organisation, which was founded as a cooperative against the market power of dairies) and those who are not, reveals highly significant differences between these groups concerning the perception of relationship quality and the willingness to build countervailing power. Another finding is that dairies with a high relationship quality are recommended by their suppliers $(\mathrm{r}=0.692 * * *)$.

TABLE 3: CORRELATION MATRIX (OUTPUT VARIABLES)

\begin{tabular}{|c|c|c|c|c|c|}
\hline & 1 & 2 & 3 & 4 & 5 \\
\hline 1 Relationship quality & 1 & & & & \\
\hline 2 Willingness to switch the dairy & $-.464 * * *$ & 1 & & & \\
\hline 3 Countervailing power & $-.233 * * *$ & $.446 * * *$ & 1 & & \\
\hline 4 Recommendation & $.692 * * *$ & $-.459 * * *$ & $-.160 *$ & 1 & \\
\hline 5 Acceptance of QM & .104 & $-.165^{*}$ & -.082 & .031 & 1 \\
\hline
\end{tabular}

$* * * \mathrm{p} \leq 0.001 ; * * \mathrm{p} \leq 0.01 ; * \mathrm{p} \leq 0.05$

Source: Own survey

There is no significant correlation between relationship quality and the acceptance of the QMMilk system. A possible reason for this might be that the dairy Humana Milchunion does not participate in the QM Milk system and campaigns against it. Thus the suppliers of Humana do not feel to benefit from a potential involvement in QM milk. If the suppliers of Humana Milchunion are eliminated from the correlation analysis, a low significant correlation between the acceptance of QM and the relationship quality becomes apparent (see table 4). 
TABLE 4: CORRELATION MATRIX WITHOUT HUMANA MILCHUNION SUPPLIERS (OUTPUT VARIABLES)

\begin{tabular}{lccccc}
\hline & 1 & 2 & 3 & 4 & 5 \\
\hline 1 Relationship quality & 1 & & & & \\
2 Willingness to switch the dairy & $-.499^{* * *}$ & 1 & & & \\
3 Countervailing power & $-.225^{* *}$ & $.435^{* * *}$ & 1 & & \\
4 Recommendation & $.689^{* * *}$ & $-.473^{* * *}$ & -.139 & 1 & \\
5 Acceptance of QM & $.192^{*}$ & $-.177^{*}$ & -.056 & .031 & 1 \\
\hline
\end{tabular}

$* * * \mathrm{p} \leq 0.001 ; * * \mathrm{p} \leq 0.01 ; * \mathrm{p} \leq 0.05$

Source: Own survey

Altogether, the hypothesis that high business relationship quality encourages the suppliers' commitment can be approved. The weak correlation between relationship quality and the acceptance of QM demonstrates that the direct influence on quality motivation is limited. This may be due to the high official quality requirements in the German dairy sector which seems to be sufficient for most of the farmers.

\section{Conclusions}

The survey reveals a difficult business relationship. Dairy farmers do not perceive cooperatives as "their" companies. For larger dairies with more than 10000 suppliers (e.g. Nordmilch or Humana Milchunion) this result indicates new challenges. It is problematic that more powerful farmers with large farms, who are also opinion leaders, are significantly more unsatisfied. A systematical supplier relationship management and continuous analysis of the business relationship are important for those companies who don't operate on a spot-market. To improve the relationship between milk producers and dairies, the farmer orientation and the communication of the business performance is a central point. Dairies should provide better supplier communication and in cooperatives a heightened investor relationship should be a prerequisite.

Supplier relationship management is a procurement tool, which focuses on supplier development and enhancement of business relationships (Stoelzle/Heusler 2003; Gerlach et al. 2004). Better relationships with suppliers offer a long list of potential advantages (table 4). In industries like the automotive sector supplier development plays an important role in the attempt to build stable supplier networks which could work as a competitive advantage. 


\section{TABLE 5: POTENTIAL ADVANTAGES OF A CLOSED SUPPLIER RELATIONSHIP IN THE AGRIBUSINESS}

$>$ Higher satisfaction of both parties

$>$ Long term orientation for the dairy through less willingness to change on the part of the farmers

$>$ Lower intensity of conflict

$>$ Flexibility and speed advantages through better information flow

$>$ Reduction of transaction costs through stable relationships

$>$ Reduction of process costs through compatible data interfaces

$>$ Better quality management through trustworthy information flow

$>$ Commitment enhances a willingness to invest on farmers side

Source: Own

From a dairies viewpoint, supplier relationship quality aims at gaining better suppliers than the competitors in order to enhance the whole supply chain. This does not solve distributional conflicts about farm prices, but opens opportunities for a more functional way of managing trade offs in the supply chain. Furthermore, the influence of price fairness in the relationship between processors and farmers may be overestimated, because of the misjudged importance of weak factors like trust and commitment. For quality management this provides new opportunities for motivating suppliers, enhancing intrinsic motivation instead of external pressure. 


\section{Literature}

Anderson, J. C.; Narus, J. A. (1990): A Model of Distributor Firm and Manufacturer Firm Working Partnerships, in: Journal of Marketing, 54 (1), 42-58.

Batt, P. J.; Rexha, N. (1999): Building trust in agribusiness supply chains: A conceptual model of buyer-seller-relationships in the seed potato industry in Asia, in: Journal of International Food \& Agribusiness Marketing, 11 (1), 1-17.

Batt, P. J.; Wilson, H. (2001): Exploring the nature of long-term buyer-seller relationships in the Western Australian wine industry, in: Australia New Zealand Wine Industry Journal, 16 (6), 87-96.

Batt, P. J. (2003): Building Trust between growers and market agents, in: Supply Chain Management, 8 (1), 65-78.

Batt, P. J.; Purchase, S. (2004): Managing collaboration within networks and relationships, in: Industrial Marketing Management, 33 (3), 169-174.

Bejou, D. et al. (1996): Determinants of Relationship Quality: An Artificial Neural Network Analysis, in: Journal of Business Research, 36 (2), 137-143.

Clare, B. G. et al. (2005): Supply base relationships in the New Zealand red meat industry: A case study. Paper presented to 15th annual world forum, symposium and case conference of the International Food and Agribusiness Management Association, Chicago, June.

Crosby, L. A. et al. (1990): Relationship Quality in Services Selling: An Interpersonal Influence Perspective, in: Journal of Marketing, 52 (2), 21-34.

Doney, P. M.; Cannon, J. P. (1997): An examination of the nature of trust in buyer-sellerrelationships, in: Journal of Marketing, 61 (2), 35-51.

Dorsch, M. J. et al. (1998): The role of relationship quality in the stratification of vendors as perceived by customers, in: Journal of the Academy of Marketing Science, 26 (2), 128-142.

Dwyer, F. R. et al. (1987): Developing Buyer-Seller Relationships, in: Journal of Marketing, 51 (2), 11-27.

Dyer, J. H.; Chu, W. (2000): The determinants of trust in supplier-automaker relationships in the US, Japan, and Korea, in: Journal of International Business Studies, 31 (2), 259285.

Frey, B. S.; Jegen, R. (2001): Motivation Crowding Theory, in: Journal of Economic Surveys, $15(5), 589-611$.

Frey, B. S.; Oberholzer-Gee, F. (1997): The Cost of Price Incentives: An Empirical Analysis of Motivation Crowding-Out, in: American Economic Review, 87 (4), 746-755.

Ganesan, S. (1994): Determinants of Long-Term Orientation in Buyer-Seller Relationships, in: Journal of Marketing, 58 (2), 1-19.

Gerlach, S. et al. (2004): Supplier Relationship Management im Agribusiness: Ein Konzept zur Messung der Geschaeftsbeziehungsqualitaet, Diskussionsbeitrag Nr. 0406 des Instituts fuer Agraroekonomie, Georg-August-Universitaet Goettingen. 
Gerlach, S. et al. (2005): Landwirte als Lieferanten und Unternehmenseigner: Zum Management von Supplier- und Investor-Relations im Agribusiness, in: Darnhofer, I.; Poechtrager, S.; Schmid, E. (Eds.): Jahrbuch der oesterreichischen Gesellschaft fuer Agraroekonomie, Wien, 221-234.

Gusti, I. et al. (2004): Factors affecting supply chain participants on choosing their preferred trading partners, Agriculture Congress 2004, Innovation Towards Modernised Agriculture, 4-7 October, Mines Resort City, University Putra Malaysia.

Hakansson, H.; Snehota, I. (1995): Developing relationships in business networks, London.

Han, S.-L. et al. (1993): Buyer-Seller Relationships Today, in: Industrial Marketing Management, 22 (4), 331-338.

Hansen, M. H. et al. (2002): The impact of trust on cooperative membership retention, performance, and satisfaction: an exploratory study, in: International Food and Agribusiness Management Review, 5 (4), 41-59.

Heide, J. B.; John, G. (1992): Do Norms Matter in Marketing Relationships?, in: Journal of Marketing, 56 (2), 32-44.

Hennig-Thurau, T. et al. (2002): Understanding relationship marketing outcomes: An integration of relational benefits and relationship quality, in: Journal of Service Research, 4 (3), 230-247.

Hobbs, J. E.; Young, L. M. (2001): Vertical linkages in agri-food supply chains in Canada and the United States, Research and Analysis Directorate, Strategic Policy Branch Agriculture and Agri-Food Canada, June 2001.

Homburg, C.; Stock R. (2001): Theoretische Perspektiven zur Kundenzufriedenheit, in: Homburg, C. (Eds.): Kundenzufriedenheit, 4th ed., Wiesbaden, 17-50.

IMP Group (1982): International marketing and purchasing of industrial goods: An interaction approach, Chichester et al.

Jaervelin, A.-M. (2001): Evaluation of relationship quality in business relationships. Dissertation, Tampere.

Jahn, G. et al. (2005): The Reliability of Certification: Quality Labels as a Consumer Policy Tool, in: Journal of Consumer Policy, 28 (1), 53-74.

Jahn, G. et al. (2004): The trade-off between generality and effectiveness in certification systems: A conceptual framework, in: Bremmers, H. J. et al. (Eds.): Dynamics in Chains and Networks. Conference Proceedings of the sixth International Conference on Chain and Network Management in Agribusiness and the Food Industry, Wageningen, 351-358.

Jahn, G.; Spiller, A: (2005): Acceptance of a processor-driven quality management system by dairy farmers: A structural equation model. Conference proceeding presented at 92nd EAAE Seminar on "Quality Management and Quality Assurance in Food Chains", 2-4 March Goettingen, Germany.

Lagace, R. R. et al. (1991): The relevance of ethical salesperson behaviour on relationship quality in the pharmaceutical industry, in: Sales Management, 4, 39-47.

Lages, C. et al. (2005): The RELQUAL scale: a measure of relationship quality in export market ventures, in: Journal of Business Research, 58 (8), 1040-1048.

Leuthesser, L. (1997): Supplier relational behaviour: an empirical assessment, in: Industrial Marketing Management, 26 (3), 245-524. 
Matanda, M. J.; Schroder, B. (2004): Business-to-Business Relationships by Categories of Suppliers in the Marketing Channel, in: Dynamics in Chains and Networks, Proceeding of the sixth International Conference on Chain and Network Management in Agribusiness and Food Industry, Wageningen, 532-537.

MIV (2004): Die groeßten deutschen Molkereien 2004, URL: http://www.milchmarkt.de/de/teaser/die_groessten_deutschen_molkereien__2004/, retrieval date: 29.09 .04 .

Moorman, C. et al. (1993): Factors affecting trust in market research Relationships, in: Journal of Marketing, 57 (1), 81-101.

Morgan, R. M.; Hunt, S. D. (1994): The Commitment-Trust Theory of Relationship Marketing, in: Journal of Marketing, 58 (3), 20-38.

Naudé, P.; Buttle, F. (2000): Assessing Relationship Quality, in: Industrial Marketing Management, 29 (4), 351-361.

Parasuraman, A. et al. (1988): SERVQUAL: A multiple-item scale for measuring consumer perceptions of service quality, in: Journal of Retailing, 64 (1), 12-40.

Rodríguez, C. M.; Wilson, D. T. (2002): Relationship Bonding and Trust as a Foundation for Commitment in U.S.-Mexican Strategic Alliances: A Structural Equation Modeling Approach, in: Journal of International Marketing, 10 (4), 53-76.

Smith, J. B. (1998): Buyer-seller relationships: similarity, relationship management, and quality, in: Psychology and Marketing, 15 (1), 3-21.

Stoelzle, W.; Heusler, F. (2003): Supplier Relationship Management, in: Bogaschewsky, R.; Goetze, U. (Eds.): Management und Controlling von Einkauf und Logistik, Gernsbach, 167-194.

Theuvsen, L. (2005): Quality Assurance in the Agrofood Sector: An OrganizationalSociological Perspective, in: Schriften der Gesellschaft fuer Wirtschafts- und Sozialwissenschaften des Landbaus e. V., 40, 173-181.

Van Weele, A. J. (2002): Purchasing and Supply Chain Management: Analysis, Planning and Practice, 3rd ed., Padstow, Cornwall.

Wilson, D. T. (1995): An Integrated Model of Buyer-Seller Relationships, in: Journal of the Academy of Marketing Science, 23 (4), 335-345.

Woo, K.; Ennew, C. T. (2004): Business-to-business relationship quality: An IMP interactionbased conceptualization and measurement, in: European Journal of Marketing, 38 (9/10), 1252-1271.

Young, L. C., Wilkinson, I. F., (1989): The Role of Trust and Co-operation in Marketing Channels: A Preliminary Study, in: European Journal of Marketing, 23 (2), 109-122. 
KAPITEL II.5

Der Markt für Milch und Milcherzeugnisse 2005 


\section{Der Markt für Milch und Milcherzeugnisse 2005*}

(mit Achim Spiller und Christian Wocken)

1 TRENDS AUF DEM MILCHMARKT.

2 ENTWICKLUNGSLINIEN IN DER WERTSCHÖPFUNGSKETTE FÜR MILCHPRODUKTE IN DEUTSCHLAND.

.258

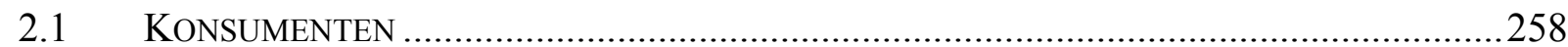

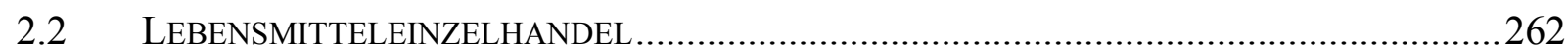

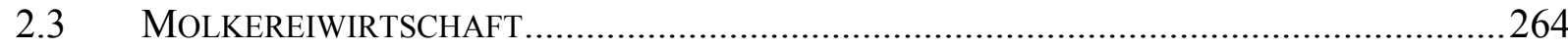

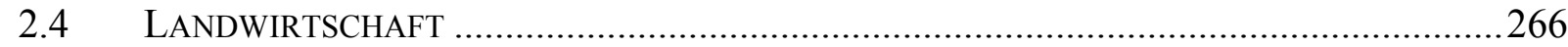

3 GLOBALE UND EUROPÄISCHE PERSPEKTIVEN DER MILCHWIRTSCHAFT..............................269

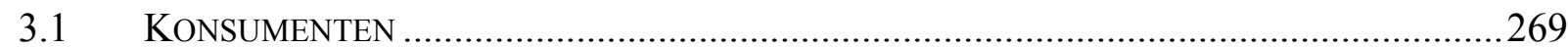

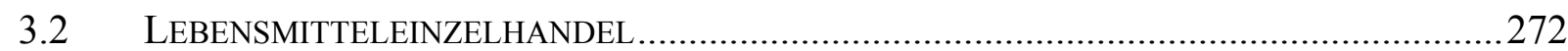

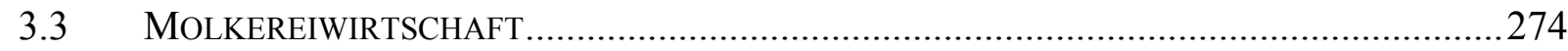

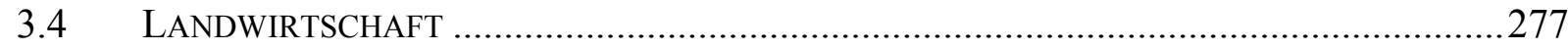

4 AKTUELLE HERAUSFORDERUNGEN AUF DEM MILCHMARKT …..........................................280

4.1 GESCHÄFTSBEZIEHUNG ZWISCHEN LANDWIRTSCHAFT UND MOLKEREIEN AUF DEM

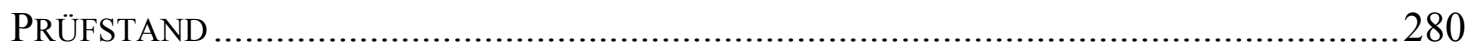

4.2 EINFÜHRUNG DES QUALITÄTSSICHERUNGSSYSTEMS QM .....................................286

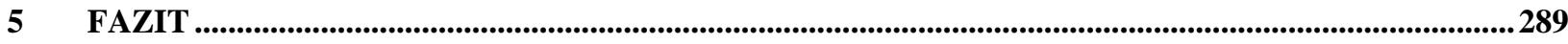

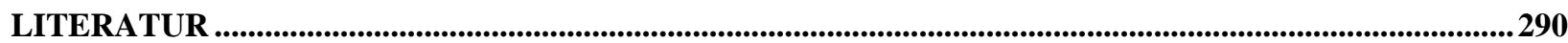

* in: Agrarwirtschaft, 54. Jg. (2005), Heft 1, S. 35-48. 


\section{Abbildungsverzeichnis}

Abbildung 1: Der deutsche Markt für Molkereiprodukte (Wertanteile in \% im Jahr 2003) .......259

Abbildung 2: Entwicklung der Absatzanteile verschiedener Einkaufsstätten in \% ..................262

Abbildung 3: Strategische Gruppen der Molkereiwirtschaft..................................................265

Abbildung 4: Verteilung der Milchkühe und Milcherzeuger nach Größenklassen im Jahr 2001267

Abbildung 5: Milcherzeugerpreis bei standardisierten Inhaltsstoffen im Vergleich zum Interventionspreis in Cent .....

Abbildung 6: Koordination der Geschäftsbeziehungen zwischen Molkereien und Landwirtschaft..... 282

Abbildung 7: Mittelwerte und Standardabweichungen für ausgewählte Statements 284

Abbildung 8: Vergleich der Molkereien.................................................................................28

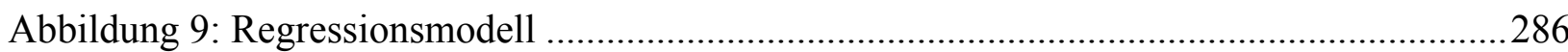

\section{Tabellenverzeichnis}

Tabelle 1: Private Nachfrage nach Milchprodukten in Deutschland: Veränderungsraten 2002 zu 2003 in \%

Tabelle 2: Verbraucherpreise für ausgewählte Milchprodukte in Deutschland

(Durchschnittspreis in $€ / \mathrm{kg}$ bzw. 1) 263

Tabelle 3: Die zehn größten Molkereiunternehmen in Deutschland 2003 (nach Umsatz) .........264

Tabelle 4: Veränderungen der Anzahl der Milchviehbetriebe von 1991-2003 (in Tausend)....267

Tabelle 5: Konsumkennzahlen für ausgewählte Ländermärkte 2002/2003 .............................2270

Tabelle 6: Überblick über die 10 global führenden Lebensmittelhändler 2003 ........................273

Tabelle 7: Marktanteil der Top 3 Lebensmitteleinzelhandelsunternehmen 2002 .....................273

Tabelle 8: Betriebsformen bei den Top 30 des internationalen Lebensmitteleinzelhandels 2003274

Tabelle 9: Die Top 20 Molkereien nach Umsätzen in $€ 2003$ weltweit ....................................275

Tabelle 10: Direktinvestitionen westlicher Milchverarbeiter in Mittel- und Osteuropa .............277

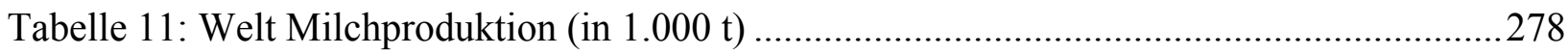

Tabelle 12: Durchschnittliche Erzeugerpreise für Milch (3,7 \% Fett) ...................................279

Tabelle 13: Kosten der weltweiten Milchproduktion 2003 in US-\$/100 kg ............................280

Tabelle 14: Typologisierung der Landwirte nach ihrer Einstellung zum QM System...............288 


\section{Trends auf dem Milchmarkt}

Der folgende Beitrag skizziert zentrale Entwicklungslinien auf dem deutschen und internationalen Milchmarkt. Da sich Lebensmittelmärkte in ihrer Dynamik häufig nur noch mit einem stufenübergreifenden Blick erklären lassen, folgt die Gliederung der Wertschöpfungskette - von Verbraucherpräferenzen bis zur landwirtschaftlichen Produktion.

Das Jahr 2004 war durch gegensätzliche Trends gekennzeichnet. So deuten einige Entwicklungen auf eine weitere Verschärfung des Wettbewerbs und eine Verschlechterung der Geschäftsbeziehungen zwischen der Landwirtschaft und den nachgelagerten Stufen hin. Die verstärkte Tätigkeit des Bundes deutscher Milchviehhalter (BDM) richtet sich zum Beispiel explizit gegen die Molkereien. Im Vordergrund steht der Versuch, im Sinne einer Gegenmachtbildung Milchmengen zu bündeln, um auf dem (Spot-) Markt bessere Erlöse für die kooperierenden Landwirte zu erzielen. Auch die öffentlichkeitswirksamen Aktionen von berufsständischen landwirtschaftlichen Organisationen gegen einzelne Unternehmen des Lebensmitteleinzelhandels (LEH) (,faire Milchpreise“) zeigen, dass sich erheblicher Unmut in der Branche aufgebaut hat. Im Gegensatz dazu stehen die gestiegenen Chancen für eine höhere Wertschöpfung durch die wachsende Bedeutung von Premiumsegmenten. Erstmals seit mehreren Jahren verringert sich das Wachstum der Discounter und Handelsmarken. Innovationen und profilierte Marken konnten Marktanteilsgewinne erzielen. Den Ursachen für diese unterschiedlichen Entwicklungen soll im folgenden Beitrag nachgegangen werden.

\section{Entwicklungslinien in der Wertschöpfungskette für Milchprodukte in Deutschland}

\subsection{Konsumenten}

In Deutschland gaben die Verbraucher im Jahr 2003 durchschnittlich $299 €$ pro Jahr für Milcherzeugnisse aus. Mit 39 \% entfällt der größte Einzelposten auf Käseprodukte (siehe Abb. 1). Im längerfristigen 10-Jahres-Trend ist der Pro-Kopf-Verbrauch von Butter (1993: 6,8 kg; 2003: 6,6 kg) annähernd konstant geblieben (ZMP 1994; ZMP 2004a). Der Trinkmilchkonsum geht zurück und lag Anfang der 1990er Jahre bei rund $70 \mathrm{~kg}$ pro Kopf, seit dem Jahr 2000 dagegen immer unter $65 \mathrm{~kg}$. Im Jahr 2003 konnte überraschend ein Anstieg auf 66,8 kg erzielt werden (vgl. Tabelle 1). Ein langfristiges Wachstumssegment ist Käse (1993: $18,5 \mathrm{~kg} ; 2003: 21,7 \mathrm{~kg})$. 
ABBILDUNG 1: DER DEUTSCHE MARKT FÜR MOLKEREIPRODUKTE (WERTANTEILE IN \% IM JAHR 2003)

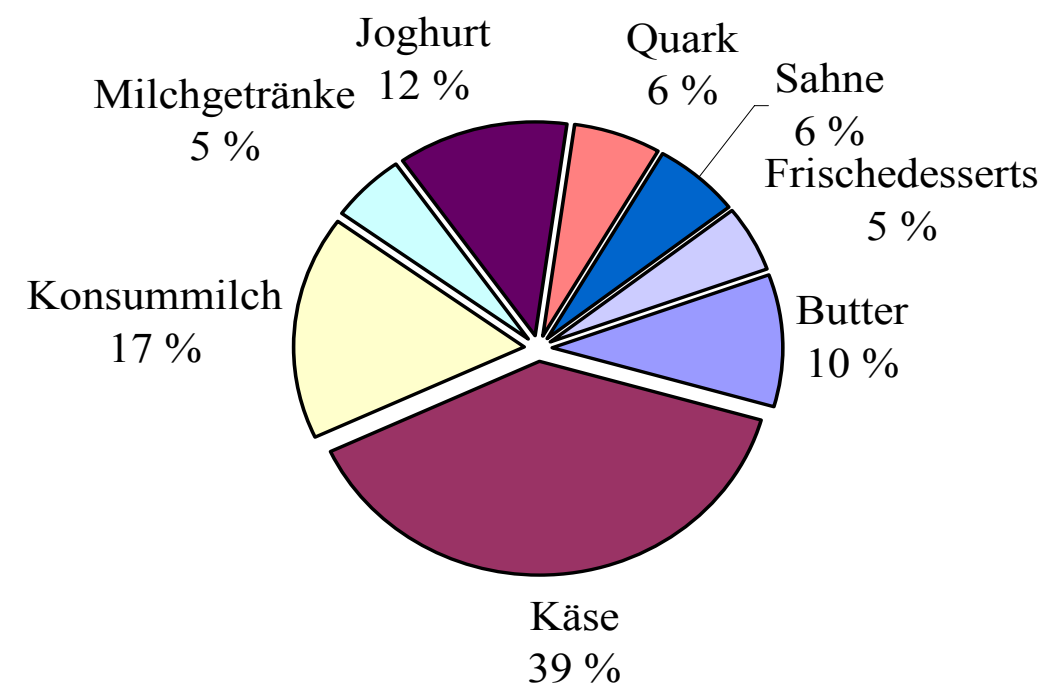

Quelle: ZMP 2004b: 23

Die Veränderungen von 2002 auf 2003 fallen bei den einzelnen Produkten sehr unterschiedlich aus (vgl. Tab.1). So stieg der Konsum von Milchgetränken im Jahr 2003 um 10 \%. Die private Nachfrage von Konsummilch auf Basis der Einzelhandelsverkäufe sank um $2 \%$, obwohl der Pro-Kopf-Verbrauch insgesamt im vergangenen Jahr um $3 \mathrm{~kg}$ auf 66,8 $\mathrm{kg}$ angestiegen ist. Ein Grund für diese Differenz ist der wachsende Außer-Haus-Verzehr, in dem z. B. die immer beliebteren Kaffeebars Absatzzuwächse erzielen (ZMP 2004a: 44). Bei der Betrachtung der Entwicklung in den ersten sieben Monaten im Jahr 2004 zeichnet sich ab, dass bei Käse eine deutliche mengenmäßige Nachfragesteigerung von $5 \%$ zu verzeichnen ist, während die Nachfrage von Konsummilch um 1 \% gesunken ist. Der Verbrauch von Joghurt bleibt hingegen stabil. Deutliche Zuwachsraten finden sich weiterhin bei Milchgetränken: Joghurtdrinks und Trinkmolke wachsen um über $20 \%$ (Brandl 2004). 
TABelle 1: Private Nachfrage NaCh MilchProdukten In Deutschland: VERÄNDERUNGSRATEN 2002 ZU 2003 IN \%

\begin{tabular}{|c|c|c|c|c|c|c|}
\hline & $\begin{array}{c}\text { Milchge- } \\
\text { tränke* }\end{array}$ & Joghurt* & Käse** & Butter & $\begin{array}{c}\text { Konsum- } \\
\text { milch }\end{array}$ & Quark \\
\hline Absatzvolumen & +10 & +4 & +2 & +1 & -2 & 0 \\
\hline Umsatz & +17 & +4 & -2 & 0 & -5 & -4 \\
\hline \multicolumn{2}{|l}{ * Einschl. Trinkjoghurt; ** Modellrechnung der GfK } \\
\hline
\end{tabular}
Quelle: ZMP 2004b: 24

Betrachtet man die Entwicklung verschiedener Marktsegmente, so zeigt sich bei Milch, dass die Verbraucher Produkte im mittleren Preis- und Qualitätsbereich weniger präferiert haben. Dagegen steigt inzwischen die Nachfrage nach Premiumprodukten wieder an. Dieser Trend ist z. B. bei den Premiummarken der Campina-Gruppe zu beobachten, die in den Jahren 2002 und 2003 Umsatzanteile eingebüßt haben, deren Umsatz aber im Jahr 2004 um rund 5 \% zunehmen konnte (LZ 2004a: 25). Aufschlussreich für die Chancen von Premiummarken ist auch, dass die Molkerei Weihenstephan in Bayern mit einem Absatzanteil von 16,4 \% (2003) Marktführer bei Frischmilch ist, obwohl der Durchschnittspreis mit 82 Cent/Liter erheblich über dem Marktpreis liegt (LZ 2004b: 88). Ein weiteres Wachstumssegment sind internationale Käsespezialitäten wie Mozzarella und Feta; der Feta-Absatz stieg 2003 beispielsweise um 19 \% (LZ-Net vom 17.09.2004).

Milchprodukte in Bio-Qualität, die ebenfalls dem Premiumsegment zugerechnet werden, da sie rund 40 \% höhere Durchschnittspreise erzielen, konnten im Jahr 2003 Umsatzzuwächse von $8 \%$ bei Milch sowie $10 \%$ bei Joghurt generieren (LZ 2004c: 24). Der Bio-Anteil bei Milch im Lebensmitteleinzelhandel liegt damit bei 3,3 \% des Umsatzes (Juni 2004, ohne Aldi), vier Jahre zuvor betrug der Wert erst 1,1 \% (Michels 2004). ZMP-Studien zeigen, dass dieses Wachstum während der vergangenen Jahre teilweise zu Lasten des konventionellen Premiumsegmentes gegangen ist, während aktuell beide Felder Umsatzzuwächse erzielen. Die Zielgruppen von Bio-Milch liegen schwerpunktmäßig bei Familien mit Kleinkindern und mit Kindern bis 14 Jahren, während konventionelle Hochpreismarken überproportional von Familien mit Kindern zwischen 6 und 14 Jahren und Singles mittleren Alters gekauft werden (Michels 2004).

Der Nachfragezuwachs bei Handelsmarken ist in jüngster Zeit etwas abgeflacht, so ging die Wachstumsrate der Handelsmarken in der Weißen Linie in der ersten Hälfte 2004 um 8 \% zurück (LZ 2004d: 50). Im Jahr 2003 lag der Umsatzanteil der Handelsmarken in der Weißen 
Linie bei $22 \%$, der Absatzanteil bei $32 \%$. In der Gelben Linie liegt der Handelsmarkenanteil im Jahr 2003 bei $48 \%$ (bezogen auf den Absatz) bzw. 38 \% (Umsatz) (LZ 2004e: 20). Der hohe Handelsmarkenanteil bei Molkereiprodukten verweist zum einen auf die Schwächen der Markenpolitik der Industrie (vgl. Kap. 2.3), zum anderen nehmen Discounter aus Sicht der Verbraucher immer mehr eine Nahversorgerfunktion ein und substituieren damit die Supermärkte, so dass gerade hier Güter des täglichen Bedarfs wie Molkereiprodukte nachgefragt werden.

Eine in den letzten Jahren verstärkt diskutierte Herausforderung des Verbraucherverhaltens ist die Präferenz vieler Kunden für Frischwaren mit langem Mindesthaltbarkeitsdatum (MHD). Der beliebte Griff in die hintere Reihe des Regals führt zu hohen Verderbquoten beim Handel und erzeugt Druck auf die gesamte Wertschöpfungskette zur Verlängerung des MHD. Eine erste Reaktion war die erfolgreiche Einführung von Extended Shelf Life-Milch (Milch mit verlängerter Haltbarkeit). In die gleiche Richtung zielt Rewe, die in den Jahresgesprächen 2004 eine Absenkung der Anlieferungstemperatur bei Molkereiprodukten um rund $2^{\circ} \mathrm{C}$ fordern, um damit eine Verlängerung des MHD von durchschnittlich 21 auf 25 Tage zu erreichen. Dies löste heftige Auseinandersetzungen mit dem Milchindustrieverband aus (Murmann 2004a: 20) und wird die Anforderungen an das Hygienemanagement bei allen Akteuren verstärken.

Zusammenfassend kann man für den deutschen Markt feststellen, dass der Konsum von Molkereiprodukten weiterhin steigt. Dies ist zum einen auf das positive Image dieser Produktgruppe zurückzuführen, zum anderen sorgen Innovationen bei Milchdrinks, Trinkjoghurts und Molkegetränken für teilweise zweistellige Zuwachsraten (Holland 2004: 62), so dass der Rückgang von traditionellen Molkereiprodukten wie Quark kompensiert werden kann. Auch in Zukunft sollte die wachsende Wellness- und Gesundheitsorientierung der Verbraucher positive Impulse für den Milchmarkt geben. Umsatzsteigerung bei probiotischen Flüssigprodukten, die im ersten Halbjahr 2004 wertmäßig bis zu 46 \% zulegen konnten, zeigen, dass weiterhin Marktpotenziale erschlossen werden können (Heimig 2004: 50). In diese Richtung könnten auch neue Diättrends (Atkins-Diät, low-carb) zielen, die in den USA bereits jetzt für Einbrüche auf dem Getreidemarkt sorgen und den Konsum tierischer Erzeugnisse beleben. 


\subsection{Lebensmitteleinzelhandel}

Deutschland ist mit 38,2 \% (2003) weltweit das Land mit dem höchsten Discountanteil an den Ausgaben im Lebensmitteleinzelhandel. In der Weißen Linie beträgt der Discountanteil sogar $42 \%$, bezogen auf die Absatzmenge rund $51 \%$ (Hemmelmann 2004; Dürr 2004). Zugleich zeigt Abbildung 2 die Marktanteilsverluste der kleinflächigen Betriebsformen. Im Jahr 2004 zeichnet sich erstmals wieder ein leichter Rückgang des Discountsegments ab, während die Großflächen ihren Anteil stabilisieren konnten. So sank der Absatzanteil bei Frischmilch in den ersten neun Monaten des Jahres 2004 um 1,1 \% auf 45,8 \%, bei Butter und Dickmilch um $4,2 \%$ auf $60,7 \%$ und bei Milchreis um $8 \%$ auf 44,3\%. Einen leichten Zuwachs um 0,8 \% konnten die Discounter bei H-Milch erzielen (QUECK 2004: 33).

\section{ABBILDUNG 2: ENTWICKLUNG DER ABSATZANTEILE VERSCHIEDENER EINKAUFSSTÄTTEN IN \%}

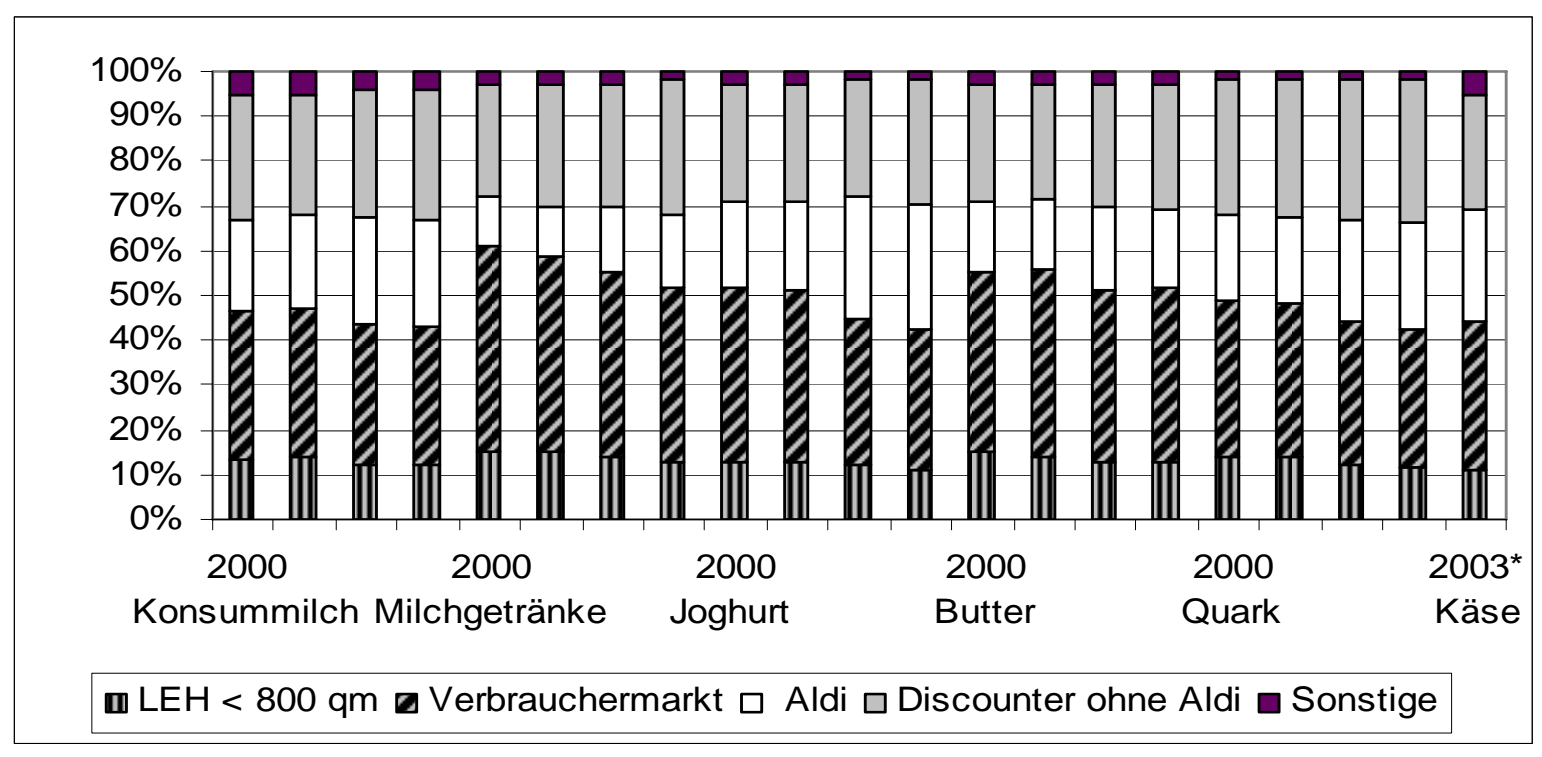

* 2003 Prognose

Quelle: ZMP 2004c;

Eng verknüpft mit dem Betriebsformenwandel sind die Probleme der Bedienungstheken für Käse. Im Handel gibt es drei Angebotsformen für Käseprodukte. Die traditionellen Bedienungskäsetheken (ca. 20.000) verlieren seit Jahren an Relevanz. In den ersten vier Monaten im Jahr 2004 sank der Umsatzanteil in der Warengruppe um 6,5 \% auf $20 \%$, was 392,3 Mio. Euro entspricht, obwohl das wachsende Segment der verpackten Thekenware (Prepacking) als neuere Kategorie hier mit erfasst wird. Ein Umsatzwachstum um 9,8\% auf nunmehr $80 \%$ erzielte die SB-Ware. Es zeichnet sich allerdings ab, dass einige serviceorientierte Handelsunternehmen versuchen, sich über das Bedienungsgeschäft vom Discount abzugrenzen. Ob dies außerhalb eines engen Premiumsegmentes angesichts der Kostennachteile gelingen wird, ist allerdings fraglich (LZ 2004d: 50), nicht zuletzt deshalb, 
weil die Handelsunternehmen in einer Befragung zwar die Kompetenz des Verkaufspersonals als das wichtigste Erfolgskriterium der Käsetheke benennen, zugleich jedoch $\mathrm{zu} 2 / 3$ ungelerntes Personal einstellen (Pfaff/Tröster 2004: 11).

Erfahrungsgemäß gelten die Preise von Aldi als Ankerpreise für die gesamte Branche und werden von den Wettbewerbern im Regelfall nachvollzogen. Im Jahr 2003 sind die Preise für Molkerei-Eckartikel weiter gesunken. Der Endverbraucherpreis für Konsummilch ging um durchschnittlich 2 Cent auf nunmehr 54 Cent/Liter zurück (vgl. Tab. 2). Auch bei Quark und Butter sind die Marktpreise gesunken. Zudem fordert der Handel von den Molkereien weiterhin mit hohem Erfindungsreichtum Konditionen und Nebenleistungen (aktuell z. B. Kühlgebühren für Milchprodukte, Murmann 2004a: 20).

TABELLE 2: VERBRAUCHERPREISE FÜR AUSGEWÄHLTE MiLCHPRODUKTE IN DEUTSCHLAND (DURCHSCHNITTSPREIS IN $€ /$ KG BZW. L)

\begin{tabular}{|l|c|c|c|c|}
\hline Produkt/Jahr & $\mathbf{2 0 0 0}$ & $\mathbf{2 0 0 1}$ & $\mathbf{2 0 0 2}$ & $\mathbf{2 0 0 3}^{*}$ \\
\hline Butter & 3,81 & 3,98 & 3,66 & 3,64 \\
\hline Käse & & & 5,58 & 5,79 \\
\hline Quark & 1,78 & 1,93 & 1,89 & 1,80 \\
\hline Konsummilch & 0,49 & 0,57 & 0,56 & 0,54 \\
\hline Joghurt & 1,70 & 1,76 & 1,72 & 1,72 \\
\hline Milchgetränke & 1,08 & 1,15 & 1,20 & 1,26 \\
\hline
\end{tabular}

Quelle: ZMP 2004c; * Prognose

Im Jahre 2004 zeichnet sich eine leichte Erhöhung der Endverbraucherpreise ab, getragen insbesondere von den Wachstumskategorien wie Trinkmilch und Molkedrinks. Welche Auswirkungen jedoch einzelne Handelskontrakte haben, zeigte sich 2004 am Beispiel der Jahresgespräche um H-Milch bei Aldi. Hier gelang es der Milchindustrie nicht, das Preisniveau des Vorjahres zu halten, da Campina Deutschland, die Unternehmensgruppe Theo Müller und die Milchunion Hocheifel eine vorher in der Branche informell anvisierte Preisuntergrenze (geplantes Frühstückskartell?) unterboten haben, um weitere Verkaufsanteile bei Aldi zu erlangen und die Produktionskapazitäten auszulasten. Das führte bei anderen Molkereien (Humana Milchunion, Hochwald usf.) zu größeren Mengenverlusten (DLGMitteilungen 2004: 42; MuRMANn 2004b: 20). Zuvor hatte es schon von Seiten der Landwirte starke Protestaktionen gegen ein Preisdumping des Lebensmitteleinzelhandels gegeben (LZ 2004f: 20; Landwirtschaftliches Wochenblatt 2004: 13). Der Fall demonstriert die alte ökonomische Erkenntnis, dass sich Wettbewerbsabsprachen in einem weiten Oligopol mit differierenden Strategien, inhomogenen Kostenstrukturen und hoher Außenseitergefahr kaum realisieren lassen. 
Neben dem großflächigen SB-Handel gibt es in Deutschland noch ein weitgehend unbeachtetes Segment von ca. 2.000 Käsefachgeschäften, ca. 1.000 Metzgereien mit Käseverkauf und mehrere Tausend Markthändler in diesem Bereich. Diese werden u. a. von 35 regionalen und einem nationalen Käsegroßhändler beliefert (Großkinsky 2003: 22). Auch der Außer-Haus-Verzehr spielt für den Markt für Milch und Milcherzeugnisse eine Rolle. Dies wird z. B. daran deutlich, dass Kaffeebars in den letzten Jahren zweistellige Zuwachsraten verbuchen konnten (ZMP 2003: 34) und damit den Rückgang des privaten Verbrauchs von Konsummilch teilweise aufgefangen haben.

\subsection{Molkereiwirtschaft}

Das wohl wichtigste Ereignis auf der Ebene der Milchindustrie war die gescheiterte Fusion zwischen Nordmilch und Humana im November 2004. Gleichwohl schreitet die Konzentration in der Branche voran. Wichtige Mergers und Acquisitions (M\&A) Aktivitäten des Jahres 2004 waren u. a. die Übernahme von Onken durch Oetker, der Ems-Land-Milch Dersum durch Humana sowie die Fusion von Starmilch und Hochwald zum Jahresende 2004. Die Konzentrationsrate $\left(\mathrm{CR}_{5}\right)$ liegt unter Einbezug dieser Transaktionen derzeit bei rund $41 \%$ (vgl. Tab. 3), während sie 1997 erst 25,1 \% betrug (eigene Berechnung, Lademann 2002).

TABELle 3: DIE ZEHN GRÖßTEN MOLKEREIUNTERNEHMEN IN DEUTSCHLAND 2003 (NACH UMSATZ)

\begin{tabular}{|c|c|c|c|}
\hline Unternehmen & Umsatz in Mio. $€$ & $\begin{array}{l}\text { Milchmenge in } \\
\text { Mio. kg }\end{array}$ & $\begin{array}{l}\text { Wertschöpf- } \\
\text { ungsindex }\end{array}$ \\
\hline 1 Humana Milchunion $^{1}$ & 2.444 & 2.175 & 1,12 \\
\hline $2 \quad$ Nordmilch eG $^{1}$ & 2.230 & 4.370 & 0,51 \\
\hline 3 Molkerei A. Müller ${ }^{1,2}$ & 1.662 & 1.717 & 0,97 \\
\hline $4 \quad$ Campina & 1.100 & 1.400 & 0,79 \\
\hline 5 Hochwald/Starmilch' & 1.046 & 1.800 & 0,58 \\
\hline 6 Bayernland & 740 & - & \\
\hline 7 Hochland & 720 & 438 & 1,64 \\
\hline $\begin{array}{ll}8 & \text { Zott }\end{array}$ & 565 & 537 & 1,05 \\
\hline $9 \quad$ Naabtaler Milchwerke $^{1}$ & 515 & 320 & 1,61 \\
\hline 10 Ehrmann $^{1}$ & 500 & 360 & 1,39 \\
\hline
\end{tabular}

Quelle: Milch \& Markt 2004; Deutsche Milchwirtschaft 2003

Die strategischen Optionen der Molkereien werden wesentlich durch ihre räumliche Präsenz und die Stärke ihrer Marken geprägt. Nach diesen Kriterien lassen sich in der deutschen Molkereiwirtschaft fünf strategische Gruppen abgrenzen (vgl. Abbildung 3). 


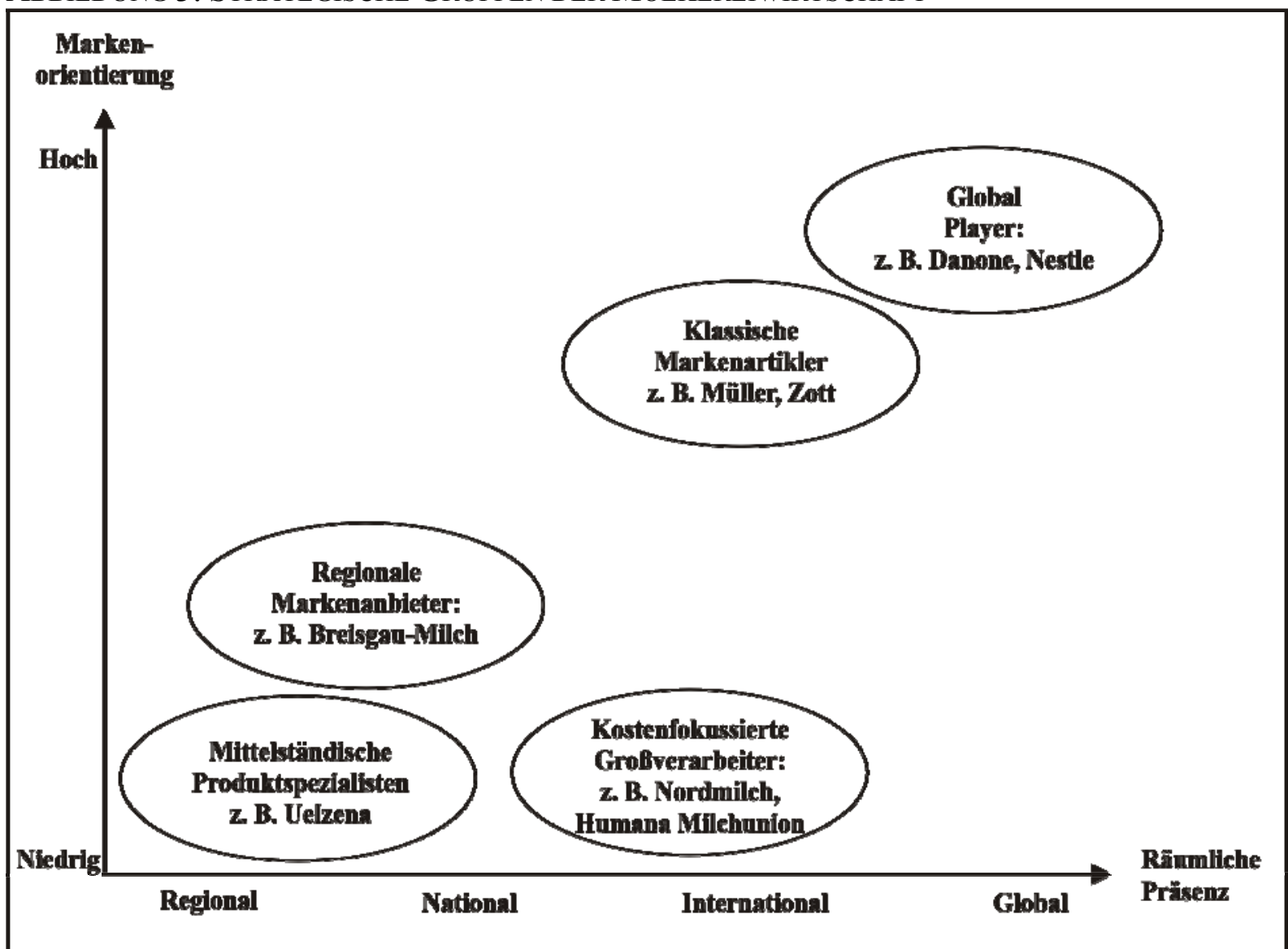

Quelle: Eigene Darstellung

Vor großen strategischen Herausforderungen stehen zzt. die kostenfokussierten Großverarbeiter, i. d. R. Genossenschaften, die eine große Milchmenge abnehmen müssen und daher keine reine Marken- oder Kostenführerschaftsstrategie realisieren können. Trotz ihrer Größe sind sie nur in wenigen Teilsegmenten Kostenführer. Zukünftig werden sie daher entweder Synergieeffekte noch konsequenter nutzen und sich auf die Rolle eines schlanken Handelsmarken- und Industrieproduktspezialisten konzentrieren müssen, was eine deutlich stärkere Internationalisierung voraussetzt. Oder sie führen die Ansätze einer Markenpolitik konsequent fort, was angesichts der notwendigen langfristigen Investitionen $\mathrm{zu}$ Problemen bei den Auszahlungspreisen führen wird (Schramm et al. 2004).

Die Position der Global Player wird durch die hohen Renditeerwartungen des Kapitalmarktes gefährdet, da Privatmolkereien als Markenartikler auf dem hart umkämpften Markt offensichtlich einen längeren Planungshorizont aufweisen. Der Kapitalmarkt erzwingt Portfolioverschiebungen, wenn die Wettbewerbsintensität und die Nachfragemacht der Discounter auf längere Sicht keine Rentabilitätssteigerungen erwarten lässt. Von besonderer Bedeutung ist dabei für globale Unternehmen die Internationalisierungsfähigkeit der Marken. 
Aus diesem Grund hat sich beispielsweise Nestlé im Jahr 2003 von den auf dem deutschen Markt gut etablierten Marken Lünebest und Bärenmarke getrennt, deren Namen nicht globalisierungsgeeignet sind.

Insgesamt zeichnet sich als Reaktion auf den Preisdruck des Handels und die Strukturentwicklungen die Notwendigkeit zur stärkeren Fokussierung der Unternehmensstrategien ab. Derzeit sind viele Molkereien in unterschiedlichen Marktsegmenten sowohl mit Kostenführerschafts- als auch mit Differenzierungsstrategien tätig. Die Auslastung der Anlagen und der Verwertungsdruck der vertraglich gebundenen Milchmenge zwingen zur Bearbeitung verschiedener Teilmärkte mit unterschiedlichem Anforderungsprofil. Allerdings sind die Kostenreduktionspotenziale nur in wenigen Unternehmen so klar ausgeschöpft wie bei der Milchunion Hocheifel. Andere Anbieter wie Campina oder Nordmilch könnten sich zukünftig stärker auf das internationale Industriekundengeschäft konzentrieren. Wettbewerbsvorteile liegen hier in der Flexibilität, der Kostensenkungsgeschwindigkeit und der Kundennähe. Das Markenartikelgeschäft verlangt eine klare Ausrichtung auf Innovationen und die Fähigkeit, Produktvorsprünge gegen die Begehrlichkeiten der Handelskunden und ihre Handelsmarkenpräferenzen $\mathrm{zu}$ verteidigen. Es ist eine spannende Frage, ob z. B. Hochwald in der neuen Rolle als (auch) Markenartikler eine Hybridstrategie mit Kosten- und Innovationsfokus zugleich erfolgreich ausfüllen kann. Hybride Wettbewerbsstrategien stellen bekanntlich den Königsweg des Managements dar.

\subsection{Landwirtschaft}

Bei der allgemeinen Agrarstrukturerhebung 2003 wurden in Deutschland 117.000 landwirtschaftliche Betriebe mit Milchkuhhaltung und einer Gesamtzahl von 4.337.500 Milchkühen festgestellt (ZMP 2004a: 23). Daraus lässt sich eine durchschnittliche Betriebsgröße von 37,1 Kühen pro Betrieb errechnen. Der Anstieg der Kuhbestände im letzten Jahr im Vergleich zum Vorjahr lag bei $6 \%$. Abbildung 4 zeigt die Verteilung der Milchkühe auf die verschiedenen Größenklassen für Niedersachsen (NDS) und Bayern, als die größten Produktionsregionen, für Deutschland insgesamt sowie die Verteilung der Erzeugerbetriebe für Deutschland. Die größten Herden sind bundesweit mit einer durchschnittlichen Anzahl von 172,2 Kühen/Betrieb in Mecklenburg-Vorpommern zu finden (ZMP 2004a: 23). 
ABBILDUNG 4: VERTEILUNG DER MILCHKÜHE UND MILCHERZEUGER NACH GRÖßENKLASSEN IM JAHR 2001

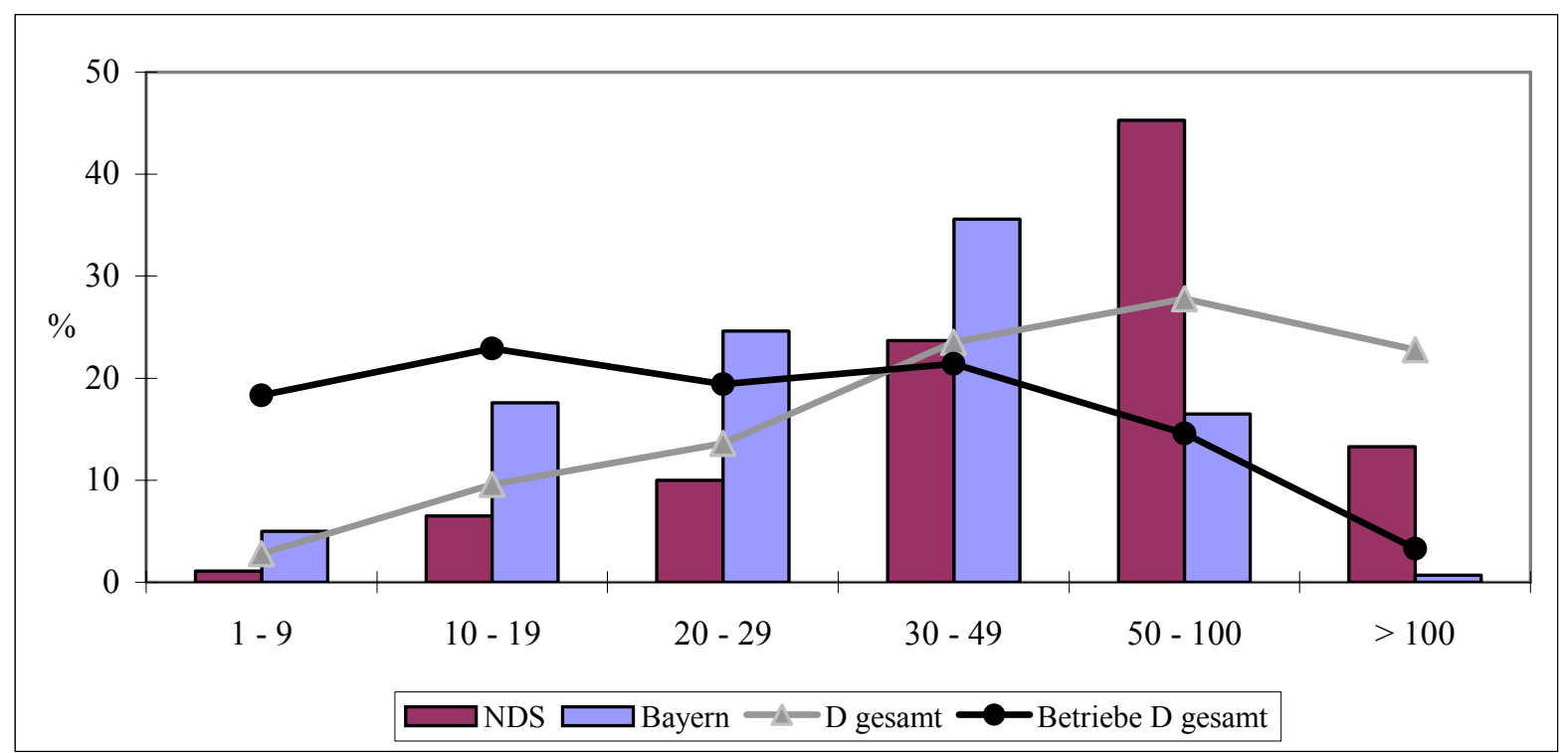

Quelle: Eigene Darstellung nach ZMP 2004a: 23

Die Geschwindigkeit des Abschmelzungsprozesses bei der Zahl der Milchviehbetriebe hat sich im Vergleich der letzten zehn Jahre nicht beschleunigt. Der Agrarstatistik weist für das Jahr $200311 \%$ Betriebsaufgaben gegenüber dem Jahr 2001 aus.

TABELlE 4: VERÄNDERUNGEN DER ANZAHL DER MiLCHVIEHBETRIEBE VON 1991-2003 (IN TAUSEND)

\begin{tabular}{|c|c|c|c|c|c|c|c|c|}
\hline & & $\mathbf{1 9 9 1}$ & $\mathbf{1 9 9 3}$ & $\mathbf{1 9 9 5}$ & $\mathbf{1 9 9 7}$ & $\mathbf{1 9 9 9}$ & $\mathbf{2 0 0 1}$ & $\mathbf{2 0 0 3}$ \\
\hline \multirow{3}{*}{$\begin{array}{c}\text { Betriebe mit } \\
\text { Milchkühen }\end{array}$} & $\mathrm{A}-\mathrm{BL}$ & 249,2 & 211,5 & 187,3 & 164,6 & 147,3 & 126,4 & 112,0 \\
\cline { 2 - 9 } & $\mathrm{N}-\mathrm{BL}$ & 6,5 & 9,2 & 8,5 & 7,6 & 6,2 & 5,4 & 5,0 \\
\cline { 2 - 9 } & $\Sigma$ & 255.7 & 220.7 & 195.8 & 172.2 & 153.5 & 131.8 & 117.0 \\
\hline \multirow{3}{*}{ Abschmelzungsrate } & $\mathrm{A}-\mathrm{BL}$ & & $-15 \%$ & $-11 \%$ & $-12 \%$ & $-11 \%$ & $-14 \%$ & $-11 \%$ \\
\cline { 2 - 9 } & $\mathrm{N}-\mathrm{BL}$ & & $41 \%$ & $-8 \%$ & $-11 \%$ & $-8 \%$ & $-15 \%$ & $-7 \%$ \\
\cline { 2 - 9 } & Ges. & & $-14 \%$ & $-11 \%$ & $-12 \%$ & $-11 \%$ & $-14 \%$ & $-11 \%$ \\
\hline
\end{tabular}

Quelle: ZMP, verschiedene Jahrgänge

Hintergrund der hohen durchschnittlichen jährlichen Abschmelzungsrate von gut $12 \%$ ist die zunehmend schwierigere Lage der Milcherzeuger. In Zukunft ist mit sinkenden Milcherzeugerpreisen $\mathrm{zu}$ rechnen (vgl. Abbildung 5), während die Kosten für Betriebsmittel (insbesondere Energie) steigen, so dass insgesamt mit einem geringeren Betriebsergebnis gerechnet werden muss (Hasert/Wesenberg 2004: 20). Ein Vergleich der Betriebszweigabrechnungen von größeren Milchviehbetrieben in Schleswig-Holstein, MecklenburgVorpommern, Nordrhein-Westfalen und Bayern zeigt, dass im Wirtschaftsjahr 2002/03 die Vollkosten nur in NRW gedeckt waren (Jochimsen 2004: 28 f.). Der Vergleich der Milchauszahlungspreise über die verschiedenen Molkereien weist im Jahr 2004 auf eine Annäherung 
hin. Der vormalige Abstand des Auszahlungspreises im Norden verringert sich. Auch die zunehmende Konzentration in der Molkereiwirtschaft erhöht den ökonomischen Druck auf die Milcherzeuger und führt dazu, dass Landwirte in einigen Regionen keine Alternativen zu ihrem Abnehmer haben. Kleinere Molkereien nehmen z. T. keine Vertragslandwirte mehr auf, da die fehlenden Mengen am Spotmarkt zugekauft werden.

Der Strukturwandel wird zudem aufgrund der Veränderungen im Rahmen der Reform des EU-Milchmarktes, die am 1. Juli 2004 in Kraft getreten sind, beschleunigt. Beschlossen wurde eine Senkung des Butterinterventionspreises um $25 \%$ sowie des Interventionspreises für Magermilchpulver um $15 \%$ in vier bzw. drei Schritten. Gleichzeitig wird eine mengenmäßige Begrenzung der Intervention durchgeführt. So können im Jahr 200470.000 t Butter zum Ankaufspreis von 90 \% des Interventionspreises eingelagert werden, bis zum Jahr 2008 sinkt diese Menge auf 30.000 t. Die Entkopplung erweitert die strategischen Optionen der Landwirte und wird die Aufgabebereitschaft bei Produzenten mit sehr ungünstigen Kostenstrukturen bzw. guten Alternativen weiter verstärken. Eine Entlastung für Wachstumsbetriebe werden die zukünftig sinkenden Quotenpreise bieten. Die derzeitigen Quotenpreise (01.11.2004 durchschnittlicher Gleichgewichtspreis: 0,46€ $/ \mathrm{kg}$ ) werden beim nächsten Milchbörsentermin am 01.04.2005 deutlich sinken (DBV 2004), da erstmals Quoten ohne Prämienansprüche gehandelt werden und zudem das Angebot an der Börse steigen wird. Der EU-Milchmarkt zeigt sich gleichwohl bisher relativ stabil. Auch der befürchtete Mengenund Preisdruck durch die neuen Mitgliedsstaaten bleibt bislang aus. Aus Sicht der ZMP ist die Stabilität des Marktes vor allem dem Rückgang der Milchanlieferung seit Dezember 2003 zu verdanken, der auch nicht durch saisonale Anstiege überlagert wurde. Andererseits erwies sich der Weltmarkt als recht aufnahmefähig und hat damit den EU-Markt entlastet (ZMP 2004a: 86). Dieser günstige Rahmen wird mittelfristig wohl nicht bestehen bleiben und darf die Erzeuger nicht in Sicherheit wiegen. 
ABBILDUNG 5: MILCHERZEUGERPREIS BEI STANDARDISIERTEN INHALTSSTOFFEN IM VERGLEICH ZUM INTERVENTIONSPREIS IN CENT

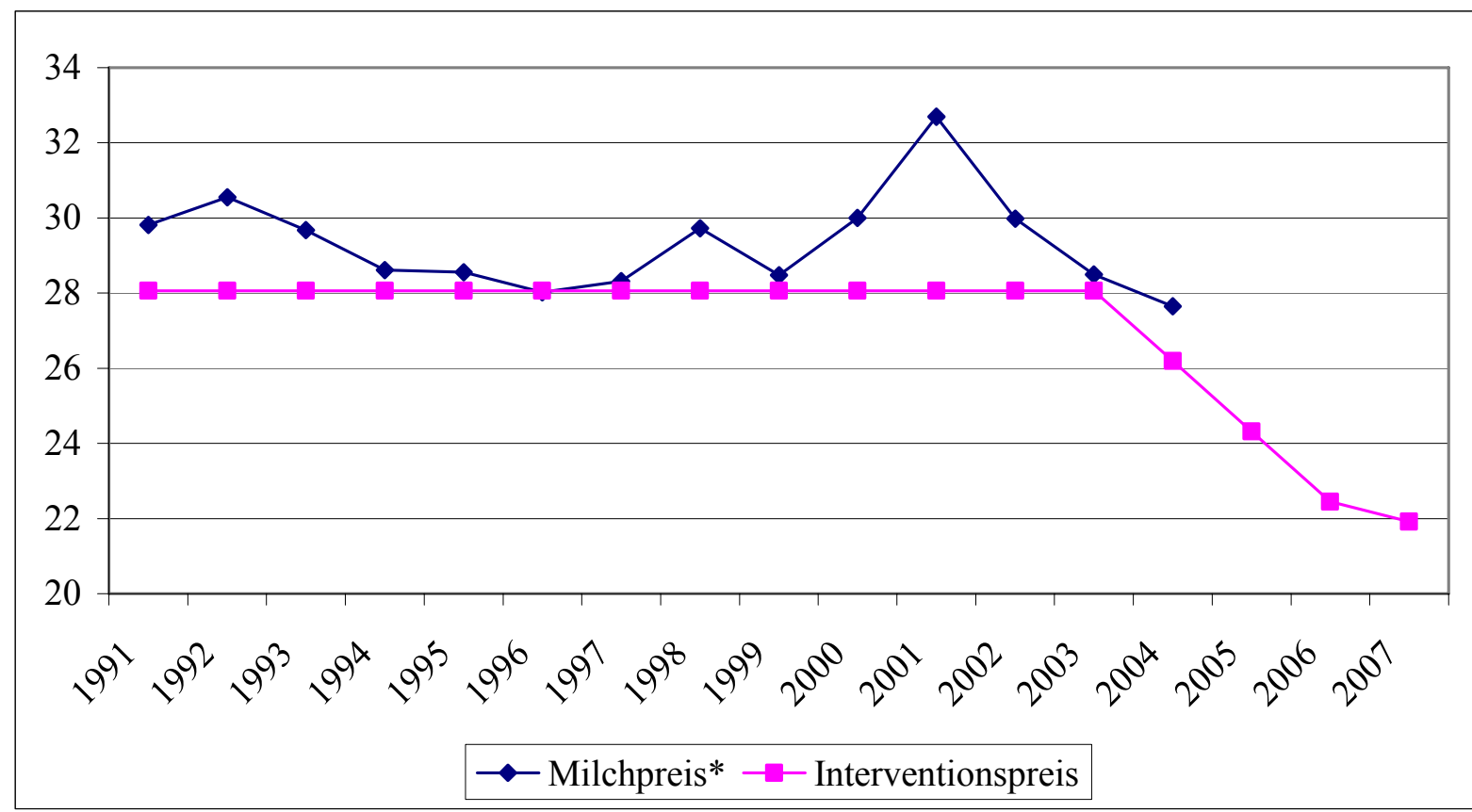

Quelle: Weindlmaier 2004 und *eigene Schätzung

Die Situation der Milcherzeuger wird sich demnach in Zukunft nochmals verschärfen. Vor dem Hintergrund der Reform der europäischen Agrarpolitik wird künftig eine Bestandsgröße von 80 bis 100 Milchkühen für einen typischen Vollerwerbsbetrieb als nötig erachtet (Weindlmaier 2004:4). Kleinere Betriebe, aber auch größere mit hoher Fremdkapitalbelastung, stehen unter erheblichem Druck.

\section{Globale und europäische Perspektiven der Milchwirtschaft}

\subsection{Konsumenten}

In globaler Hinsicht ist der Milchmarkt auf absehbare Zeit ein Wachstumsmarkt mit guten Perspektiven. Zwar stagnieren in entwickelten Märkten die traditionellen Produkte wie Konsummilch, Butter und Kondensmilch, Produkte mit Zusatznutzen sowie Käse wachsen jedoch (IDF 2004: 13). Der in Tabelle 5 aufgezeigte dramatische Unterschied im Konsumniveau verweist auf das Marktpotenzial in vielen Schwellen- und Entwicklungsländern, aber auch darauf, dass in entwickelten Märkten mit hohem Milchkonsumniveau bereits kleine Wachstumsraten zu hohen Mengenzuwächsen führen können. 
TABELLE 5: KONSUMKENNZAHLEN FÜR AUSGEWÄHLTE LÄNDERMÄRKTE 2002/2003

\begin{tabular}{|c|c|c|c|c|c|c|c|c|}
\hline Land & $\begin{array}{l}\text { BV in } \\
\text { Mio. }\end{array}$ & $\begin{array}{l}\text { KA in } \\
\text { Mrd. } €\end{array}$ & $\begin{array}{l}\text { LEH } \\
\text { insg. in } \\
\text { Mrd. } €\end{array}$ & $\begin{array}{l}\text { LEH pro } \\
\text { Kopf in } €\end{array}$ & $\begin{array}{l}\text { Milchkon } \\
\text { sum pro } \\
\text { Kopf } \\
\text { (kg)* }\end{array}$ & $\begin{array}{c}\text { Milch- } \\
\text { LM- } \\
\text { Relation }\end{array}$ & $\begin{array}{l}\text { Käsekons } \\
\text { um pro } \\
\text { Kopf } \\
\text { (kg)* }\end{array}$ & $\begin{array}{c}\text { Käse- } \\
\text { LM- } \\
\text { Relation }\end{array}$ \\
\hline USA & 284,0 & $7.360,46$ & 641,94 & $2.261,12$ & 85,8 & 3,8 & 15,4 & 0,7 \\
\hline Japan & 127,1 & $2.518,00$ & 454,13 & $3.572,59$ & $35,9 * *$ & 1,0 & $1,8^{* *}$ & 0,05 \\
\hline Deutschland & 82,2 & $1.163,13$ & 148,55 & $1.806,99$ & 95,6 & 5,3 & 21,7 & 1,2 \\
\hline Großbritannien & 59,9 & 977,34 & 113,32 & $1.891,87$ & 109,6 & 5,8 & 11,1 & 0,6 \\
\hline Frankreich & 59,2 & 756,11 & 117,04 & $1.977,82$ & 100,5 & 5,1 & 25,3 & 1,3 \\
\hline Italien & 57,7 & 694,46 & 109,29 & $1.893,99$ & $70,6 * *$ & 3,7 & $21,9 * *$ & 1,2 \\
\hline China & $1.271,0$ & 590,27 & 247,23 & 194,17 & 5,1 & 2,6 & - & \\
\hline Mexiko & 99,4 & 442,46 & 66,85 & 672,71 & $39,1 * *$ & 5,8 & $1,7^{* * *}$ & 0,3 \\
\hline Kanada & 31,0 & 403,84 & 46,05 & $1.484,42$ & 94,5 & 6,4 & 14,1 & 1,0 \\
\hline Spanien & 39,5 & 363,94 & 54,75 & $1.385,74$ & 127,6 & 9,2 & 9,5 & 0,7 \\
\hline Brasilien & 172,6 & 323,09 & 37,14 & 215,40 & 72,0 & 33,0 & - & - \\
\hline Indien & $1.033,4$ & 310,68 & 155,96 & 150,67 & 84,0 & 55,8 & 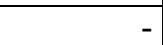 & \\
\hline Australien & 19,4 & 232,27 & 32,26 & $1.663,74$ & 100,3 & 6,0 & 12,0 & 0,7 \\
\hline Niederlande & 16,0 & 197,99 & 33,11 & $2.064,82$ & 125,7 & 6,1 & 14,6 & 0,7 \\
\hline Argentinien & 37,5 & 197,68 & 36,08 & 962,39 & 62,1 & 6,5 & 8,3 & 0,9 \\
\hline Polen & 38,7 & 117,25 & 29,60 & 766,09 & 59,8 & 7,8 & 12,5 & 1,6 \\
\hline \multicolumn{9}{|c|}{$\begin{array}{l}*=2003 ; * *=2002 ; \\
\text { BV=Bevölkerung/KA=Konsumausgaben/LEH=Lebensmitteleinzelhandel/LEH pro } \\
\text { Kopf=Lebensmitteleinzelhandelsumsatz pro Kopf/Milch-LM-Ausgabenrelation=Milchkonsum in kg:LEH- } \\
\text { Umsatz x } 100 \text { (bei Käse vergleichbar) }\end{array}$} \\
\hline
\end{tabular}

Quelle: IDF 2004; KPMG 2004; eigene Berechnungen

Die Milch-Lebensmittel-Relation ist eine Kennzahl für die Stellung der Warengruppe Milch im Verhältnis zu den Ausgaben der Einwohner eines Landes im Lebensmitteleinzelhandel insgesamt. Sie charakterisiert damit die Position der Category im Intralebensmittel-Wettbewerb und zeigt z. B. an, dass der japanische Milchkonsum, obgleich pro Kopf wesentlich höher als in China, relativ zu den Gesamtausgaben für Nahrungsmittel ausgesprochen niedrig liegt. Der brasilianische und der indische Milchmarkt werden auch bei hohem Wirtschaftswachstum kaum noch wachsen, während in China, sowohl durch das ökonomische Wachstum insgesamt als auch durch die Verdrängung anderer Lebensmittel Potenziale für Milch entstehen können. Letzteres trifft z. B. auch für die USA zu. Bei Käse überrascht das im Vergleich zu den Lebensmittelausgaben sehr hohe Konsumniveau der Polen, was die Wachstumspotenziale begrenzt erscheinen lässt.

Die Unterschiede bei den Kennzahlen zeigen, dass neben der ökonomischen Basis der Milchkonsum kulturell und geographisch bedingte Differenzen aufweist: Er ist z. B. in tropischen Regionen geringer. Die skandinavischen Länder weisen einen ausgesprochen hohen Milch- und Joghurtkonsum auf, während der Butter- und Käseverbrauch durchschnittlich ausgeprägt ist. Griechen konsumieren extrem viel Käse, aber relativ wenig Milch und Butter usf. Analysiert man den Pro-Kopf-Verbrauch von Molkereiwaren insgesamt nach 
der Milchäquivalentmethode (ME, Standardisierung der Milchprodukte nach deren Inhaltstoffen Fett und Eiweiß), können generell drei Ländergruppen unterschieden werden (Hemme et al. 2004a: 56): mehr als $150 \mathrm{~kg}$ ME pro Kopf und Jahr werden in Nordamerika, Europa, den meisten GUS-Ländern, Argentinien, Uruguay, Ecuador, Ozeanien sowie verschiedenen Entwicklungsländern wie Pakistan, Sudan, Botswana und Somalia konsumiert. Zwischen 30 und $150 \mathrm{~kg}$ ME pro Kopf und Jahr verbrauchen die Bewohner in Indien, Japan, Südkorea, Nordafrika sowie der meisten Länder im mittleren Osten und Lateinamerika. Weniger als $30 \mathrm{~kg}$ ME beträgt der Konsum in Südostasien, China, Afghanistan, Irak, Jemen, Äthiopien sowie den meisten Ländern in Zentralafrika.

Die Entwicklung des Konsums ist in den einzelnen Regionen der Welt in den letzten zehn Jahren sehr unterschiedlich verlaufen. In Westeuropa und Nordamerika wuchs der Verbrauch jährlich um rund 1-2 \%. Zentral- und Osteuropa haben nach dem Zusammenbruch des Sozialismus, von einem hohen Niveau ausgehend, einen Rückgang um 20-35 \% erlebt, da die Milchpreise nicht mehr subventioniert werden. In Lateinamerika beträgt die jährliche Wachstumsrate zwischen 0,5 und 2,5\%, in Afrika differiert die Veränderungsrate sehr stark, zwischen -5 bis $+5 \%$. Ähnliches trifft für den Nahen und Mittleren Osten zu, wo der Konsum in den letzten zehn Jahren um $12 \%$ zurückging. Während Saudi-Arabien und Iran einen Aufwärtstrend zeigen, nimmt der Konsum im Irak, in Jordanien und Afghanistan weiter ab. In Südasien stieg der Pro-Kopf-Verbrauch um insgesamt $32 \%$ in den letzten zehn Jahren. Ostund Südostasien weisen, von einem sehr niedrigen Niveau ausgehend, hohe Wachstumsraten auf. In Ozeanien wuchs der australische Markt im Zehnjahres-Rückblick mit $5 \%$, während der neuseeländische Konsum stagniert (Hemme et al. 2004a: 56).

In Entwicklungs- und Schwellenländern ist der Konsum generell stärker abhängig von der allgemeinen ökonomischen Situation, was besonders am argentinischen Beispiel deutlich wird. Hier ist der Konsum von Trinkmilch zwischen 2001 und 2002 um 12,3\% zurückgegangen und stagniert zurzeit, der Käsekonsum ist noch stärker von 11,5 kg pro Kopf (2001) auf 8,3 kg (2003) gesunken (IDF 2004: 72). Bei Wirtschaftswachstum steigt i. A. die Nachfrage nach Milchprodukten in solchen Ländern deutlich an.

Besonders interessant ist ein Blick auf den chinesischen Markt, der aufgrund seiner Größe, des rasanten Wirtschaftswachstums und des bisher geringen Milchkonsums spätestens seit dem WTO-Beitritt Chinas ein zentrales Expansionsziel der international tätigen Milch- 
wirtschaft ist. Der Pro-Kopf-Konsum von Milchprodukten liegt zzt. erst bei 5,1 kg. Allerdings ist nur ein kleinerer Teil der 1,3 Mrd. Einwohner der VR China in der Lage, in nennenswertem Umfang westliche Produkte zu kaufen, zu groß sind die Entwicklungs- und Einkommensunterschiede in den verschiedenen Regionen (Taube 2003). Westliche Anbieter könnten sich daher zunächst auf die in Chinas 660 Städten (darunter 174 Städte mit mehr als einer Mio. Einwohnern) lebende urbane Bevölkerung konzentrieren. Diese umfasst mit ca. 524 Mio. Personen inzwischen mehr Einwohner als die USA und die EU-15 zusammen (National Bureau of Statistics 2004). Allerdings steigt selbst in den großen Zentren des Landes das jährliche Pro-Kopf-Einkommen in den meisten Fällen nicht über 3.500 Euro. Lediglich 15 Mio. Menschen verfügen derzeit über ein höheres Jahreseinkommen. Hinzu kommt, dass zzt. erst rund $20 \%$ der chinesischen Bevölkerung durch moderne (westlich orientierte) Vertriebstypen erreichbar sind (LZ 2004g: 12).

Eine aktuelle Befragung der Universität Iowa in Peking, Guangzhou und Shanghai ergibt, dass in diesen Städten im Durchschnitt 90,4 \% der Haushalte Milch konsumieren (58,7 \% Joghurt, 28,0 \% Milchpulver, 53,8 \% Eis, 6,7 \% Käse und 4,5 \% Butter; FULLER ET AL. 2004). Der jährliche Milchkonsum pro Kopf liegt bei diesen städtischen Haushalten bereits über $55 \mathrm{~kg}$. Haupteinkaufsorte für Milch und Joghurt sind Supermärkte (58 \% der Haushalte), Grocery Stores (15\%) und mit $22 \%$ ist die Heimbelieferung überraschend wichtig. Schul(7\%) und Straßenverkauf (5\%) spielen dagegen eine geringere Rolle.

\subsection{Lebensmitteleinzelhandel}

Die Internationalisierung des Lebensmitteleinzelhandels hat in den letzten Jahren beachtlich an Dynamik gewonnen, auch wenn sie immer noch hinter den führenden Markenartiklern zurücksteht. Der Marktanteil der 15 führenden Unternehmen $\left(\mathrm{CR}_{15}\right)$ am weltweiten Lebensmitteleinzelhandelsumsatz liegt bei ca. $25 \%$ (KPMG 2004). Ein globales Marketing im Sinne eines standardisierten weltweiten Auftritts (Sortiment, Beschaffung, Betriebstypen) gibt es jedoch auch bei den führenden Handelskonzernen wie Wal-Mart, Metro und Carrefour erst ansatzweise (vgl. Tab. 6). Erheblich weiter fortgeschritten ist die Konzentration in den einzelnen europäischen Ländermärkten (vgl. Tab. 7), aber auch in einigen Schwellenländern wie Argentinien schreitet der Modernisierungsprozess im Handel erstaunlich schnell voran. 
TABELLE 6: ÜBERBLICK ÜBER DIE 10 GLOBAL FÜHRENDEN LEBENSMITTELHÄNDLER 2003

\begin{tabular}{|l|l|c|c|c|c|}
\hline Unternehmen & $\begin{array}{c}\text { Wichtige } \\
\text { Vertriebstypen }\end{array}$ & $\begin{array}{c}\text { Nettoumsatz } \\
\mathbf{2 0 0 3} \text { (Mio. }\end{array}$ & $\begin{array}{c}\text { Anteil } \\
\text { Lebens- } \\
\text { mittel* }\end{array}$ & $\begin{array}{c}\text { Auslands- } \\
\text { umsatz }\end{array}$ & $\begin{array}{c}\text { Anzahl } \\
\text { Länder- } \\
\text { märkte }\end{array}$ \\
\hline Wal-Mart & HM/C\&C & 226.928 & $40,0 \%$ & $18,5 \%$ & 11 \\
\hline Carrefour & HM/SM/DI & 70.500 & $70,5 \%$ & $50,0 \%$ & 24 \\
\hline Ahold & SM/HM & 62.705 & $92,0 \%$ & $83,5 \%$ & 25 \\
\hline Kroger** & HM & 54.920 & $91,0 \%$ & $0 \%$ & 1 \\
\hline Metro & C\&C/HM & 53.595 & $49,7 \%$ & $47,2 \%$ & 28 \\
\hline Tesco*** & HM/SM & 48.540 & $90,0 \%$ & $19,9 \%$ & 13 \\
\hline Target & Wareh.stores/HM & 48.163 & - & $0 \%$ & 1 \\
\hline Rewe & SM/HM/DI & 39.180 & $70,3 \%$ & $25,5 \%$ & 13 \\
\hline Costco & C\&C & 395.051 & $41,0 \%$ & $19,5 \%$ & 8 \\
\hline Aldi & DI & 35.386 & $84,0 \%$ & $38,6 \%$ & 12 \\
\hline
\end{tabular}

$\mathrm{HM}=$ Hypermarkt, SM=Supermarkt, DI=Discountgeschäft, C\&C=Cash\& Carry Großhandel, $*=$ Werte für 2001, **= Werte für 2002, ***=Geschäftsjahr weicht vom Wirtschaftsjahr ab und Bruttoumsatz

Quelle: KPMG 2004: 21; Metro 2004; M+M Planet Retail 2002: 51 ff.

Der aus Tabelle 6 ersichtliche relativ niedrige Auslandsumsatz der größten Lebensmitteleinzelhändler deutet zum einen auf die präferierte Wachstumsstrategie der Marktführer hin: ausgehend von der starken Durchdringung eines großen Heimatmarktes werden sukzessiv kleinere Ländermärkte erschlossen. Zum anderen lässt sich erkennen, dass sich die Handelsunternehmen fast alle noch in der zweiten Phase der Globalisierung befinden: Polyzentrische Markterschließung mit geringem Standardisierungsgrad. Regiozentrische Marketingkonzepte finden sich erst ansatzweise, z. B. bei den deutschen Discountern.

TABELLE 7: MARKTANTEIL DER TOP 3 LEBENSMITTELEINZELHANDELSUNTERNEHMEN 2002

\begin{tabular}{|c|c|c|c|c|c|c|c|c|c|}
\hline Land & ARG & AUS & FRA & NLD & GBR & GER & BRA & ESP & USA \\
\hline $\mathrm{CR}_{3}$ & $65 \%$ & $58 \%$ & $53 \%$ & $47 \%$ & $47 \%$ & $41 \%$ & $34 \%$ & $28 \%$ & $27 \%$ \\
\hline Land & MEX & KOR & JPN & ITA & POL & TUR & CHN & RUS & IND \\
\hline $\mathrm{CR}_{3}$ & $23 \%$ & $21 \%$ & $15 \%$ & $14 \%$ & $13 \%$ & $7 \%$ & $6 \%$ & $1 \%$ & $<1 \%$ \\
\hline
\end{tabular}

Quelle: KPMG 2004: 26

Die beiden dynamischsten Betriebsformen weltweit sind Großflächen (SBWarenhäuser/Hypermärkte) und Discounter. Zwischen 1998 und 2003 hat die Anzahl dieser Geschäftstypen im Portfolio der Top 30-Konzerne des internationalen Lebensmitteleinzelhandels um $99 \%$ resp. $49 \%$ zugenommen (KPMG 2004: 27). Tabelle 8 verdeutlicht, dass Discounter bisher vornehmlich ein westeuropäisches Phänomen darstellen. Im Wesentlichen handelt es sich um Tochterunternehmen der deutschen Discounter. Großflächen haben sich in den letzten zwei Jahrzehnten auch in den Schwellen- und Entwicklungsländern rasant verbreitet (mit Ausnahme von Afrika). Ein weiteres Wachstumssegment stellen - mit asiatischem Schwerpunkt - Convenience-Stores dar. 
TABELLE 8: BETRIEBSFORMEN BEI DEN TOP 30 DES INTERNATIONALEN LEBENSMITTELEINZELHANDELS 2003

\begin{tabular}{|l|c|c|c|}
\hline Anzahl der Geschäfte in & Großflächen & Discounter & $\begin{array}{c}\text { Convenience- } \\
\text { Stores }\end{array}$ \\
\hline Westeuropa & 2.497 & 23.278 & 8.788 \\
\hline Zentral-/Osteuropa & 338 & 826 & 0 \\
\hline Nordamerika & 4.693 & 721 & 7.195 \\
\hline Lateinamerika & 627 & 725 & 368 \\
\hline Asien/Pazifik & 1.097 & 408 & 17.808 \\
\hline Afrika & 22 & 0 & 0 \\
\hline
\end{tabular}

Quelle: KPMG 2004: 27

Die Entwicklung der Betriebsformen bietet für die Molkereiindustrie Chancen und Risiken zugleich. Deutsche Unternehmen können ggf. vom Wachstum der Discounter profitieren. Sie kennen die Usancen der Zusammenarbeit mit den beiden international marktführenden Unternehmen Aldi und Lidl und können daher versuchen, mit diesen Unternehmen in ihre Expansionsmärkte (z. B. nach Osteuropa) vorzudringen. Dies wird nur gelingen, wenn eine eindeutige Kostenführerschaft in den jeweiligen Segmenten erzielt werden kann. Die Handelsspanne der Discounter liegt im Durchschnitt 5 \% unter den Vollsortimentern.

Das Wachstum der Großflächen insbesondere in Schwellenländern, bietet Chancen für Markenprodukte und differenzierte Sortimente. Marktführer sind hier Carrefour und WalMart. Die hohe Handelskonzentration z. B. in den lateinamerikanischen Ländern ist im Wesentlichen auf das schnelle Wachstum großflächiger Betriebsformen zurückzuführen. Hier dürfte die deutsche Molkereiwirtschaft eher komparative Wettbewerbsnachteile haben, da Nachfrage und Handel in Deutschland wenig qualitätsorientiert sind.

\subsection{Molkereiwirtschaft}

Die Milchwirtschaft ist im Vergleich zu anderen Branchen der Ernährungswirtschaft im Kern relativ gering internationalisiert. Mit Nestlé, Danone, Unilever, Kraft und Fonterra gibt es nur wenige Global Player. Die meisten der in Tabelle 9 aufgeführten führenden Molkereien sind durch ihre Heimatmarktorientierung gekennzeichnet. Auch ein Unternehmen wie Arla Foods setzt noch die Hälfte seines Umsatzes in den beiden Heimatmärkten ab. Gleichwohl schreitet der Wachstumsprozess voran, zum einen um economies of scale zu nutzen, Marktanteile zu gewinnen und Marken zu etablieren, zum anderen um Zugang zu Rohstoffmärkten mit niedrigen Rohstoffpreisen zu erhalten. In einer Reihe nationaler Märkte wie Skandinavien und den Niederlanden ist der Konsolidierungsprozess weitgehend abgeschlossen, während z. B. in Deutschland noch erhebliche Verdichtungseffekte erzielt werden können. Wesentlichen 
Druck auf die Internationalisierung wird auch die oben skizzierte Expansionspolitik des Einzelhandels ausüben.

Etwas im Gegensatz zu diesem Trend steht Nestlés Teilrückzug aus dem hart umkämpften und wenig rentablen Europageschäft in der Milchwirtschaft. Auch die Insolvenz von Parmalat deutet auf den Wettbewerbsdruck und die Schwierigkeiten der Internationalisierung in einem Markt hin, in dem die Markenbildung gegen den wachsenden Anteil der Handelsmarken vorangetrieben werden muss und sich eine nationale Rohstoffbasis auch als Hemmschuh erweisen kann.

TABelle 9: Die ToP 20 MolKEREIEN NACH UMSÄTZEN IN € 2003 WELTWEIT

\begin{tabular}{|c|l|l|c|}
\hline & Unternehmen & Land & $\begin{array}{l}\text { Umsatz des Milchgeschäfts in } \\
\text { Mrd. } € \text { 2003 }\end{array}$ \\
\hline 1 & Nestlé & Schweiz & 15,3 \\
\hline 2 & Dean Foods & USA & 6,3 \\
\hline 3 & Danone & Frankreich & 6,2 \\
\hline 4 & Dairy Farmers of A. & USA & 6,1 \\
\hline 5 & Fonterra & Neuseeland & 6,1 \\
\hline 6 & Arla Foods & DK/SWE & 5,5 \\
\hline 7 & Lactalis & Frankreich & 5,4 \\
\hline 8 & Unilever & Niederlande/UK & 5,2 \\
\hline 9 & Kraft Foods & USA & 5,0 \\
\hline 10 & Parmalat & Italien & 4,5 \\
\hline 11 & Friesland Coberco & Niederlande & 4,4 \\
\hline 12 & Bongrain & Frankreich & 4,0 \\
\hline 13 & Meiji Dairies & Japan & 3,8 \\
\hline 14 & Campina & Niederlande & 3,7 \\
\hline 15 & Morinaga MilkIndustry & Japan & 3,5 \\
\hline 16 & Humana Milchunion & Deutschland & 2,7 \\
\hline 17 & Land O'Lakes & USA & 2,7 \\
\hline 18 & Sodiaal & Frankreich & 2,5 \\
\hline 19 & Nordmilch & Deutschland & 2,2 \\
\hline 20 & Saputo & Kanada & 2,2 \\
\hline
\end{tabular}

Quelle: RABOBANK 2004, zitiert nach IDF 2004: 7

Seit 1998 erhebt die Rabobank die Zahl der Fusionen, Übernahmen, Joint Ventures und Allianzen (M\&A). Pro Jahr sind weltweit ca. 150 Transaktionen zu beobachten. Ungefähr $3 / 4$ der M\&A-Aktivitäten sind Akquisitionen, der Anteil von Fusionen nimmt tendenziell ab, während Strategische Allianzen zunehmend wichtiger werden. Auffällig ist die deutlich unterproportionale Beteiligung genossenschaftlicher Anbieter. Rund 3/4 der M\&A-Aktivitäten gehen von Kapital- und Personengesellschaften aus, obwohl 60-65 \% der weltweiten Milchproduktion von Genossenschaften verarbeitet wird. Globale Transaktionen sind immer noch 
selten, $43 \%$ der M\&A-Aktivitäten in 2003 sind national orientiert, $40 \%$ beziehen sich auf Unternehmen auf dem gleichen Kontinent (IDF 2004: 26).

Bei der Auswahl der Zielmärkte stehen 2003 zwar immer noch Europa (59 \%) und Nordamerika (17\%) im Vordergrund, für amerikanische Unternehmen deutet sich aber ein Wechsel im Fokus an, von Investitionen in den regionalen Markt zu Überseeinvestitionen. Der Anstieg von M\&A-Aktivitäten in den Märkten mit starkem Konsumwachstum, insbesondere in Asien, ist beachtlich. $2 / 3$ der M\&A-Aktivitäten haben in Asien crosskontinentalen Charakter. Dort wird das M\&A-Geschäft zudem überdurchschnittlich von privaten Unternehmen geprägt. Lateinamerika ist ein weiterer Fokus für Investitionen von Unternehmen aus anderen Regionen; die meisten Investitionen tätigen allerdings regionale Anbieter. Afrika und der mittlere Osten spielen eine untergeordnete Rolle im globalen Konzentrationsprozess.

Die gewählte Markteintrittsstrategie hängt von der Entfernung des Marktes, der Rohstoffverfügbarkeit und dem Rohstoffpreis sowie dem Protektionsgrad der Märkte ab. Europäische Molkereien beliefern daher relativ nahe Märkte wie den Nahen Osten und Nordafrika aus heimischer Produktion, während Märkte mit hoher Protektion (Nordamerika), geringen Milchpreisen (Lateinamerika und Australien) oder in großer Entfernung (Asien) durch Direktinvestitionen erschlossen werden.

Vergleicht man die Marktbearbeitungsstrategien in der Milchwirtschaft, so zeigt sich, dass Global-Marketing-Konzepte bisher eine relativ geringe Rolle spielen. Der Erfolg von globalen Marken wie Philadelphia (Kraft), Danone-Joghurt oder der Eiscrememarken von Nestlé und Unilever zeigen die Potenziale auf. Die Marketingaktivitäten vieler nationaler Anbieter sind allerdings im Branchenvergleich relativ gering, die Werbeintensität liegt häufig unter $1 \%$ des Umsatzes und damit sehr niedrig (IDF 2004: 29).

Für die europäische Milchwirtschaft ist derzeit der osteuropäische Markt von herausragendem Interesse. So wurden in den vergangenen Jahren eine Reihe von Investitionen in den osteuropäischen Markt vorgenommen (siehe Tabelle 10). Die deutschen Molkereien haben dagegen in die erweiterte Union vergleichsweise wenig investiert, da sie durch ihr Engagement nach der Wende in Ostdeutschland über zu wenig Kapital verfügen (Murmann 2004: 52). 
TABElle 10: DiReKTINVESTITIONEN WESTLICHER MiLCHVERARBEITER IN MitTEL- UND OSTEUROPA

\begin{tabular}{|l|l|c|}
\hline \multicolumn{1}{|c|}{ Herkunftsland } & \multicolumn{1}{|c|}{ Zielländer } & $\begin{array}{c}\text { Anzahl der } \\
\text { Engagements }\end{array}$ \\
\hline Frankreich & $\begin{array}{l}\text { Polen, Slowakei, Tschechien, Ungarn, } \\
\text { Bulgarien, Rumänien, Russland, Ukraine }\end{array}$ & 33 \\
\hline Niederlande & $\begin{array}{l}\text { Polen, Tschechien, Slowakei, Ungarn, Estland, } \\
\text { Rumänien, Russland }\end{array}$ & 17 \\
\hline Italien & Slowakei, Ungarn, Rumänien, Russland & 13 \\
\hline Nordeuropa & Polen, Russland, Estland & 4 \\
\hline Deutsche Unternehmen & Zielländer & 13 \\
\hline Bayerische Milchindustrie & Tschechien & 1 \\
\hline e. G. & Tschechien, Russland & 2 \\
\hline Ehrmann AG & Slowakei, Bulgarien, Kroatien, Bosnien & 3 \\
\hline Meggle GmbH & Polen, Rumänien, Russland & 2 \\
\hline Hochland AG & Polen, Russland & 1 \\
\hline Onken GmbH & Polen & \\
\hline Zott GmbH \& Co. Kg & & \multicolumn{1}{|c|}{ Kmb } \\
\hline
\end{tabular}

Quelle: Murmann 2004c: 52

\subsection{Landwirtschaft}

Die Weltmilcherzeugung wird heute zu rund $50 \%$ in Europa und Südasien produziert, alle amerikanischen Länder produzieren zusammen $23 \%$ der Gesamtmenge. In den letzten 20 Jahren (1981-2001) kann ein weltweiter Anstieg der Milchproduktion um $25 \%$ festgestellt werden. Die einzelnen Regionen sind in den Entwicklungen sehr unterschiedlich. Während die höchsten Zuwächse in Ost- und Südostasien mit $300 \%$, Südasien mit $150 \%$ und Ozeanien mit $100 \%$ verzeichnet wurden, wuchs die Milchproduktion in Nordamerika und im Nahen und Mittleren Osten nur um 20-30 \%. In der EU-15 blieb die Produktion stabil, während sie in den ehemals sozialistischen Ländern signifikant zurückging (Hemme et al. 2004a: 51).

Im Jahr 2004 lag die weltweite Milchproduktion bei 612 Mio. $t$ und ist damit im Vergleich zum Vorjahr um 0,5 \% gestiegen (vgl. Tabelle 11). Damit ist das Wachstum im Vergleich zu den Vorjahren mit durchschnittlichen Wachstumsraten von 1,5\% zurückgegangen. Ausschlaggebend für diese Veränderung ist die schwächere Steigerung in West- und Ost-Europa sowie Nordamerika. Regionen mit starkem Angebotszuwachs sind im Wesentlichen Süd- und Ostasien sowie Lateinamerika, die auch durch eine stark wachsende Nachfrage geprägt sind (IDF 2004: 5). Die OECD erwartet einen Anstieg der Weltmilchproduktion bis 2013 um 11 Mio. t, mit hohen Steigerungsraten in Argentinien und insbesondere China. Das Wachstum in den Nicht-OECD-Ländern ist typischerweise am Heimatmarkt orientiert. Auf die OECD- 
Länder entfallen nach dieser Schätzung nur rund $25 \%$ des hinzukommenden Marktvolumens, schwerpunktmäßig in Neuseeland und Australien (IDF, 2004: 20). Ein ungebremst hohes Wachstum ist bei der Büffelmilch zu beobachten. Der Anteil an der Weltmilchproduktion liegt inzwischen bei $15 \%$, mit $90 \%$ Produktionsanteil sind Indien und Pakistan die Hauptproduzenten (IDF 2004: 6).

TABELLE 11: WeLT MiLCHPRODUKTION (IN 1.000 T)

\begin{tabular}{|c|c|c|c|}
\hline & Kuhmilch & Büffelmilch & Sonstige \\
\hline 1999 & 483.400 & 64.400 & 20.800 \\
\hline 2000 & 490.600 & 66.600 & 20.900 \\
\hline 2001 & 495.800 & 69.000 & 21.200 \\
\hline 2002 & 505.700 & 73.600 & 21.100 \\
\hline 2003 & 512.700 & 75.000 & 21.700 \\
\hline 2004 & 514.000 & 76.400 & 21.700 \\
\hline
\end{tabular}

Quelle: IDF 2004: 56

Die durchschnittlichen Erzeugerpreise für Milch (vgl. Tab. 12) spiegeln die bekannten Kostendifferenzen wider. Aus Sicht der deutschen Landwirte ist der niedrige Auszahlungspreis in Polen und Litauen perspektivisch bedrohlich, da beide Länder über ihren Eigenbedarf hinaus produzieren können. Derzeit stehen Qualitäts- und Strukturprobleme jedoch einem größeren Mengendruck entgegen. 
TABELLE 12: DURCHSCHNitTLICHE ERZEUGERPREISE FÜR MiLCH (3,7 \% FETT)

\begin{tabular}{|c|c|c|}
\hline & US \$ per 100 kg & $€$ per $100 \mathrm{~kg}$ \\
\hline Belgien / Luxemburg & 31,12 & 27,51 \\
\hline Dänemark & 36,23 & 32,03 \\
\hline Deutschland & 32,23 & 28,49 \\
\hline Spanien & 34,11 & 30,15 \\
\hline Frankreich & 32,47 & 28,70 \\
\hline Irland & 30,32 & 26,80 \\
\hline Italien & 38,12 & 33,70 \\
\hline Niederlande & 33,92 & 29,99 \\
\hline Österreich & 31,90 & 28,20 \\
\hline Finnland & 36,76 & 32,50 \\
\hline Schweden & 35,45 & 31,34 \\
\hline $\mathrm{UK}$ & 27,83 & 24,60 \\
\hline EU-15 Durchschnitt & 32,35 & 28,60 \\
\hline Tschechien & 26,87 & 23,75 \\
\hline Estland & 20,84 & 18,42 \\
\hline Litauen & 13,40 & 11,85 \\
\hline Ungarn (free dairy plant. 3,68 \% fat.) & 31,06 & 27,46 \\
\hline Polen & 17,85 & 15,78 \\
\hline Slowakei (3,6 \% fat) & 23,70 & 20,95 \\
\hline Norwegen & 48,90 & 43,23 \\
\hline Schweiz $(3,8 \%$ Fett $)$ & 53,72 & 47,49 \\
\hline Kroatien & 42,99 & 38,00 \\
\hline Russland & 15,00 & 13,26 \\
\hline Ukraine & 12,90 & 11,40 \\
\hline USA & 27,67 & 24,46 \\
\hline Kanada 3,6 \% Fett & 42,71 & 37,76 \\
\hline Australien & 18,33 & 16,20 \\
\hline Neuseeland & 17,45 & 15,43 \\
\hline Argentinien (3,5\% Fett): Greater Buenos Aires & 18,12 & 16,02 \\
\hline Argentinien $(3,5 \%$ Fett $)$ : Rural areas & 14,59 & 12,90 \\
\hline Chile & 13,60 & 12,02 \\
\hline Südafrika & 26,41 & 23,35 \\
\hline China $(3,4 \%$ Fett $)$ : Metropolitan Areas & 25,11 & 22,20 \\
\hline China: Rural Areas & 16,97 & 15,00 \\
\hline Indien & 19,43 & 17,18 \\
\hline Japan & 71,86 & 63,53 \\
\hline
\end{tabular}

Quelle: IDF 2004: 18

Insgesamt sind die Betriebsgrößen und die Kostenstrukturen in den verschiedenen Teilen der Welt sehr unterschiedlich. Innerhalb der EU sind in Dänemark, Großbritannien und den Niederlanden die größten Betriebe zu finden, die kleinteiligsten Strukturen hat Österreich. Ein ausgeprägter Strukturwandel vollzieht sich zzt. in Spanien, Portugal und Griechenland mit einer Verdreifachung der Lieferkontingente pro Betrieb in den letzten acht Jahren (Wohlfahrt 2004: 7). Tabelle 13 gibt auf Basis einer Auswertung des „International Farm Comparison Network“ (IFCN) der FAL einen Überblick über die Kostenstruktur verschiedener Länder. 
TABELLE 13: KOSTEN DER WELTWEITEN MILCHPRODUKTION 2003 IN US-\$/100 KG

\begin{tabular}{|c|l|}
\hline Kostengruppe & \multicolumn{1}{|c|}{ Land } \\
\hline$<18$ US-\$ & $\begin{array}{l}\text { Polen, Argentinien, Pakistan, Vietnam, Neuseeland, West-Australien; größere } \\
\text { Betriebe in Brasilien und Indien }\end{array}$ \\
\hline 18-28 US-\$ & $\begin{array}{l}\text { Estland, Tschechien, Bangladesch, China, Thailand sowie kleinere Betriebe } \\
\text { in Brasilien und Indien }\end{array}$ \\
\hline 28-35 US-\$ & $\begin{array}{l}\text { Spanien, Dänemark, Irland, UK, Ungarn, die Mehrzahl Betriebe in den USA, } \\
\text { die größeren in Deutschland sowie die Niederlande und Israel }\end{array}$ \\
\hline 35-45 US-\$ & $\begin{array}{l}\text { Österreich, Frankreich, Schweden und die kleineren Betriebe der Niederlande } \\
\text { und Israel }\end{array}$ \\
\hline$>45$ US-\$ & Schweiz, Norwegen, Finnland, Kanada und kleinere deutsche Betriebe \\
\hline
\end{tabular}

Quelle: in Ahnlehnung an Hemme et al. 2004b: 26

\section{Aktuelle Herausforderungen auf dem Milchmarkt}

Abschließend sollen zwei aktuelle Themen, die zzt. die Branche bewegen, vertieft und mit bisher unveröffentlichten Daten dargestellt werden: die sich verstärkenden Interessenkonflikte zwischen Landwirten und Molkereien sowie die Einführung des Qualitätssicherungssystems QM-Milch.

\subsection{Geschäftsbeziehung zwischen Landwirtschaft und Molkereien auf dem Prüfstand}

Ein zentrales Thema für die Akteure auf dem Milchmarkt ist die Entwicklung der Geschäftsbeziehung zwischen der Primärproduktion und den Molkereien. Die Unzufriedenheit der Milcherzeuger mit der allgemeinen Lage, insbesondere aber mit den Molkereien, äußert sich derzeit in der Gründung von Interessenverbänden wie bspw. dem Bundesverband deutscher Milchviehhalter Nord (BDM). Dessen Bestrebung ist der Zusammenschluss möglichst großer Milchmengen, um eine Gegenmacht zu den Molkereien zu schaffen. Die Bereitschaft der Landwirte, die Molkerei zu wechseln, wird so wesentlich verstärkt. Bindungen an den Abnehmer werden lockerer und der Milchauszahlungspreis tritt immer mehr in den Vordergrund.

Diese Tendenzen finden sich nicht nur in Deutschland. So versucht in den Niederlanden der Fachverband der niederländischen Milchviehhalter (NMV) eine von den Molkereien unabhängige Vermarktungsorganisation aufzubauen. Ziel ist die Gründung eines Dutch Dairy Boards zur Festlegung von Mindesterzeugerpreisen und ggf. zur Durchführung von Lieferstopps, um Molkereien und Einzelhandel zu Preiserhöhungen zu zwingen. Um nicht letztlich durch ausländische Konkurrenten unterboten $\mathrm{zu}$ werden, plant der niederländische Fachverband mittelfristig ein europäisches Erzeugernetzwerk. Auch in Großbritannien gibt es 
erste Bestrebungen zur Gründung einer zentralen Vermarktungsagentur auf landwirtschaftlicher Seite (LZ 2004h: 25.)

Klassischerweise ist der Milchmarkt durch relativ langjährige und stabile Geschäftsbeziehungen sowie die hohe Relevanz genossenschaftlicher Verarbeitungsunternehmen charakterisiert (vgl. Abb. 6). Historisch ist dies durch die Anforderungen des Produktes zu erklären. Milch verlangt traditionell eine möglichst produktionsnahe Verarbeitung, gleichzeitig amortisiert sich die Investition in eine Molkerei nur, wenn der Auslastungsgrad hoch ist. Letztlich bedeutet dies, dass innerhalb eines begrenzten räumlichen Gebiets der Aufbau von mehr als einer Molkerei ökonomisch nicht sinnvoll war. Um der daraus drohenden Gefahr einer Abhängigkeit von der Molkerei zu begegnen, schlossen sich die Landwirte in Produktionsgenossenschaften zusammen. Der Fortschritt der Transport-, Kühlungs- und Verarbeitungstechniken hat diese historische Begründung der Genossenschaften weitgehend aufgelöst. Heute kann Milch von größeren Landwirten relativ problemlos in einem Umkreis von rund $200 \mathrm{~km}$ vermarktet werden. Damit verfügen größere Landwirte trotz der Konzentration auf Industrieseite in vielen Regionen über reale Vermarktungsalternativen. Diese Entwicklung gewinnt ihre Brisanz vor dem Hintergrund der abnehmenden Marktregulierung. Mit sinkenden Garantiepreisen wächst der Wettbewerbsdruck in der Landwirtschaft erheblich. Die derzeitigen Bemühungen des BDM sind aus ökonomischer Sicht der Versuch, durch countervailing power den Wertschöpfungsanteil der Landwirtschaft $\mathrm{zu}$ erhöhen. Dazu wird eine veränderte Koordination der Geschäftsbeziehungen angestrebt. 
ABBILDUNG 6: KOORDINATION DER GESCHÄFTSBEZIEHUNGEN ZWISCHEN MOLKEREIEN UND LANDWIRTSCHAFT

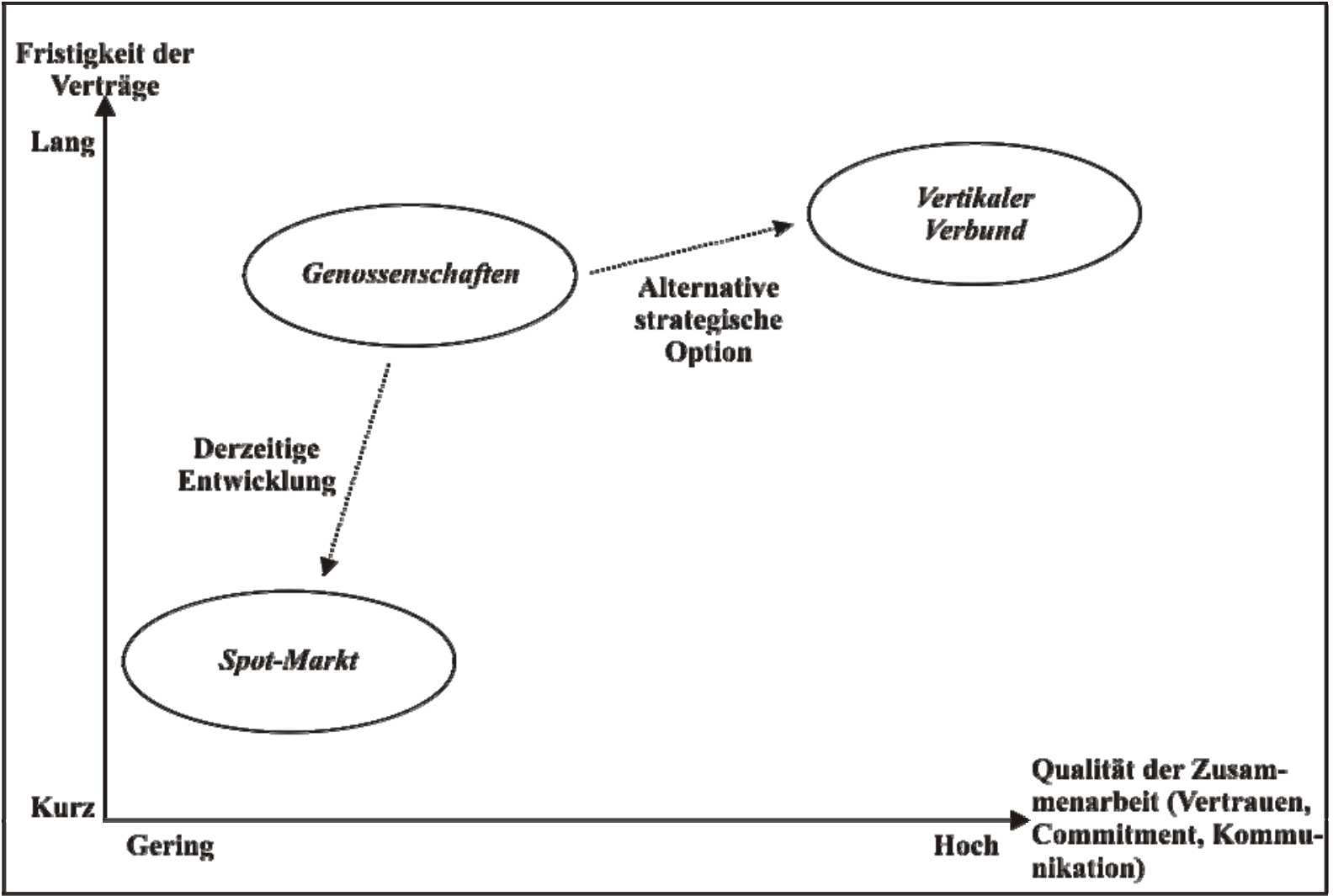

Quelle: eigene Darstellung

Die Bündelung von Milchmengen durch landwirtschaftliche Kooperationen (sei es durch den BDM oder durch größere Erzeugergemeinschaften) führt zu einem steigenden SpotmarktAnteil. Sollte sich diese Tendenz fortsetzen, würde sich der Milchmarkt in eine Richtung entwickeln, wie sie heute für weite Teile des Fleischmarktes charakteristisch ist. Trotz großer genossenschaftlicher Unternehmen dominieren hier kurzfristige Marktbeziehungen. Landwirte bzw. Erzeugerzusammenschlüsse versuchen Auszahlungspreise zu maximieren. Spotmärkte bieten für gut informierte und leistungsstarke Akteure durchaus Chancen. Sie führen allerdings zu einer stärkeren Preisdifferenzierung bei den Auszahlungspreisen und treiben damit den Strukturwandel in der Landwirtschaft - aber auch in der Industrie - voran. Probleme liegen zudem in der geringen vertikalen Koordination, wie z. B. an den zahlreichen Qualitätsproblemen im Fleischmarkt abgelesen werden kann.

$\mathrm{Da}$ die derzeitige Marktstruktur zwischen Landwirtschaft und Molkereiunternehmen offensichtlich instabil ist, bleibt neben der Entwicklung hin zum Spotmarkt der Ausbau der Geschäftsbeziehung zu einem leistungsfähigeren vertikalen Verbund. Stabile Geschäftsbeziehungen bieten nicht nur Planungssicherheit, sondern erlauben eine vertrauensvollere, besser abgestimmte Zusammenarbeit. In Branchen wie der Automobilindustrie werden diese 
Potenziale in jüngerer Zeit unter den Stichworten Supply Chain Management bzw. Supplier Relationship Management erschlossen (Stölzle/Heusler 2003). Ziel ist ein Prozess der Lieferantenentwicklung und Geschäftsbeziehungsoptimierung, der zu Vertrauen, Zufriedenheit und einem größeren Commitment beider Geschäftspartner führt. Dies kann z. B. für Unternehmen im Qualitätssegment erhebliche Vorteile bieten.

Bislang liegen allerdings keine empirischen Daten zur Entwicklung der Geschäftsbeziehung in der Milchwirtschaft und zum Vergleich der unterschiedlichen Molkereien vor. Im Frühjahr 2004 haben wir deshalb 209 milchviehhaltende Landwirte aus Nordwestdeutschland zu ihrer Einschätzung der Geschäftsbeziehungsqualität befragt. Dabei standen zukunftsorientierte Betriebe im Mittelpunkt. Die durchschnittliche Anzahl Milchkühe pro Betrieb ist mit 73,2 in der Stichprobe wesentlich größer als im deutschen Durchschnitt, gleiches gilt für die Fläche mit 97 ha und der Milchquote von $600.000 \mathrm{~kg} / \mathrm{Jahr}$ (Milchleistung bei $9006 \mathrm{~kg} / \mathrm{Laktation}$ ).

Die Gesamteinschätzung der Geschäftsbeziehung zu den Molkereien ist von einer eher skeptischen Haltung gekennzeichnet. Abbildung 7 zeigt Mittelwerte und Standardabweichungen für ausgewählte Statements, die die Geschäftsbeziehungsqualität operationalisieren. Die Gesamtzufriedenheit liegt im mittleren Bereich. Deutliche Defizite zeigen sich bei Vertrauen und Commitment, die den Molkereien entgegengebracht werden. Besonders niedrig liegen die wahrgenommene Landwirtschaftsnähe der Molkereien und das Ausmaß der empfundenen Zielharmonie. Der Bezug zur landwirtschaftlichen Basis geht bei den zumeist genossenschaftlichen Industrieunternehmen nach Einschätzung der Lieferanten verloren. Aus dieser eher negativen Einschätzung der Geschäftsbeziehung folgt eine hohe Wechselbereitschaft. 68,8 \% der Betriebe geben an, bei höheren Auszahlungspreisen den Abnehmer wechseln zu wollen. Insgesamt sind Bindungen an die Molkereien damit gering ausgeprägt und eher instabil. Die hohen Standardabweichungen weisen allerdings auf abweichende Positionen bei den befragten Milcherzeugern hin. Die skizzierten Mittelwerte zeigen hier somit nur den generellen Trend auf. 
ABBILDUNG 7: MitTELWERTE UND STANDARDABWEICHUNGEN FÜR AUSGEWÄHLTE STATEMENTS

\begin{tabular}{|c|c|c|c|c|c|c|c|c|c|}
\hline \multirow{2}{*}{ Statement } & \multirow{2}{*}{$\mu$} & \multirow{2}{*}{$\sigma$} & \multicolumn{2}{|c|}{$\begin{array}{l}\text { Lehne voll } \\
\text { und ganz } a b\end{array}$} & \multicolumn{3}{|c|}{$\longleftrightarrow$} & \multicolumn{2}{|c|}{$\begin{array}{l}\text { Stimme voll } \\
\text { und ganz zu }\end{array}$} \\
\hline & & & -3 & -2 & -1 & 0 & 1 & 2 & 3 \\
\hline $\begin{array}{l}\text { Gesamtzufriedenheit: Mit der Zusammenarbeit } \\
\text { mit meiner Molkerei bin ich... }\end{array}$ & 1,40 & 1,369 & : & : & : & : & . & 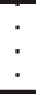 & : \\
\hline $\begin{array}{l}\text { Vertrauen: Versprechen, die uns die Molkerei } \\
\text { macht, sind verlässlich. }\end{array}$ & 0,52 & 1,641 & $:$ & : & : & & & : & : \\
\hline $\begin{array}{l}\text { Commitment: Ich fühle mich meiner Molkerei } \\
\text { verbunden. }\end{array}$ & 0,47 & 1,575 & : & $\dot{5}$ & : & & - & $:$ & : \\
\hline $\begin{array}{l}\text { Landwirtschaftsnähe: Meiner Molkerei sind die } \\
\text { bäuerlichen Wurzeln noch wichtig. }\end{array}$ & $-0,40$ & 1,757 & : & 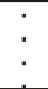 & : & & : & $:$ & : \\
\hline $\begin{array}{l}\text { Landwirtschaftlicher Einfluss: Die Stimme der } \\
\text { Landwirte zählt bei meiner Molkerei noch etwas. }\end{array}$ & 0,44 & 1,457 & $\dot{.}$ & : & $\cdot$ & & $\dot{0}$ & : & $\dot{5}$ \\
\hline $\begin{array}{l}\text { Gemeinsame Ziele: Die Molkerei und die } \\
\text { Milcherzeuger ziehen an einem Strang. }\end{array}$ & $-0,02$ & 1,547 & : & : & . & & . & $\therefore$ & : \\
\hline $\begin{array}{l}\text { Wechselbereitschaft: Wenn es sich für mich } \\
\text { finanziell lohnt, wechsle ich meine Molkerei. }\end{array}$ & 1,26 & 1,695 & : & : & . & : & & $\vdots$ & : \\
\hline $\begin{array}{l}\text { Weiterempfehlung: Würden Sie anderen Landwir- } \\
\text { raten, Lieferant Ihrer Molkerei zu werden?² }\end{array}$ & 0,50 & 1,676 & : & : & : & : & : & . & $:$ \\
\hline
\end{tabular}

' Skala von $-3=$ "Voll und ganz unzufrieden" bis $3=$ "Voll und ganz zufrieden".

${ }^{2}$ Skala von $-3=$ "Könnte ich mir absolut nicht vorstellen" bis 3 = "Könnte ich mir absolut vorstellen".

$\mathrm{n}=\mathbf{2 0 9}$

Quelle: Eigene Berechnungen

Ein Vergleich der verschiedenen Molkereien zeigt deutliche Unterschiede (vgl. Abb. 8). Aufgrund der Stichprobengröße liefern die folgenden Werte allerdings nur erste Ansatzpunkte und sind nicht repräsentativ. Die Lieferanten von Nordmilch und Campina sind insgesamt deutlich unzufriedener. Möglicherweise spiegeln sich hier die Erfahrungen der schwierigen Post-Merger-Phase. Eine besonders hohe Lieferantenbindung weisen kleinere Genossenschaftsmolkereien und die Humana Milchunion auf. Dies kann zum einen auf Managementfaktoren zurückzuführen sein, zum anderen lässt sich hier die Aussage der Genossenschaftsforschung belegen, dass sich Sozialkapital leichter in kleineren Gruppen bildet. Interessant ist schließlich, dass sich in den kleineren Privatmolkereien die deutlich wechselbereiteren Landwirte finden, hier mithin schon Tendenzen in Richtung kurzfristige Marktbeziehungen bestehen. 
ABBILDUNG 8: VERGLEICH DER MOLKEREIEN

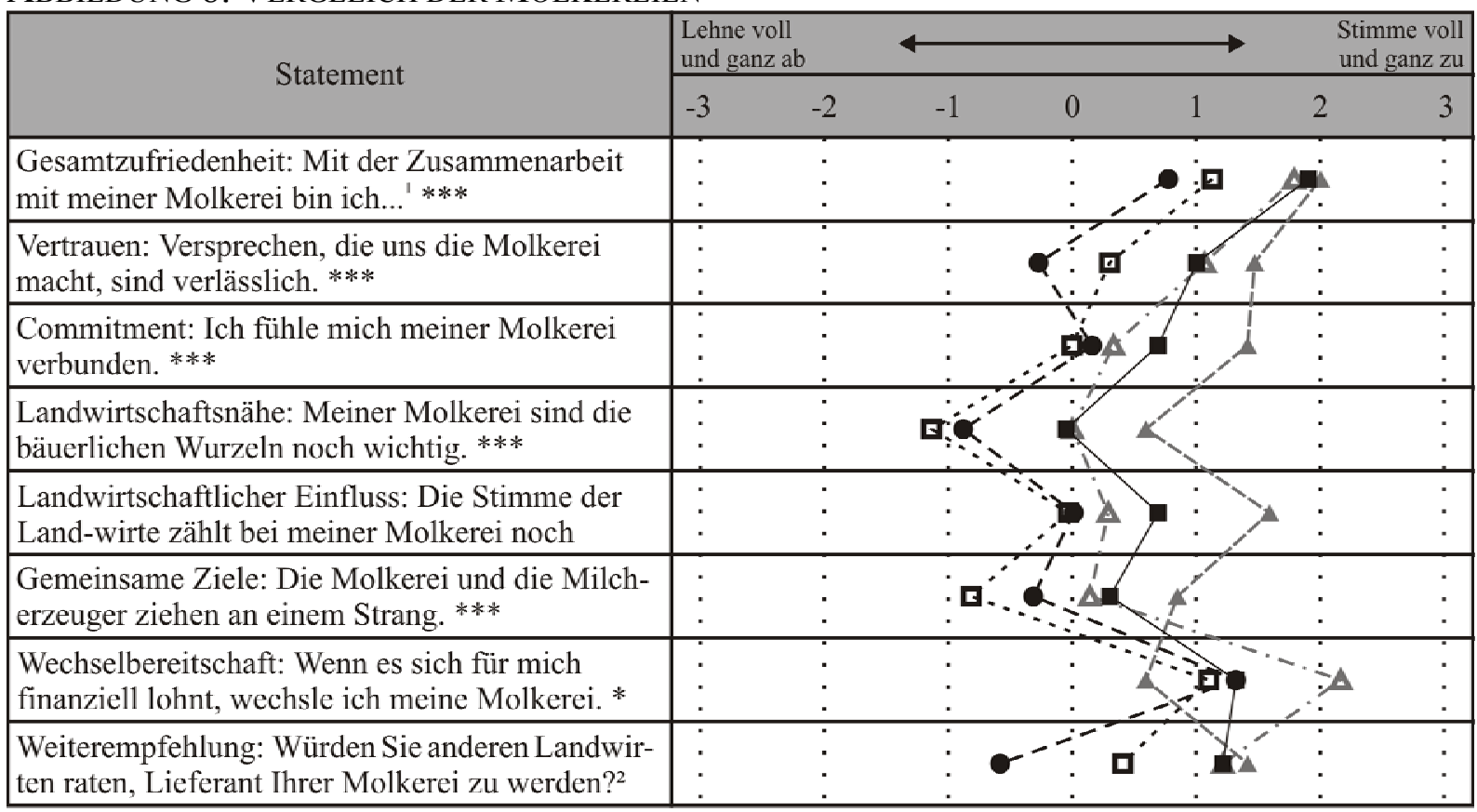

'Skala von -3 = "Voll und ganz unzufrieden" bis 3 = "Voll und ganz zufrieden".

2 Skala vơn -3 = "Kö̀mte ich mir absolưt nicht vorstellem" bis 3 = "Körnte ich mir abssolnt vorstellen".

- - Nondmilch, $\mathrm{n}=73$ - Humana Milchunion, $\mathrm{n}=50 \quad-\mathrm{E}$ - Campina Deutschland, $\mathrm{n}=3 \mathrm{I}$

- Ubrige Genossenschaftsmolkereien, $\mathrm{n}=32 \quad-\Lambda$ - ibrige Molkereien anderer Rechtsform, $\mathrm{n}=22$

***: $\mathrm{P} \leq 0,001 ; * \mathrm{P} \leq 0,01 ; * \mathrm{p} \leq 0,05$

In einer anschließenden Faktorenanalyse konnten drei Faktoren identifiziert werden, die Einfluss auf die Geschäftsbeziehungsqualität nehmen: (1) Zufriedenheit mit dem Management und der Kommunikation, (2) Landwirtschaftliche Orientierung bzw. Machtverteilung und (3) Preiszufriedenheit. In einer Regressionsanalyse (vgl. Abb. 9) erklären diese drei Größen sowie die vertragliche Bindung und der Anteil der Milchproduktion am Gesamteinkommen des Betriebes die Geschäftsbeziehungsqualität (Zufriedenheit/Vertrauen/Commitment) zu erheblichen Teilen. Überraschend ist, dass der Preis aus Sicht der Landwirte nicht der wichtigste Faktor ist. Vielmehr kommen eher emotionalen Kriterien und der wahrgenommenen Managementkompetenz eine ausgesprochen hohe Bedeutung zu. Das Verständnis für die landwirtschaftlichen Lieferanten und ihre Probleme sowie eine ausgebaute Lieferantenkommunikation sind für die Geschäftsbeziehung relevanter als der Preis. Bei größer werdenden Molkereien mit z. T. mehr als 10.000 Lieferanten stellt dieses Ergebnis die Unternehmen vor neue Herausforderungen. Ein systematisches Management der Lieferantenbeziehungen (Supplier Relationship Management) und eine regelmäßige Analyse der Geschäftsbeziehungsqualität ist zumindest für diejenigen Molkereien wichtig, die nicht auf Spotmärkten agieren wollen (Gerlach et al. 2004: 4). 
ABBILDUNG 9: REGRESSIONSMODELL

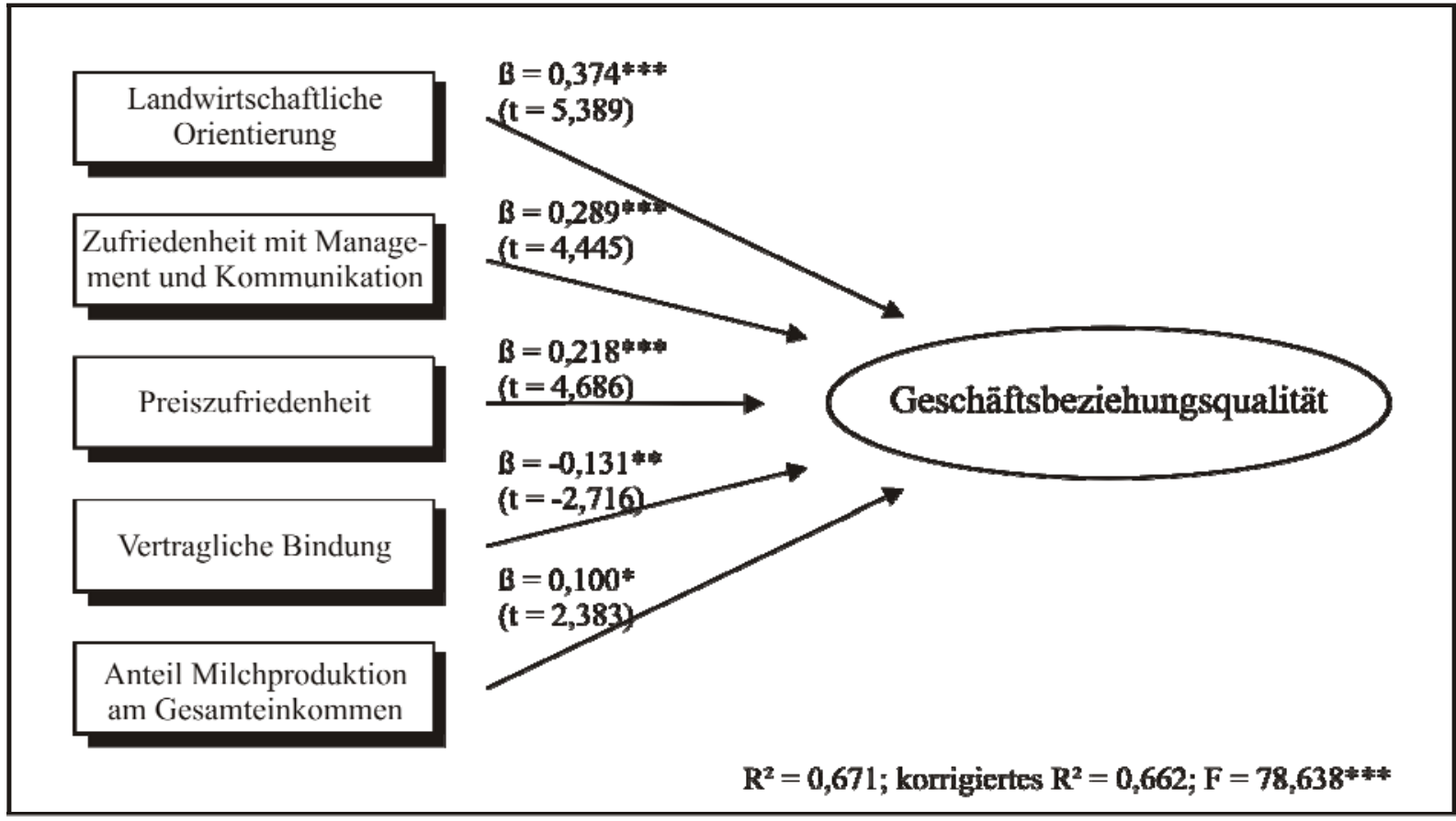

Quelle: Eigene Berechnungen

Insgesamt zeigt die Befragung eher konfliktäre Geschäftsbeziehungen. Auch die Genossenschaften werden von den Landwirten nicht als ,ihr“ Unternehmen wahrgenommen. Vielmehr nimmt die Geschäftsbeziehung eher marktliche Züge an, so dass aus Sicht der Landwirte die zweijährige Bindung an den Abnehmer problematisch wird.

\subsection{Einführung des Qualitätssicherungssystems QM}

Die Milchwirtschaft ist im Vergleich zu anderen Zweigen der Ernährungsindustrie von größeren Qualitätskrisen bisher verschont geblieben. Das Verbrauchervertrauen in die Erzeugnisse der Molkereien ist entsprechend hoch und in den letzten Jahren noch gewachsen (Kafka 1999: 24). Der Druck, Qualitätssicherungssysteme aufzubauen, ist daher geringer als beispielsweise in der Fleischwirtschaft. Gleichwohl haben Milchindustrieverband, Bauernverband sowie der Deutsche Raiffeisenverband ein Konzept zur Qualitätssicherung in der Milchwirtschaft entwickelt. Dieses Qualitätsmanagementsystem („QM-Milch“) beruht im Kern auf einer Zusammenführung der bereits gut ausgebauten Produktanalytik mit Audits in den landwirtschaftlichen Betrieben. Die Hofkontrolle ist in die Milchlieferverträge integriert. QM-Milch ist damit als System des vertraglichen Qualitätsmanagementsystems zu charakterisieren, das allerdings als Standardtool für die gesamte Branche aufgebaut wird. Es ist kein Zertifizierungskonzept, da die Kontrolle von Mitarbeitern der Molkereien oder der Landeskontrollvereinigungen durchgeführt wird und nicht durch externe Prüfinstitute, die nach DIN 45011 akkreditiert sind. Insgesamt hebt sich QM-Milch damit deutlich von den zzt. 
in der Ernährungswirtschaft diskutierten Konzepten ab. EUREPGAP und QS oder die in der niederländischen sowie in der britischen Milchwirtschaft installierten Systeme setzen allesamt auf Zertifizierung.

Die öffentlichen Diskussionen im Jahr 2004 haben gezeigt, dass es deutliche Barrieren auf landwirtschaftlicher Seite und in Teilen der Milchindustrie gegen QM gibt. So haben z. B. in Bayern bisher nur rund $25 \%$ der Erzeuger Verträge zur Systembeteiligung abgeschlossen (LZ 2004i: 20). Von den befragten 209 Betrieben sind ca. $40 \%$ bereits auditiert, weitere $40 \%$ bereiten sich derzeit auf die Prüfung vor, $20 \%$ planen keine Teilnahme an QM. Die bereits überprüften Unternehmen haben das Audit allesamt bestanden.

Insgesamt zeigt sich als Ergebnis eine skeptische Haltung zu QM. Gefragt, ob sie dieses System freiwillig einführen würden, antwortet die Mehrheit der Befragten ablehnend. Von den 209 Landwirten würden nur 68 QM aus eigener Initiative einführen, noch nicht auditierte Betriebe sind in ihrer Beurteilung noch skeptischer.

Ein detaillierter Blick auf die Einstellung der Landwirte zeigt, dass die Mehrheit der Betriebe grundsätzlich Zweifel am Sinn des Konzeptes hat. Viele Landwirte sehen die Notwendigkeit weiterer Qualitätssicherungsmaßnahmen nicht ein. Das Konzept gilt darüber hinaus als arbeitsaufwändig, bürokratisch aber auch leicht umsetzbar, da die geforderten Standards schon jetzt in der Praxis von vielen Betrieben erreicht werden. In einem weiteren Frageblock wurden den Probanden verschiedene mögliche Begründungen für das QM-System vorgelegt. Deutlich wird, dass die Landwirte den externen Druck zur Einführung mehrheitlich nachvollziehen, aber den Qualitätsnutzen eher skeptisch beurteilen. Die Unterschiede zwischen auditierten Betrieben und der Vergleichsgruppe sind hier nur gering.

Die obige Einschätzung wird auch in weiteren Fragen bestätigt, die auf das Kosten-NutzenVerhältnis von QM bezogen sind. Im Kern wird deutlich, dass gerade die gut geführten Betriebe wenige Veränderungen erwarten. Insbesondere gehen sie nur von einem geringen Nutzen für ihr Betriebsmanagement aus. Wenn, dann werden eher Vorteile in der besseren Planung der Betriebsabläufe erwartet. Unsicherheit besteht darüber, ob QM in der Lage sein wird, „Schwarze Schafe“ aus der Branche auszusortieren. Eine hohe Standardabweichung zeigt hier an, dass dieser Effekt sehr konträr beurteilt wird. Angesichts der erwähnten deutlichen Streuungen der Antworten wurden mit Hilfe einer Clusteranalyse unterschiedliche 
Einstellungsmuster innerhalb der Landwirtschaft identifiziert. Vier Cluster zeichnen sich durch deutliche Bewertungsunterschiede aus.

TABELLE 14: TYPOLOGISIERUNG DER LANDWIRTE NACH IHRER EINSTELLUNG ZUM QM SYSTEM

\begin{tabular}{|c|c|c|c|c|}
\hline $\begin{array}{ll}\text { Fragen } & \text { Cluster }\end{array}$ & $\begin{array}{c}\text { Befürworter } \\
(n=37)\end{array}$ & $\begin{array}{c}\text { Kostenskeptiker } \\
(n=74)\end{array}$ & $\begin{array}{c}\text { Gleichgültige } \\
(n=20)\end{array}$ & $\begin{array}{c}\text { Ablehner } \\
(\mathrm{n}=68)\end{array}$ \\
\hline $\begin{array}{l}\text { Gesamtbewertung } \\
\text { QM Milch (bis zu } \\
100 \text { Punkte) }\end{array}$ & 58,84 & 50,27 & 44,00 & 27,41 \\
\hline $\begin{array}{l}\text { Gesamtakzeptanz } \\
\text { QM }\end{array}$ & $0,76 /$ hoch & $-0,46 /$ gering & $-0,75 /$ gering & $\begin{array}{c}-2,18 / \mathrm{sehr} \\
\text { gering }\end{array}$ \\
\hline $\begin{array}{l}\text { Einsicht in } \\
\text { Notwendigkeit }\end{array}$ & $\begin{array}{l}\text { 1,18/deutlich } \\
\text { positiv }\end{array}$ & 0,04/indifferent & $\begin{array}{c}-0,09 / \\
\text { indifferent }\end{array}$ & $\begin{array}{c}-0,70 / \\
\text { ablehnend }\end{array}$ \\
\hline $\begin{array}{l}\text { Wahrgenommene } \\
\text { Kosten }\end{array}$ & $-0,68 /$ gering & $1,01 /$ hoch & -0,53/gering & $-0,53 /$ gering \\
\hline $\begin{array}{l}\text { Wahrgenommener } \\
\text { Nutzen }\end{array}$ & $0,39 /$ etwas & -0,01/indifferent & $\begin{array}{l}-0,25 / \text { eher } \\
\text { ablehnend }\end{array}$ & $\begin{array}{l}-0,15 / \text { leicht } \\
\text { ablehnend }\end{array}$ \\
\hline Qualitätsmotivation & 1,97/sehr hoch & 1,58/hoch & $-1,05 /$ niedrig & 1,87/sehr hoch \\
\hline $\begin{array}{l}\text { Durchschnittl. } \\
\text { Fläche (ha) }\end{array}$ & 96,86 & 97,30 & 91,20 & 93,35 \\
\hline Anzahl Milchkühe & 79,03 & 73,35 & 67,0 & 72,41 \\
\hline $\begin{array}{l}\text { Stärker vertretene } \\
\text { Molkereien }\end{array}$ & $\begin{array}{l}\text { Nordmilch, } \\
\text { Campina } \\
\text { Deutschland }\end{array}$ & $\begin{array}{c}\text { Nordmilch, } \\
\text { Molkerei } \\
\text { Grafschaft Hoya }\end{array}$ & & $\begin{array}{l}\text { Humana } \\
\text { Milchunion }\end{array}$ \\
\hline
\end{tabular}

Quelle: Eigene Erhebung, n=209, Vergleich der Mittelwerte zwischen den Gruppen

Betriebe des ersten Clusters (18,6 \% der Befragten) erkennen die Notwendigkeit von QMMilch an, stufen die Kosten als niedrig ein und messen dem System einen begrenzten Nutzen zu. Die Qualitätsmotivation dieser Gruppe ist hoch. Landwirte der relativ großen zweiten Gruppe (37,2 \%) sehen eine erhebliche Kostenbelastung durch QM-Milch auf sich zukommen und stehen deshalb dem Konzept skeptisch gegenüber. Betriebe aus Cluster 3 (10,1\%) sind insgesamt wenig qualitätsmotiviert. Diese Betriebe sind für die Einführung eines Qualitätsmanagementsystems problematisch, da sie letztlich nur durch Druck zu verstärkten Qualitätsanstrengungen zu bewegen sein werden. In Cluster 4 (34,2 \%) fallen sowohl Einstellung als auch Akzeptanz sehr niedrig aus. Diese Betriebe lehnen QM ab, obwohl sie keine höheren Kosten befürchten. Überproportional sind in dieser Gruppe Erzeuger der Molkereien Humana und Ammerland vertreten, was darauf hindeutet, dass den Molkereien eine Schlüsselposition bei der Kommunikationsarbeit zukommt und damit die Zustimmung oder Ablehnung des Systems stark beeinflusst.

Weitere Regressionsanalysen zeigen, dass das Systemverständnis und die Einsicht in die Notwendigkeit einer stufenübergreifenden Qualitätssicherung der entscheidende Faktor zur 
Erklärung der (geringen) Akzeptanz von QM-Milch ist. Offensichtlich ist es bisher nicht gelungen, die Lücken des bisherigen Systems aus Produktanalytik und Milchprüfung der Landeskontrollvereinigungen/Milchprüfringe $\mathrm{zu}$ verdeutlichen. Den Landwirten ist mehrheitlich nicht klar, welche Verbesserungen das System bringen soll. Der abstrakte Verweis auf Produkthaftung, Rückverfolgbarkeit oder Abnehmeranforderungen reicht hier nicht aus. Vielmehr bedarf es massiver Kommunikationsanstrengungen und einer klareren Systemausrichtung, wenn sich aus QM-Milch tatsächlich ein leistungsfähiges Qualitätsmanagementsystem mit intrinsischer Motivation der Landwirte entwickeln soll.

\section{Fazit}

Die deutsche Milchwirtschaft steht auf dem sich langsam liberalisierenden Markt vor großen Herausforderungen. Die Stärke der hiesigen Molkereien liegt in der Anpassung an eine äußerst aggressive Einzelhandelsstruktur, die zu konsequenter Rationalisierung zwingt. Das geringe Internationalisierungstempo ist vor diesem Hintergrund problematisch. Entwicklungsfähig sind zudem Premium- und Nischenmärkte, da viele Molkereien noch zu wenig marktorientiert aufgestellt sind (Schramm et al. 2004).

Die derzeitigen Aktivitäten des BDM auf landwirtschaftlicher Seite zeigen, dass die genannten Herausforderungen u. E. nicht zutreffend eingeordnet werden. Angetreten mit dem Anspruch einer solidarischen Gegenmachtbildung, fördern sie Tendenzen zum Spotmarkt, der mittelfristig die Auszahlungspreisdifferenzen deutlich verstärken würde. Langfristig werden bei einer Reduktion des Quotenschutzes Betriebe mit hoher Produktivität überleben und solche, die ihre spezifischen Betriebs- oder Standortnachteile zu einem Wettbewerbsvorteil am Markt entwickeln können („Alpenmilch“). Eine solche Polarisierung des Marktes verlangt eine Co-Evolution von landwirtschaftlichen Betrieben und ihren Molkerein und damit ein besseres Geschäftsbeziehungsmanagement. 


\section{Literatur}

Brandl, M. (2004): Milchmarkt 2004: Mengen positiv, Umsatz rückläufig, in: www.milchmarkt.de/de/milchaktuell/pressemitteilungen /2004/10 21 01.html, Abrufdatum: 10.11.2004.

DBV (2004): Milchbörse: $99 \%$ aller Anbieter erfolgreich, in: www.bauernverband.de/konkret_724.html, Abrufdatum 10.11.2004.

Deutsche Milchwirtschaft (Hrsg.) (2003): Die umsatzstärksten Mopro-Anbieter 2003, Gelsenkirchen.

DLG-Mitteilungen (2004): Die Molkereien stehen vor einem Scherbenhaufen, in: DLG Mitteilungen, (6): 42-43.

Dürr, A. (2004): Mopro: Discounter stützen den Markt, in: ScanLine 2/2004, in: www.infores.com/public/de/home/services/s-sline/TdM_06-2004.pdf, Abrufdatum: 10.11.2004.

Eurostat (Hrsg.) (2004): Agrarstatistik - Vierteljährliches Bulletin, 1-2004.

Fuller, F. H. et al. (2004): China's Dairy Market: Consumer Demand Survey and Supply Characteristics, Iowa State University, Staff Report 04-SR 99, Ames, Iowa.

Gerlach, S. et al. (2004): Supplier Relationship Management im Agribusiness: Ein Konzept zur Messung der Geschäftsbeziehungsqualität, Diskussionsbeitrag Nr. 0406. Institut für Agrarökonomie, Göttingen.

Großkinsky, A. (2003): Kompetenz bei Käse, in: BioPress, (36): 22-24.

Hasert, G., Wesenberg, F. (2004): So optimieren Großbetriebe, in: DLG-Mitteilungen, (10): $18-21$.

Heimig, D. (2004): Gesundheit: Milch mit Zusatznutzen, in: LZ, (38): 50.

Hemme, T. et al (2004a): Summary - Dairy sector developments 1981-2001, in : Hemme, T. et al. (2004): IFCN Dairy Report 2004, International Farm Comparison Network, Global Farm GbR, Braunschweig: 51-60.

Hemme, T. et al. (2004b): IFCN Dairy Report 2004, International Farm Comparison Network, Global Farm GbR, Braunschweig.

Hemmelmann, W. (2004): Standardsorten droht der Preisverfall, in: LZ-Net 08.04.2004, in: www.lz-net.de/specials/pages/protected/print.prl?wich..., Abrufdatum: 01.11.2004.

Holland, F. (2004): Milch: Das Problem heißt Preise, in: LZ, (38): 62.

IDF (Hrsg.) (2004): Bulletin of the International Dairy Federation, Brüssel.

Jochimsen, H (2004): Milch: Vollkosten nicht mehr gedeckt, in: top agrar, (5): 28-32.

Kafka, C. (1999): Risikowahrnehmung und -kommunikation bei Lebensmitteln, Arbeitsbericht Nr. 13. Lehrstuhl für Agrarmarketing, Kiel.

KPMG (2004): Internationalisierung im Lebensmitteleinzelhandel: Status Quo und Perspektiven, Consumer Markets, o. O.

Lademann, R. (2002): Potenziale für regionale Lebensmittelvermarktung und -handel bei zunehmender Unternehmenskonzentration, Gutachten im Rahmen des TA-Projekts Entwicklungstendenzen von Nahrungsmittelangebot und -nachfrage und ihre Folge beim TAB Deutscher Bundestag, Berlin. 
Landwirtschaftliches Wochenblatt (2004a): Doch keine höheren Milchpreise, in: Landwirtschaftliches Wochenblatt, (19): 13.

LZ (2004a): Campina ist Danone dicht auf den Fersen, in: LZ, (39): 25.

LZ (2004b): Qualität als das beste Argument, in: LZ, (39): 88.

LZ (2004c): Biomilch wird stärker gefragt, in: LZ, (42): 24.

LZ (2004d): Lichtblick für die Käsetheken, in: LZ, (41): 50

LZ (2004e): Bei Mopro zieht Aldi den Kürzeren, in: LZ, (30): 20.

LZ (2004f): Bauern kämpfen mit allen Mitteln, in: LZ, (13): 20.

LZ (2004g): Carrefour will in China auf deutsches Erfolgsmodell setzen, in: LZ, (39): 12.

LZ (2004h): Dutch Dairy Board soll helfen, in: LZ, (41): 25.

LZ (2004i): QM Milch findet mehr Anklang, in: LZ, (42): 20.

LZ-Net (2004), Feta: Macht Karriere, LZ-Net vom 17.09.2004, in: www.lz-net.de/specials/pages/protected/show.prl?id=1352\&backid=1136, Abrufdatum: 01.11.2004.

M+M Planet Retail (2002): Die 30 größten Lebensmittel-Einzelhändler der Welt 2002, in: www.planetretail.net, Abrufdatum: 01.11.2004.

Metro Group (2004): Metro-Handelslexikon, 2004/2005, Düsseldorf.

Michels, P. (2004): Bio-Produkte: Potenziale für den LEH, 1. Bio-Handelsforum 2004 der Koelnmesse, Köln.

Milch \& Markt(2004): Die größten deutschen Molkereien 2004, in: www.milch-markt.de/de/teaser/die_groessten_deutschen_molkereien_2004/ Abrufdatum 13.09.2004.

Murmann, C. (2004a): Molkereien machen Front gegen Rewe, in: LZ, (42): 20.

Murmann, C. (2004b): Abschluss bei Aldi führt zum Eklat, in: LZ, (19): 20.

Murmann, C. (2004c): Grenzverkehr nach Osten, in: LZ, (9): 52.

National Bureau of Statistics (2004): China Statistical Yearbook 2004, Beijing.

Pfaff, S., Tröster, N. (2004): Die Strategien des Handels für die Käse-Abteilungen in den Outlets, Köln.

Queck, M. (2004): Die Discounter bitten zu Tisch, in: LZ (44): 33.

Schramm, M., Spiller, A, Staack, T. (2004): Brand Orientation in der Ernährungsindustrie, Wiesbaden.

Stözle, W., Heusler, K. F. (2003): Supplier Relationship Management - Entstehung, Konzeptverständnis und methodisch-instrumentelle Anwendung, in: Bogaschewsky, R., Götze, U. (Hrsg.): Management und Controlling von Einkauf und Logistik, Gernsbach: 168-194.

Taube, M. (2003): China als Ziel deutscher Direktinvestitionen. Gesamtwirtschaftliche Rahmenbedingungen und operative Herausforderungen, in: Nippa, M. (Hrsg.) (2003): Markterfolg in China. Erfahrungsberichte und Rahmenbedingungen, Heidelberg, Berlin: 29-48.

Twardawa, W. (2004): Handelsmarken: Status Quo 2003, in: LZ-Net, 16.04.04, in: www.lznet.de/specials/pages/protected/print...., Abrufdatum: 10.11.2004. 
Weindlmaier, H. (2004): Künftige ökonomische Rahmenbedingungen der Milchwirtschaft Konsequenzen für Erzeugung und Verarbeitung in Deutschland, Vortrag beim ZMPMilchforum 2004, Berlin, ZMP 2004 03.11.04.

Wohlfahrt, M. (2003): Immer weniger Milchlieferanten, in: Ernährungsdienst, (46): 7.

ZMP (1994): ZMP-Marktbilanz Milch 2004, Bonn.

ZMP (2003): Der Außer-Haus-Markt: Strukturen der kommerziellen Gastronomie und Arbeitsplatzverpflegung, Bonn.

ZMP (2004a): ZMP-Marktbilanz Milch 2004, Bonn.

ZMP (2004b): 10. ZMP Milchforum: Milchmarkt 2010 - Wie am Markt bleiben, in: www.zmp.de/news/milchforum/praesentation_milchforum0.pdf, Abrufdatum 10.11.2004.

ZMP (2004c): Nachfrage privater Haushalte 2003, Bonn. 
KAPITEL II.6

Der Markt für Milch und Milcherzeugnisse 2006 


\title{
Der Markt für Milch und Milcherzeugnisse 2006*
}

\author{
(mit Achim Spiller und Christian Wocken)
}

1 Trends auf dem Milchmarkt

2 Entwicklungslinien in der Wertschöpfungskette für Milchprodukte in

Deutschland.

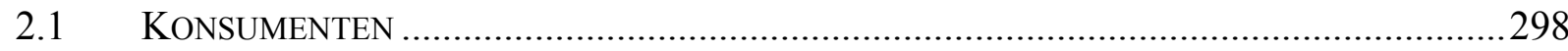

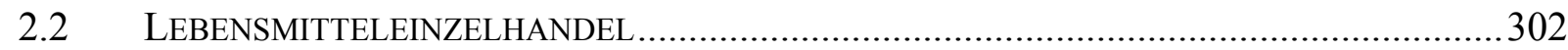

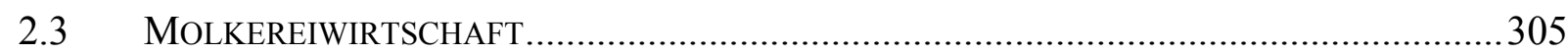

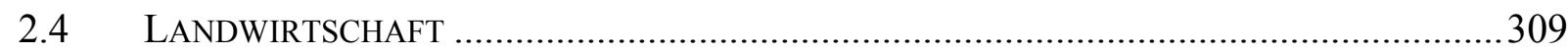

3 Globale und europäische Perspektiven der Milchwirtschaft ...................................314

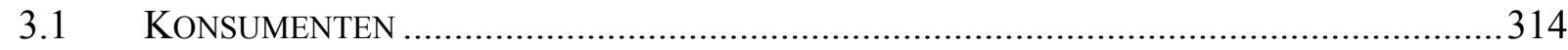

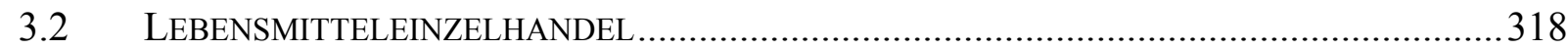

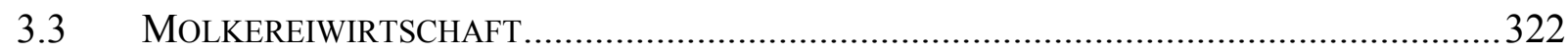

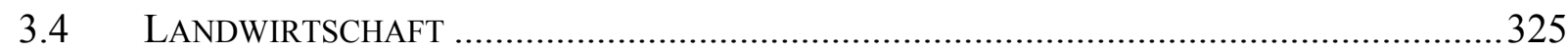

$4 \quad$ Aktuelle Herausforderungen auf dem Milchmarkt .................................................329

4.1 WETtBEWERBSFÄHIGKEIT UND ERZEUGERPREISE: EINE KETTENBETRACHTUNG..........329

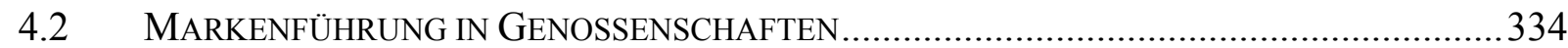

4.3 SCHUTZ GEOGRAPHISCHER HERKUNFTSANGABEN NACH DEM FetA-URTEIL DES

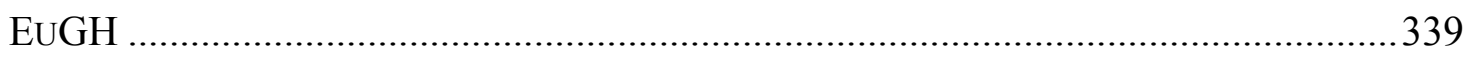

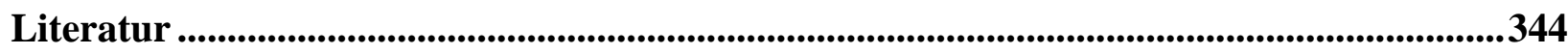

* in: Agrarwirtschaft, 55. Jg. (2006), Heft 1, S. 29-50. 


\section{Abbildungsverzeichnis}

Abbildung 1: Entwicklung von Hersteller- und Handelsmarken im Zeitablauf..........................300

Abbildung 2: Anzahl der Molkereiunternehmen nach MIV 2005 ............................................307

Abbildung 3: Anzahl der Molkereiunternehmen nach Größenklassen .....................................308

Abbildung 4: Durchschnittlicher Milchquotenpreis seit Einführung der Milchquotenbörse ....... 310

Abbildung 5: Prognostizierte Konsumentwicklung bei Molkereiprodukten..............................318

Abbildung 6: Internationalisierungsgrad europäischer Molkereigenossenschaften 2003 ...........324

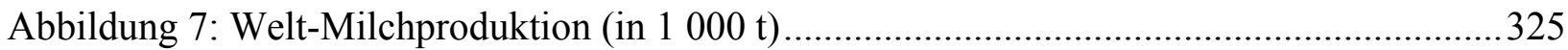

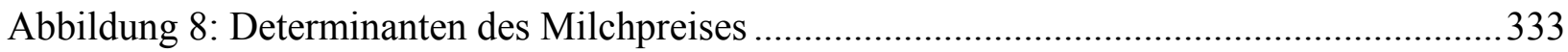

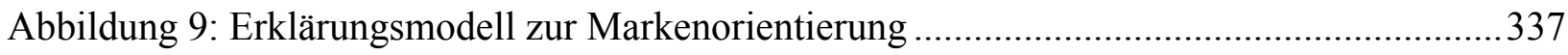

Abbildung 10: Ergebnisse der Clusteranalyse zur Markenorientierung in der deutschen

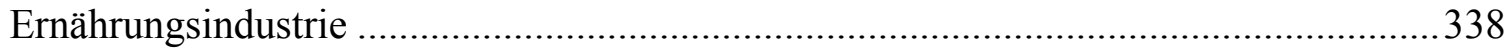




\section{Tabellenverzeichnis}

Tabelle 1: Private Nachfrage nach Molkereiprodukten: Veränderungsraten 2004 zu 2003 in \%298

Tabelle 2: Joghurt und Milchgetränke im LEH* ..................................................................... 301

Tabelle 3: Einkaufsstätten für die Weiße Linie (Umsatzanteile in \%) .....................................302

Tabelle 4: Umsatzveränderungen 2004 zu 2003 Gelbe Linie in \% ..........................................304

Tabelle 5: Verbraucherpreise für ausgewählte Milchprodukte in Deutschland

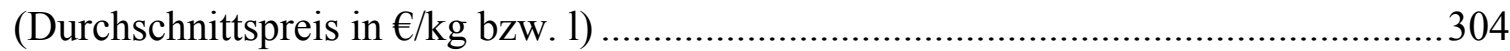

Tabelle 6: Die zehn größten Molkereiunternehmen in Deutschland 2004 (nach Umsatz) .........306

Tabelle 7: Herkunftsländer deutscher Käseimporte und Zielländer deutscher Käseexporte

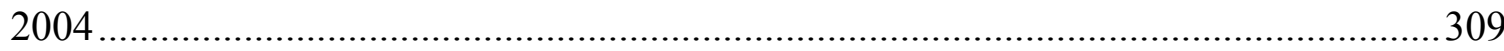

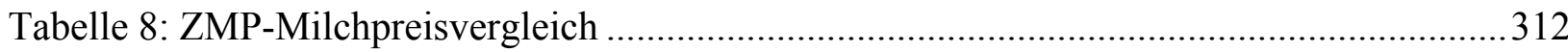

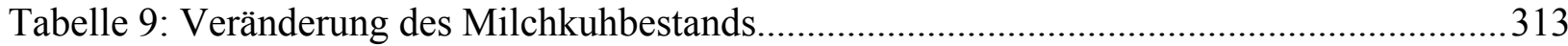

Tabelle 10: Bevölkerungs- und Einkommenswachstum in verschiedenen Regionen

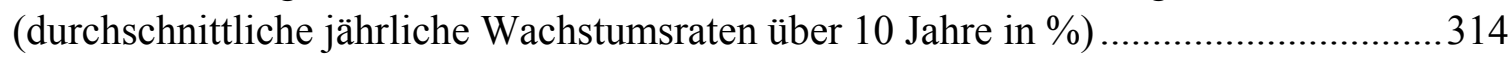

Tabelle 11: Pro-Kopf-Konsum von Milchfrisch-produkten in $\mathrm{kg} / \mathrm{Kopf}$...................................315

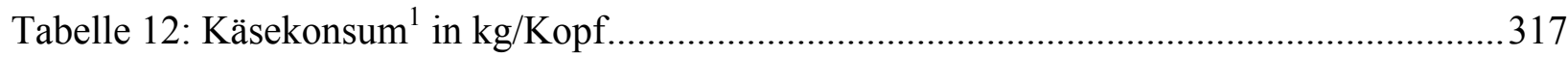

Tabelle 13: Überblick über die zehn weltweit führenden Lebensmittelhändler 2004.................319

Tabelle 14: Umsatz ausgewählter chinesischer und internationaler Filialisten 2004.................320

Tabelle 15: Osteuropaexpansion führender europäischer Lebensmittelhändler 2004 (Umsatz

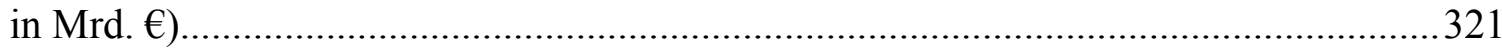

Tabelle 16: Die 20 umsatzstärksten Molkereiunternehmen weltweit ........................................323

Tabelle 17: Anteil und Wachstum der Weltmilchproduktion .....................................................326

Tabelle 18: Durchschnittliche Erzeugerpreise für Milch für ausgewählte Länder......................327

Tabelle 19: Anteil der Transportkosten an den Gesamtkosten bei ausgewählten

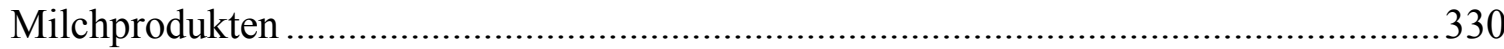

Tabelle 20: Export- und Importentwicklung von Käse in Deutschland (in 1000 t) ..................330

Tabelle 21: Markenbekanntheit bei Käse und Milch 2004 .........................................................335 


\section{Trends auf dem Milchmarkt}

Ganz Deutschland diskutierte im Jahr 2005 über Fragen des internationalen Standortwettbewerbs und der Wettbewerbsfähigkeit, über Produktionsverlagerungen und Kostensenkungen. Ganz Deutschland? Nur die Milchwirtschaft schien davon weitgehend unberührt. Das Jahr 2005 war für die Milchbranche vornehmlich durch das Fehlen einzelner Großereignisse charakterisiert - Branchenbeobachter sprechen bereits vom Jahr der „nonevents“ (IDF 2005). Zwei Begebenheiten am Jahresende lassen allerdings aufhorchen und zeigen die Richtung der weiteren Diskussion. Zum einen werden Ergebnisse eines Gutachtens im Auftrag des Raiffeisenverbandes bekannt, in dem eine radikale Strukturreform der genossenschaftlichen Molkereien gefordert wird: der Zusammenschluss zu wenigen Großmolkereien, der Kauf einer größeren Privatmolkerei, Standortschließungen, Personalreduktion, Bereinigung des Markenportfolios usf. (Murmann 2005a). Zum anderen überrascht die Humana Milchunion mit dem Plan, im Frischkäsemarkt einen massiven Verdrängungswettbewerb mittels einer bei einer polnischen Partnermolkerei produzierten Handelsmarkenlinie anzustoßen (Murmann 2005b).

Beide Themen weisen auf den roten Faden hin, der sich durch die folgende Marktberichterstattung zieht. Die deutsche Milchwirtschaft steht einem Handel gegenüber, der einen dominierenden und wachsenden Teil seiner Produkte als Handelsmarken, als SB-Produkte und im Discount absetzt. Die Branche hat sich vor diesem Hintergrund kostenorientiert aufgestellt und erzielt z. B. auf dem EU-Käsemarkt wachsende Exporterfolge. Gleichwohl: Das Handelsmarkengeschäft ist i. A. ein renditeschwaches Mengengeschäft unter extremem Kostendruck. Die Zeiten, in denen ein Handelsmarkenspezialist wie die Milch-Union Hocheifel überdurchschnittliche Renditen erzielen und hohe Auszahlungspreise für die Landwirte realisieren konnte, erscheinen begrenzt. Der Druck zur Standortverlagerung im Bereich der internationalisierungsfähigen Molkereiprodukte wird steigen. Sowohl auf landwirtschaftlicher als auch auf molkereiwirtschaftlicher Seite stehen daher die notwendigen Anpassungen an die kommende Marktliberalisierung im Mittelpunkt der Diskussionen. Allerdings ist eine Verknüpfung beider Aspekte im Sinne der Optimierung der gesamten Wertschöpfungskette noch wenig zu erkennen. Gleichzeitig erläutert der folgende Beitrag die Schwäche der deutschen Milchwirtschaft bei der Angebotsdifferenzierung (z. B. Marken, geschützte Ursprungsbezeichnungen). 


\section{Entwicklungslinien in der Wertschöpfungskette für Milchprodukte in Deutschland}

\subsection{Konsumenten}

In Deutschland gaben die Verbraucher im Jahr 2004 durchschnittlich $300 €$ pro Kopf für Milcherzeugnisse aus und damit einen Euro mehr als ein Jahr zuvor (ZMP 2005a: 13). Im 10Jahres-Trend ist der Pro-Kopf-Verbrauch von Butter (1994: 6,9 kg; 2004: 6,5 kg) annähernd konstant geblieben (ZMP 1995; ZMP 2005a) und liegt damit ca. 2 kg über dem EUDurchschnitt. Übertroffen wird dieser Wert nur von den französischen Konsumenten (ZMP 2005a: 53). Der Konsum von Milchfrischprodukten steigt dagegen seit geraumer Zeit langsam an. Im Jahr 2004 wurden durchschnittlich 94,6 kg Konsummilch und Milchfrischprodukte verbraucht; vor zehn Jahren lag der Konsum bei $92,2 \mathrm{~kg}$. Während sich klassische Milchprodukte im längerfristigen Trend kaum bewegen, zeigen sich bei Joghurt sehr deutliche Steigerungsraten. 1994 konsumierten die Deutschen durchschnittlich 12,5 kg Joghurt, 2004 waren es bereits 16,7 kg. Der langfristige Wachstumstrend im Käsesegment setzt sich auch weiterhin fort (1994: 19,1 kg; 2004: 21,9 kg) (ZMP 2005a: 43).

Diese Unterschiede spiegeln sich in den Daten des GfK-Haushaltspanels ähnlich wider (vgl. Tabelle 1). Während Absatz und Umsatz von Butter, Konsummilch und Quark zurückgingen, konnten bei Joghurt, aber vor allem bei Käse und Milchgetränken deutliche Umsatzzuwächse erzielt werden (ZMP 2005b).

TABELle 1: Private NACHFRAGE NACH MOLKEREIPRODUKTEN: VERÄNDERUNGSRATEN 2004 ZU 2003 IN \%

\begin{tabular}{|l|c|c|c|c|c|c|}
\hline & $\begin{array}{c}\text { Milchge- } \\
\text { tränke }\end{array}$ & Joghurt* & Käse** & Butter & $\begin{array}{c}\text { Konsum- } \\
\text { milch }\end{array}$ & Quark \\
\hline Absatzvol. & 2 & 0 & 4 & -1 & -2 & -3 \\
\hline Umsatz & 12 & 2 & 5 & -2 & -2 & -3 \\
\hline
\end{tabular}

*einschl. Trinkjoghurt; ** Modellrechnung der GfK Quelle: ZMP 2005b

Die skizzierten mengen- und wertmäßigen Entwicklungen in den einzelnen Produktgruppen sind in weiten Teilen das Ergebnis qualitativer Trends im Verbraucherverhalten. Zu diesen gehören die zunehmende Bedeutung von Handelsmarken sowie die Gesundheits- und Convenience-Orientierung der Verbraucher. Zunächst ein Blick auf die Bedeutung von Handelsmarken: Je nach Datenquelle und Produktgruppe wird der Handelsmarkenanteil im Bereich der Molkereiprodukte auf 50 bis $85 \%$ des Absatzes taxiert (Weindlmaier 2005a: 48; Murmann 2005c: 42). Bei Trinkmilch liegt der Absatzanteil inzwischen bei $75 \%$, ebenso wie 
bei Schnittkäse in der SB-Theke. Zwischen 50 und $85 \%$ des Absatzes nehmen Handelsmarken bei Speisequark, Naturjoghurt, Kefir, Frischkäse, Feta, Mozzarella, Sprühsahne, Schmelz- und Reibekäse ein. Handelsmarkenkäufer - dies belegen aktuelle Forschungsergebnisse - unterscheiden sich kaum durch ihre soziodemographischen Kriterien, sehr stark aber durch die Wahrnehmung von Qualitäts- und Preis-Leistungs-Unterschieden von Markenartikelkäufern (Bauer et al. 2005). Der ausgesprochen hohe Handelsmarkenanteil in der Molkereiwirtschaft deutet darauf hin, dass es den Herstellern zu wenig gelingt, Besonderheiten und Qualitätsdifferenzen aufzuzeigen.

Starke Marken können vor allem bei Kommunikation eines überzeugenden Zusatznutzens gewinnen. Das wohl herausragendste Beispiel im Milchmarkt ist Actimel. Die Marke konnte laut AC Nielsen ihren Marktanteil auf über $62 \%$ erhöhen. Bei Gebindegrößen von weniger als $250 \mathrm{ml} \mathrm{kann} \mathrm{mit} 78 \%$ fast von einer Monopolstellung gesprochen werden. Actimel ist damit die stärkste Marke bei den Molkereiprodukten (Murmann 2005d: 18). Die GfK zeigt in einer Studie zur Stellung von Marken im Zeitablauf, dass die Zunahme der Handelsmarken weniger auf Kosten der starken Marken erfolgte, sondern zur Verdrängung schwächerer Marken führte (vgl. Abbildung 1) (Weindlmaier 2005a: 48). Auch die vormals in der Molkereiwirtschaft gut vertretenen Regionalmarken können sich kaum noch am Markt behaupten (Murmann 2005c: 42). So hat die Nordmilch in den letzten Jahren ihr Regionalmarkenportfolio fast vollständig eingestellt (Enneking et al. 2004: 207) und mehr als 320 regionale Artikel aus dem Produktionsprogramm gestrichen (Nordmilch 2005: 13). 
ABBILDUNG 1: ENTWICKLUNG VON HERSTELLER- UND HANDELSMARKEN IM ZEITABLAUF

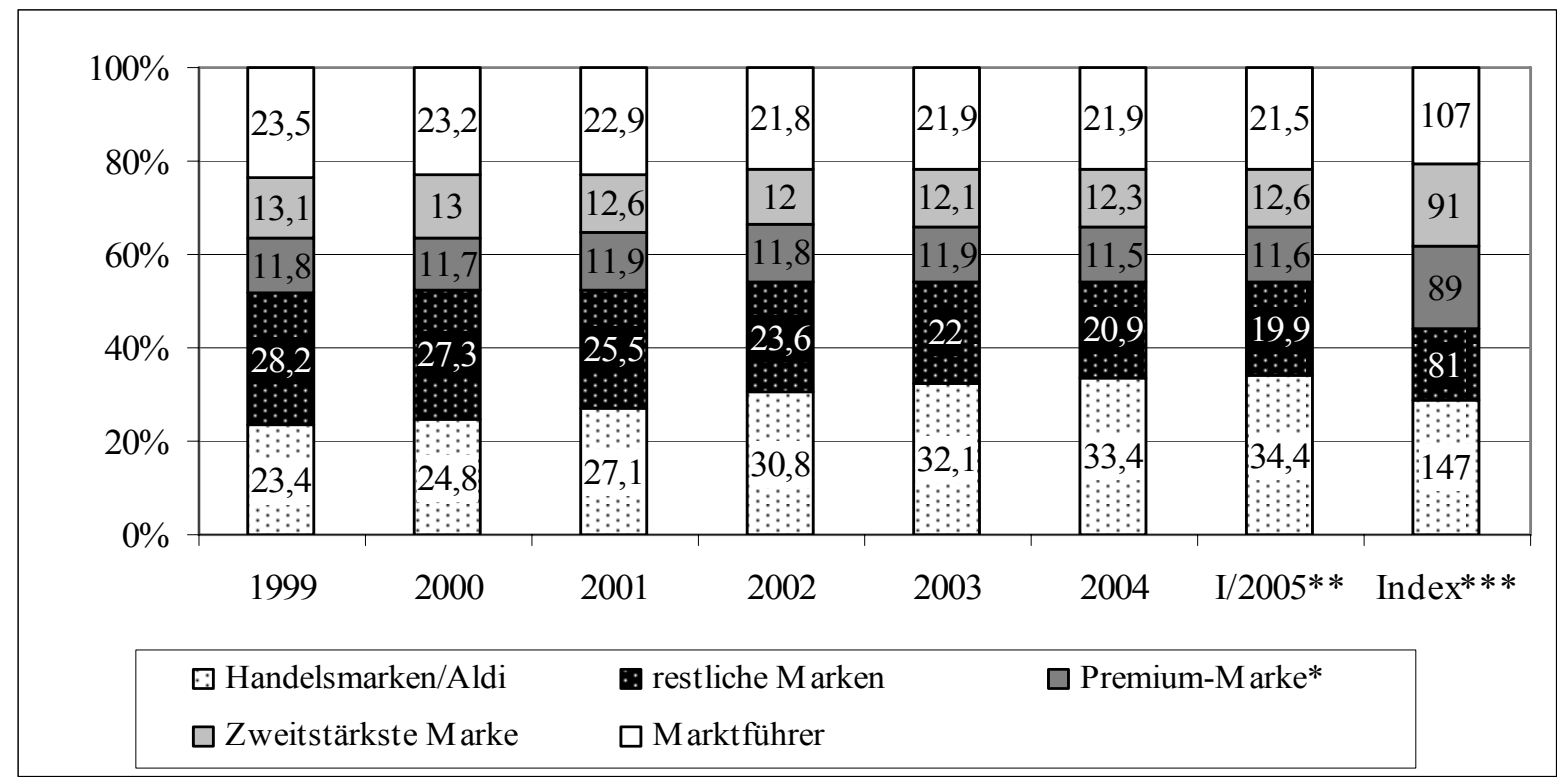

* Durchschnittspreis $\geq$ Preis des Marktführers; ** 1. Quartal 2005; *** Index: Marktanteile 2005 zu 1999 (1999=100) Quelle: Bachl 2005: 3

Ein Beispiel für das Wachstum des Premiumsegments ist der Öko-Markt. Im Vergleich zum Vorjahr stieg der Absatz von Bio-Milch um $24 \%$ und erreicht damit unter Einbeziehung von Aldi einen Umsatzanteil von ca. 2,4 \% und einen Absatzanteil von ca. 1,5 \% (BLE 2005: 12). Auch im Bio-Bereich zeigt sich ein starker Trend zu Handelsmarken. Etwa 60 \% der ÖkoMilch wird unter den Eigenmarken des Handels verkauft. Diese Entwicklung hat mehrere Ursachen: Zum einen nutzten die Handelsmarken als erste die neue ESL (Extended Shelf Live)-Technologie und konnten damit Marktanteile gewinnen, zum anderen gibt es nur wenige etablierte Bio-Herstellermarken. Auch die verstärkte Vermarktung von Bio-Milch über Discounter trägt zur hohen Relevanz der Handelsmarken bei. Neben Trinkmilch weist auch Öko-Butter einen nennenswerten Marktanteil im LEH auf. Der Umsatzanteil liegt hier bei 1,6\%, der Absatzanteil bei 1,0\%. Erstaunlich sind die $15 \%$ igen Wachstumsraten sowohl beim Um- als auch beim Absatz, da die Preisaufschläge von Öko-Butter in etwa 40 bis 66 \% betragen (BLE 2005: 17).

Ein weiterer langfristiger Konsumtrend ist die Orientierung zu fettreduzierten Produkten. Eine außergewöhnlich erfolgreiche Innovation war z. B. fettreduzierter Käse unter Lizenz von Weight Watchers. Marktforscher gehen davon aus, dass im Hart- und Schnittkäsesegment die fettreduzierten Käse einen Marktanteil von $15 \%$ erreichen können. Die aktuellen Wachstumsraten von 11,5\% im Halbjahresvergleich 2005 zu 2004 belegen den deutlichen Trend (LZ 2005a: 18). Aber auch in anderen Produktgruppen wie Joghurt und Milchgetränken zeigt 
Tabelle 2 die wachsenden Konsumentenpräferenzen für fettreduzierte Produkte (Krönert 2005: 40).

TABELLE 2: JOGHURT UND MILCHGETRÄNKE IM LEH*

\begin{tabular}{|c|c|c|c|c|c|}
\hline & & $\begin{array}{c}\text { Umsatz } 2004 \\
\text { in Mio. } €\end{array}$ & $\begin{array}{c}\text { Veränderungen } \\
\text { zum Vorjahr in } \\
\% \\
\end{array}$ & $\begin{array}{c}\text { Absatz } 2004 \\
\text { in Mio. t }\end{array}$ & $\begin{array}{c}\text { Veränderungen } \\
\text { zum Vorjahr in } \\
\% \\
\end{array}$ \\
\hline \multirow{3}{*}{ 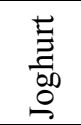 } & fest & 1400 & $-4,3$ & 809,7 & $-3,1$ \\
\hline & ,leicht“" bzw. ,light"“ & 54,8 & 15,3 & 39 & 20,5 \\
\hline & bis $0,3 \%$ Fett** & 155,6 & 8,9 & 88,3 & $-6,5$ \\
\hline \multirow{2}{*}{$\frac{\dot{2}}{0}$} & gesamt & 822,6 & 7,3 & 551,4 & $-0,1$ \\
\hline & „leicht“" bzw. „light“" & 8 & 23,6 & 5,6 & 15,9 \\
\hline
\end{tabular}

*LEH > 200 qm inklusive Harddiscount; ** ohne spezielle „Leicht“-, ,Light“- oder „Diät“-Deklaration Quelle: Krönert 2005: 40

Neben diesen allgemeinen Entwicklungen im Konsumentenverhalten stellt sich zukünftig die Frage, wie sich die Molkereiwirtschaft mit dem Einsatz von gentechnisch verändertem Futter bei Milchkühen auseinandersetzt. Laut einer Emnid-Umfrage wollen 94 \% der Verbraucher eine klare Kennzeichnung von tierischen Produkten, die von Tieren stammen, welche mit gentechnisch veränderten Futtermitteln gefüttert wurden (Medizinauskunft 2005). Wissenschaftliche Studien zeigen (auf Basis unterschiedlicher Erhebungstechniken) relativ eindeutig, dass ein erheblicher Teil der Konsumenten weiterhin Bedenken bezüglich des Einsatzes der Grünen Gentechnik hat (Loureiro/Bugbee 2005) und dass die Kritik gegenüber Gentechnik im Bereich der tierischen Produktion noch größer ist als im Pflanzenbau (Lusk et al. 2003). Zudem sind es gerade die aus Sicht der Milchwirtschaft besonders ertragreichen Zielgruppen mit hoher Bildung, Gesundheitsbewusstsein und Preisbereitschaft, die der Gentechnik skeptisch gegenüber stehen. In einer eigenen Studie zum Einsatz von Gentechnik mit dem Ziel funktioneller Milchprodukte zeigte sich, dass derzeit die Technologiewiderstände größer sind als der wahrgenommene Nutzen funktioneller Inhaltsstoffe wie z. B. Omega-3-Fettsäuren (Riethmüller 2005).

Aktuell ist die Diskussion um Gentechnik in der Milchproduktion vor dem Hintergrund einer Kampagne von Greenpeace aufgeflammt. Unter anderem wurde ein Ratgeber veröffentlicht, in dem aufgezeigt wird, welche Milchprodukte von Kühen stammen, die gentechnisch verändertes Futter bekommen haben (Langelüddeke/Deichmann 2004). Greenpeace hat darüber hinaus im vergangenen Jahr damit begonnen, auf Produkten zunächst von Müller, inzwischen auch auf der Campina-Marke „Landliebe“ Sticker mit dem Aufdruck „GENMILCH“" aufzubringen. Obwohl die Branche bislang auf die Angriffe verhalten reagiert (der Deutsche Raiffeisen Verband rät seinen Mitgliedern auf die Anfragen von Greenpeace nicht 
zu antworten), zeigt das deutliche Nein der Schweizer zum Einsatz von Gentechnik in der Landwirtschaft, dass eine Akzeptanz der Verbraucher bislang nicht vorausgesetzt werden kann (FAZ-NET 2005). Dass es möglicherweise einen Markt für Milch gibt, die von Tieren ohne gentechnisch behandeltes Futter stammt, zeigt die Einführung von Milch ,garantiert ohne Gentechnik“ bei Tegut (LZ-Net 2005a) und bei Rewe und Plus in Österreich (Österreichische Milch- \& Lebensmittelwirtschaft 2005: 877).

\subsection{Lebensmitteleinzelhandel}

Der deutsche Lebensmitteleinzelhandel (LEH) hat in den vergangenen Monaten keine wesentlichen Strukturbrüche erlebt. Im Frischwarenbereich konzentrierten sich die Marketinganstrengungen der Händler auf die Einführung bzw. den Ausbau von SB-Fleisch. Bei Milch und Käse wurden kaum neue Initiativen gestartet. Mit einer Zunahme von 1,7 \% erzielte die Weiße Linie ein geringes Wachstum (LZ 2005b: 63). Für die Gelbe Linie konnte ein Absatz- und Umsatzplus (ohne Aldi) von $11 \%$ gegenüber dem Vorjahr erzielt werden (Hemmelmann 2005a: 26).

TABELLE 3: EINKAUFSSTÄTTEN FÜR DIE WEIßE LINIE (UMSATZANTEILE IN \%)

\begin{tabular}{|l|c|c|}
\hline & $\mathbf{2 0 0 3}$ & $\mathbf{2 0 0 4}$ \\
\hline Aldi & 19,4 & 18,1 \\
\hline Discounter ohne Aldi & 23,8 & 26,1 \\
\hline SB-Warenhäuser & 11,6 & 11,6 \\
\hline Verbrauchermärkte groß & 13,3 & 13,5 \\
\hline Verbrauchermärkte klein & 13,2 & 13,4 \\
\hline Supermärkte & 10,2 & 9,9 \\
\hline Restl. unter 400 qm & 8,5 & 7,4 \\
\hline Umsatz insgesamt in Mio. $€$ & 4354,9 & 4445,0 \\
\hline
\end{tabular}

Quelle: LZ 2005b: 64

Im relativ stabilen Gesamtmarkt gewinnen die Discounter weiterhin Marktanteile hinzu. Tabelle 3 weist für alle Discounter im Jahr 2004 einen Gesamtumsatzanteil von 44,2 \% (+1 \% gegenüber 2003) in der Weißen Linie aus. Die Wachstumsgeschwindigkeit der Discounter hat sich allerdings abgeschwächt, was besonders auf schwächere Abverkaufszahlen von Aldi zurückzuführen ist. Aldi verlor 1,3\%, bei Frischmilch sogar ca. $4 \%$ des Absatzes (LZ 2005b: 63). Im Vergleich $\mathrm{zu}$ anderen Warengruppen im Lebensmitteleinzelhandel konnten die Vollsortimenter im Milchbereich damit ihre Position relativ gut behaupten. Insgesamt haben die Discounter einen Zuwachs von 2,8 \% der Haushaltsausgaben für Fast Moving Consumer Goods generieren können, der Branchenprimus Aldi konnte hingegen nur um 1,5\% wachsen. Während sich das Wachstum der Discounter in der Vergangenheit hauptsächlich zu Lasten 
des konventionellen LEH verschoben hat, sind jetzt deutliche Marktanteilsverschiebungen innerhalb der diskontierenden Betriebstypen zu beobachten, wobei die Softdiscounter profitieren (Keunecke 2005: 10). Konstante Verlierer im Betriebsformenwettbewerb sind die Kleinflächen und z. T. die Supermärkte. Die Abschwächung des Discounttrends wurde allerdings zum Teil durch eine steigende Sonderangebotsintensität der anderen Betriebsformen erreicht (ZMP 2005a: 13). 7 \% Zusatzabsätze aus Aktionen im Vergleich zum Vorjahr verdeutlichen, dass der klassische LEH sich gegen Discountpreise zur Wehr setzt (LZ 2005b: $63)$.

Auch im vergangenen Jahr hat sich der Trend weg von der Bedienungstheke hin zum SBBereich fortgesetzt (vgl. Tabelle 4). SB-Ware beim Käse erzielte in Deutschland (ohne Aldi) ein Absatz- und Umsatzplus von $11 \%$, während die Bedienungstheke einen Umsatzrückgang von $-4,9 \%$ verzeichnen musste (Hemmelmann 2005a: 26). Nur noch $18 \%$ des Käses wird über die Bedienungstheke distribuiert (ZMP 2005a: 61). An diesem Trend können auch die Cabrio-Theken mit im Outlet verpacktem Käse, die zu den Bedienungstheken gezählt werden, nichts ändern, obwohl der Absatz deutlich stieg. Der kontinuierliche Rückgang der Bedienungstheke deutet auf die unklare Positionierung aus Verbrauchersicht sowie auf das strategische Kostendilemma des Handels hin. Das Käseangebot in den Bedienungstheken ist in vielen Fällen austauschbar, da die großen Molkereien ihre Marken und Spezialitäten inzwischen regelmäßig auch als SB-Artikel anbieten. Die längere Haltbarkeit der SB-Ware und die Convenience-Vorteile beim Einkauf und im Handling lassen wenige Spielräume für die personalkostenintensive Theke. Noch scheuen viele Handelsunternehmen allerdings die radikale Umpositionierung ihrer Theke zum Spezialitätenangebot, da dies zunächst erhebliche Investitionen in Personal und Ladenausstattung voraussetzt. 
TABELLE 4: UMSATZVERÄNDERUNGEN 2004 ZU 2003 GELBE LINIE IN \%

\begin{tabular}{|l|c|c|}
\hline & Gelbe Linie SB & Gelbe Linie Theke \\
\hline Umsatzveränderungen gesamt & 10,9 & $-4,9$ \\
\hline Blauschimmelkäse & 18,6 & \\
\hline Feta & 24,0 & $-0,7$ \\
\hline Frischkäse & 7,6 & $-9,4$ \\
\hline Mozzarella & 10,7 & 86,3 \\
\hline Halbfester Schnittkäse & 10,5 & $-9,0$ \\
\hline Hart- und Schnittkäse & 15,4 & $-3,6$ \\
\hline Rotschmierkäse & 9,3 & 17,5 \\
\hline
\end{tabular}

Quelle: Hemmelmann 2005a: 26

Die ZMP-Verbraucherpreise weisen für das Jahr 2004 insgesamt ein relativ konstantes Niveau aus. Beachtenswert ist die Preisanhebung bei den wachstumsstarken Milchgetränken (siehe Tabelle 5). Bei der Konsummilch ist der Durchschnittspreis dagegen konstant geblieben. Im Jahr 2005 gibt es Anzeichen für einen stärkeren Preisdruck, z. B. die medienwirksame Verkaufsförderungsaktion der SB-Warenhaustochter real des Metro-Konzerns. Real hat einen Tag lang u. a. einen Liter Vollmilch mit 3,5 \% Fett für 33 Cent angeboten und damit Protestaktionen von Bauern ausgelöst (LZ 2005d: 50).

TABELLE 5: VERBRAUCHERPREISE FÜR AUSGEWÄHLTE MILCHPRODUKTE IN DEUTSCHLAND (DURCHSCHNITTSPREIS IN $€ /$ KG BZW. L)

\begin{tabular}{|l|c|c|c|c|c|}
\hline & $\mathbf{2 0 0 0}$ & $\mathbf{2 0 0 1}$ & $\mathbf{2 0 0 2}$ & $\mathbf{2 0 0 3}$ & 2004* \\
\hline Butter & 3,81 & 3,98 & 3,66 & 3,64 & 3,60 \\
\hline Käse & - & - & 5,58 & 5,77 & 5,79 \\
\hline Quark & 1,78 & 1,93 & 1,89 & 1,82 & 1,82 \\
\hline Konsummilch & 0,49 & 0,57 & 0,56 & 0,54 & 0,54 \\
\hline Joghurt & 1,70 & 1,76 & 1,72 & 1,71 & 1,74 \\
\hline Milchgetränke & 1,08 & 1,15 & 1,20 & 1,27 & 1,40 \\
\hline
\end{tabular}

* Prognose

Quelle: ZMP 2005c

$\mathrm{Ob}$ die verhaltene Ruhe bei den Verbraucherpreisen anhält, ist fraglich. Aufgrund der gestiegenen Konkurrenz, vor allem durch Lidl, wird der Druck, den Aldi auf die Lieferanten ausübt, zunehmend größer. Die bekanntermaßen ausgeprägte Lieferantentreue von Aldi wird fragiler. So wurden z. B. gleich mehrere große Artikel im Schokoladensortiment ausgeschrieben. Zudem kam Aldi früher Herstellern mit verkürzten Zahlungszielen entgegen, wenn beispielsweise die Rohstoffpreise stiegen, auch dies wird derzeit kaum mehr praktiziert (Chwallek 2005: 4). Im Jahr 2005 wurden die Trinkmilchkontrakte nach Branchenaussagen wiederum günstiger für Lidl abgeschlossen. Schon im vergangenen Jahr diente die von Aldi abgeschlossene Preismarke als Verhandlungsbasis und wurde dann von den Konkurrenten unterboten (LZ 2005f: 19). Problematisch ist der Druck auf Aldi, weil der Discounter die 
Preise im Niedrigpreissegment dominiert. Fast alle Handelskonzerne in Deutschland bieten bei den Standardmolkereiprodukten mit hoher Preiskenntnis der Verbraucher (Vollmilch, Butter usf.) eine Handelsmarke auf Aldi-Preisniveau an. Wenn Aldi dauerhaft die Preise für diese Artikel senkt, hat dies erhebliche Relevanz für den Marktpreis.

Einen Versuch, Milchpreise zu erzielen, die die Vollkosten der landwirtschaftlichen Betriebe decken, hat die Upländer Bauernmolkerei gestartet. Unter dem Label „Erzeuger-fair Milch - 5 Cent direkt an die heimische Landwirtschaft" wird Bio-Milch vermarktet, die den Landwirten zusätzlich zum Bio-Aufschlag einen Zusatzerlös in der genannten Größenordnung garantiert (LZ 2005e: 53). Die Milch wird bisher über ausgewählte Naturkosthändler vertrieben, die trotz der Preisanhebung über Mehrumsatz mit der „Erzeuger-fair Milch“ berichten (Upländer Molkerei 2005; Murmann 2005e: 24). Eine Ausweitung der Distribution in den konventionellen Lebensmittelhandel ist geplant. Inzwischen gibt es erste Nachahmer in Norddeutschland (Genoux 2005; Geisler 2005). Die Idee der Übertragung des Fair-TradeGedankens auf die heimische Landwirtschaft hat zunächst viel Verwunderung in der Branche hervorgerufen. In den USA ist diese Entwicklung beim führenden Premium-Handelsunternehmen WholeFoods unter dem Stichwort „Domestic Fair Trade“ allerdings ebenfalls erfolgreich (Fuchshofen 2005: 61). Offensichtlich gibt es eine (begrenzte) Zielgruppe, die eine emotionale Bindung an die heimische Landwirtschaft aufweist und die dem Fair-Trade-Ziel grundsätzlich offen gegenüber steht. Inwieweit die Konzeption über enge Nischenmärkte hinaus trägt, bleibt allerdings offen.

\subsection{Molkereiwirtschaft}

Die Molkereistruktur in Deutschland ist weiterhin ein brisantes Thema. Nicht zuletzt durch ein Gutachten, in dem auf Strukturdefizite deutscher Molkereien - insbesondere der Genossenschaften - hingewiesen wurde (Murmann 2005a: 20), ist die Diskussion am Jahresende 2005 erneut aufgeflammt. Viele Landwirte haben allerdings Bedenken gegen weitere Fusionen, nachdem der Zusammenschluss der Nordmilch in der frühen Post-MergerPhase durch Managementfehler nicht die erhofften Vorteile gebracht hat. In jüngerer Zeit hat es nur sehr wenige, eher unbedeutende Fusionen gegeben. Das vergangene Jahr stand vielmehr im Zeichen der Konsolidierung. Lediglich Hochwald ist weiter auf Wachstumskurs und hat die Kondensmilch- und Dosenproduktion im niederländischen Bolsward von Nestlé übernommen (LZ-Net 2005b). Damit hat Hochwald seine führende Stellung bei der offensichtlich lukrativen - Kondensmilchproduktion weiter ausgebaut. Dieser Markt ist in 
hohem Maße vom Export abhängig. Die Erzeugung verringerte sich in 2003 gegenüber 2002 um 13,5\% auf 481800 t (BMVEL 2005: 30).

Die Milchindustrie erzielte 2004 einen Umsatz von 20,29 Mrd. € (Deutsche Milchwirtschaft 2005: 19). Tabelle 6 zeigt Umsatz, Milchverarbeitungsmenge und Wertschöpfungsindex der zehn umsatzstärksten Molkereiunternehmen. Die Zahlen für Umsatz wie auch Milchmenge sind mit einigen Unsicherheiten behaftet, da eine Konzernzuordnung nicht immer möglich ist. Gleichwohl spiegeln Veränderungen beim Wertschöpfungsindex die unterschiedlichen Marktstrategien wider. So ist Hochland als Käsespezialist und Markenartikler sehr erfolgreich (Murmann 2005f: 20), was anhand der Steigerung des Wertschöpfungsindex deutlich wird. Ehrmann ist dagegen verstärkt in die Handelsmarkenproduktion eingestiegen (LZ 2005h: 16), entsprechend sinkt der Wertschöpfungsindex.

TABELlE 6: DiE ZEHN GRÖßTEN MOLKEREIUNTERNEHMEN IN DEUTSCHLAND 2004 (NACH UMSATZ)

\begin{tabular}{|c|c|c|c|c|}
\hline \multirow{2}{*}{ Unternehmen } & \multirow{2}{*}{ Umsatz in Mio. $€$} & \multirow{2}{*}{$\begin{array}{c}\text { Milchmenge in Mio. } \\
\text { kg }\end{array}$} & \multicolumn{2}{|c|}{ Wertschöpfungsindex } \\
\hline & & & $2004^{4}$ & $2003^{4}$ \\
\hline 1 Nordmilch $^{1}$ & 2070 & 4180 & 0,50 & 0,51 \\
\hline 2 Humana Milchunion ${ }^{1,3}$ & 1900 & 2473 & $0,74^{5}$ & $0,81^{5}$ \\
\hline 3 Molkerei A. Müller ${ }^{1,2}$ & 1766 & 1522 & 1,16 & 0,97 \\
\hline 4 Hochwald $^{1}$ & 1018 & 1783 & 0,57 & 0,58 \\
\hline 5 Campina Deutschland & 909 & 1400 & 0,65 & 0,79 \\
\hline 6 Hochland & 730 & 400 & 1,83 & 1,64 \\
\hline 7 Bayernland & 700 & k. A. & - & - \\
\hline $8 \mathrm{Zott}^{1}$ & 569 & 624 & 0,91 & 1,05 \\
\hline 9 Ehrmann & 520 & 420 & 1,24 & 1,39 \\
\hline 10 Meggle $^{1}$ & 517 & 405 & 1,28 & - \\
\hline
\end{tabular}

$\left.{ }^{1}\right)$ Konzern bzw. Gruppe; ${ }^{2}$ ) Ohne Weihenstephan und Müller UK; ${ }^{3}$ ) Konsolidierter Umsatz ohne Partnerunternehmen, Milchmenge incl.; ${ }^{4}$ ) Umsatz/Milchmenge; ${ }^{5}$ ) nur eG (Umsatz 924,9 Mio. € (916,4), Milchmenge 1244 Mio. kg (1 130) (Quelle: HumanA MiLCHUNION, 2005, in Klammern Zahlen für 2003)

Quelle: Deutsche Milchwirtschaft 2005; eigene Berechnungen

Der Strukturwandel in der Molkereiwirtschaft ist im Zeitraum von 1960 bis zum Jahr 2000 sehr schnell vorangeschritten (vgl. Abbildung 2). Die Zahl der Unternehmen verringerte sich von ca. 3000 auf 127. Auf diesem Niveau erfolgt die Branchenkonsolidierung derzeit etwas langsamer. Die Zahl der Unternehmen im Milchindustrieverband sank von 2002 auf 2003 um 5,1\% auf 112, die Anzahl der Betriebsstätten verringerte sich um 5,8\% auf 243 (vgl. Abbildung 2) (Milch \& Markt 2005). Im Jahr 2004 sind die Konzentrationsraten $\mathrm{CR}_{5}\left(\mathrm{CR}_{10}\right)$ (Umsatzanteil der fünf (zehn) größten Molkereien am Gesamtumsatz) im Vergleich zum Vorjahr von $41 \%$ auf $38 \%$ (56\% auf $53 \%$ ) zurückgegangen, was mit Umsatzrückgängen der fünf größten Molkereien zusammenhängt. In einzelnen Segmenten ist die Konzentration allerdings höher: Während bei Frischmilch neun Unternehmen rund $44 \%$ des Marktes auf 
sich vereinen (BMVEL 2005: 29), stehen die vier größten Schmelzkäsehersteller für $71 \%$ der Produktion (BMVEL 2005: 37). Die Käseproduktion ist ein stärker internationales Geschäft mit höheren economies of scale und entsprechend stärker konzentriert.

\section{ABBILDUNG 2: ANZAHL DER MOLKEREIUNTERNEHMEN NACH MIV 2005}

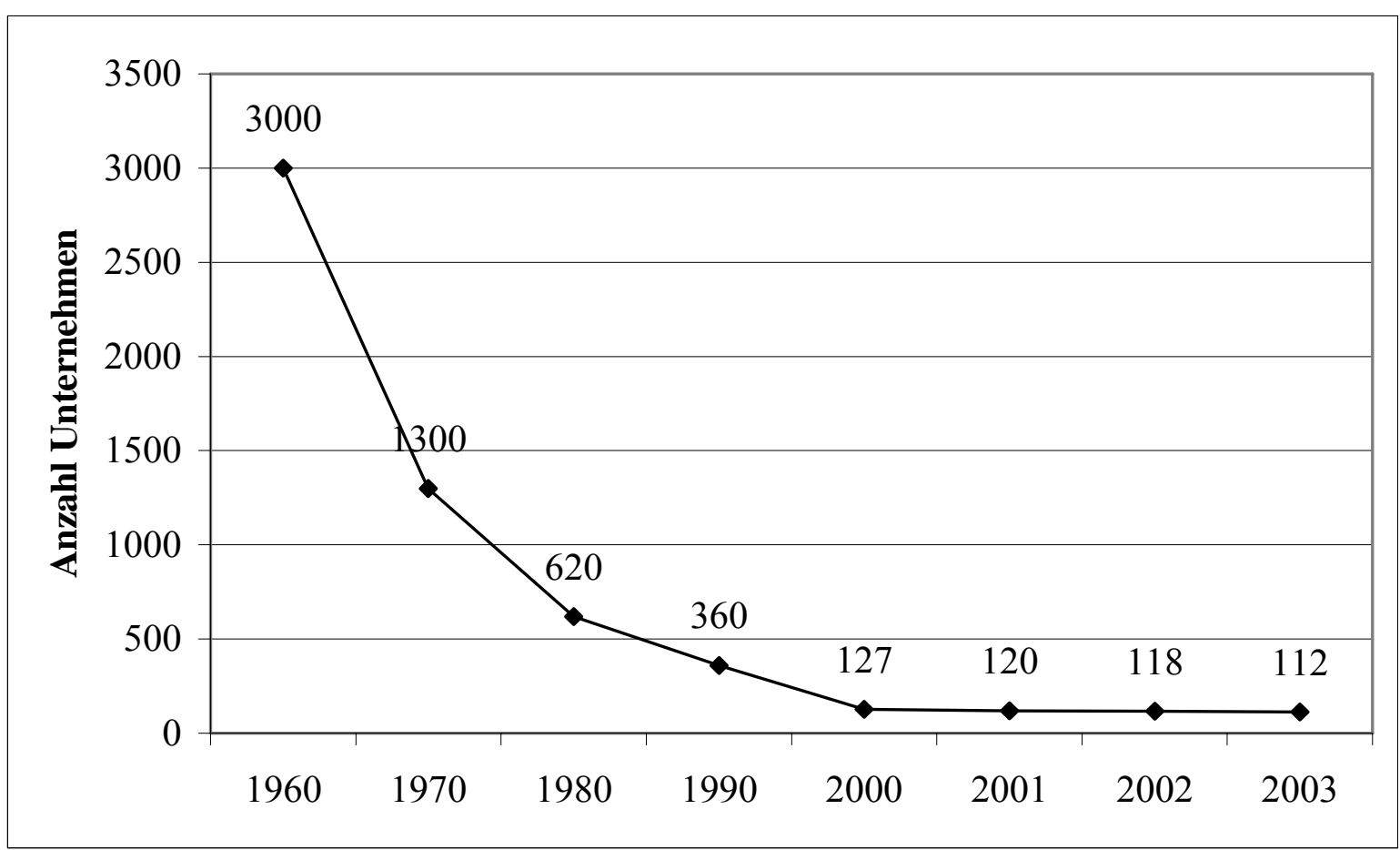

Quelle: Milch \& Markt 2005

Knapp $50 \%$ der gesamten Milch wurde 2003 in den 16 Unternehmen verarbeitet, die eine Milchverarbeitungsmenge von mehr als 500 Mio. kg aufweisen; 2000 waren dies lediglich $38 \%$ in 13 Molkereiunternehmen mit mehr als 500 Mio. kg Milchmenge (BMVEL 2005: 52) (vgl. auch Abbildung 3). Zu beachten ist, dass die Zahlen der Strukturerhebungen alle Unternehmen, die Milch be- und verarbeiten, Sauermilch- und Kochkäse sowie Schmelzkäse und Schmelzkäsezubereitungen herstellen, einschließen, also auch kleinere Hofkäsereien etc., wodurch die Gesamtzahl von der o. g. des Milchindustrieverbandes abweicht. 
ABBILDUNG 3: ANZAHL DER MOLKEREIUNTERNEHMEN NACH GRÖßENKLASSEN

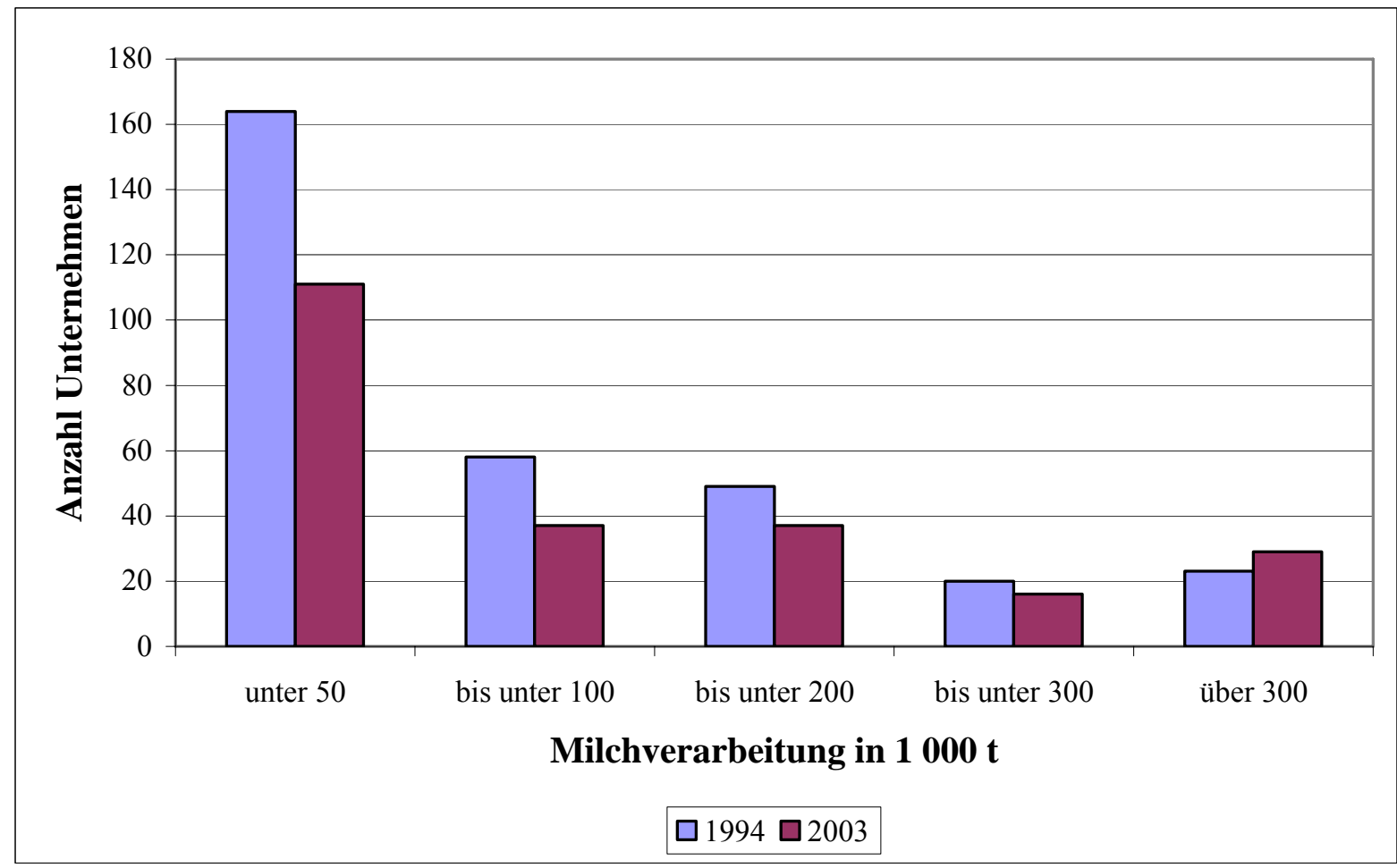

Quelle: eigene Darstellung nach BMVEL 2005: 52; ZMP 2005a: 37

Aufschlussreich für die Stärken und Schwächen der deutschen Molkereiindustrie ist eine Analyse der Import- und Export-Strukturen. Den deutschen Käseexporten in Höhe von $696200 \mathrm{t}$ in 2004 stehen Käseimporte von 518300 t gegenüber (ZMP 2005a: 145 u. 147). Tabelle 7 zeigt die Zielländer der Ausfuhren und die Herkunftsländer der Einfuhren, sowohl mengen- als auch wertmäßig. Aus diesen Zahlen lässt sich ein durchschnittlicher Wertindex in $€$ pro kg Käse errechnen. Über die wichtigsten Ländermärkte hinweg ergibt sich für die Importe ein durchschnittlicher Preis von 4,02 €/kg, für Exportkäse lediglich 2,84 €/kg. Mithin sind die deutschen Exporte im Wesentlichen niedrigpreisige Standardkäsesorten, die Importe dagegen überwiegend Spezialitäten. Der Blick auf einzelne Länder verdeutlicht dies. Insbesondere die als Käsespezialisten bekannten Länder Schweiz, Italien und Frankreich führen teure Käsesorten nach Deutschland ein. Italien und Frankreich bekommen im Gegenzug aus Deutschland Standardware wie Gouda, Feta und Mozzarella. Dies spiegelt die Handelsmarken- und Kostenführerschaftsstrategie deutscher Molkereien wider. 
TABELLE 7: HERKUNFTSLÄNDER DEUTSCHER KÄSEIMPORTE UND ZIELLÄNDER DEUTSCHER KÄSEEXPORTE 2004

\begin{tabular}{|l|c|c|c||l|c|c|c|}
\hline $\begin{array}{c}\text { Importe nach } \\
\text { Deutschland } \\
\text { von: }\end{array}$ & $\begin{array}{c}\text { in } \\
\mathbf{0 0 0} \mathbf{~ t}\end{array}$ & $\begin{array}{c}\text { in } \\
\text { Mio. } €\end{array}$ & $\begin{array}{c}\text { Wert- } \\
\text { index in } \\
\mathbf{\epsilon} / \mathbf{k g}\end{array}$ & $\begin{array}{c}\text { Exporte aus } \\
\text { Deutschland } \\
\text { nach: }\end{array}$ & $\begin{array}{c}\text { in } \\
\mathbf{1 0 0 0} \mathbf{~ t}\end{array}$ & $\begin{array}{c}\text { in } \\
\text { Mio. } €\end{array}$ & $\begin{array}{c}\text { Wert- } \\
\text { index in } \\
\mathbf{\epsilon} / \mathbf{k g}\end{array}$ \\
\hline \hline Niederlande & 176,2 & 630,02 & 3,58 & Italien & 203,4 & 599,64 & 2,95 \\
\hline Frankreich & 111,1 & 534,99 & 4,82 & Niederlande & 78,9 & 205,89 & 2,61 \\
\hline Dänemark & 78,7 & 294,47 & 3,74 & Frankreich & 60,0 & 179,70 & 3,00 \\
\hline Italien & 33,7 & 171,58 & 5,09 & Belgien & 40,6 & 114,85 & 2,83 \\
\hline Österreich & 28,0 & 102,77 & 3,67 & UK & 38,9 & 105,92 & 2,72 \\
\hline Luxemburg & 19,4 & 73,23 & 3,77 & Spanien & 36,8 & 104,58 & 2,84 \\
\hline Irland & 7,0 & 20,62 & 2,95 & Österreich & 36,7 & 121,23 & 3,30 \\
\hline Belgien & 6,7 & 27,10 & 4,04 & Griechenland & 21,7 & 63,03 & 2,90 \\
\hline \hline Schweiz & 10,4 & 78,29 & 7,53 & Russland & 54,8 & 137,07 & 2,50 \\
\hline Neuseeland & 4,2 & 9,39 & 2,24 & Japan & 14,1 & 32,62 & 2,31 \\
\hline \hline insgesamt & 518,3 & 2082,34 & 4,02 & insgesamt & 696,2 & 1978,24 & 2,84 \\
\hline
\end{tabular}

Quelle: ZMP 2005a; Zahlen für 2004 vorläufig; eigene Berechnungen

\subsection{Landwirtschaft}

Ein zentrales Thema bei Milcherzeugern ist die Agrarreform, deren Auswirkungen nun spürbar - insbesondere mit Blick auf die Milchauszahlungspreise - zum Tragen kommen. Die Senkung der Interventionspreise für Magermilchpulver (jeweils -5\% zum 1.7.2004 und 1.7.2005) und Butter (jeweils -7\%) sowie die mengenmäßige Einschränkung der Butterintervention schränken die Absicherung des Milchpreises ein. Ebenso wurden die EUExporterstattungen deutlich zurückgefahren. So beliefen sich diese z. B. für Emmentaler ab dem 15.07.2005 auf 56,18 €/100 kg, während im April 2004 noch 97,51 €/100 kg gezahlt wurden (ZMP 2005a: 200), was einer Senkung um rund $42 \%$ entspricht. Somit steht der Export von Milchprodukten unter starkem Druck. Die weitere Senkung der Exporterstattungen ist aufgrund der Ergebnisse der WTO-Verhandlungen vom Dezember 2005 unvermeidlich. Auch der Außenschutz und die interne Stützung z. B. durch Verbrauchsbeihilfen oder die Intervention werden weiter auf dem Prüfstand stehen und wesentlich zurückgefahren werden müssen (Römer 2005). Die aktuellen Haushaltsbeschlüsse der EU-Regierungschefs im Dezember 2005 werden den Druck auf eine Liberalisierung des Quotensystems und die Senkung der Agrarausgaben weiter erhöhen.

Die ZMP (2005a: 93) prognostiziert für 2005 einen Selbstversorgungsgrad der EU - bereinigt um den mit Beihilfen unterstützten Verbrauch - von 117\% (2003: 118\%; 2004: $116 \%$ ). Diese Überschussproduktion entwickelt, trotz einer Unterlieferung der Garantiemengen 2004/05 auf EU-Ebene von 1,3 Mio. t (ZMP 2005a: 195, Zahlen vorläufig), einen erheblichen Druck auf die Erzeugerpreise. Das Milchquotensystem, ursprünglich eingeführt, um den Mengenproblemen des EU-Milchmarktes entgegenzuwirken, ist damit heute als Instrument 
der Marktstabilisierung und Mengensteuerung ungeeignet. Die von der EU-Kommission für die Jahre 2006 bis 2008 beschlossene Quotenerhöhung um insgesamt 1,5\% wird dies weiter verschärfen.

Vor diesem Hintergrund und weil für die jetzt bei der Milchquotenbörse gehandelte Quote seit dem 1. Januar 2005 keine Direktzahlungen mehr von der EU gewährt werden, hatten viele Marktbeobachter mit einer Entwertung der Milchquoten gerechnet. Dies ist in Deutschland mit Blick auf einen durchschnittlichen Gleichgewichtspreis von $0,51 € / \mathrm{kg}$ Milchquote beim letzten Handelstermin der Milchquotenbörse im November 2005 nicht eingetreten. Vielmehr lagen die nicht ausgleichsberechtigten Quotenpreise am Ende des Jahres 2005 höher als in den zwei Jahren zuvor (vgl. Abbildung 4). In einzelnen Übertragungsregionen waren die Preise noch deutlich höher (z. B. Schleswig-Holstein/HH 0,70 €/kg, Niedersachsen/Bremen 0,61 $€ / \mathrm{kg})$. Niedriger lagen sie z. B. in Rheinland-Pfalz/Saarland $(0,46 € / \mathrm{kg})$, MecklenburgVorpommern $(0,39 € / \mathrm{kg})$ und Thüringen $(0,25 € / \mathrm{kg})$.

\section{ABBILDUNG 4: DURCHSCHNITTLICHER MILCHQUOTENPREIS SEIT EINFÜHRUNG DER} MILCHQUOTENBÖRSE

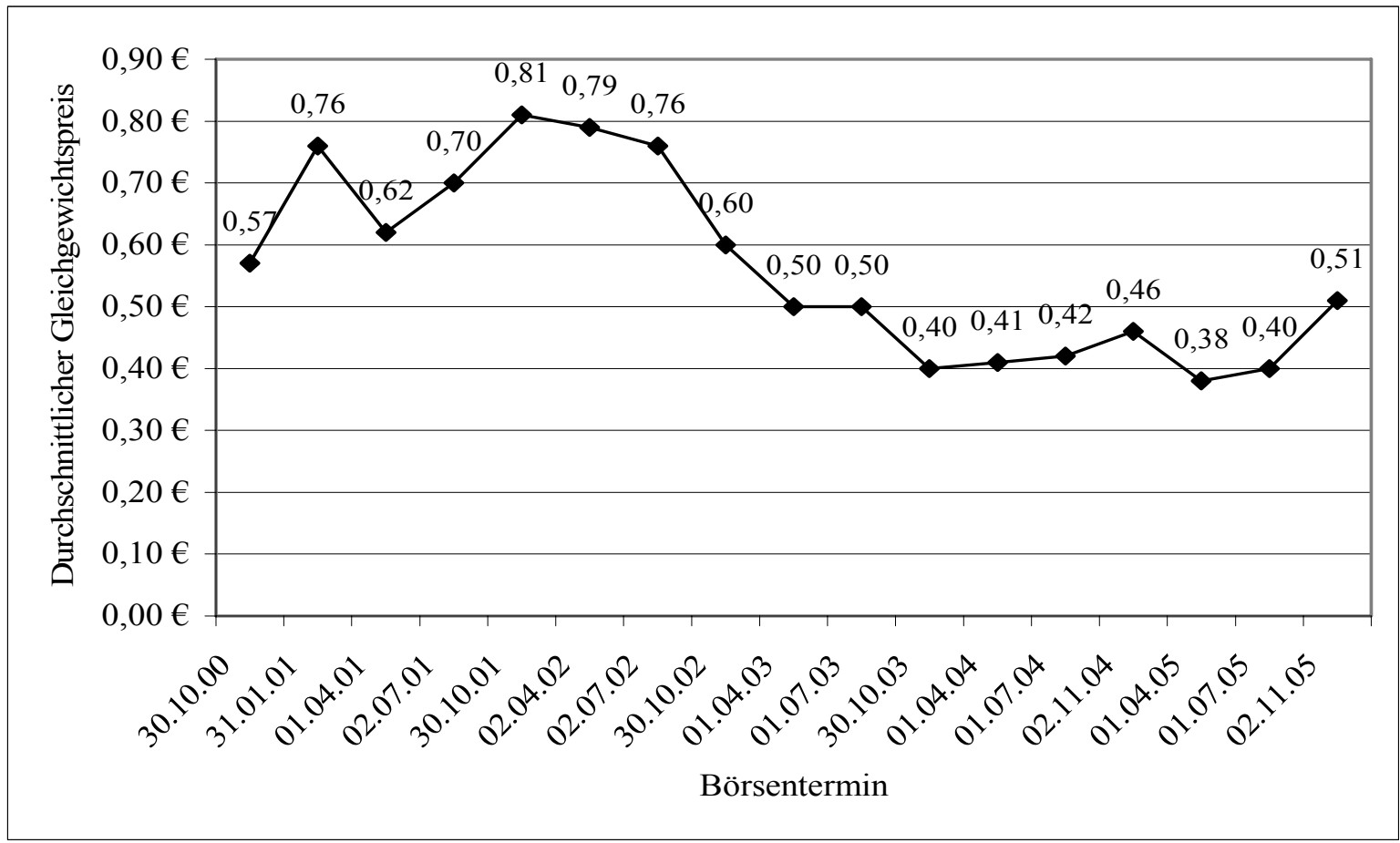

Quelle: eigene Darstellung nach ZMP 2005a: 28; ZMP 2005e; gewichteter Durchschnitt der Gleichgewichtspreise in den Übertragungsgebieten

Die deutschen Milcherzeuger überlieferten im Quotenjahr 2004/05 die Milchgarantiemenge um 403000 t, das entspricht 1,5\% (ZMP 2005a: 28). In keinem anderen EU-Land war die Überlieferung so hoch. Die Superabgaben betrugen in 2004/05 134,1 Mio. €; im Vorjahr 
lagen sie auch schon bei 129,0 Mio. € (ZMP 2005a: 28). Da sich eine Überlieferung für 2005/06 bereits andeutet (ZMP 2005d), könnte dies ein wichtiger Grund für die betriebswirtschaftlich überhöhten Quotenpreise des letzten Börsentermins sein. Auch die Diskussion um einen Wegfall der Molkereisaldierung, also der Verrechnung von Über- und Unterlieferungen, dürfte die Bereitschaft zum Quotenkauf erhöht haben, genauso wie die Tatsache, dass viele spezialisierte Betriebe ihr Einkommen hauptsächlich aus der Milchproduktion generieren oder Investitionen in neue Ställe getätigt haben und somit auf die Erlöse aus Milch angewiesen sind (Budde 2005). Die Anreize für eine Überlieferung sind für den einzelnen Milcherzeuger fallweise sehr hoch, vor allem, weil in der Vergangenheit durch die Saldierung die Wahrscheinlichkeit der Superabgabe in gewissem Maße kalkulierbar war. Alle Appelle zur Garantiemengendisziplin sind demnach wenig wirksam. Spieltheoretisch handelt es sich dabei um ein klassisches Gefangenendilemma (Güth 1999). Halten sich alle Milcherzeuger an ihre vorgegebene Milchquote, ist der Markt relativ im Gleichgewicht. Schert ein einzelner Landwirt aus und überliefert seine Quote, ist dies für ihn ein zusätzlicher Erlös, der Markt wird nicht wesentlich beeinträchtigt und durch die Saldierung wird keine oder nur eine geringe Superabgabe fällig. Verhalten sich aber eine Vielzahl von „Spielern“ so, ist das künstliche Marktgleichgewicht gefährdet und hohe Strafabgaben sind die Folge.

Angesichts der Milchmengenüberschüsse war die im ZMP-Milchpreisvergleich 2004 aufgezeigte Senkung des Milchauszahlungspreises um 1,7\% auf 29,4 Cent/kg zu erwarten (ZMP 2005f: 26). Tabelle 8 zeigt aber deutliche Unterschiede in einzelnen Regionen. Während in den nördlichen Bundesländern der generelle Abwärtstrend relativ zum Vorjahr gestoppt werden konnte, beschleunigt sich dieser im Süden und Westen - besonders in Hessen und Rheinland-Pfalz - überdurchschnittlich. Ein Grund dafür ist das vormals hohe Auszahlungspreisniveau der Molkereien in diesen Gebieten, das sich bei den aktuellen Rahmenbedingungen auf dem Milchmarkt offensichtlich nicht halten lässt. Im ersten Halbjahr 2005 ist der Milchpreis bei tatsächlichen Inhaltstoffen um 1,1\% auf 28,48 €/100 kg gesunken (ZMP 2005g); damit setzt sich der Abwärtstrend fort. 
TABELLE 8: ZMP-MILCHPREISVERGLEICH

\begin{tabular}{|l|c|c|c|c|c|c|}
\hline & $\mathbf{2 0 0 0}$ & $\mathbf{2 0 0 1}$ & $\mathbf{2 0 0 2}$ & $\mathbf{2 0 0 3}$ & $\mathbf{2 0 0 4}$ & $\begin{array}{c}\text { Veränderung } \\
\mathbf{2 0 0 4} \text { zu 2003 in \% }\end{array}$ \\
\hline \hline Nord & 31,0 & 33,5 & 29,6 & 28,4 & 28,5 & $+0,2$ \\
\hline \hline Schleswig-Holstein & 31,4 & 33,3 & 29,2 & 28,5 & 28,5 & $+0,1$ \\
\hline Mecklenburg-Vorpommern & 31,6 & 34,2 & 30,5 & 28,9 & 28,7 & $-0,7$ \\
\hline Niedersachsen & 30,6 & 33,4 & 29,4 & 28,3 & 28,4 & $+0,6$ \\
\hline \hline Ost & 31,1 & 34,1 & 31,2 & 29,9 & 29,3 & $-2,0$ \\
\hline \hline Brandenburg & 31,2 & 33,7 & 30,9 & 29,6 & 29,2 & $-1,6$ \\
\hline Sachsen & 31,4 & 34,5 & 31,5 & 30,0 & 29,5 & $-1,8$ \\
\hline Sachsen-Anhalt & 30,7 & 33,9 & 30,7 & 29,7 & 29,0 & $-2,2$ \\
\hline Thüringen & 31,0 & 33,8 & 31,9 & 30,4 & 29,4 & $-3,2$ \\
\hline West & 31,2 & 34,4 & 32,9 & 31,1 & 30,0 & $-3,4$ \\
\hline \hline NRW & 31,1 & 33,8 & 31,9 & 30,3 & 29,4 & $-3,1$ \\
\hline Hessen & 30,8 & 34,0 & 31,8 & 29,7 & 28,6 & $-3,9$ \\
\hline Rheinland-Pfalz & 31,8 & 35,7 & 34,8 & 32,6 & 31,4 & $-3,8$ \\
\hline \hline Süd & 32,2 & 35,1 & 32,2 & 30,7 & 29,9 & $-2,4$ \\
\hline Baden-Württemberg & 32,1 & 34,9 & 32,1 & 30,7 & 29,8 & $-3,0$ \\
\hline Bayern & 32,2 & 35,1 & 32,2 & 30,7 & 30,0 & $-2,3$ \\
\hline \hline Deutschland & 31,5 & 34,3 & 31,3 & 29,9 & 29,4 & $-1,7$ \\
\hline \hline
\end{tabular}

Vergleichspreis bei 4,2 \% Fett, 3,4 \% Eiweiß, inkl. aller Zu- u. Abschläge, ohne MwSt.

Quelle: ZMP 2005f: 26

Der Strukturwandel im Bereich der Milcherzeugung ist vor dem Hintergrund der Agrarreform und des sinkenden Milchpreises ein weiterhin viel diskutiertes Thema. Immer noch werden lediglich 52,8\% der Milchkühe in Beständen über 50 Tiere gehalten, während dies im Vereinigten Königreich $87 \%$, in Dänemark $82 \%$ und in den Niederlanden $75 \%$ sind (BMVEL 2005: 19). Der Milchkuhbestand nahm zwischen 2000 und 2004 um 6,1 \% ab (ZMP 2005a: 22). Dies ist zum Teil mit der Leistungssteigerung im gleichen Zeitraum von 7,6 \% zu erklären (2000: 6122 kg/Kuh u. Jahr; 2004: 6585 kg/Kuh u. Jahr). Insgesamt ist die durchschnittliche Milchleistung pro Kuh seit 1985 um 46,3 \% gestiegen (BMVEL 2005: 43).

Tabelle 9 zeigt die regionale Verteilung der Milchproduktion auf die Bundesländer und den Trend zur regionalen Verschiebung und Konzentration. In NRW geht der Milchkuhbestand deutlich weniger zurück als in den anderen Bundesländern. Innerhalb NRWs findet seit Einführung der Milchquotenbörse eine Wanderung der Milchquote von netto fast 20 Mio. $\mathrm{kg}$ ins Rheinland statt (Ernährungsdienst 2005: 2), wo traditionell größere Milchviehbetriebe angesiedelt sind. Besonders stark ist der Strukturwandel in den südlichen Bundesländern Baden-Württemberg und Bayern, die die geringste durchschnittliche Anzahl Kühe je Betrieb aufweisen. Bayern ist gleichwohl immer noch mit Abstand das Bundesland mit den meisten Milchkühen, gefolgt von Niedersachsen. Zugleich ist die Dichte der Milchkühe in Bayern mit durchschnittlich 39,9 Kühen/100 ha LF wesentlich höher als in Niedersachsen $(28,6$ Milchkühe/100 ha LF) (BMVEL 2005: 43). Lediglich in Schleswig-Holstein ist die 
Milchviehdichte mit 36,7 Milchkühen/100 ha LF ähnlich hoch. Die Neuen Bundesländer haben für die Milcherzeugung eine eher geringe Bedeutung, die Strukturen sind dort allerdings im Bundesvergleich überdurchschnittlich groß (161,1 Milchkühe/Betrieb).

TABELLE 9: VERÄNDERUNG DES MILCHKUHBESTANDS

\begin{tabular}{|l|c|c|c|}
\hline & $\begin{array}{c}\text { Veränderung 2004 zu } \\
\text { 2000 in \% }\end{array}$ & $\begin{array}{c}\text { Anteil der Milchkühe } \\
\text { am Gesamtbestand in \% }\end{array}$ & $\begin{array}{c}\text { Durchschnittliche } \\
\text { Anzahl Kühe/Betrieb* }\end{array}$ \\
\hline Baden-Württemberg & $-11,0$ & 8,9 & 24,3 \\
\hline Bayern & $-9,2$ & 30,3 & 23,4 \\
\hline Hessen & $-1,1$ & 3,7 & 28,8 \\
\hline Niedersachsen & $-2,5$ & 17,4 & 43,4 \\
\hline NRW & $-0,4$ & 8,9 & 37,3 \\
\hline Rheinland-Pfalz & $-3,7$ & 2,9 & 38,9 \\
\hline Saarland & $-4,0$ & 0,3 & 43,9 \\
\hline Schleswig-Holstein & $-3,3$ & 8,5 & 57,1 \\
\hline \hline ABL & $-5,9$ & 80,9 & 30,2 \\
\hline Brandenburg & $-8,9$ & 4,1 & 201,9 \\
\hline Mecklenburg- & $-3,2$ & 4,2 & 178,8 \\
\hline Vorpommern & $-6,0$ & 4,7 & 138,1 \\
\hline Sachsen & $-6,3$ & 3,2 & 167,3 \\
\hline Sachsen-Anhalt & $-9,2$ & 2,9 & 149,4 \\
\hline Thüringen & $-6,6$ & 19,1 & 161,1 \\
\hline NBL & $-6,1$ & 100 & 36,0 \\
\hline Deutschland ges. & & & \\
\hline
\end{tabular}

* Zahlen für 2003

Quelle: eigene Berechnungen nach ZMP 2005a: 22

Vor dem Hintergrund der skizzierten Strukturdefizite auf landwirtschaftlicher Seite kommt der Förderung größerer Betriebe von Seiten der Molkereien u. E. eine wichtige Bedeutung zu. Liefermengenzuschläge (Staffelpreise) sind ein Instrument, größeren Milcherzeugern einen besseren Milchauszahlungspreis zu gewähren. Im ZMP-Milchpreisvergleich zahlten 1997 lediglich 24 Molkereien einen Liefermengenzuschlag, während dies 2004 schon 60 Unternehmen waren (ZMP 2005f: 16). Die Differenz zwischen den Gesamtliefermengen $150000 \mathrm{~kg}$ und $500000 \mathrm{~kg}$ beträgt bei der Nordmilch und Milch-Union Hocheifel 0,5 Cent, bei Hochwald 0,8 Cent (ZMP 2005f: 64 u. 78). Bei der Humana Milchunion erfolgt die Mengendifferenzierung über ein Grundkostenmodell, der Preisunterschied beträgt zwischen 0,1 und $1 \mathrm{Cent} / \mathrm{kg}$ (ZMP 2005f: 72). Privatmolkereien zahlen häufig einen höheren Mengenzuschlag, wie z. B. die Milchwerke Gebrüder Bermes GmbH (ein Nordmilch-Tochterunternehmen) mit 1,4 Cent und die Rücker GmbH mit 1,1 Cent (ZMP 2005f: 78). In ostdeutschen Molkereiunternehmen greifen Staffelpreise i. d. R. erst oberhalb von 2 Mio. kg Jahresmilchmenge, haben aber insgesamt eine geringere Bedeutung (ZMP 2005f: 96). Insgesamt unterscheiden sich die Privatmolkereien von den genossenschaftlichen Molkereiunternehmen deutlich, da letztere aufgrund der genossenschaftlichen Philosophie Preisdifferenzierungen nur begrenzt in den internen Gremien durchsetzen können. Die erhobenen 
Grund- und Stoppkosten führen ebenfalls zu einer Differenzierung hinsichtlich der Milchmenge. Bei einer größeren Milchmenge sind die Kosten relativ je kg Milch geringer als bei einer kleineren Milchmenge (ZMP 2005f: 19).

\section{Globale und europäische Perspektiven der Milchwirtschaft}

\subsection{Konsumenten}

Die weltweite Nachfrage nach Molkereiprodukten wird mittelfristig weiter steigen. Gründe für diesen Aufwärtstrend liegen in dem steigenden Einkommen in vielen Regionen der Welt, aber auch im veränderten Konsumverhalten vieler Verbraucher, die Fleischerzeugnisse verstärkt durch Molkereiprodukte substituieren. Die größte Nachfragesteigerung wird in Nicht-OECD-Ländern erwartet, besonders in Asien, Lateinamerika und im Mittleren Osten. $\mathrm{Da}$ in vielen Industrieländern Milchprodukte fester Bestandteil der Ernährung sind, ist das Verbrauchsniveau sehr hoch und relativ konstant. Anders in Schwellen- und Entwicklungsländern: Durch das starke Bevölkerungswachstum, die Veränderungen im Ernährungsverhalten hin zu einem eher westlich geprägten Stil, die Urbanisierung der Bevölkerung sowie das steigende verfügbare Einkommen wird hier ein starker Nachfragezuwachs prognostiziert, besonders in Asien und Lateinamerika (European Commission 2005: 105). Während die weltwirtschaftlichen Wachstumsperspektiven insgesamt relativ positiv ausfallen, wird der Bevölkerungsanstieg in den nächsten Jahren etwas weniger zur Nachfrageentwicklung beitragen (vgl. Tabelle 10).

TABELLE 10: BEVÖLKERUNGS- UND EINKOMMENSWACHSTUM IN VERSCHIEDENEN REGIONEN (DURCHSCHNITTLICHE JÄHRLICHE WACHSTUMSRATEN ÜBER 10 JAHRE IN \%)

\begin{tabular}{|l|c|c|c|c|}
\hline & $\mathbf{1 9 9 5} \mathbf{- 2 0 0 4}$ & $\mathbf{2 0 0 5} \mathbf{- 2 0 1 4}$ & $\mathbf{1 9 9 5} \mathbf{- 2 0 0 4}$ & $\mathbf{2 0 0 5} \mathbf{- 2 0 1 4}$ \\
\hline & \multicolumn{2}{|c|}{ Bevölkerung } & \multicolumn{2}{c|}{ Einkommen } \\
\hline & $\%$ & $\%$ & 2,62 & $\%$ \\
\hline Welt & 1,27 & 1,01 & 3,37 & 3,10 \\
\hline Afrika & 2,28 & 1,83 & 3,02 & 3,80 \\
\hline Amerika & 1,36 & 1,04 & 2,61 & 3,24 \\
\hline Asien & 1,29 & 1,02 & 2,13 & 3,56 \\
\hline Europa & 0,01 & $-0,07$ & 3,51 & 3,40 \\
\hline Ozeanien & 1,15 & 0,73 & & 3,53 \\
\hline
\end{tabular}

Quelle: Weltbank, zitiert nach OECD/FAO 2005: 9

Hinsichtlich der Entwicklungen im weltweiten Konsum von Milchprodukten werden deutliche Unterschiede zwischen Industrie- und Entwicklungsländern und bezüglich der verschiedenen Produkte deutlich. In entwickelten Märkten stagniert z. B. der Konsum von Trinkmilch. In der EU-15 konnte nur noch in den südlichen Mitgliedsstaaten ein sehr 
bescheidenes Wachstum registriert werden, nachdem in früheren Jahrzehnten ein starker Anstieg verbucht wurde. Viele Haushalte sind in dieser Zeit von der Selbstversorgung zum Lebensmittelhandel gewechselt, der vor allem von der Entwicklung der Ultrahocherhitzung profitiert hat. Dieser Prozess ist zzt. auch in Mittel- und Osteuropa zu beobachten.

In den hoch entwickelten Volkswirtschaften sind es vornehmlich Innovationen wie die ESLTechnologie (siehe Kap. 2.1), die Anreicherung mit Vitaminen und/oder Proteinen oder die Laktosereduktion, die Wachstumsprozesse auslösen. Daher steigt in entwickelten Märkten zwar der Konsum von frischen Molkereiprodukten, einschließlich Milchgetränken, allerdings auf Kosten der traditionellen Trinkmilch. Der Konsum von Joghurt ist in diesem Segment bedeutsam, jedoch registrieren einige Märkte mit sehr hohem Konsum inzwischen Stagnationstendenzen. Ein Blick auf den Pro-Kopf-Verbrauch von Frischeprodukten zeigt deutliche Unterschiede (vgl. Tabelle 11). Führend sind demnach die Niederländer mit $42 \mathrm{~kg}$ pro Jahr und Kopf (IDF 2005: 24ff.).

TABELLE 11: PRO-KOPF-KONSUM VON MILCHFRISCH-PRODUKTEN IN KG/KOPF

\begin{tabular}{|l|c|c|c|c|}
\hline & $\mathbf{2 0 0 1}$ & $\mathbf{2 0 0 2}$ & $\mathbf{2 0 0 3}$ & $\mathbf{2 0 0 4}$ \\
\hline Dänemark & 37,0 & 40,7 & 43,0 & 44,6 \\
\hline Deutschland & 26,1 & 27,0 & 28,5 & 28,9 \\
\hline Spanien & & 21,2 & 24,4 & 24,0 \\
\hline Frankreich & 20,5 & 21,1 & 21,9 & 21,9 \\
\hline Niederlande & 44,6 & 42,8 & 42,5 & 42,0 \\
\hline Schweden & 36,7 & 34,8 & 34,9 & 34,5 \\
\hline EU 15 & $\mathbf{1 8 , 2}$ & $\mathbf{1 8 , 1}$ & $\mathbf{1 9 , 3}$ & $\mathbf{1 9 , 6}$ \\
\hline Tschechien & 14,3 & 14,1 & 14,8 & 14,9 \\
\hline Ungarn & 11,5 & 11,9 & 14,3 & 15,4 \\
\hline Polen & 8,7 & 11,1 & 11,5 & 11,9 \\
\hline Slowakei & 12,5 & 15,0 & 13,1 & 12,4 \\
\hline 10 neue EU-Mitgliedsstaaten & 9,1 & 10,5 & 10,7 & 11,1 \\
\hline EU 25 & $\mathbf{1 6 , 7}$ & $\mathbf{1 7 , 5}$ & $\mathbf{1 7 , 9}$ & $\mathbf{1 8 , 2}$ \\
\hline Norwegen & 19,0 & 20,0 & 20,7 & 21,1 \\
\hline Schweiz & 24,2 & 23,7 & 25,6 & 27,0 \\
\hline Ukraine & 4,4 & 5,4 & 5,7 & \\
\hline Kanada & 5,2 & 5,7 & 6,2 & 6,7 \\
\hline Mexiko & 3,1 & 3,2 & 3,8 & 3,9 \\
\hline Argentinien & 7,3 & 6,8 & 7,3 & 9,4 \\
\hline China & 0,3 & 0,4 & 0,6 & 1,5 \\
\hline Südafrika & 3,2 & 3,2 & 1,3 & \\
\hline
\end{tabular}

Quelle: IDF 2005: 70

Bei Butter stagniert die Nachfrage in entwickelten Märkten oder geht leicht zurück. Dabei hat sich der Nachfragerückgang in den vergangenen Jahren verlangsamt. Der Konsum in Frankreich mit dem weltweit höchsten Niveau nimmt noch ab, während sich der deutsche ebenso wie der russische Markt stabilisiert hat. Hintergrund der insgesamt besseren Prognosen für Butter ist der verstärkte Einsatz in verarbeiteten Produkten (IDF 2005: 31). 
Der Käseverbrauch steigt i. A. weiterhin, die Wachstumsraten sind jedoch umso geringer, je höher der aktuelle Verbrauch ist, was sich z. B. am französischen Markt zeigt, wo der Konsum in den letzten zwei Jahren zurückgegangen ist. In Griechenland hingegen ist der ProKopf-Verbrauch auf höherem Niveau stabil. Trotz des französischen Beispiels werden auch in absehbarer Zeit die Industrieländer den Käsemarkt dominieren (IDF 2005: 32). Dies liegt an der prozentualen Verteilung des Käsekonsums (vgl. Tabelle 12). Etwa 80 \% der Käseprodukte werden in entwickelten Märkten verzehrt. Selbst bei einem sehr starken Anstieg des Käsekonsums z. B. in China würde sich dies kaum auf den Weltmarkt auswirken, da der chinesische Konsum nur $0,1 \%$ des Weltkäsekonsums ausmacht (IFAP 2005). Ein wesentlicher Treiber für Steigerungen in der Käsenachfrage in den Industrieländern ist der Außer-Haus-Bereich (IDF 2005: 33). 
TABELLE 12: KÄSEKONSUM ${ }^{1}$ IN KG/KOPF

\begin{tabular}{|c|c|c|c|c|}
\hline & 2001 & 2002 & 2003 & 2004 \\
\hline Deutschland & 21,6 & 21,7 & 21,7 & 21,9 \\
\hline Griechenland & 26,6 & 27,5 & 28,7 & 28,7 \\
\hline Spanien & 8,7 & 9,1 & 9,5 & 9,5 \\
\hline Frankreich & 25,8 & 25,0 & 24,8 & 24,5 \\
\hline Irland & 10,3 & 10,3 & 11,2 & 10,4 \\
\hline Italien & 21,4 & 20,6 & 21,1 & 19,8 \\
\hline Niederlande & 14,7 & 14,7 & 14,7 & 14,7 \\
\hline Österreich & 17,5 & 17,8 & 18,4 & 18,8 \\
\hline Findland & 16,6 & 16,5 & 16,6 & 18,3 \\
\hline Schweden & 17,3 & 17,6 & 17,6 & 17,9 \\
\hline UK & 10 & 10,8 & 10,9 & 11,3 \\
\hline EU 15 & 18,8 & 18,7 & 18,9 & 19,1 \\
\hline Tschechien & 10,2 & 14,4 & 14,7 & 15,7 \\
\hline Lettland & 7,9 & 10,4 & & \\
\hline Ungarn & 8,7 & 8,9 & & \\
\hline Polen & 10,9 & 10,1 & 10,3 & 10,4 \\
\hline Slowakei & 6,3 & 9,1 & 9,1 & 9,3 \\
\hline 10 EU Neu-Mitgliedsstaaten ${ }^{2}$ & 11,5 & 11,7 & 12,0 & 12,0 \\
\hline EU 25 & $\mathbf{1 7 , 5}$ & 17,6 & 17,8 & 18,0 \\
\hline Schweiz & 18,2 & 18,3 & 18,4 & 20,0 \\
\hline Russland & 5,3 & 5,5 & 5,6 & \\
\hline Kanada & 14,1 & 13,9 & 14,1 & 14,3 \\
\hline USA & 15,1 & 15,3 & 15,4 & 15,7 \\
\hline Argentinien & 11,5 & 9,6 & 8,3 & 8,9 \\
\hline Mexiko & 1,9 & 2,0 & 1,9 & 1,9 \\
\hline Australien & 11,6 & 12,0 & 12,0 & 12,3 \\
\hline Neuseeland & 7,3 & 7,1 & 7,1 & 7,1 \\
\hline Japan & 1,9 & 1,8 & 1,8 & \\
\hline Südafrika & 1,0 & 1,0 & 0,8 & 0,6 \\
\hline
\end{tabular}

1) abhängig von der Verfügbarkeit der Daten, einschließlich Hüttenkäse, Quark und Schmelzkäse; ${ }^{2)}$ teilweise geschätzt Quelle: IDF 2005: 69

Zusammenfassend lässt sich festhalten, dass für die weltweite Nachfrage vor allem die Bevölkerungs- und Einkommensentwicklung wichtig sind. Zudem haben Innovationen, Kühlkapazitäten, verlängerte Haltbarkeit und Marketingmaßnahmen Einfluss auf die Nachfrage. OECD und FAO prognostizieren, dass in den nächsten zehn Jahren der Konsum von Molkereiprodukten in den OECD-Ländern abnehmen wird, mit Ausnahme des Käsekonsums, der um $17 \%$ steigt. In den Nicht-OECD-Ländern wird aber ein Anstieg für alle Produkte erwartet. Für Butter, Käse und Vollmilchpulver (WMP) wird ein Wachstum von jährlich $3 \%$ prognostiziert, für Magermilchpulver (SMP) von $1 \%$ pro Jahr (vgl. Abbildung 5) (OECD/FAO 2005: 88). 


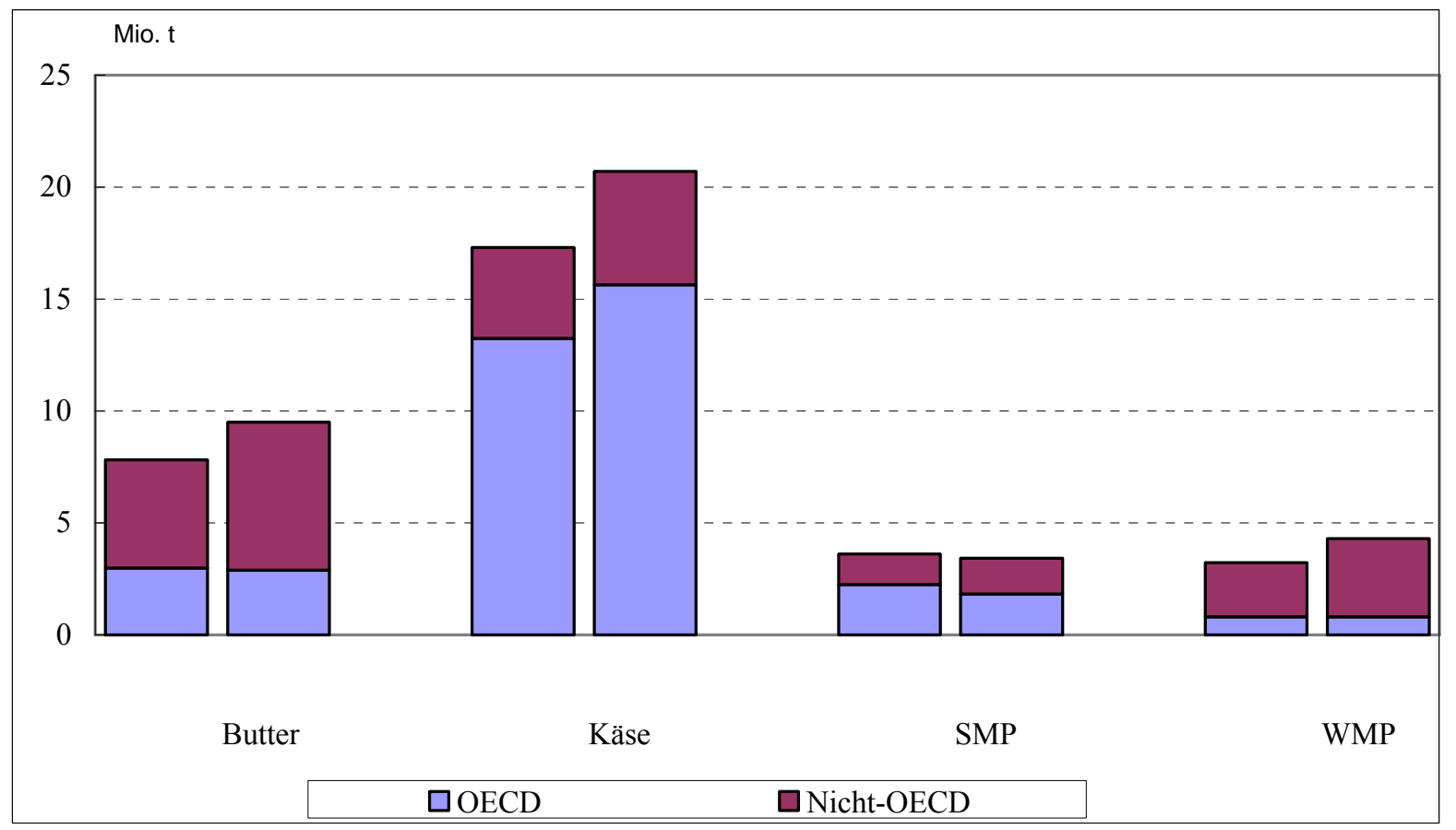

Quelle: OECD/FAO 2005: 88

\subsection{Lebensmitteleinzelhandel}

Die internationale Konzentration im Lebensmitteleinzelhandel ist für die deutsche Milchwirtschaft Chance und Risiko zugleich. Sie verstärkt die Abhängigkeit von einigen wenigen großen Kontrakten, bietet aber zugleich angesichts des Erfolges deutscher Händler im Ausland die Möglichkeit, als Lieferant mit der Handelsseite zu wachsen. Der internationale Zentraleinkauf des Handels gewinnt langsam, aber kontinuierlich an Bedeutung. Bei Milchprodukten gilt dies insbesondere für höher veredelte und länger haltbare Erzeugnisse wie Käse. Während die Handelsunternehmen bei Frischmilch heute i. d. R. auch innerhalb Deutschlands aufgrund der Transportkosten unterschiedliche Lieferanten für die jeweiligen Regionen haben, können für hoch veredelte oder haltbare Artikel „Euro-Verträge“ abgeschlossen werden. Damit gewinnt der internationale Standortwettbewerb weiter an Relevanz.

Insgesamt ist die Internationalisierung des Lebensmitteleinzelhandels noch nicht so weit fortgeschritten, wie dies die öffentliche Diskussion um die Nachfragemacht der Handelskonzerne vermuten lässt. In den großen europäischen Ländermärkten Großbritannien, Frankreich und Deutschland dominieren weiterhin einheimische Anbieter. Der relativ geringe Anteil des Auslandsumsatzes am Gesamtergebnis der meisten Handelsunternehmen zeigt, dass sie im Kern noch durch den Heimatmarkt geprägt sind. Ausnahmen sind Carrefour, Ahold und Metro. Die deutschen Discounter treiben ihre Standortexpansion jedoch ebenfalls voran. 
Tabelle 13 belegt, dass der Handel noch kein globales Geschäft ist. Aufschlussreich ist in dieser Hinsicht auch ein Blick auf den chinesischen Markt, der derzeit von vielen Unternehmen aufgrund seiner Wachstumsdynamik und Bevölkerungsgröße sondiert wird. Der Markteintritt von Unternehmen wie Wal-Mart, Metro und Carrefour in China gestaltet sich trotz globaler Marktführerschaft und Erfahrung im Bereich der Internationalisierung schwierig. Die Markterschließung erfolgt vornehmlich über die Metropolen wie Peking oder Shanghai. Carrefour führt beispielsweise fünf Großflächenoutlets in Peking und insgesamt 59 in ganz China (Sellami 2005). Neben den „China-Pionieren“ Wal-Mart, Carrefour und Metro finden sich auch Convenience-Store-Betreiber wie Seven-Eleven, der spanische Discounter DIA oder das französische SB-Warenhausunternehmen Auchan.

TABELLE 13: ÜBERBLICK ÜBER DIE ZEHN WELTWEIT FÜHRENDEN LEBENSMITTELHÄNDLER 2004

\begin{tabular}{|l|c|c|c|c|}
\hline \multicolumn{1}{|c|}{ Unternehmen } & $\begin{array}{c}\text { Wichtige Vertriebs- } \\
\text { typen }\end{array}$ & $\begin{array}{c}\text { Nettoumsatz 2004 } \\
\text { (Mio. USD) }\end{array}$ & Heimatland & $\begin{array}{c}\text { Auslandsumsatz } \\
\text { in \% }\end{array}$ \\
\hline Wal-Mart & HM/C\&C & 285,222 & USA & 22,2 \\
\hline Carrefour & HM/SM/DI & 90,284 & Frankreich & 50,9 \\
\hline Metro & C\&C/HM & 70,065 & Deutschland & 47,7 \\
\hline Ahold & SM/HM & 64,588 & Niederlande & 83,4 \\
\hline Tesco & HM/SM & 62,219 & Großbritannien & 20,7 \\
\hline Kroger & HM & 56,434 & USA & 0,0 \\
\hline Rewe & SM/HM/DI & 50,677 & Deutschland & 28,4 \\
\hline Costco & C\&C & 47,146 & USA & 19,7 \\
\hline Target & Wareh.stores/HM & 46,893 & USA & 0,0 \\
\hline Auchan* & HM/SM & 44,688 & Frankreich & 45,6 \\
\hline
\end{tabular}

HM = Hypermarkt; SM = Supermarkt; DI = Discountgeschäft; C\&C = Cash \& Carry Großhandel; * = Schätzung Quelle: LZ-Net 2005c

Insgesamt sind bis heute 108 ausländische Handelsunternehmen in China vertreten (Fiducia Management Consulting 2005). Dennoch dominieren heimische Unternehmen den Gesamtmarkt (siehe Tabelle 14). Der auf China bezogene kumulierte Umsatz der drei führenden internationalen Handelsunternehmen Carrefour, Wal-Mart und Metro für das Jahr 2004 beträgt lediglich 2,77 Mrd. €, die chinesische Shanghai Bailian Group konnte im Jahr 2003 dagegen mit 6,20 Mrd. $€$ einen mehr als doppelt so hohen Umsatz erzielen (Fiducia Management Consulting 2005). Der Gesamtmarktanteil ausländischer Handelsunternehmen betrug im Jahr 2004 lediglich 2,6\%, mithin nur eine geringe Steigerung zu 2,3\% im Jahr 2003 (Shenzhen Daily 2005). Die Zahlen weisen zusammenfassend darauf hin, dass für deutsche Molkereien aufgrund der Vertriebsstrukturen bisher wenig Absatzpotenzial in China zu erkennen ist. 
TABELLE 14: UMSATZ AUSGEWÄHLTER CHINESISCHER UND INTERNATIONALER FILIALISTEN 2004

\begin{tabular}{|c|l|c|c|}
\hline Rang & \multicolumn{1}{|c|}{ Chain Stores } & $\begin{array}{c}\text { Umsatz 2004 } \\
(\mathbf{M r d .} \boldsymbol{\epsilon})\end{array}$ & $\begin{array}{c}\text { Umsatzwachstum } \\
\mathbf{2 0 0 3 / 0 4} \text { in \% }\end{array}$ \\
\hline 1 & Shanghai Bailian & 6,20 & 22,5 \\
\hline 2 & GOME Electrical Appliance & 2,19 & 34,3 \\
\hline 3 & Dalian Dashang Group & 2,11 & 27,0 \\
\hline 4 & Suning Appliance & 2,03 & 79,6 \\
\hline 5 & Carrefour (China) & 1,49 & 20,9 \\
\hline 7 & China Resources Suguo Supermarket & 1,27 & 44,9 \\
\hline 14 & Yum! Brands & 1,09 & 26,2 \\
\hline 15 & China Resources Vanguard & 1,02 & 6,7 \\
\hline 20 & Supermarket & 0,70 & 30,5 \\
\hline 23 & Mal-Mart China & 0,58 & 13,2 \\
\hline
\end{tabular}

Quelle: Fiducia Management Consulting 2005

Deutlich wichtiger ist aufgrund des vergleichsweise geringen Exportes in Nicht-EU-Länder die Entwicklung im europäischen LEH. Der führende europäische Lebensmitteleinzelhändler, die französische Carrefour-Gruppe, die in Frankreich, Belgien und Griechenland Marktführer ist, erzielte im Jahr 2004 einen Umsatz von 76,3 Mrd. €, davon 52,7 Mrd. € mit Lebensmitteln (LZ 2005i: 15). Die Konzentrationsrate $\mathrm{CR}_{5}$ (Anteil der führenden 5 Händler) lag 2004 bei $23 \%$ und ist damit seit 1999 (23,9\%) sogar leicht gesunken (1994: 17,2\%; 1991: 15,8 \%).

In jüngerer Zeit deuten sich allerdings weitere Internationalisierungsschritte an. Aldi, bisher in Osteuropa nicht aktiv, sondiert z. B. in Polen. Die Schwarz-Gruppe (Lidl, Kaufland) verstärkt ihr Engagement. Zum Beispiel bereitet sie ebenso wie die Rewe einen massiven Einstieg in Bulgarien vor. Metro eröffnete 2005 ein erstes SB-Warenhaus in Russland. Tabelle 15 gibt einen Überblick über die Expansion der führenden europäischen Konzerne in wichtige mittelund osteuropäische Länder. 
TABELLE 15: OSTEUROPAEXPANSION FÜHRENDER EUROPÄISCHER LEBENSMITTELHÄNDLER 2004 (UMSATZ IN MRD. €)

\begin{tabular}{|l|c|c|c|c|c|c|c|c|c|c|}
\hline & $\begin{array}{c}\text { Anzahl } \\
\text { Outlets } \\
\text { in 1 000 }\end{array}$ & $\begin{array}{c}\mathbf{C R}_{\mathbf{5}} \\
\text { in \% }\end{array}$ & Rewe & Metro & $\begin{array}{c}\text { Schwarz } \\
\text {-Gruppe }\end{array}$ & $\begin{array}{c}\text { Tengel- } \\
\text { mann }\end{array}$ & $\begin{array}{c}\text { Carre- } \\
\text { four }\end{array}$ & Tesco & Auchan & Ahold \\
\hline Polen & $112,9^{*}$ & 24,0 & 0,61 & 2,91 & 1,05 & 0,65 & 0,85 & 1,15 & 0,95 & 1,07 \\
\hline Rumänien & n. b. & 31,8 & 0,47 & 1,01 & - & i. V. & 0,27 & - & - & - \\
\hline Russland & $297,2^{* *}$ & 9,3 & 0,14 & 1,04 & - & - & - & - & 0,63 & - \\
\hline Slowakei & 12,1 & 33,4 & 0,25 & 0,33 & 0,34 & - & 0,16 & 0,61 & - & 0,17 \\
\hline Tschechien & $19,5^{*}$ & 34,9 & 0,71 & 1,13 & 1,32 & 0,58 & 0,30 & 0,71 & - & 1,07 \\
\hline Ukraine & $58,0^{* *}$ & 24,7 & 0,06 & 0,14 & - & - & - & - & - & - \\
\hline Ungarn & $24,8^{*}$ & 60,0 & 0,52 & 1,16 & - & 0,61 & - & 1,65 & 0,72 & - \\
\hline
\end{tabular}

i. V. = in Vorbereitung; $\mathrm{n}$ b. $=$ nicht bekannt; $*=2003 ; * *=$ inkl. Convenience-Shops

Quelle: eigene Zusammenstellung nach LZ 2005 i und http://www.lz-net.de

Tabelle 15 enthält zunächst die Anzahl der Lebensmittelgeschäfte in den jeweiligen Ländern. Bezieht man diese auf die Zahl der Einwohner, dann findet sich in Polen die größte Geschäftsstättendichte. Auch in Ungarn, der Slowakei oder Tschechien gibt es eine große Zahl kleinbetrieblicher Einkaufsstätten (LZ 2005i: 12). In Polen liegt der Anteil der traditionellen Lebensmittelgeschäfte und Märkte am Gesamtumsatz noch bei über $50 \%$ (Brettschneider 2004). Der Konzentrationsgrad unterscheidet sich beachtlich. In Ungarn haben die führenden fünf Handelsunternehmen, unter ihnen auch drei einheimische Gruppen, bereits einen Marktanteil von ca. 60 \% erreicht, während in Russland der Lebensmittelhandel noch extrem fragmentiert ist. Der Blick auf die führenden westeuropäischen Handelskonzerne zeigt, dass nur Metro und Rewe eine flächendeckende Expansionspolitik in Osteuropa betreiben.

Das Osteuropa-Engagement der westeuropäischen Handelskonzerne verläuft nicht ohne Rückschläge. Hohe Logistikkosten, verschärfte Bauregelungen wie in Polen, aggressive einheimische Wettbewerber wie in Russland und die bekannten Korruptionsprobleme verzögern die Expansion (Dawson 2006: 48). Insgesamt deuten diverse Standortkonsolidierungen zwischen den internationalen Konzernen darauf hin, dass diese ihre Internationalisierung aufgrund der skizzierten Probleme zunächst auf ausgewählte Märkte konzentrieren. So hat Tesco die in Tabelle 15 aufgeführten Betriebe von Carrefour in Tschechien und der Slowakei übernommen und im Gegenzug sein Taiwan-Geschäft an Carrefour abgegeben (Dawson 2005). Die Schwarz-Gruppe (Lidl, Kaufland) hat zzt. erst drei osteuropäische Märkte erschlossen, ist in diesen aber relativ stark vertreten.

Für die deutsche Molkereiwirtschaft ergeben sich aus der dargestellten Entwicklung erhebliche Potenziale, um mit den bisherigen Kunden in deren Wachstumsmärkte zu 
expandieren. Dies trifft gleichermaßen auf das Marken- wie auf das Handelsmarkengeschäft zu. Die starke Position der deutschen Molkereien im Niedrigpreissegment bietet gerade für letzteres erhebliche Potenziale, auch wenn damit die Abhängigkeit vom Discountgeschäft noch weiter zunimmt.

\subsection{Molkereiwirtschaft}

Die internationale Molkereiwirtschaft ist in den vergangenen Monaten durch verstärkte Konsolidierungsanstrengungen charakterisiert worden, so dass die gescheiterte Fusion zwischen Arla Foods und Campina bereits eines der wichtigsten Ereignisse darstellte. Nachdem im Jahr zuvor bereits die Fusionsgespräche zwischen Nordmilch und Humana Milchunion erfolglos verlaufen waren, zeigten sich erneut große Bedenken hinsichtlich umfassender Fusionen. Im Fall Arla/Campina waren es wohl nicht zuletzt die Mitglieder im Umfeld des Vorstandes von Arla, die das Scheitern herbeigeführt haben (LZ 2005g: 25). Arla/Campina wäre mit einem Umsatz von knapp $10 \mathrm{Mrd}$ € der weltweit zweitgrößte Molkereikonzern geworden.

Unter den umsatzstärksten 20 Molkereiunternehmen weltweit hat sich im Vergleich zum Vorjahr wenig verändert (vgl. Tabelle 16). Neben der schweizerischen Nestlé sind 11 der 20 Milchverarbeiter europäische Unternehmen, darunter aber nur zwei deutsche. Humana Milchunion und Nordmilch rangieren lediglich am unteren Ende der Liste, obwohl Deutschland mit 28245000 t der größte europäische Milcherzeuger ist (ZMP 2005a: 96). Im internationalen Vergleich sind deutsche Milchverarbeiter auf das Niedrigpreissegment fokussiert, so dass ihre Umsatzbedeutung geringer ist, als dies der Milchverarbeitung nach zu erwarten wäre. 
TABELLE 16: DIE 20 UMSATZSTÄRKSTEN MOLKEREIUNTERNEHMEN WELTWEIT

\begin{tabular}{|c|c|c|c|c|}
\hline & Unternehmen & Land & $\begin{array}{c}\text { Umsatz des Milchgeschäfts in } \\
\text { Mrd. } € 2004\end{array}$ & $\begin{array}{c}\text { Umsatz des Milchgeschäfts in } \\
\text { Mrd. } € 2003\end{array}$ \\
\hline 1 & Nestlé & SUI & 14,7 & 15,3 \\
\hline 2 & Dean Foods & USA & 7,0 & 6,3 \\
\hline 3 & $\begin{array}{l}\text { Dairy Farmers of } \\
\text { America }\end{array}$ & USA & 6,8 & 6,1 \\
\hline 4 & Danone & FRA & 6,5 & 6,2 \\
\hline 5 & Arla Foods & DEN/SWE & 6,4 & 5,5 \\
\hline 6 & Fonterra & NZL & 6,3 & 6,1 \\
\hline 7 & Lactalis & FRA & 5,7 & 5,4 \\
\hline 8 & Kraft Foods & USA & 5,0 & 5,0 \\
\hline 9 & Unilever & NED/GBR & 4,8 & 5,2 \\
\hline 10 & Friesland Foods & NED & 4,3 & 4,4 \\
\hline 11 & Bongrain & FRA & 4,1 & 4,0 \\
\hline 12 & Meiji Dairies & JPN & 3,7 & 3,8 \\
\hline 13 & Campina & NED & 3,6 & 3,7 \\
\hline 14 & $\begin{array}{l}\text { Morinaga Milk } \\
\text { Industry }\end{array}$ & JPN & 3,3 & 3,5 \\
\hline 15 & Parmalat & ITA & 3,3 & 4,5 \\
\hline 16 & Land O'Lakes & USA & 3,2 & 2,7 \\
\hline 17 & Humana Milchunion $^{1}$ & GER & 2,7 & 2,7 \\
\hline 18 & Saputo & CAN & 2,3 & 2,2 \\
\hline 19 & Schreiber Foods & USA & 2,3 & - \\
\hline 20 & Nordmilch & GER & 2,1 & 2,2 \\
\hline
\end{tabular}

$\left.{ }^{1}\right)$ Umsatz hier höher als in anderen Publikationen, evtl. inkl. Partnerunternehmen

Quelle: RABOBANK 2005, zitiert nach IDF 2005; RABOBANK, 2004, zitiert nach IDF 2004

Die Internationalisierung ist nach wie vor ein wichtiger Aspekt der globalen Molkereiwirtschaft. Betrachtet man den Internationalisierungsgrad bei Genossenschaften, so zeigen sich deutliche Unterschiede zwischen einzelnen Unternehmen (vgl. Abbildung 6). Während die größten europäischen Molkereiunternehmen Arla Foods, Friesland und Campina mehr als die Hälfte ihres Umsatzes außerhalb des Heimatmarktes realisieren, deuten sich bei den deutschen genossenschaftlichen Milchverarbeitern Schwächen in diesem Punkt an. Problematisch ist insbesondere, dass sich die Auslandsaktivitäten häufig auf den Export beschränken. Vor dem Hintergrund der zunehmenden Liberalisierung des internationalen Handels, der skizzierten Internationalisierung des LEH und der Absenkung der EU-Exporterstattungen gewinnen Direktinvestitionen jedoch an Relevanz. 
ABBILDUNG 6: INTERNATIONALISIERUNGSGRAD EUROPÄISCHER MOLKEREIGENOSSENSCHAFTEN 2003

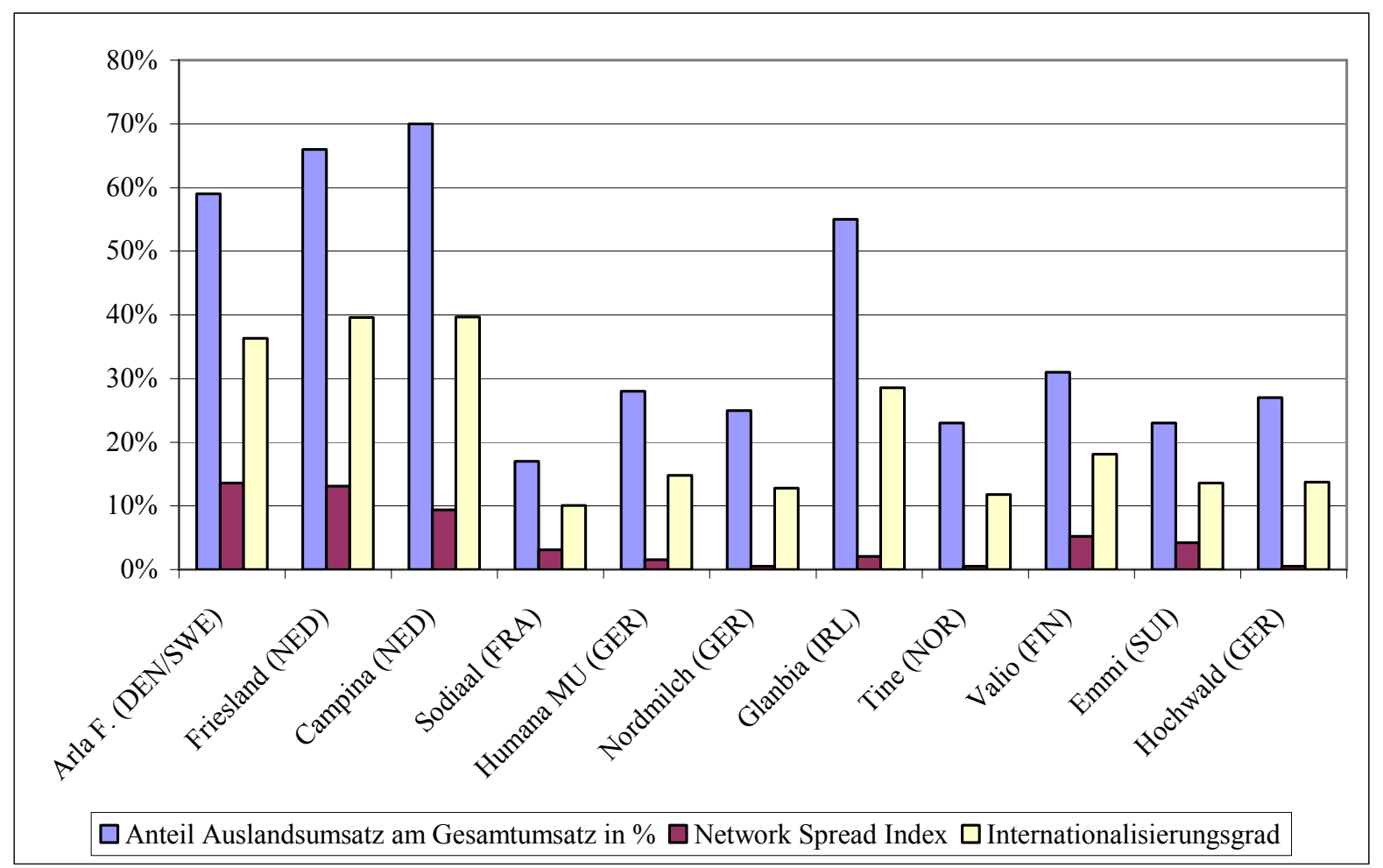

Quelle: EBNETH 2005

Ausnahmen sind neben Müller einige mittelständische Privatmolkereien wie Meggle, Hochland und Ehrmann, die Produktionsanlagen in Osteuropa - z. T. auch in Südeuropa aufgebaut bzw. übernommen haben. Hochland bspw. konnte im Jahr 2004 bei den osteuropäischen Tochterunternehmen eine Umsatzsteigerung von $7 \%$ erwirtschaften, während der Umsatz in Deutschland trotz der Absatzsteigerung von $2 \%$ gleich geblieben ist (Murmann 2005f: 20). Direktinvestitionen gehen i. d. R. aber nicht über die EU-Grenzen hinweg.

In Abbildung 6 sind verschiedene Maßgrößen der Internationalisierung abgebildet. Der Network Spread Index spiegelt die Streuung der Tochterunternehmen, d.h. die Anzahl der Länder, in denen ein Unternehmen Tochtergesellschaften unterhält, geteilt durch die Gesamtzahl der Länder, die Direktinvestitionen empfingen. Die zweite Größe, der Internationalisierungsgrad, wird hier gemessen als Auslandsanteil am Umsatz addiert zum Network Spread Index und geteilt durch den Faktor 2 (Ebneth 2005).

Wie in Kapitel 3.2 ausgeführt, liegt die Internationalisierung des Lebensmittelhandels hinter vielen Branchen der Lebensmittelindustrie zurück, gewinnt allerdings langsam an Dynamik. Die deutsche Molkereiwirtschaft ist - bedingt durch die hohe Relevanz der Transportkosten vielfach noch national ausgerichtet. Die Effizienzvorteile der deutschen Molkereiunter- 
nehmen, die in einem Land mit ausgesprochen hartem Handelswettbewerb und Preiskriegen wirtschaften, werden im internationalen Marketing noch zu wenig genutzt.

\subsection{Landwirtschaft}

Für das Jahr 2005 konnte wiederholt eine Steigerung der Weltmilcherzeugung festgestellt werden. Mit 10 Mio. $t$ mehr Milch als im Vorjahr liegt die Weltmilchproduktion inzwischen bei etwa 626 Mio. t, vor zehn Jahren waren es etwa 85 Mio. t weniger (vgl. Abbildung 7). Das Wachstum entspricht in etwa $16 \%$ in der Dekade bzw. einem durchschnittlichen Jahreswachstum von 1,6\%. Die Weltmilchproduktion besteht immer noch zu $85 \%$ aus Kuhmilch, die Produktion von Büffelmilch wächst jedoch vor allem in Indien und Pakistan sehr dynamisch (IDF 2005: 3).

\section{ABBILDUNG 7: WeLT-MiLCHPRODUKTION (IN 1000 T)}

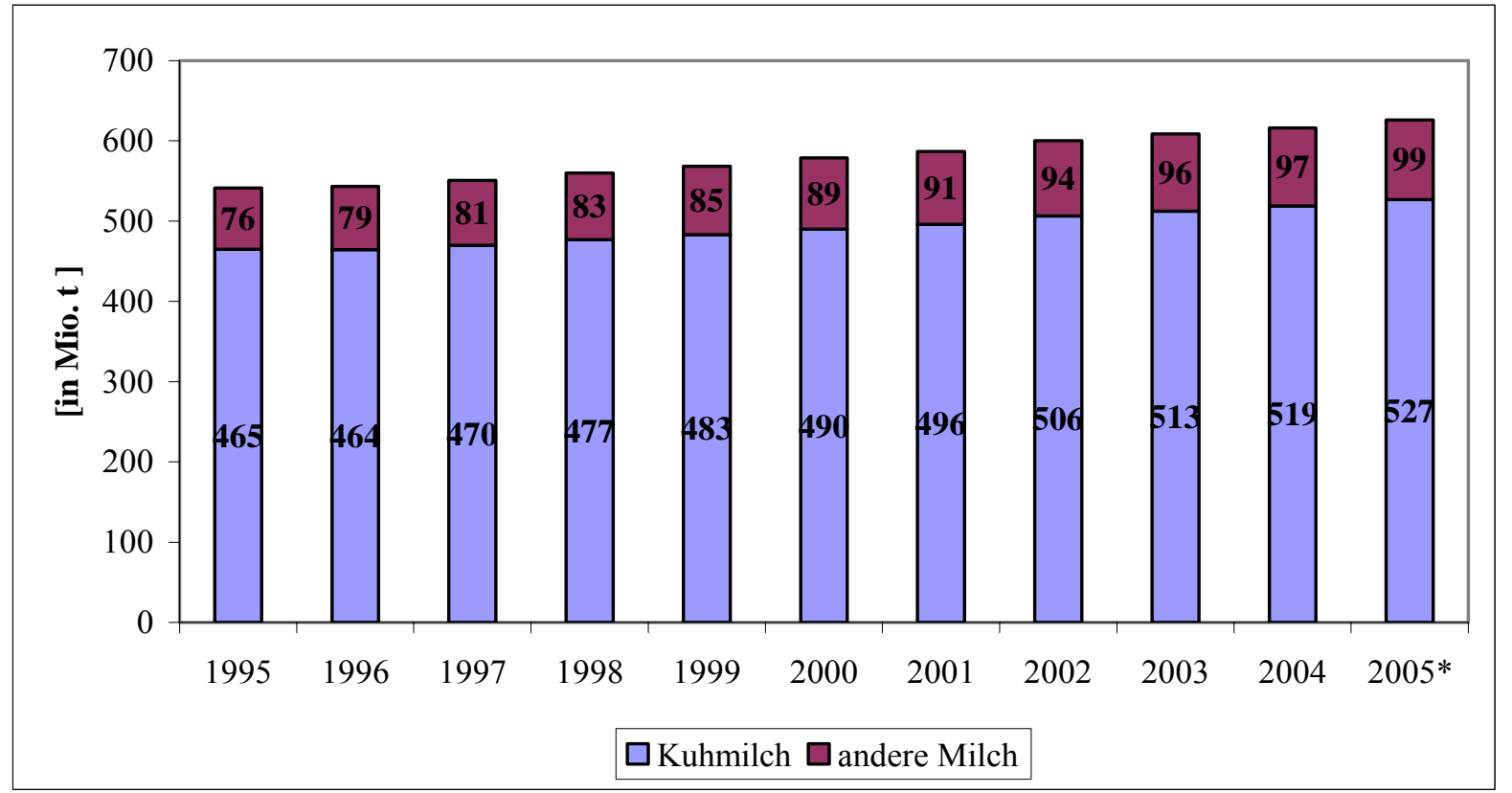

* Schätzung

Quelle: IDF 2005: 4

Eine Analyse der Produktionsregionen weist auf die sehr großen Unterschiede hin. In entwickelten Märkten ist Stagnation oder nur ein leichtes Wachstum der Milchproduktion zu erkennen, was häufig auf Produktionsbeschränkungen zurückzuführen ist. In sich entwickelnden Märkten sind zum Teil sehr hohe Wachstumsraten zu beobachten. Der chinesische Markt ist mit über $14 \%$ jährlichem Wachstum am dynamischsten (Tabelle 17) (Hemme et al. 2005a: 60). 
TABELLE 17: ANTEIL UND WACHSTUM DER WELTMILCHPRODUKTION

\begin{tabular}{|c|c|c|}
\hline Region & $\begin{array}{c}\text { Anteil an der } \\
\text { Weltmilchproduktion } \\
(2004) \\
\end{array}$ & $\begin{array}{l}\text { Durchschnittliche jährliche Wachstumsraten } \\
\text { (1999-2004) }\end{array}$ \\
\hline EU-15 & $20 \%$ & $-0,15 \%$ \\
\hline EU-25 & $24 \%$ & $\begin{array}{ll}-0,59 \% \\
-\quad+1,6 \% \text { in Slowenien } \\
-\quad 2,8 \% \text { in Litauen } \\
\end{array}$ \\
\hline Süd-Asien & $\begin{array}{l}20 \% \text { (bes. Pakistan } \\
\text { und Indien) }\end{array}$ & $\begin{array}{ll}3,4 \% \\
-\quad 4 \% \text { in Indien } \\
-\quad 2,8 \% \text { in Pakistan } \\
\end{array}$ \\
\hline USA & $13 \%$ & $1,4 \%$ \\
\hline GUS & $11 \%$ & $\begin{array}{l}0,46 \% \\
\bullet \quad-0,5 \% \text { in Russland } \\
\text { - }\end{array}$ \\
\hline Lateinamerika & $9,3 \%$ & $\begin{array}{l}\text { 1\% } \\
\text { - } \quad>2 \% \text { in Bolivien, Peru, Brasilien, } \\
\text { Mexiko und Kolumbien } \\
\text { - } \quad \text { abnehmend in Argentinien, Paraguay und } \\
\text { Venezuela } \\
\text { - } \\
\end{array}$ \\
\hline $\begin{array}{l}\text { Ost- und Südost- } \\
\text { asien }\end{array}$ & $5,8 \%$ & $\begin{array}{l}, 8 \% \\
-\quad 14 \% \text { in China } \\
-\quad 12 \% \text { in Thailand } \\
\end{array}$ \\
\hline Afrika & $4,9 \%$ & $3 \%$ \\
\hline Ozeanien & $4,1 \%$ & $\begin{array}{ll}3 \% & \\
- & 4,6 \% \text { in Neuseeland } \\
- & 1,3 \% \text { in Australien } \\
\end{array}$ \\
\hline $\begin{array}{l}\text { Naher und } \\
\text { Mittlerer Osten }\end{array}$ & $3,9 \%$ & $\begin{array}{l}1,8 \% \\
\bullet \quad>5 \% \text { in Saudi-Arabien und Libanon }\end{array}$ \\
\hline
\end{tabular}

Quelle: Hemme et al. 2005a: 60

Analysiert man die Entwicklung des Milchauszahlungspreises in den einzelnen Regionen, dann waren bezogen auf die nationalen Währungen in der Regel normale Niveaus zu beobachten. Das IFCN, das seit 1996 Milchpreise vergleicht, stellte in den Ländern Indien, Pakistan, Brasilien, Peru, Chile, Kanada, USA und Polen den höchsten Preis seit Beginn des Vergleichs fest. In der Schweiz ist der Milchpreis 2004 im Vergleich zu den Vorjahren am niedrigsten gewesen (Hemme/Deeken et al. 2005: 14). Die ZMP weist die in Tabelle 18 dargestellten Erzeugerpreise für Milch aus. 
TABELLE 18: DURCHSCHNITTLICHE ERZEUGERPREISE FÜR MILCH FÜR AUSGEWÄHLTE LÄNDER

\begin{tabular}{|l|c|c|}
\hline & $\begin{array}{c}\text { Erzeugerpreis 2004 in } \\
\mathbf{E} / \mathbf{1 0 0} \mathbf{~ k g}\end{array}$ & $\begin{array}{c}\text { Durchschnitt 1999 bis } \\
\mathbf{2 0 0 4}\end{array}$ \\
\hline Dänemark & 30,25 & 31,50 \\
\hline Deutschland & 27,95 & 29,62 \\
\hline Frankreich & 27,82 & 28,83 \\
\hline Italien & 32,00 & 33,41 \\
\hline Niederlande & 28,04 & 29,95 \\
\hline Österreich & 27,88 & 28,98 \\
\hline Polen & 18,67 & 17,75 \\
\hline Tschechische Republik & 24,45 & $23,97^{*}$ \\
\hline Ungarn (3,68 \% Fett, frei Molkerei) & 24,65 & 26,39 \\
\hline Vereinigtes Königreich & 25,70 & 26,14 \\
\hline EU-15 (gew. Mittel) & 28,50 & 29,41 \\
\hline Argentinien (marktferne Gebiete) & 11,25 & $10,85^{* *}$ \\
\hline Indien & 16,25 & $17,75^{* *}$ \\
\hline Japan & 61,51 & $64,89^{* *}$ \\
\hline Kanada (3,6\% Fett) & 36,60 & $37,45^{* *}$ \\
\hline Neuseeland & 19,88 & $17,22^{* *}$ \\
\hline Norwegen & 42,77 & $44,03^{* *}$ \\
\hline Russland & 13,67 & $13,92^{* *}$ \\
\hline Schweiz (3,8 \% Fett) & 48,34 & $50,10^{* *}$ \\
\hline Südafrika & 22,25 & $21,39^{* *}$ \\
\hline USA (3,67 \% Fett, frei Molkerei) & 28,78 & $27,21^{* *}$ \\
\hline
\end{tabular}

alle Preise ab Hof, ohne Umsatz- bzw. Mehrwertsteuer; für 2004 vorläufig; * Durchschnitt 2001 bis 2004; ** Durchschnitt 2002 bis 2004

Quelle: ZMP 2005a; eigene Berechnungen nach ZMP, verschiedene Jahrgänge

Hinsichtlich der Kosten der Milchproduktion unterscheidet das IFCN fünf Länderkategorien (Hemme/Deeken et al. 2005: 14):

- $<18$ US\$100 kg: Polen, Argentinien, Pakistan, Vietnam, West-Australien, Central/West-Brasilien, große Betriebe in Indien und kleine Betriebe in Chile, Nord-China und mittelgroße Betriebe in Australien (Viktoria);

- 18-23 US\$/100 kg: Ukraine, Bangladesh, Tschechien (428 Tiere/Betrieb), China (428 Tiere/Betrieb), die „High-Cost“-Betriebe in Brasilien, Chile, Indien (1-2 Tiere/Betrieb), Neuseeland;

- 23-30 US\$/100 kg: Tschechien (535 Tiere), größere US-Betriebe, Peru, SüdChina, Thailand, größere Betriebe in Australien (Viktoria);

- 30-37 US\$/100 kg: UK, Irland, Ungarn, Israel, kleine US-Betriebe, große deutsche Betriebe, Spanien, Dänemark und kleine australische Betriebe (Viktoria);

- $>37$ US\$/100 kg: Schweiz, Österreich, Niederlande, Luxemburg, Frankreich, Spanien, Italien, Dänemark, Schweden, Norwegen, Kanada und die kleinen deutschen Betriebe. 
Auf Basis der Kosten der reinen Milchproduktion verortet das IFCN die wettbewerbsfähigsten Betriebe in den Regionen folgendermaßen: In Südamerika sind Betriebe in Argentinien mit ungefähr 1400 Kühen die wettbewerbsstärksten. In Asien sind dies die ländlichen Gebiete Pakistans mit etwa 10 Kühen. In Zentral- und Osteuropa ist es der polnische Nordwesten, in Westeuropa Irland, gefolgt von dem Vereinigten Königreich und Spanien. Im ozeanischen Raum liegen die wettbewerbsstärksten Betriebe in West-Australien, in Nordamerika sind es die USA mit ungefähr 1700 bis 2400 Kühen (Hemme/Deeken et al. 2005: 14).

Die Wettbewerbsfähigkeit der Betriebe ist von vielen Faktoren abhängig. Hier spielen vor allem die unterschiedlichen Kostenstrukturen der Betriebe eine Rolle. Kleine Betriebe müssen i. d. R. auf Größeneffekte verzichten, profitieren allerdings davon, dass keine Fremdarbeitskräfte entlohnt werden müssen. Ein Blick auf die durchschnittlichen Herdengrößen zeigt dennoch interessante Entwicklungen. Die durchschnittlich größten Kuhherden sind in Neuseeland und Australien zu finden, gefolgt von Argentinien, der Tschechischen Republik, Israel und den USA mit 100-140 Kühen pro Betrieb. Dagegen sind die kleinsten durchschnittlichen Herdengrößen in südasiatischen Ländern und in einigen ost- und zentraleuropäischen Ländern zu finden, wo 1-4 Kühe je Betrieb gehalten werden. Eine Abnahme der Herdengröße findet sich in Südasien, wo viele Subsistenzbetriebe mit nur einer Kuh in den Milchsektor eingetreten sind und damit den Durchschnitt absenken. Ebenso kann eine Abnahme der Herdengröße in einigen ost- und zentraleuropäischen Ländern beobachtet werden, z. B. in Estland und der Tschechischen Republik, da hier eine Transformation von Genossenschaften zu privaten Betrieben stattfindet.

Der generelle Trend ist aber ein Anstieg der Herdengrößen. Ein sehr schnelles Wachstum von über $50 \%$ in den letzten acht Jahren war in Spanien, Dänemark, Italien, Ungarn und Australien zu beobachten. Besonders bemerkenswert ist, dass Spanien seine Herdengröße verdoppelt hat. Die Entwicklung der Herdengrößen ist ursächlich auf die Ab- bzw. Zunahme von landwirtschaftlichen Betrieben zurückzuführen. Gerade in Entwicklungs- und Schwellenländern steigt die Anzahl von Subsistenzbauern. Eine teilweise rapide Abnahme von landwirtschaftlichen Betrieben zeigt sich dagegen in allen westeuropäischen Ländern und den USA. Die Abschmelzungsrate über die letzten 10 Jahren lag typischerweise bei ca. 50 \%. Ein geringerer Strukturwandel zeigt sich in Ländern mit einer sehr hohen Protektion der Milchwirtschaft. Dazu gehören Norwegen, Österreich und Kanada. Interessanterweise weisen 
aber auch Frankreich und das Vereinigte Königreich eine geringere Abschmelzungsrate auf. Auch eine Abnahme, aber mit langsameren Verlauf, findet in Südamerika, Israel und Ozeanien statt (Hemme et al. 2005b: 66).

\section{Aktuelle Herausforderungen auf dem Milchmarkt}

Im folgenden Kapitel werden drei zentrale Herausforderungen für die Milchwirtschaft skizziert, die die gesamte Wertschöpfungskette berühren. Zunächst stehen die Strukturveränderungen in Landwirtschaft und Molkereiwirtschaft durch die weitere Liberalisierung der Märkte im Vordergrund. Anschließend geht es um zwei unterschiedliche Reaktionsmöglichkeiten auf den wachsenden Preisdruck. Beide thematisieren die wachsende Bedeutung der Markenpolitik.

\subsection{Wettbewerbsfähigkeit und Erzeugerpreise: Eine Kettenbetrachtung}

Zentrales Thema für Landwirte und Molkereien werden in den nächsten Jahren die Strukturund Preisveränderungen sein, die mit einer weiteren Marktliberalisierung einhergehen. Das Quotensystem begrenzt bisher den Intra-EU-Wettbewerb, der Außenschutz den globalen Markteinfluss. Zudem ist die Molkereiwirtschaft eine Branche, deren Internationalisierung durch die Produktspezifika (hohe Transportkosten, Frische, Kühlung) Grenzen gesetzt sind. Ein globaler Standortwettbewerb wie z. B. bei Zucker, wo einige Länder grundsätzlich aus der Produktion aussteigen werden, ist bei Milch nicht $\mathrm{zu}$ erwarten. Bestimmte Produktgruppen wie Konsummilch und einfache Milchfrischprodukte sind durch die kurze Haltbarkeit und die hohen Transportkosten weitgehend ein regionales bzw. nationales Geschäft (IDF 2005: 19).

Daneben gibt es aber Produkte mit hoher Affinität für Standortverlagerungen in einem liberalisierten Markt. Dies gilt insbesondere für haltbare Artikelgruppen wie Milchpulver, Butter und Käse, bei denen der Transport einfach ist, sowie für einige hoch veredelte Milchprodukte, bei denen die Transportkosten in Relation zu den Produktions- und Marketingkosten eher unbedeutend sind. In grober Näherung gibt der Transportkostenanteil an den Gesamtkosten einen Eindruck von der Internationalisierungsfähigkeit eines Artikels. Der wissenschaftliche Beirat beim BML hat diesen in einem Gutachten aus dem Jahr 2000 für verschiedene Produkte ausgewiesen (vgl. Tabelle 19). Internationalisierungsgeeignete Molkereiprodukte sind Käse, Butter, Milchpulver, Kondensmilch und Ingredients. Um diese Artikel geht es bei Fragen des Standortwettbewerbs. 
TABELLE 19: ANTEIL DER TRANSPORTKOSTEN AN DEN GESAMTKOSTEN BEI AUSGEWÄHLTEN MILCHPRODUKTEN

\begin{tabular}{|l|c|c|c|c|c|c|c|}
\hline & $\begin{array}{c}\text { Past. Konsum- } \\
\text { milch }\end{array}$ & H-Milch & Gouda & $\begin{array}{c}\text { Schlag- } \\
\text { sahne }\end{array}$ & $\begin{array}{c}\text { Speise- } \\
\text { quark }\end{array}$ & Butter & Joghurt \\
\hline $\begin{array}{l}\text { Anteil der } \\
\text { Transportkosten }\end{array}$ & $11,8 \%$ & $7,1 \%$ & $2,9 \%$ & $4,6 \%$ & $10,4 \%$ & $2,0 \%$ & $8,6 \%$ \\
\hline
\end{tabular}

Quelle: eigene Berechnung nach BML 2000: 64

In der Fachöffentlichkeit wird die Struktur der deutschen Molkereiwirtschaft vielfach mit Bezug auf die geringen Unternehmensgrößen und Auslastungsdefizite kritisiert. Betrachtet man jedoch beispielhaft die deutschen Import-Export-Daten für Käse (vgl. Tabelle 20), so zeigt sich eine Steigerung der Ausfuhren deutscher Unternehmen über die letzten zehn Jahre um 71,2 \%. Der Import ist dagegen lediglich um 8,2 \% gestiegen. 84,0 \% der Exporte gehen in EU-Länder (ZMP 2005a: 71).

TABELLE 20: EXPORT- UND IMPORTENTWICKLUNG VON KÄSE IN DEUTSCHLAND (IN 1000 T)

\begin{tabular}{|l|c|c|c|c|c|c|c|c|c|c|c|}
\hline & & & & & & & & & & & $\begin{array}{c}\text { Veränderung } \\
\mathbf{2 0 0 4} \text { zu 1995 in } \\
\text { \% }\end{array}$ \\
\hline Export & $\mathbf{1 9 9 5}$ & $\mathbf{1 9 9 6}$ & $\mathbf{1 9 9 7}$ & $\mathbf{1 9 9 8}$ & $\mathbf{1 9 9 9}$ & $\mathbf{2 0 0 0}$ & $\mathbf{2 0 0 1}$ & $\mathbf{2 0 0 2}$ & $\mathbf{2 0 0 3}$ & $\mathbf{2 0 0 4} *$ & 483,9 \\
\hline Import & 478,9 & 488,9 & 499,5 & 468,8 & 522,0 & 483,1 & 488,2 & 499,5 & 561,5 & 518,3 & $+8,2$ \\
\hline
\end{tabular}

* vorläufig

Quelle: ZMP, verschiedene Jahrgänge

Im europäischen Vergleich sind deutsche Molkereien in der Käseproduktion offensichtlich gut aufgestellt. Allerdings sind die Unternehmen strategisch ganz eindeutig auf das Niedrigpreissegment fokussiert. Es handelt sich bei Käseexporten, wie in Kapitel 2.3 berechnet, fast ausschließlich um Standardware, während Spezialitäten und Markenartikel importiert werden. Deutsche Molkereiunternehmen haben - von wenigen Ausnahmen abgesehen - keine internationalen Marken aufgebaut. Es gibt im Vergleich zu Italien und Frankreich wesentlich weniger anerkannte Spezialitäten. Der Schwerpunkt liegt auf der Kostenführerschaftsstrategie, die sich nicht zuletzt durch den hohen Handelsmarken- und Discountanteil herausgebildet hat.

Aus den bisherigen Ausführungen lässt sich ableiten, dass sich die deutsche Milchwirtschaft in einem stärker liberalisierten Markt auf die Verteidigung ihres bestehenden Kostenvorsprungs konzentrieren muss. Qualitäts- und Nischenmarketing sind nicht die Kernkompetenzen der meisten großen deutschen Molkereiunternehmen (vgl. aber Kapitel 4.3). Es stellt sich die Frage, ob die Kostenführerschaft durch eine Marktliberalisierung bedroht ist. Als wahrscheinlichste Option gehen wir davon aus, dass die EU die bisher eingeschlagenen Richtung zur Quotenausweitung weitergehen wird und es dadurch zu einer 
weiteren Senkung des Milchauszahlungspreises sowie zu einer Reduktion der Quotenpreise kommen wird. $\mathrm{Zu}$ einer Senkung der Quotenpreise würde in Deutschland auch eine Liberalisierung des Quotenhandels durch Schaffung größerer Quotenübertragungsregionen beitragen. Zusätzlichen Druck auf die Milchpreise wird die zugesagte Abschaffung der Exportbeihilfen ausüben. Im Jahr 2004 hat die EU 13,5 Mio. t Milchäquivalent in Drittländer exportiert und nur 3,3 Mio. t importiert (Weindlmaier 2005c).

Vor dem Hintergrund eines solchen Szenarios mit sinkenden Erzeugerpreisen wird sich in der Landwirtschaft der Standortwettbewerb verschärfen, wodurch sich die Milchproduktion noch stärker auf bestimmte Regionen konzentrierten wird. Dies sind insbesondere Regionen mit hohem Grünlandanteil und guten Flächenstrukturen, wie die Küstengebiete und einige Mittelgebirgslagen. Daneben gibt es Agglomerationseffekte und Clusterbildungen, wie man sie z. B. im Rheinland beobachten kann.

Die Erfahrungen der vergangenen Jahre und der aktuell hohe Quotenpreis trotz fehlender Prämienrechte zeigen, dass ein erheblicher Teil der Milchlandwirte investitionswillig ist. Viele landwirtschaftliche Betriebe verfügen über nicht ausgelastete Stallanlagen und können kurzfristig Kapazitäten hochfahren. Andere werden ihre Anlagen erweitern, um zukunftsfähig zu werden. In den letzten Jahren haben viele Landwirte in Quote investiert, obwohl die meisten Berater und Marktbeobachter davon abgeraten haben. Sie sind damit in aller Regel ökonomisch erfolgreich gewesen, stehen heute im Vergleich zu Berufskollegen, die den Empfehlungen gefolgt sind, besser da und haben ihre Betriebe zu zukunftsfähigen Größen entwickelt. Diese Erfahrungen prägen die Rentabilitätserwartungen und werden die Investitionsbereitschaft zusätzlich verstärken. Hinzu kommen z. T. geringe Ausweichalternativen und niedrige Opportunitätskosten. Kurz: Vieles spricht dafür, dass es bei einer Marktliberalisierung zunächst zu einer Aufstockung der Bestände kommt, was die bereits jetzt vorhandenen Angebotsüberschüsse verstärkt und den Marktpreis noch weiter senken wird. In der Folge nicht ausreichender Markterlöse wird es zu Betriebsaufgaben bzw. Insolvenzen bei kleineren Betrieben und Milcherzeugern mit Liquiditätsproblemen kommen, so dass mittelbis langfristig die Überschüsse zurückgehen werden. Ungewiss und wenig erörtert ist indessen die Frage, wie genossenschaftliche Molkereien mit der dann unumgänglichen Mengensteuerung umgehen. Sicherlich werden diese Molkereien ein Wachstum sehr vieler Mitglieder verbunden mit der uneingeschränkten Abnahmeverpflichtung gegenüber allen Anteilseignern nicht mittragen können. Dennoch sind sie auf leistungsfähige, zukunfts- 
gerichtete und damit wachsende Milchlieferanten angewiesen, wodurch ein „Einfrieren“ der Milcherzeugerstruktur ebenso wenig möglich erscheint.

Welche Auswirkungen hat die stärkere regionale Konzentration der Milchviehhaltung auf die Molkereien? Sie senkt aus Sicht der Industrie die relative Bedeutung der Erfassungskosten im Vergleich zu den Herstellungskosten und erlaubt damit größere Molkereien. Die optimale Betriebsgröße steigt. Der gleiche Effekt geht von der wachsenden Betriebsgröße in der Landwirtschaft aus. Auch dies ermöglicht aufgrund der abnehmenden Stoppkosten größere Betriebsstätten.

Regionale Verdichtung der Landwirtschaft und Konzentration im Molkereigewerbe verstärken sich mithin gegenseitig. Im Interesse der Verteidigung der Kostenführerschaft muss es das Ziel der deutschen Agrarpolitik sein, diesen Prozess zu fördern. Zukünftig entscheidet immer weniger die Leistungsfähigkeit von Landwirten oder Molkereien allein über den Erfolg im Standortwettbewerb, sondern die Kostengünstigkeit der gesamten Kette. Kostengünstige Molkereien sind solche mit geringen Rohstoffkosten, großen, spezialisierten Betriebsstätten, geringen Erfassungskosten, flexibler Logistik und schlanker Verwaltung. Sie benötigen eine landwirtschaftliche Basis, die bei relativ geringen Auszahlungspreisen rentabel arbeiten kann und die räumlich arrondiert ist.

Eine Liberalisierung des Marktes wird mithin den räumlichen und unternehmensstrukturellen Konzentrationsprozess verstärken und, zumindest solange, bis die Überschussproduktion abgebaut ist, $\mathrm{zu}$ nicht tragfähigen Auszahlungspreisen führen. Vor diesem Hintergrund werden in vielen landwirtschaftlichen Diskussionsveranstaltungen in jüngerer Zeit die Möglichkeiten der Milchbauern diskutiert, durch veränderte Vermarktungskonzepte Einfluss auf den Milchpreis zu nehmen. In Anbetracht dessen hat Weindlmaier (2005b) in einem aktuellen Beitrag die Möglichkeiten der Landwirte und ihrer Institutionen erörtert, höhere Auszahlungspreise durchzusetzen.

In Abbildung 8 fasst Weindlmaier die zentralen Bestimmungsfaktoren für die Höhe des Auszahlungspreises zusammen. Die Senkung des Interventionspreises und der Exporterstattungen sowie zwar steigende, aber immer noch deutlich unter EU-Preisniveau liegende Weltmarktpreise werden in den nächsten Jahren die Auszahlungspreise weiter unter Druck setzen. Der Autor weist am Beispiel ausgewählter Molkereien nach, dass diese in den 
letzten drei Jahren jeweils eine Differenz von ca. 0,6 Cent/kg Rohstoff zwischen der Nettoverwertung und der Rohstoffvergütung aufweisen und damit betriebswirtschaftlich zu hohe Milchpreise auszahlen (Weindlmaier 2005c). Die Milcherzeugerpreise sind in der jüngeren Vergangenheit nicht in vollem Umfang dem Rückgang der Marktpreise für Milcherzeugnisse gefolgt (ZMP 2005h: 9). Vor diesem Hintergrund ist es angesichts der Kostenorientierung der meisten deutschen Molkereien wohl auszuschließen, durch Milchstreiks und Erzeugerzusammenschlüsse dauerhafte Preiserhöhungen durchzusetzen. Die Langfristigkeit der Verträge, die am Molkerei-Spotmarkt verfügbaren Milchmengen, die fehlende Lagerfähigkeit des Produktes und die bekannten Trittbrettfahrerprobleme lassen ein überregionales Angebotsmonopol nicht zu.

\section{ABBILDUNG 8: DETERMINANTEN DES MILCHPREISES}

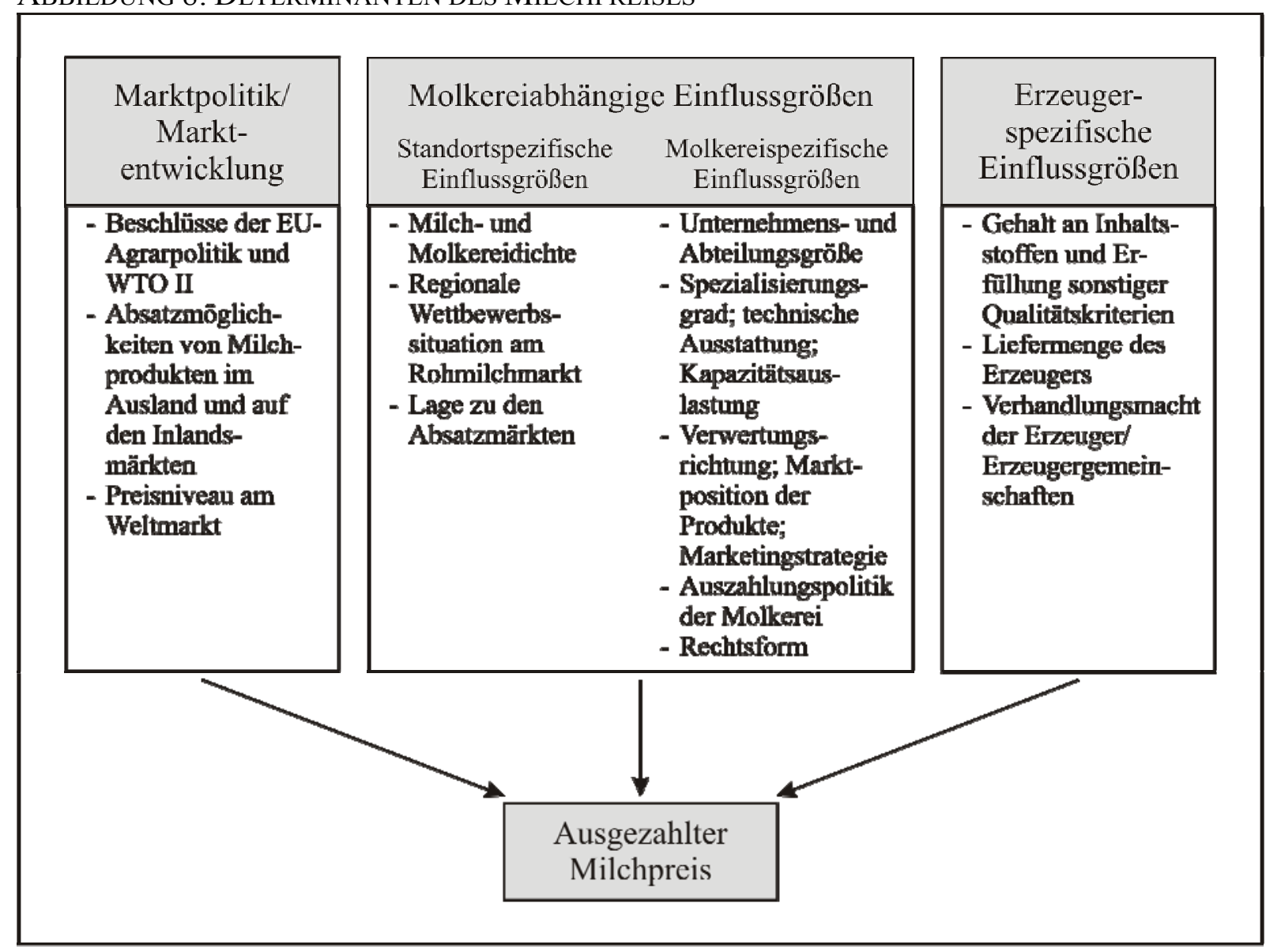

Quelle: Weindlmaier 2005b

Erst dann, wenn sich „nach einem Tal der Tränen“ (Weindlmaier 2005b) ein Gleichgewicht zwischen Angebot und Nachfrage ohne Exporterstattungen einstellen wird, können die Erzeugerpreise auf das Niveau der langfristigen Durchschnittskosten der Produktion ansteigen. Der Abbau von ca. 15 bis $20 \%$ der Milchmenge wird allerdings angesichts der Investitionsbereitschaft vieler Landwirte nicht kurzfristig erfolgen und noch erhebliche 
Friktionen hervorrufen. Die Politik sollte im Sinne der langfristigen Wettbewerbsfähigkeit der gesamten Wertschöpfungskette den Ausstieg der nicht dauerhaft konkurrenzfähigen Landwirte fördern und abfedern.

Die vorangegangenen Ausführungen haben sich im Kern auf den Kosten- und Preiswettbewerb bezogen, da die deutsche Molkereiwirtschaft hier ihre Stärke hat. Der ausgesprochen hohe Handelsmarkenanteil und die Stärke der Discounter führen dazu, dass in vielen Warengruppen mehr als die Hälfte des Absatzes zu dem von Aldi bzw. Lidl gesetzten Einstiegspreis erfolgt. Wettbewerbsfähigkeit bedeutet hier niedrige Kosten. Die folgenden beiden Kapitel beziehen sich dagegen auf Optionen, die Wertschöpfung durch Möglichkeiten der Produktdifferenzierung $\mathrm{zu}$ steigern. Als Lieferant spezialisierter Molkereien haben Landwirte auch dann Wettbewerbsoptionen, wenn sie kleinbetrieblich strukturiert sind, aber besondere Leistungen produzieren (z. B. silofreie Milch, Alpenmilch usf.).

\subsection{Markenführung in Genossenschaften}

Profilierte Marken gelten heute in der Ernährungsindustrie als zentrale Treiber des Unternehmenswertes (Meffert et al. 2002). Allerdings werden die ökonomischen Risiken angesichts steigender Werbeaufwendungen und des Drucks der Handelsmarken ebenfalls größer. In dieser Situation verfügen genossenschaftliche Hersteller heute im Durchschnitt eher über schwache Marken. Auf dieses Problem weist z. B. die Kommunikationsanalyse des Verlags Gruner \& Jahr (2004) hin, die die gestützte Markenbekanntheit für deutsche Molkereiprodukte erhoben hat. Unter den führenden fünf Käse- bzw. Milchmarken ist keine deutsche Genossenschaft vertreten - trotz eines genossenschaftlichen Milchmengenanteils von ca. $42 \%$ (BMVEL 2005) (vgl. Tabelle 21). Bezogen auf die verarbeitete Milchmenge erzielen die marktführenden Genossenschaften Nordmilch, Humana Milchunion oder Hochwald einen wesentlich geringeren Umsatz als konkurrierende Anbieter (z. B. Müller oder Emmi) (Tabelle 6). Ihr Werbebudget liegt häufig unter 0,5 \% des Umsatzes. Im Vergleich dazu investieren klassische Markenartikler bis zu $10 \%$ des Umsatzes in ihre Brands (Spiller 2000). 
TABELLE 21: MARKENBEKANNTHEIT BEI KÄSE UND MILCH 2004

\begin{tabular}{|l|c|}
\hline & Gestützter Bekanntheitsgrad bei Frauen \\
\hline Philadelphia & $81 \%$ \\
\hline Bresso & $78 \%$ \\
\hline Exquisa & $76 \%$ \\
\hline Bonbel & $73 \%$ \\
\hline Kraft & $72 \%$ \\
\hline \multicolumn{2}{|c|}{} \\
\hline Danone & $90 \%$ \\
\hline Bauer & $86 \%$ \\
\hline Ehrmann & $86 \%$ \\
\hline Fruchtzwerge & $85 \%$ \\
\hline Obstgarten & $85 \%$ \\
\hline
\end{tabular}

Quelle: Gruner \& Jahr 2004

Was sind die Ursachen für diese Markenschwäche der Genossenschaften? Zum einen steht das Genossenschaftsgesetz der Markenführung entgegen (Cook 1995). Die ökonomische Theorie spricht hier von der Gefahr des Trittbrettfahrerverhaltens. Dieses ergibt sich aus der im Genossenschaftsgesetz niedergelegten Einschränkung, grundsätzlich keine zeitliche Diskriminierung der einzelnen Genossen vornehmen $\mathrm{zu}$ dürfen. Genossenschaftlichen Molkereien ist es zwar möglich, Landwirten mit hohen Milchlieferungen bessere Auszahlungspreise zu zahlen bzw. niedrigere Stoppkosten in Rechnung zu stellen (sachliche Diskriminierung). Es ist aber nicht gesetzeskonform, neuen Mitgliedern niedrigere Auszahlungen zuzubilligen als langjährigen Genossen (zeitliche Diskriminierung). Marken sind jedoch langfristige Investitionen, die zunächst über einen erheblichen Zeitraum zu Renditedefiziten führen. Wenn langjährige Genossen über einen längeren Zeitraum auf Rendite verzichtet haben, sollten sie später auch höhere Auszahlungen erhalten. Dazu ist es notwendig, Genossen an der Steigerung des Unternehmenswertes teilhaben zu lassen, was eine Gesetzesänderung verlangt. Solange kann die Praxis nur auf Hilfswege wie z. B. die Verpflichtung von neuen Mitgliedern zur Kapitalzuzahlung in Rücklagen zurückgreifen, wie dies beispielsweise bei Hochwald üblich ist.

Hinzu kommt das sog. Horizon-Problem (Cook 1995). So haben zukunftsorientierte landwirtschaftliche Betriebe aufgrund ihrer Betriebsausrichtung und der damit einhergehenden Notwendigkeit eines professionellen Managements langfristigere Ziele als Landwirte, die von einer nahenden Betriebsaufgabe ausgehen. Zudem haben kleinere und z. T. auch gewachsene Betriebe mit hohen Kapitaldiensten nicht den finanziellen Spielraum, um eine mittelfristige Senkung der Auszahlungspreise zur Finanzierung von Marken zu kompensieren. Sie sind daher an langfristigen Investitionen nicht interessiert, sofern diese die Auszahlungspreise unter ein bestimmtes Mindestniveau drücken. In grober Näherung ist davon auszugehen, dass 
mehr als die Hälfte aller Landwirte älter als 50 Jahre und in weniger als $50 \%$ der Fälle die Nachfolge geregelt ist (Hendrikse/Veerman 2004). In der Milchproduktion liegt die jährliche Ausstiegsrate zzt. bei ca. $6 \%$. Da es keinen Markt für die Kapitalanteile an einer Genossenschaft gibt, aus der Steigerung des Unternehmenswertes selbst folglich kein individueller Gewinn erwirtschaftet werden kann, muss sich jede Investition im Rahmen höherer Auszahlungspreise amortisieren. Gerade in Genossenschaften mit einem hohen Anteil an ausstiegsorientierten Genossen sind daher keine Impulse für langfristige (Marken-) Investitionen zu erwarten.

Es ist nicht nur die Rechtsform, die die Probleme vieler Genossenschaften im Markengeschäft erklärt. Marken sind in der Konsumgüterindustrie heute emotional und stark symbolisch geprägte Werte. Sie verlangen entsprechend andere Denkmuster im Management als wenn es um Kostenreduktion und Produktionsoptimierung geht (Urde 1999). Dies ist in der Forschung bisher kaum untersucht worden. In einer eigenen (Online-) Befragung wurden deshalb 400 markenführende deutsche Hersteller, unter ihnen die Top 100, kontaktiert (Schramm et al. 2004). Geantwortet haben insgesamt 100 Unternehmen. Die verwertbare Stichprobe beträgt 73 vollständig beantwortete Fragebögen, schwerpunktmäßig aus den Branchen Fleisch, Milch, alkoholische sowie alkoholfreie Getränke. Großunternehmen sind im Vergleich überrepräsentiert.

Als wichtigster Faktor für den Erfolg in der Markenpolitik konnte die Markensteuerung identifiziert werden, die sich aus folgenden Gesichtspunkten zusammensetzt (vgl. Abbildung 9):

- ein kennzahlenorientiertes Markenwertcontrolling,

- integrierte (Marken-) Kommunikation,

- antizyklische Werbepolitik und

- eine Betrachtung der Marke als Investitionsobjekt. 


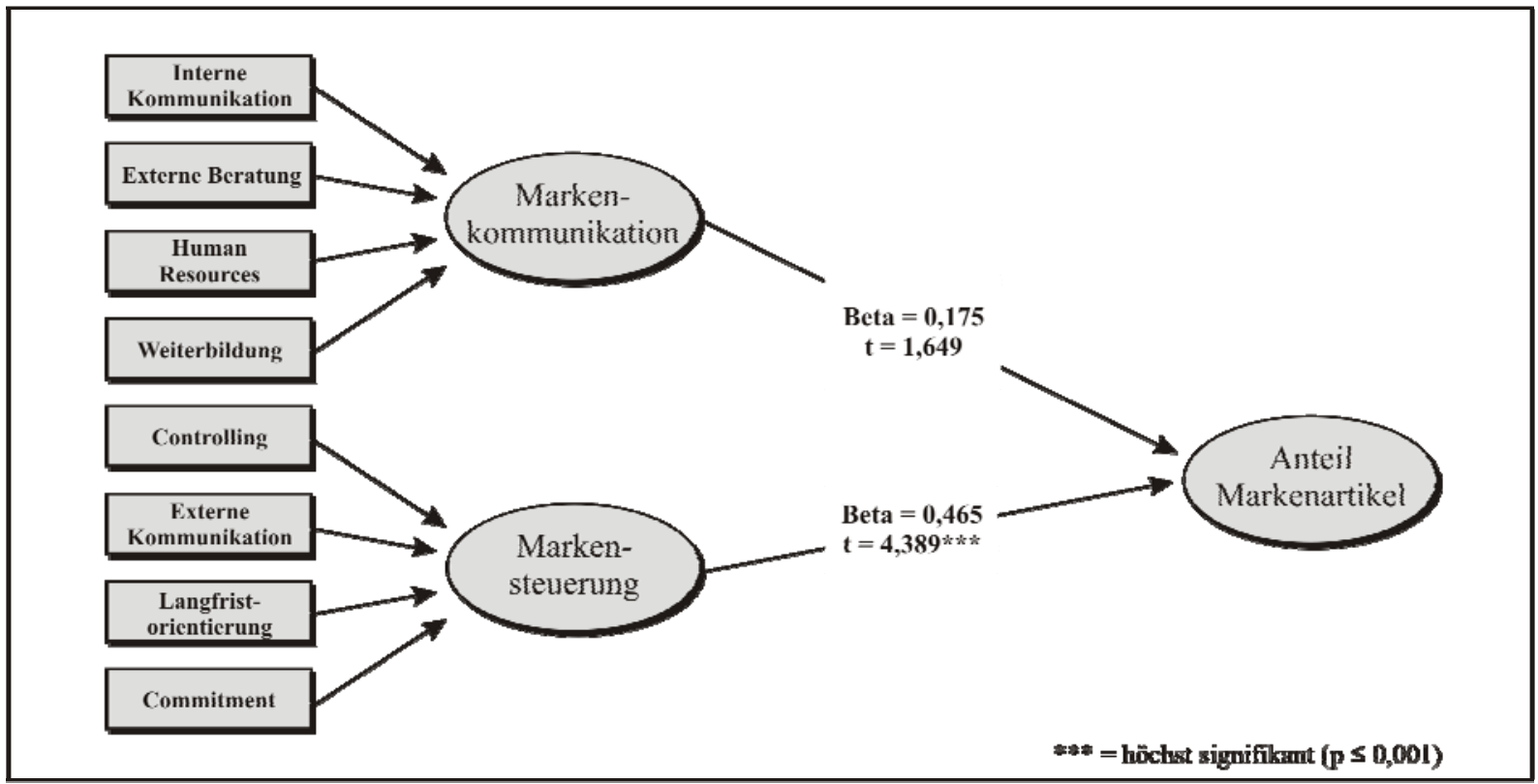

Quelle: Eigene Berechnungen

Diese Elemente verdeutlichen die spezifischen Anforderungen an die Langfristorientierung eines Markenartiklers. Unternehmen, die diese Charakteristika erfüllen, verfügen über einen deutlich höheren Markenanteil. Neben dem Faktor Markensteuerung trägt eine entsprechende Organisation des Unternehmens zum Markenerfolg bei: Ein starkes Brand-Management, eine intensive interne Kommunikation über Markenziele, Investitionen in Human Resources und ggf. auch die Hinzuziehung externer Beratung sind wichtige interne Treiber des Markenerfolges (vgl. Abbildung 9).

Auf Basis der unterschiedlichen Brand-Orientation konnten im nächsten Schritt mit Hilfe einer Clusteranalyse vier Unternehmensgruppen in der Ernährungsindustrie identifiziert werden (vgl. Abbildung 10). Es zeigt sich eine Gruppe von sehr eindeutig markenorientierten Unternehmen, während die drei weiteren Cluster über einen geringer ausgeprägten Markenfokus mit jeweils spezifischen Schwachpunkten verfügen. Die Cluster „Markenorientierte“ (44\%) und „Innovationsschwache“ (14\%) sind zwar beide auf Herstellermarken fokussiert, aufgrund von Defiziten, schwerpunktmäßig im Bereich Markeninnovation, ist das Cluster der „Innovationsschwachen“ allerdings als eingeschränkt markenorientiert zu klassifizieren. Die Gruppe der „Kostenorientierten“ stellt mit $16 \%$ die erweiterte Gruppe der Markenorientierten dar, d.h. bei diesem Cluster ist der Markenfokus in punkto Kommunikation und Innovation vorhanden. Eine Vertriebsdominanz beeinträchtigt das Markenmanagement allerdings erheblich. Unternehmen dieses Clusters schwanken häufig zwischen Vertriebs- und Marketingzielen. Dieses „klassische“ Konkurrenzverhältnis und die 
daraus resultierende Gefahr der Wechselhaftigkeit in der Markensteuerung beeinflussen die Entwicklung der Marke und die Generierung eines Markenwertes negativ. Eine eindeutige Vertriebsorientierung lässt sich bei der Gruppe der „Handelsorientierten“ (26\%) identifizieren. Der Fokus der Geschäftstätigkeit dieser Unternehmen liegt klar auf dem Handelsmarkengeschäft. Da die Marketingführerschaft dann eindeutig beim Handel liegt, ist die Markenorientierung in diesem Cluster verständlicherweise schwach ausgeprägt.

ABBILDUNG 10: ERGEBNiSSE DER CLUSTERANALYSE ZUR MARKENORIENTIERUNG IN DER DEUTSCHEN ERNÄHRUNGSINDUSTRIE

\begin{tabular}{|c|c|c|c|}
\hline $\begin{array}{c}\text { Die } \\
\text { Markenorientierten } \\
\qquad \mathrm{N}=32 ; 44 \% \\
\end{array}$ & $\begin{array}{c}\text { Die } \\
\text { Innovationsschwachen } \\
\mathrm{N}=10 ; 14 \% \\
\end{array}$ & $\begin{array}{c}\text { Die } \\
\text { Kostenorientierten } \\
\mathrm{N}=12 ; 16 \% \\
\end{array}$ & $\begin{array}{c}\text { Die } \\
\text { Handelsorientierten } \\
\mathrm{N}=19 ; 26 \% \\
\end{array}$ \\
\hline $\begin{array}{c}\text { Markenorganisation/ } \\
\text {-filhrung } \\
+ \\
\text { Markensteuerung } \\
+ \\
\text { Markeninnovation } \\
+ \\
\end{array}$ & $\begin{array}{c}\text { Markenorganisation' } \\
\text {-fithrung } \\
\mathbf{0} \\
\text { Markensteuerung } \\
\mathbf{0} \\
\text { Markeninnovation } \\
- \\
\end{array}$ & $\begin{array}{c}\text { Markenorganisation/ } \\
\text {-führung } \\
\mathbf{0} \\
\text { Markensteuerung } \\
- \\
\text { Markeninnovation } \\
\mathbf{0}\end{array}$ & $\begin{array}{c}\text { Markenorganisation' } \\
\text {-fuihrung } \\
- \\
\text { Markensteuerung } \\
\mathbf{0} \\
\text { Markeninnovation } \\
\mathbf{0}\end{array}$ \\
\hline $\begin{array}{l}\text { zunehmende } \\
\text { Markenorientierung }\end{array}$ & & & $\begin{array}{c}\text { zunehmende } \\
\text { Handelsorientierung }\end{array}$ \\
\hline
\end{tabular}

Quelle: Eigene Berechnungen

Insgesamt zeigen die Befragung wie auch weiterführende Fallstudien, warum sich viele Genossenschaften in der Milchwirtschaft mit Marken schwer tun: Relativ durchgängig dominieren Vertriebsziele das Marketing, die Marketingabteilung ist dem Vertrieb untergeordnet, so dass immer wieder kurzfristige Absatzziele über die Imageprofilierung der Marke siegen. Ein kennzahlenorientiertes Markenwertcontrolling fehlt bei den Genossenschaften in aller Regel. Die Konzentration auf finanzwirtschaftliche Kennzahlen verstärkt die Kurzfristigkeit der Kalküle. Hier müssen Marktforschungsverfahren zur Markenwertmessung eingeführt werden und auch in ein umfassendes Steuerungssystem (z. B. Balanced Scorecard) integriert werden. Das Commitment in die Marke ist gering ausgeprägt, in schwierigen Phasen werden Markeninvestitionen zurückgefahren. Eine in der Forschung immer wieder geforderte antizyklische Werbebudgetpolitik findet sich selten. Die Werbeausgaben und die Marktforschungsintensität sind insgesamt zu gering; externe Berater werden unterproportional genutzt. Schließlich absorbieren fusionsbedingte Integrationsprobleme einen erheblichen Teil der Managementkapazität. Die Wachstumsorientierung hat Priorität gegenüber der Markenführung. 
Fazit: Nicht nur Markenartikler sind erfolgreich. Es gibt gerade in der Milchwirtschaft Beispiele für erfolgreiche Kostenführer wie die Milch-Union Hocheifel. Auch unsere Befragung hat gezeigt, dass die Unternehmen mit sehr hohem Markenanteil auf der einen und die Spezialisten für das Handelsmarkensegment auf der anderen Seite am erfolgreichsten waren. Probleme haben vornehmlich die Anbieter, die beides halbherzig tun. Allerdings: Die Kostenführerschaftsstrategie ist riskant, da es in jedem Segment nur einen Kostenführer geben kann. Wenn viele Anbieter allein auf Niedrigpreise setzen, drohen verlustreiche Preiskriege. Wie sollen sich daher Genossenschaften in Zukunft positionieren? Hier gibt es drei strategische Optionen:

- Konzentration auf Kostenführerschaft, d. h. das Handelsmarken- und Industriekundengeschäft. Konsequente Ausrichtung der Werksstrukturen, hohe Flexibilität und Reaktionsgeschwindigkeit auf Abnehmeranforderungen, Wachstum mit den Discountern ins Ausland usf.

- Da die Milchmenge der Großmolkereien nicht allein über Marken abgesetzt werden kann, liegt die zweite Option in einer hybriden Wettbewerbsstrategie. Weil die Unternehmenskulturen allerdings nicht kompatibel sind, ist dies mehr als ein einfaches Nebeneinander von Kostenführerschaft und Marke. In diesem Fall sollte das Markengeschäft strikt organisatorisch getrennt werden.

- Kleinere Genossenschaften sollten sich auf Segmente spezialisieren. Hier kommt der Markenführung und der Kundennähe eine hohe Bedeutung zu.

\subsection{Schutz geographischer Herkunftsangaben nach dem Feta-Urteil des EuGH}

Der Europäische Gerichtshof $(\mathrm{EuGH})$ hat im Oktober dieses Jahres „Feta“ als Ursprungsbezeichnung für Schafskäse aus Griechenland bestätigt und die Klage von Deutschland und Dänemark abgewiesen. Damit darf ein Käse nach Ablauf einer Übergangsfrist im Oktober 2007 die Bezeichnung „Feta“ nur noch tragen, wenn er in einem bestimmten Teil Griechenlands aus Schafsmilch oder einer Mischung von Schafs- und Ziegenmilch hergestellt ist. Die Entscheidung des EuGH ist ein vorläufiger Endpunkt in dem jahrelangen Streit um die Ursprungsbezeichnung „Feta“ und stellt vor allem die deutsche Milchindustrie vor die Aufgabe, ihr Produktportfolio in Hinblick auf zukünftige Urteile dieser Art proaktiv zu überprüfen und Handlungsalternativen zu entwickeln. 
Seit 1992 können Herkunftsbezeichnungen bei Lebensmitteln und Agrarprodukten EU-weit nach der Verordnung (EWG) 2081/92 gegen missbräuchliche Nutzung geschützt werden. Es werden dabei drei Kategorien von Herkunftsangaben unterschieden: Bei der geschützten Ursprungsbezeichnung (g. U.) muss die Erzeugung, Verarbeitung und Herstellung eines Erzeugnisses in einem bestimmten geographischen Gebiet vorgenommen werden, bei der geschützten geographischen Angabe (g. g. A.) besteht mindestens eine Verbindung zwischen einer der Produktionsstufen und dem Herkunftsgebiet. Die garantiert traditionelle Spezialität (g. t. S.) bezieht sich nicht auf einen geographischen Ursprung, sondern betont die traditionelle Zusammensetzung oder ein traditionelles Herstellungsverfahren eines Produkts. Ein als g. t. S. geschützter Artikel kann überall produziert werden, solange die Spezifikationen eingehalten und überprüft werden.

Die Anzahl der Neueintragungen ist in den letzten Jahren deutlich gestiegen, allein in 2004 sind über 45 neue Begriffe hinzugekommen. Insgesamt kann Südeuropa bei den rund 700 geschützten Herkunftsbezeichnungen einen deutlichen Vorsprung gegenüber den nordeuropäischen Ländern vorweisen. Die wirtschaftliche Bedeutung herkunftsgeschützter Produkte ist z. T. beachtlich. In Italien lag der Umsatz mit diesen Produkten im Jahr 2003 bei rund 7,7 Mrd. €, in Frankreich bei rund 3,2 Mrd. € (Anton 2005). Im Bereich Käse werden in Frankreich ca. $25 \%$ der gesamten Käseproduktion durch Herkunftsangaben geschützt, in Italien sogar rund 55 \% (Anton 2005). In Deutschland haben die vier geschützten Käsesorten Allgäuer Bergkäse, Allgäuer Emmentaler, Altenburger Ziegenkäse und Odenwälder Frühstückskäse einen bescheidenen Anteil von 0,5 \% an der gesamten Käseproduktion. Europaweit sind im Jahr 2005155 Käse nach der Verordnung 2081/92 geschützt.

Der Streit um die Eintragung von „Feta“ als geschützte Ursprungsbezeichnung beschäftigt die Mitgliedsstaaten, die Europäische Kommission sowie den Europäischen Gerichtshof nunmehr seit über einer Dekade. Einer ersten Klage von Dänemark und anderen Mitgliedsstaaten gegen die Eintragung durch die Verordnung EWG 1107/96 wurde 1999 stattgegeben. Der Gerichtshof stellte in seinem Urteil fest, dass die Kommission bei der Prüfung der Frage, ob „Feta“ eine Gattungsbezeichnung ist, nicht ordnungsgemäß alle notwendigen Faktoren berücksichtigt hatte. Aufgrund des Urteils sandte die Kommission den klagenden Mitgliedsstaaten einen Fragebogen über die Herstellung und den Verzehr von Feta-Käse sowie über die Bekanntheit der Bezeichnung „Feta“ bei den Verbrauchern in diesen Staaten zu. Basierend auf den Ergebnissen dieser Befragung kam der wissenschaftliche Ausschuss der Europäischen 
Kommission in $2001 \mathrm{zu}$ dem Ergebnis, dass die Bezeichnung „Feta“ keine Gattungsbezeichnung sei. „Feta“ wurde somit in 2002 durch die Europäische Kommission erneut als geschützte Ursprungsbezeichnung eingetragen. Der abermaligen Anfechtung der Eintragung durch Dänemark und Deutschland ist im Oktober dieses Jahres nicht stattgegeben worden, so dass nun der Schutz der Käsebezeichnung „Feta“ als Ursprungsbezeichnung rechtmäßig ist.

Neben dem Problemfall „Feta“, der nach Ansicht der Kläger eine Gattungsbezeichnung darstellt, streiten EU-Kommission und Mitgliedsstaaten unter anderem auch über „Parmesan“ und „Emmentaler“. Alle genannten Käsesorten werden in zahlreichen Mitgliedsstaaten seit Jahrzehnten hergestellt, unter dieser Bezeichnung vermarktet und haben sich zu üblichen Namen für Lebensmittel entwickelt. Besonders prekär ist im Fall Feta, dass dieser Käse seinen Ursprung in Bulgarien findet und selbst Bulgarien nach einem EU-Beitritt bei bisheriger Rechtslage keinen Feta vermarkten dürfte. Ferner hat Feta-Käse seine Popularität bei den hiesigen Konsumenten und die Assoziation mit Griechenland vornehmlich den nordeuropäischen Großmolkereien zu verdanken, die in den letzten 20 Jahren die Vermarktung vorangetrieben haben - wenn auch unter etwas missbräuchlicher Ausnutzung der Herkunftsassoziationen zu Griechenland. Insgesamt liegt damit eine relativ komplexe Gemengelage aus wirtschaftlichen Interessen und rechtssystematischen Erwägungen vor.

Die Verordnung (EWG) 2081/92 sieht zur Vermeidung solcher Problemfälle eigentlich vor, dass Lebensmittelbegriffe, die im Laufe der Zeit zu Gattungsbezeichnungen geworden sind, nicht eingetragen werden dürfen (Artikel 3, Abs. 1). Zu diesem Zweck sollte der Europäische Rat vor Inkrafttreten der Verordnung auf Vorschlag der Kommission eine Liste mit solchen Namen veröffentlichen, die als Gattungsbezeichnungen anzusehen und somit nicht eintragungsfähig sind. Bis zum heutigen Tage ist eine solche Liste nicht verabschiedet worden: Eine erste Vorschlagsliste der EU-Kommission, in der als Gattungsbezeichnungen unter anderem Edamer, Gouda, Camembert, Brie, Emmentaler und Cheddar aufgeführt sind, wurde zurückgezogen, da diese Aufstellung im Europäischen Rat nicht die erforderliche Mehrheit gefunden hatte.

Die aktuellen Entwicklungen haben tief greifende Auswirkungen auf die Milchindustrie. Betroffen sind zzt. alle Hersteller von Feta-Käse außerhalb Griechenlands, allen voran Arla mit einer jährlichen Produktion von 80000 t (Hemmelmann 2005b: 48). In Deutschland müssen sich Hersteller wie die Feinkäserei Hochland, die Milchwerke Crailsheim, Rücker 
oder die Bergader Privatkäserei mit den Effekten des Urteils beschäftigen. Es steht dabei außer Frage, dass die EU-weite Nachfrage nach Feta-Käse von griechischen Produzenten kurz- bis mittelfristig nicht erfüllt werden kann. Zudem dürften die Konsumenten in Mittelund Nordeuropa den aus Schafs- und/oder Ziegenmilch hergestellten Feta, der im Gegensatz zu dem aus Kuhmilch hergestellten einen weitaus kräftigeren Geschmack aufweist, nur zum kleineren Teil präferieren. Allerdings werden die Wachstumsmöglichkeiten von Feta-Käse aus Schafsmilch als durchaus hoch eingestuft, so dass Griechenland hier ein lukratives Marktsegment gewinnt.

Feta-Hersteller außerhalb Griechenlands müssen neue Kommunikationsstrategien für ihre Produkte entwickeln. Für Großmolkereien mit entsprechenden Werbebudgets bietet sich die Möglichkeit, eine Marke für den „Weichkäse griechischer Art“ aufzubauen und die Gattungsbezeichnung „Feta“ in den Hintergrund zu rücken. Bei einer solchen schrittweisen Überführung werden zumeist im Sinne der Überblendtechnik (Liedtke 1994) alte und neue Produktbezeichnung gleichzeitig verwendet, die neue Bezeichnung substituiert dann sukzessive die vorherige Bezeichnung und rückt auf der Verpackung immer stärker in den Vordergrund. Beispielhaft kann hier Hochland mit seiner Feta-Produktlinie „Patros“ aufgeführt werden, die Nennung der Käseart „Feta“ ist schon heute nachrangig. Ein besonderes Problem bei der Namenswahl haben Handelsmarkenlieferanten. Der Anteil der Handelsmarken beträgt derzeit rund $60 \%$ der Gesamttonnage von Feta und ist damit außergewöhnlich hoch (Hemmelmann 2005b: 48). Da hier der Handel als Markeneigner in aller Regel keine Marketingaufwendungen für die Bekanntmachung eines neuen Namens vornimmt, bleiben nur neue Verpackungskonzepte, die über die Namensassoziation und ggf. bildliche Unterstützungen das Produkt erkennbar machen. So wird z. B. von der Bergader Privatkäserei zukünftig der Name „Fetissima“ verwendet. Der Konsument wird sein gewünschtes Produkt mit einer solchen namensverwandten Bezeichnung erkennen, allerdings ist die Anzahl der ähnlich klingenden, aber wettbewerbsrechtlich möglichen (weil nicht unzulässig anlehnenden) Begriffe begrenzt.

Eine zweite Dimension des Themas betrifft die weitere industriepolitische Ausrichtung der deutschen Molkereiwirtschaft. Vor dem Hintergrund der starken Fokussierung der deutschen Großmolkereien auf das Mengengeschäft - und in Teilen die Markenpolitik - hat der Milchindustrieverband die Verordnung bisher durchweg abgelehnt. Nun aber muss sich die Milchindustrie mit der Tragweite des Urteils beschäftigen. Sollte dieses wegweisend sein, 
könnten zukünftig auch andere Mitgliedsstaaten (z. B. Italien mit Parmesan, Niederlande mit Edamer) ihre strittigen Ursprungsbezeichnungen anmelden und sich auf das Feta-Urteil berufen. Eine solche Entwicklung würde die deutschen Molkereien vor erhebliche Probleme stellen, da leistungsfähige Konkurrenten Wettbewerbsvorteile erzielen würden. Es ist deshalb zu überlegen, ob die bisherige „Fundamentalopposition“ gegen die Verordnung nicht einer stärker lösungsorientierten Strategie weichen sollte, um die Einflussmöglichkeiten auf die EU-Kommission zu erweitern. Nach dem aus Sicht der Verordnung positiven WTO-Urteil ist zu erwarten, dass die Kommission an dem Instrument zukünftig festhalten wird. Vor diesem Hintergrund sind das Feta-Urteil des EuGH und die Verordnung (EWG) 2081/92 in ihrer jetzigen Form kritisch zu hinterfragen und neue Ideen zur Auflösung des Streits um Gattungsbegriffe zu entwickeln (Voss/Spiller 2006).

Gleichzeitig sollte die deutsche Molkereiwirtschaft das System der EU-Herkunftsbezeichnung aber akzeptieren und eigene Nutzungskonzepte differenzierter bewerten. Zweifelsohne könnten deutsche Molkereien und Käsehersteller in größerem Maße auf das Instrument der geschützten Ursprungsbezeichnungen zurückgreifen: Die CMA gibt an, dass in Deutschland 150 traditionelle Käsesorten zu finden sind (z. B. Frankfurter Handkäse, Magdeburger Bördespeck, Harzer Roller usf.). Erstaunlich ist, dass bis heute nur vier deutsche Käsesorten bei der EU als geschützte Ursprungsbezeichnungen eingetragen sind. Potenziale bieten diese Begriffe vor allem dann, wenn von einer weiter steigenden Nachfrage der Verbraucher nach regionalen Spezialitäten ausgegangen wird. Im Kern schützt die VO 2081/92 mittelständische Hersteller ohne eigene Möglichkeiten der Markenbildung. Diese sollten auch in Deutschland verstärkt über das Instrument nachdenken. Sie werden in einem zunehmend liberalisierten Milchmarkt nur wettbewerbsfähig bleiben, wenn sie das Spezialitätenmarketing ausbauen. 


\section{Literatur}

Anton, A. (2005): Trademarks, Geographical Indications and Generics in Cheeses. Vortrag im Rahmen der World Intellectual Property Organization (WIPO)-Tagung „Worldwide Symposium on Geographical Indications“ vom 27.-29. Juni 2005 in Parma.

Bachl, T. (2005): Consumer's Choice 05. Trends in Food and Beverages. In: www.bveonline.de/presse/archiv/archivaktuell_071005/bachl071005.pdf.

Abrufdatum 05.12.2005.

Bauer, H. H. et al.(2005): „Heavy User“ von Handelsmarken. In: Jahrbuch der Absatz- und Verbrauchsforschung 51 (1): 4-25.

BLE (Bundesanstalt für Landwirtschaft und Ernährung) (Hrsg.) (2005): Ökologische Märkte erschließen, Marktinformationen zu Öko-Milch \& Öko-Molkereiprodukten in Deutschland. Bonn.

BML (Bundesministerium für Ernährung, Landwirtschaft und Forsten) (Hrsg.) (2000): Zur Wettbewerbsfähigkeit der deutschen Milchwirtschaft: Gutachten des Wissenschaftlichen Beirats beim Bundesministerium für Ernährung, Landwirtschaft und Forsten. Schriftenreihe des Bundesministeriums für Ernährung, Landwirtschaft und Forsten, Reihe A, Angewandte Wissenschaft, Heft 486. Landwirtschaftsverlag, Münster-Hiltrup.

BMVEL (Bundesministerium für Verbraucherschutz, Ernährung und Landwirtschaft) (Hrsg.) (2005): Die Unternehmensstruktur der Molkereiwirtschaft in Deutschland. Bonn.

Brettschneider, R. (2004): 6 Monate EU-25: wie sehen sie aus, die Märkte in den Erweiterungsländern. Vortrag bei den 17. CMA Marketingtagen, 02.12.2004. Berlin.

Budde, F.-J. (2005): Sind die Milchbauern verrückt geworden? In: Landwirtschaftliches Wochenblatt Westfalen-Lippe 34 (45): 11.

Cook, M.L. (1995): The Future of U.S. Agricultural Cooperatives: A Neo-Institutional Approach. In: American Journal of Agricultural Economy 77 (5): 1153-1159.

Chwallek, A. (2005): Die Discounter zeigen die Zähne. In: LZ 57 (8): 4.

Dawson, J. (2005): Die große Tauschbörse. In: LZ 57 (42): 42.

Dawson, J. (2006): Retail Trends in Europe. In: Krafft, M. und M. K. Mantrala (Hrsg.): Retailing in the 21st Century. Springer, Berlin u. a.: 41-58.

Deutsche Milchwirtschaft (Hrsg.) (2005): Die umsatzstärksten Mopro-Anbieter 2005. Deutsche Milchwirtschaft-Spezial. Gelsenkirchen.

Ebneth, O. (2005): Internationalisierung und Unternehmenserfolg - Ein Vergleich europäischer Molkereigenossenschaften. Vortrag bei der 45. GEWISOLA (Gesellschaft für Wirtschafts- und Sozialwissenschaften des Landbaues)-Tagung 2005 in Göttingen. In: www.uni-goettingen.de/docs/1966ef774357d81e528bfb84836a77d1.pdf. Abrufdatum 12.10.2005.

Enneking, U. et al. (2004): „Global brands“ und „local heroes“: Überlebenschancen für Regionalmarken im Portfolio internationaler Lebensmittelhersteller? In: Ahlert, D. (Hrsg.) (2004): Internationalisierung von Vertrieb und Handel. Jahrbuch Vertriebsund Handelsmanagement. Deutscher Fachverlag, Frankfurt a. M.: 205-222.

Ernährungsdienst (2005): Milch wandert weiter ins Rheinland. In: Ernährungsdienst 60 (88): 2. 
European Commission (2005): Prospects for agricultural markets and income 2005-2012. In: http://europa.eu.int/comm/agriculture/publi/caprep/prospects2005/fullrep.pdf. Abrufdatum 05.12.2005.

FAZ-NET (2005): Schweizer stimmen klar gegen Gentechnik. In: www.faz.net/s/Rub8E1390D3396F422B869A49268EE3F15C/Doc E2285A70C11A94129B4F10D4 02B547A3B ATpl Ecommon Scontent.html. Abrufdatum 03.12.2005.

Fiducia Management Consulting (2005): Are Foreign Chain Stores Threatening Domestic Players in China. In: http://www.fiducia-china.com/Information/Newsletter/681407.html. Abrufdatum 02.06.2005.

Fuchshofen, W. (2005): Der Biomarkt in den USA. In: BioPress 4 (60): 60-61.

Geisler, B. (2005): Fair gehandelte Milch in Hamburger Supermärkten. In: Hamburger Abendblatt, 03.12.2005.

Genoux, J. (2005): „Faire“ Milch aus Schleswig-Holstein wird getestet. In: www.lnonline.de/news/print/1745909. Abrufdatum 27.11.2005.

Gruner \& Jahr (Hrsg.) (2004): Brigitte Kommunikationsanalyse 2004. Gruner\&Jahr-Verlag, Hamburg.

Güth, W. (1999): Spieltheorie und ökonomische (Bei)Spiele. 2. Aufl., Springer, Berlin u. a.

Hemme, T. und E. Deeken et al. (2005): IFCN Dairy Report 2005. International Farm Comparison Network. Global Farm GbR, Braunschweig.

Hemme, T., et al. (2005a): Status and development of milk production. In: Hemme, T. und E. Deeken et al. (2005): IFCN Dairy Report 2005. International Farm Comparison Network. Global Farm GbR Braunschweig: 60-61.

Hemme, T., et al. (2005b): Status and development of farm structure. In: Hemme, T. und E. Deeken et al. (2005): IFCN Dairy Report 2005. International Farm Comparison Network. Global Farm GbR, Braunschweig: 66-67.

Hemmelmann, W. (2005a): Läuft wie geschmiert. In: LZ 57 (11): 26.

Hemmelmann, W. (2005b): Hoffnungsträger im SB-Regal. In: LZ 57 (14): 48.

Hendrikse, G.W.J. und C.P. Veerman (2004): On the Future of Cooperatives: Talking Stock, Looking Ahead. In: Hendrikse, G.W.J. (ed.): Restructuring Agricultural Cooperatives. Erasmus University, Rotterdam: 91-108.

Humana Milchunion (Hrsg.) (2005): Geschäftsbericht 2004. Everswinkel.

IDF (International Dairy Federation) (Hrsg.) (2004): Bulletin of the International Dairy Federation. Brüssel.

IDF (International Dairy Federation) (Hrsg.) (2005): Bulletin of the International Dairy Federation. Brüssel.

IFAP (International Federation of Agricultural Producers) (2005): IFAP Commodities Conference, Group on Dairy Products. Summary Report. In: http://www.ifap.org/en/commodities/reportdairybrugges0405.html. Abrufdatum 05.12.2005.

Keunecke, K. (2005): Softdiscounter auf dem Vormarsch. In: ZMP (Hrsg.): Märkte im Wandel: Agrarreform, Liberalisierung, EU-Osterweiterung: 11. ZMP-Milchforum 10./11. März 2005 in Berlin. Bonn: 10-12.

Krönert, A. (2005): Leichtgewichte schwer in Fahrt. In: LZ 57 (6): 38-40. 
Langelüddeke, P. und T. Deichmann (2004), Was Konsumenten wollen müssen. In: www.novo-magazin.de/71/novo7124.htm. Abrufdatum 02.12.2005.

Liedtke, A. (1994): Der Wechsel des Markennamens. In: Bruhn, M. (Hrsg.): Handbuch Markenartikel. Gabler, Stuttgart: 792-811.

Loureiro, M.L. und M. Bugbee (2005): Enhanced GM Foods: Are Consumers Ready to Pay for the Potential Benefits of Biotechnology? In: The Journal of Consumers Affairs 39 (1): $52-70$.

Lusk, J. et al. (2003): Demand for Beef from Cattle Administered Growth Hormones and Fed Genetically Modified Corn: A Comparison of Consumers in France, Germany, the United Kingdom, and the United States. In: American Journal of Agricultural Economics 85 (1): 16-29.

LZ (Lebensmittelzeitung) (2005a): Neue Partner bei Weight Watchers. In: LZ 57 (47): 18.

LZ (Lebensmittelzeitung) (2005b): Weiße Linie weiter unter Druck. In: LZ 57 (9): 63-64.

LZ (Lebensmittelzeitung) (2005c): Molkereien zwischen allen Stühlen. In: LZ 57 (13): 22.

LZ (Lebensmittelzeitung) (2005d): Milchbauern warnen vor Nachahmern. In: LZ 57 (14): 50.

LZ (Lebensmittelzeitung) (2005e): Preise für innovative Leistungen. In: LZ 57 (41): 53.

LZ (Lebensmittelzeitung) (2005f): Lidl kauft Milch wenig billiger. In: LZ 57 (23): 19.

LZ (Lebensmittelzeitung) (2005g): Dänen bringen Mega-Fusion zu Fall. In: LZ 57 (17): 25.

LZ (Lebensmittelzeitung) (2005h): Ehrmann meldet sich zurück. In: LZ 57 (32): 16.

LZ (Lebensmittelzeitung) (2005i): Der Lebensmittelhandel in Europa. Deutscher Fachverlag, Frankfurt a. M.

LZ-Net (2005a): Tegut verkauft Milch „ohne Gentechnik“. In: http://www.lznet.de/news/topnews/pages/protected/showPrint.prl?id=46629. Abrufdatum 02.12.2005.

LZ-Net (2005b): Hochwald baut weiter um. In: www.lz-net.de/news/topnews/pages/protected/showPrint.prl?id=49011. Abrufdatum 05.11.2005.

LZ-Net (2005c): Top 30 Welt. In: http://www.lz-net.de/companies/index.prl\#rhandel. Abrufdatum 7.12.2005.

Medizinauskunft (2005): Trinken Sie Gen-Milch? In: www.medizinauskunft.de/artikel/gesund/Tipps/01_02_genmilch.php. Abrufdatum 05.12.2005.

Meffert, H. et al. (Hrsg.) (2002): Markenmanagement - Grundlagen der identitätsorientierten Markenführung. Gabler, Wiesbaden.

Milch \& Markt (2005): Umsatz und Export Anteil der deutschen Milchindustrie. In: www.milch-markt.de/de/milch/brancheninformationen/spitzenstellung_milchwirtschaft.html. Abrufdatum 05.11.2005.

Murmann, C. (2005a): Einsparpotential scheint gigantisch. In: LZ 57 (50): 20.

Murmann, C. (2005b): Humana kündigt Großoffensive an. In: www.lz-net.de/news/marketnews/pages/protected/showPrint.prl?id=49751. Abrufdatum 18.12.2005.

Murmann, C. (2005c): Trendsortiment mit Sorgen. In: LZ 57 (38): 40-42.

Murmann, C. (2005d): Danone meldet Durchbruch für Activa. In: LZ 57 (37): 18.

Murmann, C. (2005e): Upländer versuchen es. In: LZ 57 (3): 24. 
Murmann, C. (2005f): Hochland nutzt Chancen im Ausland. In: LZ 57 (16): 20.

Murmann, C. und A. Wessels (2005): Umwälzung im Trinkmilchangebot. In: LZ 57 (18 ): 22.

Nordmilch (Hrsg.) (2005): Geschäftsbericht 2004. Bremen.

OECD/FAO (2005): Agricultural Outlook: 2005-2014. Paris.

Österreichische Milch- \& Lebensmittelwirtschaft (2005): „Gentechnikfrei“ und die Sorge um die Folgen. In: Deutsche Milchwirtschaft 56 (20): 877-878.

Queck, M. (2005): Aldi haut kräftig rein. In: LZ 57 (15): 41-42.

Riethmüller, R.C. (2005): The acceptance of GM food with health benefits by consumers in Germany: a Structural Equation Model. Unveröffentlichte Masterarbeit. Institut für Agrarökonomie, Universität Göttingen.

Römer, D. (2005): Milcherzeuger vor schweren Zeiten. In: ZMP (2005): ZMP-Marktbericht Milch (11), 19. März 2005: 2-3.

Schramm, M. et al. (2004): Brand Orientation in der Ernährungsindustrie. Deutscher Universitätsverlag, Wiesbaden.

Sellami, H. (2005): Carrefour China: A Local Market, City Weekend 28.04.2005. In: http://www.cityweekend.com.cn/en/beijing/.... Abrufdatum 04.05.2005.

Shenzhen Daily (2005): Foreign Retailers Take Growing Market Share. In: http://www1.cei.gov.cn/ce/doc/ceno/200503221409.htm. Abrufdatum 05.12.2005.

Spiller, A. (2000): Erfolgschancen mittelständischer Hersteller als Handelsmarkenspezialisten: Eine institutionenökonomische Analyse. In: Meyer, J.-A. (Hrsg.): Marketing in kleineren und mittleren Unternehmen. Jahrbuch der KMU-Forschung. Vahlen, München: 391-412.

Thiedig, F. (2002), Erfahrungen mit der Umsetzung der EWG-Verordnung Nr. 2081/92 in Deutschland. In: Begemann, F. (Hrsg.): Schriften zu Genetischen Ressourcen. Band 17: Vielfalt auf den Markt. Bonn: 14-23.

Upländer Bauernmolkerei (2005): Information zur Erzeuger-fair Milch. Informationsblatt, Willingen-Usseln.

Urde, M. (1999): Brand Orientation: A Mindset for Building Brands into Strategic Resources. In: Journal of Marketing Management 10 (6): 346-360.

Voss, J. und A. Spiller (2006): Quo Vadis Herkunftsschutz. In: Milchmarketing (erscheint 02/2006).

Weindlmaier, H. (2005a): Konsequentes Sowohl-als-auch. In: LZ 57 (38): 47-48.

Weindlmaier, H. (2005b): Entwicklung der Erzeugermilchpreise: Welche Chancen bietet eine aktive Marktbeeinflussung. In: dmz Deutsche Molkereizeitung 126 (14) Teil I bzw. (15) Teil II: 26-31 bzw. 20-25.

Weindlmaier, H. (2005c): Entwicklung der Erzeugerpreise: Welche Chancen bietet eine aktive Marktbeeinflussung. Vortrag beim 1. Nordmilch-Unternehmerforum in Oldenburg, 6. Dezember 2005.

ZMP (Hrsg.) (1995): ZMP-Marktbilanz Milch 1995. Bonn.

ZMP (2005a): ZMP-Marktbilanz Milch 2005. Bonn.

ZMP (2005b): Nahrungsmittelnachfrage 2004: Sinkende Zahlungsbereitschaft für Bedienung. In: www.zmp.de/mafo/haushaltskonsum/highlights.asp. Abrufdatum 05.12.2005. 
ZMP (2005c): Nachfrage privater Haushalte 2004. Bonn.

ZMP (2005d): Garantiemenge 2005/06 deutlich überschritten. In: www.zmp.de/news/News.asp?DatumsZahl=20051104\&DataId=23543\&rPos=0. Abrufdatum 07.11.2005.

ZMP (2005e): Quotenpreise stiegen deutlich. In: http://www.zmp.de/presse/agrarwoche/marktanalysen/ma44.pdf. Abrufdatum 07.11.2005.

ZMP (2005f): ZMP-Milchpreisvergleich 2005 - Jahresauswertung 2004. Bonn.

ZMP (2005g): Milchpreise leicht gesunken. In: www.zmp.de/presse/agrarwoche/marktanalysen/ma36.pdf. Abrufdatum 07.11.2005.

ZMP (2005h): Jahresbericht 2005/2006. In: www.zmp.de/info/Jahresbericht.pdf. Abrufdatum 19.12.2005. 
KAPITEL III

Stakeholder Relationship Management 


\section{KAPITEL III.1}

Die Agrarwende - Neustrukturierung eines Politikfeldes 


\section{Die Agrarwende - Neustrukturierung eines Politikfeldes*}

(mit Cordula Kropp, Achim Spiller und Harald Ulmer)

$1 \quad$ Problemstellung und Zielsetzung des Beitrags ........................................................352

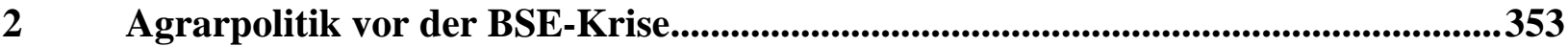

$3 \quad$ BSE-Krise und Neuorientierung der Policy-Konstellation .......................................356

4 Teilziele und Instrumente der Agrarwende.........................................................360

4.1 DifFusion VON Bio-LEBENSMITTELN IN DEN MASSENMARKT .....................................361

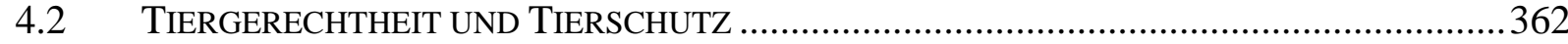

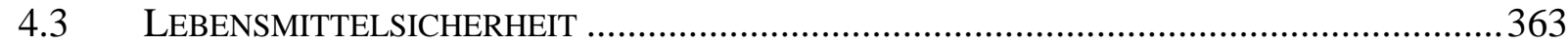

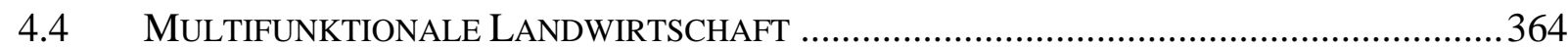

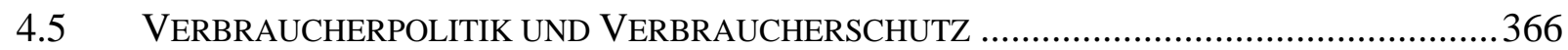

$5 \quad$ Harte und weiche Politikinstrumente in der Agrarwende ............................................367

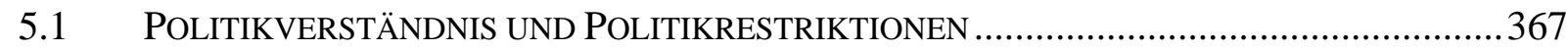

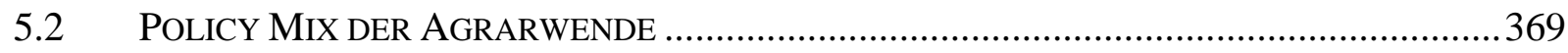

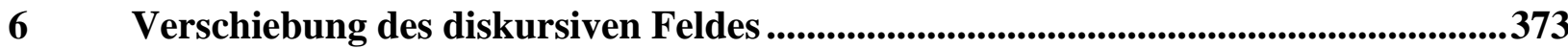

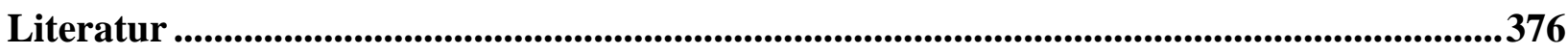

\section{Abbildungsverzeichnis}

Abbildung 1: Ziele der Agrarwende. 361

\section{Tabellenverzeichnis}

Tabelle 1: Die Agrarwende als Politikkampagne ..................................................................360

Tabelle 2: Verantwortungszuschreibung für Lebensmittelqualität ...........................................364

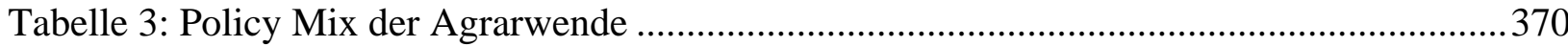

Tabelle 4: Prämien zur Förderung und Beibehaltung des ökologischen Landbaus im Rahmen

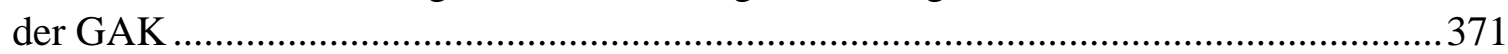

* Veröffentlicht als Diskussionspapier Nr. 10 des BMBF-Projekts „Von der Agrarwende zur Kosumwende“. 


\section{Problemstellung und Zielsetzung des Beitrags}

Die BSE-Krise und die daran anschließende Agrarwendeprogrammatik der Bundesregierung liegen inzwischen gut vier Jahre zurück. Sie sind - stellt man die damalige Medienbeachtung in Rechnung - bereits erstaunlich verblasst und heute durch Themen wie die Reform der EUAgrarpolitik auch in der Fachöffentlichkeit verdrängt. Gleichwohl hat die Agrarpolitik durch diese Politikimpulse Veränderungen grundsätzlicher Art erfahren, die Bestand haben.

Mit der Agrarwende ist eine strukturelle Neuorientierung des Policy-Feldes verbunden, eine Öffnung des klassischerweise durch enge Lobbyverflechtungen charakterisierten Agrarbereichs gegenüber der Gesellschaft und kritischen Anspruchsgruppen. Mit der Agrarwende hat sich aber auch eine kulturelle Umorientierung Gehör verschafft, in deren Rahmen nun alte Selbstverständlichkeiten neu begründet werden müssen und neue Leitbilder die alten Diskurskonstellationen und Akteursrationalitäten verändern (Boschert 2005; Kropp/Wagner 2005; Oosterveer 2002). Hinzu kommt der Fokus auf neue Politikinstrumente. Während traditionell Subventionen und Ordnungsrecht dominierten, gewinnen im Rahmen der Agrarwende weiche Politikinstrumente (z. B. Öffentlichkeitsarbeit, Labelling usf.) an Relevanz. Es gibt vielfältige Hinweise darauf, dass weiche Politikmaßnahmen auch in Zukunft wesentlich stärker eingesetzt werden, z. B. in der zweiten Säule der EU-Agrarpolitik.

Vor diesem Hintergrund zielt das vorliegende Diskussionspapier auf die Einordnung der Agrarwende aus politikwissenschaftlicher Perspektive. Der folgende Beitrag ist Bestandteil eines umfangreichen Forschungsprojektes („Von der Agrarwende zur Konsumwende?“, www.konsumwende.de). Das Projekt zielt auf die Analyse von Politikwirkungen mit dem spezifischen Fokus auf die gesamte Wertschöpfungskette der Ernährungswirtschaft.

Eine Beschreibung der so genannten „Agrarwende“ kann sich in unterschiedlicher Weise auf das politische Programm und seine Maßnahmen beziehen (Feindt/Ratschow 2003; Isermeyer 2001a; Künast 2002), aber auch auf die politischen Diskurse wie die mediale Rhetorik (Boschert 2005), auf Akteure und ihre Handlungskontexte (Waskow/Rehaag 2004; Schmidt/Jasper 2001) und auf intendierte und nicht intendierte Wirkungen in vielfältigen Feldern (Schneider et al. 2003; Stodieck et al. 2002). Im vorliegenden Artikel geht es um eine Untersuchung der politischen Agrarwendeprogrammatik und in einem zweiten Teil um deren spezifische Resonanzen. Diese Untersuchung kann statisch oder dynamisch angelegt sein. Im 
ersten Fall ist sie auf die direkt in der Folge der BSE-Krise implementierten Ziele und Instrumente bezogen. Eine dynamische Analyse verfolgt den Entscheidungs- und Aushandlungsprozess während der Gültigkeit dieses neuen Politikparadigmas. Im Weiteren gehen wir zunächst auf die ursprünglichen Politikimpulse ein, um uns dann in weiteren Beiträgen auf ihre Rezeption im sozialen Feld und die erwünschten wie unerwarteten Folgen und Nebenwirkungen zu konzentrieren.

Weiterhin wird eine Analyse der Agrarwende in Abhängigkeit vom wissenschaftlichen Hintergrund des Betrachters zu anderen Rahmungen kommen. Ernährungswissenschaftler betonen die verstärkte Betrachtung von Themen wie Gesundheit, vollwertiger Ernährung, Umweltauswirkungen des Konsums usf., wie sie sich derzeit beispielhaft in der vom Bundesministerium initiierten Adipositas-Debatte zeigen (Körber/Leitzmann 2004; Hoffmann/Lauber 2001: 108 ff.). Ökonomen heben vornehmlich auf Marktwirkungen und veränderte Wettbewerbsstrukturen ab, z. B. auf komparative Wettbewerbsnachteile durch neue Tierhaltungsvorschriften, aber auch auf wohlfahrtsökonomische Kosten-NutzenAnalysen und externe Effekte der Ernährungswirtschaft (Isermeyer 2001a). Soziologen rücken bspw. veränderte Netzwerkkonstellationen im Agrar- und Ernährungssektor sowie deren Auswirkungen auf gesellschaftliche Teilgruppen, Teilsysteme und Wahrnehmungen in den Mittelpunkt (Kropp/Wagner 2005; Boschert 2005; Brandt et al. 2004; Waskow/Rehaag 2004). Politikwissenschaftler konzentrieren sich zumeist auf die strukturelle und kommunikative Konstruktion der institutionellen Netzwerke und deren Leistungs- und Problemlösungsfähigkeit. Hier wird vor allem zwischen normativen und symbolischen Politikstilen unterschieden, letztere gewinnen mit der hohen öffentlichen Resonanz der BSEKrise zunehmend an Relevanz.

Auch in diesem Beitrag wird zunächst die Policy-Konstellation vor der „BSE-Krise“, die letztlich zur Konzipierung der „Agrarwende“ geführt hat, skizziert. Anschließend werden Programm, Teilziele und Instrumente vorgestellt. Dieser Blickwinkel wird in späteren Beiträgen des Forschungsprojektes erweitert.

\section{Agrarpolitik vor der BSE-Krise}

Über Jahrzehnte wurde die deutsche Landwirtschaftspolitik sowohl auf Bundes- wie auf Landesebene „von Bauern für Bauern“ gemacht. Im Sinne der Neuen Politischen Ökonomie lässt sich die Agrarpolitik vor der BSE-Krise als Erfolg organisierter Interessen und als 
Ausrichtung der Politik auf eine kleine, aber wohl organisierte Wählergruppe charakterisieren (Hagedorn 1996; Henrichsmeyer/Witzke 1994; Waskow/Rehaag 2004). Landwirtschaftliche Interessenverbände sind ausgezeichnet organisiert. Es handelt es sich um eine relativ kleine Gruppe mit spezifischen Interessen, die mit geringen Transaktionskosten koordiniert werden kann. Trittbrettfahrerprobleme können durch selektive Anreize und sozialen Druck gelöst werden. Zugleich ist Lobbyarbeit durch die Höhe der politisch zu vergebenden Subventionen lukrativ. Die Kosten-Nutzen-Relation des Rent Seeking, d. h. das Abschöpfen von Produzentenrenten, ist einzelbetrieblich deutlich positiv, wenn je nach Betriebsform gut die Hälfte des landwirtschaftlichen Einkommens heute durch staatliche Förderung bestimmt wird (Olson 1991: 65; DBV 2005: 181).

In Deutschland gibt es zzt. 388.500 landwirtschaftliche (Familien-)Unternehmen (BMVEL 2004a: 21), die zusammen mit angestellten Arbeitskräften und dem vor- und nachgelagerten Bereich ein Wählerstimmenpotenzial von min. 3,9 Millionen (BMVEL 2004a: 20) Personen repräsentieren. Diese sind aufgrund ihrer räumlichen Dominanz in bestimmten Wahlkreisen eine relevante Wählergruppe. Berücksichtigt man darüber hinaus die ökonomische, soziale und kulturelle Bedeutung der Ernährungswirtschaft in ländlichen Regionen, erhöht sich das Wählerpotenzial noch einmal erheblich. Zugleich sind die Verbände aufgrund des hohen Organisationsgrads ausgesprochen konfliktfähig (Schubert/Klein 2001). Sie verfügen über eine eigenständige Medienstruktur mit hoher Verbreitung sowie vielfältige personale Kontakte in die Ministerialbürokratie. Fast alle Agrarminister auf Bundes- und Länderebene entstammten in Deutschland in den letzten fünf Jahrzehnten dem Berufsstand (Henrichsmeyer/Witzke 1994: 506). Die Ministerialbürokratie setzt sich im Wesentlichen aus den Absolventen der agrarwissenschaftlichen Fakultäten zusammen. Quereinsteiger sind selten.

Im Gegensatz zu dieser internen Leistungsfähigkeit steht die geringe öffentliche Beachtung des Themas Landwirtschaft. Die Politikstrukturen sind komplex, da die EU-Agrarpolitik die zentralen Impulse setzt. EU-Politik insgesamt und die durch zahlreiche produktbezogene Sonderregeln ausgesprochen differenzierte Agrarpolitik im Speziellen sind für den Wähler nicht transparent. Es gibt für EU-Politikthemen nur eine sehr begrenzte Medienöffentlichkeit. In seiner Rolle als Verbraucher ist das Publikum zudem im Allgemeinen nur sehr indirekt betroffen. 
Insgesamt fanden landwirtschaftliche Themen keine größere öffentliche bzw. mediale Beachtung. Zwar gab es ein beachtliches Unbehagen gegenüber landwirtschaftlichen Interessengruppen und den Entwicklungslinien der größeren Betriebe und speziell der Veredelungsindustrie, dem stand aber eine positive Einstellung zum Landwirt als Person gegenüber, der als etwas altmodisch, aber hart arbeitend und ehrlich galt (Piel 2003: 24 f.).

Aus den skizzierten Gründen ist die Agrarpolitik über lange Jahre ein Musterbeispiel für Klientelpolitik im Sinne der Neuen Politischen Ökonomie gewesen, die vor allem durch die Zweierbeziehung Landwirtschaft - Politik geprägt war. Diese Beziehung wird in der Literatur auch als Basissystem des Agrarsektors bezeichnet (Henrichsmeyer/Witzke 1994: 504). Agrarthemen wurden von der Öffentlichkeit nur in Krisenfällen wahrgenommen, die komplexen Zusammenhänge waren und sind dem durchschnittlichen Wähler/ Konsumenten nicht zu vermitteln. Als Folge war Landwirtschaftspolitik für die städtische Bevölkerung nicht wahlbestimmend, so dass vor allem die beiden Volksparteien sowie die FDP sich durch eine an den Interessen der landwirtschaftlichen Verbände orientierte Politik profilieren wollten. Als Korrektiv diente vornehmlich die EU-Agrarpolitik, die aufgrund der Haushaltszwänge und weltwirtschaftlicher Restriktionen seit der MacSharry-Reform Impulse für eine Liberalisierung der Agrarpolitik, aber auch für eine Sensibilisierung gegenüber Umweltthemen setzte. Dafür wurden 1992 die Garantiepreise gesenkt, zum Ausgleich bekommen die Bauern seitdem Tier- und Flächenprämien. Mit dem Reformprogramm Agenda 2000, unter deutscher Präsidentschaft beim Berliner EU-Gipfel im März 1999 beschlossen, wurde diese Politik fortgesetzt. Das Problem der Überschüsse, die teilweise abgebaut werden konnten, und die geringen Anreize für Qualitätsproduktion wurden damit nicht grundsätzlich gelöst. Die Prämienzahlungen, die von der Hektargröße und der Zahl der Tiere abhängen, begünstigen den hoch produktiven, großflächigen Pflanzenanbau sowie die großen Mastbetriebe in der Rinderproduktion bzw. Milchwirtschaft. Dazu äußerte sich der damalige Agrarkommissar Fischler mit den Worten: "Wir sind damals auf halbem Weg stehen geblieben." (Der Spiegel 2001a: 30).

Die Reformen, die in der europäischen Agrarpolitik in der Vergangenheit durchgeführt wurden, waren vor allem durch den Druck von Einsparungen bzw. den Abbau von Handelsbeschränkungen motiviert. Verbraucherschutz spielte in den 90er Jahren keine zentrale Rolle (Rieger 1995), auch wenn es sowohl auf EU- wie auf Länderebene eine Vielzahl von Detailregulierungen zu Lebensmittelsicherheit und Umweltschutz gab. 
Schließlich galt insbesondere Deutschland im EU-Vergleich als Blockierer einer restriktiveren, umwelt- und verbraucherorientierten Regulierungsstrategie - auch und gerade im Zusammenhang mit BSE vor seiner Manifestation in Deutschland (Boschert 2005: 98; Wolters 1998).

\section{BSE-Krise und Neuorientierung der Policy-Konstellation}

Mit dem 24. November 2000 änderte sich das öffentliche Interesse an der Landwirtschaft schlagartig. Die Nähe der Politik zur Branche, vorausgegangene Beruhigungsversuche, offensichtliche Vertuschungsmaßnahmen und eine ungeschickte Öffentlichkeitsarbeit auf der einen sowie die hohe potenzielle Gefahr von BSE und die Betroffenheit fast aller Konsumenten auf der anderen Seite ließen ein einfaches Krisenmanagement nicht opportun erscheinen. In dieser Situation boten die Partei der Grünen und eine Ministerin ohne „Stallgeruch“ aus Sicht der Regierungskoalition die Gewähr für eine glaubwürdigere Krisenkommunikation und die Demonstration von Veränderungswillen. Diese Entscheidung verschaffte das erste Mal auch den Ideen der bis dahin marginalisierten Agraropposition einen Resonanzraum im institutionell etablierten, agrarpolitischen Zentrum.

Die BSE-Krise ist damit ein klassisches window of opportunity, ein Einfallstor für weitreichende Politikveränderungen und institutionelle Neuorientierungen. Sie stieß auf eine ausgesprochen große Medienresonanz. Allein in der FAZ findet man auf der CD-ROM Ausgabe des Jahres 2001 unter der Eingabe des Suchbegriffs Agrarwende 176 Artikel. Auch über die Hälfte der Bevölkerung (54 \%) kannten das Schlagwort Agrarwende, wie eine repräsentative Umfrage ergab (Feindt/Ratschow 2003: 4 f.).

Der Zusammenbruch des Rindfleischmarktes in einem bis zu diesem Zeitpunkt nicht gekannten Ausmaß verunsicherte die Lebensmittelbranche in hohem Maße, so dass auch in der Wirtschaft Veränderungsnotwendigkeiten anerkannt wurden. Im Zuge der BSE-Krise änderte mehr als die Hälfte der Bevölkerung ihre Ernährungsgewohnheiten, ca. $47 \%$ aller deutschen Haushalte verzichteten in der Zeit von Dezember 2000 bis Februar 2001 auf den Konsum von Rindfleisch (ZMP 2002: 33).

Vor diesem Hintergrund ist die Regierungserklärung von Renate Künast zu sehen. „Der BSESkandal markiert das Ende der Landwirtschaftspolitik alten Typs. Wir stehen vor einem Scherbenhaufen“ (Künast 2001). Unter dem Stichwort „Agrarwende“ vollzog die Regierung 
eine Öffnung der Agrarpolitik, im Rahmen derer die bisherige Fachdiskussion für eine breitere, gesellschaftspolitische Öffentlichkeit zugänglich wurde. Der Begriff und die Zuständigkeitsbereiche bzw. die Folgen der Landwirtschaftspolitik wurden programmatisch umfassender definiert, was nicht zuletzt in der Namensänderung des Bundesministeriums für Verbraucherschutz, Ernährung und Landwirtschaft seinen Ausdruck fand. Zudem wurde für die Parteien deutlich, dass mit diesem Politikfeld auch außerhalb der Landwirtschaft Wählerstimmen zu gewinnen sind.

Noch einmal mit Blick auf die Neue Politischen Ökonomie interpretiert: In den Vordergrund der neuen Agrarpolitik rückt der Medianwähler. Im Speziellen hat die Partei der „Grünen“, die traditionell den ökologischen Landbau präferiert, dieses Themenfeld besetzt, da sie zum einen aufgrund der geringen personellen Verflechtungen eine höhere Glaubwürdigkeit besaß und ihr zum anderen Kompetenzen im Bereich des Verbraucherschutzes zugesprochen wurden. Den „Grünen“ bot sich die Möglichkeit, ihre Wählergruppe, die für Ernährung und Gesundheit besonders aufgeschlossen ist, prägnant anzusprechen. Sie hatten zudem kaum Wählerstimmen im klassischen Agribusiness zu verlieren.

Die bisherigen Ausführungen machen deutlich, dass die institutionelle Öffnung der Agrarpolitik kaum rückgängig zu machen ist. Die Umgestaltung des Ministeriums, die Definition neuer Kompetenzbereiche, die Institutionalisierung neuer Institute (Bundesinstitut für Risikobewertung und Risikokommunikation (BFR), Bundesamt für gesundheitlichen Verbraucherschutz und Lebensmittelsicherheit (BVL)), der teilweise Austausch des wissenschaftlichen Beirats für Agrarpolitik, langsame, inzwischen aber doch relativ umfangreiche personelle Veränderungen im Bundesministerium etc. belegen, dass auch bei einem politischen Wechsel die Rückkehr zur Agrarpolitik „alten Typs“ nicht mehr umstandslos vollzogen werden kann.

Damit verliert das Rent Seeking nicht gänzlich an Bedeutung. Besonders die Gemeinsame Agrarpolitik der Europäischen Union (GAP) wird angesichts der Höhe der Subventionen weiterhin Rent Seeking-Prozesse lukrativ machen. Aber auch auf Bundesländerebene bestehen viele traditionelle Strukturen und damit die klassische Klientelpolitik fort. So gilt es noch als strittig, inwieweit mit der „Agrarwende“ ein policy change vollzogen wurde bzw. überhaupt vollzogen werden konnte (Feindt/Ratschow 2003; Oosterveer 2002; Boschert 2005; van Zwanenberg 2005). Gleichwohl: Auch in der Nachfolge zeigen Themen wie MKS, 
Geflügelpest u. a., dass eine latente Aufmerksamkeit der Massenmedien bleibt. ${ }^{1}$ Die Agrarpolitik ist aus dem Schatten der Lobby in die Arena des Mediendiskurses gerückt.

Mit der Aufmerksamkeit der Medien gewannen Nicht-Regierungsorganisationen (NGOs) an Relevanz. Umwelt-, Verbraucher- und Tierschutzinstitutionen hatten zwar bereits traditionell einen landwirtschaftlichen Schwerpunkt, so etwa bei großen Mitgliederverbänden wie dem Bund für Umwelt- und Naturschutz (BUND) und dem Naturschutzbund Deutschlands (NABU). Im Zuge der tradierten Policy-Konstellationen waren deren Einflussmöglichkeiten auf den Kern des Agribusiness aber begrenzt. Ihr Fokus lag deshalb auf der Förderung eines Gegenentwurfs, der ökologischen Landwirtschaft, die gerade in Deutschland in einem tiefen ideologischen und personellen Konflikt zur konventionellen Landwirtschaft sowie zur traditionellen Agrarforschung und -politik gewachsen war. Das Bio-Segment wuchs seit geraumer Zeit, hatte jedoch unzweifelhaft nur den Charakter einer Marktnische.

Während die einzelnen politischen Maßnahmen und Instrumente der Agrarwende allgemein als weniger bedeutend eingeschätzt werden, bestand ihr Kernelement in der Neuorientierung der Policy-Konstellationen im Agrar- und Ernährungsbereich. In der Ausgangslage war diese gekennzeichnet durch:

- Eine Mehrebenenpolitik mit einer in diesem Politikfeld einzigartigen Verflechtung von EU-, Bundes- und Landespolitik (z. B. Kofinanzierungsmodelle wie Modularisierung, Gemeinschaftsaufgabe Küstenschutz usf.; nationale und landespolitische Umsetzung von Richtlinien etc.).

- Eine parteipolitische Fixierung auf Klientelpolitik bei geringer Öffentlichkeitswirksamkeit des Themas, insgesamt war die Landwirtschaft als „nicht-moderner“ Bereich dem öffentlichen Einfluss weitgehend entzogen.

- Eine ausgeprägte Lobbyarbeit der Branche (Rent Seeking) durch den hohen Anteil der Subventionen am Betriebseinkommen.

- Ein Abdrängen kritischer Anspruchsgruppen in ein alternatives Marktsegment und eine korrespondierende Nischenstrategie seiner VertreterInnen.

- Im Gegensatz dazu war auf EU-Ebene, bedingt durch finanzielle Zwänge, seit Anfang der 90er Jahre ein Trend in Richtung einer stärkeren Anbindung der Agrarpolitik an

\footnotetext{
${ }^{1}$ Generell hängen mediale Konjunkturen und Themenlebenszyklen von der themenspezifischen Eignung für die mediale Berichterstattung und deren selektive Aufmerksamkeitsstrukturen ab sowie von ihrer kulturellen Resonanzfähigkeit (Eder 1997; Luhmann 1996).
} 
die Interessen der Gesellschaft erkennbar, der heute unter dem Stichwort Multifunktionalität programmatisch gefasst wird (OECD 2001).

Vor diesem Hintergrund erzwang die BSE-Krise und ihre diskursive Rahmung eine grundsätzliche Umgestaltung. Die SPD, strategisch durch die bisherige Einbindung gefangen und sich ohnehin stärker als Modernisierungspartei positionierend, gab das traditionelle Politikfeld auf Bundesebene an den grünen Koalitionspartner ab, nachdem Bundeskanzler Gerhard Schröder in seiner programmatischen Rede eine Woche nach dem ersten BSE-Fall bei einem in Deutschland geborenen Rind mit der vielfach zitierten Kritik an „deutschen Agrarfabriken“ die bisherige agrarpolitische Kontinuität aufgekündigt hatte. Die Grünen kaprizierten sich im Sinne der Wählerstimmenmaximierung zum einen auf die Befriedung ihrer Kernwähler in der Naturkostbranche, den Umweltschutzverbänden und bei den BioKäufern. Zum anderen bot Lebensmittelsicherheit eine Chance zur umfassenden Positionierung der „Grünen“ als Verbraucherschutzpartei. Den politischen Akteuren war ohne Zweifel bewusst, dass diese „Agrarwende“ tiefgreifende Konflikte mit dem traditionellen Agribusiness und der gut organisierten Landwirtschaftslobby mit sich bringen musste, in dieser Wählergruppe konnten sich die „Grünen“ allerdings ohnehin kaum Wählerstimmen ausrechnen.

Im Politikfeld selbst fühlten sich die etablierten Agrarinstitutionen durch die proklamierte Agrarwende, insbesondere als angekündigte „tief greifende“ Abkehr von den bisherigen Orientierungen in Politik, Wissenschaft und Wirtschaft (Künast 2001), zunächst brüskiert. So gelang es ihnen nicht unmittelbar an den „Wende-Diskurs“ anzuknüpfen, eine Lücke, die Vertreter der Agraropposition sofort mit entsprechenden Veranstaltungen und Stellungnahmen für sich nutzten. Auf diese Weise kam es vor allem zu Beginn zur Herausbildung und Konfrontation zweier antagonistischer „belief systems“ und der sie tragenden „advocacy coalitions“ (Sabatier 1998 sowie insb. Boschert 2005). Damit wurde zumindest teilweise die Chance von politikorientiertem Lernen, im Rahmen dessen die bis dato hegemoniale Koalition ihre Grundüberzeugungen und Politikstrategien überdenkt und anpasst (Sabatier 1998: 104; Böschen et al. 2002), zugunsten einer positionellen Strategie vergeben. $\mathrm{Zu}$ dieser Konfrontation trug auch bei, dass die mediale Skandalisierung der offensichtlich widerlegten Rede vom „BSE-freien Deutschland“ die bisherigen Politikleitlinien in ihrer Gänze delegitimierte und demgegenüber sowohl Gerhard Schröder in seiner Parlamentsrede als auch Renate Künast in ihrer Regierungserklärung vom 8. Februar 2001 
erfolgreich an den öffentlich-medialen Ruf nach einer notwendigen Stärkung des Verbraucherschutzes als Antwort auf eine politikverursachte Krise anknüpften (Boschert 2005: 105 ff.).

Zusammenfassend bleibt damit festzustellen, dass der Terminus „Agrarwende“ für eine Neuorientierung der Policy-Konstellation mit einer stärkeren Verantwortung gegenüber der Gesellschaft und ihren verschiedenen Akteursgruppen steht. Als übergreifendes Leitbild dieser proklamatischen Politikkampagne ist die umfassende Öffnung der Agrarpolitik gegenüber der Gesellschaft und kritischen Anspruchsgruppen anzusehen.

TABelle 1: Die Agrarwende als PolitikKampagne

\begin{tabular}{|c|c|}
\hline Leitbild: & $\begin{array}{l}\text { - Öffnung gegenüber der Gesellschaft und kritischen } \\
\text { Anspruchsgruppen } \\
\text { - Orientierung an alternativen Leitbildern, die dem bislang } \\
\text { weitgehend unangefochtenen Mainstream entgegengesetzt } \\
\text { wurden; etwa Qualität statt Quantität, Verbraucherschutz versus } \\
\text { Agrarklientelpolitik, Nachhaltige Entwicklung ländlicher Räume } \\
\text { versus produktionistische Wettbewerbsorientierung; ökologischer } \\
\text { Landbau versus intensive Landbewirtschaftung }\end{array}$ \\
\hline $\begin{array}{ll}\text { Strategische } & \text { Ziele } \\
\text { der „Grünen““: } & \end{array}$ & 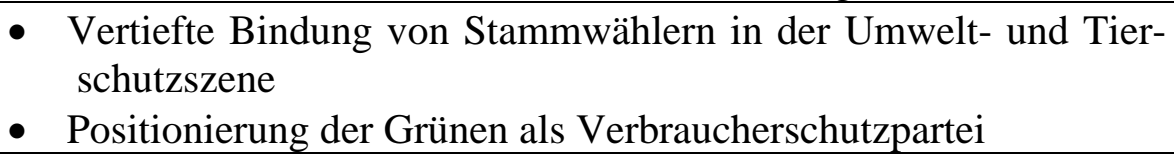 \\
\hline $\begin{array}{l}\text { Neukonfiguration } \\
\text { des Politikfeldes }\end{array}$ & $\begin{array}{l}\text { - } \quad \text { Landwirtschaftspolitik als Teil der Ernährungspolitik } \\
\text { - Stärkung von NGOs } \\
\text { - Neuer Politikstil, der auf Medienwirkung setzt } \\
\text { - Verstärkung von partizipativen Elementen (Runder Tisch) } \\
\text { - Tief greifende Veränderungen in den zugrunde liegenden Politik- } \\
\text { diskursen, die nicht ohne Rückwirkungen bis in die Akteurs- } \\
\text { konstellationen und -koalitionen blieben }\end{array}$ \\
\hline
\end{tabular}

Quelle: Eigene Zusammenstellung

\section{Teilziele und Instrumente der Agrarwende}

Die einzelnen Elemente der Agrarwendepolitik sind in der Forschung in jüngerer Zeit wiederholt aufgearbeitet worden (Feindt/Ratschow 2003; Isermeyer 2001a) und sollen hier nur im Überblick dargestellt werden. Im Vordergrund steht weniger die inhaltliche Ausgestaltung einzelner Maßnahmen als die politisch-konzeptionelle Einordnung der in Abbildung 1 dargestellten Ziele. 
ABBiLdung 1: ZIELE DER AgRARWENDE

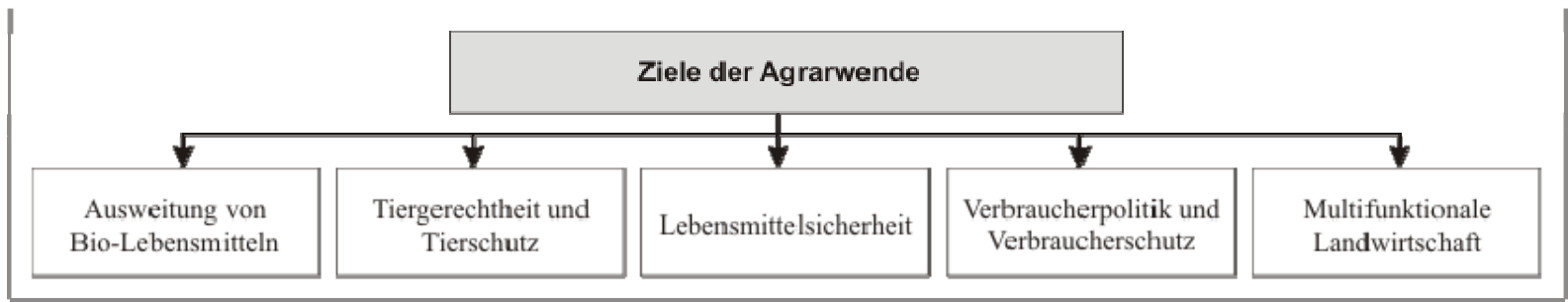

Quelle: Eigene Darstellung

\subsection{Diffusion von Bio-Lebensmitteln in den Massenmarkt}

Das wohl bekannteste Ziel der Agrarwende ist die Ausweitung des ökologischen Landbaus auf 20 \%. Dabei wurde zunächst vom Markt-, später vom leichter zu erreichenden Flächenanteil gesprochen. Diese Ausweitung von Biolebensmittel, die bislang ca. 2,4 \% Markt- und 4, 3 \% Flächenanteil (SOEL 2004; ZMP 2005: 4) haben, soll durch eine Reihe von Maßnahmen erreicht werden (siehe Kap. 5).

Kultureller Hintergrund der Ausweitung des Ökologischen Landbaus ist zum einen das Framing, welches in der Frühphase der BSE-Krise verwendet wurde (Schröder: „Agrarfabriken“). Der ökologische Landbau mit seinen traditionell kleinbetrieblicheren Strukturen und seinem positiven Image in der breiten Öffentlichkeit bot hier Anknüpfungspunkte. Zum anderen ermöglicht der ökologische Landbau in einem begrenzten Maße Schutz vor landwirtschaftlichen Krisen, da er aufgrund der angestrebten Kreislaufwirtschaft (z. B. Verwendung hofeigenen Futters) inhärent sichere Strukturen aufweist. So waren die in der Vergangenheit aufgetretenen Landwirtschaftskrisen (BSE, MKS, Schweinepest) zum einen durch Futtermittelprobleme, zum anderen durch die intensive Tierhaltung ausgelöst bzw. begünstigt worden. Der (traditionelle) ökologische Landbau mit seinem ganzheitlichen Ansatz von geschlossenen Kreisläufen weist hier Vorteile auf, auch wenn der Nitrofenfall zeigt, dass die Unterschiede gradueller Natur sind.

Mit der Ausweitung des ökologischen Landbaus als zentralem Element der Agrarwende wurde ein leicht kommunizierbares Ziel geschaffen (20\% in 10 Jahren). Programmatisch knüpft dies an die umweltpolitischen Wendediskussionen der 80er und 90er Jahre an (Chemiewende, Energiewende, Verkehrswende). Der ökologische Landbau war in der Umweltbewegung eindeutig als Gegenmodell etabliert, Vorstellungen über andere „Konversionsszenarien“ der Landwirtschaftspolitik waren in den Think Tanks der alternativen Wissenschaftsszene nicht erarbeitet worden. Insofern war dieses Ziel aus Sicht der unter Entscheidungsdruck stehenden Politik alternativlos. Die Probleme, ob der Bio-Landbau in der 
bestehenden Form in den Massenmarkt transferiert werden kann, sind nur randständig diskutiert worden, nicht zuletzt deshalb, weil im Vorfeld von BSE keine entsprechende Entwicklung denkbar schien. Die Ausweitung des ökologischen Landbaus kann allerdings durch klassische Politikinstrumente nicht erreicht werden und macht neue politische Formen erforderlich (siehe Kap. 5).

\subsection{Tiergerechtheit und Tierschutz}

Die verstärkte Durchsetzung von Tiergerechtigkeits- und Tierschutzzielen ist in besonderem Maße Ausdruck der Orientierung auf eine breite Öffentlichkeit und andere Wählergruppen. In einer von der Landwirtschaft weitgehend entfremdeten Bevölkerung, die zum Thema Tierschutz im Wesentlichen über die eigene Tierliebe und Haustierhaltung motiviert ist, stoßen produktionswirtschaftliche Gesichtspunkte der Landwirte auf große Skepsis. Der Kontrast zwischen konventioneller Landwirtschaft und städtisch geprägter Gesellschaft ist hier besonders groß: Während großbetriebliche Pflanzenproduktion nur für Fachleute der Naturschutzdiskussion ein relevantes Thema darstellt, sind die Haltungsbedingungen der Nutztierwirtschaft ein bereits lange Zeit immer wieder krisenhaft diskutiertes Thema (Pohlmann Eierproduktion, Birkel-Flüssigeikrise usf.). Gerade in der Geflügelmast und Eierproduktion haben sich aufgrund hoher economies of scale großbetriebliche Haltungsformen herausgebildet. Durch die Einbindung in vertikal integrierte Konzerne (Beispiel Wiesenhof) und die hohe räumliche Konzentration der Produktion (VechtaCloppenburg) entstanden prominente Brennpunkte der Diskussion. Im Gegensatz dazu sind die Schweine- und insbesondere die Rindermast in Deutschland noch weitgehend kleinbäuerlich geprägt.

Die BSE-Krise war insofern faktisch kein Problem landwirtschaftlicher „Agrarfabriken“, sondern der Futtermittelwirtschaft. Eine öffentliche Differenzierung zwischen Eier- und Geflügelwirtschaft auf der einen und der weitgehend bäuerlichen Rindermast und Milchwirtschaft auf der anderen Seite wurde jedoch in der medial gerichteten Agrarwendedebatte nicht vorgenommen.

Vielmehr bot die BSE-Krise die Gelegenheit, die grundsätzlichen Bedenken vieler Verbraucher und Wähler gegen die modernen Formen der Nutztierhaltung aufzugreifen. 
Tiergerechtheit ist ein ethisches Anliegen, welches in gesellschaftlichen und politischen Prozessen verhandelt und entschieden wird.

Die Entscheidungsgrundlage boten hier neuere Ergebnisse der tierethologischen Forschung, wobei vor allem Haltungsbedingungen, Haltungsmanagement, Transport und Schlachtung untersucht wurden. Diese ordnet sich in eine breite gesellschaftlich-philosophische Diskussion um Tiergerechtheit und Tierschutz ein, die bis zur Forderung nach „Menschenrechten“ für höhere Tierarten reicht (Jürgens 2005: 160; Singer 1997).

\subsection{Lebensmittelsicherheit}

BSE als eine Frage der Lebensmittelsicherheit $\mathrm{zu}$ rahmen, liegt angesichts der gesundheitlichen Bedrohung und der hohen Verbraucherverunsicherung nahe. Zudem stand auf EU-Ebene dieser Fokus sehr eindeutig im Vordergrund, so dass die Bundespolitik schon aus diesem Grund reagieren musste. Gerade in Großbritannien war die lange Abwehr dieser gesundheitspolitischen Einordnung wesentliches Element der politischen Krise (Dressel 2002).

Traditionell ist die Ernährungswirtschaft durch die Dominanz hoheitlicher Verantwortung für die Lebensmittelsicherheit gekennzeichnet (Spiller/Schramm 2003), zurückzuführen u. a. auf historische Erfahrungen, da vormals die hohen technischen Schwierigkeiten der Lebensmittelsicherheit und die entsprechenden Gesundheitsrisiken nicht den vielen kleinbetrieblichen Akteuren überlassen werden konnten. Auch heute noch wird in Deutschland bei fast allen Lebensmittelkrisen zunächst der Staat in die Pflicht genommen. Im Gegensatz zu vielen anderen Branchen gibt es in der Lebensmittelwirtschaft eine tiefsitzende Verankerung der staatlichen Primärverantwortung. Diese Einstellung hat z. B. die niederländische Lebensmittelwirtschaft in den 30er Jahren angesichts einer staatlichen Finanzkrise dazu gebracht, freiwillig die Hälfte der amtlichen Überwachungskosten zu tragen, damit die Lebensmittelkontrolle fortgeführt werden konnte (Verführt 1996: 15 f.).

Diese Staatsfixierung ist den globalen und fragmentierten Strukturen der modernen Lebensmittelwirtschaft mit ihren immer unübersichtlicher werdenden Produktions- und Zulieferketten nicht mehr angemessen. Die ökonomischen Akteure „verstecken“ sich ansonsten mehr oder weniger stark hinter der staatlichen Überwachung. Im Ergebnis führt dies zu der von Beck (1988) als „organisierte Unverantwortlichkeit“ bezeichneten Situation, 
bei der die vielfach kleinteilige ökonomische Struktur, der fehlende Bekanntheitsgrad der Unternehmen und erhebliche Defizite beim Aufbau von Rückverfolgbarkeitssystemen eine gezielte Zurechnung der Fehler verhindern und für die Betroffenen und die Öffentlichkeit der Staat in eine Verantwortung tritt, die er kaum noch gewährleisten kann.

\section{TABELLE 2: VERANTWORTUNGSZUSCHREIBUNG FÜR LEBENSMITTELQUALITÄT}

\begin{tabular}{|c|c|}
\hline \multicolumn{2}{|c|}{ Verteilung der Primärverantwortung } \\
\hline Staatliche Primärverantwortung & Privatwirtschaftliche Primärverantwortung \\
\hline $\begin{array}{l}\text { - Öffentlichkeit nimmt den Staat in die } \\
\text { Verantwortung } \\
\text { - Hohe Regelungsdichte } \\
\text { - Geringe Eigenmotivation der Akteure }\end{array}$ & $\begin{array}{l}\text { - Öffentlichkeit nimmt die Unternehmen in die } \\
\text { Verantwortung } \\
\text { • Eigenkontrollsysteme } \\
\text { - Staatliche Kontrolle der Kontrolle }\end{array}$ \\
\hline
\end{tabular}
Quelle: Spiller et al. 2002

Auch wenn es mithin viele Gründe für eine Verschiebung der Lebensmittelsicherheit in den Bereich der Wirtschaft (z. B. Zertifizierungssysteme, Vertragslandwirtschaft u. Ä.) gibt, so war die Politik in der BSE-Krise aufgrund der öffentlichen Wahrnehmung der Lebensmittelsicherheit als staatlicher Verantwortungsbereich gezwungen zu reagieren.

Sie tat dies durch einen Mix verschiedener institutioneller Neuorganisationen. Unter dem Begriff des „magischen Sechsecks“ wurde versucht, die wirtschaftlichen Akteure des Agribusiness und verschiedene Stakeholdergruppen in einen Branchendiskurs zu integrieren. Zielrichtung war die stärkere Qualitäts- und Sicherheitsorientierung in der konventionellen Produktion („Klasse statt Masse“), wobei u. a. durch die Androhung einer politischen Initiative für ein neues Qualitätslabel für konventionelle Produkte Handlungsdruck auf die Unternehmen ausgeübt wurde. Hinzu kam die Neuorganisation von Bundesbehörden, da im Vergleich etwa zu den USA (FDA) die deutschen untergeordneten Bundesbehörden über keine größere öffentliche Reputation in Fragen der Lebensmittelsicherheit verfügten. Schließlich wurde ein Beratungsgremium zur Neuorganisation des Politikfeldes insgesamt eingesetzt (v. Wedel 2001).

\subsection{Multifunktionale Landwirtschaft}

Während die zuvor skizzierten Elemente direkt an die BSE-Krise anknüpften, ist das Thema „Multifunktionelle Landwirtschaft“ kein direktes Resultat der Agrarwende, es ließ sich allerdings gut in diesen Kontext integrieren und stellte die Anschlussfähigkeit der nationalen Politikanstrengungen in den internationalen Politikkontext sicher. 
Ausgangspunkt für die Forderung nach einer multifunktionalen Landwirtschaft ist der in der Gesellschaft und Politik zunehmende Verlust der Legitimitätsgrundlage der Transferleistungen in die Landwirtschaft. Anders ausgedrückt: Die Transferzahlungen in die Landwirtschaft werden von der Gesellschaft nur dann als gerechtfertigt wahrgenommen, wenn sie darin einen Beitrag zum Gemeinwohl erkennt. Bis zur aktuellen Agrarreform wurden die Direktzahlungen an die Landwirte mit Preisausgleichszahlungen, die an den Anbau bestimmter Kulturen gekoppelt sind, begründet. Dieses reine Marktregulierungsinstrument ist heute gesellschaftlich nicht mehr akzeptiert bzw. auch nicht mehr finanzierbar.

Multifunktionalität ist vor diesem Hintergrund ein Brückenkonzept für die weitreichende Neurahmung der Agrarpolitik, unter dem sich verschiedenste Interessen formulieren können. ${ }^{2}$ Der Begriff verweist zunächst darauf, dass Landwirte über ihre marktgängige Produktionsleistung hinaus weitere positive externe Effekte erbringen, die gesellschaftlich wertvoll sind, aber bisher als Kuppelprodukte der landwirtschaftlichen Produktion nicht hinreichend entlohnt werden. Wenn Landwirte zukünftig nicht allein Rohstoffproduzenten für die Nahrungsmittelindustrie sind, sondern auch Aufgaben als Dienstleister für Natur- und Umweltschutz übernehmen, so sollten diese Tätigkeiten auch honoriert werden. Entsprechend bietet Multifunktionalität einen Rahmen sowohl zur Neulegitimation von Rent SeekingProzessen wie zur Ankopplung von Subventionen an Naturschutzziele. Wie nun Leistungen der Landwirtschaft im Einzelnen ausgestaltet werden sollen und für welche Leistungen der Landwirt letztlich bezahlt werden soll, wird je nach Interessengruppe kontrovers diskutiert.

Mit der Reform der EU-Agrarpolitik im Jahr 2004 (Fischler-Reform) wurde tatsächlich eine weitreichende Entkoppelung der Preisausgleichszahlungen von den Produkten vereinbart. Im gleichen Zug wurde eine Ausweitung der zweiten Säule der EU-Agrarpolitik beschlossen, die auf die Stärkung des ländlichen Raums und der gesellschaftlichen Funktionen der Landwirtschaft zielt. Langfristig soll ein erheblicher Teil der landwirtschaftlichen Subventionen mit Gegenleistungen im Bereich des Verbraucher-, Umwelt-, Natur- und Tierschutzes verbunden sein. Die Ausgestaltung der Agrarreform in Deutschland mit dem so genannten „Kombimodell“, welches die umweltpolitisch vernachlässigte Grünlandwirtschaft

\footnotetext{
${ }^{2}$ In seinen diskursorientierten Policy-Analysen weist Hajer (1995: 61) ausdrücklich auf die politische Macht von „multi-interpretativen“ Diskursen hin, die es einer Vielzahl unterschiedlicher Akteure ermöglichen, sich in der breiten Diskurskoalition zu verorten und dieser Bedeutung zu verleihen.
} 
gegenüber den klassischen Subventionsfeldern stärkt, ist damit das aktuelle Ergebnis einer „Agrarwende“ im weiteren Sinne, die die veränderten europäischen Rahmenbedingungen einbezieht.

Eine von dieser Diskussion weitgehend unabhängige Entwicklung ist die stetige Zunahme des Anbaus von Kulturpflanzen für die Energiegewinnung. Hintergrund dieser Entwicklung ist die Überproduktion in der Landwirtschaft, die mit der Förderung eines neuen Marktsegmentes „Rohstoffproduktion auf dem Feld“ gelöst werden soll. Durch die Reform des Energieeinspeisungsgesetzes (Weck 2004) ist hier die bisherige Übervorteilung von anderen technischen Systemen (z. B. Photovoltaik, Windkraft) relativiert und ein zusätzlicher Anreiz für Landwirte geschaffen worden, alternative Einkommensmöglichkeiten wahrzunehmen. Auch dies schreibt die stärkere Einbindung der Landwirte in die gesellschaftspolitische Diskussion weit in die Zukunft fort.

Multifunktionale Landwirtschaft stellt insgesamt ein Instrument der Agrarpolitik dar, das zum einen die Legitimation der Transferleistungen in die Landwirtschaft sicherstellen soll und zum anderen den Landwirten Möglichkeiten zu alternativen Einkommensmöglichkeiten eröffnet. Damit verbunden ist die bereits oben angesprochene Öffnung des bisher relativ autonom agierenden Felds der Agrar- und Ernährungspolitik gegenüber einer größeren Öffentlichkeit. Diese Entwicklung ist nicht auf Deutschland beschränkt, sondern wird in allen Industrieländern diskutiert, da die Landwirtschaft zukünftig in weit stärkerem Maße als heute in Konkurrenz zur Produktion in Schwellen- und Entwicklungsländern stehen wird (vgl. die aktuelle Diskussion zur Zuckermarktordnung).

\subsection{Verbraucherpolitik und Verbraucherschutz}

Über die Agrarpolitik im engeren Sinne hinaus hat die Agrarwende Lebensmittelqualität als Teilbereich der Verbraucherpolitik definiert. Die mit der Namensänderung des Bundesministeriums proklamierte Gewichtungsverschiebung und Neuzuordnung ist nur vor dem Hintergrund einer umfassenderen verbraucherpolitischen Diskussion in Deutschland zu verstehen.

Moderne Verbraucherpolitik erfolgte in Deutschland in Anlehnung an amerikanische Vorbilder in den 60er und 70er Jahren. Sie setzte sich aus drei zentralen Elementen zusammen: Rechtlicher Verbraucherschutz (z. B. AGB-Gesetz), Verbraucherinformation 
(z. B. Gründung der Stiftung Warentest) und Verbraucherbildung (z. B. Gründung der Verbraucherschutzzentralen) (Scherhorn 1975; Biervert et al. 1978). Nach einer ersten Initialphase, in der umfassende Politikmaßnahmen auf den Weg gebracht wurden, geriet die Verbraucherpolitik in der Nachfolge der Wirtschaftskrisen der 70er und 80er Jahren in Deutschland weitgehend in den Hintergrund (zur Problemdiagnose und dem neuen verbraucherpolitischen Anspruch vgl. Reisch 2003). Als einem dem Wirtschaftsministerium untergeordneten Ressort fehlte bislang der politische Einfluss und die institutionelle Basis.

Eine wissenschaftliche Diskussion zum Thema war in den letzten zwei Jahrzehnten abgesehen von Ausnahmen wie dem Konsumpolitiklehrstuhl an der Universität Stuttgart-Hohenheim fast nicht mehr existent (Reisch/Farsang 2003). Es verwundert daher nicht, dass die Ministerin in ihrer Grundsatzrede zur Neuausrichtung des Ministeriums auf die proklamatischen Aussagen der 60er Jahre (Kennedy-Rede) zurückgegriffen hat.

Die Agrarwende bot damit wie einleitend skizziert die Möglichkeit, Verbraucherschutzpolitik wieder wählerwirksamer zu gestalten. Deutlichster Ausfluss dieser Konzeption ist die derzeitige Diskussion um Adipositas und Fehlernährung bei Kindern, aber auch Debatten um Alcopops, Zigarettenkonsum und eine Aufnahme dieser Debatten in strategische Überlegungen der Krankenkassen.

Insgesamt zeigen die vorherigen Ausführungen, dass die Agrarwende über das Ziel „20 \% Bio-Landbau“ weit hinausgeht. Auch wenn der Begriff Agrarwende zzt. keine große Rolle mehr spielt, hat er ein Politikfeld auf lange Sicht für die Gesellschaft geöffnet. Da dies coevolutorisch mit kompatiblen Trends z. B. im Rahmen der EU-Agrarpolitik geschah („Entkopplung, Multifunktionalität“), ist diese Entwicklung auch bei anderen Regierungskonstellationen nicht mehr grundsätzlich umkehrbar.

\section{Harte und weiche Politikinstrumente in der Agrarwende}

\subsection{Politikverständnis und Politikrestriktionen}

Den oben skizzierten umfassenden Zielen der Agrarwendepolitik stehen begrenzte Handlungsmöglichkeiten des Bundesministeriums gegenüber. Wie bereits ausgeführt, erfolgen die wesentlichen ausgabenwirksamen Entscheidungen in der Agrarpolitik auf EUEbene, z. T. in Kofinanzierung mit den Bundesländern. Die Bundespolitik selbst hat in der 
Agrarpolitik beschränkte finanzielle Handlungsmöglichkeiten. Ihr Spielraum für eine Umgestaltung der Subventionspolitik ist gering. Verdeutlicht wird dies, wenn man sich den Haushalt des Bundesministeriums für das Jahr 2004 näher ansieht (BMVEL 2004b). Aus dem Gesamtetat von rund 5,2 Mrd. € fließen allein 3,7 Mrd. € in landwirtschaftliche Sozialpolitik. Da in der Landwirtschaft eigene Sicherungssysteme aufgebaut wurden und die Anzahl der Einzahler durch den permanenten Strukturwandel zurückgeht, ist dieser Posten besonders hoch. Betrachtet man die beschränkten finanziellen Handlungsmöglichkeiten des BMVEL aus der Perspektive der seit dem Amtsantritt von Renate Künast forcierten Ziele, klärt sich diese Einschätzung weiter auf. Für die Agrarwendeziele Tierschutz, Demonstrationsbetriebe des Ökologischen Landbaues, ,Region aktiv’, Bundesprogramm Ökologischer Landbau, Verbraucherpolitik und Verbraucheraufklärung standen im Haushaltsjahr 2004 lediglich rund 147 Mio. € zur Verfügung. Was nicht einmal $3 \%$ des Gesamtetats des BMVEL entspricht. Dass auch die 764 Mio. €, die über das Gemeinschaftsinstrument von Bund und Ländern „Verbesserung der Agrar- und Küstenstruktur“ (GAK) verteilt werden, nicht unproblematisch sind, zeigt ein Blick auf die Zusammensetzung der Akteure des darüber entscheidenden Gremiums, des „Planungsausschusses Agrarstruktur und Küstenschutz“ (PLANAK): Neben der Bundesministerin sind hier auch der Bundesminister der Finanzen sowie die Landwirtschaftsminister der Länder beteiligt. Zudem spielen die Mitglieder des Unterausschusses, deren Vertreter und die Haushalts- und Koordinierungsreferenten des Bundes und der Länder eine mitentscheidende Rolle. Aufgrund der verfassungsmäßigen Verpflichtung, bundeseinheitliche Agrarstrukturen anzustreben, bewegen sich die Verhandlungsziele in einem engen Spielraum, der auch durch Einflussgruppen schwer zu verändern ist. Zudem sind die Verhandlungsergebnisse durch das begrenzte Budget und durch die Verteilungen der letzten Jahre zum Teil prädeterminiert.

Hinzu kommen einige Zweifel an der Wirksamkeit klassisch ordnungsrechtlicher Maßnahmen in der Umwelt- und Verbraucherschutzpolitik. Die politikwissenschaftliche wie die ökonomische Forschung haben in den letzten Jahrzehnten vielfältige Belege für die Grenzen tradierter ordnungsrechtlicher Steuerungsformen geliefert. Aber auch die gesellschaftsübergreifende Bedeutung von Leitbildern und kollektiv verbindlichen Handlungsanweisungen wird zunehmend kritisch betrachtet. In den Politikwissenschaften steht dabei die Steuerungsunfähigkeit des Staates beim Eingriff in komplexe gesellschaftliche Teilsysteme im Vordergrund (Scharpf 1991; Mayntz 1997; Willke 1995). Soweit überhaupt noch Raum für staatliche Steuerung gesehen wird, wird auf Kontextsteuerung verwiesen, die jedoch eher auf einer 
stärkeren Gewichtung von Teilsystemen beruht, welche ihre eigene Einheit entdecken und ihre Wirkung auf die Umwelt reflektieren. Daraus entsteht letztlich ein Prozess der dezentralen Kontextsteuerung, der positive Effekte für die Anliegen des Gemeinwohls mit sich bringt. Dabei verändert sich auch die Rolle des Staates, der die Rolle eines „Supervisors“ einnimmt und dessen Aufgabe dann hauptsächlich darin besteht, die Reflexionsfähigkeit der Teilsysteme zu steigern und zur Selbstorganisation beizutragen.

Aus einer anderen Perspektive, aber in dieselbe Richtung zielend betont die Ökonomie die negativen volkswirtschaftlichen Effekte einer zu weit gehenden Branchenregulierung im internationalen Wettbewerb und die Vorzüge von neuen marktkonformen Instrumenten wie Steuern oder Informationspolitiken. Diese setzen gezielter an gesellschaftlich unerwünschten Problemstellen von Produktions- und Vermarktungsprozessen an.

Vor dem skizzierten doppelten Hintergrund aus Begrenzungen im Mehrebenensystem der Politik und konzeptionellen Zweifeln an tradierten Steuerungsformen ist es nicht verwunderlich, dass in der Agrarwendeprogrammatik ein „moderner“ Policy-Mix erarbeitet wurde, der die wenigen harten Steuerungsoptionen um ein Portfolio weicher Instrumente ergänzt.

\subsection{Policy Mix der Agrarwende}

Die Politik der Agrarwende stand nach der BSE-Krise vor mehreren Herausforderungen. Neben der krisenhaften Beschleunigung der Entwicklung spielt die o. g. strukturelle Verschränkung der Mehrebenenpolitik im Agrarbereich (EU, Bund, Länder) ebenso eine Rolle wie die komplexe Struktur der Wertschöpfungskette. Die Besonderheit der Lebensmittelwirtschaft liegt u. a. in ihrer arbeitsteiligen Struktur, wobei sich die wirtschaftlichen Einheiten auf den verschiedenen Stufen der Wertschöpfung durch deutlich abweichende strukturelle Voraussetzungen auszeichnen. Während in der Landwirtschaft mit fast 400.000 mittelständischen Betrieben Einfluss auf eine Vielzahl kleiner Akteure genommen werden muss, ist der Lebensmittelhandel durch die Dominanz weniger Großunternehmen geprägt. Die dazwischen liegende Ernährungsindustrie ist in Deutschland polarisiert. Es gibt insgesamt rund 6.000 Hersteller, darunter aber auch eine Reihe international tätiger Großunternehmen. Hinzu kommt, dass die Produktion und Vermarktung von Bio-Lebensmitteln in einer von der konventionellen Produktion weitgehend getrennten Wertschöpfungskette erfolgt, die wiederum mittelständisch geprägt ist. 
Aus den genannten Gründen musste die Politik ein relativ umfassendes Instrumentarium für ihre „Wendeprogrammatik“ entwickeln. Dieses konnte sich nur zu einem Teil auf ordnungsrechtliche Instrumente stützen, da etwa die Sortimentsentscheidungen der Großunternehmen des Lebensmittelhandels nicht vorgegeben werden können. Die in Tabelle 3 skizzierte Übersicht über die Vielzahl der einbezogenen Instrumente macht deutlich, dass die Agrarwende in Kernelementen auf die Motivation der Akteure und auf weiche Anreizmechanismen wie Information und öffentliche Unterstützung setzt.

Tabelle 3: Policy Mix der Agrarwende

\begin{tabular}{|c|c|c|}
\hline & „Harte“ Instrumente & „Weiche“ Instrumente \\
\hline Ausweitung von Bio & $\begin{array}{l}\text { Öko-Landbau-Gesetz; } \\
\text { Reformierung der GAK } \\
\text { zugunsten einer Förderung } \\
\text { des ökologischen Landbaus }\end{array}$ & $\begin{array}{l}\text { Bio-Siegel, Bundesprogramm } \\
\text { Öko-Landbau, Förderpreis Öko- } \\
\text { Landbau; } 70 \text { Mill. } € \text { 2002/2003 } \\
\text { für Information und Aufklärung }\end{array}$ \\
\hline Tierschutz & $\begin{array}{l}\text { Haltungsverordnungen } \\
\text { (Tierschutz-Nutztier- } \\
\text { haltungsverordnung; } \\
\text { „Legehennenverordnung“; } \\
\text { die Aufnahme des } \\
\text { Tierschutzes ins } \\
\text { Grundgesetz) } \\
\end{array}$ & $\begin{array}{l}\text { Kampagne „Freiheit schmeckt“ } \\
\text { bei der Einführung der } \\
\text { Legehennenverordnung }\end{array}$ \\
\hline Lebensmittelsicherheit & $\begin{array}{l}\text { Einrichtung der } \\
\text { Bundesämter für } \\
\text { Risikobewertung und } \\
\text { Risikokommunikation } \\
\text { (BFR) und gesundheitlichen } \\
\text { Verbraucherschutz und } \\
\text { Lebensmittelsicherheit } \\
\text { (BVL) }\end{array}$ & $\begin{array}{l}\text { Magisches Sechseck; Androhung } \\
\text { eines zweiten Gütezeichens für } \\
\text { konventionelle Lebensmittel }\end{array}$ \\
\hline Verbraucherschutz & $\begin{array}{l}\text { Einrichtung des } \\
\text { Bundesamtes für } \\
\text { Verbraucherschutz }\end{array}$ & $\begin{array}{l}\text { Umbenennung des Ministeriums, } \\
\text { mehr Geld für Beratung, } \\
\text { versuchte Einführung des } \\
\text { Verbraucherinformationsgesetzes }\end{array}$ \\
\hline Multifunktionalität & $\begin{array}{l}\text { Zweite Säule, Flächen- } \\
\text { prämie, Kombimodell }\end{array}$ & $\begin{array}{l}\text { (Pilotprojekt) Regionen Aktiv - } \\
\text { Land gestaltet Zukunft }\end{array}$ \\
\hline
\end{tabular}

Quelle: Eigene Darstellung

Im Folgenden sollen ausgewählte Elemente der Agrarwende kurz vorgestellt werden, um die Dualität von Ordnungsrecht und flankierenden Informationsinstrumenten deutlicher herauszuarbeiten. Deutlich wird, dass die Politik in hohem Maße auf eine gelingende Kommunikation im Zusammenspiel mit einer Vielzahl gesellschaftlicher Gruppen (BioVerbände, Umweltverbände, regionale Bündnisse usf.) angewiesen ist. 
Als eine der ersten „harten“ Maßnahmen nach dem Ministerwechsel ist die Erhöhung der Prämien zur Umstellung oder Beibehaltung des Ökologischen Landbaus zu nennen. Dass dies gelungen ist - obwohl diese Maßnahme im Rahmen der GAK erfolgte und damit der Zustimmung der Landwirtschaftsminister aus den unionsgeführten Bundesländer bedurfte, die zu diesem Zeitpunkt schon eine Bundesratsmehrheit hatten - kann man der zeitlichen Nähe zwischen der BSE-Krise und der Verabschiedung des damaligen GAK-Rahmenplans zuschreiben. Wichtig zu vermerken ist an dieser Stelle, dass die Bundesländer die Freiheit haben, die in der Tabelle 3 angegebene Prämienhöhe nicht vollständig auszuschöpfen. Aus Gründen der notwendigen Kofinanzierung muss man auch nicht bei allen Bundesländern politische Motive für die geringere Ausschöpfung annehmen. So zahlen - im Gegensatz zu Bayern und Baden-Würtenberg - nicht alle SPD-regierten Länder immer den Höchstsatz.

TABELLE 4: PRÄMiEN ZUR FÖRDERUNG UND BEIBEHALTUNG DES ÖKOLOGISCHEN LANDBAUS IM RAHMEN DER GAK

\begin{tabular}{|l|c|c|c|c|}
\hline & $\begin{array}{c}\text { Einführungs- } \\
\text { prämie } \\
\text { pro ha bis 2001 }\end{array}$ & $\begin{array}{c}\text { Einführungs- } \\
\text { prämie } \\
\text { pro ha seit 2002 }\end{array}$ & $\begin{array}{c}\text { Beibehaltungs } \\
\text { prämie } \\
\text { pro ha bis 2001 }\end{array}$ & $\begin{array}{c}\text { Beibehaltungs } \\
\text { prämie } \\
\text { pro ha seit 2002 }\end{array}$ \\
\hline Gemüseanbau & $360 €$ & $480 €$ & $180 €$ & $300 €$ \\
\hline Ackerflächen & $150 €$ & $210 €$ & $100 €$ & $160 €$ \\
\hline Grünland & $150 €$ & $210 €$ & $100 €$ & $160 €$ \\
\hline Dauerkulturen & $715 €$ & $950 €$ & $510 €$ & $770 €$ \\
\hline
\end{tabular}

Quelle: BMVEL 2001

Die zweite „harte“ Maßnahme, die es in diesem Kapitel zu nennen gilt, ist das ÖkolandbauGesetz, welches als Reaktion auf den „Nitrofen-Skandal“ und damit auf eine Krise des Systems Ökolandbau erfolgte. Das kurz ÖLG genannte Gesetz trat am 1. April 2003 in Kraft und regelt vor allem die Zulassung von privaten Ökokontrollstellen neu, die nun nur noch von der Bundesanstalt für Landwirtschaft und Ernährung zugelassen werden können. Während dies bis dahin über die Landesanstalten organisiert war. Das entlastet die Kontrollbehörden der Länder, die bis zu diesem Zeitpunkt die Zulassung selbst durchführen mussten. Das damit verbundene aufwändige Mitteilungs- und Abstimmungsverfahren zwischen den Kontrollbehörden entfiel damit ebenso. Folgende Regelungen sind im Gesetz enthalten.

Das Bundesprogramm Ökolandbau soll die politisch schwierig umzusetzende direkte Förderung für den ökologischen Landbau um Maßnahmen ergänzen, die auf eine verbesserte Informationspolitik und werbewirksame Effekte abzielen. Für umstellungswillige Landwirte werden konkrete Hilfen in Form differenzierter Informations-, Bildungs- und Beratungsangebote geschaffen. Zudem wird im Internet, auf Messen, bei Multiplikatoren und in Seminaren verstärkt über den Ökolandbau informiert. Um den Lebensmittelhandel 
vorzubereiten, werden Fortbildungsmöglichkeiten und Beratungsleistungen angeboten. Durch zahlreiche Forschungsprojekte sollen Marktinformationen für alle Akteure bereitgestellt werden.

Weiterhin sollen institutionelle Abnehmer gezielte Informationen über den Wert und die Vorzüge ökologischer Produkte erhalten. Hier wird ein besonderer Schwerpunkt auf eine qualifizierte Umstellungsberatung für Großküchen sowie die Aufbereitung des Themas für Kindertagesstätten und allgemein bildende Schulen gelegt. Für das Programm wurden in den Jahren 2002 bis 2003 jeweils rund 35 Mio. Euro bereitgestellt, und es soll mit einem jährlichen Finanzvolumen von 20 Mio. Euro noch bis 2007 laufen.

Darüber hinaus hat das BMVEL einen jährlichen „Förderpreis Ökologischer Landbau“ ausgeschrieben, der mit 25.000 Euro dotiert ist. Damit sollen besondere Leistungen ausgezeichnet werden, u. a. im Bereich des Pflanzenbaus, der artgerechten Tierhaltung oder Tierzüchtung, der Land- und Produktionstechnik oder des landwirtschaftlichen Bauens und der Vermarktung, die von Betrieben in die Praxis umgesetzt worden sind. Des Weiteren sollen Modell- und Demonstrationsvorhaben finanziert werden. Dafür stehen jeweils 25 Mio. Euro jährlich zur Verfügung. In einem Wettbewerb sollen künftige Modellregionen ausgewählt werden, um eine breite Vorbildwirkung zu erzielen.

Zudem wurde im September 2001 ein staatliches Biosiegel eingeführt, das die Herkunft eines Produktes als ökologisch gemäß der VO (EWG) 2092/91 ausweist. Es ging auf Verhandlungen zwischen dem BMVEL und den relevanten Interessens- und Verbraucherschutzverbänden und dem Einzelhandel zurück, die sich im Mai 2001 auf gemeinsame Standards und Kontrollverfahren geeinigt hatten. Das Biosiegel wurde durch eine außergewöhnlich umfangreiche Werbekampagne beworben (2001: 57.000 Euro; 2002: 7,7 Mio. Euro; 2003: 6,6 Mio. Euro) (Kuhnert et al. 2004: 7) und erfolgreich eingeführt. Inzwischen kennzeichnet das Siegel 29.500 Produkte (Bio-Siegel 2005).

Umstellungsförderung und Bio-Siegel stehen nicht nur exemplarisch für die Dualität von Subventions- und Informationspolitik in der Agrarwende, sondern auch für die gleichzeitige Beeinflussung von Bio-Angebot und -Nachfrage. Eine koordinierte Steuerung zur Gewähr- 
leistung von Marktgleichgewichten ist in einem engen Marktsegment von hoher Relevanz, da hier Angebotsüberschüsse und entsprechende Preissenkungen die Effekte der Subventionspolitik konterkarieren können.

Subventions- wie Informationspolitik zur Förderung des Bio-Marktes trafen auf eine Branche, die sich im Laufe mehrerer Jahrzehnte als ausdifferenziertes Marktsegment neben der konventionellen Lebensmittelwirtschaft entwickelt hatte. In der Landwirtschaft handelte es sich traditionell um kleinere Betriebe abseits der Gunststandorte bzw. Veredelungsregionen. Auf Bio spezialisierte Industriebetriebe waren nicht selten aus handwerksnahen Kleinstbetrieben hervorgegangen. Der Absatz wurde dominiert durch den Direktvertrieb und insbesondere den Naturkostgroß- und -einzelhandel. Insgesamt unterschieden sich die Strukturen fundamental vom klassischen Agribusiness. Die Instrumente der Agrarwende waren vor diesem Hintergrund von vorneherein mit dem Risiko von Wettbewerbsverzerrungen verbunden, dies umso mehr, je schneller eine Ausweitung des Marktsegmentes erreicht werden sollte und deshalb auch konventionelle Großunternehmen gefördert werden mussten. Es verwundert daher nicht, dass frühzeitig auf nicht-intendierte Folgewirkungen verwiesen wurde, z. B. auf:

- Fairnesseffekte: Die Verteilung der Öko-Fördermittel auf die Bio-Branche oder die konventionelle Lebensmittelwirtschaft hängt von der Zielsetzung, aber auch von der Wahrnehmung früherer Verdienste um den ökologischen Landbau ab (Schinzel 1999). Die Politik steht hier vor diffizilen Bewertungsfragen.

- Motivationale Verdrängungseffekte: Mit einer stärkeren Förderung gewinnen ökonomische Gründe bei der Umstellung gegenüber idealistischen Motiven an Bedeutung, was langfristig zur Verdrängung intrinsischer durch extrinsische Motivation führen kann (Frey/Jegen 2001). Dies hat z. B. zur Forderung nach einem Wertemanagement für die Naturkostbranche geführt (Lautermann et al. 2005).

\section{Verschiebung des diskursiven Feldes}

Skandale und Risiken im Agrarsektor sind nicht neu. Aber erst 2000/2001 hat die rasche Folge der weit reichenden und medial dramatisierten Krisen um BSE und MKS, insbesondere die erschreckenden Bilder der gewaltigen, apokalyptisch anmutenden Scheiterhaufen, auf denen Abertausende von Rindern verbrannt wurden, das politische Establishment und auch die traditionelle Lobby zu einer Öffnung für kritische Ansprüche gezwungen. Dazu trug auch die von Bundeskanzler Gerhard Schröder und Landwirtschaftsministerin Renate Künast 
begrifflich durch die Rede von „Agrarfabriken“ und „Agrar-Wende“ nahegelegte Problemrahmung bei. Ursächlich seien weniger einzelfallartige Missstände in der Futtermittelindustrie oder individuelles Fehlverhalten einzelner Akteure als vielmehr die gesamte bisherige agrarpolitische Orientierung auf Produktivität und internationale Wettbewerbsfähigkeit. In diesem Sinne sprach „Der Spiegel“ (2001b: 24) in der heißen Phase Anfang 2001 vom „Tschernobyl der deutschen Landwirtschaft“.

In der Folge wurden BSE, MKS und schließlich das Lösungsversprechen „Agrarwende“ zusammen mit weiteren Agrarskandalen, neuen Reformansätzen sowie politisch inszenierten Problemlösungsversuchen (etwa das Bundesprogramm Ökologischer Landbau) zum Sammelbecken der Kritik an einem Bereich, der bis dahin Zumutungen der Umorientierung etwa unter dem Druck des Leitbilds Nachhaltiger Entwicklung - weitgehend erfolgreich zurückgewiesen hatte. So galten dem DBV, aber auch dem ehemaligen Landwirtschaftsministerium oder dem bisherigen Naturschutzgesetz die „gute fachliche Praxis“ per se als natur- und umweltgerecht. Die möglichen Nebenfolgen der Landwirtschaft, die in den 1960/70er Jahren der Nährboden der entstehenden ökologischen Bewegung gewesen waren (Carson 1962; Meadows 1972), schienen lange Zeit unvermeidlich und kaum der Debatte wert. Das starke, in den Agrarwissenschaften wie in der Agrarpolitik mehr oder weniger hegemoniale Bekenntnis für das industriemoderne Weiter-So und die Kontinuität in der landwirtschaftlichen Entwicklungsperspektive sind mit der Agrarwende unwiderruflich in Frage gestellt (Kropp/Wagner 2005).

In der Konsequenz kann keine der betroffenen Akteursgruppen unproblematisiert an die Sprachspiele und -codes aus der Epoche vor der Agrarwende anknüpfen. Die früheren Selbstverständlichkeiten müssen neu begründet und legitimiert werden. Gemeinsam mit dem allgegenwärtigen Sparzwang führt die Agrarwende bei den zentralen Akteuren (Isermeyer 2001b; Initiativkreis Agrar- und Ernährungsforschung 2002), aber auch bei einer in ihrem Gefolge entstandenen Fachöffentlichkeit $\mathrm{zu}$ neuen Leitbildern und neuen Rechtfertigungszwängen, die nolens volens in andere Bereiche überschlagen, bspw. in die Entscheidungsverfahren zum Einsatz gentechnisch modifizierter Nutzpflanzen oder in die Selbstdarstellungen großer Konzerne des Lebensmittelhandels. In der Summe hat die diffuse Agrarwende-Programmatik das diskursive Feld im Agrarbereich beinahe erdrutschartig verschoben und die zentralen Narrationen neu orientiert. 
Gleichzeitig ist die „Agrarwendepolitik“ als moderne Politikform in einem Handlungsfeld mit begrenzten bundespolitischen Kompetenzen durch eine Vielzahl weicher Politikinstrumente gekennzeichnet. Sie ist deshalb wesentlich stärker auf die Unterstützung durch die Akteure in der Wirtschaft und der Zivilgesellschaft angewiesen. Exemplarisch sei hier auf die Umstellungsmotivation landwirtschaftlicher Betriebe oder auf die Nutzung des Bio-Siegels durch Industrie- und Handelsbetriebe verwiesen. Beide Fragen sind zentral für die Ausweitung des ökologischen Landbaus, zugleich können solche unternehmensstrategischen Entscheidungen nur begrenzt durch die Politik beeinflusst werden. Die Politik ist vielmehr auf die Akzeptanz der Wirtschaft und die Unterstützung durch gesellschaftliche Gruppen angewiesen.

Eine Politikform wie die Agrarwende benötigt damit neue Formen der wissenschaftlichen Begleitforschung. Ihre Wirksamkeit hängt ganz wesentlich von einem komplexen Transferprozess zwischen Politik und den ökonomischen Destinataren ab. Vereinfacht lässt sich dies in folgender Form abbilden:

Politikimpulse->Wahrnehmung->Akzeptanz->Motivation->Handlung

Eine solche Trivialdarstellung des Informationstransfers verkennt allerdings die vielfältigen Wahrnehmungsbrüche, den Einfluss von Medien, die Verschränkung mit der Binnenlogik der Akteure und letztlich die komplexen intendierten und nicht beabsichtigten Neben- und Folgewirkungen auch von weichen Politikinstrumenten.

Wirkungsforschung in diesem Sinne ist mithin mehr als z. B. die von der Bundesregierung selbst in Auftrag gegebene Begleitforschung zum Bundesprogramm Ökolandbau, in der weitgehend theoriefrei auf einige wenige Primärziele der Politik abgehoben wird. Vielmehr gewinnt gerade hier sozialökologische Forschung mit ihrem transdiziplinären Ansatz an Relevanz. Im Vordergrund des Projektes „Von der Agrarwende zur Konsumwende“ steht deshalb die problemzentrierte und theorienpluralistische Analyse der Agrarpolitik neuen Stils. Die Agrarwende ist ja keineswegs das einzige Beispiel für neue Politikformen in der Ernährungswirtschaft. Vielmehr werden in der Folge des Ausbaus der zweiten Säule der EUAgrarpolitik in den nächsten Jahren zahlreiche weitere weiche Politikinstrumente Eingang in die Agrarpolitik finden. 


\section{Literatur}

Beck, U. (1988): Gegengifte: die organisierte Unverantwortlichkeit, Frankfurt a. M.

Biervert, B., Fischer-Winkelmann, W. F., Rock, R. (1978), Verbraucherpolitik in der Marktwirtschaft, Reinbek bei Hamburg.

Bio-Siegel (2005): Künast: Fast 30.000 Produkte mit Biosiegel, unter: www.bio-siegel.de/index.php?id=23\&backPID=23\&tt_news=74, Abrufdatum: 17.09.2005.

BMVEL (2004a): Ernährungs- und Agrarpolitischer Bericht der Bundesregierung 2004, Berlin.

BMVEL (2004b): Künast: Agrarreform Basis für Zukunft der Landwirtschaft, Pressemitteilung Nr. 152 vom 29.06.2004, unter: www.dorfwettbewerb.bund.de/index-000AAE5B179E10E1B9F16521C0A8D816.html, Abruf am 07.11.2005.

BMVEL (2001) Informationen, 6.12.2001 unter: www.verbraucherministerium.de/index000CBAE09F081F7A9B1A6521C0A8D816.html , Abrufdatum: 7.11.2004

Boschert, K. C. (2005): „Agrarwende“: cognitive-normative approaches to policy change in German agro-biotechnology. Open University Milton Keynes, UK.

Böschen, S. et al. (2002): Rinderwahnsinn: Können Gesellschaften aus Krisen lernen? in: Berliner Journal für Soziologie 13, S. 35-58.

Brandt et al. (2004): Von der Agrarwende zur Konsumwende? Entwicklungen anhand eines Szenarios. Diskussionspapier Nr. 4 des Projekts „Von der Agrarwende zur Konsumwende“, München.

Carson, R. (1962): Silent Spring, Boston.

DBV (Deutsche Bauernverband) (2005): Situationsbericht 2005: Trends und Fakten zur Landwirtschaft, Bonn.

Der Spiegel (2001a): "Fleisch darf keine Ramschware sein". EU-Kommissar Franz Fischler über die Chancen der neuen deutschen Agrarpolitik, in: Der Spiegel, Heft 3, S. 30-31.

Der Spiegel (2001b): Von der Krise zur Agrarwende, in: Der Spiegel, Heft 3, S. 20-24.

Dressel, K. (2002): BSE - The new dimensions of uncertainty: the cultural politics of science and decision-making, Berlin.

Eder, K. (1997): Zur soziologischen Analyse des ökologischen Diskursfeldes, in: Brand, K.W. et al. (Hrsg.): Ökologische Kommunikation in Deutschland, Opladen, S.38-53.

Feindt, P. H., Ratschow, C. (2003), „Agrarwende“: Programm, Maßnahmen und institutionelle Rahmenbedingungen, BIOGUM-Forschungsbericht Nr. 7, Hamburg.

Frey, B., Jegen, R. (2001): Motivation Crowding Theory: A Survey of Empirical Evidence, in: Journal of Economic Surveys, Vol. 15 (5), S. 589-611.

Hagedorn, K. (1996) (Hrsg.): Institutioneller Wandel und politische Ökonomie von Landwirtschaft und Agrarpolitik. Festschrift zum 65. Geburtstag von Günther Schmitt. Frankfurt a. M.

Hajer, M. (1995): The Politics of Environmental Discourse. Ecological modernisation and the policy process, Oxford. 
Henrichsmeyer, W., Witzke, H. P. (1994), Agrarpolitik, Teil 2: Bewertung und Willensbildung, Stuttgart.

Hoffmann, I., Lauber, I. (2001): Gütertransporte im Zusammenhang mit dem Lebensmittelkonsum in Deutschland, Teil 1: Ausmaß und Verteilung, in: Zeitschrift für Ernährungsökologie, 2. Jg., Heft 2, S. 108-113.

Initiativkreis Agrar- und Ernährungsforschung (2002): Bonner Erklärung, Bonn.

Isermeyer, F. (2001a): Agrarwende - Was kann die Politik tun? Arbeitsbericht der Bundesforschungsanstalt für Landwirtschaft (FAL) 2/2001, Braunschweig.

Isermeyer, F. (2001b): Kurswechsel in der Agrarpolitik - Umorientierung in der Agrarforschung? Arbeitsbericht der Bundesforschungsanstalt für Landwirtschaft (FAL) 4/2001, Braunschweig.

Jürgens, K. (2005): Mensch-Nutztier-Beziehung, in: Beetz, S. et al. (Hrsg.): Handwörterbuch zur ländlichen Gesellschaft in Deutschland, Wiesbaden, S. 160-167.

Körber, K. v., Leitzmann, T. C. (2004): Vollwert-Ernährung: Konzeption einer zeitgemäßen und nachhaltigen Ernährung, 10. Aufl., Stuttgart.

Kropp, C., Wagner, J. (2005): „Agrarwende“: Über den institutionellen Umgang mit den Folgeproblemen der Folgenreflexion im Agrarbereich. Erscheint in: Soziale Welt 2/2005.

Kuhnert, H. et al. (2004): Ausweitung des ökologischen Landbaus in Deutschland Voraussetzungen, Strategien, Implikationen, politische Optionen, Münster-Hiltrup.

Künast, R. (2002): Klasse statt Masse. Die Erde schätzen, den Verbraucher schützen. München.

Künast, R. (2001): Regierungserklärung zur neuen Verbraucherschutz- und Landwirtschaftspolitik, unter: www.verbraucherministerium.de/pressedienst/pd2001-0607.htm, Abrufdatum: 08.01.2004.

Lautermann, C. et al. (2005): Ethikmanagement in der Naturkostbranche: Eine Machbarkeitsstudie, Marburg.

Luhmann, N. (1996): Die Realität der Massenmedien, Opladen.

Mayntz, R. (1997): Politische Steuerung: Aufstieg, Niedergang und Transformation einer Theorie, in: dies. (Hrsg.): Soziale Dynamik und politische Steuerung, Theoretische und methodologische Überlegungen, Frankfurt a. M.

Meadows, D. (1972): The Limits to Growth, New York.

OECD (2001): Multifunctionality. Towards an Analytical Framework, Paris.

Olson, M. (1991), Umfassende Ökonomie, Tübingen.

Oosterveer, P. (2002): Reinventing Risk Politics: Reflexive Modernity and the European BSE Crisis, in: Journal of Environmental Policy \& Planning 4, S. 215-22.

Piel, E. (2003): Wie werden Landwirte von der Gesellschaft gesehen?, in: Deutsche Landwirtschafts-Gesellschaft (Hrsg.), Wege zu besserem Image und Ansehen Landwirte in der Gesellschaft: Analysen, Erfahrungen, Perspektiven, Frankfurt a. M., S. 13-28.

Reisch, L. A. (2003): Strategische Grundsätze einer neuen Verbraucherpolitik. Diskussionspapier des Wissenschaftlichen Beirats für Verbraucher- und Ernährungspolitik beim BMVEL, Stuttgart-Hohenheim/ Berlin. 
Reisch, L., Farsang, A. (2003): Studie zum Stand der Verbraucherforschung in Deutschland, Hohenheim.

Rieger, E. (1995): Bauernopfer. Das Elend der europäischen Agrarpolitik. Frankfurt a. M., New York.

Sabatier, P. A. (1998): The Advocacy Coalition Framework: revision and relevance for Europe, in: Journal of European Public Policy, 5/1, S. 98-130.

Scharpf, F. W. (1991): Die Handlungsfähigkeit des Staates am Ende des zwanzigsten Jahrhunderts, in: Politische Vierteljahresschrift 32/4, S. 621-634.

Scherhorn, G. (1975): Verbraucherpolitik: Grundzüge ihrer Theorie und Praxis, München.

Schinzel, I. A. M. (1999): Einfluß der wahrgenommenen distributiven, prozeduralen und interaktionalen Gerechtigkeit von Leistungsbeurteilungen auf die Firmenverbundenheit - Eine Überprüfung der Referent Cognitions Theory, Mainz.

Schmidt, G., Jasper, U. (2001): Agrarwende oder die Zukunft unserer Ernährung, München.

Schneider, M. et al.(2003): Der kritische Agrarbericht 2003. Rheda-Wiedenbrück.

Schubert, K., Klein, M. (2001): Das Politiklexikon, Bonn.

Singer, P. (1997): Alle Tiere sind gleich, in: Krebs, A. (Hrsg.): Naturethik, Frankfurt a. M., S. 13-32.

SOEL (2004): Entwicklung des ökologischen Landbaus in Deutschland, unter: www.soel.de/inhalte/oekolandbau/dokumente/entw_flaeche_betriebe_04.pdf,

Abrufdatum: 24.07.2005.

Spiller, A., Schramm, M. (2003): Zur Ausgestaltung von Qualitätssicherungssystemen in der Lebensmittelwirtschaft, in: Perspektiven in der Landnutzung: Regionen, Landschaften, Betriebe, Entscheidungsträger und Instrumente: 43. Jahrestagung der Gesellschaft für Wirtschafts- und Sozialwissenschaften des Landbaus (GEWISOLA) 2003 in Hohenheim, S. 159-167.

Spiller et al. (2002): Qualitätskonzepte für Nahrungsmittelverarbeitung und -handel, Gutachten im Auftrag des Deutschen Bundestages, vorgelegt dem Büro für Technikfolgen-Abschätzung beim Deutschen Bundestag (TAB).

Stodieck, F. et al. (2002): Beiträge zur Agrarwende, Abl Bauernblatt Verlags-GmbH.

Van Zwanenberg, P. (2005): BSE: risk, science and governance, Oxford.

Verführt, L. C. (1996): Effektive Lebensmittelüberwachung und Verbraucherschutz, Bayreuth.

Waskow, F.; Rehaag, R.; unter Mitarbeit von E. Barlösius (2004): Ernährungspolitik nach der BSE-Krise - ein Politikfeld in Transformation. Diskussionspapier 6 des SÖF-Projekts „Ernährungswende“, Frankfurt a. M.

Wedel, H. von (2001): Organisation des gesundheitlichen Verbraucherschutzes (Schwerpunkt Lebensmittel), Stuttgart et al.

Weck, M. (2004): Die garantierte Einspeisevergütung für Strom nach dem Gesetz über den Vorrang erneuerbarer Energien: Anwendungsprobleme, europa- und verfassungsrechtliche Fragen, Frankfurt a. M.

Willke, H. (1995): Systemtheorie III: Steuerungstheorie, Stuttgart und Jena.

Wolters, C. (1998): Die BSE-Krise: Agrarpolitik im Spannungsfeld zwischen Handelsfreiheit und Konsumentenschutz, Frankfurt a. M. 
ZMP (Hrsg.) (2002): BSE: Was bleibt hängen? Bonn.

ZMP (Hrsg.) (2005): Ökomarkt Jahrbuch 2005, Bonn. 
Anwohnerkonflikte bei landwirtschaftlichen Stallbauten:

Hintergründe und Einflussfaktoren - Ergebnisse einer empirischen Analyse 


\section{Anwohnerkonflikte bei landwirtschaftlichen Stallbauten: Hintergründe und Einflussfaktoren - Ergebnisse einer empirischen Analyse*}

(mit Achim Spiller)

$1 \quad$ Einleitung ......................................................................................................................383

2 Theoretische Bezugspunkte von Standortkonflikten in der Landwirtschaft ...........384

3 Ausgewählte Ursachen von Standortkonflikten in der Landwirtschaft ...................387

3.1 SOZIOLOGISCHE ERKLÄRUNGSANSÄTZE DER LANDWIRTSCHAFTLICHEN

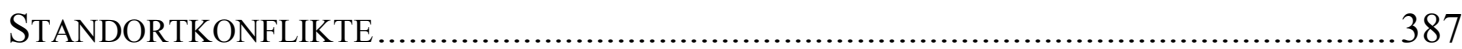

3.2 TIERETHISCHE ANSÄTZE ZUR ERKLÄRUNG VON KONFLIKTEN IM BEREICH

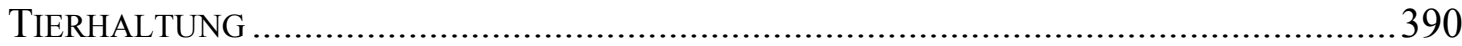

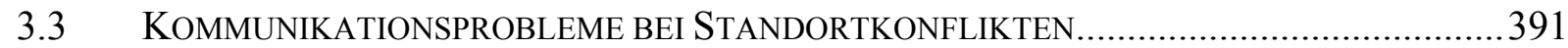

$4 \quad$ Fallbeispiel Diemarden: Der Stallbau in einer Nicht-Veredlungsregion ..................393

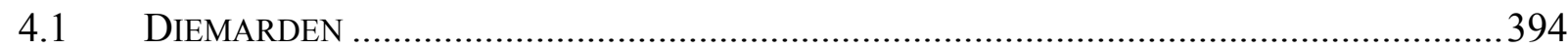

4.2 PERSPEKTIVEN DER BÜRGERINITIATIVE UND LANDWIRTE .........................................395

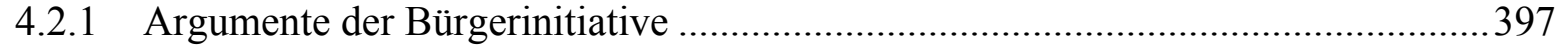

4.2.2 Sichtweise der betroffenen landwirtschaftlichen Familien ...................................398

4.2.3 Hypothesen und Modell der quantitativen Untersuchung ......................................399

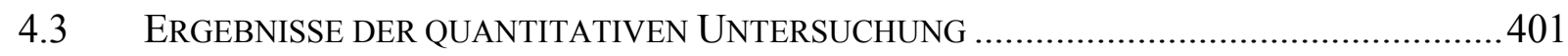

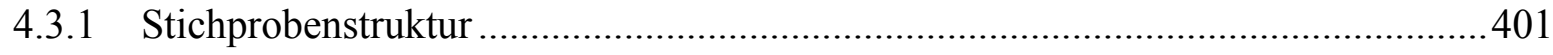

4.3.2 Einstellung der Bevölkerung zum Stallbau........................................................ 401

4.3.3 Soziodemografie der Befürworter und Ablehner................................................403

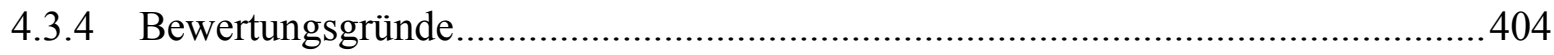

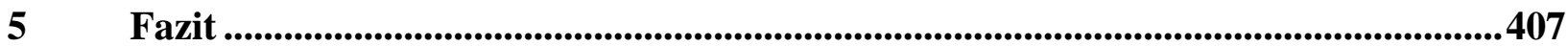

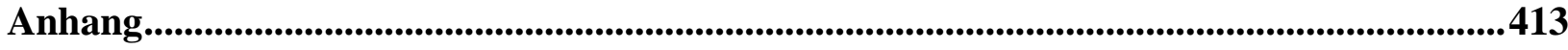

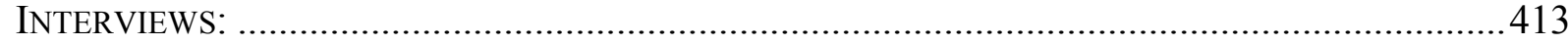

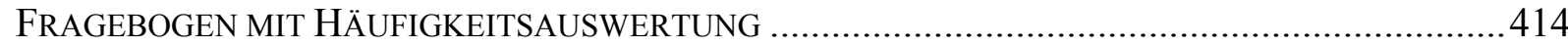

* Veröffentlicht als Diskussionsbeitrag 0602 des Instituts für Agrarökonomie. 


\section{Abbildungsverzeichnis:}

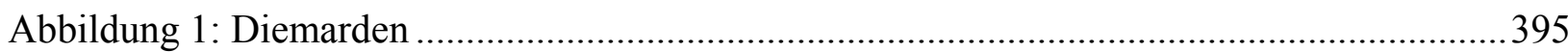

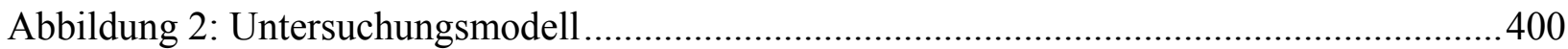

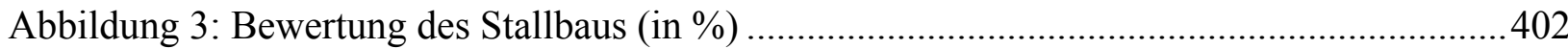

\section{Tabellenverzeichnis}

Tabelle 1: Besonderheiten von landwirtschaftlichen Stallbauten im Vergleich zu klassischen Nimby-Anlagen.

Tabelle 2: Theoretische Ansatzpunkte bei der Betrachtung von Standortkonflikten in der

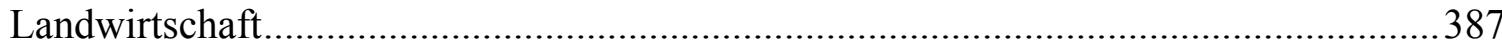

Tabelle 3: Veränderungen in der Landwirtschaft im Zeitablauf ............................................. 388

Tabelle 4: Gründe für und gegen den Stallbau (offene Frage, Mehrfachantworten) .................402

Tabelle 5: Charakterisierung der Befürworter und Ablehner....................................................404

Tabelle 6: Faktorladungen der einzelnen Statements ............................................................... 405

Tabelle 7: Regressionsmodell zur Bewertung des Stallbaus ...................................................406

Tabelle 8: Korrelationen Abstimmungs-Frage mit Umwelt- und Tierhaltungsmotiven .............407

Tabelle 9: Kreuztabelle der beiden Bewertungsfragen zum Stallbau......................................424 


\section{Einleitung}

In landwirtschaftlichen Praxiszeitschriften werden seit einigen Jahren immer wieder Fälle aufgeführt, in denen Landwirte ${ }^{1}$ bei Stallneubauten und anderen landwirtschaftlichen Investitionsvorhaben auf Probleme mit ihrem sozialen Umfeld oder Genehmigungsbehörden stoßen (Dorsch 2004: 14; o. V. 2004: 97; Neumann 2001: 40). Zudem zeigen Untersuchungen, dass nahezu jede Landwirtin über Probleme mit Anwohnern berichten kann (Becker 1996: 28). Auch der Wissenschaftliche Beirat des Bundesministeriums für Verbraucherschutz, Ernährung und Landwirtschaft sieht durch die schwindende Akzeptanz der Tierhaltung in viehschwachen Regionen verstärkte Probleme beim Neu- bzw. Ausbau von Tierhaltungssystemen (BMVEL 2005: 33). Aber nicht nur die Anzahl der Akzeptanzprobleme nimmt $\mathrm{zu}$, die Initiatoren der Proteste sind zunehmend professionell organisiert. So bietet beispielsweise der BUND im Internet zum kostenlosen Download einen Leitfaden zum Protest gegen Massentierhaltung an (BUND 2004), zudem können Bürgerinitiativen auf die Hilfe von spezialisierten Rechtsanwälten zurückgreifen (Pitschmann 2005: 15). Zwar liegen bislang keine statistisch gesicherten Analysen zu Konfliktzahl und -intensität vor, Experten gehen aber davon aus, dass besonders bei der Genehmigung von Stallbauten verstärkt Probleme auftreten, speziell wenn Anwohnerinnen gegen Investitionsvorhaben protestieren.

Der folgende Beitrag beschäftigt sich mit den Ursachen von Akzeptanzproblemen bei Stallbauten. Nach einer theoretischen Analyse der Einflussfaktoren steht exemplarisch ein Stallbaukonflikt in Diemarden, einem Dorf in der Nähe von Göttingen, im Mittelpunkt. Auf Grundlage von qualitativen Interviews mit den betroffenen Landwirtsfamilien, dem Sprecher der Bürgerinitiative sowie dem Bürgermeister des Dorfes wurde im Dezember 2003 eine quantitative Befragung zur Einstellung der Dorfbevölkerung bezüglich des Stallbaus durchgeführt. Zentrale Fragestellungen dieser Untersuchung sind die Analyse der Zustimmung bzw. Ablehnung des Stallbaus, der Gründe, die zu dieser Einstellung führen, sowie eine Charakterisierung der Befürworterinnen bzw. Ablehner des Stallbaus (Pitschmann 2005:14).

Die Genehmigung neuer Stallbauten ist insgesamt für die sektorale Entwicklung und die Zukunftsfähigkeit landwirtschaftlicher Unternehmen wichtig. Es zeigt sich, dass gerade in

\footnotetext{
${ }^{1}$ An dieser Stelle soll darauf hingewiesen werden, dass es sich bei den angesprochenen Personen jeweils sowohl um Frauen als auch um Männer handeln kann. Daher wird in diesem Papier die männliche und weibliche Form abwechselnd benutzt.
} 
Nicht-Veredlungsregionen besondere Schwierigkeiten auftreten, so dass sich eine weitere räumliche Konzentration der Tierhaltung abzeichnet. Aus Sicht der betroffenen Familienbetriebe können Konfliktdauer und -kosten die Investitionen unrentabel werden lassen. Aber auch das dörfliche Zusammenleben kann durch diese Konflikte immens gestört werden. Eine breitere Diskussion ist nötig, die die Entwicklung von Landwirtschaft und die Ansprüche der Öffentlichkeit an ihre Produktionsmethoden aufgreift, nicht nur, weil Landwirtschaft sich nicht unabhängig von gesellschaftlichen Entwicklungen machen kann, sondern auch, weil die Kompensationszahlungen der zweiten Säule der EU-Agrarpolitik gesellschaftliche Akzeptanz unumgänglich machen. Über das Thema Stallbau hinaus gewinnen Akzeptanzfragen auch bei anderen Geschäftsfeldern wie Bioenergie oder Windkraft an Relevanz.

\section{Theoretische Bezugspunkte von Standortkonflikten in der Landwirtschaft}

Der Strukturwandel in der Landwirtschaft führt zum einen zur Aufgabe vieler landwirtschaftlicher Betriebe, zum anderen dazu, dass die bestehenden Betriebe wachsen und ihre Produktion intensivieren (DBV 2005: 95). Vorteile in der Spezialisierung von landwirtschaftlichen Betrieben liegen z. B. im Aufbau von Fachwissen und der Erleichterung von Arbeitsabläufen durch spezielle Maschinen. Zudem amortisieren sich hohe Investitionen schneller in einem spezialisierten Betrieb. Für die Tierhaltung bedeutet dies, dass größere Einheiten rentabler sind und die Nutzung von economies of scale für viele Unternehmer unumgänglich ist.

Diese Intensivierung in der tierischen Produktion führt wie bereits eingangs erwähnt immer häufiger zu Konflikten, besonders mit Anwohnern. Dabei spielen auch die rechtlich nicht immer eindeutigen Regelungen eine Rolle (BFL 2003; Nüssle 2004: 23), auf die hier jedoch nicht näher eingegangen werden soll. Im Folgenden sollen vielmehr Erklärungsansätze für die Ursachen der mangelnden Akzeptanz vorgestellt werden. Der Arbeit liegt dabei eine Konfliktdefinition von Glasl (1996: 14 ff.) zu Grunde. Demnach sind „soziale Konflikte Spannungssituationen, in denen zwei oder mehrere Parteien, die voneinander abhängig sind, mit Nachdruck versuchen, scheinbare oder tatsächlich unvereinbare Handlungspläne zu verwirklichen und sich dabei ihrer Gegnerschaft bewusst sind“. Für Konflikte bei Stallbauten bedeutet dies, dass von Seiten der Dorfbevölkerung bzw. Anwohnern die Nicht-Nutzung eines Standorts gefordert wird und Aktivitäten stattfinden, die die Landwirtin von ihren Nutzungsabsichten abhalten soll. 
Die Akzeptanz landwirtschaftlicher Investitionsvorhaben ist bisher in der agrarökonomischen Literatur nur anhand einer Untersuchung zu bestehenden und geplanten Schweineställen in Ostdeutschland untersucht worden (Mann/Kögl 2003: 243). Hier wurde mittels einer schriftlichen Befragung in 18 Gemeinden in Ostdeutschland die Akzeptanz von bereits bestehenden und geplanten Schweineställen untersucht. Insgesamt zeigt diese Studie interessante Ergebnisse u. a. hinsichtlich der Unterschiede in der Akzeptanz von vorhandenen und in Planung befindlichen Ställen, auf die im späteren Ergebnisteil näher eingegangen wird. Der vorliegende Beitrag fokussiert aber auf Konflikte, die bei geplanten Stallbauten auftreten können. Um diese Ursachen näher zu analysieren, wird daher auf verschiedene Forschungsstränge von Nachbardisziplinen zurückgegriffen, die sich mit Auseinandersetzungen um Industriestandorte, Müllverbrennungsanlagen, Atommülllager etc. beschäftigen. Bei diesen Konflikten handelt es sich häufig um so genannte „NIMBY“-Güter bzw. -Dienstleistungen (Not in my Backyard). Darunter werden lokal unerwünschte Güter und Dienstleistungen verstanden, die der großen Mehrheit einen Nettonutzen zu schaffen versprechen, von der räumlich betroffenen Bevölkerung dagegen abgelehnt werden (Hart/Pommerehne 1994: 1).

Standortkonflikte können bei öffentlichen sowie privaten Gütern und Dienstleistungen auftreten, sofern von ihnen auch negative externe Effekte (z. B. potenzielle Risiken, Gerüche etc.) ausgehen. Bisher haben sich Forschungen zum Thema NIMBY vor allem auf technische Anlagen mit Risikopotenzial (z. B. Kernkraftwerke, Chemieanlagen und Mülldeponien) oder soziale Einrichtungen wie Obdachlosenheime oder Psychiatrien (Horah et al. 1993: 1) bezogen. Landwirtschaftliche Stallbauten gehörten bislang nicht zu den NIMBY-Gütern. Dies liegt u. a. daran, dass landwirtschaftliche Investitionsvorhaben eine Reihe von Besonderheiten aufweisen, die sie von klassischen NIMBY-Anlagen unterscheiden (siehe Tabelle 1). 
TABELLE 1: BESONDERHEITEN VON LANDWIRTSCHAFTLICHEN STALLBAUTEN IM VERGLEICH ZU KLASSISCHEN NIMBY-ANLAGEN

\begin{tabular}{|c|c|}
\hline Landwirtschaft & Klassische NIMBY-Anlagen \\
\hline - privatwirtschaftliche Entscheidungen & - öffentliche Entscheidungen \\
\hline - klein- und mittelständische Betriebe & $\begin{array}{l}\text { - Großunternehmen/ öffentliche } \\
\text { Unternehmen }\end{array}$ \\
\hline $\begin{array}{l}\text { - privilegiertes Baurecht der } \\
\text { Landwirtschaft }\end{array}$ & - vielfältige spezialrechtliche Grenzen \\
\hline $\begin{array}{l}\text { - Wahrnehmung von Risiken der } \\
\text { Tierproduktion als neues Phänomen }\end{array}$ & - Klassische Risikothemen \\
\hline $\begin{array}{l}\text { traditionell keine Hinterfragung der } \\
\text { Standortakzeptanz von Seiten der } \\
\text { Landwirtschaft }\end{array}$ & - Akzeptanz als Standortfaktor \\
\hline
\end{tabular}

Quelle: Eigene Zusammenstellung

Die wissenschaftliche Auseinandersetzung mit NIMBY-Gütern rückt neben der Entscheidungsfindung bei der Standortwahl (top-down versus bottom-up) die monetäre Entschädigung für die betroffenen Standorte in den Vordergrund (Frey/Jegen 2001: 601), vor allem die Suche nach dem unter Kosten-Nutzen-Abwägungen günstigsten Standort (Feinerman et al. 2005: 369). Diese Ansätze sind für landwirtschaftliche Stallbauten nicht Ziel führend, da es sich um privatwirtschaftliche Investitionen mit geringen Gemeinwohleffekten handelt, die zum einen nicht von der öffentlichen Hand durchgesetzt werden können und zum anderen keine Ausgleichsmaßnahmen für die betroffenen Gemeinden vorsehen. Es handelt sich zudem bei dem vorliegenden Beitrag nicht um eine volkswirtschaftliche Betrachtung, die Wohlfahrtsveränderungen analysiert, sondern es wird eine betriebswirtschaftliche Perspektive eingenommen.

Im Vordergrund der folgenden Ausführungen steht daher die grundlegende Frage, warum Stallbauinvestitionen nicht oder weniger akzeptiert werden. Insgesamt beschäftigen sich eine Reihe von Theorien und Forschungsrichtungen mit Aspekten, die landwirtschaftliche Standortkonflikte betreffen. In Tabelle 2 sind die Forschungsgegenstände, Forschungsrichtungen und Hauptthemen im Überblick dargestellt. 
TABELle 2: THEORETISCHE ANSATZPUNKTE BEI DER BETRACHTUNG VON STANDORTKONFLIKTEN IN DER LANDWIRTSCHAFT

\begin{tabular}{|c|c|c|}
\hline Gegenstand & Forschungsrichtung & Hauptthemen \\
\hline $\begin{array}{l}\text { Dorf, ländlicher } \\
\text { Raum }\end{array}$ & Agrarsoziologie & $\begin{array}{ll}\text { - } & \text { Dorfentwicklung } \\
\text { - } & \text { Landwirtschaftliche Erwerbsformen } \\
\text { - } & \text { Kommunikationsnetzwerke } \\
\text { - } & \text { Dörfliche Wohnsituation } \\
\end{array}$ \\
\hline $\begin{array}{l}\text { Gesellschaft- } \\
\text { licher Wandel }\end{array}$ & Soziologie & $\begin{array}{ll}\text { - } & \text { Bedeutungsverlust der Landwirtschaft } \\
\text { - } & \text { Wertewandel } \\
\text { - } & \text { Neue soziale Bewegungen } \\
\end{array}$ \\
\hline Konflikt & Soziologie & $\begin{array}{ll}\text { - } & \text { Konfliktursachen } \\
\text { - } & \text { Konflikttheorien } \\
\end{array}$ \\
\hline Öffentlichkeit & $\begin{array}{l}\text { Betriebswirtschaft/ } \\
\text { Kommunikations- } \\
\text { wissenschaften }\end{array}$ & $\begin{array}{ll}\text { - } & \text { Stakeholdermanagement } \\
\text { - } & \text { Kritische Anspruchsgruppen }\end{array}$ \\
\hline Kommunikation & $\begin{array}{l}\text { Kommunikations- und } \\
\text { Medienwissenschaften }\end{array}$ & $\begin{array}{ll}\text { - } & \text { Risikokommunikation } \\
\text { - } & \text { Technikakzeptanz } \\
\text { - } & \text { Akzeptanzmanagement } \\
\end{array}$ \\
\hline Baurecht & $\begin{array}{l}\text { Landwirtschafts- bzw. } \\
\text { Verwaltungsrecht }\end{array}$ & $\begin{array}{ll}\text { - } & \text { Genehmigungsverfahren } \\
\text { - } & \text { Rechtliche Regelungen } \\
\text { - } & \text { Mediation } \\
\end{array}$ \\
\hline $\begin{array}{l}\text { Produktions- } \\
\text { ausrichtung }\end{array}$ & Ethik & $\begin{array}{ll}\text { - } & \text { Tiergerechtheit } \\
\text { - } & \text { Ökologische Landwirtschaft } \\
\end{array}$ \\
\hline Standortwahl & Volkswirtschaftslehre & $\begin{array}{ll}\text { - } & \text { Kosten-Nutzen-Analyse } \\
\text { - } & \text { Versteigerung bei NIMBY-Gütern }\end{array}$ \\
\hline $\begin{array}{l}\text { Räumliche } \\
\text { Standortwahl }\end{array}$ & $\begin{array}{l}\text { Naturwissenschaftliche } \\
\text { Ansätze (z. B. Geo- } \\
\text { logie) }\end{array}$ & $\begin{array}{ll}\text { - } & \text { Technische Machbarkeit } \\
\text { - } & \text { Standortvorzüglichkeit }\end{array}$ \\
\hline $\begin{array}{l}\text { Betriebsgröße/ } \\
\text {-struktur }\end{array}$ & Betriebswirtschaft & $\begin{array}{ll}\text { - } & \text { Optimale Betriebsgröße } \\
\text { - } & \text { Betriebsorganisation } \\
\text { - } & \text { Diversifikation/Spezialisierung } \\
\end{array}$ \\
\hline
\end{tabular}

Quelle: Eigene Darstellung

Anhand dieses kurzen Abrisses wird deutlich, dass sich dem Thema auf unterschiedliche Weise genähert werden kann, es aber keine geschlossene Theorie gibt, welche uneingeschränkt auf den Problemkomplex übertragbar ist. Im Folgenden sollen daher einige wichtige Ursachen von Standortkonflikten aufgegriffen werden.

\section{Ausgewählte Ursachen von Standortkonflikten in der Landwirtschaft}

\subsection{Soziologische Erklärungsansätze der landwirtschaftlichen Standortkonflikte}

Bei der Betrachtung der Ursachen von Standortkonflikten ist das sich in den letzten Jahrzehnten verändernde gesellschaftliche Umfeld besonders augenfällig. Hervorzuheben ist der Bedeutungsverlust der Landwirtschaft, festgemacht z. B. an der immensen Abnahme der 
Zahl landwirtschaftlicher Betriebe. Während 1950 noch 1.647.000 Betriebe in Deutschland wirtschafteten, sind es 50 Jahre später nur noch 421.000 (siehe Tabelle 3).

TABELLE 3: VERÄNDERUNGEN IN DER LANDWIRTSCHAFT IM ZEITABLAUF

\begin{tabular}{|l|l|l|l|l|l|l|l|}
\hline & Einheit & $\mathbf{1 9 5 0}$ & $\mathbf{1 9 6 0}$ & $\mathbf{1 9 7 0}$ & $\mathbf{1 9 8 0}$ & $\mathbf{1 9 9 0}$ & $\mathbf{2 0 0 0}$ \\
\hline Zahl der Betriebe ab 1 ha & 1.000 & 1.647 & 1.385 & 1.083 & 797 & 630 & 421 \\
\hline Durchschnittliche Betriebsgröße & ha LF & 8,1 & 9,3 & 11,7 & 15,3 & 18,7 & 37,2 \\
\hline Anteil an allen Erwerbstätigen & $\%$ & 23,9 & 13,2 & 7,8 & 4,8 & 3,0 & 2,4 \\
\hline
\end{tabular}

Quelle: Agrarbericht, verschiedene Jahrgänge

Zudem ist der Anteil der Arbeitskräfte, die in der Landwirtschaft beschäftigt sind, im gleichen Zeitraum von 23,9 \% auf 2,4 \% gesunken (Agrarbericht, verschiedene Jahrgänge). Dieser Bedeutungsverlust spiegelt sich entsprechend auf dörflicher Ebene wider. So wird in einer Panel-Untersuchung der Forschungsgesellschaft für Agrarpolitik und Agrarsoziologie Bonn, in der im Abstand von jeweils 20 Jahren zehn Dörfer untersucht wurden (1952, 1972 und 1992), deutlich, dass der betriebliche Strukturwandel in der Landwirtschaft zunächst über einen Ausstieg aus der Haupterwerbsfunktion hin zum Nebenerwerb und schließlich beim Generationswechsel zum Ausstieg aus der Landwirtschaft vollzogen wird (Becker 1997: 26). Landwirtschaft entwickelt sich demnach zum „einsamen Beruf“ (Stegemann zitiert nach Struff 1999: 9), die Landwirte geraten im Dorf in eine Minderheitenposition.

\section{Das Dorf: Vom Arbeits- zum Wohnstandort}

Nicht nur diese sektoralen Veränderungen, sondern auch Veränderungen im sozialen Umfeld der Landwirtinnen bedingen Standortkonflikte. Als besonders wichtig sind hier die Veränderungen im Dorf zu erwähnen. Unter einem Dorf wird in Mitteleuropa eine große Gruppensiedlung verstanden, was in etwa $1.000-1.500$ Einwohnern entspricht. Dabei werden die Kernbereiche der meisten ländlichen Siedlungen durch Bauernhäuser und -höfe geprägt. Obwohl diese Gebäude nicht mehr alle für landwirtschaftliche Funktionen eingesetzt werden, gehört das bäuerliche Anwesen zum aktuellen Leitbild des Dorfes (Henkel 2005: 42 ff.). Heute gibt es allerdings Dörfer, in denen keine Landwirte mehr zu finden sind. Diese Abnahme der landwirtschaftlichen Bedeutung auf dörflicher Ebene, aber auch die zunehmende Attraktivität des Dorfes als Wohnstandort führt zu Veränderungen des Zusammenlebens. Fand der erste Zuzug von Dorffremden nach dem 2. Weltkrieg durch die Vertriebenen statt, sind es heute vielfältige Gründe, die Dörfer zu attraktiven Wohnstandorten werden lassen. Dazu zählt einmal das im Vergleich zur Stadt günstige Bauland. Das Dorf ist 
für viele ein Ort, an dem der Traum vom Eigenheim realisierbar ist. Aber nicht nur die Grundstückspreise sind für den vermehrten Zuzug verantwortlich, auch natürliche und physische Umweltbedingungen spielen eine wichtige Rolle. Bei empirischen Untersuchungen zu den Motiven der Wohnortwahl war das Argument „Ländlichkeit“ besonders wichtig. „Ländlichkeit““ als mehrdimensionales Konstrukt wird dabei vor allem so verstanden, dass das Dorf als „Hort der Freiheit““ und Garant individueller Entfaltungsmöglichkeiten gewinnt, Landwirtschaft hingegen keine Rolle spielt oder negativ besetzt ist („Es stört uns schon, wenn es $a b$ und zu nach Landwirtschaft stinkt, nach Spritzmitteln und Gülle“). Gerade bei Zugezogenen stört die Landwirtschaft das Idealbild vom ländlichen Wohnen (Johaentges 1996: 23). Hinzu kommt die emotionale Bedeutung des Wohneigentums, das für viele Hausbesitzer „eine Belohnung für zahlreiche Entbehrungen“ (z. B. Verzicht auf Urlaubsreisen, Überstunden etc.) darstellt. Zudem spielt beim Erwerb vom Wohneigentum weniger die materielle Sicherungsfunktion, als vielmehr der Wunsch nach Selbstverwirklichung und der damit verbundene Wunsch nach Freiheit eine Rolle (Johaentges 1996: 21). Damit wird deutlich, dass das neu errichtete Haus für Zugezogene in Dörfern oftmals viel mehr ist als ein Wohnort - es ist ein unter Entbehrungen aufgebauter Hort der Individualität und Freiheit.

\section{Veränderte Kommunikationsstrukturen und -inhalte}

Veränderungen in einem Dorf, das attraktiv ist für den Zuzug von Dorffremden, wirken sich auch auf die dörflichen Kommunikationsstrukturen aus. Eine Untersuchung sozialer Netzwerke zeigt zum einen, dass landwirtschaftliche Inhalte zum Expertenthema werden und damit aus der alltäglichen Dorfkommunikation verschwinden (Retter et al. 2002: 451). Dies trifft verstärkt für die moderne Tierhaltung $\mathrm{zu}$, die als Teil der nicht-öffentlichen Landwirtschaft für Außenstehende nicht mehr einsehbar ist. Zum anderen verändern Zugezogene und die Größe der Neubaugebiete die dörflichen Kommunikationsstrukturen grundlegend. Bei einem Zuzug von mehr als $15 \%$ der ursprünglichen Dorfbevölkerung kann davon ausgegangen werden, dass eine intensive Gruppenbildung stattfindet und damit der Bezug zum Gesamtort verloren geht. Neu entstandene Gruppen koppeln sich von Altgruppen ab bzw. werden nicht integriert (Retter et al. 2002: 451 ff.; Stahr 2000: 153). Für landwirtschaftliche Investitionsvorhaben bedeuten diese Erkenntnisse, dass mit dem Verschwinden der bäuerlichen Themen aus der Alltagskommunikation die Hintergründe und Notwendigkeiten von Investitionsvorhaben schwerer zu vermitteln sind und, falls der Anteil der Zugezogenen in einem Dorf sehr groß ist, diese Gruppe nur begrenzt zu erreichen ist. 


\section{Wertewandel und gesellschaftliche Partizipationsansprüche}

Nicht nur die Veränderungen des sozialen Zusammenlebens begünstigen Konflikte. Auch der gesamtgesellschaftliche Wertewandel hat Auswirkungen auf die Akzeptanz von Stallbauten. Unter Wertewandel wird der Prozess verstanden, der seit Beginn der sechziger Jahre in westlichen Industrieländern $\mathrm{zu}$ finden ist und $\mathrm{zu}$ umfassenden Verhaltens- und Einstellungsänderungen geführt hat (Abramson/Inglehart 1995). Nicht-materielle Werte, z. B. Emanzipation oder Umweltschutz, haben an Bedeutung gewonnen, zudem wird eine stärkere Individualisierung festgestellt (Schubert/Klein 2001). Als Ursachen des Wertewandels werden besonders das Abflachen des Wirtschaftswachstums, die Grenzen des Wohlfahrtsstaates, die Entwicklung von Großtechnologien mit hohem Abstraktionsgrad sowie die bessere Information von Bürgern gesehen. Diese Entwicklungen führen zu Zweifeln am technischen Fortschritt, wachsender Kritik an Experten und Forderungen nach offenerer Kommunikation in der Gesellschaft (Röglin/Grebmer 1988: 31 f.). Für Stallbauten bedeutet dies, dass Teile der (Dorf-) Bevölkerung auch hier Zweifel an der „Technik der Tierproduktion“ hegen und mit Expertenmeinungen nicht leicht $\mathrm{zu}$ überzeugen sind, da diese kritisch hinterfragt werden, bzw. teilweise als nicht objektiv empfunden werden (Peters 1995: 232).

\subsection{Tierethische Ansätze zur Erklärung von Konflikten im Bereich Tierhaltung}

Ethische Fragestellungen stellen sich in der Landwirtschaft vor allem bei Mensch-NutztierBeziehungen. $\mathrm{Zu}$ diesem Themenkomplex gibt es eine ausgedehnte Diskussion. Besonders der Stellenwert von Tieren, die Frage ihrer Würde, Haltungsbedingungen, die Zulässigkeit von Tötung etc. wurden in den letzten Jahren sehr kontrovers diskutiert (siehe u. a. Hoerster 2004; Fenneker 2002; Badura 1999; Leven 1999; Singer 1997). Diese generellen Fragestellungen richten sich besonders auf die Landwirtschaft. Speziell im Bereich der konventionellen Tierhaltung wird zum Umdenken aufgefordert (Schneider 2001: 228 ff).

Diese zunächst allgemein geführte Diskussion entlädt sich auf lokaler Ebene bei geplanten Stallbauten. Vor allem von Seiten der Natur- und Tierschutzverbände wird die Kritik an der „Massentierhaltung“ als Argument gegen Stallbauten angeführt (BUND 2004: 11, o. V. 2004 : 97). Damit spielen bei Standortkonflikten nicht allein der jeweilige Betrieb und die lokalen Auswirkungen (z. B. Geruchsbelästigung) eine Rolle. Die generelle Diskussion, ob eine intensive Tierproduktion grundsätzlich akzeptabel ist, wird stattdessen auf lokaler Ebene in Form von Stellvertreterkonflikten geführt. Mit dieser Diskussion sind Landwirtinnen möglicherweise überfordert, was vor allem auf die unterschiedliche Mensch-Tier-Beziehung 
von Landwirten und nicht-landwirtschaftlicher Bevölkerung zurückzuführen ist (Jürgens 2005: 166).

Am Beispiel des Begriffs „Massentierhaltung“ werden die Schwierigkeiten der Kommunikation bzw. (ethischen) Rechtfertigung deutlich. „Massentierhaltung“ rückt intensive Tierhaltung in die Nähe von „Massenware“ und der Künast'sche Slogan „Klasse statt Masse“ verdeutlicht die Vorstellung, dass ,die Produktion in großer Menge und Zahl notwendig hohe Qualität ausschließt“" (Busch/Kunzmann 2004: 32). Für Teile der Bevölkerung bedeutet dies, dass Massentierhaltung zum Nachteil der Tiere betrieben wird und Tierhaltung in kleinen bäuerlichen Einheiten stets vorzuziehen sei (Busch/Kunzmann 2004: 33). Diese Vorstellung ist nicht zuletzt darauf zurückzuführen, dass sich der Blickwinkel bei der Betrachtung von Tieren verändert hat. Während über Jahrhunderte hinweg die Nutztierperspektive dominierte, tendiert die Betrachtung heute zum „Lebenskameraden“, das Tier wird als „Mitgeschöpf“ betrachtet (Dirscherl 2001). Diese Perspektive formuliert grundlegende ethische Anforderungen an die landwirtschaftliche Nutztierhaltung. „Massentierhaltung“ wird zudem nicht in Bezug zur Wirklichkeit traditioneller Haltungsformen gesetzt, sondern mit romantisierenden Vorstellungen über diese Haltungsformen verglichen (Busch/Kunzmann 2004: 35).

Die kurze Darstellung macht die Vielschichtigkeit des Themas deutlich. Für die Landwirtschaft stellt sich die Frage, wie intensive Tierhaltung zu kommunizieren ist. Die bisherigen Ansätze, die darauf setzen, auf Basis naturwissenschaftlicher Erkenntnisse über ideale Haltungsformen bestimmte Haltungsbedinungen $\mathrm{zu}$ kommunizieren, werden wahrscheinlich angesichts der verschiedenen Problemperspektiven zu kurz greifen. Auch die bereits beschriebenen Glaubwürdigkeitszweifel von Expertenmeinungen verdeutlichen, dass Landwirte in der Diskussion mit Gegnern dieser Haltungssysteme auf Schwierigkeiten stoßen werden.

\subsection{Kommunikationsprobleme bei Standortkonflikten}

Die vorhergehenden Ausführungen zeigen, dass es sich bei Stallbaukonflikten auch um Kommunikationsprobleme handelt. Rechtlich gesehen hängt die Informationspflicht der Landwirte mit der Größe des geplanten Stallbaus zusammen. Das Bundesimmissionsschutzgesetz sieht bei der Schweineproduktion eine förmliche Öffentlichkeitsbeteilung sowie eine Umweltverträglichkeitsprüfung ab 2.000 Mastplätzen vor, ab 1.500 Tieren wird eine 
standortbezogene Vorprüfung gefordert, bei geringeren Tierzahlen wird ein vereinfachtes Verfahren ohne Öffentlichkeitsbeteiligung durchgeführt (Grimm 2003: 30).

Diese rechtlichen Grundlagen schützen aber nicht vor Konflikten mit Anwohnern. Vielmehr stellt sich die Frage, wie die betriebswirtschaftliche Notwendigkeit eines Stallbaus kommuniziert und die Verfahren der Produktion gerechtfertigt werden können, um die Akzeptanz eines Stalles vor Ort sicherzustellen. Diese Herausforderung trifft auf mittelständische Betriebe, die über keine adäquate kommunikative Ausbildung verfügen und zudem häufig bereits grundsätzlich die Notwendigkeit einer öffentlichen Rechtfertigung ihrer Investitionsentscheidungen ablehnen.

Wie auf Anspruchsgruppen eingegangen werden kann, die Einfluss auf ein Unternehmen nehmen können, ist u. a. Inhalt des Stakeholderansatzes. Dyllick arbeitet heraus, warum sich Unternehmen als „quasi-öffentliche Institutionen“ (Dyllick 1990: 13; Ulrich 1978) mit Forderungen von Anspruchsgruppen auseinander setzen müssen und stellt vier allgemeingültige Merkmale vor, die Anhaltspunkte darstellen, wann Unternehmen mit Ansprüchen rechnen müssen: (1) Ansprüche, die im Namen übergeordneter Interessen der Gesellschaft insgesamt erhoben werden und den privaten Interessen des Unternehmens gegenüber gestellt werden. (2) Ein weiteres Merkmal ist die mehr oder weniger direkte Auseinandersetzung zwischen Unternehmung und Betroffenen. Dabei werden die Betroffenen in zunehmendem Maße selbst aktiven und öffentlichen Druck auf Behörden aufbauen und es nicht dem Staat überlassen, der allgemeingültige Regeln erstellt. (3) Zudem sind der öffentliche Druck und damit die Rolle der Medien wichtig. In vielen Fällen hat öffentlicher Druck und nicht die gesetzlichen Vorgaben dazu geführt, dass Großunternehmen ihre Pläne änderten (z. B. Shell Brent Spar). (4) Schließlich geht es um die Bedeutung der moralischen Position in der öffentlichen Auseinandersetzung. Die Wirkung des öffentlichen Drucks basiert demnach primär auf ethisch begründeten Forderungen. Diese häufig als „weich“ und unverbindlich eingestuften Forderungen erweisen sich in der späteren Auseinandersetzung oft als „harte“ Instanzen. Dyllick weist an dieser Stelle darauf hin, dass diejenigen, denen es gelingt solche Ansprüche zu verkörpern, damit über eine „Quelle der Macht“ (Dyllick 1990: 22) verfügen, die sich zunächst auf Moral stützt und sich später institutionalisieren und verfestigen kann. Aufgrund dieser Überlegung wird der Einfluss von Bürgerinitiativen verständlich. Diese Merkmale können auch auf landwirtschaftliche Stallbauten übertragen werden. Dabei scheint es zunehmend unwichtiger zu sein, welche Größe die Unternehmung hat. Wichtiger ist an 
dieser Stelle festzustellen, dass Ansprüche von Dritten, in diesem Fall den Dorfbewohnern, auch an landwirtschaftliche Familien gestellt werden. Eine Entwicklung, die durch die beschriebenen Veränderungen begünstigt wird.

Wenn gesellschaftliche Anspruchsgruppen als relevant für ein landwirtschaftliches Unternehmen erkannt werden, was viele Landwirte wohl eher skeptisch sehen, stellt sich im nächsten Schritt die Frage, ob und mit welcher Kommunikationsstrategie die Akzeptanz von Stallbauten erhöht werden kann. In der Forschung wird unter dem Begriff „Risikokommunikation“ diskutiert, wie die Akzeptanz von Großtechnologien durch Kommunikationsmaßnahmen erhöht werden kann. Dabei wurden Akzeptanzprobleme zunächst auf fehlende Informationen zurückgeführt. Anders ausgedrückt lautete die Ausgangshypothese: Werden nur genug Informationen vermittelt, steigt die Akzeptanz (einer Anlage, Technologie etc.). In empirischen Untersuchungen konnte dieser Zusammenhang nicht durchgängig nachgewiesen werden, vielmehr zeigt sich nur ein schwacher, nicht monotoner Zusammenhang. Sowohl die Befürworter als auch die Gegner sind informierter als diejenigen Befragten, die sich unentschieden zeigen (Peters 1991: 11).

Die Diskussion über Kommunikationsform, -inhalt und -zielgruppen ähnelt stark den Diskursen, die im Zusammenhang mit der Risikokommunikation stattfinden. In der Risikokommunikationsforschung steht vor allem die Akzeptanz von Großtechnologien im Mittelpunkt. Dabei werden die Ursachen von Akzeptanzmängeln, die verschiedenen Zielgruppen und Lösungsansätze vorgestellt. Um die Akzeptanz der Großtechnologien zu erhöhen, schlagen einige Autoren eine ergebnisoffene, transparente Diskussion mit der Gesellschaft bzw. ihren Vertretern vor. Nur im diskursiven Umgang können die unterschiedlichen Bewertungen von Risiken und Nutzen durch Befürworter, Gegner und Wissenschaft zu einer für alle tragfähige Lösung beitragen (Röglin 1994: 64). Diese ergebnisoffene Diskussion über die Nutzung der Technologien wird als Voraussetzung zur Akzeptanz gesehen. PR-Konzepte, die versuchen, Bürger zu informieren bzw. zu überzeugen werden dagegen abgelehnt, da diese von den Gegnern als nicht objektiv und als Beeinflussung empfunden werden.

\section{Fallbeispiel Diemarden: Der Stallbau in einer Nicht-Veredlungsregion}

Standortkonflikte in der Landwirtschaft sind - wie gezeigt - öffentliche Auseinandersetzungen vor dem Hintergrund gewandelter Dorfstrukturen. Dies trifft besonders auf Fallkonstellationen außerhalb der Intensivregionen der Veredlungswirtschaft $\mathrm{zu}$, in denen 
Akzeptanzprobleme nicht auf innerlandwirtschaftliche Nutzungskonflikte (z. B. in Vechta/Cloppenburg: Geflügel- versus Schweinehaltung), sondern allein oder überwiegend auf NIMBY-Probleme zurückzuführen sind.

Im Folgenden wird ein solcher Stallbaukonflikt näher untersucht, der in einem Dorf in der Nähe von Göttingen stattfindet. Basis sind qualitative Interviews mit dem Leiter der Bürgerinitiative, die sich gegen den Stallbau formiert hat, den betroffenen landwirtschaftlichen Familien und dem Bürgermeister sowie eine ausführliche quantitative Befragung der Dorfbevölkerung.

\subsection{Diemarden}

Diemarden ist ein Dorf mit etwa 1.400 Einwohnern, das ca. $9 \mathrm{~km}$ von der Universitätsstadt Göttingen entfernt liegt. Die dörfliche Entwicklung der letzten Jahrzehnte verlief in etwa drei Phasen (siehe Abbildung 1): Siedlung 1 im Bereich Friedhofsweg (1960er Jahre), Siedlung 2 im Bereich Schmalenberg (1970er Jahre) und die aktuelle Neubausiedlung „Zum Gelenberg“ (Bürgermeister 2003). Durch die Nähe zu Göttingen leben viele Zugezogene in Diemarden und bilden nach Aussage des Leiters der Bürgerinitiative mit zweidrittel die Mehrheit der Diemardener (Bürgerinitiative 2003). In Diemarden sind damit ähnliche Tendenzen zu beobachten, wie sie bereits in Untersuchungen der FAA-Bonn festgestellt werden, die einen Anteil der gebürtigen Einwohner von $12 \%$ in Elliehausen sowie $28 \%$ in Groß Schneen, beides Dörfer in der Nähe von Göttingen, ausweisen (Becker 1997: 49). 


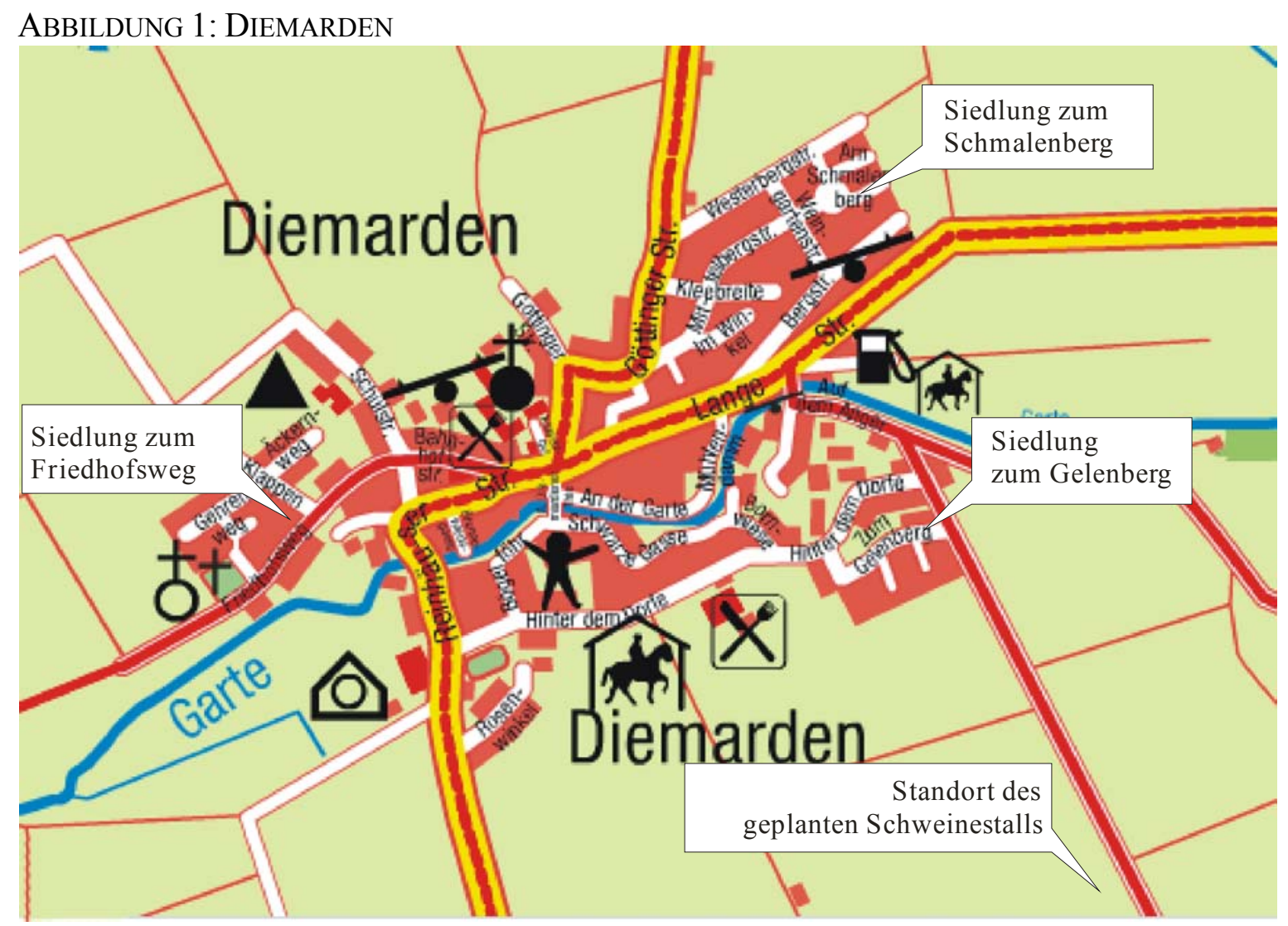

Quelle: Stadtplannet 2005

\section{Daten zum Stallbauvorhaben}

Der von den Landwirten geplante Stall soll für 440 Schweine und 224 Ferkel mit Spaltenboden gebaut werden, die maximale nachträgliche Aufstockungsmöglichkeit beträgt 50 \%. Geplant ist ein Standort südöstlich von Diemarden in einer Senke (siehe Abbildung 1). Die Entfernung zum nächstgelegenen Wohnhaus beträgt $330 \mathrm{~m}$, erlaubt sind nach TA-Luft 220 m (Jarass 2002: 1219). Die Landwirtschaftskammer stellte dazu am 20.06.2003 fest, dass „keinerlei Beeinträchtigungen der im Umfeld der Stallanlage bestehenden Wohnbebauung zu befürchten sind“ (LWK Northeim 2003).

\subsection{Perspektiven der Bürgerinitiative und Landwirte}

Im Frühjahr 2003 stellten die beiden Landwirte eine Bauvoranfrage an den Landkreis als Genehmigungsbehörde, der diese an die Gemeinde weiter reichte. Der Umweltausschuss der Gemeinde hatte keine Einwände. Zunächst wurden fünf Standorte diskutiert, wovon ein Standort ausgewählt wurde, da sich die anderen $\mathrm{zu}$ nah an der Wohnbebauung, der Kreisstraße oder im Vorzugsgebiet für Windkraftanlagen befanden. Nach Festlegung des Standorts reichten die Landwirte den Bauantrag in den Bau- und Planungsausschuss ein. Die 
Bewohner des Dorfes wurden von den Landwirten nicht informiert, da dies nach dem Bundesimmissionsschutzgesetz erst ab 1.500 Schweinen notwendig ist (Landwirte 2003).

Durch einen Zufall erfuhren die Dorfbewohner von dieser Bauvoranfrage, und es gerieten viele Gerüchte über Standort, Größe und Haltungsform in Umlauf. In dieser Phase (ca. April 2003) formierte sich eine Protestgruppe, die Rundschreiben verfasste und über den geplanten Stall informierte. Aufgrund der heftigen Reaktionen fand am 25.04.2003 eine Informationsveranstaltung statt, zu der mehr als 100 Bürger erschienen. Moderiert wurde diese Veranstaltung von dem Bürgermeister des Dorfes, der von einer hitzigen Diskussion sprach, die eine sachliche Auseinandersetzung sehr schwierig machte (Bürgermeister 2003). Die Stallbaugegner kritisierten vor allem die Standortwahl, einige aber lehnten generell die geplante Haltungsform (Spaltenböden) bzw. die „Massentierhaltung“ ab. Das Informationsgespräch führte nicht zu einer Lösung des Konflikts, vielmehr formierten sich zwei Fronten: „Altbürger gegen Neubürger“ (Bürgerinitiative 2003). Schließlich gründete sich aus der Protestgruppe der Verein „Natürlich Diemarden“, der nach einem Monat bereits 80 Mitglieder verzeichnete und u. a. zum Ziel hatte, den Stallbau zu verhindern.

Am 30.04.2003 reichten die Landwirte ihren Bauantrag ein, woraufhin der Verein „Natürlich Diemarden“ den Petitionsausschuss des niedersächsisches Landtags anrief. Bei einer Ortsbegehung, die am 03.11.2003 stattfand, empfahlen die Petitionsmitglieder die Erstellung eines unabhängigen Gutachtens über die Windverhältnisse vor Ort, wobei die Kostenübernahme für ein solches Gutachten unklar blieb (Schubert 2003).

Nach langen Diskussionen zwischen den einzelnen Parteien und Genehmigungsbehörden, die sich vor allem um die Geruchsbelästigung, Windrosen etc. drehten, lehnte der Landkreis im Juni 2004 die Baugenehmigung ab. Begründet wird dies damit, dass ein nah gelegener Wald durch die Ammoniakemissionen gefährdet sei. Nach Aussagen der Forstverwaltung handelte es sich hierbei jedoch nicht um einen Wald, sondern um eine wildgewachsene Baumgruppe (Schubert 2004). Gegen die Nicht-Erteilung der Baugenehmigung reichten die Landwirte Klage ein. Auch im Januar 2006 ist über die endgültige Ablehnung oder Erteilung des Bauantrags noch nicht entschieden (Landwirt A 2006). 


\subsubsection{Argumente der Bürgerinitiative}

Die Argumentationslinie der Bürgerinitiative, die in einem qualitativen Interview vom Vorsitzenden des Vereins „Natürlich Diemarden“ dargestellt wurde, betrifft verschiedene Punkte des Stalls sowie des Genehmigungsverfahrens. In erster Linie befürchten die Stallbaugegner Geruchsbelästigungen. Sie argumentieren, dass an dem geplanten Standort auch Bärlauch wachsen würde. Der von ihm ausgehende Geruch sei im ganzen Dorf wahrnehmbar. Das Tierschutzargument ist aus Sicht der Bürgerinitiative auch ein Grund gegen den Stallbau, sei aber aus rechtlichen Gründen nicht benutzbar und würde daher gegen den Stallbau nicht nach außen kommuniziert (Bürgerinitiative 2003). In einem offenen Brief, den ein Dorfbewohner an die Bürger in Diemarden, die örtlichen Politiker und Parteien, sowie die Presse geschrieben hat, spielt das Argument der Tierhaltung jedoch eine Rolle. Dort heißt es „(die Bürger in Diemarden werden jetzt) mit höchst zweifelhafter 1) Massenschweintierhaltung (es gibt auch alternative Tierhaltung!) 2) massiven Geruchbelästigungen $u$. Gewässerbelastungen durch Gülle und 3) erhöhtem, gefährlichen Verkehrsaufkommen konfrontiert“ (Werner-Lellau 2003). Dagegen betont der Vorsitzende der Bürgerinitiative, dass die Bürgerinitiative sehr sachlich anhand von Strömungskarten und Windrosen naturwissenschaftliche Argumente vorbringt, die deutlich machen, dass der Stall an dieser Stelle zu einer Geruchsbelästigung des ganzen Dorfes führen würde. Zudem bemängelt der Verein, dass die zuständige Landwirtschaftskammer eine andere und aus ihrer Sicht falsche Windrose benutzt hat (Bürgerinitiative 2003).

An einigen Stellen im Interview tauchen dennoch emotionale Äußerungen auf. So lässt der Vorsitzende des Vereins „Natürlich Diemarden“ seine Kinder ausrechnen, wie viel Platz die einzelnen Tiere im Stall haben werden, was zum Streit in der örtlichen Grundschule führt. Zudem spricht er bei der Haltungsform von einer „Aufbewahrungsanstalt“, in der die Tiere „auf engstem Raum zusammengepfercht“ sind. Schließlich wird im Laufe des Gesprächs zunehmend deutlich, dass auch das Verhältnis zwischen Neu- und Altbürgern des Dorfes eine Rolle spielt („Man kommt auch nicht richtig in Kontakt. Die Bauern sitzen dann mal irgendwo zusammen und die Neubürger dann anderswo. Ich bin ein paar mal in die Dorfkneipe gegangen [...] und dann wurde an der Theke immer von dem Baugebiet geredet. Ich habe gedacht, na das ist diese Ökosiedlung hier. Nein, nein, ach darüber reden wir gar nicht. [...] Sondern von einer Siedlung, die ist in den 70ern errichtet worden. So, und die haben uns (Neubausiedlung „Zum Gelenberg“, bebaut Mitte der 90er Jahre Anm. d. V.), noch gar nicht realisiert, dass es uns da gib. (Pause) Doch jetzt mittlerweile schon.). 
Insgesamt wird aus dem Interview ein ambivalentes Bild von Landwirtschaft deutlich. So wird auf der einen Seite ein gewisses Maß an Verständnis für die Landwirte geäußert (,Wir wollen ihnen nicht die wirtschaftliche Grundlage entziehen"), auf der anderen Seite aber gesagt, dass es bislang ökonomisch auch für ein Überleben gereicht habe. Zudem wird die Einhaltung bestimmter Regeln gefordert. Dabei spielt in diesem Fall vor allem die Einbeziehung der Öffentlichkeit in die Bauplanung eine Rolle. Die Dorfbewohner, die sich von dem Stallbau betroffen sehen, wollen zu diesem Vorhaben gehört werden. Sie bemängeln, dass die Landwirte nicht offen vorgegangen sind. Nur durch Zufall sei herausgekommen, dass ein Stall gebaut werden soll: „Wir sollten hier über den Tisch gezogen werden“. Der Leiter der Bürgerinitiative gibt Beispiele von Landwirten, die vorher informiert haben und am Stall Besucherterrassen einrichten, was er als deutlich positiv empfindet (Bürgerinitiative 2003).

Bei der Argumentation der Bürgerinitiative ist zwischen Selbstdarstellung und tatsächlicher Kommunikation zu unterscheiden. Nach außen werden vor allem vermeintlich unumstößliche naturwissenschaftliche Fakten kommuniziert. Emotionale und nicht vollständig rationale Argumente spielen dennoch auch eine Rolle. Damit wird eine insgesamt vielfältige Motivlage deutlich, allerdings wird der Stellenwert der einzelnen Argumente aus den qualitativen Interviews nicht ersichtlich. Die quantitative Befragung soll diese Lücke schließen.

\subsubsection{Sichtweise der betroffenen landwirtschaftlichen Familien}

Der Schweinestall wird von zwei Familien geplant. Davon lebt eine Familie in Diemarden (im Weiteren Landwirt A) und hat bislang in einer GbR mit zwei weiteren Familien ihren Hauptbetriebszweig im Ackerbau (zusammen ca. 275 ha). Zudem werden auf der Hofstelle, die sich im Dorfkern befindet, ca. 40 Milchkühe gehalten. Die andere landwirtschaftliche Familie (im Weiteren Landwirt B) hat ihre Hofstelle im Nachbarort Klein Lengden. Sie betreibt neben dem Ackerbau auch Schweineproduktion und vermarktet diese über einen eigenen Hofladen.

Die Landwirtsfamilien sahen sich sehr überrascht von den Ereignissen. Sie hatten sich auf die Einhaltung der gesetzlichen Vorschriften verlassen und mit solch massivem Widerstand nicht gerechnet. Die Argumente der Stallbaugegner, die sich in erster Linie auf den zu befürchteten Geruch beziehen, halten sie für wenig glaubwürdig. Auch das Argument, dass der Bärlauch, der an dem geplanten Standort wächst, im Dorf wahrnehmbar sei, halten sie für wenig glaubwürdig, denn der Bärlauch wächst ihrer Aussage nach an anderer Stelle. Die Familien 
gehen vielmehr davon aus, dass eine Teilgruppe der Zugezogenen einfach gegen sämtliche Veränderungen in ihrem Umfeld seien („... als man auf die andere Straßenseite eine Siedlung bauen wollte, waren auch alle dagegen" Landwirt A). Sie sind der Meinung, dass es auch bei anderen baulichen Vorhaben zu massive Protesten kommen würde. Sie sehen keinen glaubwürdigen Grund darin, dass der Stall wahrnehmbar sei. Zudem geben sie an, dass gerade der von den Ablehnern bemängelte Standort aus Rücksicht auf die Dorfbevölkerung ausgewählt wurde, da der Stall dort vom Dorf aus nicht sichtbar sei.

Eine Bereitschaft zur Information der Dorfbevölkerung bzw. die Notwendigkeit, vor Beginn des Bauantrags mit dem Dorf in Kontakt zu treten, sahen die betroffenen Familien nicht („Die haben uns ja auch nicht gefragt, als sie gebaut haben " Landwirtin A). Als der Konflikt aber eskalierte, nahmen die Landwirte an dem organisierten Informationsabend teil, der aber als wenig hilfreich angesehen wurde. Nach diesem Abend scheinen die beiden Seiten so verhärtet zu sein, dass keinerlei Austausch mehr zwischen den Gruppen stattfand. LANDWIRT B: „Ich habe denen gesagt, wir bauen den Stall sowieso, aber wir können da noch mal drüber reden“. Das Argument, dass der Stall notwendig sei, um die wirtschaftliche Zukunft der Betriebe zu sichern, hat aus Sicht der Landwirtsfamilien für Teile der Gegner keine Relevanz. Als an dem Informationsabend die Sprache auf diesen Punkt kam, sagte ein Anwesender, „die Betroffenen sollten sich halt woanders Arbeit suchen oder Sozialhilfe beantragen“ (Landwirte 2003).

\subsubsection{Hypothesen und Modell der quantitativen Untersuchung}

Mann und Kögl (2003) konnten nachweisen, dass bestehende Anlagen generell weniger kritisch gesehen werden als geplante. Die Ergebnisse ihrer Studie zeigen, dass bestimmte Faktoren einen signifikanten Einfluss auf die Bewertung von Stallbauten haben. Als soziodemografische Einflussfaktoren auf die Akzeptanz von geplanten Ställen spielt nach dieser Untersuchung lediglich die Entfernung zum Wohnort eine Rolle. Als Einstellungsvariablen konnten die Einschätzung zur Schaffung von Arbeitsplätzen und Einkommen in der Region identifiziert werden. Ökologisch motivierte Argumente haben hingegen keinen Effekt (Mann/Kögl 2003: 248). Bei bestehenden Anlagen hat das Alter der Befragten einen signifikanten Einfluss auf die Bewertung von Stallbauten. Zudem befürworten - wenig überraschend - besonders Landwirte diese Anlagen. Neben diesen Faktoren sind aber auch die Einschätzung der Geruchsbelästigung und vermutete Gesundheitsgefährdung, sowie Umweltund Tierschutzargumente für die Zustimmung oder Ablehnung eines Stallbaus von Bedeutung. Zusammenfassend folgern die Autoren, dass große Produktionsanlagen mit 
günstigen Produktionskosten $\mathrm{zu}$ bevorzugen sind, da die Größe des Stalls und die vorgesehene Haltungsform keinen Einfluss auf die Zustimmung haben. Sie empfehlen, zukünftige Anlagen möglichst weit entfernt von der Wohnbevölkerung zu planen. Ihrer Meinung nach ist dies der sicherste Weg, Konflikte zu vermeiden.

Anhand der theoretischen Vorüberlegungen und der qualitativen Interviews wurde ein Befragungsmodell entwickelt, das der quantitativen Befragung zu Grunde liegt. Demnach haben soziodemografische Variable wie der Zuzug, die Wohndauer, das Alter etc. Einfluss auf die Bewertung des Stallbaus, ebenso das klassische NIMBY-Verhalten, die Einschätzung der persönlichen Belastung, die Stellung der Landwirtschaft im Allgemeinen und im Dorf, das Themeninvolvement sowie die Beurteilung des Genehmigungsprozesses.

\section{ABBILDUNG 2: UNTERSUCHUNGSMODELL}

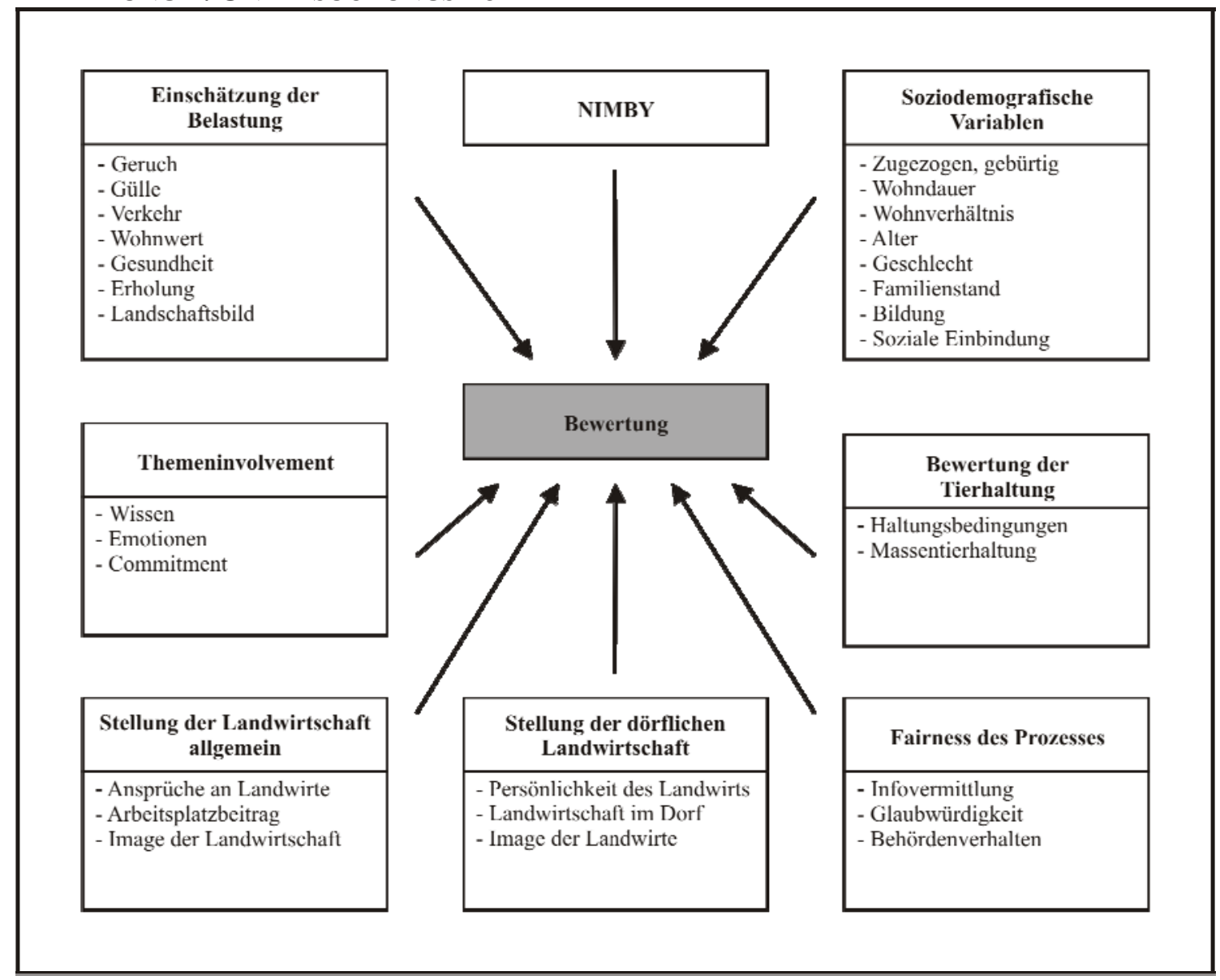

Quelle: Eigene Darstellung 


\subsection{Ergebnisse der quantitativen Untersuchung}

\subsubsection{Stichprobenstruktur}

Im Dezember 2003 wurde in Diemarden von geschulten studentischen Interviewern der Universität Göttingen eine Haushaltsbefragung von 154 Anwohnern mit Hilfe eines standardisierten Fragebogens durchgeführt. Dies entspricht $11 \%$ der Gesamtbevölkerung. Aufgrund dieses hohen Anteils und der Zusammensetzung der Stichprobe kann die Studie als hinreichend repräsentativ für dieses Dorf angesehen werden.

Die Stichprobe setzt sich aus $55 \%$ männlichen und $45 \%$ weiblichen Probanden zusammen. Rund $26 \%$ der Probanden sind gebürtige Diemardener, ca. $63 \%$ sind zugezogen. Auf die Frage, warum die Zugezogenen in Diemarden leben, sind die häufigsten Antworten, dass sie sich hier wohl fühlen (55\%), die Schönheit der Landschaft (53\%) sowie die ruhige Lage (53\%). Das günstige Bauland wurde von $22 \%$ der Befragten angegeben.

\subsubsection{Einstellung der Bevölkerung zum Stallbau}

In einer ersten Frage wurde die grundsätzliche Haltung zum Stallbau abgefragt. Hier zeigt sich eine deutliche Zweiteilung der Dorfbevölkerung in Befürworter (39\%) und Ablehner des Stalles (47\%). Nur $14 \%$ sind unentschlossen (siehe Abbildung 3). Weiterhin wurde am Ende der Befragung danach gefragt, wie die Dorfbewohner im Falle einer Abstimmung entscheiden würden. Hier zeigt sich ein ähnliches, leicht polarisiertes Bild, was dafür spricht, dass sich einige Befragte (ca. 7 \%) im Laufe der Befragung auf eine Position festgelegt haben. Dieser „Informationseffekt“ führt aber $\mathrm{zu}$ keiner grundsätzlich anderen Bewertung, wie der Vergleich der Mittelwerte und Standardabweichungen (siehe Abbildung 3), sowie der sehr hohe Korrelationswert von $(0,925 * * *)$ zeigen. Eine Kreuztabelle (vgl. Anhang) zeigt, dass nur sieben Probanden im Laufe des Interviews ihre Position geändert haben. Dies spricht für eine manifestierte Einstellung. 
ABBiLDUNG 3: BEWERTUNG DES STALLBAUS (IN \%)

Wie Sie sicherlich wissen, planen zwei Landwirte am Ortsrand von Diemarden einen Schweinestall zu bauen. Was meinen Sie zu diesem Vorhaben? Bitte benutzen Sie dafür folgende Skala. (Interviewer bitte die Skala zeigen). Stimmen Sie dem Stallbau zu oder lehnen Sie ihn ab?(Angaben in \%) $(\mu=-0,22 ; \sigma=2,3)$

\begin{tabular}{|c|c|c|c|c|c|c|}
\hline $\begin{array}{c}\text { Stimme voll } \\
\text { und ganz zu }\end{array}$ & Stimme zu & $\begin{array}{c}\text { Stimme eher } \\
\mathbf{z u}\end{array}$ & Teils, teils & $\begin{array}{c}\text { Lehne eher } \\
\text { ab }\end{array}$ & Lehne ab & $\begin{array}{c}\text { Lehne voll } \\
\text { und ganz ab }\end{array}$ \\
\hline 15,6 & 18,1 & 5,0 & 14,4 & 8,8 & 10,6 & 27,5 \\
\hline
\end{tabular}

Stellen Sie sich vor, es gäbe eine Dorfabstimmung über den Stallbau in Diemarden, wie würden Sie entscheiden? (Angaben in \%) $(\mu=-0,14 ; \sigma=2,4)$

\begin{tabular}{|c|c|c|c|c|c|c|}
\hline $\begin{array}{c}\text { Ja, ich } \\
\text { stimme auf } \\
\text { jeden Fall } \\
\text { dafür }\end{array}$ & $\begin{array}{c}\text { Ja, ich } \\
\text { stimme } \\
\text { dafür. }\end{array}$ & $\begin{array}{c}\text { Ja, ich } \\
\text { würde eher } \\
\text { dafür } \\
\text { stimmen. }\end{array}$ & $\begin{array}{c}\text { Ich bin } \\
\text { unentschlossen } \\
\text { und würde mich } \\
\text { enthalten. }\end{array}$ & $\begin{array}{c}\text { Nein, ich } \\
\text { würde eher } \\
\text { dagegen } \\
\text { stimmen. }\end{array}$ & $\begin{array}{c}\text { Nein, ich } \\
\text { würde } \\
\text { dagegen } \\
\text { stimmen. }\end{array}$ & $\begin{array}{c}\text { Nein, ich } \\
\text { stimme auf } \\
\text { jeden Fall } \\
\text { dagegen }\end{array}$ \\
\hline 20,1 & 16,2 & 7,8 & 7,1 & 10,4 & 10,4 & 27,9 \\
\hline
\end{tabular}

Quelle: Eigene Berechnung

In einer offenen Frage wurde nach den Gründen gefragt, warum die Befragten für oder gegen einen Stall sind (siehe Tabelle 4). Die häufigste Nennung war mit $33 \%$ der Geruch, $19 \%$ kritisierten die Art der Tierhaltung, 10 \% nannten den Standort als Grund für die Ablehnung. Allerdings zeigten $23 \%$ der Befragten deutliches Verständnis für die Landwirte, 10 \% waren ohne nähere Begründung einfach dafür. Das Argument, dass Landwirtschaft zum Dorf gehört und damit auch der geplante Stallbau, nannten 7,5 \% der Befragten. Das Arbeitsplatzargument wurde von $6,5 \%$ der Befragten angeführt.

TABELLE 4: GRÜNDE FÜR UND GEGEN DEN STALLBAU (OFFENE FRAGE, MEHRFACHANTWORTEN)

\begin{tabular}{|l|l|l|l|}
\hline \multicolumn{2}{|l|}{ Negative Äußerungen } & Positive Äußerungen \\
\hline Befürchtete Geruchsbelästigung & $32,9 \%$ & Verständnis für Landwirte & $23,2 \%$ \\
\hline Art der Tierhaltung & $18,7 \%$ & $\begin{array}{l}\text { Einfach dafür (ohne nähere } \\
\text { Begründung) }\end{array}$ & $9,7 \%$ \\
\hline Nähe zum Dorf/Standort & $10,3 \%$ & Landwirtschaft gehört zum Dorf & $7,5 \%$ \\
\hline Naturschutz & $6,5 \%$ & Arbeitsplätze & $6,5 \%$ \\
\hline Zunahme des Verkehrs & $5,8 \%$ & & \\
\hline $\begin{array}{l}\text { Minderung des Erholungswertes der } \\
\text { Umgebung }\end{array}$ & $5,8 \%$ & & \\
\hline Wohnwert & $2,6 \%$ & & \\
\hline $\begin{array}{l}\text { Verhalten der Landwirte (keine } \\
\text { Informationen) }\end{array}$ & $2,6 \%$ & & \\
\hline $\begin{array}{l}\text { Negative Auswirkungen auf die } \\
\text { Gesundheit }\end{array}$ & $1,3 \%$ & & \\
\hline
\end{tabular}

Quelle: Eigene Darstellung 


\subsubsection{Soziodemografie der Befürworter und Ablehner}

Betrachtet man die Personen, die sich für oder gegen den Stallbau aussprechen, anhand ihrer soziodemografischen Merkmale (siehe Tabelle 5), fallen vor allem die deutlichen Unterschiede zwischen den Zugezogenen und gebürtigen Diemardenern auf. Die in Diemarden Geborenen stimmen eher für den Stallbau, während ihn die Zugezogenen mehrheitlich ablehnen. Auch die Wohndauer hat einen Einfluss: 71 \% aller Personen, die erst in den letzten zehn Jahren nach Diemarden gezogen sind, lehnen den Stall ab, dagegen nur $36 \%$ der Personen, die mehr als 25 Jahre dort leben. Dieser Zusammenhang ist zum einen auf die im theoretischen Teil erklärten Zuzugsmotive zurückzuführen. Schon hier wurde Landwirtschaft eher als störend wahrgenommen (Johaentges 1996). Zum anderen leben einige der Zugezogenen in der am potenziell stärksten betroffenen Siedlung. In den qualitativen Interviews wurde berichtet, dass die gebürtigen Diemardener und die Befürworter in anderen Vereinen sind als die Zugezogenen und Ablehner. Das bestätigte sich auch in der Anwohnerbefragung: Im Schützen- und Heimatverein, besonders aber bei der Feuerwehr stimmen die Mitglieder überwiegend für den Stallbau. Im Schulförderverein, der von den Neu-Diemardenern gegründet wurde, sind dagegen überwiegend Ablehner vertreten. Auch hier zeigt sich, dass zugezogene und gebürtige Diemardener nicht unbedingt im Kontakt zueinander stehen. Wie auch andere Untersuchungen in Dörfern mit Zuzug zeigen umfassen die Kommunikationsnetzwerke nicht das ganze Dorf (Stahr 2002).

Das Bildungsniveau der Diemardener ist aufgrund der Nähe zur Universitätsstadt Göttingen besonderes hoch. Personen mit einem hohen Bildungsabschluss, einem Universitätsabschluss oder einer Promotion lehnen den Stall überwiegend ab. Bei dieser Gruppe handelt es sich vorwiegend um Zugezogene, die oftmals an der Universität als Angestellte arbeiten. Keinen Einfluss auf die Einstellung gegenüber dem Vorhaben hat das Wohnverhältnis der Befragten. Mieter und Eigentümer lehnen es gleichermaßen eher ab. 
TABELLE 5: CHARAKTERISIERUNG DER BEFÜRWORTER UND ABLEHNER ${ }^{2}$

\begin{tabular}{|c|c|c|c|c|}
\hline \multirow{4}{*}{$\begin{array}{l}\text { Wohndauer in } \\
\text { Jahren }\end{array}$} & & Befürworter (\%) & Ablehner (\%) & Anzahl \\
\hline & mehr als 25 & 57,1 & 35,7 & 70 \\
\hline & $11-25$ & 23,3 & 48,8 & 43 \\
\hline & 10 und weniger & 19,4 & 71,0 & 31 \\
\hline & in Diemarden geboren & 59,0 & 25,6 & 38 \\
\hline \multirow[t]{5}{*}{ Verein } & Schützenverein & 57,1 & 35,7 & 14 \\
\hline & Heimatverein & 60,0 & 20,0 & 15 \\
\hline & Schulförderverein & 17,6 & 70,6 & 17 \\
\hline & „Natürlich Diemarden“ & 0 & 100 & 19 \\
\hline & Feuerwehr & 86,7 & 6,7 & 15 \\
\hline \multirow[t]{2}{*}{ Bildung } & Ohne Abitur & 55 & 38,5 & 42 \\
\hline & Mit Abitur & 30,3 & 60,8 & 34 \\
\hline \multirow{2}{*}{$\begin{array}{l}\text { Landwirte im } \\
\text { Freundeskreis }\end{array}$} & $\mathrm{Ja}$ & 56,0 & 35,2 & 91 \\
\hline & Nein & 25,8 & 69,4 & 62 \\
\hline \multirow[t]{2}{*}{ Geschlecht } & Männlich & 51,3 & 45,0 & 80 \\
\hline & Weiblich & 32,3 & 56,9 & 65 \\
\hline
\end{tabular}

Quelle: Eigene Berechnung

\subsubsection{Bewertungsgründe}

\section{Faktorenanalyse zur Dimensionsreduktion}

Zur Erklärung, welche Gründe für oder gegen einen Stallbau sprechen, ist eine Vielzahl von Einflussfaktoren zu berücksichtigen. Um diese Variablenvielfalt zu reduzieren, wurde eine Faktorenanalyse durchgeführt. Neben der Komplexitätsreduktion dient sie der Aufdeckung voneinander unabhängiger Einflussgrößen und beugt somit a priori dem Problem der Multikollinearität in der sich anschließenden Regressionsanalyse vor. Für die nachstehende Untersuchung wurde die Hauptkomponentenanalyse als Faktorextraktionsverfahren gewählt. Die Güte der Daten für die Faktorenanalyse wurde zusammen mit dem Bartlett-Test durch das Kaiser Meyer Olkin-Kriterium getestet. Der ermittelte Wert von 0,862 belegt eine gute Tauglichkeit der Datengrundlage (Backhaus et al. 2003: 276). Insgesamt konnten 4 Faktoren (mit Eigenwerten $>1$ ) extrahiert werden, die kumuliert eine Gesamtvarianz von 65,96 \% erklären. Die hohen Alpha-Werte sprechen für reliable Faktoren. Diese decken sich in etwa mit dem theoretischen Modell und werden folgendermaßen charakterisiert:

- Faktor 1: Einschätzung der persönlichen Belastung durch den Stallbau

- Faktor 2: Stellenwert und Image der Landwirtschaft

- Faktor 3: Wissen über Landwirtschaft (Selbsteinschätzung)

- Faktor 4: Not In My Backyard

\footnotetext{
2 Befürworter und Ablehner wurden anhand ihres Antwortverhaltens bei den Fragen 1 und 15 in die entsprechende Gruppe eingeteilt. Die Probanden, die mit teils, teils geantwortet haben und sich unentschlossen zum Stallbau zeigten, wurden nicht berücksichtigt.
} 
Die folgende Tabelle gibt die hinter den jeweiligen Faktoren stehenden Statements und die zugehörigen Faktorladungen wieder:

TABELLE 6: FAKTORLADUNGEN DER EINZELNEN STATEMENTS

\begin{tabular}{|l|r|}
\hline Faktor 1: Cronbachs Alpha = 0,936; 28,29 \% der Varianz & Faktorladung \\
\hline Durch den Schweinestall würde ganz Diemarden stinken. & 0,862 \\
\hline Die Gründung eines Vereins gegen den Schweinestall finde ich übertrieben. & $-0,848$ \\
\hline Der Verein ,Natürlich Diemarden“ hat dafür gesorgt, dass wir endlich informiert werden. & 0,821 \\
\hline Durch den Stall wird die gesundheitliche Belastung stark steigen. & 0,755 \\
\hline Die Belastung durch den Schweinestall wird man kaum bemerken. & $-0,743$ \\
\hline Der Güllegeruch beim Ausbringen wird unerträglich sein. & 0,722 \\
\hline Faktor 2: Cronbachs Alpha = 0,753; 18,1\% der Varianz & 0,718 \\
\hline Polaritätenprofil: Landwirte sind bescheiden-gierig & 0,711 \\
\hline Ohne die Bauern wäre Diemarden nur halb so lebenswert. & 0,696 \\
\hline Ohne Landwirtschaft hätten wir in Deutschland noch viel mehr Arbeitslose. & 0,641 \\
\hline Polaritätenprofil: Landwirte sind sympathisch-unsympathisch & 0,608 \\
\hline Polaritätenprofil: Landwirte sind Landschaftspfleger-Landschaftszerstörer & \\
\hline Faktor 3: Cronbachs Alpha = 0,81; 13,62 \% der Varianz & 0,926 \\
\hline Von Landwirtschaft habe ich eigentlich keine Ahnung. & $-0,903$ \\
\hline Ich kenne mich in landwirtschaftlichen Themen aus. & \\
\hline Faktor 4: Cronbachs Alpha = 0,620; 9,78 \% der Varianz & 0,819 \\
\hline Würde der Stall in Diemarden an anderer Stelle stehen, wäre mir das Ganze egal. & 0,801 \\
\hline $\begin{array}{l}\text { Eigentlich habe ich nichts gegen solch einen Stall, nur sollte er nicht direkt vor unserer } \\
\text { Haustür gebaut werden. }\end{array}$ & \\
\hline
\end{tabular}

Quelle: Eigene Berechnungen

Auf Basis der Faktorenanalyse wurde im nächsten Schritt eine Regressionsrechnung durchgeführt. Die Abstimmungsfrage zum Stallbau wurde als abhängige Variable definiert. Tabelle 7 stellt die Ergebnisse des Regressionsmodells dar. Die Schätzung zeigt, dass die vier extrahierten Faktoren signifikanten Einfluss auf die Bewertung des Stallbaus haben. Dabei ist der Faktor 1 „Einschätzung der persönlichen Belastung“ der wichtigste zur Erklärung des Zusammenhangs. Befragte, die eine starke Belastung erwarten, lehnen den Stallbau ab. Interessant ist, dass weiterhin der zweite Faktor „Stellenwert und Image der Landwirtschaft“ im Allgemeinen, aber auch im Dorf, für die Bewertung wichtig ist. Dorfbewohner, die der Landwirtschaft einen hohen Stellenwert einräumen, stimmen eher für den Stall. Die Fragen zum Image der Landwirtschaft und der Landwirte zeigen ein sehr ambivalentes Bild (vgl. Anhang Fragen 6 und 7). Landwirte werden als fleißig und freundlich wahrgenommen. Die Mehrzahl der Befragten findet Landwirtschaft wichtig und Landwirte glaubwürdig, aber auch altmodisch und skandalträchtig. Auch das Wissen über Landwirtschaft, das in dieser Befragung mittels zweier Selbsteinschätzungsfragen modelliert wurde, hat signifikanten Einfluss auf die Bewertung. Probanden mit wenig Wissen über Landwirtschaft lehnen den 
Stallbau tendenziell ab. Weiterhin spielt das St.-Florians-Prinzip eine Rolle, eigentlich hat man nichts gegen einen solchen Stall, doch bloß nicht vor der eigenen Haustür (NIMBY).

TABELLE 7: REgRESSIONSMODELl ZUR BEWERTUNG DES STALLBAUS

\begin{tabular}{|c|c|c|c|}
\hline Einflussfaktoren & Beta & T-Wert & Signifikanz \\
\hline Konstante & &,- 082 & ,935 \\
\hline Faktor 1: Einschätzung der persönlichen Belastung &,- 780 & $-17,052$ &, 000 \\
\hline Faktor 2: Stellenwert und Image der Landwirtschaft & ,320 & 6,984 & 000 \\
\hline Faktor 3: Wissen über Landwirtschaft (Selbsteinschätzung) &,- 178 & $-3,879$ &, 000 \\
\hline Faktor 4: NIMBY & 177 & 3,858 &, 000 \\
\hline Wohndauer &,- 145 & $-2,950$ &, 004 \\
\hline
\end{tabular}

Quelle: Eigene Berechnung

Interessant sind aber nicht nur die signifikanten Einflussgrößen, sondern auch, dass Tierhaltungsproblematik und Umweltschutzfragen in dieser Befragung keinen signifikanten Einfluss auf die Bewertung haben. Hier scheint es sich doch eher um ein vorgeschobenes Argument von Seiten der Stallbaugegner zu handeln. Für die Mehrzahl der Befragten ist dieses Argument bei der Stallbaufrage nicht entscheidend. Ein Blick auf die Korrelationen zwischen der Bewertung des Stallbaus und Tierschutz- sowie Umweltfragen zeigt ein uneinheitliches Bild. Die Korrelation zwischen der Abstimmungsfrage und dem Statement „Von Massentierhaltung kann bei 660 Schweinen nicht geredet werden“ ist mit 0,612*** sehr hoch. Mit dem Statement „Wenn die Schweine auf Stroh stehen würden, hätte ich gegen den Stall nichts einzuwenden“, ist aber kein Zusammenhang festzustellen (siehe Tabelle 8). Vielmehr scheint es eine generelle Einstellung zu Art der Tierproduktion und konventioneller Landwirtschaft $\mathrm{zu}$ geben. So finden sich sehr hohe Korrelationen auch bei dem Statement „Eigentlich sollten alle Landwirte ökologisch wirtschaften“. 
TABELLE 8: KoRRELATIONEN ABSTIMMUNGS-FraGE MIT UMWELT- UND TIERHALTUNGSMOTIVEN

\begin{tabular}{|c|c|c|c|c|c|}
\hline & $\begin{array}{l}\text { Von } \\
\text { Massentierhaltung } \\
\text { kann bei } 660 \\
\text { Schweinen nicht } \\
\text { geredet werden. }\end{array}$ & $\begin{array}{l}\text { Die gesetzlichen } \\
\text { Anforderungen an } \\
\text { die } \\
\text { Schweinehaltung } \\
\text { sind insgesamt zu } \\
\text { niedrig. }\end{array}$ & $\begin{array}{l}\text { Wenn die } \\
\text { Schweine auf } \\
\text { Stroh stehen } \\
\text { würden, hätte } \\
\text { ich gegen den } \\
\text { Stall nichts } \\
\text { einzuwenden. }\end{array}$ & $\begin{array}{l}\text { Die Gülle } \\
\text { belastet die } \\
\text { Umwelt in } \\
\text { unserer } \\
\text { Umgebung. }\end{array}$ & $\begin{array}{l}\text { Eigentlich } \\
\text { sollten alle } \\
\text { Landwirte } \\
\text { ökologisch } \\
\text { wirtschaften. }\end{array}$ \\
\hline $\begin{array}{l}\text { Stellen Sie sich } \\
\text { vor, es gäbe eine } \\
\text { Dorfabstimmung } \\
\text { über den Stallbau } \\
\text { in Diemarden, } \\
\text { wie würden Sie } \\
\text { entscheiden? }\end{array}$ & $0,612 * * *$ & $-0,705^{* * *}$ & 0,151 & $-0,700 * * *$ & $-0,552 * * *$ \\
\hline
\end{tabular}

\section{Fazit}

Das vorgestellte Fallbeispiel verdeutlicht verschiedene Aspekte von Standortkonflikten bei Stallbauten. Zunächst sind es vor allem Zugezogene, die sich gegen Ställe aussprechen. Dies mag zum einen daran liegen, dass sie keinem sozialen Druck ausgesetzt sind, da familiäre oder persönliche Kontakte zu den betroffenen Landwirten fehlen. Zum anderen sind es aber die Motive und die Bedeutung des Wohneigentums, die eine hohe emotionale Betroffenheit und viele Befürchtungen auslösen, wenn bekannt wird, dass ein Stall geplant ist. In der dargestellten Untersuchung zeigt sich, dass vor allem der Geruch und damit die Einschätzung der persönlichen Belastung der entscheidende Faktor zur Bewertung des Stallbaus ist. Tierschutzargumente scheinen hier weniger eine Rolle zu spielen. Einiges spricht dafür, dass der vorliegende Stall gerade aufgrund seiner kleinen Größe Probleme aufwirft. Ein erheblich größerer Stall hätte die - in Intensivregionen heute bereits üblichen - Abluftreinigungstechniken wirtschaftlich ermöglicht und damit die zentrale Konfliktursache entschärft.

Ein weiterer wichtiger Faktor ist die Stellung der Landwirtschaft im Allgemeinen und im Dorf. Hier ist für Landwirte und deren Berufsverbände Potenzial, das Image der Berufsgruppe zu festigen und damit Akzeptanz für ihre Anliegen zu gewinnen. Zudem deutet der Einfluss des Wissens über die Landwirtschaft darauf hin, dass mit Wissensvermittlung die Akzeptanz für Investitionsvorhaben gesteigert werden kann. Diese Erkenntnis widerspricht Ergebnissen aus Studien zur Akzeptanz von Großtechnologien. Es ist davon auszugehen, dass mit Informationen auch die Unentschlossenen für einen Stallbau gewonnen werden können. Die harten Ablehner, besonders wenn ein möglicher Konflikt sich auf einer Stufe bewegt, in der eine sachliche Auseinandersetzung nicht mehr möglich ist, werden dagegen mit Wissenver- 
mittlung nur schwer zu überzeugen sein. Damit sind ein gezielter Imageaufbau und eine generelle Wissensvermittlung vor allem als Präventionsstrategie im Vorfeld von Investitionsmaßnahmen zu sehen. Allerdings sind die Landwirte vor Ort auf Unterstützung von Berufsverbänden und Organisationen wie der CMA oder dem Agrarinformationsdienst (AID) angewiesen, um verbrauchergerechtes Informationsmaterial und Argumentationsanleitungen zu erhalten.

Insgesamt können anhand der dargestellten Untersuchungen einige Aussagen über die Einflussfaktoren auf die Bewertung landwirtschaftlicher Stallbauten gemacht werden. Dennoch unterliegt diese Analyse einigen Einschränkungen, die sich aus der Eigenart des untersuchten Dorfes und Falles ergeben. So wäre es interessant zu analysieren, wie Auseinandersetzungen in Dörfern mit weniger Zuzug, mit geringerem Anteil an Akademikern, in anderen Regionen sowie bei Ställen anderer Tierarten verlaufen. Trotzdem lässt sich schlussfolgern, dass Stallbauten zukünftig vor allem in Nicht-Veredlungsregionen vor besonderen Akzeptanzproblemen stehen werden. Um bevorstehenden Konflikten entgegen zu wirken, muss auf verschiedenen Ebenen angesetzt werden. Dazu gehören zum einen rechtlich klare Regelungen sowie ein gesellschaftlicher Konsens zur Tierproduktion. Es zeigt sich, dass die Konflikte, die vor Ort zu erheblichen ökonomischen sowie sozialen Problemen führen können, verschiedene Dimensionen beinhalten. Obwohl die Regressionsanalyse verdeutlicht, dass neben dem klassischen NIMBY-Problem, das nur schwer zu lösen ist, vor allem die Einschätzung der persönlichen Belastung eine Rolle spielt, zeigen die qualitativen Interviews, dass in der Diskussion vor Ort eine Reihe grundlegender Probleme mit eingebracht werden. Die Diskussion um Tierschutzstandards, Haltungsbedingungen sowie der generellen Frage, welche Tierproduktion eigentlich gesellschaftlich gewünscht und akzeptiert wird, spielt auch in der öffentlichen Auseinandersetzung um Stallbauten eine Rolle. Sie überdeckt teilweise die offensichtlichen Konfliktgegenstände und trägt zur emotionalen und politischen Aufladung der Auseinandersetzung bei. Diese Diskussion überfordert aber in der Regel die Landwirte. Ein Konsens kann nur schwer gefunden werden.

Überträgt man die Ergebnisse der Risikokommunikationsforschung auf Stallbauten, wäre ein Vorschlag, zu Beginn eines Vorhabens ergebnisoffene Diskussionen mit den Gegnern zu führen. Das Ziel ist, einen für beide Seiten tragbaren Kompromiss zu finden, bzw. verhandelbare Alternativen zu diskutieren. Dieses Konzept ist allerdings im Bereich der Tierhaltung für die meisten Investitionen schwierig. Bei Tierhaltungssystemen, technischer 
Ausstattung und teilweise der Standortwahl können aufgrund der geringen Gewinnmargen in diesem Bereich kaum verhandelbare Angebote gemacht werden. Zum Beispiel sind Abluftreinigungssysteme nur bei größeren Vieheinheiten rentabel, die Größe des Stalles ist dann allerdings für viele Anwohner ein weiterer Kritikpunkt. Tierfreundlichere oder technisch aufwändige Ställe sind aber ohne besondere Vermarktungswege i. d. R. aus landwirtschaftlicher Sicht nicht rentabel und können daher nicht ernsthaft angeboten werden.

Dieser Ansatz stößt allerdings nicht nur auf ökonomische Grenzen bei landwirtschaftlichen Stallbauten. Eine auf Transparenz und Offenheit ausgelegte Kommunikationsstrategie wird auch in der Organisationsforschung kritisch diskutiert. Hier finden sich für diese Strategie ebenso viele Ablehner, die auf eine komplementäre Strategie setzen: Mit der so genannten „Bombenwurfstrategie“ sollen die Betroffenen erst am Ende des Entscheidungsprozesses informiert werden und möglichst vor vollendete Tatsachen gestellt werden (Kirsch et al. 1979: 180).

Zusammenfassend zeigen die dargestellten Probleme bei Standortkonflikten, dass es sich um eine Kombination aus klassischen NIMBY-Problemen und generellen und langfristigen einstellungs- und personenbezogenen Merkmalen (Wohndauer und Wissen) handelt. Debatten um die Art der Tierhaltung überdecken die Diskussion und führen dazu, dass besonders auf lokaler Ebene für diese grundsätzlichen Fragen keine Lösungen gefunden werden können. Für den einzelnen Landwirt bedeutet dies, dass eine offene und proaktive Kommunikation mit den Dorfbewohnern nicht generell zum Erfolg führen muss.

Ein Blick auf die Situation in Veredelungszentren verdeutlicht die regionalen Unterschiede im Umgang mit Stallbauten. In viehstarken Gebieten findet sich eine sehr viel professionellere Herangehensweise von Seiten der Genehmigungsbehörden und Investoren. Dass besonders in viehschwachen Gebieten die dargestellten Schwierigkeiten auf treten führt zu der Frage, ob Entscheidungen auf lokaler Ebene für oder gegen einen Stallbau die geeignete Ebene ist, um eine Verteilung der Tierproduktion in der Fläche zu gewährleisten, oder ob nicht mit Hilfe politischer Lösungen und rechtlich eindeutigeren Regelungen Tierhaltung besser im Raum zu platzieren sind. 


\section{Literatur:}

Abramson, P., Inglehart, R. (1995): Value Change in a Global Perspective. Ann Arbor, University of Michigan Press.

Badura, J. (1999): Moral für Mensch und Tier. Tierschutzethik im Kontext, München.

Backhaus, K. et al. (2003): Multivariate Analyseverfahren: Eine anwenderorientierte Einführung, 10. Auflage, Berlin.

Becker, H. (1997): Dörfer heute - Ländliche Lebensverhältnisse im Wandel, 1952, 1972, 1993/1995, Bonn.

Becker, H. (1996): Ländliche Lebensverhältnisse im Wandel 1952, 1972, 1993/1994 Verhandlungen der Öffentlichen Arbeitstagung am 16. November 1995, Bonn.

BFL (2003) (Hrsg.): Hilfestellung bei Genehmigungsverfahren für Tierhaltungen, MünsterHiltrup.

BMVEL (1950-2000): Agrarbericht der Bundesregierung, Bonn.

BMVEL (2005): Zukunft der Nutztierhaltung: Gutachten des Wissenschaftlichen Beirats Agrarpolitik, nachhaltige Landbewirtschaftung und Entwicklung ländlicher Räume beim BMVEL, Berlin.

BUND (Hrsg.) (2004): Gegen die Errichtung von Massentierhaltungsanlagen, Köln.

Busch, R. J.; Kunzmann, P. (2004): Leben mit und von Tieren: Ethisches Bewertungsmodell zur Tierhaltung in der Landwirtschaft, München.

DBV (Hrsg.) (2005): Situationsbericht 2004: Trends und Fakten zur Landwirtschaft, Bonn.

Dorsch, K. (2004): Flugblatt-Hetze gegen Schweinemäster, in: top agrar, 32. Jg., Heft 6, S. 14-15.

Dirscherl, C. (2001): Die Landwirtschaft im Spannungsfeld gesellschaftsethischer Erwartungen, unter: www.hohebuch.de/Presse/Pressearchiv/landberichte.htm, Abrufdatum 02.04.2005.

Dyllick, T. (1990): Management der Umweltbeziehungen: öffentliche Auseinandersetzungen als Herausforderung, Wiesbaden.

Fenneker, A., (2002): Tiergerechte Schweinehaltung unter ethischen, rechtlichen und ökonomischen Aspekten: untersucht anhand von Betrieben des ökologischen Landbaus und des Markenfleischprogramms Neuland, Aachen.

Feinerman, E. et al. (2004): On a political Solution to the NIMBY-Conflict, in: The American economic Review, Vol. 94, No. 1, pp. 369-381.

Frey, B., S., Jegen, R. (2001): Motivation Crowding Theory: A Survey of Empirical Evidence, in: Journal of Economic Surveys, Vol. 15 (5), pp. 589-611.

Glasl, F. (1996): Konfliktmanagement. Ein Handbuch für Führungskräfte und Berater, 4. unv. Aufl., Bern et al.

Grimm, E. (2003): Rechtliche Grundlagen zum Immissionsschutz und zur Umweltverträglichkeitsprüfung, in: Bauförderung Landwirtschaft e. V. (BFL) (Hrsg.): Hilfestellung bei Genehmigungsverfahren für Tierhaltungen, Münster-Hiltrup, S. 22-34.

Hart, A., Pommerehne, W. (1994): Zur Standortwahl von NIMBY-Gütern, Diskussionsbeiträge des Fachbereich Wirtschaftswissenschaft, Universität des Saarlandes, Nr. 9403, Saarbrücken. 
Henkel, G. (2005): Dorf und Gemeinde, in: Beetz, S. et al. (Hrsg.): Handwörterbuch zur ländlichen Gesellschaft in Deutschland, Wiesbaden, S. 41-54.

Hoerster, D. (2004): Haben Tiere eine Würde? München.

Horah, J. et al. (1993): NIMBYs and LULUs, Knoxville.

Jarass, H. D. (2002): Bundes-Immissionsschutzgesetz: (BImSchG); Kommentar, 5. Auflage, München.

Johaentges, A. (1996): Das Dorf als Wohnstandort - Eine Analyse von Wanderungsbewegungen in ländliche Räume, Bonn.

Jürgens, K. (2005): Mensch-Nutztier-Beziehung, in: Beetz, S. et al. (Hrsg.): Handwörterbuch zur ländlichen Gesellschaft in Deutschland, Wiesbaden, S. 160-167.

Kirsch, W. et al. (1979): Das Management des geplanten Wandels von Organisationen, Stuttgart.

Leven, C. (1999): Tierrechte aus menschenrechtlicher Sicht: der moralische Status der Tiere in Vergangenheit und Gegenwart unter besonderer Berücksichtigung des PräferenzUtilitarismus von Peter Singer, Hamburg 1999.

LWK Northeim (2004): unveröffentlichtes Schreiben an den Landkreis Göttingen (liegt der Autorin vor).

Mann, S., Kögl, H. (2003): On the acceptance of animal production in rural communities, in: Land Use Policy, Vol. 20, S. 243-252.

Neumann, H. (2001): Eine Region mit dem Rücken an der Wand, in: top agrar, 29. Jg., Heft 8, S. 40-43.

Nüssle, P. (2004): Novelle zum Baugesetzbuch - Gesetzgeber folgt der Argumentation des Deutschen Bauernverbandes, in: dbk, H. 7, S. 23-24.

o. V. (2005): Früher acht, heute 80 Kühe, in: Landwirtschaftliches Wochenblatt WestfalenLippe, 35. Jg., Heft 1, S. 15-17.

o. V. (2004): Rufmordkampagne gegen Schweinemäster, in: dlz, 10. Jg, Heft 6, S. 97-98.

Peters, H.-J. (2002): Gesetz über die Umweltverträglichkeitsprüfung: Handkommentar, 2. Auflage, Baden-Baden.

Peters, H. P. (1995): Massenmedien und Risikogesellschaft, in: Joussen, W., Hessler, A. G. (Hrsg.): Umwelt und Gesellschaft: eine Einführung in die sozialwissenschaftliche Umweltforschung, Berlin, S. 229-255.

Peter, H. P. (1993): Durch Risikokommunikation zur Technikakzeptanz? Die Konstruktion von Risiko,,wirklichkeiten“ durch Experten, Gegenexperten und Öffentlichkeit, in: Krüger, J., Russ-Mohl, S. (Hrsg.): Technikakzeptanz, Medien und Kommunikationsrisiken, Berlin, S. 11-66.

Pitschmann, T. (2005): Prüfen Sie das Umfeld, in: DLG-Mitteilungen, 30. Jg., Heft 10, S. 1315.

Retter, C., Stahr, K., Boland, H., (2002): Zur Rolle von Landwirten in dörflichen Kommunikationsnetzwerken, in: Berichte über Landwirtschaft, 80. Jg., S. 446-467.

Röglin, H. Ch., (1994): Technikängste und wie man damit umgeht, Düsseldorf.

Röglin, H. Ch., Grebmer, K. v. (1988): Pharma-Industrie und Öffentlichkeit: Ansätze zu einem neuen Kommunikationskonzept, Basel. 
Schneider, M. (2001); Über die Würde des Tieres. Zur Ethik der Mensch-Tier-Beziehung, in: Schneider, M. (Hrsg.): Den Tieren gerecht werden. Zur Ethik und Kultur der MenschTier-Beziehung, Kassel 2001, S. 228-238.

Schubert, U. (2004): Streit um Schweinestall geht in nächste Runde, in: Göttinger Tageblatt, 11.06.2004, S. 12.

Schubert, U. (2003): Petitionsausschuss greift ein, in: Göttinger Tageblatt, 04.11.2003.

Schubert, K., Klein, M. (2001): Das Politiklexikon, Bonn.

Singer, P. (1997): Alle Tiere sind gleich, in: Krebs, A. (Hrsg.): Naturethik, Frankfurt a. M., S. 13-32.

Stadtplannet (2005): Gemeinde Gleichen, unter: www.stadtplan.net/index.asp?direct=SRL1000690156381002004638100001914746133; Abrufdatum 03.05.2005.

Stahr, K., (2000): Dörfliche Kommunikationsnetzwerke, Giessen.

Statistisches Bundesamt (2004): Statistisches Jahrbuch der Bundesrepublik Deutschland, Wiesbaden.

Struff, R. (1999): Regionale Lebensverhältnisse, Teil 2: Sozialwissenschaftliche Dorf- und Gemeindestudien in Deutschland, Bonn.

Ulrich, P. (1978): Management, eine konzentrierte Einführung, 2. Aufl., Stuttgart.

Werner-Lellau, G. (2003): Offener Brief vom 10.04.2003 an die Bürger in Diemarden, Landrat, Bürgermeister i. Reinhausen, Ortsbürgermeister in Diemarden, Parteien in Gleichen, Hurkut Gleichen ev., Fam. Pawlowski, Göttinger Tageblatt und BUND (liegt der Autorin vor). 


\section{Anhang}

\section{Interviews:}

Bürgermeister am 14.12.2003.

Landwirte am 9.12.2003; Telefoninterview am 29.01. 2006.

Vorsitzender des Vereins „Natürlich Diemarden“, 02.12.2003. 


\section{Fragebogen mit Häufigkeitsauswertung}

Universität Göttingen

Meinungsforschung zum Stallbau in Diemarden

Guten Tag!

Wir sind Studenten der Universität Göttingen. Im Rahmen einer Vorlesung führen wir eine Umfrage zum Thema „Stallbau in Diemarden“ durch. Ziel der Umfrage ist es, ein neutrales Meinungsbild über den Stallbau zu erhalten. Die Ergebnisse dieser Umfrage haben keinerlei Einfluss auf den Stallbau, sondern dienen rein wissenschaftlichen Zwecken. Wir würden uns sehr freuen, wenn Sie sich zu einer Teilnahme bereit erklären würden. Alle erhobenen Daten werden anonym und ohne Rückschlussmöglichkeit auf Ihre Person bearbeitet.

Die Beantwortung dieses Fragebogens dauert ungefähr 15 Minuten.

\begin{tabular}{|l|l|}
\hline Interviewer & \\
\hline Datum & \\
\hline Uhrzeit bei Beginn & \\
\hline
\end{tabular}

1. Wie Sie sicherlich wissen, planen zwei Landwirte am Ortsrand von Diemarden einen Schweinestall zu bauen. Was meinen Sie zu diesem Vorhaben? Bitte benutzen Sie dafür folgende Skala. (Interviewer bitte die Skala zeigen). Stimmen Sie dem Stallbau zu oder lehnen Sie ihn ab?(Angaben in \%)

\begin{tabular}{|c|c|c|c|c|c|c|}
\hline $\begin{array}{c}\text { Stimme } \\
\text { voll und } \\
\text { ganz zu }\end{array}$ & Stimme zu & $\begin{array}{c}\text { Stimme } \\
\text { eher zu }\end{array}$ & Teils, teils & $\begin{array}{c}\text { Lehne eher } \\
\text { ab }\end{array}$ & Lehne ab & $\begin{array}{c}\text { Lehne voll } \\
\text { und ganz } \\
\text { ab }\end{array}$ \\
\hline 15,6 & 18,1 & 5,0 & 14,4 & 8,8 & 10,6 & 27,5 \\
\hline
\end{tabular}

2. Können Sie kurz sagen, warum Sie dafür oder dagegen sind?

\begin{tabular}{|l|c|c|}
\hline & Absolute Nennungen & Nennungen in \% \\
\hline Geruch & 51 & 32,7 \\
\hline Gesundheit & 2 & 1,2 \\
\hline Verkehr & 9 & 5,6 \\
\hline Erholung & 9 & 5,6 \\
\hline Tierhaltung & 29 & 19,1 \\
\hline Wohnwert & 4 & 3,1 \\
\hline Nähe/ Standort & 16 & 11,1 \\
\hline Arbeitsplätze & 10 & 6,8 \\
\hline Einfach dafür & 15 & 9,3 \\
\hline Naturschutz & 10 & 6,2 \\
\hline Verständnis für LWS & 36 & 22,8 \\
\hline Gehört zum Dorf & 12 & 7,4 \\
\hline
\end{tabular}




\section{3. Über den Stallbau in Diemarden kann man unterschiedlicher Meinung sein. Wir haben dazu einige Äußerungen aufgeführt und möchten Sie bitten, diese Äußerungen anhand dieser 7-stufigen Skala zu bewerten (in \%).}

\begin{tabular}{|c|c|c|c|c|c|c|c|}
\hline & \begin{tabular}{|c|} 
Stimme \\
voll \\
und \\
ganz zu \\
\end{tabular} & $\begin{array}{l}\text { Stimme } \\
\mathrm{zu}\end{array}$ & $\begin{array}{l}\text { Stimme } \\
\text { eher zu }\end{array}$ & $\begin{array}{l}\text { Teils, } \\
\text { teils }\end{array}$ & $\begin{array}{l}\text { Lehne } \\
\text { eher } \\
\text { ab }\end{array}$ & $\begin{array}{l}\text { Lehne } \\
\text { ab }\end{array}$ & $\begin{array}{l}\text { Lehne voll } \\
\text { und ganz } \\
\text { ab }\end{array}$ \\
\hline $\begin{array}{l}\text { Durch den Stall wird die } \\
\text { gesundheitliche Be- } \\
\text { lastung stark steigen. }\end{array}$ & 7,5 & 10,3 & 7,5 & 8,2 & 15,8 & 26,7 & 24,0 \\
\hline $\begin{array}{l}\text { Würde der Stall in } \\
\text { Diemarden an anderer } \\
\text { Stelle stehen, wäre mir das } \\
\text { Ganze egal. }\end{array}$ & 9,0 & 9,7 & 6,9 & 15,3 & 6,9 & 20,1 & 31,9 \\
\hline $\begin{array}{l}\text { Der Güllegeruch beim } \\
\text { Ausbringen wird } \\
\text { unerträglich sein. }\end{array}$ & 21,1 & 20,4 & 9,2 & 16,4 & 5,9 & 18,4 & 8,6 \\
\hline $\begin{array}{l}\text { Ich glaube nicht, dass ein } \\
\text { Stall die Grundstücks- } \\
\text { preise in Diemarden } \\
\text { verändert. }\end{array}$ & 16,0 & 19,3 & 7,3 & 13,3 & 8,7 & 19,3 & 16,0 \\
\hline $\begin{array}{l}\text { Wenn ein Stall ordentlich } \\
\text { begrünt ist, stört er optisch } \\
\text { nicht weiter. }\end{array}$ & 22,5 & 26,5 & 9,3 & 9,9 & 6,0 & 10,6 & 15,2 \\
\hline $\begin{array}{l}\text { Ich rechne nicht mit einer } \\
\text { persönlichen Belastung } \\
\text { durch den Stall. }\end{array}$ & 21,6 & 24,8 & 5,2 & 5,9 & 3,9 & 18,3 & 20,3 \\
\hline $\begin{array}{l}\text { Die Freizeitmöglichkeiten } \\
\text { in Diemarden werden } \\
\text { durch den Stall nicht } \\
\text { beeinträchtigt. }\end{array}$ & 22,9 & 27,5 & 3,9 & 6,5 & 9,2 & 17,6 & 12,4 \\
\hline $\begin{array}{l}\text { Wenn der Stall erst mal } \\
\text { steht, wird der Verkehr } \\
\text { stark zunehmen. }\end{array}$ & 15,1 & 10,5 & 11,2 & 14,5 & 9,2 & 21,7 & 17,8 \\
\hline $\begin{array}{l}\text { Die Belastung durch den } \\
\text { Schweinestall wird man } \\
\text { kaum bemerken. }\end{array}$ & 7,9 & 17,8 & 7,2 & 13,8 & 11,2 & 18,4 & 23,7 \\
\hline $\begin{array}{l}\text { Durch den Schweinestall } \\
\text { würde ganz Diemarden } \\
\text { stinken. }\end{array}$ & 17,7 & 14,3 & 7,5 & 10,2 & 8,2 & 16,3 & 25,9 \\
\hline $\begin{array}{l}\text { Eigentlich habe ich nichts } \\
\text { gegen solch einen Stall, } \\
\text { nur sollte er nicht direkt } \\
\text { vor unserer Haustür gebaut } \\
\text { werden. }\end{array}$ & 11,6 & 23,3 & 6,8 & 9,6 & 3,4 & 19,2 & 26,0 \\
\hline $\begin{array}{l}\text { Wenn man alle Vor- und } \\
\text { Nachteile des Schweine- } \\
\text { stalls vergleicht, über- } \\
\text { wiegen die Vorteile. }\end{array}$ & 9,9 & 13,8 & 5,9 & 13,2 & 9,9 & 21,7 & 25,7 \\
\hline $\begin{array}{l}\text { Wenn ich an den Stallbau } \\
\text { denke, ärgere ich mich } \\
\text { sehr. }\end{array}$ & 15,1 & 12,5 & 3,3 & 13,2 & 5,9 & 19,7 & 30,3 \\
\hline
\end{tabular}


4. Es gibt unterschiedliche Bedenken oder Ängste im Zusammenhang mit dem Bau des geplanten Schweinestalls. Welche Bedenken sind für Sie die wichtigsten? Bilden Sie bitte eine Rangfolge Ihrer drei wichtigsten Bedenken. (Bitte den wichtigsten Einwand mit einer 1, den zweitwichtigsten mit einer 2 usf. kennzeichnen.)

\begin{tabular}{|c|c|c|c|c|c|l|}
\hline \multicolumn{2}{|c|}{ Rang 1 } & \multicolumn{2}{c|}{ Rang 2 } & \multicolumn{2}{c|}{ Rang 3 } & Argument \\
\hline Häufigkeit & in \% & Häufigkeit & in \% & Häufigkeit & in \% & \\
\hline 10 & 9,4 & 7 & 6,8 & 8 & 8,2 & $\begin{array}{l}\text { Erhöhung des } \\
\text { Verkehrsaufkommens }\end{array}$ \\
\hline 30 & 28,3 & 18 & 17,5 & 12 & 12,2 & Keine artgerechte Tierhaltung \\
\hline 5 & 4,7 & 11 & 10,7 & 15 & 15,3 & $\begin{array}{l}\text { Wertverlust von Häusern und } \\
\text { Grundstücken }\end{array}$ \\
\hline 48 & 45,3 & 24 & 23,3 & 14 & 14,3 & Starke Geruchsbelästigung \\
\hline 3 & 2,8 & 11 & 10,7 & 10 & 10,2 & $\begin{array}{l}\text { Baldige Erweiterung der } \\
\text { Stallanlagen }\end{array}$ \\
\hline 4 & 3,8 & 21 & 20,4 & 22 & 22,4 & $\begin{array}{l}\text { Erhöhung der } \\
\text { Gmweltbelastung durch } \\
\text { Gülleausbringung }\end{array}$ \\
\hline 4 & 3,8 & 9 & 8,7 & 14 & 14,3 & $\begin{array}{l}\text { Minderung des Freizeit- und } \\
\text { Erholungswertes }\end{array}$ \\
\hline 2 & 1,9 & 2 & 1,9 & 1 & 1,0 & Sonstige \\
\hline \multicolumn{7}{|c|}{47 Nennungen; $30,9 \%$} \\
\hline
\end{tabular}

\begin{tabular}{|l|c|c|}
\hline Argument & Absolute Nennungen & Nennungen in \% \\
\hline Erhöhung des Verkehrsaufkommens & 25 & 16,4 \\
\hline Keine artgerechte Tierhaltung & 60 & 39,5 \\
\hline Wertverlust von Häusern und Grundstücken & 32 & 21,1 \\
\hline Starke Geruchsbelästigung & 85 & 55,9 \\
\hline Baldige Erweiterung der Stallanlagen & 24 & 15,8 \\
\hline $\begin{array}{l}\text { Erhöhung der Umweltbelastung durch } \\
\text { Gülleausbringung }\end{array}$ & 48 & 31,6 \\
\hline Minderung des Freizeit- und Erholungswertes & 48 & 31,6 \\
\hline Sonstige & 5 & 3,6 \\
\hline
\end{tabular}


5. Die folgenden Aussagen beziehen sich auf die Landwirtschaft im Allgemeinen, aber auch in Diemarden. Auch hierzu gibt es eine Vielzahl von Meinungen. Bitte bewerten Sie die folgenden Aussagen anhand der bereits verwendeten Skala (in \%).

\begin{tabular}{|c|c|c|c|c|c|c|c|}
\hline & $\begin{array}{l}\text { Stimme } \\
\text { voll und } \\
\text { ganz zu }\end{array}$ & $\begin{array}{c}\text { Stimme } \\
\mathrm{zu}\end{array}$ & $\begin{array}{l}\text { Stimme } \\
\text { eher zu }\end{array}$ & $\begin{array}{l}\text { Teils, } \\
\text { teils }\end{array}$ & $\begin{array}{c}\text { Lehne } \\
\text { eher } \\
\text { ab }\end{array}$ & $\begin{array}{c}\text { Lehne } \\
\text { ab }\end{array}$ & $\begin{array}{c}\text { Lehne voll } \\
\text { und ganz } \\
\text { ab }\end{array}$ \\
\hline $\begin{array}{l}\text { Die Bedeutung der } \\
\text { Landwirtschaft in der } \\
\text { Gesellschaft wird } \\
\text { überbewertet. }\end{array}$ & 2,7 & 7,5 & 4,8 & 19,0 & 15,0 & 29,9 & 21,1 \\
\hline $\begin{array}{l}\text { Der Stall ist für die } \\
\text { Landwirte die einzige } \\
\text { Möglichkeit, ihren } \\
\text { Arbeitsplatz zu erhalten. }\end{array}$ & 17,2 & 15,9 & 9,0 & 17,9 & 7,6 & 15,2 & 17,2 \\
\hline $\begin{array}{l}\text { Wenn man aufs Dorf } \\
\text { zieht, muss man die } \\
\text { Landwirtschaft } \\
\text { akzeptieren. } \\
\end{array}$ & 47,7 & 29,4 & 9,2 & 7,2 & 1,3 & 2,0 & 3,3 \\
\hline $\begin{array}{l}\text { Ich kenne mich in land- } \\
\text { wirtschaftlichen Themen } \\
\text { aus. }\end{array}$ & 25,7 & 19,7 & 14,5 & 23,7 & 5,9 & 5,3 & 5,3 \\
\hline $\begin{array}{l}\text { Die Subventionen für die } \\
\text { Landwirtschaft sind } \\
\text { generell zu hoch. }\end{array}$ & 7,4 & 10,7 & 13,2 & 33,9 & 10,7 & 18,2 & 5,8 \\
\hline $\begin{array}{l}\text { Ohne die Bauern wäre } \\
\text { Diemarden nur halb so } \\
\text { lebenswert. }\end{array}$ & 15,9 & 27,8 & 15,9 & 16,6 & 4,0 & 13,9 & 6,0 \\
\hline $\begin{array}{l}\text { Ohne Landwirtschaft } \\
\text { hätten wir in } \\
\text { Deutschland noch viel } \\
\text { mehr Arbeitslose. }\end{array}$ & 17,6 & 27,7 & 14,9 & 12,2 & 10,1 & 12,2 & 5,4 \\
\hline $\begin{array}{l}\text { Landwirte müssen im } \\
\text { Allgemeinen mehr } \\
\text { Rücksicht auf andere } \\
\text { Bürger nehmen. } \\
\end{array}$ & 4,0 & 10,1 & 10,7 & 26,8 & 13,4 & 27,5 & 7,4 \\
\hline $\begin{array}{l}\text { Die Landwirte in } \\
\text { Diemarden haben sich } \\
\text { ungeschickt verhalten. }\end{array}$ & 8,1 & 18,4 & 9,6 & 17,6 & 10,3 & 23,5 & 12,5 \\
\hline $\begin{array}{l}\text { Eigentlich sollten alle } \\
\text { Landwirte ökologisch } \\
\text { wirtschaften. }\end{array}$ & 19,1 & 23,0 & 13,8 & 15,1 & 5,9 & 14,5 & 8,6 \\
\hline $\begin{array}{l}\text { Von Landwirtschaft } \\
\text { habe ich eigentlich keine } \\
\text { Ahnung. }\end{array}$ & 6,0 & 6,0 & 3,3 & 22,0 & 13,3 & 24,7 & 24,7 \\
\hline
\end{tabular}




\section{Bitte vervollständigen Sie folgende Sätze, indem Sie Ihre Meinung an der zutreffenden Stelle ankreuzen (in \%):}

Landwirtschaft ist......

\begin{tabular}{|c|c|c|c|c|c|c|c|c|}
\hline & $\begin{array}{c}\text { trifft } \\
\text { voll } \\
\text { und } \\
\text { ganz } \\
\text { zu }\end{array}$ & $\begin{array}{c}\text { trifft } \\
\text { zu }\end{array}$ & $\begin{array}{c}\text { trifft } \\
\text { eher } \\
\text { zu }\end{array}$ & $\begin{array}{l}\text { teils, } \\
\text { teils }\end{array}$ & $\begin{array}{c}\text { trifft } \\
\text { eher } \\
\text { zu }\end{array}$ & $\begin{array}{c}\text { trifft } \\
\mathrm{zu}\end{array}$ & $\begin{array}{c}\text { trifft } \\
\text { voll } \\
\text { und } \\
\text { ganz } \\
\text { zu }\end{array}$ & \\
\hline & 3 & 2 & 1 & $\mathbf{0}$ & 1 & 2 & 3 & \\
\hline wichtig & 62,5 & 27,0 & 5,9 & 3,9 & 0 & 0 & 0,7 & unwichtig \\
\hline altmodisch & 0 & 1,3 & 5,3 & 26,7 & 22,7 & 26,7 & 17,3 & innovativ \\
\hline glaubwürdig & 20,8 & 21,5 & 8,3 & 33,3 & 8,3 & 5,6 & 2,1 & unglaubwürdig \\
\hline $\begin{array}{l}\text { skandal- } \\
\text { verursachend }\end{array}$ & 2,7 & 10,1 & 4,7 & 44,3 & 12,8 & 11,4 & 14,1 & $\begin{array}{l}\text { skandal- } \\
\text { unschuldig }\end{array}$ \\
\hline familiär & 17,0 & 24,8 & 12,4 & 25,5 & 8,5 & 7,8 & 3,9 & industriell \\
\hline modern & 8,2 & 21,1 & 15,6 & 36,7 & 6,8 & 7,5 & 4,1 & traditionell \\
\hline
\end{tabular}

Landwirte sind ......

\begin{tabular}{|c|c|c|c|c|c|c|c|c|}
\hline & $\begin{array}{c}\text { trifft } \\
\text { voll } \\
\text { und } \\
\text { ganz } \\
\text { zu } \\
\end{array}$ & $\begin{array}{c}\text { trifft } \\
\mathrm{zu}\end{array}$ & $\begin{array}{c}\text { trifft } \\
\text { eher } \\
\text { zu }\end{array}$ & $\begin{array}{l}\text { teils, } \\
\text { teils }\end{array}$ & $\begin{array}{c}\text { trifft } \\
\text { eher } \\
\text { zu }\end{array}$ & $\begin{array}{c}\text { trifft } \\
\mathbf{z u}\end{array}$ & $\begin{array}{c}\text { trifft } \\
\text { voll } \\
\text { und } \\
\text { ganz } \\
\mathrm{zu} \\
\end{array}$ & \\
\hline & 3 & 2 & 1 & $\mathbf{0}$ & 1 & 2 & 3 & \\
\hline fleißig & 44,4 & 36,4 & 4,6 & 13,9 & 0,0 & 0,0 & 0,7 & faul \\
\hline arm & 3,4 & 2,0 & 6,7 & 68,5 & 13,4 & 3,4 & 2,7 & reich \\
\hline freundlich & 22,4 & 26,3 & 11,2 & 34,2 & 2,0 & 2,6 & 1,3 & unfreundlich \\
\hline dumm & 0 & 0 & 1,4 & 32,9 & 20,3 & 29,4 & 16,1 & clever \\
\hline $\begin{array}{l}\text { Landschafts- } \\
\text { pfleger }\end{array}$ & 18,5 & 15,9 & 16,6 & 32,5 & 9,3 & 4,0 & 3,3 & $\begin{array}{l}\text { Landschafts- } \\
\text { zerstörer }\end{array}$ \\
\hline kommunikativ & 10,2 & 17,0 & 15,6 & 34,7 & 12,2 & 9,5 & 0,7 & verschlossen \\
\hline gierig & 2,1 & 2,7 & 6,2 & 59,6 & 10,3 & 14,4 & 4,8 & bescheiden \\
\hline sympathisch & 12,8 & 20,9 & 14,9 & 43,9 & 1,4 & 3,4 & 2,7 & unsympathisch \\
\hline
\end{tabular}


7. Der Stallbau hat in Diemarden einige Wellen geschlagen und wahrscheinlich haben Sie sich mit anderen Bürgern darüber ausgetauscht. Wie würden Sie die folgenden Aussagen bewerten (in \%)?

\begin{tabular}{|l|c|c|c|c|c|c|c|}
\hline & $\begin{array}{c}\text { Stimme } \\
\text { voll } \\
\text { und } \\
\text { ganz zu }\end{array}$ & $\begin{array}{c}\text { Stimme } \\
\text { zu }\end{array}$ & $\begin{array}{c}\text { Stimme } \\
\text { eher zu }\end{array}$ & $\begin{array}{c}\text { Teils, } \\
\text { teils }\end{array}$ & $\begin{array}{c}\text { Lehne } \\
\text { eher } \\
\text { ab }\end{array}$ & $\begin{array}{c}\text { Lehne } \\
\text { ab }\end{array}$ & $\begin{array}{c}\text { Lehne voll } \\
\text { und ganz } \\
\text { ab }\end{array}$ \\
\hline $\begin{array}{l}\text { Hätten die Landwirte uns } \\
\text { Bürger von Anfang an } \\
\text { informiert, wäre die Ak- } \\
\text { zeptanz größer. }\end{array}$ & 7,3 & 20,5 & 11,9 & 8,6 & 9,3 & 25,2 & 17,2 \\
\hline $\begin{array}{l}\text { Ich fühle mich von den } \\
\text { Landwirten unfair be- } \\
\text { handelt. }\end{array}$ & 6,7 & 12,1 & 7,4 & 10,1 & 11,4 & 25,5 & 26,8 \\
\hline $\begin{array}{l}\text { Ich habe meine } \\
\text { Einstellung zu diesem } \\
\begin{array}{l}\text { Thema bei vielen } \\
\text { Gelegenheiten zum } \\
\text { Ausdruck gebracht. }\end{array}\end{array}$ & 17,3 & 23,3 & 10,7 & 18,7 & 5,3 & 16,7 & 8,0 \\
\hline $\begin{array}{l}\text { Der Verein ,Natürlich } \\
\text { Diemarden“ hat dafür } \\
\text { gesorgt, dass wir endlich } \\
\text { informiert werden. }\end{array}$ & 18,7 & 19,3 & 9,3 & 12,7 & 3,3 & 18,7 & 18,0 \\
\hline $\begin{array}{l}\text { Die Diskussion um den } \\
\text { Stallbau interessiert mich } \\
\text { überhaupt nicht. }\end{array}$ & 2,6 & 2,6 & 3,2 & 13,0 & 11,7 & 27,3 & 39,6 \\
\hline $\begin{array}{l}\text { Ich informiere mich sehr } \\
\text { ausführlich über alles, } \\
\text { was mit dem Stallbau } \\
\text { zusammen hängt. }\end{array}$ & 16,9 & 23,4 & 14,9 & 22,1 & 6,5 & 10,4 & 5,8 \\
\hline $\begin{array}{l}\text { Ich stehe voll auf der } \\
\text { Seite der Landwirte. }\end{array}$ & 19,1 & 15,8 & 7,2 & 19,1 & 7,9 & 15,8 & 15,1 \\
\hline $\begin{array}{l}\text { Die Gründung eines } \\
\text { Vereins gegen den } \\
\text { Schweinestall finde ich } \\
\text { übertrieben. }\end{array}$ & 25,5 & 23,5 & 5,9 & 8,5 & 4,6 & 16,3 & 15,7 \\
\hline
\end{tabular}

8. Wenn Sie an die Argumente der Landwirte und des Vereins „Natürlich Diemarden“ denken, wen halten Sie für glaubwürdig? Verteilen Sie bitte 100 Punkte und geben Sie der glaubwürdigsten Partei die höchste Punktzahl (Mittelwerte).

\begin{tabular}{|l|l|}
\hline Landwirte & 51,82 \\
\hline Natürlich Diemarden & 52,64 \\
\hline Summe & \\
\hline
\end{tabular}


9. Im Göttinger Tageblatt wurde von Seiten der Ablehner z. B. die Tierhaltung bemängelt. Wir haben zu verschiedenen Themenbereichen Aussagen gesammelt, zu denen man wiederum unterschiedlicher Meinung sein kann. Bitte beurteilen Sie die Aussagen anhand dieser Skala (in \%):

\begin{tabular}{|l|c|c|c|c|c|c|c|}
\hline & $\begin{array}{c}\text { Stimme } \\
\text { voll und } \\
\text { ganz zu }\end{array}$ & $\begin{array}{c}\text { Stimme } \\
\text { zu }\end{array}$ & $\begin{array}{c}\text { Stimme } \\
\text { eher zu }\end{array}$ & $\begin{array}{c}\text { Teils, } \\
\text { teils }\end{array}$ & $\begin{array}{c}\text { Lehne } \\
\text { eher } \\
\text { ab }\end{array}$ & $\begin{array}{c}\text { Lehne } \\
\text { ab }\end{array}$ & $\begin{array}{c}\text { Lehne } \\
\text { voll und } \\
\text { ganz ab }\end{array}$ \\
\hline $\begin{array}{l}\text { Die Gülle belastet die } \\
\text { Umwelt in unserer Um- } \\
\text { gebung. }\end{array}$ & 23,3 & 21,3 & 9,3 & 15,3 & 12,0 & 12,7 & 6,0 \\
\hline $\begin{array}{l}\text { Von Massentierhaltung } \\
\text { kann bei 660 Schweinen } \\
\text { nicht geredet werden. }\end{array}$ & 11,2 & 15,8 & 2,6 & 11,8 & 9,2 & 25,0 & 24,3 \\
\hline $\begin{array}{l}\text { Die gesetzlichen An- } \\
\text { forderungen an die } \\
\text { Schweinehaltung sind } \\
\text { insgesamt zu niedrig. }\end{array}$ & 21,5 & 20,7 & 10,4 & 17,0 & 8,9 & 15,6 & 5,9 \\
\hline $\begin{array}{l}\text { Wenn die Tiere auf Stroh } \\
\text { stehen würden, hätte ich } \\
\text { gegen den Stall nichts } \\
\text { einzuwenden. }\end{array}$ & 13,6 & 14,3 & 10,9 & 17,0 & 8,2 & 23,1 & 12,9 \\
\hline
\end{tabular}

10. Wenn Sie jetzt mal weg von Diemarden gehen und die gesamte gesellschaftliche Entwicklung betrachten, wie bewerten Sie dann folgende Aussagen (in \%)?

\begin{tabular}{|l|c|c|c|c|c|c|c|}
\hline & $\begin{array}{c}\text { Stimme } \\
\text { voll } \\
\text { und } \\
\text { ganz zu }\end{array}$ & $\begin{array}{c}\text { Stimme } \\
\text { zu }\end{array}$ & $\begin{array}{c}\text { Stimme } \\
\text { eher zu }\end{array}$ & $\begin{array}{c}\text { Teils, } \\
\text { teils }\end{array}$ & $\begin{array}{c}\text { Lehne } \\
\text { eher } \\
\text { ab }\end{array}$ & $\begin{array}{c}\text { Lehne } \\
\text { ab }\end{array}$ & $\begin{array}{c}\text { Lehne voll } \\
\text { und ganz } \\
\text { ab }\end{array}$ \\
\hline $\begin{array}{l}\text { Für das Allgemeinwohl ist } \\
\text { niemand mehr bereit, auf } \\
\text { etwas zu verzichten. }\end{array}$ & 20,5 & 35,8 & 15,2 & 17,2 & 6,0 & 3,3 & 2,0 \\
\hline $\begin{array}{l}\text { Bei jedem größeren Bauvor- } \\
\text { haben muss man in } \\
\text { Deutschland inzwischen mit } \\
\text { einer Bürgerinitiative } \\
\text { rechnen. }\end{array}$ & 19,7 & 43,4 & 11,8 & 13,8 & 5,3 & 3,3 & 2,6 \\
\hline $\begin{array}{l}\text { Dass die Landwirte einfach } \\
\text { einen Stall bauen können, } \\
\text { finde ich nicht akzeptabel. }\end{array}$ & 16,6 & 18,6 & 6,2 & 15,9 & 9,7 & 22,1 & 11,0 \\
\hline $\begin{array}{l}\text { Als Bürger muss man sich } \\
\text { schon einiges gefallen } \\
\text { lassen. }\end{array}$ & 16,0 & 17,3 & 10,0 & 28,7 & 6,0 & 16,0 & 6,0 \\
\hline $\begin{array}{l}\text { Eigentlich müssten die } \\
\text { Bürger immer vor Beginn } \\
\text { eines größeren Bauvor- } \\
\text { habens informiert werden. }\end{array}$ & 22,0 & 32,0 & 12,0 & 14,7 & 3,3 & 8,7 & 7,3 \\
\hline
\end{tabular}


11. Sind Sie in Vereinen in Diemarden aktiv?

$\square \quad$ Nein

$\square \quad$ Ja, ich bin Mitglied im

\begin{tabular}{|l|c|c|}
\hline Verein & Absolute Nennungen & Nennungen in \% \\
\hline Schützenverein & 15 & 9,7 \\
\hline Heimatverein & 15 & 9,7 \\
\hline Sportverein & 56 & 36,1 \\
\hline Schulförderverein & 17 & 11 \\
\hline „Natürlich Diemarden“ & 19 & 12,3 \\
\hline Chor & 13 & 8,4 \\
\hline Feuerwehr & 15 & 9,7 \\
\hline
\end{tabular}

12. Können Sie sich in eine der drei Bewohnergruppen in Diemarden einordnen?

\begin{tabular}{|l|c|c|}
\hline & Absolute Nennungen & Nennungen in \% \\
\hline Gebürtige/r DiemardenerIn & 41 & 25,6 \\
\hline Zugezogene/r DiemardenerIn & 102 & 63,8 \\
\hline Eingeheiratete/r DiemardenerIn & 16 & 10,0 \\
\hline
\end{tabular}

13. Seit wann wohnen Sie in Diemarden?

$\varnothing 1975$

14. Können Sie kurz sagen, warum Sie in Diemarden leben? (Mehrfachantworten möglich)

\begin{tabular}{|l|c|c|}
\hline & Absolute Nennungen & Nennungen in \% \\
\hline Ich bin hier geboren & 38 & 24,5 \\
\hline Meine Frau / mein Mann lebt hier & 36 & 23,2 \\
\hline Zufall bzw. es hat sich so ergeben & 41 & 26,5 \\
\hline Günstiges Bauland & 25 & 16,1 \\
\hline Ruhige Lage & 67 & 43,2 \\
\hline Nähe zum Arbeitsplatz & 63 & 40,9 \\
\hline Weil ich mich hier wohl fühle & 92 & 59,4 \\
\hline Vielzahl von Freizeitmöglichkeiten & 15 & 9,7 \\
\hline Schönheit der Landschaft & 75 & 48,4 \\
\hline Sonstiges & 15 & 9,7 \\
\hline
\end{tabular}


15. Stellen Sie sich vor, es gäbe eine Dorfabstimmung über den Stallbau in Diemarden, wie würden Sie entscheiden?

\begin{tabular}{|c|c|c|c|c|c|c|}
\hline $\begin{array}{c}\text { Ja, ich } \\
\text { stimme } \\
\text { auf jeden } \\
\text { Fall dafür }\end{array}$ & $\begin{array}{c}\text { Ja, ich } \\
\text { stimme } \\
\text { dafür. }\end{array}$ & $\begin{array}{c}\text { Ja, ich } \\
\text { würde } \\
\text { eher dafür } \\
\text { stimmen. }\end{array}$ & $\begin{array}{c}\text { Ich bin } \\
\text { unentschlossen } \\
\text { und würde } \\
\text { mich } \\
\text { enthalten. }\end{array}$ & $\begin{array}{c}\text { Nein, ich } \\
\text { würde } \\
\text { eher } \\
\text { dagegen } \\
\text { stimmen. }\end{array}$ & $\begin{array}{c}\text { Nein, ich } \\
\text { würde } \\
\text { dagegen } \\
\text { stimmen. }\end{array}$ & $\begin{array}{c}\text { Nein, ich } \\
\text { stimme } \\
\text { auf jeden } \\
\text { Fall } \\
\text { dagegen }\end{array}$ \\
\hline 20,1 & 16,2 & 7,8 & 7,1 & 10,4 & 10,4 & 27,9 \\
\hline
\end{tabular}

Zum Ende des Fragebogens würde ich gerne noch ein paar allgemeine Angaben zu Ihrer Person notieren.

16. In welchem Jahr sind Sie geboren?

$1919-1990 ; \varnothing=1952$

17. Was ist Ihr höchster Bildungsabschluss? (Nennungen in \%)

$\begin{array}{llll}\text { (noch) keinen Abschluss } & \mathbf{2 , 6} & \text { Fachhochschule } & \mathbf{1 1 , 9} \\ \text { Hauptschule/Volksschule } & \mathbf{2 7 , 2} & \text { Universität } & \mathbf{1 6 , 6} \\ \text { Realschule } & \mathbf{2 3 , 8} & \text { Promotion } & \mathbf{4 , 6} \\ \text { Gymnasium } & \mathbf{1 0 , 6} & \text { Sonstige } & \mathbf{2 , 6}\end{array}$

18. Zu welcher Berufsgruppe gehören Sie? (Nennungen in \%)

$\begin{array}{llll}\text { Schüler/in } & 3,2 & \text { Arbeiter/in } & 4,6 \\ \text { Student/in } & 1,3 & \text { zzt. ohne Beschäftigung } & 1,3 \\ \text { Angestellte/r } & 34,0 & \text { Rentner/Pensionär/in } & 22,2 \\ \text { Selbständige/r } & 11,1 & \text { Hausfrau/-mann } & 6,5 \\ \text { Beamtin/er } & 12,4 & \text { Bundeswehr/Zivildienst } & \\ \text { Auszubildender/r } & 2,6 & \text { Sonstiges } & 0,7\end{array}$


19. Wie ist Ihr Familienstand? (Nennungen in \%)

$\begin{array}{llll}\text { Ledig } & \mathbf{1 2 , 4} & \text { verwitwet } & \mathbf{6 , 5} \\ \text { Verheiratet } & \mathbf{7 3 , 9} & \text { Lebensgemeinschaft } & \mathbf{2 , 6} \\ \text { Geschieden } & \mathbf{3 , 9} & \text { Getrennt lebend } & \mathbf{0 , 7}\end{array}$

20. Wie viele Personen leben in Ihrem Haushalt (Sie eingeschlossen)? (Nennungen in \%)

\begin{tabular}{|c|c|c|c|}
\hline 1 & 11,1 & 4 & 19,0 \\
\hline 2 & 33,3 & 5 & 9,2 \\
\hline & 23,5 & 6 und mehr & 3,9 \\
\hline
\end{tabular}

21. Zählen Landwirte zu Ihrem engeren Familien- oder Freundeskreis? (Nennungen in \%)

$\begin{array}{lll}\text { Ja } & \mathbf{5 9 , 7} & \mathbf{4 0 , 3}\end{array}$

22. Sind Sie..... (Nennungen in \%)

$\begin{array}{llll}\text { Mieter } & \mathbf{1 5 , 0} & \text { Eigentümer } & \mathbf{8 1 , 0} \\ \text { Sonstiges } & \mathbf{3 , 9} & & \end{array}$

Vielen Dank für Ihre Teilnahme!

Bitte vom Interviewer ausfüllen

Geschlecht:

$55,5 \%$ männlich

44,5\% weiblich

Uhrzeit beim Interviewende 
TABelle 9: Kreuztabelle DER BeIDEN BeWertungSFRAGEN ZUM STALLBAU

\begin{tabular}{|c|c|c|c|c|c|c|c|c|c|}
\hline & & \multicolumn{7}{|c|}{$\begin{array}{c}\text { Stellen Sie sich vor, es gäbe eine Dorfabstimmung über den Stallbau in Diemarden, wie } \\
\text { würden Sie entscheiden? }\end{array}$} & \multirow[b]{2}{*}{ Gesamt } \\
\hline & & $\begin{array}{l}\text { Nein, ich } \\
\text { stimme } \\
\text { auf jeden } \\
\text { Fall } \\
\text { dagegen } \\
\end{array}$ & $\begin{array}{l}\text { Nein, ich } \\
\text { würde } \\
\text { dagegen } \\
\text { stimmen }\end{array}$ & $\begin{array}{l}\text { Nein, ich } \\
\text { würde } \\
\text { eher } \\
\text { dagegen } \\
\text { stimmen. }\end{array}$ & $\begin{array}{l}\text { Ich bin } \\
\text { unent- } \\
\text { schlossen } \\
\text { und würde } \\
\text { mich } \\
\text { enthalten }\end{array}$ & $\begin{array}{c}\text { Ja, ich } \\
\text { würde eher } \\
\text { dafür } \\
\text { stimmen } \\
\end{array}$ & $\begin{array}{c}\text { Ja, ich } \\
\text { stimme } \\
\text { dafür } \\
\end{array}$ & $\begin{array}{c}\text { Ja, ich } \\
\text { stimme } \\
\text { auf jeden } \\
\text { Fall } \\
\text { dafür } \\
\end{array}$ & \\
\hline \multirow[t]{7}{*}{$\begin{array}{l}\text { Gesamteinschätzung } \\
\text { Stallbau }\end{array}$} & \multirow{8}{*}{$\begin{array}{l}\text { Lehne voll und ganz } \\
\text { ab } \\
\text { Lehne ab } \\
\text { Lehne eher ab } \\
\text { Teils, teils } \\
\text { Stimme eher zu } \\
\text { Stimme zu } \\
\text { Stimme voll und } \\
\text { ganz zu }\end{array}$} & 36 & 3 & 2 & 0 & 0 & 0 & 0 & 41 \\
\hline & & 5 & 9 & 2 & 0 & 1 & 0 & 0 & 17 \\
\hline & & 1 & 3 & 5 & 2 & 3 & 0 & 0 & 14 \\
\hline & & 1 & 1 & 5 & 9 & 1 & 3 & 1 & 21 \\
\hline & & 0 & 0 & 2 & 0 & 2 & 2 & 1 & 7 \\
\hline & & 0 & 0 & 0 & 0 & 4 & 15 & 8 & 27 \\
\hline & & 0 & 0 & 0 & 0 & 1 & 5 & 19 & 25 \\
\hline Gesamt & & 43 & 16 & 16 & 11 & 12 & 25 & 29 & 152 \\
\hline
\end{tabular}




\section{KAPITEL III.3}

Stallbaukonflikte in Nicht-Veredlungsregionen: Empirische Analyse und Folgerungen für effiziente Governancestrukturen 


\section{Stallbaukonflikte in Nicht-Veredlungsregionen: Empirische Analyse und Folgerungen für effiziente Governancestrukturen* (mit Achim Spiller)}

$1 \quad$ Einleitung. 427

2 Erklärungsansätze für landwirtschaftliche Standortkonflikte 427

3 Fallbeispiel: Standortkonflikt in einer Nicht-Veredlungsregion ..............................430

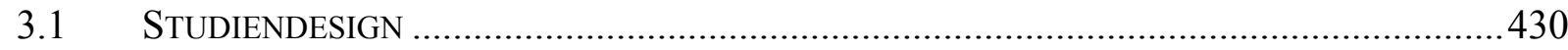

3.2 SOZIODEMOGRAFIE DER BEFÜRWORTER UND ABLEHNER ….....................................430

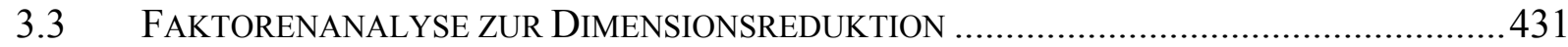

4 Steuerungsmechanismen zur räumlichen Verteilung von tierischer Produktion... 433

4.1 GOVERNANCE-TYPEN UND POTENZIELLE PROBLEMLÖSUNGEN .....................................433

4.2 STEUERUNGSANSÄTZE ZUR ENTSCHÄRFUNG VON STANDORTKONFLIKTEN.................436

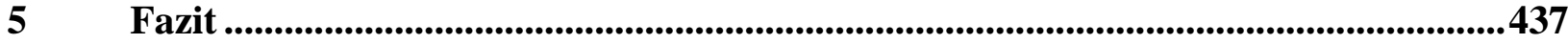

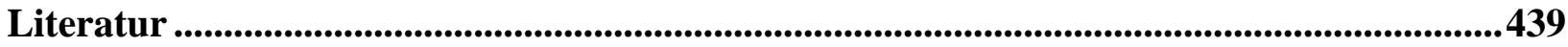

\section{Abbildungsverzeichnis}

Abbildung 1: Theoretische Einflussfaktoren auf Stallbaukonflikte

\section{Tabellenverzeichnis}

Tabelle 1: Charakterisierung der Befürworter und Ablehner. 431

Tabelle 2: Faktorladungen der einzelnen Statements

Tabelle 3: Lineares Regressionsmodell zur Bewertung des Stallbaus ..................................... 432

Tabelle 4: Governance-Typen im Überblick .......................................................................... 434

Tabelle 5: Argumente gegen Verhandlungslösungen auf lokaler Ebene ..................................437

\footnotetext{
* Angenommen für die 46. Gewisola Jahrestagung "Good Governance in der Agrar- und Ernährungswirtschaft".
} 


\section{Zusammenfassung}

Auf Basis einer größeren empirischen Untersuchung zu einem Stallbaukonflikt kann gezeigt werden, dass entgegen der öffentlichen Diskussion besonders die Einschätzung der persönlichen Beeinträchtigung durch einen Stallneubau zur Ablehnung führt. Tier- und Umweltschutzargrumente spielen zwar in der Auseinandersetzung eine prominente Rolle, sind aber wie eine Regressionsanalyse zeigt - wenig entscheidungsrelevant. Stallbaukonflikte und die Entzerrung der Tierproduktion können nur durch gesetzlich eindeutige Regelungen gelöst werden. Verhandlungen im Rahmen von Netzwerken tragen nicht zur Konfliktlösung bei, da es sich primär um einen Nimby-Konflikt handelt.

Keywords: Stallbaukonflikte, Governance, Nimby, Regressionsanalyse

\section{Einleitung}

Der wissenschaftliche Beirat für Agrarpolitik, nachhaltige Landwirtbewirtschaftung und Entwicklung ländlicher Räume des BMVEL weist in seinem Gutachten „Zukunft der Nutztierhaltung“ darauf hin, dass eine Entzerrung der regionalen Konzentration der Schweineproduktion aus Sicht des Umweltschutzes und aus tierseuchenhygienischen Gründen sinnvoll ist, aber besonders in viehschwachen Regionen eine Ansiedlung bzw. Ausweitung von Tierbeständen auf Probleme stößt (BMVEL 2005: 33). Die Akzeptanzprobleme von Stallbauten werden auch in landwirtschaftlichen Praxiszeitungen immer wieder thematisiert (Dorsch 2004: 14; Neumann 2001: 40). Dabei protestieren Anwohner bei Anlagen mit 480 Mastschweinen (Zahn 2003) ebenso wie bei 80.000 Tieren (Löhr 2005: 4). Im vorliegenden Beitrag sollen aufgrund theoretischer Vorüberlegungen Gründe für die unzureichende Akzeptanz von Stallbauten vorgestellt werden. Anhand eines empirischen Fallbeispiels werden Einflussfaktoren auf die Bewertung identifiziert. Mithilfe theoretischer Überlegungen zu unterschiedlichen Governanceformen sollen die Probleme bei der Durchsetzung von Stallbauten in viehschwachen Regionen vorgestellt und Lösungsvorschläge zur Steuerung von Standortkonflikten erarbeitet werden.

\section{Erklärungsansätze für landwirtschaftliche Standortkonflikte}

Die zunehmenden Akzeptanzprobleme für landwirtschaftliche Investitionsvorhaben sind auf eine Reihe von Faktoren zurückzuführen. Eine Ursache liegt in dem ökonomischen Bedeutungsverlust des landwirtschaftlichen Sektors. Während 1950 noch 1.647 .000 Betriebe in Deutschland wirtschafteten, sind es 50 Jahre später nur noch 421.000. Zudem ist der Anteil 
der Arbeitskräfte, die in der Landwirtschaft beschäftigt sind, im gleichen Zeitraum von 23,9 \% auf 2,4 \% gesunken (BMVEL, verschiedene Jahrgänge). Dieser Bedeutungsverlust spiegelt sich auf lokaler Ebene wider. Inzwischen gibt es Dörfer ohne praktizierende Landwirte, fast immer geraten sie in eine Minderheitenposition. Damit wird Landwirt zu einem ,einsamen Beruf“ (Struff 1999: 9). Mit dieser Entwicklung verlieren Landwirte Rückhalt in ihren Gemeinden. Nicht nur diese sektoralen Veränderungen, sondern auch soziale Umfeldentwicklungen bedingen Standortkonflikte. Dörfer entwickeln sich immer mehr zu attraktiven Wohnstandorten und erleben einen Zuzug von Ortsfremden. Durch das vergleichsweise günstige Bauland ist das Dorf für viele ein Ort, an dem der „Traum vom Eigenheim“ realisierbar ist. Aber auch der Wunsch, näher ,,an der Natur“ zu leben, konnte in empirischen Untersuchungen nachgewiesen werden. Dabei spielt das Motiv der „Ländlichkeit“ eine besondere Rolle, Landwirtschaft hingegen ist negativ besetzt (Johaentges 1996: 23).

Der Zuzug von Dorffremden wirkt sich auch auf die dörflichen Kommunikationsstrukturen aus. Eine Untersuchung über Kommunikationsnetzwerke und -inhalte zeigt zum einen, dass landwirtschaftliche Gegenstände zu Expertenthemen werden und aus der alltäglichen Dorfkommunikation verschwinden (Retter et al. 2002: 451). Zum anderen verändern sich die dörflichen Kommunikationsstrukturen grundlegend. Bei einem Zuzug von mehr als ca. 15 \% der ursprünglichen Dorfbevölkerung kann eine intensive Gruppenbildung angenommen werden, in der der Bezug zum Gesamtdorf verloren geht. Neu entstandene Gruppen koppeln sich von Altgruppen ab bzw. werden nicht integriert (Stahr 2000: 153).

Neben Veränderungen auf der lokalen Ebene sind es auch gesamtgesellschaftliche Fragestellungen, die einen Einfluss auf die Akzeptanz von Tierproduktion haben. Dazu zählt besonders die Mensch-Nutztier-Beziehung. Zu diesem Themenkomplex gibt es eine ausgedehnte Diskussion. Besonders der Stellenwert von Tieren, die Frage ihrer Würde, Haltungsbedingungen, die Zulässigkeit von Schlachtungen etc. wurden in den letzten Jahren sehr kontrovers diskutiert (siehe u. a. Hoerster 2004; Badura 1999; Singer 1997). Diese generellen Fragestellungen richten sich besonders an die Landwirtschaft. Speziell im Bereich der konventionellen Tierhaltung wird zum Umdenken aufgefordert (Schneider 2001: 228 ff). Diese zunächst allgemein geführte Diskussion entlädt sich auf lokaler Ebene bei geplanten Stallbauten. Vor allem von Seiten der Natur- und Tierschutzverbände wird die Kritik an der „Massentierhaltung“ als Argument gegen Stallbauten angeführt (BUND 2004: 11). Damit sind bei Standortkonflikten nicht allein der jeweilige Betrieb und die lokalen Auswirkungen (z. B. Geruchsbelästigung) 
wichtig, sondern die generelle Diskussion nach der Akzeptanz intensiver Tierproduktion wird auf lokaler Ebene in Form von Stellvertreterkonflikten geführt.

\section{ABBILDUNG 1: THEORETISCHE EINFLUSSFAKTOREN AUF STALLBAUKONFLIKTE}

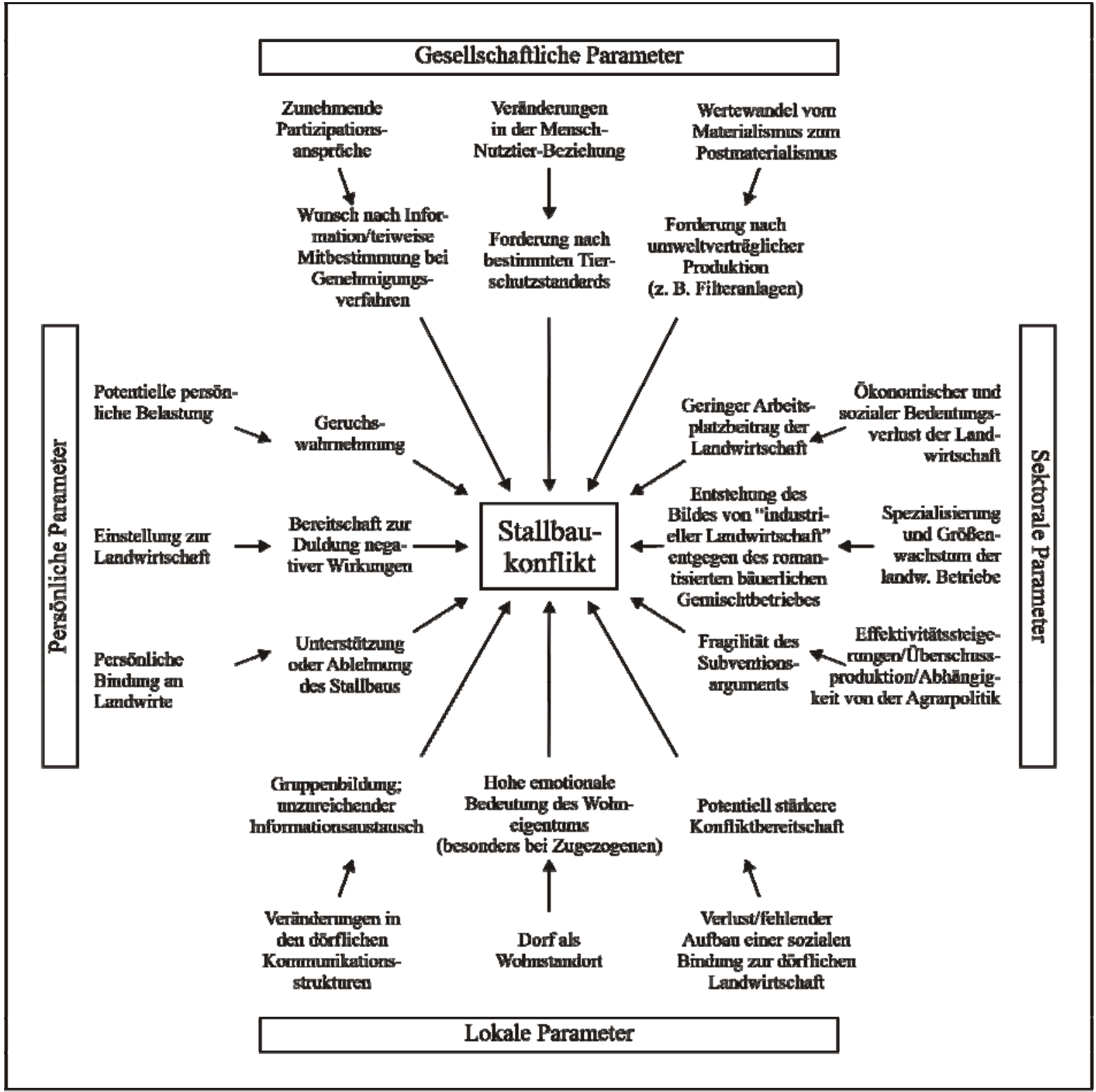

Quelle: Eigene Darstellung

Bei der Betrachtung von Standortkonflikten ist damit prima facie eine Vielzahl unterschiedlicher Argumente relevant, die in Abb. 1 noch einmal im Überblick aufgeführt sind. Neben der Geruchsproblematik von Stallbauten werden Tier- und Umweltschutzargumente angeführt, die generelle Rolle der Landwirtschaft und ihre Subventionierung in Frage gestellt und die Art des Genehmigungsverfahrens kritisiert (Zahn 2003; Löhr 2005: 3). Befürworter führen die Notwendigkeit der Nahrungsmittelproduktion sowie den Arbeitsplatzbeitrag von Landwirtschaft auf. Aber auch persönliche Animositäten spielen eine Rolle. Letztlich sind bei Stall- 
baukonflikten verschiedene Argumentationsebenen betroffen. Neben der lokalen Ebene werden generelle Fragestellungen diskutiert, deren Lösung nicht auf lokaler Ebene erreicht werden kann.

\section{Fallbeispiel: Standortkonflikt in einer Nicht-Veredlungsregion}

\subsection{Studiendesign}

Um die tatsächliche Relevanz der verschiedenen potenziellen Ablehnungsfaktoren von Stallbauten zu analysieren, wurde eine quantitative Befragung von Bewohnern des Dorfes Diemarden (Südniedersachsen, Nähe Göttingen), in dem sich ein Konflikt um einen geplanten Mastschweinestall für 660 Tiere zugetragen hat, durchgeführt. Die Region ist mit 100-249 Schweinen je 100 ha LF veredlungsschwach (Freisinger/Windhorst 2005: 30). Grundlage des Fragebogens waren qualitative Interviews mit Landwirten, dem Leiter der sich gegen dieses Vorhabens gegründeten Bürgerinitiative sowie dem Bürgermeister. Zudem wurden die dargestellten theoretischen Vorüberlegungen und eine Studie von Mann und Kögl zur Akzeptanz von Schweineställen in Ostdeutschland in das Befragungsmodell aufgenommen. Insgesamt konnten von etwa 1.400 Einwohnern 153 persönlich durch studentische Interviewer befragt werden, dies entspricht ca. $11 \%$ der Gesamtbevölkerung. Aufgrund dieses hohen Anteils und der Zusammensetzung der Stichprobe kann die Studie als hinreichend repräsentativ für dieses Dorf angesehen werden.

\subsection{Soziodemografie der Befürworter und Ablehner}

Die generelle Einstellung der Probanden zum Stallbau wurde anhand zweier Gesamtbewertungsfragen abgeprüft. Es zeigt sich als Ausdruck der heftigen Auseinandersetzung im Dorf (die u. a. zur Einschaltung des Landtagspeditionsausschusses geführt haben), eine sehr polarisiertes Meinungsbild. Insgesamt stimmten $39 \%$ für und $47 \%$ gegen den Stallbau. Auf Basis der polarisierten Verteilung wurden die Befürworter und Ablehner in zwei Gruppen eingeteilt. Die Probanden, die sich unentschlossen zum Stallbau zeigen, wurden nicht berücksichtigt.

Die im Dorf geborenen Probanden stimmen eher für den Stallbau (siehe Tabelle 1), während ihn die Zugezogenen mehrheitlich ablehnen. Auch die Wohndauer hat einen Einfluss: 78 \% aller Personen, die erst in den letzten zehn Jahren zugezogen sind, lehnen den Stall ab, dagegen nur $39 \%$ der Personen, die mehr als 25 Jahre dort leben. Dieser Zusammenhang findet sich auch in anderen Untersuchungen. Landwirtschaft wird von Zugezogenen als eher störend wahrgenommen (Johaentges 1996). Zudem leben einige der Zugezogenen in der vom Geruch 
am potenziell stärksten betroffenen Siedlung. In den qualitativen Interviews wurde berichtet, dass die gebürtigen Dorfbewohner in anderen Vereinen aktiv sind, als die Zugezogenen. Das bestätigte sich auch in der Anwohnerbefragung: Im Schützen- und Heimatverein, besonders aber bei der Feuerwehr stimmen die Mitglieder überwiegend für den Stallbau. Im Schulförderverein, der von den Zugezogenen gegründet wurde, sind dagegen mehrheitlich Ablehner vertreten. Auch hier zeigt sich, dass zugezogene und gebürtige Bewohner selten im Kontakt zueinander stehen. Die Kommunikationsnetzwerke umfassen nicht das ganze Dorf, wie auch andere Untersuchungen zeigen (Stahr 2002).

TABELLE 1: CHARAKTERISIERUNG DER BEFÜRWORTER UND ABLEHNER

\begin{tabular}{|c|c|c|c|c|}
\hline & & Befürworte (in \%) & Ablehner (in \%) & Signifikanz \\
\hline \multirow{3}{*}{ Wohndauer in Jahren } & mehr als 25 & $61(\mathrm{~N}=42)$ & $39(\mathrm{~N}=27)$ & \multirow{3}{*}{.000} \\
\hline & $11-25$ & $33(N=9)$ & $67(\mathrm{~N}=18)$ & \\
\hline & 10 und weniger & $22(\mathrm{~N}=7)$ & $78(\mathrm{~N}=25)$ & \\
\hline in Diemarden & Geboren & $70(\mathrm{~N}=23)$ & $30(\mathrm{~N}=10)$ & .000 \\
\hline \multirow[t]{5}{*}{ Verein } & Schützenverein & $62(\mathrm{~N}=8)$ & $38(\mathrm{~N}=5)$ & .220 \\
\hline & Heimatverein & $75(\mathrm{~N}=9)$ & $25(\mathrm{~N}=3)$ & .310 \\
\hline & Schulförderverein & $20(\mathrm{~N}=3)$ & $80(\mathrm{~N}=12)$ & .035 \\
\hline & $\begin{array}{l}\text { „Natürlich Die- } \\
\text { marden“ }\end{array}$ & $0(\mathrm{~N}=0)$ & $100(\mathrm{~N}=19)$ & .000 \\
\hline & Feuerwehr & $93(\mathrm{~N}=13)$ & $7(\mathrm{~N}=1)$ & .000 \\
\hline \multirow{2}{*}{$\begin{array}{l}\text { Landwirte im Freundes- } \\
\text { kreis }\end{array}$} & $\mathrm{Ja}$ & $61(\mathrm{~N}=47)$ & $39(\mathrm{~N}=7)$ & \multirow{2}{*}{.000} \\
\hline & Nein & $24(\mathrm{~N}=13)$ & $76(\mathrm{~N}=41)$ & \\
\hline \multirow[t]{2}{*}{ Geschlecht } & Männlich & $53(\mathrm{~N}=39)$ & $47(\mathrm{~N}=34)$ & \multirow{2}{*}{.170} \\
\hline & Weiblich & $32(\mathrm{~N}=17)$ & $68(\mathrm{~N}=36)$ & \\
\hline
\end{tabular}

Quelle: Eigene Berechnung

\subsection{Faktorenanalyse zur Dimensionsreduktion}

Zur Erklärung, welche Gründe bzw. Ursachen für oder gegen einen Stallbau sprechen, ist eine Vielzahl von Einflussfaktoren zu berücksichtigen. Um diese Variablenvielfalt zu reduzieren, wurde eine Faktorenanalyse durchgeführt. Neben der Komplexitätsreduktion soll sie vor allem zur Aufdeckung voneinander unabhängiger Einflussgrößen dienen und beugt somit a priori dem Problem der Multikollinearität in der sich anschließenden Regressionsanalyse vor. Insgesamt konnten 4 Faktoren (mit Eigenwerten $>1$ ) extrahiert werden, die kumuliert eine Gesamtvarianz von 65,96 \% erklären. Die hohen Werte für Cronbachs Alpha sprechen für reliable Faktoren. Diese decken sich in etwa mit dem theoretischen Modell und werden folgendermaßen charakterisiert:

- Faktor 1: Einschätzung der persönlichen Belastung durch den Stallbau

- Faktor 2: Stellenwert und Image der Landwirtschaft

- Faktor 3: Wissen über Landwirtschaft (Selbsteinschätzung)

- Faktor 4: Not In My Backyard 
Die folgende Tabelle gibt die hinter den jeweiligen Faktoren stehenden Statements und die zugehörigen Faktorladungen wieder:

TABELLE 2: FAKTORLADUNGEN DER EINZELNEN STATEMENTS

\begin{tabular}{|l|r|}
\hline Faktor 1: Cronbachs Alpha = 0,936; 28,29 \% der Varianz & Faktorladung \\
\hline Durch den Schweinestall würde ganz Diemarden stinken. & 0,862 \\
\hline Die Gründung eines Vereins gegen den Schweinestall finde ich übertrieben. & $-0,848$ \\
\hline „Natürlich Diemarden“ hat dafür gesorgt, dass wir endlich informiert werden. & 0,821 \\
\hline Durch den Stall wird die gesundheitliche Belastung stark steigen. & 0,755 \\
\hline Die Belastung durch den Schweinestall wird man kaum bemerken. & $-0,743$ \\
\hline Der Güllegeruch beim Ausbringen wird unerträglich sein. & 0,722 \\
\hline Faktor 2: Cronbachs Alpha = 0,753; 18,1\% der Varianz & 0,718 \\
\hline Polaritätenprofil: Landwirte sind bescheiden-gierig & 0,711 \\
\hline Ohne die Bauern wäre Diemarden nur halb so lebenswert. & 0,696 \\
\hline Ohne Landwirtschaft hätten wir in Deutschland noch viel mehr Arbeitslose. & 0,641 \\
\hline Polaritätenprofil: Landwirte sind sympathisch-unsympathisch & 0,608 \\
\hline Polaritätenprofil: Landwirte sind Landschaftspfleger-Landschaftszerstörer & \\
\hline Faktor 3: Cronbachs Alpha = 0,81; 13,62 \% der Varianz & 0,926 \\
\hline Von Landwirtschaft habe ich eigentlich keine Ahnung. & $-0,903$ \\
\hline Ich kenne mich in landwirtschaftlichen Themen aus. & \\
\hline Faktor 4: Cronbachs Alpha = 0,620; 9,78 \% der Varianz & 0,819 \\
\hline Würde der Stall in Diemarden an anderer Stelle stehen, wäre mir das Ganze egal. & 0,801 \\
\hline $\begin{array}{l}\text { Eigentlich habe ich nichts gegen solch einen Stall, nur sollte er nicht direkt vor unserer } \\
\text { Haustür gebaut werden. }\end{array}$ & \\
\hline
\end{tabular}

Quelle: Eigene Berechnungen

Auf Basis der Faktorenanalyse wurde im nächsten Schritt ein Regressionsmodel geschätzt (Tabelle 3). Die Abstimmungsfrage zum Stallbau wurde als abhängige Variable definiert. Die Schätzung zeigt, dass die vier extrahierten Faktoren sowie die Wohndauer einen signifikanten Einfluss auf die Bewertung des Stallbaus haben und die Einstellung in hohem Maße (korr. $\mathrm{R}^{2}=077$ ) erklären.

TABELLE 3: LINEARES REGRESSIONSMODELL ZUR BEWERTUNG DES STALLBAUS

\begin{tabular}{|l|r|r|r|}
\hline Einflussfaktoren & Beta & T-Wert & Signifikanz \\
\hline Konstante & &,- 082 &, 935 \\
\hline Faktor 1: Einschätzung der persönlichen Belastung &,- 780 & $-17,052$ &, 000 \\
\hline Faktor 2: Stellenwert und Image der Landwirtschaft &, 320 & 6,984 &, 000 \\
\hline Faktor 3: Wissen über Landwirtschaft (Selbsteinschätzung) &,- 178 & $-3,879$ &, 000 \\
\hline Faktor 4: NIMBY &, 177 & 3,858 &, 000 \\
\hline Wohndauer &,- 145 & $-2,950$ &, 004 \\
\hline Abhängige Variable: Abstimmungsfrage zum Stallbau, korr. R ${ }^{2}=0,77 ; \mathrm{F}=77,15(\mathrm{p} \leq 0,001)$ \\
\hline
\end{tabular}

Quelle: Eigene Berechnung

Interessant sind aber nicht nur die aufgezeigten Einflussgrößen, sondern auch, dass die Tierhaltungsproblematik und die Umweltschutzfragen in dieser Befragung keinen signifikanten Einfluss auf die Bewertung haben. Hier scheint es sich doch eher um ein vorgeschobenes Ar- 
gument von Seiten der Stallbaugegner zu handeln. Für die Mehrzahl der Befragten ist dieses Argument für die Stallbaufrage nicht entscheidend. Aufgrund der massiven Diskussion um die Art der Tierhaltung, die in diesem Beispiel wie auch in anderen Fällen sowie der generellen Auseinandersetzung eine große Rolle spielt, war dieses Ergebnis überraschend. Theoretisch erläutert Dyllick (1990) die Relevanz von moralischen Positionen. Seiner Meinung nach basiert öffentlicher Druck primär auf ethisch begründeten Forderungen. Diejenigen, denen es gelingt, solche Ansprüche zu verkörpern, verfügen demnach über die „Quelle der Macht“ (Dyllick 1990: 22) und haben ein breites Mobilisierungspotenzial.

\section{Steuerungsmechanismen zur räumlichen Verteilung von tierischer Pro- duktion}

Ausgangspunkt der weiteren Überlegungen ist die hier nicht weiter problematisierte Prämisse, dass eine bessere räumliche Verteilung der Tierhaltung aus ökologischen- und seuchenpraktischen Gründen anzustreben ist. Es stellt sich dann die Frage, wie die Akzeptanz von Stallbauten in viehschwachen Regionen durch geeignete Steuerungsmechanismen sichergestellt werden kann. Die empirischen Ergebnisse zeigen, dass die wichtigsten Ablehnungsgründe von Stallbauten typische Nimby-Argumente sind. Wird die persönliche Belastung als hoch eingeschätzt, so wird der Stallbau abgelehnt. Die Lösung dieses Problems wird in der Literatur bei klassischen Nimby-Anlagen wie Mülldeponien, Obdachlosenheimen etc. diskutiert. NimbyGüter sind zwar gesamtgesellschaftlich erwünscht, werden aber von der lokalen Bevölkerung aufgrund persönlicher Beeinträchtigung abgelehnt (Horah et al.: 1993). Veröffentlichungen zur Standortwahl von Nimby-Gütern zielen vor allem darauf ab, wohlfahrtsoptimale Standorte durch Kompensationslösungen zu finden (Hart/Pommerehne: 1994). Solche Ansätze sind für die vorliegende Fragestellung nicht hilfreich, da keine Ausgleichszahlungen vorgesehen sind. Daher werden im Folgenden verschiedene andere Steuerungsmechanismen und ihre potenzieller Beitrag zur Problemlösung vorgestellt.

\subsection{Governance-Typen und potenzielle Problemlösungen}

Governance bedeutet Steuern und Koordinieren mit dem Ziel, mit Interdependenzen von Akteuren umzugehen. Dabei beruht die Steuerung auf institutionalisierten Regelsystemen, die das Handeln der Akteure lenken sollen, wobei unterschiedliche Systeme oft in Kombination vorliegen. Nicht nur die Systeme, sondern auch die sich dadurch ergebenen Interaktionsmuster werden erfasst. Diese Prozesse sind meist organisationsübergreifend (Benz 2004: 25). 
Grundsätzlich können je nach Forschungsblickwinkel und Ansatz verschiede Steuerungsmechanismen unterschieden werden. In der politischen Ökonomie besteht ein weitgehender Konsens über die Typen Markt, Hierarchie, Staat, Verbände und Netzwerke (Zimmermann 2005: 92). Einen Überblick liefert Tabelle 4. Für die Steuerung von Standortfragen eigenen sich die Mechanismen Hierarchie und Verband aufgrund der beschränkten Mitgliedschaft nicht und werden daher im Folgenden nicht näher betrachtet.

TABELLE 4: GOVERNANCE-TYPEN IM ÜBERBLICK

\begin{tabular}{|c|c|c|c|c|c|}
\hline & Markt & Hierarchie & Netzwerk & Verband & Staat \\
\hline $\begin{array}{l}\text { Zentraler Koor- } \\
\text { dinationsmodus }\end{array}$ & $\begin{array}{l}\text { - Preis } \\
\text { - Wettbewerb }\end{array}$ & $\begin{array}{l}\text { - Kontrolle } \\
\text { - Anweisung }\end{array}$ & $\begin{array}{l}\text { - Vertrauen } \\
\text { - Ressourcenaus- } \\
\text { tausch auf Basis } \\
\text { von Reziprozi- } \\
\text { tät }\end{array}$ & $\begin{array}{l}\text { - Intra- und inter- } \\
\text { organisatorische } \\
\text { Konzertierung }\end{array}$ & $\begin{array}{l}\text { - Hierarchische } \\
\text { Kontrolle } \\
\text { - Befehl }\end{array}$ \\
\hline $\begin{array}{l}\text { Normative Basis } \\
\text { der Mitglied- } \\
\text { schaft }\end{array}$ & $\begin{array}{l}\text { - Verträge } \\
\text { - Eigentumsrechte }\end{array}$ & $\begin{array}{l}\text { - Arbeits- } \\
\text { verhältnis }\end{array}$ & $\begin{array}{l}\text { - Komplementäre } \\
\text { Stärken }\end{array}$ & $\begin{array}{l}\text { - Formale Mit- } \\
\text { gliedschaft }\end{array}$ & - Bürgerstatus \\
\hline Konfliktregelung & $\begin{array}{l}\text { - Abwanderung } \\
\text { - Gerichtsverfahren }\end{array}$ & $\begin{array}{l}\text { - Anweisung } \\
\text { - Befehl, auch } \\
\text { Anreiz } \\
\text { - Loyalität }\end{array}$ & $\begin{array}{l}\text { - Diskurs } \\
\text { - Verhandlung }\end{array}$ & $\begin{array}{l}\text { - Paritätische } \\
\text { Beteiligung } \\
\text { - Paketabstimmung }\end{array}$ & $\begin{array}{l}\text { - Zwang } \\
\text { - Staatliches } \\
\text { Gewalt- } \\
\text { monopol } \\
\end{array}$ \\
\hline
\end{tabular}

Quelle: Lütz 2004: 152

Der Markt ermöglicht in der neoklassischen Theorie eine effiziente Allokation von Gütern und Dienstleistungen. Akteure mit Eigentumsrechten an bestimmten Ressourcen können sich an einem Austausch beteiligen. Im Preis, dem zentralen Steuerungsmechanismus des Marktes, sind alle tauschrelevanten Informationen enthalten (Lütz 2003: 6). Obwohl Coase (1960) gezeigt hat, dass Märkte auch mit Externalitäten umgehen können, ist eine Lösung der Standortfrage nur schwer vorstellbar. Zum einen ist eine Grundannahme von Coase aufgrund der Existenz von Transaktionskosten für die Lösung des Problems (z. B. Anwälte) verletzt. Zum anderen ist davon auszugehen, dass sowohl bei dem Recht auf Aktivität, als auch beim Recht auf Unversehrtheit unter realen Bedingungen die Kosten der Anwohner/ der Nutzen des Betreibers sich stark von der Zahlungsbereitschaft der Anwohner/ des Betreibers unterscheidet. Anders ausgedrückt: Landwirte müssten hohe Summen aufbringen, um sich die Nutzung „kaufen“" zu können und Anwohner müssten hohe Summen aufbringen, um dem Landwirt das verloren gegangene Einkommen zu kompensieren.

Eine anderer relevanter Steuerungsmechanismus sind Netzwerke. Sie zeichnen sich dadurch aus, dass ihre Mitgliedschaft freiwillig ist und einen langfristigen Charakter hat. Eine wichtige Rolle in Netzwerken spielt dabei Vertrauen, das auch den Handel mit preislich nicht kalkulierbaren Gütern ermöglicht (z. B. Akzeptanz). Oftmals liegt Netzwerken ein gemeinsames 
Ziel zugrunde und um dies zu erreichen, werden opportunistische Handlungen zurückgestellt. Die typische Interaktionsform von Netzwerken ist die Verhandlung. Konflikte werden so zu lösen versucht, dass Kooperationsgewinne entstehen gehen (Klenk/Nullmeier 2004: 35). Die Steuerung des Standortsproblems über Netzwerke ist vorteilhaft, da verschiedene, auch nicht marktliche Akteure, in die Entscheidungsfindung einbezogen werden können und damit die Akzeptanz von Stallbauten sichergestellt werden kann.

Der Staat ist bei der Koordination der Wirtschaft ein zentrales Element. Hier dominiert die auf Anordnung und Kontrolle ausgerichtete Koordination der Mitglieder. Der Staat stützt sich auf sein legitimes Monopol der physischen Gewaltanwendung und kann die Einhaltung von Vorgaben in letzter Instanz erzwingen. Verglichen mit allen anderen Mechanismen spielt der Staat eine herausragende Rolle. Er stellt Kollektivgüter zur Verfügung, ohne die Märkte, Unternehmen, Netzwerke und Verbände nicht funktionsfähig wären. Mit der Definition von Eigentumsrechten ist die herausragende Bedeutung für Stallbaukonflikte ersichtlich (Lütz 2003: 10).

Bei Stallbauten hat der Staat eine besondere Rolle, die im Folgenden getrennt nach Legislative und Judikative getrennt betrachtet werden soll. Mit den Gesetzgebungsorganen werden allgemeingültige Rahmenbedingen für Stallbauten (BImSchG, BauGB und Bauordnungsrecht der Länder) vorgegeben (Graulich 1999: 35). Die Verwaltung entscheidet anhand dieser Vorgaben auf lokaler Ebene. Bei klaren gesetzlichen Regelungen dürften in der Genehmigungspraxis keine Unterschiede vorkommen. Das Baurecht ist allerdings durch eine Vielzahl unbestimmter Rechtsbegriffe gekennzeichnet, die Ermessensspielräume für Behörden einräumen. Damit kann ein Landwirt zu Beginn eines Bauantrags nur bedingt absehen, ob der von ihm gewählte Standort ohne Probleme akzeptiert wird (Graulich 1999: 50). Durch die unbestimmten Rechtsbegriffe und Auslegungsmöglichkeiten von Abstandsvorgaben etc. entstehen Entscheidungsspielräume, mit denen auf lokale Besonderheiten eingegangen werden kann. Auf der anderen Seite sind diese Ermessensspielräume Ausgangspunkte für Diskussionen bzw. Konflikte, die zur Blockade eines Verfahrens führen und nicht selten vor Gericht enden. Damit ist dann ein anderer staatlicher Akteur, die Gerichtsbarkeit, mit der Lösung des Problems betraut. Letztlich wird dann zwar die formelle Auseinandersetzung beendet, die Effizienz ist allerdings aufgrund der häufig langjährigen Auseinadersetzungen (im Fall Diemarden: 1. Antrag 30.04.2003, Verfahren noch nicht abgeschlossen) und hohen psychosozialen Kosten (im 
untersuchten Fall gingen die Streitigkeiten bis in die Schulklassen hinein) sehr skeptisch zu bewerten.

\subsection{Steuerungsansätze zur Entschärfung von Standortkonflikten}

Auch die Konfliktlösung im Netzwerk durch Verhandlungen und Diskurse (siehe Tabelle 3) die von zahlreichen Autoren präferiert wird (u. a. Renn 1999: 104), kann aus unserer Sicht nicht zur Einigung beitragen. Von landwirtschaftlichen Investoren werden frühzeitige Informationen, Einbindung der Kritiker, Bargaining-Prozesse, Moderation und Mediation - gefordert, um die Akzeptanz ihrer Bauvorhaben zu sichern. Auf Basis der empirischen Ergebnisse und der agrarsoziologischen Forschungsarbeiten zur Dorfentwicklung sind wir hier skeptisch. Ein Blick auf den Steuerungsmechanismus „Netzwerk“ zeigt, warum in Veredlungsregionen Ställe leichter genehmigt werden und sich Gegner von Stallbauten nur schwer durchsetzen können. In Intensivregionen spielen Landwirte und landwirtschaftsnahe Branchen wie Futtermittelindustrie, Stalleinrichter, Schlachthöfe und Dienstleistungsunternehmen eine wichtige Rolle und dominieren lokale Netzwerke. Umgekehrt fällt in viehschwachen Regionen die ökonomische Relevanz von Stallbauten kaum ins Gewicht fällt. Landwirte sind hier deutlich in der Minderzahl und haben vielfach nur noch eine schwache Position im Dorf. Der Netzwerkansatz erklärt sehr plausibel, warum (u. a.) Durchsetzungsunterschiede in Regionen vorhanden sind, eine Entzerrung der Tierproduktion kann mit Hilfe dieses Ansatzes nicht gewährleistet werden. Zwar können über die Suche nach neuen Verbündeten Landwirte zu mehr Macht kommen und somit ihre Situation verbessern, und auch in der Praxis ist zu beobachten, dass nicht jeder geplante Stall in Nichtveredlungsregionen eine Bürgerinitiative nach sich zieht. Aber nicht nur der langwierige Aufbau von Macht, bei zunehmender sozialer Vereinzelung und die hohen Transaktionskosten, sprechen gegen diese Lösung. Ein weiterer Grund ist, dass Landwirte sich nur mit relativ geringen Gegenleistungen (z. B. Baulandverkauf, Arbeiten mit dem Schlepper) revanchieren können.

Wie anhand der theoretischen Überlegungen deutlich wurde, spielen in der öffentlichen Diskussion eine Vielzahl von Argumenten und Motiven eine Rolle. Die empirische Studie zeigt dagegen, dass vor allem „egoistische“ Motive und nicht Tier- und Umweltschutzargumente wichtig sind. Aufgrund der moralisch begründeten Diskussionsstandpunkte (Tier- und Umweltschutz) werden von Stallbaugegnern Elemente eingefordert, die auf lokaler Ebene nicht zu verhandeln sind, sondern die übergreifende Politikebenen betreffen. Zudem verschleiern sie das wichtigste Motiv: die persönliche Belästigung. Würde nur dieses Argument Gegens- 
tand von Verhandlungen sein, wäre eine Problemlösung theoretisch denkbar. Es ist aber davon auszugehen, dass Stallbaugegner ihre Präferenzen nicht vollständig offen legen. Theoretische Überlegungen kommen dann zum Schluss, dass die Verhandlungslösung von der wohlfahrtsmaximierenden Lösung abweicht (Holzinger 1998: 26). Letztlich sprechen die in Tabelle 5 aufgeführten Punkte gegen eine Verhandlungslösung.

TABELLE 5: ARGUMENTE GEGEN VERHANDLUNGSLÖSUNGEN AUF LOKALER EBENE

O Minderheitenposition in Nichtveredlungsregionen

o Überlagerung der eigentlichen Konfliktursache durch moralische Konflikte

o Geringe Schulung der Landwirte

o Fehlende Unterstützung durch ein Netzwerk aus vor- und nachgelagerter Industrie Quelle: Eigene Zusammenstellung

Um die Durchsetzung von Stallbauten in Nichtveredlungsregionen zu gewährleisten ist daher eine stärkere staatliche Regulierung nötig. Mit Hilfe klarer gesetzlicher Regelungen wäre es für Landwirte und Bürgerinitiativen zu Beginn eines Verfahrens abzusehen, ob der Bauantrag genehmigt wird. Damit werden Auseinandersetzungen entschärft, weil Konflikte sich ansonsten zu Beginn eines Verfahrens hochschaukeln können. Partizipative Ansätze, die in Form von runden Tischen etc. durch Verhandlungen zur Problemlösung beitragen sollen, sind aus Sicht der Autoren zumindest auf lokaler Ebene nicht hilfreich. Auf übergeordneter Ebene, bei Gesetzgebungsverfahren, ist allerdings die Einbeziehung von Tier- und Umweltschutzverbänden gemeinsam mit Vertretern des Berufstandes sinnvoll. Wie empirische und theoretische Untersuchungen zeigen, können besonders bei Umweltgütern über Verhandlungen wohlfahrtsoptimale Lösungen erreicht werden (Holzinger 1998: 31).

\section{Fazit}

Um die Standortkonflikte bei Stallbauten zu entschärfen, sind eindeutige rechtliche Bestimmungen nötig. Eine Konfliktreglung durch Verhandlung ist auf lokaler Ebene aufgrund der in der Diskussion vorgebrachten generellen Probleme und der schwachen Machtposition von Landwirten in lokalen Netzwerken in Nicht-Veredlungsregionen kaum Erfolg versprechend. Damit werden nicht grundsätzlich Paritzipationsmethoden und -ansprüche abgelehnt, vielmehr wird dafür plädiert, dass diese Aushandlungsprozesse auf den Ebenen geführt werden, die diese Auseinandersetzungen lösen können. Wenn die Mehrheit der Bürger sich gegen bestimmte Tierhaltungsformen (Spaltenböden/Käfighennen) ausspricht, höhere Ansprüche an technische Möglichkeiten stellt etc., dann müssen diese Präferenzen auf Bundes- und EU- 
Ebene in Politikprozesse einfließen. Die bisherigen, durch Stellvertreterkonflikte aufgeladenen Nimby-Auseinandersetzungen sind gesellschaftlich ineffizient. 


\section{Literatur}

Badura, J. (1999): Moral für Mensch und Tier. Tierschutzethik im Kontext, München.

Benz, A. (2004). Governance - Modebegriff oder nützliches sozialwissenschaftliches Konzept? in: Benz, A. (Hrsg.): Governance - Regieren in komplexen Regelsystemen, Wiesbaden, S. 11-28.

BMVEL (2005): Zukunft der Nutztierhaltung: Gutachten des Wissenschaftlichen Beirats Agrarpolitik, nachhaltige Landbewirtschaftung und Entwicklung ländlicher Räume beim BMVEL, Berlin.

BMVEL (1950-2000): Agrarbericht der Bundesregierung, Bonn.

BUND (Hrsg.) (2004): Gegen die Errichtung von Massentierhaltungsanlagen, Köln.

Coase, R. H. (1960): The Problem of Social Costs, in: Journal of Law and Economics, Vol. 3, S. 1-44.

Dorsch, K. (2004): Flugblatt-Hetze gegen Schweinemäster, in: top agrar, 32. Jg., Heft 6, S. 14-15.

Dyllick, T. (1990): Management der Umweltbeziehungen: öffentliche Auseinandersetzungen als Herausforderung, Wiesbaden.

Freisinger, U. und H.-W. Windhorst (2005): Sektorale und regionale Strukturen der Nutztierhaltung in Niedersachsen, Vechta.

Graulich, V. (1999): Immissionsschutzrechtliche Konflikte zwischen Landwirtschaft und Wohnbebauung, Baden-Baden.

Hart, A. und W. Pommerehne. (1994): Zur Standortwahl von NIMBY-Gütern, Diskussionsbeiträge des Fachbereich Wirtschaftswissenschaft, Universität des Saarlandes, Nr. 9403, Saarbrücken.

Hoerster, D. (2004): Haben Tiere eine Würde? München.

Horah, J. et al. (1993): NIMBYs and LULUs, Knoxville.

Holzinger, K. (1998): Die Leistungsfähigkeit umweltpolitischer Kooperationslösungen, in: Bartmann, H. und K. D. John (Hrsg.): Kooperative Umweltpolitik: Beiträge zum 8. Mainzer Umweltsymposium, Mainz, S. 39-73.

Johaentges, A. (1996): Das Dorf als Wohnstandort - Eine Analyse von Wanderungsbewegungen in ländliche Räume, Bonn.

Klenk, T. und F. Nullmeier (2004): Public Governance als Reformstrategie, 2. korr. Aufl., Düsseldorf.

Lütz, S. (2003): Governance in der politischen Ökonomie, MPIfG Discussion Paper 03/05, Köln.

Löhr, S. (2005): Der Schweine Alarm, in: taz, Nr. 7794 vom 15.10.2005, S. 4.

Mann, S. und H. Kögl (2003): On the acceptance of animal production in rural communities, in: Land Use Policy, Vol. 20, pp. 243-252.

Neumann, H. (2001): Eine Region mit dem Rücken an der Wand, in: top agrar, 29. Jg., Heft 8, S. 40-43. 
Renn, O. (1999): Kooperativer Diskurs - Kommunikation und Konfliktschlichtung in der Umweltpolitik, in: Bartmann, H. und K. D. John (Hrsg.): Kooperative Umweltpolitik, Aachen.

Retter, C. et al. (2002): Zur Rolle von Landwirten in dörflichen Kommunikationsnetzwerken, in: Berichte über Landwirtschaft, 80. Jg., S. 446-467.

Schneider, M. (2001); Über die Würde des Tieres. Zur Ethik der Mensch-Tier-Beziehung, in: Schneider, M. (Hrsg.): Den Tieren gerecht werden. Zur Ethik und Kultur der MenschTier-Beziehung, Kassel 2001, S. 228-238.

Singer, P. (1997): Alle Tiere sind gleich, in: Krebs, A. (Hrsg.): Naturethik, Frankfurt a. M., S. $13-32$.

Stahr, K., (2000): Dörfliche Kommunikationsnetzwerke, Gießen.

Struff, R. (1999): Regionale Lebensverhältnisse, Teil 2: Sozialwissenschaftliche Dorf- und Gemeindestudien in Deutschland, Bonn.

Zahn, M. (2003) Schweinerei lässt Bürgern keine Ruhe, in: General-Anzeiger, 15.05.2003.

Zimmermann, K. (2005): Soziale Stadt und Local Governance, Hannover. 


\section{Danksagung}

Die vorliegende Arbeit wurde am Institut für Agrarökonomie der Georg-August-Universität Göttingen angefertigt. Im Laufe meiner Promotionszeit haben viele Personen auf ihre Weise zum Gelingen beigetragen, denen ich an dieser Stelle herzlich danken möchte.

Mein besonderer Dank gilt Prof. Dr. Achim Spiller für die sehr lehrreiche und anregende Zusammenarbeit, den gewährten Rückhalt und das Vertrauen bei allen Projekten. Der fachliche Austausch und das unübertroffene Arbeitsklima an seinem Lehrstuhl waren stets Motivation und werden auch zukünftig dafür sorgen, dass ich an die Promotionszeit in Göttingen gerne zurückdenke.

Auch bei den Kolleginnen und Kollegen am Lehrstuhl und Institut möchte ich mich an dieser Stelle bedanken. Nur einige kann ich hier namentlich erwähnen, wohl wissend, dass das gute Institutsklima auf allen basiert und ich mit fast jedem eine nette Anekdote verbinde. Besonders erwähnen möchte ich Maren Lüth, Zazie von Davier, Christian Wocken und Birgit Schulze, die die ein oder andere Diskussion ertragen mussten, Petra Geile, die auch beim zweiten und dritten Korrekturlesen tapfer durchgehalten hat, Oliver Balkhausen, ungeachtet seines immer noch einen schlechten Fußballgeschmacks, die Kollegen vom 11. Stock für Kaffee und gute Laune, trotz Singverbot. Auch die Unterstützung der studentischen MitarbeiterInnen Nina Stockebrand und Raphael Kennerknecht möchte ich hier noch einmal ausdrücklich erwähnen. Mein ganz besonderer Dank gilt Thorsten Hollmann-Hespos, der mich mit seinen Formatierungsfähigkeiten und seiner unnachahmlichen Ruhe am Ende der Dissertationszeit unglaublich unterstützt hat.

Schließlich gilt das größte Dankeschöne meiner Familie, ohne deren Unterstützung ich niemals diese Arbeit angefertigt hätte. 